\title{
Translation accuracy and dissemination of disclosure of patent information
}

Citation for published version (APA):

Azevedo Larroyed, A. (2019). Translation accuracy and dissemination of disclosure of patent information: an analysis of translation and its influence on patent law. [Doctoral Thesis, Maastricht University]. ProefschriftMaken Maastricht. https://doi.org/10.26481/dis.20190925al

Document status and date:

Published: 01/01/2019

DOI:

10.26481/dis.20190925al

Document Version:

Publisher's PDF, also known as Version of record

\section{Please check the document version of this publication:}

- A submitted manuscript is the version of the article upon submission and before peer-review. There can be important differences between the submitted version and the official published version of record.

People interested in the research are advised to contact the author for the final version of the publication, or visit the DOI to the publisher's website.

- The final author version and the galley proof are versions of the publication after peer review.

- The final published version features the final layout of the paper including the volume, issue and page numbers.

Link to publication

\footnotetext{
General rights rights.

- You may freely distribute the URL identifying the publication in the public portal. please follow below link for the End User Agreement:

www.umlib.nl/taverne-license

Take down policy

If you believe that this document breaches copyright please contact us at:

repository@maastrichtuniversity.nl

providing details and we will investigate your claim.
}

Copyright and moral rights for the publications made accessible in the public portal are retained by the authors and/or other copyright owners and it is a condition of accessing publications that users recognise and abide by the legal requirements associated with these

- Users may download and print one copy of any publication from the public portal for the purpose of private study or research.

- You may not further distribute the material or use it for any profit-making activity or commercial gain

If the publication is distributed under the terms of Article $25 \mathrm{fa}$ of the Dutch Copyright Act, indicated by the "Taverne" license above, 


\section{Translation Accuracy and Dissemination of Disclosure of Patent Information: An Analysis of Translation and its Influence on Patent Law}


ISBN: 9789463804967

Cover by: Bregje Jaspers | ProefschriftOntwerp.nl

Layout by: Bregje Jaspers | ProefschriftOntwerp.nl

Printed by: ProefschriftMaken | www.proefschriftmaken.nl

(c) Aline Azevedo Larroyed, 2019 


\title{
Translation Accuracy and Dissemination of Disclosure of Patent Information: An Analysis of Translation and its Influence on Patent Law
}

\author{
DISSERTATION \\ To obtain the degree of Doctor \\ At Maastricht University \\ On the authority of the Rector Magnificus, \\ Prof. dr. Rianne M. Letschert \\ In accordance with the decision of the Board of Deans, \\ To be defended in public
}

On Wednesday, September 25, 2019, at 14:00 hours

by

Aline Azevedo Larroyed 


\section{Supervisors}

Prof. dr. Anselm Kamperman Sanders

Prof. dr. Luiz Otávio Pimentel

\section{Co-Supervisor}

Dr. Ana Quintela Ribeiro Neves Ramalho

\section{Assessment Committee}

Prof. dr. Dick van Engelen, professor of Intellectual Property Litigation and Transaction Practice, Maastricht University (Chairman);

Prof. dr. Josef Drexl, Director of the Max Planck Institute for Innovation and Competition, Munich, Germany.

Prof. mr. Gerard René de Groot, Em. professor of Private International Law and Comparative Law, Maastricht University;

Dr. Christopher Heath, Member of the Boards of Appeal, The European Patent Office, Munich, Germany;

Dr. Anke Moerland, Assistant professor of Intellectual Property Law, Maastricht University. 
I dedicate this work to Antônio Carlos Souza de Abrantes, for the inspiring teachings and dialogues and for the masterful way he disseminates his knowledge about patents. Our long conversations about patents and translation will never be forgotten. 



\section{Acknowledgements}

I would like to express my gratitude to some people who supported and encouraged me during my PhD.

First and foremost, I wish to thank my supervisor in the Netherlands, Professor Anselm Kamperman Sanders, who made it possible to explore an innovative, exciting and interdisciplinary topic, allowing me to work on a research which I truly believe is a meaningful contribution to patent law, giving me the freedom to think, explore and create. Professor Kamperman is certainly not only a global reference in intellectual property studies, but also one in leading researchers to give their best to their scientific production. It was an honour and a pleasure to work under his supervision.

I thank the constant support of Professor Luiz Otávio Pimentel. I was so lucky to work with a Brazilian icon in the area of industrial property. As the Head of the Brazilian National Patent Office, Professor Pimentel has brought advances to the patent system in Brazil. He is, in addition, an admirable human being, capable of understanding and supporting projects that stand out from the common place and open new perspectives to bring the Brazilian patent system in a global level.

I would like to express my sincere gratitude to my co-supervisor, Dr. Ana Ramalho, for the insightful comments which encouraged me to improve my research from various perspectives.

All my gratitude to Professor Josef Drexl for the unique opportunity of my stay in the Max Planck Institute for Innovation and Competition. I've always deeply admired the scientific production of the Institute and was so proud and happy to be part of it. My stay in Munich at the Institute was crucial to the production of my thesis, as I could interact with patent attorneys, patent examiners and IP academics and researchers from all over the world. I will never find the right words to show all my thankfulness for this exceptional opportunity.

I would like to thank Dr. Benoît Battistelli, the former President of the European Patent Office, and the EPO officers who supported this research with interviews and study material. My special thanks to Dr. Ingrid Cailhol. Lots of thanks to Dr. Bertrand Le Chapelain, Dr. Carmen Salvador and Dr. Stefan Luginbühl. The opportunity for visiting the EPO and learning from its outstanding history in translation evolution certainly made this research much more special. The EPO represents the strongest world reference in patent translation. All of its ground-breaking developments did not only signify large leaps in the patent system, but in the improvement of machine translation in general. The EPO is certainly a model of excellence to be studied and followed in this area. I was very happy to investigate and understand its remarkable journey in patent translation as one of the central objects of my research.

I am particularly grateful to Professor Cees Mulder, who accompanied each stage of my production, from the beginning to the end, always supportive in every possible 
way, opening doors to my interviews and searches and giving me the privilege of critical, sometimes sharp evaluation, so vital to intellectual growth and scientific awareness. All my gratitude to the privilege of his careful reading and for the always precious advice.

I thank all the Professors and members of the European Intellectual Property Institutes Network. I will always remember EIPIN meetings and discussions as rare moments of knowledge exchange. Presenting my work at EIPIN's events and receiving feedback from its members, as well as attending other presentations, opened new perspectives to my research. In this regard, I specially thank Professor Manuel Desantes Real, who helped me rethink my methodological approach, shortening my path to find solutions in investigating a totally new object.

Lots of thanks to the Professors and Professor Assistants who inspired and supported me, in the Netherlands, in Brazil and in Germany: Prof. Arno Dal Ri Júnior, Prof. Aires José Rover, Prof. Cláudio Regis de Figueiredo, Prof. José Rubens Morato Leite, Prof. João Artur Souza, Prof. Henryk Siewierski, Prof. Hans Peter Grieneisen, Prof. Luiz Henrique U. Cademartori, Prof. Lincoln Fernandes, Dr. Matthias Lamping. Special thanks to Prof. Dick van Engelen, Prof. Gerard de Groot and Dr. Anke Moerland. Very special thanks to Dr. Christopher Heath.

I am deeply grateful to all the people who co-operated with me in my surveys and interviews. The information given by them is what gave consistency to this work and allowed me to describe and analyse a topic that had not been investigated before from this perspective. Special thanks to: Adriana Brigante Deorsola, André Fontes, Antonio Carlos Souza de Abrantes, Araken Alves de Lima, Catia Regina P. Gentil da Silva, Deniz Karci, Giovanni Batista Souza, Gisela A.S. Nogueira, Guido Vermeer, Han Deokwon, Hans Peter Henrik Grieneisen, Hirano Takashi, Krishnamani Jayaraman, Kitty Veldman, Liane Elizabeth Caldeira Lage, Lindsay Yang, Linxiao Lu, Lucas Cunico, Marcos Trevisan Vasconcelos, Nyske Blokhuis, Paulo C. Brandão, Rafaela Di Sabato Guerrante, Ryoko Oshikamo, Sander van Rijnswou, Shin Tokii, Stefan Luginbühl, Tetsutaro Yukutake, Tianyu Hang, Viola Pendl, Zedequias Alves.

All my gratitude to Mr. Justice André Fontes, for the long and fruitful conversation about patents and translation related to the Judiciary in Brazil.

I owe many thanks to Mr. Justice Peter Blok. I am grateful for having had the privilege of a very fruitful conversation about patent translation related to the European Judiciary.

I would like to thank Guido Coumans, a wonderful friend I met in the Netherlands.

I thank Ms. Licette Poll, the dream person of any foreign researcher recently arriving in a new country and a new academic environment, full of doubts and difficulties. Thank you for your kindness and constant support.

I thank my colleagues at Maastricht University and at Max Planck Institute. I met many nice, supportive colleagues in both places. My special thanks to: Daria Kim (thank you for all the encouragement to my adaptation in Munich and for your precious 
friendship); Margaret Lin (thank you for helping me so many times, for your kindness and for your motivating words); Shin Tokii (thank you for all the support for me to understand - and, at the end, deeply admire! - the Japanese patent system). Many thanks to Adriana Ortiz, Agnieszka Bień-Kacała, Laura Valtere, María Alejandra Arcila, Michael Neumann, Moritz Sutterer, Natale Rampazzo, Tian Lu, Tongle Si, Türker Ertaş, Tien-hsin Wang, Xiao Wang, Yan Yu, Zullay Poggi.

I thank my colleagues at UFSC and at the Group of Studies on Intellectual Property, Technology Transfer and Innovation. All my gratitude to Ana Marchesan, Chiara M. Biasi, Jaqueline Albino, Janaína Peixer, and Juliano Rossi. Very special thanks to Camila Matos.

I would like to thank the teachers and colleagues of Edeltraud. Improving my German was really important for my adaptation in Munich. All the activities of the German Conversation Group were really memorable. Special thanks to Ilker, Stephanie, Myrian, Astrid, Friederike and Sascha.

Thanks to my dear (old and new) friends Antônio Filho, Gemma and Marcel Mingels, Ayşe Özlenen Çığ, Dessislava Konstadinova, Elke James, Janaína Peixer, Luiz Mayr, Martha Stoffella, Paulo Soler, Tatiana Cascardo, always helping me to rekindle the flame of self-confidence and enthusiasm. Lots of thanks to three lovely girls who made me feel at home in Munich: Betina D'ávila, Danny Calderaro and Renata Cardoso. Lots of thanks to Ricardo Freitas.

I am so grateful I have met Fabio and Yvana, who became really special to me.

Thanks to my beloved William, who has supported my dreams and projects, unconditionally, offering them brightness and meaning, with the sweetest Dutch words.

All my gratitude to my parents (in memoriam), Leda and Décio Larroyed, who taught me the value of creativity, curiosity and knowledge. 


\section{Table of Contents}

Acknowledgements $\quad 9$

List of Abbreviations $\quad 16$

List of Figures $\quad 18$

List of Tables $\quad 21$

Introduction 23

Chapter 1 - Innovation, disclosure and patent law 35

1.1. Fundamental concepts and legal references 37

1.1.1. The concept of innovation and the relationship between science and 38 technology: what patents disclose and in which context

1.1.2. Patent rights as intellectual property rights related to innovation - 43 historical development and main current definitions

1.1.3. From the regime of the Convention of Paris to the international intellectual 53 property regime of the TRIPS Agreement: a trend to integration and harmonization

1.2. The patent scenario as an intercultural space 60

1.2.1. Nature of the patent system: disclosure as a prerequisite for a competitive 60 market

1.2.2. Disclosure as the main linking element between patent systems and 70 innovation systems

1.2.3. Innovation, patents and disclosure in an intercultural space 76

1.2.4. Disclosure and translation: legal references 79

1.3. Conclusions and correlation of the chapter with the research question 83

Chapter 2: Methodology $\quad \mathbf{8 7}$

2.1. Scope of the research 89

2.1.1. Research question and sub-questions 80

2.1.2. Delimitations and hypotheses 91

2.2. Societal Relevance 93

2.3. Methodological approach and techniques 95

2.3.1. Overview of the used methods and techniques 95

2.3.2. Theoretical background and detailed description of the methodological 103 steps

2.3.3. Data collection techniques and investigated players: content analysis and 106 interviews 

based on (especially machine) translation

3.1. Law as an autopoietic system based on communication by Niklas 119 Luhmann: the communicative event and the "legal language"

3.2. Klaus Günther and the two levels of the legal discourse: justification and application of norms

3.3. Justification and application discourses on the patent system

3.4. Communication and translation as keys to maintain the integrity of the legal system

3.5. Communication and translation in patent systems

3.6. Conclusions and correlation of the chapter with the research question

4.1. Innovation, language and translation: historical developments and necessary updates

4.2. Machine translation, human translation and English as lingua franca in patent systems

4.3. A technical text is a text

4.4. Patent writing and patent translation

4.5. Patent translation: limits and possibilities

4.6. Conclusions and correlation of the chapter with the research question

Chapter 5: Patent translation and its influence on the disclosure of technological information

5.1. Translation and disclosure of patent information

5.2. Sample analysis - clean energy patents: results and conclusions

5.2.1. A language of innovation

5.2.2. Machine translation enables the disclosure of technological information through the patent system

5.3. Conclusions and correlation of the chapter with the research question

6.1. The Patent Cooperation Treaty (PCT): patent information, language and translation

6.1.1. Regulations, history and operation of the PCT

6.1.2. The advantages of a harmonized system

6.1.3. The use of the PCT for the strategic management of technology: why universalizing disclosure is important to patent law

6.1.4. PCT's language regime

6.2. The language regime of the European Patent Office and the European Patent with Unitary Effect 
6.2.1. The European Union's approach to language and translation and the language regime (s) of the EPO

6.2.2. European Unitary Patent and Unitary Court

6.2.3. Spain's actions against the regulations of the Unitary Patent

6.2.4. Other controversies and negative reactions towards the Unitary Patent System

6.3. Accuracy of translation of international treaties and national legal effects

6.4. Conclusions and correlation of the chapter with the research question

Chapter 7: The influence of translation on the different legal stages of a patent

7.1. Translation on the timeline of a patent

7.2. Translation and patent prosecution on PTO's stages: patent examination, opposition and appeal

7.2.1. Examination guidelines and translation regimes in different national systems

7.2.2. Examples of PTO's cases where translation played an important role

7.3. Main aspects in patent court cases involving translation

7.4. Patent and translation: examples of court cases

7.5. Complementary results obtained through the interviews

7.6. Conclusions and correlation of the chapter with the research question

Chapter 8: Summary, conclusions and recommendations

8.1. Achieved results: Main points and conclusions

8.1.1. Office, opposition and infringement cases: the influence of translation on patent law and its snowball effect

8.1.2. Translation discloses patent information and enables the universal dissemination of innovative inventions

8.2. Translation and its influence on international agreements as a network effect

8.3. Recommendations to improve the dissemination of the disclosure of patent information in courts and patent offices

8.4. Recommendation concerning translation and disclosure in the language regulations of the European Unitary Patent and Unitary Court

8.5. Recommendations to improve search tools and expert systems in terms of optimizing the use of machine translation to disclose and disseminate patent information

8.6. Recommendations for future developments and studies

8.7. Fallacies and generalizations to be avoided in dealing with the subject of patent translation and disclosure 
9.1. Literature

9.2. European Union and EPO Documents

9.3. Case Law

9.4. Other Policy Documents

9.5. Articles on Journals and Webpages

Appendix 1: List of Interviewees and Collaborators 403

Appendix 2: Interview Guides 407

Appendix 3: Forms used for Survey and Content Analysis

413

Valorization

415

About this author 

Translation is one of the few human activities in which the impossible occurs by principle.

Mariano Rato

Without translation, we would be living in provinces bordering on silence.

George Steiner

I don't know whether machine translation will eventually get good enough to allow us to browse people's websites in different languages, so you can see how they live in different countries.

Tim Berners-Lee (in 2004)

(...) for better or for worse, translation technology is playing a far-reaching role that hardly anybody would have predicted before the turn of the millennium

Federico Gaspari

Placing the knowledge of one person into the hands of another involves the transfer of certain powers: powers of expression in the case of literary or artistic knowledge; powers over the patterns and organization of life in the case of political, legal, or religious ideas; and, in the case of science, powers of imagination and practice with regard to the material world and uses of it. Scott Montgomery 


\section{List of Abbreviations}

\begin{tabular}{|c|c|}
\hline ALPAC & Automatic Language Processing Advisory Committee \\
\hline AMC & Arbitration and Mediation Centre \\
\hline BGB & Bürgerliches Gesetzbuch \\
\hline CAT & Computer Assisted Translation \\
\hline CJEU & Court of Justice of the European Union \\
\hline CUP & Convention de Paris pour la Protection de la Propriété Industrielle \\
\hline ECJ & European Court of Justice \\
\hline EIPIN & European Intellectual Property Institutes Network \\
\hline ELF & English as Lingua Franca \\
\hline EP & European Patent \\
\hline EPC & European Patent Convention \\
\hline EPO & European Patent Office \\
\hline EQE & European qualifying examination \\
\hline EU & European Union \\
\hline GATT & General Agreement on Tariffs and Trade \\
\hline IB & International Bureau \\
\hline ICJ & International Court of Justice \\
\hline INPI & $\begin{array}{l}\text { Instituto Nacional de Propriedade Industrial (Brazilian National Institute } \\
\text { of Industrial Property) }\end{array}$ \\
\hline IP & Intellectual Property \\
\hline IP5 & Refers to the cooperation of the five largest IP offices in the world. \\
\hline IPC & International Patent Classification \\
\hline IPE & International Preliminary Examination \\
\hline IPRs & Intellectual Property Rights \\
\hline ISA & International Search Authority \\
\hline IT & Information technology \\
\hline JPO & Japan Patent Office \\
\hline KIPO & Korean Intellectual Property Office \\
\hline LISA-QA & Localization Industry Standards Association Quality Assessment Metric \\
\hline MT & Machine Translation \\
\hline MU & Maastricht University \\
\hline PCT & Patent Cooperation Treaty \\
\hline PEA & Preliminary Examining Authority \\
\hline $\mathrm{PPH}$ & Patent Prosecution Highway \\
\hline PTOs & Patent and Trademark Offices \\
\hline RO & Receiving Office \\
\hline SIPO & State Intellectual Property Office of the People's Republic of China \\
\hline SMEs & Small and Medium Enterprises \\
\hline
\end{tabular}




$\begin{array}{ll}\text { TEU } & \text { Treaty on European Union } \\ \text { TFEU } & \text { Treaty on the Functioning of the European Union } \\ \text { TM } & \text { Translation Machine } \\ \text { TRIPS } & \text { Trade-Related Aspects of Intellectual Property Rights } \\ \text { TTOs } & \text { Technology Transfer Offices } \\ \text { UFSC } & \text { Abbreviation in Portuguese for Federal University of Santa Catarina } \\ \text { UK } & \text { United Kingdom } \\ \text { UP } & \text { Unitary Patent } \\ \text { UPC } & \text { Unitary Patent Court } \\ \text { UPCA } & \text { Unitary Patent Court Agreement } \\ \text { UPTR } & \text { Unitary Patent Transitional Regulations } \\ \text { USPTO } & \text { United States Patent and Trademarks Office } \\ \text { WIPO } & \text { World Intellectual Property Organization } \\ \text { WMT } & \text { World Machine Translation (Conference) } \\ \text { WTO } & \text { World Trade Organization }\end{array}$




\section{List of Figures}

Figure 1: Pasteur's Quadrant 39

Figure 2: $\quad$ Model of the Triple Helix III 42

Figure 3: The Economist Cover - August 8, 2015

Figure 4: Diagram representing the relation between the legal system and the 75 patent system within the social system

Figure 5: $\quad$ LISA-QA - Metric of translation assessment as applied to the sample 99

Figure 6: Example of score table used to evaluate the translation of a patent text 100

Figure 7: Part of the form shared with researchers for assessing the level of 101 disclosure of patent information through machine translation

Figure 8: Diagram representing the steps followed on the analysis 103

Figure 9: Content analysis procedures followed during the research 107

Figure 10: Searching sequence of opposition cases 113

Figure 11: Searching sequence of infringement cases 113

Figure 12: Sample form for content analysis of opposition cases $\quad 115$

Figure 13: Example of sample form for content analysis of infringement cases $\quad 115$

Figure 14: Annual court decisions involving patents 140

Figure 15: Front page or summary page of a patent of a bicycle rear suspension, 167 containing the patent number, the name of the inventor; the serial number, the abstract; prior art references and a representative drawing

Figure 16: The official languages of the EU and EPO states and their coverage 170 within Patent Translate

Figure 17: Average score obtained by each language according to LISA-QA $225 \quad 207$

Figure 18: Relation between type of errors and severity of errors - English patents 208 sample

Figure 19: Relation between type of errors and severity of errors - Latin languages 208 patents sample

Figure 20: Relation betweentype oferrorsand severity oferrors-Germanlanguage patents sample

Figure 21: Average of errors according to type of errors, language and severity of error - minor errors

Figure 22: Average of errors according to type of errors, language and severity of 210 error - major errors

Figure 23: Average of errors according to type of errors, language and severity of error - critical errors

Figure 24: Relation between type of errors and severity of errors - Chinese 214 language patents sample

Figure 25: Overview of the PCT System

Figure 26: Overview of the PCT Stages 
Figure 27: PCT-PPH 236

Figure 28: 2011 and 2014 PCT key numbers review 238

Figure 29: Ten main applicants 239

Figure 30: Applications by fields of technology 239

Figure 31: Languages accepted in selected Receiving Offices 241

Figure 32: Structure of the European Patent Office 249

Figure 33: Summary of UPC's functioning and regulation 262

Figure 34: Representation of the patenting process at the EPO 293

Figure 35: Representation of the patenting process at the USPTO 293

Figure 36: EPO's Annual Report 2015

Figure 37: Timeline of a patent from the perspective of language and translation 295

Figure 38: Average percentage of use of human and machine translation in each 295 legal stage of a patent

Figure 39: Parts of a JPO survey assessing the quality of machine translated 231 documents

Figure 40: Patent case filling and grants in the US - 1991-2015 316

Figure 41: Classification of national patent systems in terms of their interaction 340 with foreign documents 



\section{List of Tables}

Table 1: Arguments that justify the importance of patent systems 65

Table 2: $\quad$ Arguments against patent protection for software and responses to 66 these arguments

Table 3: Association between the system's theory by Maturana and Varela and 69 the innovation systems theory by Lundvall:

Table 4: $\quad$ Comparison between innovation systems and patent systems 72

Table 5: $\quad$ Three guiding sub-questions 90

Table 6: Criteria for selecting the sample 96

Table 7: Description of the sample used for the first step of analysis 98

Table 8: Details of the sample size 100

Table 9: Differences between "patent language" and legal language 152

Table 10: Characteristics of the Language of Innovation 205

Table 11: Different Aspects shown by each Language 212

Table 12: Advantages and limitations of patent databases in terms of language 221 search

Table 13: $\quad$ PCT's Language and translation aspects in different stages of patent 244 application

Table 14: Forms Used by International Authorities according to PCT 246 Administrative Instructions - Section 103

Table 15: Evolution of the Unitary Patent 260

Table 16: Language regime of the Unitary Patent Court 263

Table 17: Important concepts related to translation of international treaties 278

Table 18: Number of court cases and patent grants in Brazil 2005-2017 316

Table 19: Possibilities of dealing with foreign documents in patent courts 339 (predominant situations)

Table 20: General results of the content analysis of the opposition cases 341

Table 21: General results of the content analysis of the infringement cases 342 
INTRODUCTION 
Introduction 


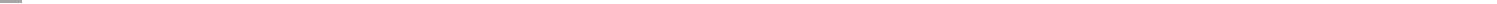




\section{Introduction}

This research aims to assess how accuracy of translation influences the dissemination of disclosure of patent information within the patent legal system, during the timeline of a patent, which means, during the stages of examination/validation, opposition and on court disputes concerning patent infringement and revocation. The intention is to contribute to the social and scientific discussion on the roles, features and future perspectives of patent translation and its legal effects. It was motivated by the reality of a fast-changing scenario, where machine translation and digital communication, together with globalization and new standards of competition, radically overhauled the patent system.

\section{Research question}

The main research question addressed in this thesis is the following: How does accuracy of translation influence the dissemination of the disclosure of patent information on patent law?

The problem that led to this research question was the necessity to understand the current role of translation in the patent system. The research question was rather kept broad due to the lack of previous studies on the problem that motivated it. Answering to this question is important if the performance of the patent system is to be improved in terms of ensuring legal certainty to its users and stakeholders. The patent system still holds many gaps and discrepancies involving language and translation and can be improved in some central features. Those improvements, vital to the enforcement of patent rights, are explained throughout this thesis and summed up in its conclusions.

\section{Background to the research question}

Patent translation has become increasingly sophisticated and relevant to the patent system in the last years. Accuracy in expert systems has been gradually lowering language-related barriers at a rate that was unconceivable no more than one decade ago. Machine translation has improved the disclosure of patent information to a level which allows the patent system to be considered as a global system, when interpreted from the perspective of disclosure. ${ }^{1}$

The broader dissemination of disclosure of patent information accredited to machine translation increased the importance of the patent system in fostering innovation, through activities such as technology assessment, creation and management of technological portfolio, identification or evaluation of sources for generation of

$1 \quad$ The expression. "Global patent system”, as used in this thesis, should not be understood as related to the (possible) existence of an international patent stricto sensu, as such a patent would have no legal fundament, to the date. The expression should be understood as referred to a set of international agreements, guidelines and legal instruments which allow a certain coherence to the patent system at the international level, and to the understanding that the disclosure of patent information is performed at a global level. 
technological knowledge, among many others. A mere decade ago, the activities of patent examiners, attorneys and other stakeholders of the patent system were confined to printed documents and to prior art accessible in languages mastered by them.

Human translation has also changed, after the necessary interaction with translation technologies. Likewise, it is now associated with tasks such as the triage of prior art documents through huge global archives and operations that remind those of intelligence agencies, for their complexity and the level of sensibility of the translated information. Professional translators are facing an increasingly digitized future, which makes translation remarkably different from a purely human process and involve the offer of networked services, such as post-editing and e-discovery.

Patent examiners, attorneys and judges have been using a variety of information provided by patent expert systems through machine and human translation. The accuracy of these translations may produce different outcomes in the disclosure of patent information in legal environments. Translation discrepancy, either generated by the machine translation engines or by human translators, can influence decisions taken by these agents, adversely affecting the legal system. That may happen especially during the stages of validation and opposition and in patent infringement related disputes.

The volume of the information available through these systems is huge, as the patent system can be defined, nowadays, as a global, multilingual structure. The automatic access to all those patent documents is enabled, and constantly improved, by machine translation, in combination with platforms which permit different ways of searching for patent information. These changes are a recent phenomenon and stand in stark contrast with a picture to a time when large rooms were filled with files and printed documents in patent offices, and European patent attorneys were struggling to learn languages such as Korean and Japanese to be able to develop business relations with those countries.

Language and translation practices, policies and regimes, related to the global patent system, include agreements, treaties and the structure of patent/IP offices and organizations. They involve a whole range of costs and activities and influence not only the system itself, but the set of legal and social structures related to it. The way patent agreements are internalized into national regulations and the way global guidelines and basic concepts relate to patent rights are also understood to involve an adaptation to a national system that is deeply related to language and translation, shaped by local legal cultures.

In this regard, language and translation pervadeall different stages of the patenting procedure, from the occasion of patent application, to prior art search, examination, publication, and grant. This influence may be described as a constant, prevalent process, being difficult to measure in all its extent, but showing material evidence in each and every stage of the legal timeline of a patent. This evidence frequently represents a snowball effect. For example, if a translation error or an inaccurate analysis of prior art occurs during the examination, it can lead to further challenges, as opposition and appeal 
procedures. If the error is not identified, the consequence can be an infringement case, typically triggering counterclaims for invalidity of one of the patents.

Another important issue is related to the costs of translations. Applicants who want to protect their inventions may have to bear both preliminary and secondary costs related to translation when a patent authority does not operate in their working language or when the application enters the national phase, in the case of PCT patents or regional patents. Translation costs are, in general, high, as patent translations are considered highly specialized. Some offices require that all the answers to office actions are translated, which can increase the costs and compromise the efficiency of communication. Further legal challenges (appeal, infringement, for example) can increase these costs even more.

In the case of multilingual patent offices and communities, the central relevance of language and translation for patent systems becomes even more evident. The EPO, for instance, has direct translation service costs estimated at around $€ 8.2$ million per year. Its language service department counts on 38 permanent staff members and is divided into separate translation sections for each of the three official languages, counting also on interpretation units. Additionally, the EPO is as a good example of a multilingual provider of technical information, being a central unit, in this perspective, for accessing global patent information. ${ }^{2}$

Language and translation policies and regimes will also necessarily affect the route of knowledge dissemination, through how patent information is disclosed, because they determine in what language the disclosed content will be published. In a globalized economy, that will enable disclosure and transfer of technology in multiple languages. This diversity of languages and the quality of the text of disclosed information will guide a whole set of related communication-based activities, such as research planning and exploitation of knowledge spill-overs.

In this regard, language and translation processes can be described as the components of one of the most important inputs on which inventors build innovation, because they affect the diversity of languages in which the stock of new patent information is available. That makes the semantics of all this complex and multi-language exchange of information fundamental to patent bargaining, which has a global impact on scientific development.

Patent texts should therefore be written to be translated. In other words, patent documents should give global access to their technological content. This access is jeopardized when the patent text (or its translation) is not clear enough to allow the invention to be reproduced, in the event of the patent expiring or in the case of a compulsory licence, for example. Patent writing and translation is also related to the scope of protection of an invention. On this matter, a detail and a slight difference in their respective texts can be crucial in legal decisions.

2 M. Gazzola, The Evaluation of Language Regimes: Theory and Application to Multilingual Organizations, John Benjamins Publishing Company, 2014, p. 291. 
Another point is the importance of machine translation to patent law. The transformation represented by the advent and improvement of machine translation and its interaction with human translation has led to radical changes in the patent system. The new translation technologies enabled prior art search at the global level and changed the very concept of translation. At the same time, the challenges of a fast-changing scenario for new technologies are growing, considering the advent of more sophisticated inventions and the growing number of correlated patents, which make patent infringement harder to prove and which will require more efficient flows of communication.

To date, little has been published on research involving language and translation and patent rights. In this respect, the investigation of the proposed research question required a great deal of empirical work and implied the opening of new grounds and perspectives not only for patent law, but for intellectual property law, in general. Moreover, translation is a pervasive feature of the international intellectual property scenario. Reaching ideal levels of integration and harmonization in patent law depends very much on understanding the role of translation in all its legal stages, from the application for obtaining the property rights to post-grant legal challenges.

The present research approaches a current debate on patent systems: the necessity of searching for more interaction and integration between cross-border patent regulation in a context of globalizing markets and at a time when Europe is taking a historic step on its way to establishing a European Unitary Patent and a European Unitary Court, whereas one of the main obstacles is represented by language diversity and the possibilities of conciliating different language regimes.

Adopting the perspective of language and translation was effective in presenting solutions for this debate. It was also important for identifying gaps in the global patent system and for proposing recommendations for its improvement. Due to the scarcity of previous correlated literature, it was necessary to elaborate a methodological plan combining different primary sources and existing techniques to cross, on one side, the disclosure of patent information through translation, and, on the other, the decisions taken during the process of patent prosecution and its consequences for patent court cases.

\section{Thesis and answers to the research question}

The main contribution of this thesis is the conclusion that the advent of quality machine translation and the changes on its interaction with human translation characterise a true revolution to patent rights and represent the basis of the patent system in its current configuration. This idea leads to the understanding that, without the improvement of machine translation, the patent system would not have been reshaped into a global structure.

New ways to combine machine and human translation have allowed the patent system to reach higher levels of harmonization and the disclosure of technological 
information to be disseminated at a global level. Previous language barriers, which represented the main obstacle to the integration and interaction of national patent systems, were dramatically reduced. This transformation is recent and is the starting point of a set of necessary changes in patent law, enabled not only through cross-border treaties, aiming at more harmonization of national regulations, but through higher levels of (academic, political, scientific...) integration and interaction between national patent systems. This conclusion was based on results and answers obtained during this investigation, which are summarized below.

The patent system can be defined as a sub-system of the legal system, associated with other systems, like the scientific and the economic systems. The patent system could only exist as a global system after the advent of quality machine translation. Therefore, machine translation (while interacting with various types of human translation and translation technologies) is the linking element and the basis of communication of the patent system. Disclosure of patent information has, recently and finally, reached global standards. It overcame the limits of the patent offices, as patent information is nowadays accessible to anyone who is interested in exploring patent search engines, many of which are free and user friendly. Arguably, machine translation universalized the reach of patent information disclosure.

However, the extent to which machine translation discloses patent information still depends on languages, contexts and receivers. This means that there is still a long way to go until the patent system attains an optimal use of automatic translation tools. In this regard, there are outstanding gaps in the patent system, as translation does not only influence the decisions taken by patent examiners, attorneys and judges, but is able to mislead them.

National courts and patent offices obey language regimes and approaches to foreign documents which considerably differ from each other. This creates inconvenient discrepancies in the global patent system, corrupting the system and impairing legal certainty for companies operating in multiple countries. Likewise, translation can influence patent cases in different ways. In this respect, Chapter 7 presented examples of cases where translation was alleged to be purposely inaccurate in order to bias legal decisions. Also, the triage of documents to be used in a court case as evidence may lead to different results, as it frequently depends on machine translation and on correlated subjective choices. Other examples showed in this thesis concern errors made by local agents or translators which undermined the whole process of patent prosecution, creating undesirable challenges for the applicant.

The best solutions for minimizing discrepancies between cross-border cases and to increase the rule of law correlated to patent rights can be summarized in two concepts discussed in Chapter 3 and related to the notion of system: integration and interaction. More than the idea of harmonization, those concepts suggest a continuous process of exchange between the national patent systems. In this respect, it is important to create 
more guidelines and international forums to debate common understandings of patent prosecution associated with language and translation, and to propose solutions related to the gaps indicated by this research. It is also important to develop more studies comparing the efficiency of national patent courts and court systems to deal with translated documents.

In any event, the level of globalization of the patent system has increased according to the pace that machine translation and digital communication has advanced, enabling disclosure to operate much more effectively in a universal level. Understanding and describing this process is relevant to justify the existence of the patent system and to improve its functioning, in order to provide more integration, harmonization and legal certainty.

\section{Methodology}

Due to the lack of previous studies on the topic, it was necessary to study and combine some methodological techniques, associating related resources in order to investigate the research object. The methodology used was the product of those studies and the subsequent combination of sources and techniques, explained at length in Chapter 2. The sources and techniques used are summed up below, in association with sub-questions derived from the main research question:

Research question: How does accuracy of translation influence the dissemination of the disclosure of patent information on patent law?

\section{Sub questions Methods and techniques}

What kind of role does translation play on Literature review on correlated topics: nature of the patent the current configuration of patent law? system; law and communication; historical influence of translation on science and innovation; nature of the patent text; technical translation and patent translation.

Objective: Describe the current configuration of the patent system in order to associate it with the role that translation plays on its functioning.

Does machine translation disclose patent Applying the methodology of LISA-QA for translation assessment information? To what extent? to a sample of 100 patents. Survey filled up by scientists, considered as the persons skilled in the art.

Objective: Obtain and analyse data over the level of disclosure of patent information through machine translation.

What is the influence of translation on the International agreements and language regimes regulations different legal stages of a patent? documental analysis combined with interviews and literature review.

Office stages: documental analysis and interviews.

Court stages: documental analysis and interviews (complemented by isolated cases described on the literature).

Objective: Explain the influence of translation on each of the main legal stages of a patent through particular examples. 


\section{Societal relevance}

The present study is based on the problem of understanding the current role of translation in the patent system in the interest of improving its performance in terms of the dissemination of disclosure of patent information and in order to ensure more legal certainty to its users and stakeholders. It offers relevant contributions to associated fields and tools, by enabling, through its conclusions and recommendations:

- To find solutions to a more integrated patent system in Europe and to point out gaps that may lead to a more harmonized global patent system;

- To use the model of the European Unitary System as one to be debated in the sense of promoting integration and interaction in developing countries;

- To find solutions for a"unitary language regime"in Europe as a basis to the Unitary System, by analysing its current regulations and presenting recommendations for their improvement;

- To pave the way for new possibilities of studies associating language diversity and legal integration and interaction in patent law, bringing a relevant discussion in the current scenario of the patent system at the global level.

- To provide useful information for improving patent expert systems and patent search tools.

- To present proposals for further interdisciplinary and empirical studies that can continue to search for solutions for global justice related to language/ translation and patent rights.

- To encourage similar interdisciplinary studies in other fields and forms of intellectual protection (copyrights, geographical indication, trademarks, etc.).

\section{Challenges faced during the period of research}

The first and most relevant difficulty faced on carrying out this investigation was an academic resistance towards the topic. It is still hard to convince academies of intellectual property studies or related law departments that language and translation represent an important field for patent rights and for IP studies, in general. At the same time, it was challenging to prove the value of a contribution that is "out of the box", and that opens a whole new field of study, beyond the area of language planning and policies, that still has a lot to add to patent/IP studies. In this regard, it is recommended that more projects and studies involving heterogeneous groups (different languages, background or experiences with IP) are formally arranged to deal with the topic.

The second challenge faced during the research was related to its level of novelty. It was necessary to create a methodology to approach the topic by combining existing methods and techniques to cross legal and language related information. The solutions were found through detailed planning, followed by stages of trial and error, until it was possible to define the initial sample of patents to be assessed and to find ways to get substantial results from the content analysis. Most of the analysis of data was manual, 
being repetitive and time consuming. The questions to interviews were elaborated according to the positions and nationalities of the interviewees, and the interviews were performed personally, at the time and place indicated by the interviewees. ${ }^{3}$

\section{Structure of the dissertation}

The dissertation is divided into 8 Chapters. Chapter 1 presents a theoretical and legal framework to associate innovation, disclosure and patent law. The concepts and theories presented in this chapter were developed as an essential background to explain the role of translation to disclose patent information in the current global patent scenario. Chapter 2 describes the methodological approach and techniques used to collect and analyse the data, by giving a detailed description of each methodological step followed during the research. Chapter 3 introduces the concept of law as a communication system and explains the role of communication and translation to patent law interpreted as a system. These introductory chapters establish a necessary and informative basis for the subsequent Chapters. They are followed by extensive legal analysis of the object of research presented in Chapters 4, 5, 6 and 7.

The last chapters focus on the legal effects, features and functions of translation on the patent system. Chapter 4 describes translation as a vehicle to patent rights, aiming at the characteristics of patent translation, its limits and possibilities. Chapter 5 debates the influence of translation on the disclosure of technological information. Chapter 6 discusses the influence of translation on international patent agreements, showing the importance of language and translation regimes in the context of international patent law and giving some examples of translation inaccuracies involving these agreements. Chapter 7 describes the influence of translation on the legal timeline of a patent, bringing specific examples of translation inaccuracies and its effects on the office stages (examination, opposition/appeal) and the court stages (infringement/revocation).

Chapter 8 concerns the summary of the research, its conclusions and recommendations. The main conclusion consists in defining the current patent system as a (global) system based on (especially machine) translation, since the process of disclosure was universalized after the advent of quality machine translation. It is also concluded that patent texts are texts, and no matter how accurate their translation may be, there will always remain discrepancies and nuances that may influence legal decisions. Therefore, Chapter 8 ends up with recommendations that may minimize the associated negative effects of translation on the patent system. It also brings recommendations for future developments and studies and a list of fallacies and generalizations that should be avoided when approaching the topic.

3 See Chapter 2 of this dissertation for a detailed overview of the research methods. 


\section{Products and contributions resulting from the research}

The research resulted in a set of products and contributions, summed up as follows and thoroughly described on Chapter 8:

- Recommendations for future developments and studies, also concerning other forms of intellectual protection;

- Recommendations to patent offices concerning language and translation;

- Recommendations concerning the language regime of the Unitary System in Europe;

- Recommendations for improvements in search tools and expert systems;

- A discussion over fallacies and generalizations to be avoided in dealing with the subject of patent translation. 
CHAPTER 1

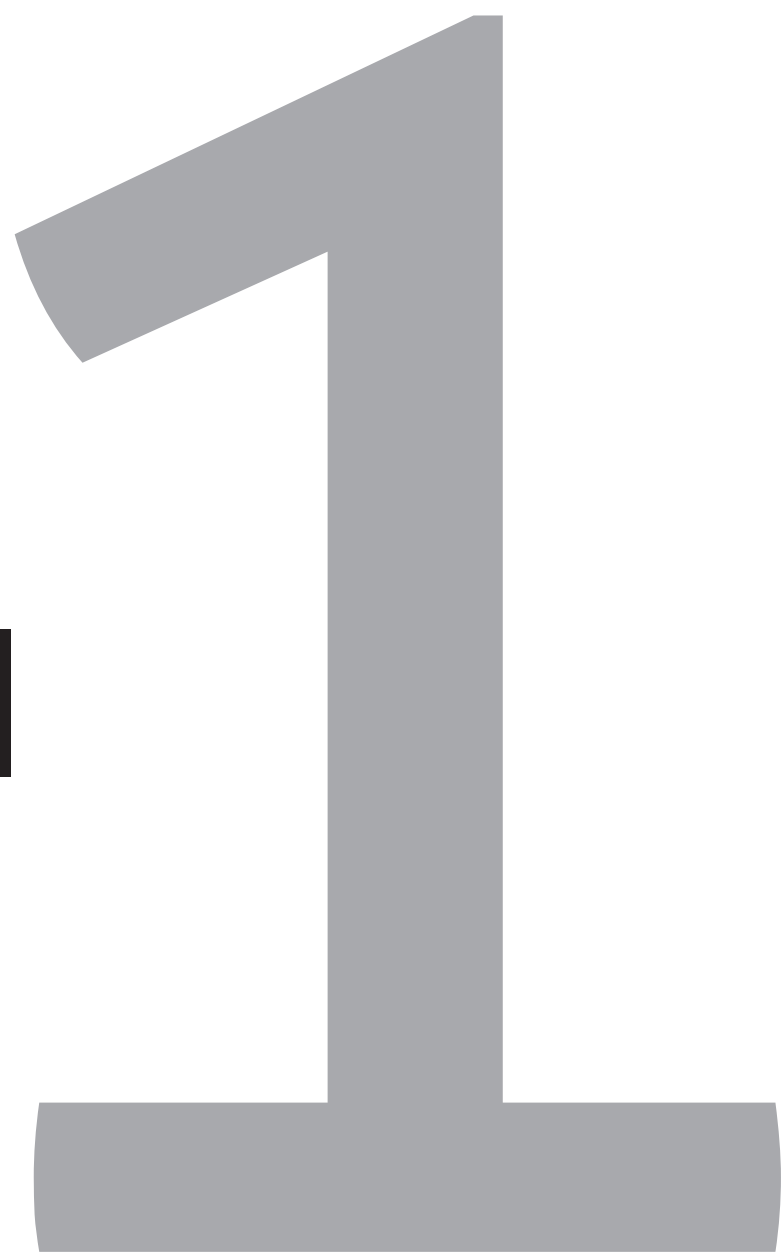




\section{Innovation, disclosure and patent law}




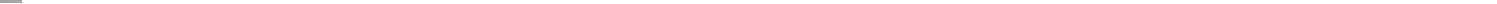




\subsection{Fundamental concepts and legal references}

\subsubsection{The concept of innovation and the relationship between science and technology: what patents disclose and in which context}

This Section aims to provide a panoramic view of the concept of innovation as key to understand the role of disclosure in the patent system. It is known that the major justification to support the existence of the patent system refers to the effects of the disclosure of patented inventions on innovation. Hence patents disclose the content of new technologies in a way that new research can benefit from the disclosed information and other inventions can be created, which basically defines the idea of innovation. Yet the concept of innovation is complex and dynamic and has changed in time, as a consequence of the development of globalized markets and global networks, in a context of new arrangements for knowledge creation and transfer.

The theories discussed in this Section, known as evolutionary theories, were selected in order to provide a contemporary view of the concept of innovation as a background to what patents disclose and to the context where disclosure operates. These theories and their key definitions have some aspects in common. Primarily, although they belong to the field of economics, they are important for understanding the economic nature of patent rights and the role of disclosure in the patent system.

The mentioned theories explain technological innovation as the advent of new effective products in the market, which can be the basis of economic development. Equally important, they focus on the idea of innovation as a dynamic concept which associates science and technology and the production, application and transfer of knowledge, through compounded networks and models. Finally, and most important, they describe a new scenario for scientific research and innovation, characterized by new political arrangements and much more intensive processes of knowledge transfer and interaction between its participants.

As previously mentioned, these theories have addressed the concept of innovation from the evolutionary perspective. The evolutionary theory, in economics, is so called because it is based on analogies inspired by biology to explain the evolutionary character of capitalist development, with emphasis on the process of technological change. The main point in common among evolutionists (also called neo-Schumpeterian) is the fact that they are based on an initial idea, advocated by Joseph Schumpeter, according to which innovation is the central element of economic dynamics, functioning as the main engine of development. ${ }^{4}$ Hence the more sophisticated and consolidated innovative practices are the higher standards of economic competitiveness, especially in the current framework of regional and global competitiveness.

4 J. Schumpeter, Capitalism, Socialism and Democracy, Taylor \& Francis e-Library, 2003. 
The theory developed by Donald Stokes mentions the stability with which the world interpreted the role of basic science on technological innovation after World War II. For the author, a paradox between basic research and applied research was established in that moment. A major reason for that to happen was the influence of Vannevar Bush's report, published at the end of World War II, at the request of President Roosevelt and as a result of Bush's work as Director of the Office of Scientific Research and Development. ${ }^{5}$

On the grounds of his experience during the war and under the influence of the socio-political context of the post-war era, Stokes describes the evolution of models of interpretation of the relationship between basic science and innovation. Stokes advocates thus the thesis that the relationship between science and technology would be marked by the paradox coined by Bush. Accordingly, Bush's paradigm, built up in this initial historical context, still finds resonance in the current preparation of the scientific agendas, although it did not really follow the evolution of the praxis of scientific research and its relationship with technology. ${ }^{6}$ In practice, the relationship between science/technology/ innovation has been intensified and reshaped according to a complex array of emerging social networks, highly dependent on knowledge transfer and disclosure.

Thus, the fragmentation fabricated by the report that divided research based on understanding and research inspired by use still distorts the relationship between basic science and technological innovation, not making sense as a fundamental theoretical model for describing a new scope of relations between science and technology (and innovation). In this sense, Bush's paradigm keeps a scenario which does not make sense in today's scientific activity, especially when it comes to industrial demands. Stokes advocates, then, that to interpret the innovation phenomenon at this juncture, it is necessary to break with this dichotomy between basic research and applied research, seeking to reconfigure the perception of the relationship between science and technology.

For Stokes, all research is driven by a series of decisions or choices. However, traditionally, scientific institutions emphasize the conceptual difference between applied research and basic research as a difference in the goals that drive one and the other ${ }^{7}$. The concepts accepted for basic research are described by a common basis for resignation to practical application and by certain related aspects, as originality, freedom of the researchers, peers review of published results and distance in time between the discovery and the practical use. ${ }^{8}$ However, these concepts do not seem to realize the full range of issues that the relationship between basic research and technological innovation raises, and, from a close-up view, they are all related to the disclosure of technological information.

Stokes explains that, although a number of examples that may be enumerated in order to counteract this dichotomy between basic research and applied research, and in

D. Stokes, O quadrante de Pasteur: a ciência básica e a inovação tecnológica. Editora da UNICAMP, 2005, p. 17 Ibid., p. 17-38.

Ibid., p. 22.

Ibid., p. 23. 
spite of the existence of a group of sciences that make it very difficult to maintain this view, there persists an emphasis on the need to frame the types of research in this perception that became crystallized in science. ${ }^{9}$

Therefore, after presenting an extended sequence of examples that demonstrate the fragility of this dichotomy, the author concludes that it is necessary to propose a new model of interpretation which undertakes, more usefully, the complexity of the relationship between science and technology. This model is inspired by the example of the scientist Louis Pasteur and called by Stokes schematically as "Pasteur's Quadrant". Stokes shows by this scheme, reproduced below in Figure 1, that Pasteur worked with experiments which can fit, at the same time, the concept of basic research and research inspired by use. ${ }^{10}$

Figure 1: Pasteur's Quadrant

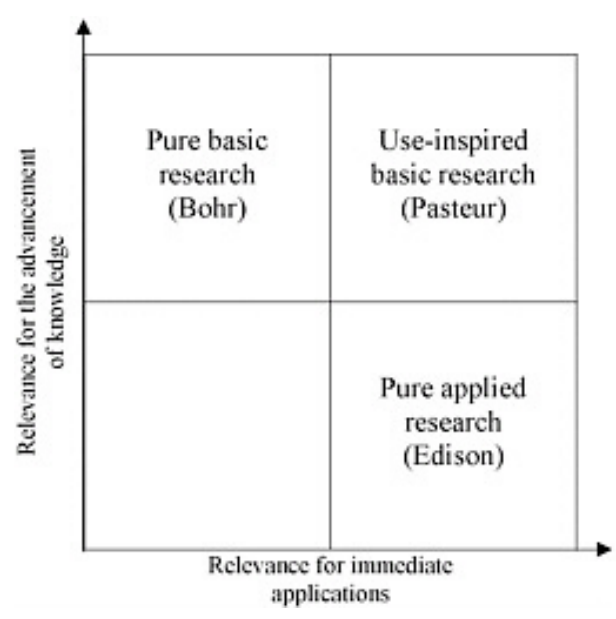

Source: Stokes, 2005, p. 118

Consequently, for remodelling the paradigm that defined the relationship between basic science, applied science and technology, the book re-interprets this relationship, proposing a conceptual framework that can bring the scientific research to national interests and promote more conscious investment and policies. In the light of the present research question, planned investment can greatly benefit from the information disclosed by patents. 
For more conscious investments, Stokes points the convenience of an institutionalized effort to assess the strength of the fields of science that can be prioritized to address the national needs. ${ }^{11}$ Thus, he argues that this issue should be debated according to an updated view of knowledge and use, with the goal of not only raising the fraction of the budget for supporting research, but to build basic research agendas inspired by use that relate more consistently to the needs of economic growth.

In addition, the book demonstrates the importance of the grounds of the research choices in the nation's needs for maintaining scientific integrity in order to better establish the pact between science and government and to influence the allocation of funds for purposes that can really serve practical concerns. The relevance of this reinterpretation for the present research is related to the roles played by communication in these new arrangements. Stoke's theory foresees a scenario of a tenuous line (if there is any) maintaining the dichotomy between science and technology. This perception has wider implications for the dynamic of innovation and its regulation through patent law. The relationship between science and technology has changed, so has the idea of innovation and the function of the patent system.

Stokes thesis is compatible with the theory founded by Joseph Schumpeter, the main precursor of the current definitions and theories about innovation, and resonates in the evolutionary, or neo-Schumpeterian economic movement, which subsequently unfold these concepts to design the most emblematic theories on different aspects of innovation up to the present.

The economist Joseph Schumpeter defined innovation as the enterprise search for making profits from the development of new products. According to Schumpeter, innovation is the driving force of capitalism, meaning the creation, by firms, of new consumer goods, that is to say, of new products and technologies to achieve market success ${ }^{12}$.

To understand this idea, another central concept in the work of Schumpeter, which became the base for all evolutionary theory, is the concept of "creative destruction". For Schumpeter, the creative destruction concerns the creations that revolutionize the economic structure, establishing new markets, offering temporary monopoly to the entrepreneur and affecting the foundations of firms and even the existence of well-established ones. ${ }^{13}$

To Perez, a neo-Schumpeterian theorist, innovation occupies an important space in economic development, including its dynamic of grouping and establishing new interrelations between firms. Innovation studies have shown that the introduction of technical change is not random but follows a path-dependent trajectory and is interdependent in relation to other innovations, being part of a system of networks, which is in turn linked to cyclical movements, called technological paradigms ${ }^{14}$. This approach

1 Ibid., p. 227.

12 Ibid.

13 Ibid., p. 110-112.

14 C. Perez, 'Technological Revolutions and Technoeconomic Paradigms', Cambridge Journal of Economics no 34, 2010, pp. 185-202. 
is important for informing the role of (intercultural) disclosure to innovation, as all those processes are pervaded by language and translation. On this matter, Section 3.1 of the present dissertation follows up the understanding of innovation as a dynamic, noncontinuous process, by correlating historical developments and necessary updates on the relation between innovation, language and translation.

Thus, according to this author, although innovation is constant in the market economy, it is not always continuous. There are changes in its rate, which tend to follow a logical curve. In each technological paradigm, incremental innovations are influenced by a technology cycle in which they are incorporated. From this logic, there are discontinuities in technological trajectories, which are stimulated by the exhaustion of possibilities over a particular paradigm. The discontinuities occur when productivity and markets are nearing exhaustion. All these asymmetries, related to (continuous, radical...) changes, are intermediated by complex communication flows, centralized in possible ways of sharing knowledge and disclosing technical information. Innovation, in this sense, represents a language, a discourse, as shown in Section 5.2 of this thesis.

All this activity described by Perez depends also, and primarily, on the system in which it operates, whose organizational skills and co-ordination are crucial to the success of the productive sector in bringing innovation to domestic and foreign markets. At this point, it is very important to define national innovation systems, by addressing Lundvall's seminal work. ${ }^{15}$ The purpose of presenting Lundvall's theory is to later describe the patent system as a system based on (especially machine) translation, the conclusion which constitutes the main thesis resulting from the present research.

According to Lundvall, an innovation system consists of elements that interact to shape innovative processes and elements that link the economic performance of these processes. Among these elements, the most important one is knowledge, accompanied by a technological learning process. Therefore, the success of a particular national innovation system depends in large part on the accumulated knowledge and capacity of a continuous process of technological learning. ${ }^{16}$

One way to promote this learning movement is open innovation, and it is also deeply related to the definition of disclosure. For Chesbrough, the theorist who introduced this concept, open innovation is a paradigm shift for the production of knowledge and the expansion of markets in companies. ${ }^{17}$ The concept is the result of a study of large US companies, which concludes that the closed model of innovation no longer meets the increasing complexity in technology management and global market service.

Thus, the mobility (dissemination, disclosure...) of knowledge between companies and research centres is essential to the success of the innovative process in a network society. ${ }^{18}$

15 B. Lundvall, 'National Innovation Systems - Analytical Concepts and Development Tool', Industry and Innovation, vol. 14, 2007.

16 Ibid., p. 99.

17 H. Chesbrough, 'Open Innovation: The New Imperative for Creating and Profiting from Technology', HBS Press, 2003, p. 20.

18 Ibid, p. 193. 
Through this logic, innovation must be developed within and outside laboratories as well as research and development departments of organizations, being a dynamic process that involves practices such as the exchange of information in networks, exchange of people, collaborative processes, joint ventures, spin-offs and licensing agreements - all of which being able to benefit from the information disclosed by patent systems.

This process of interaction and exchange of knowledge in the context of a national innovation system can follow a specific model according to the triple helix theory, by Etzkowitz and Leydesdorff, one of the most mentioned theories in the elaboration of public policies for innovation and technological development. In short, the triple helix consists of a model of interaction between university, government and industry, from the idea that only the articulation between these three spheres can provide a pivot level appropriate to the development and consolidation of a national innovation system. ${ }^{19}$ This theory is important in the context of this research because it levers the idea of innovation and its articulation with supporting regulatory systems (the patent system being the most crucial one) to a very central place in terms of the interpretation of knowledge production and dissemination. It means that innovation is, more than ever, what articulates three of the main structures of one society: university, industry and government.

Etzkowitz and Leydesdorff describe an evolutionary path to its configuration from a system (triple helix I) in which the Nation-State covers the universities and industry, directing their relations to a second system (triple helix II) based on different institutional spheres, and finally a third model (triple helix III), in which the trilateral networks and hybrid organizations generate a dynamic knowledge infrastructure, whose centre is the University and whose aim is fostering innovation. ${ }^{20}$

\section{Figure 2: Model of the Triple Helix III}

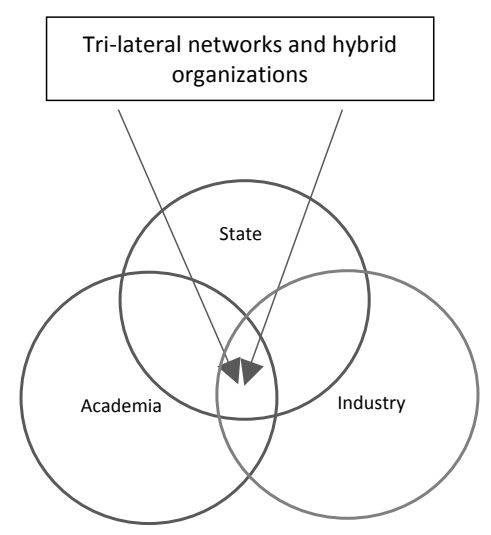

Source: Etzkowitz \& Leydesdorff, 2000

19 H. Etzkowitz \& L. Leydesdorff. 'The Dynamics of Innovation: from National Systems and 'Mode 2 to a Triple Helix of university-Industry-Government Relation', Research Policy, no. 29, 2000, 109-123. 
To Etzkowitz, the university becomes the centre from which emanate the main ideas and activities that support innovation in the industry, which sets up the concept of the entrepreneurial university. This is justified by the fact that universities, being the most creative spaces of a society, should incorporate this "new mission", associated with economic and social development. For the author, the concept of the entrepreneurial university portrays a natural evolution of the university's role in the same way that integrated scientific research in the late nineteenth century did. The last one encountered resistance from professors who said the role of the university was only to educate, and the same is happening to the entrepreneurial university. This new model for the university should integrate incubators and activities for the productive sector, from a non-linear view of the concept of innovation. ${ }^{21}$ In short, the triple helix model inaugurates a new era for science and innovation, where the articulation between knowledge creation and dissemination impregnate the main structures of societies reshaped by this new model. Knowledge has changed, and it is highly dependent on the existence of patent systems today.

To conclude this Section, in the light of this theoretic view of the main aspects of innovation, the next sections of this dissertation discuss how innovation is transferred and protected. The concept of disclosure is analysed as a key to understand the patent system, a system designed to foster innovation, through the disclosure of technological information, in a global, intercultural space. In the following sections, the main aspects relevant to this association are presented in order to set up an integrated perception of disclosure, innovation and the patent system.

\subsubsection{Patent rights as intellectual property rights related to innovation - historical development and main current definitions}

The concepts and theories presented in this Section give rise to taking intellectual property rights from an internationalized perspective, which allows understanding the functions and effects of the intellectual property (and particularly the patent) system for international trade and global market, in terms of knowledge transfer and scientific development. Moreover, they illustrate the interdisciplinary nature of intellectual property rights in light of a trend to integration and harmonization observed in the evolution of correlated international agreements.

This Section also brings examples of difficulties in internalizing these agreements into national jurisdictions, due to cultural differences and problems in incorporating their guidelines and concepts in national law. Bringing these concepts and theories are important to understand the empirical analysis presented in Chapters 5, 6 and 7 of this dissertation and on interpreting its main conclusions as basis to justify the existence of the patent system and to cooperate with its improvement.

21 H. Etzkowitz, 'The Evolution of the Entrepreneurial University', Int. J. Technology and Globalization, vol. 1, no. 1, 2004, p. 76. 
For WIPO, intellectual property refers to creations of the mind, such as inventions, literary and artistic works, designs and symbols, names and images, when used in commerce. That requires law protection and, dealing with the complexity and reach of the definition, a division into sub-concepts. Hence, IP is divided in patents, trademarks, industrial design, geographical indications and copyrights (and related rights). ${ }^{22}$

Conversely, despite the young definitions or regulations brought by WIPO since its foundation, in 1967, the history of intellectual property is much older, presenting the background of two distinct visions of symbiotic competition, highlighted by May \& Sell. ${ }^{23}$ On the one hand, it has the benefit of monopoly, which favours the creator; on the other, the idea that knowledge should be made public in order to promote the community, considering, as well, as a good belonging to all the people. ${ }^{24}$

In analysing this historical process and the long evolution of IP, the authors demonstrate that most historians refer to the letters of privilege concessions in the Middle Ages as its starting point. Another important milestone is the Statute of Monopolies, sanctioned by the English Court in 1623, already setting rules and protection periods. ${ }^{25}$

Until the mid-nineteenth century, intellectual property is strictly constrained to the principle of territoriality. However, the industrial revolution, accelerating the development of new technologies and the circulation of ideas and goods strongly demanded the need for international cooperation among States on intellectual property. ${ }^{26}$

Intellectual property rights, from the letters of privilege and until today, have enabled inventors or creators to earn recognition or financial benefit from what they invent or create. Therefore, intellectual property is closely related to the concepts of creation, innovation and knowledge dissemination. IP is historically defined as a means to strike the right balance between the interests of innovators and the wider public interest. By finding this balance, the IP system developed based on the intentions to foster an environment in which creativity and innovation can prosper. ${ }^{27}$

The history of IP rights is related to the history of scientific advance, especially through the disclosure of strategic information. Disclosure is only effective when correlated with the protection and compensation of all the efforts dispensed to promote an invention or a creation. Therefore, this can also be considered as a history of economic development, insofar the new scientific and technological paradigms increasingly required more sophisticated and globalized protection instruments and regulations.

However, the history of IP rights shows that this idea has never been devoid of controversy, and there has always been a multiplicity of voices, opinions and demands

22 See: WIPO, What is Intellectual Property? 2015, http://www.wipo.int/edocs/pubdocs/en/intproperty/450/wipo_pub_450. pdf, (accessed 12 April 2018).

23 C. May and S. Sell, Intellectual Property Rights: a critical History, London, Lynne Rienner Publishers, 2006.

24 Ibid.

25 Ibid.

26 P. Drahos, The Universality of Intellectual Property Rights: Origins and Development, Intellectual Property and Human Rights, World Intellectual Property Rights Organization (website), 1999.

27 May and Sell, 2003. 
related to the structure of the IP international system. That means it is a history of contestations and of clash of different interests. Below follows a brief description of the main controversies and counter-arguments important to elaborate a clear definition of IP rights. The intention of bringing up this discussion is to connect these arguments with the findings of the present thesis. It is believed that the key to respond to this (still unsolved) debate over patent rights is the definition of disclosure, brought into new light when associated with translation and dissemination of knowledge.

Machlup and Penrose describe the patent controversy in the Nineteenth Century as a very turbulent event, which included various types of anti-patent movements in different parts of the world, related to free trade movements. Therefore, recent claims for reform and agitation around whether the patent system really spurs innovation by rewarding inventors for their efforts and serves the public good, being really necessary to scientific and technological development, are not new developments. ${ }^{28}$

As an example of current discussions that recover old arguments, the Journal "The Economist" has published an entire edition focusing on this same liberal approach that defended the abolition of the intellectual property system during the nineteenth century. The Economist was founded by opponents of the Corn Laws ${ }^{29}$, and represented an enthusiastic vehicle for promoting the abolitionist movement, being part of the free trade movement.

A controversial article of the Journal seems to go back to a nineteenth century scenario, while it brings back long discussed arguments. The article brings the whole trail of the Journal in opposing intellectual property rights backed by a pro free trade speech. It relates that an editorial published on July $26^{\text {th }}$, during 1851 , the same year as "The Great Exhibition of London", was already bringing reasons for abolishing the IP system that are still valid today. Some of these reasons are listed and discussed in the article, as if they were still plausible as a means to confront IP regulation nowadays. ${ }^{30}$

According to the arguments already present in the edition of 1851, the grant of patents "excites fraud, stimulates men to run after schemes that may enable them to levy a tax on the public, begets disputes and quarrels between inventors, provokes endless lawsuits [and] bestows rewards on the wrong persons."

The Journal sees these arguments as a first reference to what is now called "patent trolls" and continues bringing this old discussion in a new package. There are other claims that, in the same way, pretend to be new. The Journal defends the idea that patents rarely generated security for really good inventions, by giving the example of inventions of all

28 F. Machlup and E. Penrose, The Patent Controversy in the Nineteenth Century, The Journal of Economic History, New York, Economic History Association, vol. 10, no.1, pp. 1-29, May 1950, http://c4sif.org/wp-content/uploads/2010/09/MachlupPenrose-The-Patent-Controversy-in-the-Nineteenth-Century-1950-b.pdf, (accessed 12 April 2018).

29 Corn Laws refer to any of the regulations governing the import and export of grain in England. They were designed to keep grain prices high to favor domestic producers. The laws were protective measures that imposed steep import duties and, therefore, raised food prices. Source: Encyclopaedia Britannica, http://www.britannica.com/event/Corn-Law-British-history (accessed 12 April 2018).

30 'A question of utility', The Economist, 8 Aug 2015, http://www.economist.com/node/21660559, (accessed 12 April 2018). 
times, like the spinning machines, the railways, the steamships and the gas lamps, that did not "need" patents to be created. It also alleges that the industrial revolution did not "need" an IP system to happen.

The article goes on, presenting additional arguments, such as: patents were helping large corporations to monopolize entire industries; the experience of the Netherlands to temporarily abolish the patent system in the XIX century, in order to promote development via imitation, shows that development is possible without intellectual property; it was the pressure exerted by the association to the WTO that forced countries such as China to adopt intellectual property regulations.

The final (and herein the most important) arguments, which are also key to respond to all the others are: patent writing is obscure and made in a way that disclosure does not allow others to understand it and use it as a source of technological learning; generic drugs have much lower production costs and negotiated dealt to the lack of costs with protection, so that biotech researches would gain with the abolition of patents; the free software movement was a natural reaction to IP rights, and the development of the Android system is an example of how successful it can be; drugs such as aspirin were developed under low protection; among some other examples that try to show, through numbers, that the patent system does not foster innovation and is not a lever for economic development.

Figure 3: The Economist Cover - August 8, 2015

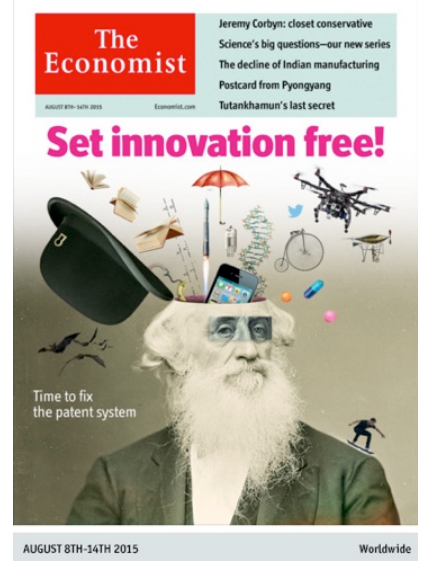

Source: http://www.economist.com/

All those arguments have already been refuted by the idea of the social contract related to patent rights. ${ }^{31}$ In this respect, the aim of the present research is to update the mentioned theory giving new light to the concept of disclosure. Thus, the conclusions of

31 For an in-depth definition of the social contract as relating patent grants to the disclosure of technological information, see Sections 1.2.1 and 1.2.2 of this dissertation. 
the present thesis strengthen the reasoning of the social contract through the definition of the patent system as a system based on translation and through the demonstration that machine translation has universalized the dissemination of the disclosure of patent information.

Curiously, and not for no reason, hyper liberal approaches, such as the one presented in the Journal, tend to repeat the same urgings that are persistently repeated by radical socialist, anti-TRIPS speeches, and, at least in this sense, they meet, apparently for opposed reasons. The fact is that these arguments are easy to deconstruct, as they make no sense in a network society, especially when it comes to a context where open innovation, interactivity and various new forms of scientific cooperation are changing the rhythm of economic and scientific development. In this context, disclosure became more operative and more important for innovation.

Another important counter-argument is that patent databases, in their function to disseminate patent information, have proven to be an excellent source of technological knowledge and have long been used strategically by firms and scientific institutions, as exhaustively debated in previous research, which attest it with dependable numbers and arguments. $^{32}$

In this regard, the present thesis intends to demonstrate that the evolution of the patent system brought by marked advantages and functionalities in terms of disclosure. For example, a system such as the PCT clearly shows that only a systematized structure can lead to improved trade relations and property regulations. As a follow-up to consistent studies which make it clear that such opposing arguments to the patent system are not to be taken seriously, the present research aims to indicate that this is especially valid when the current configuration of scientific/technological development and trade relations are considered.

Along the same lines, for Sell, the history of intellectual property protection proclaims a relationship between three major factors, represented by the conceptions of ownership, authorship, and invention. These concepts change in a historical non-linear movement, which involve legal institutionalization of these changes in law. Likewise, new power relationships and privileges favour some at the expense of others, which situate IP rights within broader historical structures of global capitalism, sometimes reproducing and sometimes transforming these structures. Sell establishes some conditioning aspects for the notion of intellectual property defending its history as contingent and rife with unexpected consequences, in contexts of path dependence, and circumstances where institutions deviate from their original aims: ${ }^{33}$

32 This discussion follows in Chapters 4 and 5 of this dissertation.

33 S. Sell, 'Intellectual Property and Public Policy in Historical Perspective: Contestation and Settlement', 38 Loy. L.A. L. Rev. 267, 2004, p. 267, http://digitalcommons.Imu.edu/IIr/vol38/iss1/6 (accessed on 12 April 2018). 
Depending on the world in which one lives, piracy may be construed as theft or as an important tool of public policy. Whether one is talking about books or drugs, movies or software, the definition of what constitutes property depends upon time, place, geography, constellation of interests, degree of competition present, stage of economic development, and power. Insofar as intellectual property is an instrument of public policy, all of these factors are relevant. ${ }^{34}$

However, it is possible to observe a tendency of an increasingly harmonized and internationalized IP system, especially when it comes to patent rights, as will be discussed in Chapter 6, section 6.1, which refers to the Patent Cooperation Treaty (PCT). In this respect, Sell's viewpoint deserves a more attentive interpretation, as intellectual property assumes a central, globalized role, in an era that requires high costs for scientific development and new paradigms that affect trade and innovation.

In this regard, in the current scenario of innovation, piracy or counterfeiting represent more a threat to established law and to scientific development than to corporations that are only interested in profiting from new technologies. Besides, patent protection isn't eternal, as its term ends in 20 years, in most of the countries - that being the minimum term according to the TRIPS Agreement, but the maximum term in practice. ${ }^{35}$

Therefore, the notion of intellectual property, as a founding concept of this research, is more complex and broader than the classic definitions or isolated approaches of international conventions and treaties can make it seem. Thus, it cannot be depicted through one-dimensional methods, as it involves complex thinking and an attitude that should consider its current function and impact in global development.

On this matter, intellectual property may also be described as the set of principles and rules governing the acquisition, use, exercise and loss of rights and interests of differentiating intangible assets that are likely to be used in trade. ${ }^{36}$ As may be observed, it is a quite general definition, bringing the idea of rights over intangible assets, using, thus, an economic concept.

For the most important references on intellectual property, it may be said that IP has three important goals: to encourage innovation, to reward the inventor and to ensure that innovation is widespread socially, referring to the already mentioned social contract. The first two goals are meant to grant creators exclusive ownership of their invention, even if temporarily, allowing them to earn profits as a reward for their inventiveness and in return for their investment. The third goal requires that the inventor and the owner of the invention, who have exclusive rights over it, make it available to society so that others can explore it. ${ }^{37}$

34 Ibid., p. 268.

35 Article 33 of the TRIPs Agreement provides that the term of protection for patents shall not end before the expiration of a period of twenty years counted from the filing date. See:WTO, Agreement on Trade-Related Aspects of Intellectual Property Rights (TRIPS Agreement), 1994, https://www.wto.org/english/docs_e/legal_e/27-trips.pdf (accessed 24 April 2018).

36 N. P. Carvalho, A estrutura dos sistemas de patentes e de marcas: passado, presente e futuro, Rio de Janeiro, Lumen Juris, 2009.

37 I. Lianos, 'A Regulatory Theory of IP: Implications for Competition Law', London, CLES Working Paper Series, 2008, http:// discovery.ucl.ac.uk/10045081/ 
In fact, that is how innovation and scientific development can be achieved. It is expected that when the inventor feels encouraged to develop innovations in exchange for a reward, intellectual property will fulfil one of its main functions, which is to encourage innovation. In other words, only encouraging and rewarding the creator or individual inventor (with the property and benefits associated with the market) society can ensure that other creators will continue developing socially valuable innovations. That will help to make science and technology more available to the whole society, creating well-being and life quality in areas such as information and communication technologies, public transport, health and safety. ${ }^{38}$

Lianos' definition of IP rights is closely associated with the ideas of disclosure and dissemination of valuable information. He points to differences between the economic theory of property rights and the economic theory of intellectual property. For this author, the economic theories related to intellectual property tend to describe the functions and economic advantages of intellectual property by associating it with theories and arguments that explain its existence. One of them is the "free rider" argument, which justifies the existence of an IP system through the necessity to confer property rights in order to avoid congestion externalities, an argument that is refuted by Lianos through the idea that scarcity may be a rationale belonging to physical property, but not necessarily to intellectual property. ${ }^{39}$

The other approach mentioned is the one that considers Intellectual property as business assets, focusing on the cost of information. According to the economic arguments belonging to this tendency, intellectual property rights should make it easier for innovators to commercialize their inventions and conclude transactions with other economic units. Intellectual property rights, in this case, allow the existence of a market for the transformation of the inventions into commercially viable products. In virtue of this, IP rights also open doors to inventors to develop commercially valuable products without having to bargain in each firm for the necessary capital and commercial expertise to keep their activities. This, however, is not the same for tangible property rights, as transaction costs are higher concerning intellectual property, because of the difficulty of identifying such property. ${ }^{40}$

On the other hand, IP rights are depicted as related to the intervention of the public authorities in protecting intellectual creations and inventions. Lianos also enhances the fact that IP rights may be considered as more systematic and intensive than rights related to tangible property, as the first ones start from the grant of the intellectual property rights, requiring examination which involves specific knowledge and specific communication rules. In this sense, it is important to understand the two (tangible and

38 For understanding the economic function of the IP system, see: C. May and S. Sell, Intellectual Property Rights: A Critical History, London, Lynne Rienner Publishers, 2006, pp. 17-22.

39 Ibid., pp. 7-14.

40 Ibid. 
intangible) property systems to recognise the peculiarities related to IP rights. IP rights then require the understanding of IP systems or even as the IP system as a system.

The example given by Lianos is the examination of the conditions of patentability being done by a Patent Office (which is related to a much broader and sophisticated system, as described in Chapter 7). Therefore, the intervention of regulatory agencies represents one of the most important differences between intellectual property rights and property rights on physical things.

To this idea, it is possible to add the fact that the intellectual property system is a global system, built on the basis of a whole set of regulations defined by international guidelines. That makes Lianos's position peculiar in defining intellectual property rights. He describes them in terms of the emergence of particular discourses, which are often the response to a situation of dispute between policies pursuing different objectives. ${ }^{41}$ In this regard, the property rights rhetoric can be seen as instrumental in providing different degrees of deference or rejection to intellectual property rights during different periods and contexts.

According to Fisher, the term "intellectual property" may be associated to a loose cluster of legal doctrines that regulate the uses of different sorts of ideas and insignia. ${ }^{42}$ For Barbosa, whose position is also relevant in the light of the present research, the notion of intellectual property relates to an internationalized field of law and covers industrial property, copyrights and a number of other intangible assets. ${ }^{43}$ However, for the same author, the most important agreements and guidelines related to the notion of intellectual property need to be interpreted through the logics of a coherent development that, in fact, links these objects ${ }^{44}$ :

There is, thus, currently, the notion of intellectual property as a chapter of law, extremely internationalized, comprising the field of industrial property, copyright and other rights related to intangible assets of various genres. However, neither the Convention of WIPO, merely adjectival, not even the latest TRIPS Agreement, of the World Trade Organization, tried to structure the legal common rules to each and every chapter of the Legal Encyclopaedia. The purpose of this last international law is not, in fact, the construction of any legal system, but the overthrow of the national legal individuality, which can certainly lead to a harmonization but not necessarily to a logical development of a common substrate, unless inductively. ${ }^{45}$

41 Lianos, 2008, p. 54.

42 W. Fisher, 'Theories of intellectual property', originally published in Stephen Munzer, ed., New Essays in the Legal and Political Theory of Property, Cambridge University Press, 2001, https://cyber.harvard.edu/people/tfisher/IP/Fisher_IP_Theories.pdf (accessed 4 December 2018).

43 D. Barbosa, Uma Introdução à Propriedade Intelectual, Lumen Juris, 2010, p. 10.

44 Ibid.

45 D. Barbosa, Uma Introdução à Propriedade Intelectual, Lumen Juris, 2010, p. 10. Underline added for emphasis. 
Conjointly, Barbosa points out differences between jurisdictions and the diverse views taken on the concept of intellectual property nationwide. He gives the example of the French Intellectual Property Code, from 1992, which he considers as an inaugural attempt for an integrated body of national rules on the subject. Besides, he mentions the French Civil Code as a rational parameter and example of systematization that should be followed by other States. He mentions the French experience as a legal consolidation of existing rules in a nation. ${ }^{46}$

The French model could be considered, in this sense, as an example to be followed for the development of a set of regulations on intellectual property, in which not only a professional practice field persists, but gives turn to the institution of an administrative object which is both national and supranational. ${ }^{47}$ That idea is harmonic to trend to more integration and harmonization and to what Lianos expresses as a need to interpret IP rights through a regulatory specific approach, conceptualizing IP as a form of regulation, that should provide a useful theoretical basis for a better understanding of the interactions between competition law and intellectual property. ${ }^{48}$

Barbosa compares different legal approaches on intellectual property. The new code of French intellectual property, for example, lists, among its objects, semiconductor products, breeding, typefaces and fashion creations, in different regimes. The American Law encompasses, in addition to traditional forms, two patent systems for breeding, the protection of semiconductor topographies and specific repression for misleading advertisement, regarding copyrights, whether as legal or jurisprudential creation. ${ }^{49}$ In this sense, Barbosa's ideas show that the definition of intellectual property is highly dependent on specific regulatory systems and on what they encompass (or not) as objects of protection. This author additionally mentions that the possibilities do not cease in what is already built in terms of national, regional or international law, as intellectual property is so complex as to build more and more intermediate legal forms between copyrights, patent law and other ways of protection, creating not only legal hybrids, but new protection institutes.

The way international intellectual property treaties and agreements is internalized in national jurisdictions depends on a variety of cultural and legal aspects peculiar to each national system. One example is presented by Barbosa and Barbosa. ${ }^{50}$ The authors propose a critical assessment on the Brazilian post-TRIPS new set of regulations on intellectual property, starting from Act N. 9729/96, the so called "Industrial Property Act", which, according to them, does not regulate, as proposed, rights and obligations relating to industrial property. Such an argument is justified by a number of shortcomings and extrapolations already shown from its own design process. ${ }^{51}$

46 Ibid.

47 Barbosa, 2010, pp. 12-14

48 Lianos, 2008, p. 54

49 Barbosa, 2010, pp. 10-15.

50 P. M. Barbosa and D. Barbosa, O Código de Propriedade Industrial conforme os Tribunais, Lumen Juris, 2011, p. 3.

51 Ibid., pp. 3-9 
The act, according to the authors, should have been integrated into the national legal system as a Code, which better characterizes its true function in the legal system, but it did not happen, for reasons that, according to them, are unjustified. Being considered as a Code but approved as an Act, this Act represented a hindrance in a necessary debate of those who were interested in its results: society, in general, and, in particular, the productive sector. The Act was therefore named as an Act due to the speed with which this particular instrument accounts for pending approval. ${ }^{52}$

The scope of the Act $9729 / 96$ also does not reflect, according to the authors, ${ }^{53}$ the complexity with which the Berne Convention, in the late century XIX, and the Convention of the Paris Union described the intellectual property rights. It also does not reflect the definitions of industrial property in Sections 1-7, Part II, of the TRIPS Agreement. ${ }^{54}$ The Act fails to include in its text agricultural and extractive industries, thus neglecting important sectors of the Brazilian economy. ${ }^{55}$

Another example of the extent to which internalizations of the same IP international guidelines and agreements can be discrepant is given by Larroyed \& Pimentel, who describe the differences between the evolution of software protection in Brazil and in Russia. Their study is illustrative in terms of showing the space of IP regulation as an intercultural space. It demonstrates how different two national approaches can be in terms of intellectual property legislation and how dependent on a series of (historical, ideological, political, etc.) aspects IP regulation can be. ${ }^{56}$ Software protection is regulated by Chapter 4 of the Civil Code in Russia ${ }^{57}$, and by the Act No 9.609/98 in Brazil. ${ }^{58}$

The Russian regulation is much more detailed than the Brazilian Act and contains remnants of an old face of the USSR. ${ }^{59}$ The Brazilian Act is, on the other hand, very general, in which it may hinder the effective protection of software and decrease the credibility of intellectual property instruments. ${ }^{60}$ Such discrepancies, associated with ideological, political or legal cultures still demand more comparative studies in the field of intellectual property, specially concerning the patent system.

The theories mentioned above prove the complexity of conceptualizing intellectual property. As seen, IP is derived from the notion of ownership but pronouncedly

52 lbid., pp. 3-9

53 Barbosa and Barbosa, 2011, p. 4.

54 TRIPS Agreement, Part II, Sections 1-7.

55 Barbosa and Barbosa, p. 5.

56 A. Larroyed and L.O. Pimentel,'A atual legislação de proteção intelectual para software na Rússia-conceitos e entendimentos', X Congresso de Direito da UFSC, 2015, https://drive.google.com/file/d/0BzJB68887u_nRm1GclJiNjRWSUk/view (accessed 12 April 2018).

57 Russia, Fundamental Principles of Civil Legislation of the U.S.S.R. and Union Republics, 1961, reviewed in 2006, http://www. wipo.int/wipolex/en/details.jsp?id=6775 (accessed 12 April 2018).

58 Brasil, Lei № 9.609, de 19 de fevereiro de 1998. Dispõe sobre a proteção da propriedade intelectual de programa de computador, sua comercialização no País, e dá outras providências, http://www.planalto.gov.br/ccivil_03/leis//9609.htm (accessed 12 April 2018).

59 Russia. The Criminal Code of The Russian Federation. Adopted by the State Duma on May 24, 1996. Adopted by the Federation Council on June 5, 1996. Federal Law No. 64-FZ of June 13, 1996 on the Enforcement of the Criminal Code of the Russian Federation, http://legislationline.org/documents/section/criminal-codes/country/7 (accessed 12 April 2018).

60 Larroyed \& Pimentel, 2015. 
different from tangible property. In virtue of this, the idea of intellectual property can be understood from theoretical references of law and economy. To Leopardi and Esteves ${ }^{61}$, it is recommendable to integrate the views of the legal and economic plan on property rights through the development of an interdisciplinary concept of IP, bringing together elements of both.

The authors also reiterate the importance of opening up an economic field to analyse property rights, referring to concepts like externalities and opportunity cost. Starting from an interdisciplinary view, which links property rights to the notion of assets and the idea that these rights have a practical impact on the social and economic sense, it is possible to address the concept of intellectual property from a richer perspective than through law in isolation. ${ }^{62}$

As shown, comparative works clearly demonstrate how variable the theoretical, legal and practical methods can be when it comes to intellectual property and how necessary the efforts for globalization and harmonization still are, for building a coherent system. That may happen through international law, in the form of agreements and guidelines, and may also improve through more advanced communication systems, which involve more attention to the area of IP and patent rights as an intercultural space, where language and translation play a central role, as will be discussed in the following chapters.

As the focus of this research is the patent system only, the next sections of this work propose an interpretation of the nature of the patent system necessary to understand its current configuration. It debates the patent system and the function of disclosure in terms of a relation between patent information and economic development through the formation of competitive markets.

\subsubsection{From the regime of the Convention of Paris to the international intellectual property regime of the TRIPS Agreement: a trend to integration and harmonization}

As discussed above, Intellectual property rights originate in the exercise of human intellectual creation. Furthermore, intellectual property law can be considered as arguably (and increasingly) an internationalized field of law, which includes the field of industrial property (patents, trademarks, industrial designs), copyrights and other rights related to intangible property.

This understanding has been consolidated since 1967, with the creation of the World Intellectual Property Organization (WIPO), but is also a result of the release of a previous first convention on IP, in an effort to integrate intellectual property protection worldwide. Being one of the first intellectual property treaties, the Paris Convention was adopted on 20 March $1883 .^{63}$ The provision of the convention was followed by a trend

61 M. Leopardi and H. Esteves, Droits de proprieté - éléments pour la construction d'un concept interdisciplinaire, XIII Colloque International de l'Association Charles Gide pour l'Étude de la Pensée Economique, 2010.

62 Ibid.

63 Ibid., p. 10. 
to harmonize and integrate IP rights in international law, marked by some large steps, as the settlement of the TRIPS Agreement, ${ }^{64}$ the Patent Cooperation Treaty ${ }^{65}$ and the, more recent and still not in force, European Patent with Unitary Effect. ${ }^{66}$

This trend to integration is deeply associated with the advent of network societies, defined as scenarios of relations mediated by information and communication technologies, which embrace specific social structures related to the possibilities of this new locus. The scenario of a network society is, accordingly, characterized by enabling a large volume of multimodal information, simultaneous and multiplexed communication of many-to-many, ${ }^{67}$ and, in the case of IP rights, enabling a fragmented structure to interact and communicate, and to, finally, be seen as a coherent whole that constitutes a system ${ }^{68}$.

The existence of networks promotes a radical transformation of economic and social relations. Science and technology institutions begin to restructure such relationships in order to allow the emergence of new types of producers, distributors and communities. ${ }^{69}$ Speaking about knowledge production and transfer, this scenario leads to the need to develop transition policies for the network society and demands a more harmonized and globalized intellectual property system, which should also follow the logic of the network. In such context, it is worth to describe how this trend to integration was incorporated by a succession of IP (hereof patent, in particular) related international agreements.

The Convention of Paris inaugurated the international intellectual property regime. It can be said that this is a successful regime, since the Convention has been in force for over 120 years. This success has been associated with the fact that the Convention was not directed to the standardization of substantive rules regarding patents and the other institutes of intellectual property. On this basis, a possible interpretation is that the roots that sustain the longevity of this code are directly related to certain autonomy of the states in the management of intellectual property, a feature that changes with the advent of the TRIPS Agreement, which was accused by its opponents of dishonouring the principles of autonomy and territoriality. ${ }^{70}$

In this sense, there are other important features and principles of the Convention of Paris which are distinct to the regime established later by the TRIPS Agreement. Among the principles mentioned are: the principle of territoriality, the principle of national treatment, the principle of priority, the principle of independence. The last one is

64 WTO, Agreement on Trade-Related Aspects of Intellectual Property Rights (TRIPS Agreement), 1994, https://www.wto.org/ english/docs_e/legal_e/27-trips.pdf (accessed 24 April 2018).

65 See Section 6.1 of this dissertation.

66 See Section 6.2 of this dissertation.

67 M. Castells and G. Cardoso, The Network Society: From Knowledge to Policy, Washington DC, Johns Hopkins Center for Transatlantic Relations, 2005.

68 See Chapter 3 of this dissertation.

69 M. Castells and G. Cardoso (2005).

70 C. Ardissone, 'Ideias, Instituições e Lideranças na Política Brasileira de Propriedade Intelectual: uma Abordagem Comparada dos Governos Fernando Henrique Cardoso e Luiz Inácio Lula da Silva (1995-2010)', PhD Thesis, Catholic University of Rio de Janeiro, 2011, p. 164. 
fundamental to this analysis, as it provides that the grant of a patent in one of the member states does not require that it is granted in other States. In addition, different from TRIPS, the Paris Convention cannot be considered as a minimum standard agreement. In this regard, TRIPS was configured as a single undertaking convention, linked to the whole set of WTO agreements, implying an all or nothing strategy and leaving two options to the potential member States: either committing to all agreements or to none of them. ${ }^{71}$

In the period prior to the TRIPS Agreement, the States enjoyed considerable discretion on their national regulatory scenarios of intellectual property, maintaining their sovereignty, and obeying certain general founding principles. ${ }^{72}$ One example is the case of Brazil. Brazil did not allow the granting of patents in some technological fields beforeTRIPS, such as patents related to some kinds of medication. After TRIPS, the country changed its legislation in a way that the so called "pipeline" or patent prosecution highway (PPH) was allowed. This permitted that many patents of medication that were not valid before in the national territory had a simplified process of validation. ${ }^{73}$ The event generated adverse reactions in the national and international level and a still lively discussion about TRIPS and the new legislation.

This transition shows a process similar to what happened to intellectual property during the industrial revolution. The current influence of this new dynamics which reconfigure modes of production and spatiality, now associated with the phenomenon of globalization, lead to changes in principles which underlie intellectual property. Interestingly, territoriality, once again, is central. In consequence, the power of the States moves partially in another direction, associated with these new trends and with the requirement of a single undertaking Agreement. ${ }^{74}$

One cannot deny that the advent of the TRIPS Agreement during the Uruguay Round of GATT (General Agreement on Tariffs and Trade) in 1994 was motivated by the interest of large enterprise groups to establish a link between intellectual property and trade. In this sense, the agreement was the result of the relationship between several high-tech companies, especially from the pharmaceutical and software sectors. ${ }^{75}$ The purpose of these companies was to raise international levels of protection of intellectual property rights ${ }^{76}$ since they were losing considerable amounts of revenues in large markets such as Brazil, Russia and China. ${ }^{77}$ As said, the advent of the Agreement caused some heated reactions.

71 See: D. Gervais, The Internationalization of Intellectual Property: New Challenges from the Very Old and the Very New, Fordham Intellectual Property, Media and Entertainment Law Journal, Vol. 12, no 4, 2002, https://ir.lawnet.fordham.edu/cgi/ viewcontent.cgi?article=1232\&context=iplj (accessed 19 November 2018).

72 Ibid., p. 167.

73 Ardissone (2011), pp. 248-249.

74 See: N. Brenner, Beyond State-Centrism? Space, Territoriality, and Geographical scale in Globalization Studies, Theory and Society, Kluwer Academic Publishers, 1999, 39-78. https://link.springer.com/content/pdf/10.1023/A:1006996806674.pdf (accessed 13 April 2018).

75 Ardissone, 2011, p. 167.

76 P. Drahos, 'Global Property Rights in Information: the story of TRIPS at the GATT', Prometheus, vol. 13, no 1, 1995, pp. 1-4.

77 M. Vermeer, 'A new era in Russian copyright law: protecting computer software in the post-Soviet Russian Federation', Transnat'I L. \& Contemp. Probs., 1995, p. 171. 
In summary, it is possible to assume that the strategy contained in the TRIPS Agreement did not arise suddenly. It evolved over years of pressure from countries interested in stricter rules of protection, and over a number of other international agreements involving intellectual property. ${ }^{78}$ This process is easier to illustrate through the study of the evolution of the IP legislation in socialist countries. Russia is one of the most emblematic cases. The study of Vermeer ${ }^{79}$ demonstrates, clearly, how Russia, from the fall of the Soviet Union, was resisting the international pressure to adapt its legislation to the required parameters, with loopholes for counterfeiting even in the current legislation. Russia's late entry into the WTO also reflects such resistance. ${ }^{80}$

Chang believes the purpose of the TRIPS Agreement was to crystallize the technology gap - hence the disparity also in the economic and social level - that exists between the highly developed countries and developing countries, minimizing the threat of loss of economic hegemony by the richest nations. ${ }^{81} \mathrm{He}$ justifies his thesis stating that the same strategies used by developed countries to achieve the levels of knowledge they have today are denied to developing countries, to prevent them from climbing the same "ladder" used by the former. He argues further that, during the nineteenth century, intellectual property regimes were used much more in favour of a nation in growth in terms of its possibilities to raise technological learning, for example, by importing technologies. $^{82}$

At this point, it should be noted that these early intellectual property rights regimes (IPRs) were very "disabled", judging by today's standards. In many countries, the patent system did not present clear disclosure requirements. It also was characterized by very high costs to proceed to usage requirements. Most patent regulations were described as negligent in terms of checking the originality of the invention. In the US, for example, before the establishment of new regulation in 1836, there was no requirement of novelty to grant a patent. This scenario could be characterized by strategies to the patenting of imported technologies, as it encouraged patentees to profit from false patents. ${ }^{83}$

Thus, a fundamental reflection is related to the fact that TRIPs, by establishing a relation between IP rights and the World Trade Organization, affected the correlated international legal system. In this regard, if TRIPS is taken under the logic of a globalized economy, or, in other terms, a network society, a harmonized international IP system, having an organized set of rules and guidelines for regulations, and a higher level of adherence over the world, is much more pertinent to the rationale of the current economic scenario

78 See: P. Drahos, 'Global Property Rights in Information: the story of TRIPS at the GATT', Prometheus, vol. 13, no 1, 1995, pp. 1-4; R. Fiani,'Saber tecnológico para quem e para o quê? A questão das patentes', Anais da 64a Reunião Anual da SBPC, São Luís, 2012.

79 Vermeer, 1995.

80 See: A. Larroyed and L. O. Pimentel, 'A atual legislação de proteção intelectual para software na Rússia - conceitos e entendimentos', X Congresso de Direito da UFSC, 2015, https://drive.google.com/file/d/0BzJB68887u_nRm1GclJiNjRWSUk/ view (accessed 12 April 2018).

81 Chang, H-J., Kicking Away the Ladder-Development Strategy in Historical Perspective, London, Anthem Press, 2002, pp. 1-14.

82 Chang, 2002, pp. 38-98.

83 Chang, 2002, p. 146. 
than a fragmented set of legal statutes related to divergent expectations on intellectual property.

A strong argument in support of TRIPS is, according to the same logic of a network society, the contemporary significance of the knowledge economy. For the contemporary economic structure related to science and technology, private intellectual property represents a major component, especially due to the importance of international trade, which leads to necessary demands of international regulation. ${ }^{84}$

The Agreement also represented a very significant change both to the international trade system and to intellectual property rights, as the last ones, before relegated to being peripheral to the jurisdiction of trade institutions, assumed a status of a core obligation of the global trading system. Such displacement is undoubtedly a definite change of direction for international trade and, contrary to what is argued against TRIPS, can signify a powerful global development policy. ${ }^{85}$

As described by Willis under a set of WTO's positions related to TRIPS, the absence of protection constitutes significant non-tariff barriers to trade. In this sense, the WTO defends the idea that TRIPS is the result of an international demand for a robust multilateral framework to replace what was an ineffective patchwork of pre-existing IPRs agreements. ${ }^{86}$ All those changes have provoked strong effects on and were pervaded by language and translation issues, as detailed in Chapters 5, 6 and 7 of this dissertation. Likewise, describing this continuous trend to integration in international patent law is crucial for underpinning the idea that (especially machine) translation has universalized the dissemination of the disclosure of patent information, following (when not provoking) the same trend to integration.

In this case, integration leads to legal certainty and transparency. Putting in place a global minimum standard of IP protection obligatory to all WTO members can also be seen as an assurance of security to rights-holders, which certainly signifies, in a broader sense, an incentive to innovation and to a far-reaching debate over intellectual property. IP rights are, in this sense, major instruments for legality in a global dimension, and legality is important to fair trade. Willis enhances the fact that the Agreement covers copyrights, trademarks, industrial designs, geographical indications, patents, integrated circuit designs, trade secrets, and anti-competitive contract restrictions, bringing, therefore, a very broad and systemic approach of IP rights. ${ }^{87}$

Moreover, TRIPS, like other WTO agreements, applies the fundamental principle of non-discrimination. Included in this fundamental principle is the principle of mostfavoured-nation treatment, which prescribes no discrimination between trading partners,

84 See: R. Brewster, R., The Surprising Benefits to Developing Countries of Linking International Trade and Intellectual Property, Trade and Intellectual Property, 12 Chicago Journal of International Law, 2011, pp. 1-54.

85 Ibid.

86 B. Willis, The Arguments for and Against the TRIPS Agreement, 2013, E-International Relations Students [website], http:// www.e-ir.info/2013/12/23/the-arguments-for-and-against-the-trips-agreement/ (accessed 13 April 2018).

87 Ibid. 
and the principle of national treatment, which guarantees foreigners the same treatment given to nationals of one country. ${ }^{88}$ In this regard, as discussed at length in the following sections of this dissertation, there are various benefits to society from the adoption of temporary monopolies as a result of an intellectual property rights system. Similarly, strengthening legal protection is the only way found in democratic societies to tackle piracy and counterfeiting, therefore, the only way to protect creators and allow the disclosure of new knowledge. Hence, only a general agreement with global reach and high adherence would be able to carry out an overall promotion of trade and economic development. $^{89}$

Likewise, developing states can act strategically due to some benefits of the TRIPS Agreement. By strengthening domestic protection in a way to reach higher levels of protection, the developing economies can profit from their strong characteristics. That is the case, for example, of biogenetical resources, that reach a much higher level of international protection after TRIPS, making developing countries less vulnerable to the exploitation of developed economies, freeing them from the threat to suspend intellectual property rights in their own markets, as described by Brewster..$^{90}$

Moreover, the TRIPS Agreement ended up being less constraining than planned by intellectual property holders in consonance with the Governments of developed states. The engagement of some developing countries was crucial in this sense, as in the case of the compulsory license allowed to AIDS medication. ${ }^{91}$ On this, enforcing intellectual property rights can be a way to embed an intellectual property culture in developing countries. That means more access to technological knowledge through the disclosure of patent information all over the world and the possibility to make strategic use of this information.

Through this rationale, TRIPS represents much more a survival and updating mechanism of the international legal system, and then by the exact vision of the law as a system, as proposed by Luhmann, ${ }^{92}$ than a corruption of it. Hence it isn't a result of a simple "invasion" of an economic demand, but a positive consequence (depending on the way it is managed and controlled) of scientific, technological and sociological requests for an update of the legal system, in a necessary evolution to new paradigms in all those fields. More than this, by establishing a system which leads to the enforcement of minimum levels of protection on a global scale, reaching all the signatory countries, TRIPS represents an expansion of the legal system and of legality as a strong means to knowledge sharing on a global level.

Moreover, no fee is charged to firms or science and technology institutions to compensate the use of patent databanks as "inspiration" for the development of new

\footnotetext{
88 Ibid.

89 Ibid.

90 Ibid.

91 Ardissone, op. cit., pp 305-315.

92 See Chapter 3 of this dissertation.
} 
technologies, as a powerful, vast and language diverse system with a huge quantity of valuable information for inventors and investors. Patent platforms allow the strategy of "inventing around" as soon as their information is used on the basis of strategic plans and policies. ${ }^{93}$ That does not mean, however, that the system brings no gaps or cannot be improved.

Another remarkable move towards integration was the settlement of the Patent Cooperation Treaty (PCT). The PCT substantially intensified cooperation between States on patents. The Agreement rationalized the path of patent application, by enabling the simultaneous application for protection in a number of countries through the filing of a single international patent application. The Agreement yielded very tangible advantages to the patent system, as improving the dissemination of technical information and avoiding the multiplicity of filing requirements, research publications and tests and procedures. Although WIPO refers to the PCT as "The International Patent System", the Agreement did not go so far as to grant an international patent, as PCT patents still have to be validated in each country where the protection is required. ${ }^{94}$

Following the same trend to integration and harmonization, it is important to briefly comment the case of the European Union, a complex supranational multilingual organization. The settlement of the EPO already represented an important movement towards integration and harmonization. The following step will be the establishment of a unitary system, which is in countdown to come into effect. It represents a major advance in the direction of integration, valuable in terms of improving the global patent system, with an impact throughout other regions of the world, especially in the ones where the patent systems are still insulated. ${ }^{95}$

The European Unitary Patent represents the first truly supranational patent. In this respect, the PCT is commonly misunderstood to provide an international patent, but although it has brought extensive advance to the global patent system, it does not provide an international patent. Unlike the PCT, the unitary system will not require the validation or translation of the patent in national jurisdictions, not demanding local administration either. ${ }^{96}$

The idea of a unitary court can also simplify and integrate the post-grant administration of patents, lowering considerably the costs of innovative companies and favouring small and medium businesses from all over the world, which are an important basis for local economic development. There are plenty of examples of monumental costs, especially involving patent translation and language services in the current patent system. A simplified system will give transparency to litigation procedures and expressively

93 For strategic uses of the patent system, see: W. Landes and R. Posner, The Economic Structure of Intellectual Property Law, Harvard University Press, 2003.

94 WIPO, Patent Cooperation Treaty (PCT), Done at Washington on June 19, 1970, amended on September 28, 1979, modified on February 3, 1984, and on October 3, Art. 3, 2001, http://www.wipo.int/export/sites/www/pct/en/texts/pdf/pct.pdf, (accessed 17 April 2018).

95 See: O. Sousa e Silva, 'O Tribunal Unificado de Patentes', Revista de Direito Intelectual, n. 2014-I, pp.243-257.

96 See Sousa e Silva, op. cit. 
diminish the costs for patent owners, fostering the innovation system as a whole. That will guarantee a more dynamic and efficient European patent system, which will also attract more inventors to Europe and, probably, represent the next trend to integration and harmonization at the global level. ${ }^{97}$

However, the regulations for implementing a community patent and a Unitary Patent Court have inspired serious controversy related to language and translation. The most relevant of them, Spain refused to participate in the unitary package due to its language regime, which was also initially contested by Italy. In 2013, Spain launched two actions (C-146/13 and C-147/13) before the Court of Justice of the European Union. The Actions sought annulment of the Unitary Patent Regulation and the associated Translation Regulation, claiming that the language regime of the unitary system is contrary to the European Union law..$^{98}$ The whole case is described and discussed in Section 6.2 of this dissertation.

\subsection{The patent scenario as an intercultural space}

\subsubsection{Nature of the patent system: disclosure as a prerequisite for a competitive market}

As seen in the previous section, the concept of intellectual property isn't homogeneous. Theories, approaches and practices related to intellectual property are varied and complex and can decisively impact upon economic and scientific development in both national and international spheres. The same can be said about IP law and its set of national, regional and international treaties, rules and regulations.

Thinking intellectual property law by encompassing the variable and complex structure of a network society can be an answer to reach the best decisions and policies that define global interaction and national development in terms of IP regulation. Another crucial step for a better understanding of this association between economic and legal fields for a reasonable interpretation of intellectual property is to focus on IP as a multifaceted system, composed itself by sub-systems. Arguably, the patent system is its most significant sub-system in terms of scientific and economic development. ${ }^{99}$

97 Ibid.

98 See: Judgement of 5 May 2015, Spain vs Council, C-147/13, ECLI:EU:C:2015:299, 5 May 2015, http://curia.europa.eu/juris/ document/document.jsf?text=\&docid=164093\&pagelndex=0\&doclang=EN\&mode=Ist\&dir=\&occ=first\&part=1\&cid= 4884012 (accessed 25 November 2018). See also: Judgement of 5 May 206, C-146/13, ECLI:EU:C:2015:298, http://curia.europa.eu/juris/document/document.jsf?text=\&docid=164092\&pagelndex=0\&doclang=en\& mode=Ist\&dir=\&occ=first\&part=1\&cid=5301416 (accessed 26 November 2018); Opinion of Advocate General Bot, delivered on 18 November 2014, Case C-146/13, ECLI:EU:C:2014:2380, http://curia.europa.eu/juris/document/ document.jsf?text=\&docid=159764\&pagelndex=0\&doclang=en\&mode=Ist\&dir=\&occ=first\&part=1\&cid=3008161 (accessed 26 November 2018). Opinion of Advocate General Bot, delivered on 18 November 2014, Case C-147/13, ECLI:EU:C:2014:2380, http://curia.europa.eu/juris/document/document.jsf?text=\&docid=159763\&pagelndex=0\&doclang= EN\&mode=Ist\&dir=\&occ=first\&part=1\&cid=2838 (accessed 26 November 2018).

99 See: W. Landes and R. Posner, The Economic Structure of Intellectual Property Law, Harvard University Press, 2003. 
On the other hand, the patent system requires justification, as it does not bring only bonuses to its users. In this regard, there are many theories and ways to justify it. An important explanation is that the existence of the patent system is related to the possibility of patent bargain (the grant of the right of exclusivity in exchange for the disclosure of the invention). Although patent bargain also presents its costs and disadvantages, the monopoly conceded to the patentee, which normally lasts twenty years, naturally entails a whole set of social benefits, since this cost is proportional to the value of the covered invention. ${ }^{100}$

Granting a patent to the owner (s) of an invention allows the disclosure of its content to society as a whole. When the content of a patent is not kept in secret, it can inspire other inventions and innovative activities. In this regard, the disclosure of patent information can be interpreted as a limitation to the temporary monopoly conferred by the patent. Hence disclosure represents a disadvantage to the patent owner and a bonus given to society, as other inventions will be developed under the possibility of "inventing around" the content of the granted patent. ${ }^{101}$

If the patent system would not exist, inventions would be kept in secret. That is why disclosure is so relevant to knowledge transfer and innovation. From this perspective, inventions would be protected only by trade secret and the stock of knowledge available to society would diminish. A patent, on the other hand, enables a person who is knowledgeable about the technology to follow each step of its production. The disclosure of the invention must follow some rules, which will guarantee that each necessary detail of its manufacture will be accessible for the person skilled in the art. ${ }^{102}$

Disclosure is the main characteristic that distinguishes patents from copyrights. Inventors, different from authors, will chose to keep the invention secret if they have no other means of protection. In this sense, duplicating an invention is more difficult than copying the content of an artistic or literary work. In other words, the object of copyrights is directly revealed, while the object of inventions requires a whole set of technical explanations, schemes and drawings to be understood in order that one can duplicate the invention. Another important distinguishing feature of patents is related to the possibility of tracking back the content of inventions, through the search of prior art, as inventions represent technical solutions that can be found even simultaneously. ${ }^{103}$

Hence disclosure represents a device used to minimize the social costs related to the grant of an exclusive monopoly to inventors. ${ }^{104}$ Disclosure is socially important because it accelerates discovery of the second innovation, ${ }^{105}$ which would not be the same if the inventions would be kept secret, as there could be a tendency to duplication and

100 A. Devlin, The Misunderstood Function of Disclosure in Patent Law, Harvard Journal of Law \& Technology, Vol. 23, no 2, 2010.

101 W. Landes and R. Posner, 2003, p. 295.

102 Ibid, p. 294.

103 Ibid, p. 295.

104 lbid, p. 299.

105 S. Scotchmer and J. Green, Novelty and disclosure in patent law, The RAND Journal of Economics, vol. 21, no. 1, 1990, pp. 131146, https://www.jstor.org/stable/pdf/2555499.pdf (accessed 8 November 2018). 
a difficulty in assessing the quality of technologies through the possibility of searching, comparing and using, in various ways, all the information available in patents.

In the case of disruptive technologies, or, in other words, when the invention is so useful as to have no substitutes, the award of a patent can lead to a stable economic monopoly, favouring exclusively the owner of the patent and giving him the possibility of a whole set of improvements that characterize a new technological trail or paradigm. ${ }^{106}$

There is another very important reason in granting legal protection to inventions that justifies the existence of a patent system. It is very difficult for a creator or investor to recover his fixed costs of research and development when the product embodied by a new invention is launched on the market. This product will be easily copied by competitors and contrary to the heavy costs it required from the "first" developer before its commercial application, it will cost much less, in terms of financial and personal investments, to the competitor who will just copy it. ${ }^{107}$ The competitor, without the existence of a patent system, would have a great advantage over the creator, and that would establish an unfair process. The developer, in turn, would not be able to recover his fixed costs.

Abrantes ${ }^{108}$ presents a very comprehensive review of arguments for the existence of the patent system, referring mainly to software patents and to the importance of patentability for information technologies. He visits the main classic and current works that deal with the social relevance of the patent system, which include a broad range of quantitative researches that technically prove the positive effects of the existence of a patent system to foster innovation and development. He also recovers most of the arguments that criticize the use of patents for software protection, showing that they fail to interpret relevant aspects of the current innovation economy. The arguments retrieved by him lead to an in-depth comprehension of the concept of disclosure and of its importance for the patent system. ${ }^{109}$

A factor that should be considered to justify the existence of patent systems is that the industry has grown at a fast rate of innovation during the 1960s, but that does not mean it will maintain the same rate of growth at the present time, requiring greater protection mechanisms for intellectual assets to continue stimulating innovation. ${ }^{110}$ Likewise, the types and the complexity of technologies have changed, in a context where artificial intelligence pervades various technological fields, requiring more effective means of protection.

Some other important arguments should be considered. However, knowledge dissemination is the main aspect to validate the importance of intellectual property protection. The dilemma "access versus incentive" brings a dynamic benefit of intellectual property rights. When the access to knowledge becomes restricted, making it artificially

106 For understanding the association between the concept of patent bargain and technological paradigms, see Devlin, 2010, and Perez, 2010.

107 W. Landes and R. Posner (2003).

108 A. C. Abrantes, 'May Patents Contribute to Innovation in the Sector of Information Technology?', PIDCC, Aracaju, Ano II, no 02/2013, pp.45-72, Feb 2013, www.pidcc.com.br

109 lbid.

110 Abrantes, 2013. 
scarce and causing a social cost, there is, at the same time, incentive to new creations, which offset these restrictions in terms of social advantages. ${ }^{111}$

The distinctive nature of the assets that are the object of intellectual protection are exactly what requires the existence of patent systems. In turn, these systems only make sense in a competitive environment present only in market economies. Patent systems exist because they represent the only legal institutions that allow the inventor to assign a price tag to the technology, and, at the same time, allow the company to measure the appropriateness of that price. ${ }^{112}$

One of the strongest arguments in favour of IP rights is the one which affirms that economic development may be endorsed or delayed by an effective system of intellectual protection. However, it is known that intellectual property rights do not necessarily play a positive role for innovation and economic development. Hence these are difficult conclusions to take and they should not be limited to establishing a direct relation between intellectual property rights and economic development. Anyway, there is evidence that this relationship is positive, when depending on (or combined with) other factors. ${ }^{113}$

In brief, IPRs could be effective and market-based mechanisms for overcoming problems that exist in markets for information creation and dissemination. However, their existence could pose problems in terms of their potential for costs and anti-competitive abuse. ${ }^{114}$

In this vein, intellectual property systems are not sufficient by themselves to encourage effective technology transition. For being effective in fostering innovation and development, they must integrate a coherent and broad set of complementary policies. These policies can maximize their potential to increase dynamic competition. The mentioned author names the referred policies: strengthening human capital and skill acquisition, promoting flexibility in enterprise organization, ensuring a robust and competitive domestic market, and advancing on a transparent, non-discriminatory, and effective competition regime. ${ }^{115}$

One of WIPO's studies proves that the emergence of technology markets results from two main factors: increased use of intellectual property and greater collaboration between businesses through the development of patent pools. To confirm the importance of the pools, the same study shows the values generated by the global import of goods grew at a rate of $6.5 \%$ per year, a lower rate than the royalties paid to the licensing of

111 Landes and Posner, 2003.

112 N. Carvalho, A Estrutura dos Sistemas de Patentes e de Marcas: Passado, Presente e Futuro, Rio de Janeiro, Lumen Júris, 2009, pp.27-38; 57-62, cited in Abrantes, 2013.

113 K. Maskus, 'Intellectual property rights and economic development', Case Western Reserve Journal of International Law, 32, 2000, pp. 447-485

114 Ibid.

115 Ibid. 
intellectual assets, with an annual growth of 9.9\%. ${ }^{116}$ Another study published in 2011 shows that revenues by licensing patents increased from US $\$ 2.8$ billion in 1970 to US $\$ 27$ billion in 1990 and approximately US $\$ 180$ billion in 2009, exceeding the growth of world GDP over the same period. Global patent licensing increased from $\$ 10$ billion in 1990 to about $\$ 100$ billion in 2000 , which shows the economic importance of patents. ${ }^{117}$

Intellectual property facilitates the establishment of technology markets because it protects the seller information during the sensitive period leading up to the signing of formal agreements, allowing the pre-contractual disclosure of information. It also provides the information vendor with more legal options, including stronger legal tools in disputes over the negotiated object. ${ }^{118}$

On that point, the role of intellectual property is much broader than encouraging innovation. The existence of IP systems allows the recovery of R\&D costs, but an economic analysis shows many other benefits, such as the role in reducing transaction costs. That is what proposes the author of the theory of transaction costs and Nobel Prize in Economics, Ronald Coase, affirming that intellectual property not only has the role of offering an incentive for innovation, but provides its wider dissemination as facilitating the terms of technology trade while minimizing transaction costs. ${ }^{119}$

The strengthening of intellectual property and its ability to ensure the effectiveness of technology sales agreements have also affected investment decisions of companies. There is a positive correlation between patents and licensing of foreign technologies in countries such as Korea, Mexico, Brazil and Indonesia. In the period of 1985 to 1995 , TRIPS showed a positive impact on technology transfer to such countries, with fewer results in the poorer countries. ${ }^{120}$

The licensing or the cross-licensing of any form of intellectual property can facilitate the integration of licensed intellectual property with complementary factors of production. This integration can lead to a more efficient exploitation of intellectual property, benefiting consumers by reducing costs and introducing new products. Such arrangements increase the value of intellectual property both to consumers and to technology developers. ${ }^{121}$

The tables below summarize the most important arguments for and against the patent system, as the most significant responses to justify its existence. All the arguments are, directly or not, related to the idea of disclosure and dissemination of patent information as part of a social contract.

116 WIPO, World Intellectual Property Report: The Changing Face of Innovation, 2012, cited in Abrantes, 2013.

117 WIPO, 2011, World Intellectual Property Report, p. 9, cited in Abrantes, 2013, http://www.wipo.int/publications/en/details. jsp?id=227 (accessed 13 April 2018).

118 R. Merges, Justifying Intellectual Property, Harvard University Press, 2011, pp. 2351-6102, cited in Abrantes, 2013.

119 W. Posner and R. Coase, 'The Nature of the Firm', 4 Economica, 386-405, 1937; R. Coase, 'The Federal Communications Commission', 2 Journal of Law, 1959, pp. 1-40; R. Coase,'The Problem of Social Cost', 3 Journal of Law and Economics, pp. 1-44, 1960.

120 K. Maskus, 'Intellectual property rights and economic development', 32 Case Western Reserve Journal of International Law, 2000, p.485, cited in Abrantes, 2013.

121 The United States Department of Justice, Antitrust Guidelines for the Licensing of Intellectual Property, 1995, http://www. justice.gov/atr/public/guidelines/0558.htm\#t23_(accessed 13 April 2018). 


\section{Table 1: Arguments that justify the importance of patent systems}

Anti-trust Guidelines
for the Licensing of
Intellectual Property

The licensing, cross-licensing or other forms of intellectual property transfer can facilitate licensed property integration with complementary factors of production. This integration can lead to a more professional management of intellectual property, benefiting consumers by reducing expenses and introducing new products. Such actions increase the value of intellectual property to consumers and technology developers.

\begin{tabular}{|c|c|}
\hline A. Abrantes & $\begin{array}{l}\text { Keeping a reasonable growth pace of innovation in the industry at the present } \\
\text { time may need stronger protection mechanisms for intellectual assets to stimulate } \\
\text { higher rates of innovation. }\end{array}$ \\
\hline Pricewaterhouse & The global patent licensing jumped from $\$ 10$ billion in 1990 to about $\$ 100$ billion \\
\hline Coopers'study & in 2000, which shows the economic importance of patents. \\
\hline WIPO's studies & $\begin{array}{l}\text { There are two factors for the emergence of technology markets: } 1 \text { ) increase in } \\
\text { the use of intellectual property; } 2 \text { ) greater collaboration between companies and } \\
\text { development of patent pools. Values generated by royalties paid to the licensing } \\
\text { certificate ( } 9.9 \% \text { per year) grew more than values generated by the overall import } \\
\text { of goods ( } 6.5 \% \text { per year). Revenues in patent licensing increased from US } \$ 2.8 \\
\text { billion in } 1970 \text { to US } \$ 27 \text { billion in } 1990 \text { and approximately US } \$ 180 \text { billion in } 2009 \text {, } \\
\text { exceeding the growth of world GDP in the same period. }\end{array}$ \\
\hline
\end{tabular}

Keith Maskus Strengthening intellectual property and its ability to ensure the effectiveness of technology commercialization contracts has an important role in investment decisions of multinational companies. There is a positive correlation between patents and licensing of foreign technologies in emerging countries in the period of 1985-1995, showing a constructive impact of TRIPS.

Nuno Carvalho Intellectual property has the distinctive nature of the assets that are the object their protection, so it only makes sense in a competitive environment. The patent system exists because it is the only legal institution that allows the inventor to establish a price for the technology and, at the same time, allows the measurement of society adequacy of that price.

Richard Posner The issue of the dissemination of knowledge is not the only advantage of IP systems. There is a dynamic benefit in the dilemma 'access versus incentive'. When we give a price to a public asset, we reduce the access to it, making it artificially scarce and causing a social cost. On the other hand, we increase the inventiveness for new creations, offsetting the restrictions in terms of social benefits. The other advantage is the reduction of transaction costs.

Robert Merges Industrial property acts as a facilitator for the establishment of technology markets for two reasons: it protects the seller of information during the sensitive period leading up to the signing of the formal agreement facilitating the pre-contractual disclosure of information. It provides the information vendor with more legal options, including stronger legal tools in the event of a dispute over the negotiated agreement.

Ronal Coase Intellectual property not only has the role of providing an incentive for innovation, but of providing its wider dissemination as it facilitates the requisites for switching technology, minimizing transaction costs.

Source: Based on Abrantes (2013) 
Table 2: Arguments against patent protection for software and responses to these arguments

\begin{tabular}{|c|c|c|c|}
\hline \multirow[t]{3}{*}{ Richard Stallman } & \multirow{3}{*}{$\begin{array}{l}\text { The software should } \\
\text { be understood as } \\
\text { distinct from other } \\
\text { technological areas } \\
\text { because it is an } \\
\text { abstraction. We cannot } \\
\text { accept property or sale } \\
\text { for intangible property. }\end{array}$} & Peter Burke & $\begin{array}{l}\text { The idea of bargaining knowledge is old: } \\
\text { Plato already criticized the sophists for this } \\
\text { practice; there were common ownership } \\
\text { models in guilds in the Middle Ages; the } \\
\text { term Plagiarius was used in ancient Rome } \\
\text { about literary theft. }\end{array}$ \\
\hline & & Kevin Rivette & $\begin{array}{l}\text { Even Netscape, one of the first large } \\
\text { companies to adhere to the open source } \\
\text { movement, in report to the SEC, states } \\
\text { that: "free source code can lead to the } \\
\text { proliferation of incompatible competing } \\
\text { products, potentially creating market } \\
\text { confusion". }\end{array}$ \\
\hline & & Ronald Mann & $\begin{array}{l}\text { In the proprietary model, the direction of } \\
\text { research and development, centred within } \\
\text { the boundaries of a company, maximizes } \\
\text { the use of resources and the rapid } \\
\text { reorientation of research on surprise events. } \\
\text { In the open model, control is more diffuse, } \\
\text { and the empirical evidence of higher quality } \\
\text { in the final product is ambiguous. }\end{array}$ \\
\hline Sérgio Amadeu: & $\begin{array}{l}\text { "If I have an Idea, and } \\
\text { you have an Idea, and } \\
\text { we exchange our ideas, } \\
\text { I get two ideas, and } \\
\text { you too."The property } \\
\text { of material assets is } \\
\text { different from the } \\
\text { property of intangible } \\
\text { assets. }\end{array}$ & Robert Merges & $\begin{array}{l}\text { The intellectual property rights encourage } \\
\text { the creation of new technologies, in a } \\
\text { dynamic creation context. Unlike physical } \\
\text { property, intellectual creation is dynamic } \\
\text { and guarantees access to all to the existing } \\
\text { content. In this dynamic environment, } \\
\text { maintaining the widest possible access to a } \\
\text { set of creations, by expanding the concept } \\
\text { of the public domain, is only one aspect of } \\
\text { the matter. Encouraging the next round of } \\
\text { new additions is much more important. }\end{array}$ \\
\hline $\begin{array}{l}\text { Idea repeated by } \\
\text { opponents of the IP } \\
\text { system }\end{array}$ & $\begin{array}{l}\text { Non-rival assets cannot } \\
\text { be protected by } \\
\text { property rights. There } \\
\text { is more advantage in } \\
\text { simply sharing them. }\end{array}$ & Robert Merges & $\begin{array}{l}\text { Assets considered as non-rival should be } \\
\text { protected, although they can be enjoyed } \\
\text { simultaneously. The speed of information } \\
\text { exchange is not the only relevant aspect } \\
\text { in the world of intellectual property. The } \\
\text { generation of new information is equally } \\
\text { important. Information can be easily } \\
\text { shared, but new and useful information is } \\
\text { still difficult to generate. }\end{array}$ \\
\hline
\end{tabular}




\begin{tabular}{|c|c|c|c|}
\hline \multirow[t]{2}{*}{$\begin{array}{l}\text { The free software } \\
\text { movement }\end{array}$} & \multirow[t]{2}{*}{$\begin{array}{l}\text { The appropriation of } \\
\text { information technology } \\
\text { invariably leads to a } \\
\text { lock-and obstacle in the } \\
\text { formation of patterns } \\
\text { as they restrict the } \\
\text { diffusion of technology. }\end{array}$} & $\begin{array}{l}\text { Varian e } \\
\text { Shapiro }\end{array}$ & $\begin{array}{l}\text { The company should seek to maximize } \\
\text { the value of its technology and not its } \\
\text { control over it. There is no use of excessive } \\
\text { protection of a technology if it does not } \\
\text { diffuse and finds no market. The same } \\
\text { company can adopt open and proprietary } \\
\text { strategies as a way to maximize its market } \\
\text { presence. There is no incompatibility in } \\
\text { the coexistence of free and proprietary } \\
\text { technologies established as industry } \\
\text { standards. }\end{array}$ \\
\hline & & Abrantes & $\begin{array}{l}\text { There are examples of successful companies } \\
\text { by combining proprietary strategies with } \\
\text { open strategies. An example is the case of } \\
\text { Intel, which kept a tight control over the } \\
\text { MMX multimedia specifications of their } \\
\text { chips, but at the same time, promoted the } \\
\text { opening of new specifications for graphics } \\
\text { drivers for its graphics acceleration port } \\
\text { (AGP). }\end{array}$ \\
\hline
\end{tabular}

Source: Based on the study of Abrantes (2013)

These can be considered the main arguments for the use of intellectual property and patents to protect intangible assets. However, a justification that does not appear is that intellectual property stands on the idea of a system based on communication. This is a contribution that this research intends to offer, presenting the concept of system, related to the idea of disclosure/dissemination, as part of an argument that may be key to justifying the patent system, and entangling this idea with the basis of this system: multilingual communication allowed by translation and with the conclusion that (especially machine) translation has (recently, in historical terms) universalized the disclosure of patent information. ${ }^{122}$

In Section 3.1, the features that define a system as a system will be discussed at length. What is worth to anticipate hereof is that Niklas Luhmann created a system theory, rooted in the works of Humberto Maturana and Francisco Varela, in a biological background that seeks to understand the systemic organization of living organisms. What defines a system is, accordingly, its autopoietic organization, its continuous structural coupling (in a permanent structural change while interacting with the environment) and its operational closure. A system produces its own knowledge, a peculiar knowledge, which characterizes its evolution. ${ }^{123}$

122 See, for example, Section 6.1.2, which shows the advantage of harmonization and integration in the patent system.

123 N. Luhmann, Law as a Social System. Oxford University Press, 2004. 
Systems, being holders of autonomy and autopoiesis, are also able to recognize and specify their own laws. That implies ability to self-creation and reproduction. The operational closure means they accept only changes that can be translated in their own structure, making their transformations coherent to their inner rationale. Their relationship with the environment, that is, in the case of the patent system, with politics, economics, society, or, in other words, with other correlated systems, are defined by their rules and kept so that their integrity as systems is preserved ${ }^{124}$.

Therefore, a system can be reorganized, studied, controlled and improved. It can also be a rich source of information, as this information will be categorized by its rules. That is not only about mentioning the scientific information contained in the disclosure of patents, but also other types of material such as: the history of the patent systems and their evolution in terms of new tools and methods, new regimes (of various types, including linguistic regimes), new ways to interact with other systems and to insert in international trade, among many other possibilities.

The operational links between system and environment are possible, meeting certain inclusion and exclusion patterns. The system does not allow the entry of what will destroy it as such, otherwise it loses its systemic character and can no longer be considered as a system. The more coherent, integrated and organized, the more the system will manage to be clearly recognized and to be improved and reproduced.

In the case of patent systems, it is possible to affirm that, in exchange for the high price experienced as a result of the monopoly period awarded to the patentee when the patent is granted, only a systemic structure can recompense the demands of society. This recompense happens through the disclosure of the information encompassed by a patent. Disclosure is hence a very strong justification for the existence of the patent system. As patents involve international trade and the exchange of scientific information among nations, the more developed and the better structured this system is, the better it is for the dissemination of high-quality information, which include numerous possibilities of fostering innovation. ${ }^{125}$

The concept which refers to innovation systems is widespread, contrary to the concept of patent systems, which has not even been properly formulated yet, ${ }^{126}$ despite its relevance to the innovation systems which have been mentioned, and the wide (mostly unconscious) use of the term. Many authors or professionals of the area refer to intellectual property as a system, without, however, defining why they call it so or understanding the importance of this association. For Lundvall, an innovation system is distinguished by the interaction of elements that shape innovative processes and elements that link the economic performance of these processes. Knowledge, accompanied by technological learning, is a central element. The success of a particular national innovation system is

124 Ibid.

125 Devlin, 2010.

126 There is a semantic difference in approaching innovation systems and IP systems on the literature. The last concept is diffused in theoretical works on the nature of IP rights. 
contingent on the accumulated knowledge and capacity of a continuous process of technological learning, depending on the same characteristics that define a system: autopoiesis, structural coupling and operational closure, that means, cohesion, capacity of articulation, and autonomy associated with interaction. The table below presents the association of these two blocks of ideas:

Table 3: Association between the system's theory by Maturana and Varela and the innovation systems theory by Lundvall:

\begin{tabular}{ll}
\hline System's theory by Maturana and Varela & Application to innovation systems \\
\hline Autopoiesis & $\begin{array}{l}\text { Cohesion, well-structured purpose and high level of } \\
\text { organization. Internal capacity to operate accumulated } \\
\text { knowledge and maintain technological learning. }\end{array}$ \\
\hline Structural Coupling & $\begin{array}{l}\text { Capacity of articulation - among its own structures and with } \\
\text { other systems }\end{array}$ \\
\hline Operational closure & $\begin{array}{l}\text { Autonomy associated with interaction and interdependence } \\
\text { with other systems, other structures and other elements. }\end{array}$ \\
\hline
\end{tabular}

Source: Elaborated by this author based on the mentioned theories ${ }^{127}$

The intellectual property system could be considered as a subsystem of the legal system, considering the latter as defined by Luhmann, as detailed in Section 3.1. On this matter and recalling the central point of the definition of Luhmann, the legal system is built upon a long and intricate evolution of social and cultural nature. One of its most essential aspects is its communication structure, which is configured in specific codes, that differentiate it from other systems. Accordingly, the intellectual property system, as a subsystem of law, has its own rules and codes, and was developed through a complicated historical evolution, which remains controversial and convoluted, and still has a long way to go, and in which translation and multilingual communication has always played a central role.

It is possible to affirm that the constitution of patent systems is the best justification that can be raised about their existence and maintenance. It is precisely the existence of a cohesive and integrated structure that lets one control the effects of production and regulation of new technologies for various purposes, of which the one related to fair competition deserves notice, supported by the improvement of the communication processes that allow a greater level of interaction between its users from all over the world.

But what defines a patent system? Which are its most important elements? What preserves its autonomy? Are there differences between national patent systems? In which ways are these differences a result or a consequence of national economic systems? In which way do they relate to an international major system? Chapter 3 debates some of 
these questions, which deeply involve issues associated with language and translation. It aims to bring definitions of what a patent system is, what its main elements are and why these concepts are vital to describe, understand and justify its existence.

One thing which is important to point out, in advance, is that national patents systems interact through translation, which involve various source and target languages. Hence language and communication are an important basis of their functioning and part of their definition. A clear description of these characteristics of the patent systems is very important for researchers dealing with them currently. National patent systems are not isolated and cannot be interpreted as if they were. The disclosure of patent information, which is, as seen, one of the most important reasons to justify the existence of patent systems, intrinsically involves language and translation.

\subsubsection{Disclosure as the main linking element between patent systems and innovation systems}

For Landes and Posner the theory of public choice fails to explain the political powers that allowed the formation and emergency of the system of intellectual property rights. The theory's central idea is the use of economic tools to explain political behaviour. It claims, as one of its main contributions, that political behaviour is guided by the interests of economical agents. According to the authors, it reaches certain types of regulations, and is relatively successful as an economic explanation of legislation, based on the idea that government action is the result of the workings of demand and supply.

Public-choice theory has had only limited success in explaining political behaviour and government action. Limited is not zero; the theory has made significant contributions to our understanding of public utility and common carrier regulation, certain other forms of regulation including occupational licensure and other labour-market (including safety and health) regulation, and tariffs. But it has not, for example, succeeded in explaining the forces that brought into being the system of property rights that is fundamental to a capitalist economy. Can it say anything about the extension of that system to encompass intellectual property and the spurt in intellectual property protection that we have dated to the 1976 copyright statute? ${ }^{128}$

Landes and Posner explain that the analysis of public-choice focuses on legislation, as it is based on the actions of interest groups in the legislative process. Legislation is considered as a product demanded by and supplied to influential interest

128 W. Landes and R. Posner, The Political Economy of Intellectual Property Law, Washington D.C., AEI-Brookings Joint Center for Regulatory Studies, 2004. 
groups. These groups attend third parties' interests for political support, including campaign contributions. ${ }^{129}$

In this sense, the judicial process is different from the legislative process. Contrary to the second one, the first one is structured to minimize the role of interest groups, and judges are pressured by their positions not to join amicus curiae briefs. For the authors mentioned, this former pattern is recognizable as dominant in intellectual property law, ${ }^{130}$ being the object of protection patents, utility models, industrial designs, trademarks, service marks, trade names, indications of source or appellations of origin, and the repression of unfair competition. ${ }^{131}$

Regulating intellectual property rights, according to this interpretation, represents a natural need of a global economy based on knowledge. Building consolidated IP systems is what guarantees legal certainty and a certain stability to investments in research and development, which will turn to innovation, in a context where these activities became expensive and sophisticated. Hence, counting on fair regulation of intellectual property is a requirement of national innovation systems or of what could be called a "global innovation system", composed by the interaction of national systems, especially the more structured ones, and dependant on the information disclosed by patents and on the protection they give to the developers of new products. On this matter, it is important to review the demands required from the patent systems to attend this need and what exactly constitutes and characterizes what is being called here as a patent system, in connection with the idea of innovation systems.

Proposing this debate will first require a review of Lundvall's theory of innovation national systems. And, to make it possible, some questions are proposed to this theory. Among them, the most relevant are: is there such a thing as a global innovation system, or should innovation systems necessarily be conceptualized in a national level? Is the same valid for the ideas of a regional or local innovation system, which is the same as asking if the concept allows a geographical/cultural flexibility? Should patent systems be interpreted through the same point of view in terms of this flexibility, or is their maximum level of geographical limitation the national level (due to the principle of territoriality)? How should both concepts be interpreted in their relationship with global trade practices and requirements? How dependent is an innovation system on the IP system? Which one is more international, and which one is more national, and which of them depends more on a flow of linguistic exchange and an intense interaction with other national systems and the global system?

It is not intended to thoroughly answer to all those questions, but to start a discussion which is judged as necessary, although it has not been really raised yet in the literature, due to what is here interpreted as a semantic gap between research and

129 Ibid., pp. 25-26.

130 lbid.

131 Paris Convention for the Protection of Industrial Property of March 20, 1883, http://www.wipo.int/wipolex/en/treaties/text. jsp?file_id=288514 (accessed 18 April 2018). 
debates about patent systems and innovation systems. ${ }^{132}$ By proposing a systemic vision of patent law, it is believed that it is possible to relatively fill in this gap. For this, it is useful to establish a comparison between patent systems and innovation systems and to reinterpret the idea of disclosure as the main linking element of these systems.

To start, it is necessary to rescue the original concept of Lundvall of national innovation systems and, by using it as a conceptual basis, propose an idea of patent systems as systems. According to the theory of Lundvall, presented in Section 1.1, an innovation system consists of elements that interact to shape innovative processes and elements that link the economic performance of these processes. ${ }^{133}$

By paraphrasing this passage, it is possible to show that patent systems entail (legal, economic, political, among other) elements that interact to shape processes and elements of protection to inventions, by linking these processes to the innovative activity (through disclosure) and to the economic success of the protected elements. It is critical to consider that patent systems can be classified as national, regional, global (or operating at a global level) and (potentially) supranational, and to admit the existence of a global patent system, based on treaties, agreements and guidelines involving and regulating patents in a considerable number of States around the world.

It is important to remark that the concepts of innovation systems and patent systems should be seen as deeply inter-related, as the success of an innovative system depends, to a considerable level, on the success of its correlated patent system (the contrary being also true, but under different parameters). Likewise, the achievement of a successful (national) patent system depends on a set of factors.

In this regard, most of the success factors related to a patent system are based on an interaction process (inside its own structures, with other offices, with other sectors, with other systems...), which makes networks as important to patent systems as they are known to be to innovation systems. From that, it is concluded that (also and especially linguistic) isolation is not a positive characteristic of a patent system.

Here the term 'isolation' is understood as 'a resistance to interaction and to consistent dialogue', which limits the structural coupling ${ }^{134}$ of the system with other systems, keeping it in stagnation. Dynamism and interaction are central characteristics of a successful patent system, deeply associated with the idea of disclosure of knowledge and with the relation between patent systems and innovation systems.

The characteristics described above about patent systems allow one to state that patent systems are more connected to legal rights whereas innovation systems can be more

132 Leopardi and Esteves (2010) present a relevant proposal over the need to integrate the views of the legal and economic levels on property rights through the development of an interdisciplinary concept of IP. The authors recommend opening up an economic field to analyse property rights, starting from an interdisciplinary view, which links property rights to the notion of assets and the idea that these rights have practical impact. What is proposed on the present research is first defining IP as a system and then confronting this idea with the concept of the innovation systems, which brings a different perspective from what Leopardi and Esteves propose but can gain from their suggestions of common concepts that should brought together when the economic and the legal views of IP are approximated.

133 Lundvall, 2007.

134 H. Maturana and F. Varela, 2001. 
conceptually related to economics. Therefore, it is worth establishing differences between innovation systems and patent systems in terms of this conceptual distinction, in order to better assess their interaction zone, which can be defined as a zone between legal rights (related to the notion of property) and economic impact (related to the notion of assets), based on the disclosure of the information contained in the inventions protected by patents. ${ }^{135}$ To that end, the most important distinctive elements are summed up on the table below.

\section{Table 4: Comparison between innovation systems and patent systems}

\begin{tabular}{ll}
\hline Innovation systems & Patent systems \\
\hline More related to economics conceptually & More related to the law conceptually \\
\hline Related to the notion of 'assets', as innovation & Related to the notion of 'property', as intellectual \\
happens when an invention is successful in the protection happens through legal regulation and \\
market. & $\begin{array}{l}\text { protects the rights of the inventor and of the owner of } \\
\text { the protection tool. }\end{array}$
\end{tabular}

Depends on the appropriate functioning of the Depends on a strong legal system able to assure legal patent system to compensate the investments certainty and protect the rule of law to investors and made in research and development by investors and creators.

creators.

Can be interpreted in terms of a national, regional or Can be interpreted in terms of a global, regional or local level. national level.

Have in universities important centres for their Also have in universities important centres for their improvement, especially in the activities of research improvement, but in the activities of TTOs, in the and development, in the creation of incubators and improvement of an "intellectual property education" technological parks and in the model of education and in the interaction with the national patent office followed in each institution (the concepts of triple and other governmental institutions related to IP. helix and entrepreneurial universities are very important to define this model).

Are internationalized systems, to the extent that Are internationalized systems par excellence, as they science is internationalized. Researchers and depend on examination and on investigations that investors interact in a global level, in many ways, in require the use of international data bases which order to produce knowledge. disseminate the disclosed content of other inventions universally, and also as they constitute the regulatory bases for global trade. Translation is a key factor in its interaction processes and ways to communicate.

Source: Elaborated by this author on the basis of the theories mentioned ${ }^{136}$

135 For reaching this conclusion, it was important to consider the idea of an interdisciplinary concept of intellectual property, as defined by Leopardi and Esteves (2010), and described in Section 1.2.2. However, it is believed that, more than proposing a concept of IP situated at the border of the law and economics, a clear definition of IP systems and innovation systems and the description of an interaction zone between them can be helpful in terms of understanding and improving this relation in a pragmatic scenario.

136 See Section 1.2.1 
According to WIPO, a patent is an exclusive right granted for an invention, which is a product or a process that provides a new way of doing something or offers a new technical solution to a problem. ${ }^{137}$ Thus, it is possible to affirm that patents represent the most crucial form of intellectual protection in terms of supporting and improving innovation systems. Under this view, patents can be considered as the channel through which inventions can reach the market in a manner that the efforts that made them possible can still be rewarded and in order to recreate the same cycle for new inventions. Therefore, the existence of patent rights fosters innovation and encourages creative investigation, generating, in the end, positive economic impact in a national level and making knowledge available to all productive sectors and scientific institutions at a global level.

Patents are also (to their owners) a way to protect the right to decide who may use or commercialize the patented invention ${ }^{138}$, which does not prevent others from using the knowledge they contain or to "invent around" the disclosed content. Additionally, patent rights are limited in time, as patent protection lasts 20 years ${ }^{139}$, a period when the costs with the invention are compensated and new investments for new inventions can be established.

The scope of the patent protection allows the owner to license other parties to use the invention, which will happen on the bases of mutually agreed terms. It also allows the owner to sell the rights to the invention. After the expiration of the protection term, the protection ends, and the invention enters the public domain. After that, the owner of the patent rights no longer holds exclusive rights to the invention, no more receiving (at least through patent protection) material reward for it, which means anyone can commercially exploit the disclosed content of the invention without consulting the former owner or inventor. ${ }^{140}$

As described above, successful patent systems depend on many factors: the quality and speed of the examination, the capacity to avoid backlog, the educational background and ability of the examiners, the integration of the patent office to a global system. In general terms, it is worth mentioning: the efficiency of the TTOs in providing suitable protection to researchers and inventions developed in their institutions, the efficiency of patent courts in providing fast and fair judgments in disputes involving patents, the level of integration and dialogue among the main institutions that compose the patent system (patent offices, courts and TTOs). Below follows a representation of the position of patent systems among correlated social systems.

137 See the concept on WIPO's official webpage: https://www.wto.org/english/tratop_e/trips_e/t_agm3_e.htm (accessed 13 April 2018).

138 lbid.

139 Minimum period according to the TRIPS Agreement.

140 Ibid. 
Figure 4: Diagram representing the relation between the legal system and the patent system within the social system

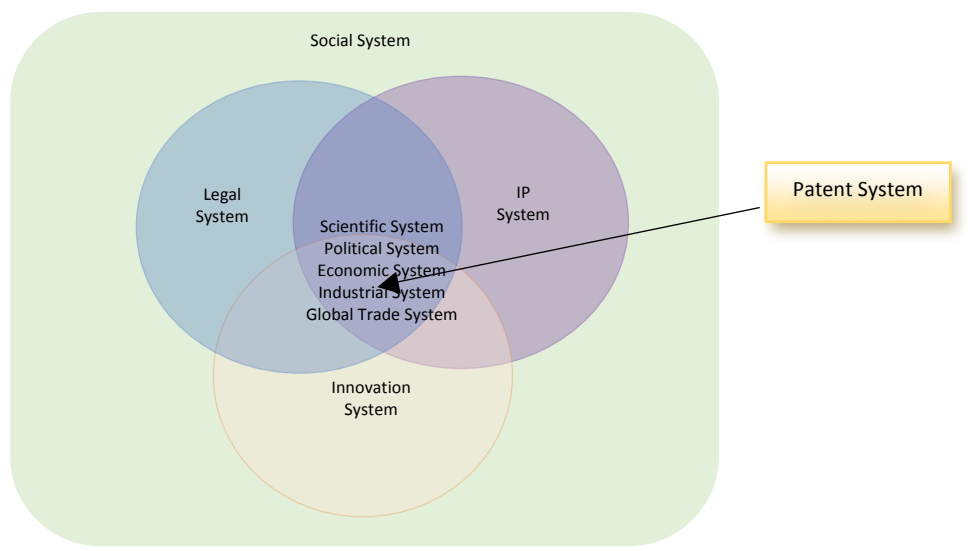

Source: The diagram was created by this author on the basis of Luhmann's theory of social systems and Lundvall's national innovation system's theory ${ }^{141}$

Patent systems are also characterized by being accessible through multilingual/ multinational data bases and expert systems and by being based on international agreements and guidelines. Therefore, their success depends directly on some factors related to language and communication: the accuracy and clearness of the original text of the patent document; the accuracy of the information contained in these systems (which directly involves translation), the availability of these systems and investment in them at a national level (not only to patent offices, but to TTOs and educational institutions involved with IP programs); the accuracy of the information given to patent courts (which may imply translation of various types of documents, including not only the patent document itself, but all the exchanged communication and legal credentials related to it), the accuracy of translations of international treaties to a national language and its influence on local regulations.

141 The proposal for a patent system theory is one of the results of the present research and a conclusion of the analysis of the legal system theory and the national innovation systems' theory. See Section 1.2. See also Luhmann (2009) and Lundvall (2007). 


\subsubsection{Innovation, patents and disclosure in an intercultural space}

An intercultural space can be defined as a space of interaction between members of different cultures. It is connected with the flow of influences and impacts that can exist between cultures, and the patterns which are established and followed as common means to communicate. In this regard, even the creation of a study field called intercultural communication was motivated by an experience in a micro intercultural environment, where members from different cultures had problems in understanding generalizations outside the context of their particular culture. ${ }^{142}$

The history of intercultural communication can be divided in different stages and historical periods, each one characterized by its particularities in terms of the interaction between local identities. The one that is particularly associated with this thesis is defined by globalization, as, according to Weiming, a movement that produced new bodies of knowledge, falsified "self-evident" conventional truths, and new possibilities for democratization. ${ }^{143}$ In all events, from a positive perspective, globalization is marked by the trend to more open societies, by a revolution in communication and information technology and by the intensification of cross-border interaction. ${ }^{144}$

The afore mentioned description is important to establish an association between innovation, patents and disclosure. In turn, this association allows language to be understood as part of the complexity of the innovation landscape, placing innovation as a phenomenon increasingly related to the subjectivities and peculiarities of an intercultural space. Innovation is supposed to have an impact at the global level, especially when carried by patent documents, which are analysed from the perspective of the world, in terms of granting or denying patent rights in different (national or regional) jurisdictions. Therefore, the way these documents are written, analysed or used, is dependent on a set of local perceptions or values. Patent documents cross the borders of this intercultural space and make the content of innovative inventions available through disclosure.

Hence disclosure moves through this intercultural, multilingual space, where languages represent the main vehicle to identity, and to social structures and practices related to the use of the disclosed information. The distribution and the absorption of the available information is asymmetric and distinguished, through a process which is neither direct nor passive. In other words, knowledge cannot be dissociated from knowers. ${ }^{145}$

Hereof it is important to understand that languages, being associated with culture and identity, can shape perceptions of different phenomena (facts, structures, texts...) and can increase or decrease the level of socio-economic opportunities of different nations or

142 M. Asante et al., The global intercultural communication reader, $2^{\text {nd }}$ ed., Routledge, 2014, pp. 17-18. See also: E. Hall and W. Whyte, 'Intercultural communication: a guide to men of action', Human Organization, vol. 19, no. 1, 1960, pp. 5-12. JSTOR, JSTOR, www.jstor.org/stable/44124458 (accessed 8 November 2018).

143 T. Weiming, The context of dialogue: globalization and diversity, in M. Asante et al., 2014, pp. 496-514.

144 Ibid.

145 P. Riley, 'Language, Culture and Identity: An Ethnolinguistic Perspective', Continuum, 2007, p. 6. The same work defines the idea of an intercultural space. 
communities, as languages are not a decontextualized phenomenon. ${ }^{146}$ In an intercultural space, as the (global) patent system can be considered, language, and the whole set of perceptions it carries, plays an important role, that should not be taken for granted in patent studies and should be understood from the perspective of the globalization of technology.

Montobbio and Sterzi consider international knowledge spill overs as key drivers for globalization of technology. The authors observed that knowledge transfer depends on resources such as patents and publications as much as on local tacit knowledge, such as know-how and routines. They also defend the idea that knowledge diffuses more rapidly through research collaborations, in their capacity of creating social networks and encouraging mutual learning. ${ }^{147}$

Likewise, Huang et al. recognize the rapid and continued growth of cross-border patents, fruit of collaborative creativity networks. The authors observed that the advent of those networks has tended to have been affected more by geographical distance than by language. Their study points that this type of collaboration is concentrated in Europe and North America, and that patents, in global collaborative creativity, have grown linearly, while inventors have grown exponentially. They mention the evolution of communication technology as a factor which influences the expansion of patents and inventors associated with cross-border collaboration. ${ }^{148}$

Concomitant with this trend to more collaboration and knowledge exchange, according to Chakroun, there has been a tendency for major patent offices in the world to centralize a system of global governance of knowledge. The author sees some risks related to this movement in terms of public disclosure and diffusion of technological information. The solutions indicated are improving patent quality, disclosing patent information to the fullest extent, and actively rendering it transparent and easily accessible to the public. ${ }^{149}$

Another trend is related to extensive patent protection coverage and to speeding up the process of patent prosecution and validation. ${ }^{150}$ This trend responds to the new configuration of the patent system, explained in this dissertation under the perspective and as a result of improved translation tools and the mitigation of language barriers which once prevented the system's communication flow. ${ }^{151}$

Globalization, together with a tendency to a more harmonized and internationalized patent system has intensified the spread and diffusion of ideas, practices, knowledge and technologies across the nations. It also increased the possibilities and speed

146 D. Evans, D, Language and Identity. Discourse in the World, Bloomsbury, 2015, pp. 3-9, p. 201.

147 F. Montobbio and V. Sterzi, 'The Globalization of Technology in Emerging Markets: A Gravity Model on the Determinants of International Patent Collaborations', World Development, vol. 44, 2013, pp. 281-299.

148 Huang et al., 'Globalization of collaborative creativity through cross-border patent activities', Journal of Informetrics, vol. 6 , 2012, 226-236.

149 N. Chakroun, Patents for development: improved patent information disclosure for incremental innovation, Cheltenhan, Edward Elgar, 2016, pp. 45-46.

150 N. Chakroun, op. cit., p. 44.

151 Chapter 6 discusses the role of translation on international patent treaties and agreements. 
of knowledge transfer among developed and developing countries. This is what the study of Murthy and Alam evidences, while analysing the impact of the economics of patents and its benefits for innovation in the Indian economy. ${ }^{152}$

The lack of uniformity and consistency of the patent system is still a burden to companies that wish to enforce their rights in various jurisdictions:

Companies that conduct business across international borders have long dealt with significant costs associated with apprising themselves of the varying laws of a multitude of jurisdictions. For U.S. corporations worrying about the protection and enforcement of their intellectual property rights on a worldwide scale, this lack of consistency and uniform enforceability has been a significant concern for years. (...) Fortunately, representatives from the U.S. have been working with various governing organizations in an effort to standardize many intellectual property laws across jurisdictions. ${ }^{153}$

The afore mentioned studies present a description of a complex, globalized scenario for knowledge transfer associated with the patent system. What they also evidence is that this scenario is diverse, being dependent on local cultures and other factors, such as linguistic or geographic distance. Although none of the referred studies directly discusses the role of disclosure of technological information in this intercultural scenario, it is clear that there is an association of a patent globalized scenario with the idea of disclosure, as knowledge transfer and international collaboration would not be facilitated by the existence of a patent system if patents were not an instrument for revealing the content of inventions.

Disclosure shapes and is shaped by this intercultural space, which is configured as a multilingual, complex and nonsymmetric structure. Although this space counts on some centres of knowledge governance, represented by the largest patent offices, and although it reached a certain level of coherence in terms of presenting a common substratum of legal guidelines and concepts, there is still much to do in order to reach an optimal level of coherence and harmonization. Language and translation, as the object of this research, represent an important way to follow in order to deal with these discrepancies.

152 K. V. Murthy and T. Alam, Globalisation and Patents: A Study of Patents filed by India, MANTHAN: Journal of Commerce and Management, vol. 1, no. 2, 2014, pp. 29-46.

153 B. Lillis, Globalization and harmonization of intellectual property, Buffalo Law Journal, Dec 31, 2015, https://www.bizjournals. com/buffalo/news/2015/12/31/globalization-and-harmonization-of-intellectual.html (accessed 7 November 2018). 


\subsubsection{Disclosure and translation: legal references}

Although the association of disclosure of patent content and translation is recent historically, there are already important legal references testifying the current role of translation to the disclosure of patent information. In the present research, those references focus on European regulations and will be summarized in this section, although they deserve further, more detailed investigation, which could comprise other national patent statutes.

The concept of disclosure is a central one on the European Patent Convention. It is connected to other legal concepts and cannot be interpreted in isolation. The main correlated concepts, as previously explained, are "sufficiency of disclosure", "novelty" and "inventive step". ${ }^{154}$ The idea of sufficiency of disclosure refers to a legal requirement. A patent should contain a detailed description of at least one way of carrying out the invention. Additionally, the invention should be understandable to a person skilled in the art. ${ }^{155}$

The same way, the definitions of novelty and inventive step are linked to the success of the application in disclosing the invention. Novelty is defined, by the EPC, to be the feature of "being new" or being not part of the state of the art, while the inventive step relates to the non-obviousness of the invention for the person skilled in the $\mathrm{art}^{156}$. Furthermore, the state of the art shall be held to comprise everything made available to the public by means of a written or oral description, by use, or in any other way, before the date of filing of the European patent application. ${ }^{157}$ Therefore, the EPC, in supra-mentioned Article 54, defines disclosure through an extensive perspective, acknowledging even oral descriptions that could have made the invent available, strictly speaking, disclosed, to the public. ${ }^{158}$

Those concepts, interpreted in association, make it clear that language and translation may be determinant on the quality of a patent application and may guide the decision of patent examiners in considering the inventive step and the novelty of the invention. Some passages of the EPC ${ }^{159}$, the EPO's Guide for Applicants ${ }^{160}$ and the Guidelines for examination ${ }^{161}$ - among many other legal sources - focus on the clarity of the writing of a patent application. Other (less abundant) passages explicitly reflect this association, valuing the role of (especially machine) translation to the process of disclosure of the content of the patent document. ${ }^{162}$

\footnotetext{
154 SeeArticles83,54and56oftheEPC, http://documents.epo.org/projects/babylon/eponet.nsf/0/029F2DA107DD667FC125825 F005311DA/\$File/EPC_16th_edition_2016_en.pdf (accessed 21 December 2018).

155 See Art. 83 of the EPC for the complete definition.

156 Article 56 of the EPC

157 Article 54 of the EPC

$158 \mathrm{lbid}$.

159 See, for example: EPC, Articles 83 to 85 and Rules 42, 43, 47 and 48.

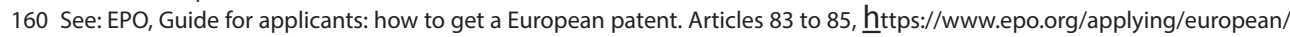
Guide-for-applicants/html/e/ga_c_ii_3.html

161 EPO, Guidelines for examination, https://www.epo.org/law-practice/legal-texts/html/guidelines/e/g_iv_4_1.htm (accessed 30 November 2018). See especially: 'Part F - The European Patent Application' of the Guidelines.

162 The passages are cited and commented below in this Section of the dissertation.
} 
The legal literature presents profuse regulations and guidelines to the writing of a patent and its relationship with patent disclosure. Lack of sufficiency of disclosure represents a reason for revocation, when the patent is opposed, and invalidation, in infringement cases. Case law associates the lack of sufficiency of disclosure with the clearness of the patent claims. The whole subject matter defined in the claims must be capable of being performed without undue burden and without invention. ${ }^{163}$

In this regard, the skilled person should be able to read and understand the invention without major efforts, which evidences the textuality of a patent. The patent text is meant to be read, understood and interpreted (in its original language or via translation) by the person skilled in the art. ${ }^{164}$ The legal literature indicates that this process of interpreting the patent text can be associated or complemented by other texts. However, the intertextuality ${ }^{165}$ of the patent text also finds limitations, associated with the concept of disclosure. It includes textbooks and general technical literature ${ }^{166}$, but excludes other patent documents and scientific articles ${ }^{167}$. Therefore, the person skilled in the art is seen as a reader of the patent text, who should be able to understand its content without having to perform complex, comprehensive research. ${ }^{168}$

T 243/96 brings important reference associating translation and disclosure. The case reverted a decision where the abstract of JP-A-57 041 891, a Japanese patent, was considered the basis of which an application was refused. The Boards of Appeal considered this disclosure inadequate and requested the full document to be translated into English. The analysis of the translation of the full document clarified the divergent interpretations of the abstract in Japanese. Remarkably, although the language chosen for the translation of the document was English, the proceedings were conducted in French. ${ }^{169}$

The EPO's Guide for applicants introduces commands about patent writing on Articles 83 to $85 .{ }^{170}$ Rules $42,43,47$ and 48 of the EPC also concern guidelines related to the form and content of description, claims, drawings and abstract. Article 85 states that the abstract should concern only technical information and should not serve the purpose of grounding the scope of the protection. It differs from the claims; whose main purpose

163 See: Regeneron Pharmaceuticals vs Kymab Novo Nordisk, EWHC, 2016; Novartis AG v Johnson \& Johnson Medical Ltd EWCA, 2010; T 435/91, Case Law of the Boards of Appeal, Decision of 9 March 1994, https://www.epo.org/law-practice/ case-law-appeals/pdf/t910435ex1.pdf (accessed 27 December 2018).

164 The mentioned legal sources do not make any references to or limit the languages in which patent documents or associated material will be consulted. However, it is evident that the process of reading or interpreting a patent document frequently involves translation or multilingual communication.

165 The term "intertextuality" refers to the interaction of texts with other texts, or to their interdependence. See, for example: G. Allen, Intertextuality, Routledge, 2000.

166 T 171/84, T 51/87, T 580/88, T 772/89, EPO, Case Law of the Boards of Appeal, Eighth Edition, August, 2016, pp. 330-332, http://www.epo.org/law-practice/legal-texts/html/caselaw/2016/e/clr_iii_f_1.htm (accessed 18 April 2018).

167 See T 766/91, point 8.2 of the Reasons; T 1253/04, point 10 of the Reasons.

168 T 206/83, T 654/90.

169 T 0243/96, Decision of 25 May 1998, https://www.epo.org/law-practice/case-law-appeals/recent/t960243fu1. htmI\#D4N_T_1996_0243 (accessed 23 December 2018).

170 EPO, Guide for applicants. 
is to define the matter for which protection is sought. ${ }^{171}$ The claims should be clear and as concise as possible. The description and drawings have the purpose to support the claims in defining the scope of protection and in disclosing the invention. ${ }^{172}$

WIPO's Patent Drafting Manual also represents an important source for defining the association between translation and disclosure in the current global patent scenario. The Manual brings recommendations and guidelines over the writing of a patent in terms of clearly disclosing its technological content. Section 1 of Chapter III of the Manual concerns a step-by-step explanation on how to obtain invention disclosures from inventors. The Manual also provides an Invention Disclosure Form to be used for facilitating the understanding between agent and inventor on the disclosure of the invention. The Manual brings various references to translation, and to the possibility of the applicant to have to provide translations on the national phase (s) of the application:

The client may need to provide a translation of the priority application in those countries that do not accept applications written in the language of the priority application. The timeline for providing such translations can vary from country to country. As noted above, the costs for obtaining a translation of a complicated legal/technical document like a patent can be expensive. Thus, if the client is interested in filing counterpart applications in five countries other than the priority application's filing, and none of those five countries accepts applications written in the language of the priority application, the client will need to provide five translations (which can amount to a substantial sum). ${ }^{173}$

In terms of the role of machine translation to disclosure of patent information, it is worth to mention the Guidelines for Examination of the EPO, which encompass various practical references related to translation and a section exclusively dedicated to machine translation. The Guidelines recognize distinctly the relevance of machine translation to patent examination, by disposing that in order to overcome the language barrier constituted by a document in an unfamiliar non-official language, it might be appropriate for the examiner to rely on a machine translation of said document. ${ }^{174}$

Furthermore, the Guidelines are assertive in acknowledging the use of machine translation as legitimate means to access and understand prior art. In this regard, general statements over the "bad quality" of machine translations do not invalidate the use of machine translation as a means for translation purposes. The party who objects to its use for some specific document bears the burden of offering evidence of that translation as

171 EPC, Articles 83 to 85 and Rules 42, 43, 47 and 48

172 EPC, Article 84

173 WIPO Patent Drafting Manual, http://www.wipo.int/edocs/pubdocs/en/patents/867/wipo_pub_867.pdf (

174 EPO, Guidelines for examination, Section 4.1, available at: https://www.epo.org/law-practice/legal-texts/html/guidelines/ e/g_iv_4_1.htm 
inaccurate. ${ }^{175}$ Still according to the Guidelines: $A$ translation has to serve the purpose of rendering the meaning of the text in a familiar language (...) Therefore, mere grammatical or syntactical errors which have no impact on the possibility of understanding the content do not hinder its qualification as a translation. ${ }^{176}$

The Council Regulation (EU) no 1260/2012 is also fairly emblematic as one of the first regulations which clearly recognizes the relevance of machine translation to disclosure. It describes machine translation as a key feature of the European Union. It also predicts a short term (maximum 12 years, according to the settled 'transitional period') availability of high-quality machine translation to access patent content. According to Recital 11:

In order to promote the availability of patent information and the dissemination of technological knowledge, machine translations of patent applications and specifications into all official languages of the Union should be available as soon as possible. Machine translations are being developed by the EPO and are a very important tool in seeking to improve access to patent information and to widely disseminate technological knowledge. The timely availability of high-quality machine translations of European patent applications and specifications into all official languages of the Union would benefit all users of the European patent system. Machine translations are a key feature of European Union policy. Such machine translations should serve for information purposes only and should not have any legal effect. ${ }^{177}$

Associated case law shows that there are general principles regarding the clarity and completeness of disclosure of a patented invention. It must be possible to reproduce a claimed step using the original application documents without any inventive effort over and above the ordinary skills of a practitioner (T 10/86). ${ }^{178}$ Case law also shows situations where the applicant did not provide details of the production process in the description in order to prevent the invention from being reproduced easily (T 219/85, OJ 1986, 376). ${ }^{179}$ The EPO's Boards of Appeal has identified cases where missing information related to reproduction of the invention could not be deduced from the usual knowledge of a person skilled in the art, getting the invention to be insufficiently disclosed (T 322/93 and T 524/01). ${ }^{180}$

There are many possible associations between disclosure and translation found in case law (T 323/87 (OJ 1989, 343), T 193/87 (OJ 1993, 207), T 170/83 (OJ 1984, 605), for

175 lbid.

176 Ibid.

177 Council Regulation (EU) 1260/2012 Of 17, December 2012.

178 EPO, Case Law of the Boards of Appeal, Eighth Edition, August, 2016, pp. 333-334, http://www.epo.org/law-practice/legaltexts/html/caselaw/2016/e/clr_iii_f_1.htm (accessed 18 April 2018).

179 Ibid.

180 Ibid. 
example). ${ }^{181}$ Chapter 7 of this dissertation presents and discusses cases where translation has influenced the disclosure of patent information. Translation can affect the scope of an invention, by altering the disclosed content, which may compromise the whole process of examination and grant, as in T 265/11 182 . In this respect, newly filed translations (related to other translations) can be used as a basis for review of the analysis (see T 265/11) ${ }^{183}$. Even more important, decisions taken by the examiner on the basis of machine translated prior art can be reconsidered under the light of a newly filed human translation, when there are doubts concerning the accuracy of examination (T 1332/12) ${ }^{184}$.

At this point, it is important to associate the mentioned legal sources and concepts with the essence and origin of the patent system, defined by disclosure, as the core of a "social contract", where patents represent a win-win deal between society and innovators. ${ }^{185}$ The mentioned regulations and guidelines make it clear that, if a patent does not disclose the content of the protected invention, the bargain is violated. The mentioned sources also validate the significance of disclosure for patent law, as it is clear that disclosure is a basis for the definition of the other operational concepts of the patent system, such as sufficiency of disclosure, novelty and inventive step, and is the main fundament to the examination and grant of a patent.

On the other hand, the afore described sources point to a more intense association of disclosure with translation, with emphasis to a visible role played by machine translation to universalize disclosure in the patent system. Likewise, the present research identified the relation between disclosure and translation as increasingly important and frequent in case law. In this regard, Chapter 7 describes and analyses particular cases which evidence the relevance of this association.

\subsection{Conclusions and correlation of the chapter with the research question}

For summing up the main points and conclusions of Chapter 1, it is important to retrieve the research question which guided this research: how does accuracy of translation influence the dissemination of the disclosure of patent information on patent law? This question was based on the assumption that the influence of translation on the patent system has been under-estimated by scientific studies. It was also motivated by the supposition that explaining the role of translation to the patent system may lead to its improvement and to a higher level of harmonization.

\footnotetext{
181 lbid.

182 lbid.

183 Ibid.

184 T 1332/12 () of 11.10.2017, https://www.epo.org/law-practice/case-law-appeals/recent/t121332eu1.html (accessed 2 December 2018).

185 See: Landes and Posner, 2003. See previous Sections 1.2.1, 1.2.2 and 1.2.3.
} 
The initial step taken was to introduce the fundamental concepts for the research and to characterize the current configuration of the patent system. The global, complex nature of the patent system was demarcated through the association between innovation, disclosure and patent law. The idea of disclosure of scientific/technological knowledge was defined as a dynamic process, located in an intercultural space, where knowledge depends on knowers, and its (local, particular) appropriation is conditioned to ("general", "global based") international agreements, conceptions and guidelines.

Section 1.1 presented a panoramic view of the concept of innovation, seen as belonging to the boundary between science and technology, in order to delimit the content and context of disclosure in association with the patent system. The section also brought up main definitions and legal references of patent rights as part of intellectual property rights. The main current definitions and legal developments correlated with the patent system indicated a trend to integration and harmonization, authenticated by the settlement of the TRIPs Agreement.

Section 1.2 depicted the patent scenario as an intercultural space, having disclosure as a key concept for its justification and definition. Disclosure was interpreted as a prerequisite for competitive markets, working as a bonus given to society by the patent system, and as a lever to knowledge transfer and innovation (Sub-sections 1.2.1 and 1.2.2). Section 1.2.3 defined the space where patents disclose and disseminate their technological content as an intercultural space. Hence the disclosed information moves in a space of interaction between members of different cultures, facilitating knowledge transfer and fostering innovation. Section 1.2.4 reviewed legal references acknowledging the current role of translation to the disclosure of patent information, with a focus on the European patent regulations and guidelines. 


\section{CHAPTER 2}


Methodology 


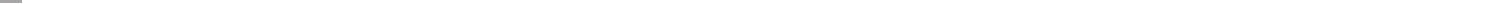




\subsection{Scope of the research}

\subsubsection{Research question and sub-questions}

The main research question which guided the present research is the following: how does accuracy of translation influence the dissemination of the disclosure of patent information on patent law? ? It aimed, primarily, to bring to light the association between translation and patent rights. Therefore, it intended to contribute to the law on the role of patent translation to the dissemination of disclosure of patent information. ${ }^{186}$

This research question implies a closer analysis of the concepts it brings. In this regard, there are two central concepts that guided the research: a. the concept of disclosure, explained and analysed in Chapter 1 of this work; b. the concept of (patent) system, which defines the framework of patent law representing its operational basis, where translation works as its main communication channel, and is described and analysed in Chapter 3.

The research question mentioned also implied the elaboration and investigation of some sub-questions. At this point, it is important to explain that the sub-questions were divided into 3 groups, which represent three distinct, although associated, scopes, essential to find answers to the main research question: a. What is the current configuration of the patent system and what does translation represent to it?; b. Does translation disclose patent information?; c. How does translation influence patent law on each different legal stage of a patent? The table below represents these three blocks and the issues being investigated in each one of them.

186 A similar methodology was used in A. Larroyed (2019), with the purpose of answering to a research question related to the importance of translation to the patent system and with a focus on the case of the Brazilian patent office. The data and methodology used in the present dissertation on the light of a distinct research question are similar due to the difficulties related to collecting and analysing patents in various pairs of languages and on crossing these data with associated infringement, office and opposition cases. The same data were suitable to respond to the present research question on the investigation of the accuracy of translation correlated with the dissemination of disclosure of patent information in patent law cases. 
Table 5: Three guiding sub-questions

\begin{tabular}{|c|c|c|}
\hline $\begin{array}{l}\text { Three guiding sub- } \\
\text { questions }\end{array}$ & Scope of investigation: derived questions & $\begin{array}{l}\text { Related concepts, tools and } \\
\text { elements }\end{array}$ \\
\hline $\begin{array}{l}\text { What does translation } \\
\text { represent to the current } \\
\text { patent global system? }\end{array}$ & $\begin{array}{l}\text { - Why should the patent system be called a } \\
\text { system? } \\
\text { - What is the association of its evolution with } \\
\text { translation? } \\
\text { - What does translation represent to it in its } \\
\text { current configuration? }\end{array}$ & $\begin{array}{l}\text { - System; innovation system; } \\
\text { legal system; IP system; patent } \\
\text { system. } \\
\text { - Machine translation } \\
\text { and human translation: } \\
\text { distinctions and associations. }\end{array}$ \\
\hline
\end{tabular}

Does translation disclose patent information?
- How is patent information disclosed? To whom is it disclosed? In which ways and which levels is it disclosed?

- Do different pairs of languages differ in terms of disclosure results?

- Does the level of disclosure differ in terms of its receivers (scientists, laymen, examiners...) of the translated texts?
How does translation influence patent law on each different legal stage of a patent?
- Do language and translation influence international agreements involving patent law and their internalization in national patent regulations and in the national legal systems?
-What is the relation between translation and patent application? Do language issues influence decisions for applying or not for a patent in terms of different patent systems?
-What is the relation between translation and patent examination (search for prior art; analysis of patentability - novelty, industrial application, inventive step)?
- How can translation influence opposition cases?
- How can translation influence infringement cases?

\section{- Disclosure}

- Source language and target language

- Searching tools and platforms

\section{vinternational agreements involving patent rights. \\ - Patent application and examination: stages and steps. \\ - Patent opposition and infringement cases: stages and steps. \\ - National language regimes and legal cultures.}

Source: Elaborated by this author based on the main research question and on its previous investigation and research plan ${ }^{187}$

The first sub-question approached the current configuration of patent systems. This part of the research presents relevant theories and concepts over the relation between innovation disclosure and patent law (Chapter 1). It also aimed to investigate the connexion between patent systems, its current legal outlines and translation (Chapters 3 and 4), which demanded a deeper overview of the patent text and of the roles of machine and human translation on patent systems (Chapter 4 and 5).

The second sub-question is related to the disclosure of technological information through patent translation. It focused on how machine translation enables the disclosure

187 Ibid. For additional information over a distinct research question, see my research in Brazil in Larroyed (2019). The path used for dealing with the collected data was similar to the one accomplished previously in order to give a new scientific contribution focusing on the disclosure of patent information in patent cases. 
of the relevant information of a patent depending on different situations and contexts (distinct pairs of languages, parts of the patent text, types of patents and receivers of the translated texts). The methods used to assess the level of disclosure of patent information through machine translation are explained in Section 2.3.

The third sub-question focused on the influence of translation on the different legal stages of a patent, which include: the guidelines defined by cross-border agreements and their internalization through national law; the processes of application and examination related to language and translation regimes and to the disclosure of information allowed by machine translation; the importance of translated texts and documents to the stages of opposition and infringement. These different stages were analysed separately in Chapters 6 and 7 (Chapter 6 focused on cross-border agreements; Chapter 7, Section 7.2, on patent examination; Section 7.3, on opposition and infringement cases; Sections 7.4 and 7.5, on the results of the sample analysis and interviews). It is important to explain, that, although each stage of a patent is analysed independently, the legal "life" of a patent can be represented by a time line, where each stage depends on the previous ones and all of them are connected to the guidelines of the global patent system through international agreements and their internalization. ${ }^{188}$

Although the chosen research question is very specific to the operational level of patent law, associated with all the legal stages of patents, the scope of the research demanded a broad, interdisciplinary understanding of the concept, meaning and functioning of patent rights and their regulations, both in national and global levels.

\subsubsection{Delimitations and hypotheses}

Due to the inter-disciplinary nature of the research question presented in the previous section and to the seminal character of the present investigation, for selecting the sample and developing the methodological techniques, it was necessary to establish delimitations in terms of: historical time, geographical approach, conceptual approach, types of patents and consulted players.

The historical time was defined as the current configuration of the patent system, allowed by the recent improvements of information and communication technologies, which is, in the case, especially represented by machine translation and searching platforms and tools. Further analysis of the evolution of these tools, and of the historical growing importance of machine translation to the patent systems, are left to further studies.

The geographical approach was limited to possibilities of accessing stakeholders and documents from different national systems, and also from the representative relevance of the interviewees. The main focus was on the European patent system, as the richest

188 Section 7.1 describes the timeline of a patent from the perspective of translation, explaining the interdependence of the different stages. Chapter 6 presents a thorough description of the most important international agreements for patent law, associated with language regimes and aspects related to translation. 
source of agreements and developments related to patent translation. Stakeholders and documents from the following countries were involved (interviewed and/or consulted): Brazil, China, Europe, India, Japan, Korea and the United States. The idea, however, was not to develop a comparative study of the mentioned jurisdictions.

Due to the level of novelty of the research, the conceptual approach aimed to understand, describe and approximate the most important associated concepts and ideas, which are basically: the current patent system and its relationship with language/ translation; machine and human translation and their roles to the current patent system, especially on the process of disclosure of technological information, the influence of translation on the distinct legal stages of a patent.

Section 2.3 thoroughly explains the delimitation of the type of patents and pair of languages chosen to carry out the documentary analysis. The same section elucidates the steps followed to select the investigated players and the data collection techniques both for the interviews and content analysis. As it comes to a seminal work, a lack of prior art and references also concerning methods and techniques to approach the object was faced. Hence it was necessary to investigate ways to carry out the research and build a methodological plan to collect and cross check sufficient and appropriate data. Section 2.3 brings a detailed explanation of all the steps followed in "building' this methodological plan. It also characterizes the theoretical bases involved in this planning, as well as the selection of the tools and techniques which were developed and applied.

The thesis that guided the present work was the following: accuracy of patent translation has an enormous influence on patent law and a central importance to it and to the interchanges within the patent system - the patent system is based on (especially machine) translation. Machine translation allowed a global configuration of the patent system. Investigating how translation operates in patent systems can bring answers and guidelines to their improvement and offer a clearer view of their functioning.

The main hypotheses which guided the research to the above-mentioned thesis are described below:

- Machine translation completely overhauled patent rights and is the basis of the patent system (Chapters 1 and 4);

- The patent system can be defined as a sub-system of the legal system, associated with other systems (scientific, economic...) based on (especially machine) translated multilingual communications. This idea is useful for understanding the role of translation as the basis of communication of the patent system (Chapters 1 and 3);

- Machine translation discloses patent information. To what extend? It depends on languages, contexts and receivers (chapters 3 and 4);

- Translation influences patent related cross-border agreements and their internalization into national law (Chapter 6); 
- Machine translation does not only influence the decisions taken by patent examiners, attorneys and judges. It can mislead them (Chapter 6 and 7);

- National courts and patent offices obey different language regimes and different approaches to foreign documents. This creates inconvenient discrepancies in the global patent system, corrupting the system and impairing legal certainty in complex patent cases (Chapter 7);

- Integration and interaction are the best solutions for minimizing discrepancies between cross-border cases and for increasing the rule of law correlated to patent rights (chapter 8). ${ }^{189}$

These hypotheses were all confirmed by the results of the research, shown in the associated chapters presented above. Their investigation also generated a considerable number of enquiries over possible further research problems and common opinions and statements that may overshadow future perspectives over the association between translation and the patent system. These enquiries and conclusions are summarized in Chapter 8.

\subsection{Societal Relevance}

In terms of societal relevance, it is easy to defend the research question proposed here as an answer to the following questions: How relevant are language and translation to patent law? Why should a study about the influence of translation on patent law be important to society in general, among whom the majority are not familiar with the concept of patent and with the functioning of patent systems? ${ }^{190}$

The first reason is related to the economic importance of patents for the whole society and the relevance (and costs) of translation to the efficiency of a national patent system. Patents are closely related to the universality of science, to foreign trade and to the consequences of globalization, including fast and automatic communication allowed by digital tools. Patent rights serve this vast, multilingual, complex global system, owing it reliable solutions. Costs with patent translation can represent a burden to smaller companies or independent inventors to protect their inventions and get the fair revenues for them.

There are examples of patent disputes involving huge profits in fees for translations that extended to more than 100 million words. Translation is not only critical to patent disputes, but to the whole "life" of a patent and to all the international regulations and their internalization in national law. That involves the stages of application, examination and validation; opposition and infringement; and the whole process of patent bargain, with an emphasis on the disclosure of technological information.

189 Ibid. See the two previous notes.

190 For a different perspective using a similar methodology, see my research in Brazil in A. Larroyed (2019). 
This scenario requires an appropriate organization of each national patent system. That involves a whole understanding from each society of the importance of patents and its capacity to provide efficient direct and associated services, the necessary education of future professionals who will be able to deal with this complexity, a set of academic initiatives which can cope with the improvement of the patent system and its correlated governmental structures able to develop conscious and efficient policies in order to integrate the national patent system with the global patent system. All of this involves language and cultural integration and interaction and demands a closer look at the patent system from the perspective of language and translation. ${ }^{191}$

This research intends to bring both theoretical and pragmatic contributions related to the influence of translation on patent law. It is an example of an inter-disciplinary, empirical study. In this regard, the description of this influence and of the present role and future perspectives of translation within the patent system would already have added much to patent studies. However, this research presents some concrete products and contributions, which can be used as a new reference to studies associating patent and translation, the most important of them being:

- A set of statistics and data over the level of disclosure of technological information enabled by machine translation.

- An outline of the most common issues related to translation in opposition and infringement cases.

- An analysis of the implications of language and translation for a more integrated patent system in Europe and of the language regime of the Unitary Patent and the Unitary Court, with a set of recommendations to improve its language regime.

- A debate over the model of the European Unitary System as one to be disseminated in the sense of promoting integration and interaction in developing countries;

- A list of recommendations to future studies that open grounds to a whole new field of study which associates language diversity and legal integration and interaction in the patent system as a very relevant issue in the current situation of the patent system at the global level and the future of patent rights.

- A list of recommendations for improving patent expert systems and online platforms in terms of the best use of translation functionalities.

- A set of proposals to further interdisciplinary and empirical studies involving patents and translation that can continue to contribute with solutions for global justice and harmonization of patent rights.

- A deeper and more reliable portrait of the difficulties with language and translation faced by the main players of the patent system: patent examiners,

191 Ibid. 
patent attorneys, judges, specialized translators, administrators and policy makers.

- A set of guidelines to optimize the level of interaction and integration of national patent systems to the global system through the perspective of language and translation. ${ }^{192}$

Lastly, by providing an overview of the role of translation to patent systems, this work represents an important reference to related scientific future studies, as well as to projects and reports aimed at the improvement of national systems, the preparation of professional translators who can better serve the patent system, the elaboration of language regimes on international agreements and to a more realistic view on the role of language and translation to patent law.

\subsection{Methodological approach and techniques}

\subsubsection{Overview of the used methods and techniques}

The purpose of this section is to present an overview of the methods and techniques used in the research, in order to help understanding the steps followed to answer the research question. The next section will present more details over the theoretical background and all the steps followed in the process of studying, developing and combining the techniques involved. ${ }^{193}$

Defining and narrowing a sample of patents was one of the most challenging tasks of the present research. The first difficulty was to choose the type of technology that should characterize the sample. The second and hardest stage was to combine the information disclosed by the patents with their machine translated texts and with legal information about them with the purpose of associating these three spheres. ${ }^{194}$

In order to obtain complete information about the sample, it was decided to work with three databases in a complementary way, two of them being paid databases, Patsnap and DartsIP, and one of them, Espacenet, being the free database offered by the EPO. The three chosen databases presented different types of filters, focusing on different types of information about the patents. ${ }^{195}$ The research programme of IGIR encouraged the preference for green technologies, which was a first step to narrowing the patent sample. ${ }^{196}$

Patsnap is an analytic platform, which focuses on the competitive landscape of patents. It provides tools which allow companies to plan their IP strategy according to the

\footnotetext{
192 Ibid.

193 See notes on the previous Section over a similar methodological approach associated with a different research question in my research in Brazil. See A. Larroyed (2019).

194 Ibid.

195 Contrasting the structure and functionalities of the databases allowed a contribution on searching tools improvement presented on Section 4.2.2 and Chapter 8.

196 Ibid.
} 
contexts that surround a technology. In the case of the present research, it was the most suitable platform for understanding the scenario of green technologies and selecting a valid sample by its economic relevance and geographical/linguistic reach. ${ }^{197}$

Darts-IP is an expert system which focuses on industrial property-related case law. It enables the possibility of searches by points of law, parties, patents or courts. Its free text search tool also enables different searches in different languages (separately or simultaneously). In the case of this research, it was useful for accessing the most important legal issues involving the sample, giving an idea of the legal global scenario that surrounds the selected patents. It also helped to find emblematic cases related to the sample. ${ }^{198}$

Espacenet, the free platform developed by the EPO in 1998, is a very complete platform, showing data on more than 90 million patents from around the world. It offers a tool named SmartSearch, which allows a composed search using a subset of Contextual Query Language. ${ }^{199}$ For this research, one of its services considered especially useful was the "Patent Translate" service, exploited as the main reference for the assessment of the quality of patent machine translation. ${ }^{200}$

The sample of green patents was narrowed as it was possible to get more familiar with the databases and the types of technologies that would compose it. The criteria to choose the type of technology was its economic importance, the time period when the patent was published (in this case, patents published from 2012 to 2015) and the possibility of finding a reasonable number of patents with international relevance. Only granted patents were the object of analysis. After testing some possible samples, the choice was wind power and solar energy patents, understanding these patents could give enough information to the aspects analysed.

\section{Table 6: Criteria for selecting the sample}

\footnotetext{
- Economic importance (when possible);

- Proximity in time - from 2012 to 2014;

- Legal situation - only granted patents were selected (with these criteria, it was intended to guarantee that the patent text had a minimum quality to fulfil the requirements of the analysis, as granted patents are the ones which actually correspond to new inventions).
}

Source: Elaborated by this author based on the information available on the mentioned patent platforms 201

197 Homepage of Patsnap: http://www.patsnap.com/ (accessed 13 April 2018).

198 Homepage of Darts-IP: http://www.darts-ip.com/ (accessed 13 April 2018).

199 Wikipedia's entry over Espacenet: https://en.wikipedia.org/wiki/Espacenet (accessed 13 April 2018).

200 Homepage of Espacenet: http://www.epo.org/searching-for-patents/technical/espacenet.html\#tab1 (accessed 13 April 2018).

201 See footnotes on the previous Section. 
By combining the information contained in the three platforms mentioned, it was decided to carry out the analysis in two steps. The first step aimed to assess how much of a patent's information is disclosed by machine translation. The second step aimed to go deeper into some emblematic cases involving validation, opposition and infringement of patents based on translated documents. The second step also aimed to understand and describe the opinions of players of the patent system about the influence of translation on these cases. The results of the second step were presented in Chapter 7. ${ }^{202}$

For performing the first step of analysis, it was important to initially evaluate the possibilities of working with different sizes of the sample related to clean energies, consisting of wind power and solar energy patents. Then a sample size calculator (Raosoft) was used over the average number of these patents applications per year given by Patsnap in the years of 2013, 2014 and 2015 (considering only the granted patents). ${ }^{203}$ As the average number of patents result was 6,523 patents, and considering a margin of error of $10 \%$, a confidence level of $90 \%$ and a response distribution of $50 \%$, the minimum recommended sample size was 67 patents. For working with a round number, 100 patents were selected among the applications made between 2013 and 2015. ${ }^{204}$

The set of languages chosen for the analysis was English, French, German, Italian, Spanish, Chinese and Portuguese. This set of languages was chosen because of this author's familiarity with most of them, except for Chinese, and the convenience (in the case of French, Italian and Spanish) of being languages with a closer structure to the author's mother tongue. For the same reason, Portuguese was the main reference as a target language in the process of analysis. It was also possible to find support of native speakers for the analysis of German and Chinese texts. This set of languages is also representative of three groups of languages that are important to the patent system: Anglo-Saxon, Asian and Latin languages are included. ${ }^{205}$

The inclusion of Chinese is justified by the noticeable percentage of patents in Chinese among the applications in the selected sample. So noticeable was this number that, while searching for patents to analyse, it was necessary to eliminate the filter for the Chinese patents in order to avoid a clear predominance of these patents on the first pages of results given by the expert systems.

202 Ibid.

203 For accessing Raosoft sample size calculator: http://www.raosoft.com/samplesize.html (accessed 13 April 2018).

204 lbid.

205 Ibid. 
Table 7: Description of the sample used for the first step of analysis

\begin{tabular}{|c|c|}
\hline \multicolumn{2}{|c|}{ First Step of Analysis - Level of Disclosure: Description of the Sample } \\
\hline Types of patents & Green patents - clean energy - solar energy and wind power patents \\
\hline $\begin{array}{l}\text { Search by geographical } \\
\text { location }\end{array}$ & $\begin{array}{l}\text { First set: patents from different parts of the world except from China and Japan } \\
\text { aiming to find the selected languages: English, French, German, Italian and } \\
\text { Spanish; } \\
\text { Second set: patents from China }\end{array}$ \\
\hline Languages & $\begin{array}{l}\text { First set: preference to: English, French, German, Italian, Spanish and Portuguese. } \\
\text { Second set: English (target language) and Chinese (source language) }\end{array}$ \\
\hline Sample size & $\begin{array}{l}100 \text { patents, chosen from an average number of } 6,523 \text { patents per year } \\
\text { (considering a margin of error of } 10 \% \text {, a confidence level of } 90 \% \text { and a response } \\
\text { distribution of } 50 \% \text { ) }\end{array}$ \\
\hline Platforms used & Patsnap and Espacenet (Darts-IP was used in the second step of analysis) \\
\hline $\begin{array}{l}\text { Time period of the } \\
\text { selected sample }\end{array}$ & Patent applications from 2013 to 2015 \\
\hline
\end{tabular}

Source: The table was created by this author in order to organize the information about the sample and its characteristics ${ }^{206}$

After narrowing the sample and defining its characteristics, it was important to decide on the best method to assess the quality of the machine translations provided by patent translate. It was decided to base the methodology on the LISA (Localization Industry Standards Association) Quality Assessment (LISA-QA) default model, a system created for managing the quality of translations certificated by ISO 9001 . According to this metric, errors are regarded as Minor, Major or Critical. ${ }^{207}$

For each category, the number referring to the error is multiplied by a weighting figure, as depicted by the table below. For example, if you identify four minor mistranslations, they will generate a score of 4; but if a segment of a text contains 2 critical problems of translation, one should write twice 10 in the column referred to as "critical" for "mistranslation", which will result in a score of $20 .{ }^{208}$ The table below describes the method used for characterizing each patent.

206 See footnotes on the previous Section.

207 See details about the metric in the Localization Industry Standards Association's official website: http://web.archive.org/ web/20110101195746/http://www.lisa.org/LISA-QA-Model-3-1.124.0.html (accessed 13 April 2018). See also LISA Best Practice Guide - Implementing Machine Translation, http://www.mikedillinger.com/papers/MT_BPG2004.pdf (accessed 13 April 2013) and http://web.archive.org/web/20110102030235/http://www.lisa.org/globalizationinsider/2010/08/the_lisa_ qa_mod.html, for more information on the usage of the metric for translation quality assessment software (accessed 13 April 2013). See footnotes on the previous Section. 
Figure 5: LISA-QA - Metric of translation assessment as applied to the sample

\begin{tabular}{|l|l|l|l|l|}
\hline \multicolumn{2}{|c|}{} & Minor & Major & Critical \\
\hline Doc Language & 2 & 5 & 10 \\
\hline Mistranslation & 1 & 5 & 10 \\
\hline Accuracy & 2 & 5 & 10 \\
\hline Terminology & 2 & 5 & 10 \\
\hline Language & 2 & 5 & 10 \\
\hline Style & & & & \\
\hline \hline
\end{tabular}

Source: Based on Lisa's Best Practice Guide ${ }^{209}$

Although LISA-QA model does not establish a level for assuring excellence in translation (some companies work with 99\%), ${ }^{210}$ considering the type of translation which was being analysed and the possibility of counting on the support of source texts and drawings, a lower level of $70 \%$ of correction was established (30\% of errors) as a parameter. The texts were analysed one by one and the results were registered manually, in order to guarantee their reliability.

Other important information about the sample analysis is the part and size of the text of the patent considered in order to obtain more precise results. The two parts of the patents considered as crucial to the disclosure of the technological information and representative of the patent as a whole in terms of textual structure were the abstract and the patent claim. It was decided not to bring the description because of the importance of focusing on text information only, without the addition of the drawings, as the last ones make disclosure much easier and would interfere in the language analysis. Working with the chosen parts, in this sense, meant to choose the stricter way, in order to have a better level of confidence in the analysis.

In terms of text extension, the abstract has a reasonable amount of textual information, possible to manage in the size defined for the sample. However, for having a homogeneous sample, it was decided to work with the first 100 words of this part of the patent text (having the flexibility of adding or excluding a small number of words in order to have complete sentences).

The patent claim can be represented by a much longer text than the abstract. It is a very crucial textual part for the disclosure of the technical information and a more technical text than the abstract in terms of its language structure, as the abstract functions as an introduction. Hence, in order to have more homogenous and manageable text material, the size of the patent claims was defined to be around 200 words, a number which is sufficient for having enough textual content for a reliable analysis. This last figure was defined after some practical work with the sample and was shown by the characteristics of the texts of the selected patents.

209 Ibid. See footnotes on the previous Section.

210 Ibid. 
Table 8: Details of the sample size

\begin{tabular}{lll}
\hline & Total number & $\mathbf{1 0 0 + 1 0}$ Chinese patents \\
\hline & "English patents" - patents having & 50 (30 on solar energy and 20 \\
& English as their original language & on wind power) \\
\cline { 2 - 3 } & "French patents" & 20 \\
\cline { 2 - 3 } & "German patents" & 10 \\
\cline { 2 - 3 } & "Spanish patents" & 10 \\
\cline { 2 - 3 } & "Italian patents" & 10 \\
\cline { 2 - 3 } "Chinese patents" & 10 \\
\hline \multirow{2}{*}{ Level of correction } & At least 70\% of correction (30\% of errors) to be considered as a \\
& reasonable translation. & \\
\hline \multirow{2}{*}{ Size of the texts } & Abstract: \pm 100 words & $\begin{array}{l}\text { Claims: } \pm \text { 200 words (results } \\
\text { should be divided by 2. }\end{array}$ \\
\hline
\end{tabular}

Source: Developed on the basis of the information contained on Patsnap and Raosoft ${ }^{211}$

After choosing the method, it was important to create a form containing the information of the patent considered as crucial (title, economic value of the patent, publication number and date, application number and date, assignee, original language), the source and target texts that were analysed and the forms based on LISA-QA model. An example of the score table form is presented below.

Figure 6: Example of score table used to evaluate the translation of a patent text

\begin{tabular}{|c|c|c|c|c|c|c|}
\hline \multicolumn{7}{|c|}{ TITLE: Altemating Bias Hot Carrier Solar Cells } \\
\hline \multicolumn{2}{|c|}{ Value: : $\$ 1,500,000$ (S S S S } & \multicolumn{5}{|c|}{ Assignee-: OSTENDO TECHNOLOGIES, INC. } \\
\hline \multicolumn{2}{|l|}{ Pub. N.: US20140083492A1 } & \multicolumn{5}{|c|}{ Pub. Date: 27 Mar 2014} \\
\hline \multicolumn{2}{|l|}{ App. N.: US14/028344 } & \multicolumn{3}{|c|}{ App. Date: 16 Sep 2013} & & \\
\hline \multirow{2}{*}{ Doc. Language (s): } & \multicolumn{2}{|c|}{ Minor $=1$} & \multicolumn{2}{|c|}{ Major $=5$} & \multicolumn{2}{|c|}{ Critical $=10$} \\
\hline & Abstract & Claims & Abstract & Claims & Abstract & Claims \\
\hline Mistranslation & & & & 1 & 2 & 4 \\
\hline Accuracy & 1 & & 1 & & & \\
\hline \multicolumn{7}{|l|}{ Terminology } \\
\hline Language & 3 & 7 & & 3 & 1 & \\
\hline \multicolumn{7}{|l|}{ Style } \\
\hline Total score & Abstract & \multicolumn{2}{|c|}{39 (100 words) } & Claims & \multicolumn{2}{|c|}{67 (200 words) } \\
\hline
\end{tabular}

Source: Developed on the basis of Lisa's Best Practice Guide ${ }^{212}$

211 For Patsnap, see supra note 197; and for Raosoft, supra note 203. See footnotes of the previous Section.

212 Ibid. 
Besides using LISA-QA model based analysis, it was relevant to assess how researchers and experts belonging to the research field of the sample would react to the machine translated texts, considering the question to be responded to in this step of analysis concerned how much a machine translated text of a patent could disclose about the content of the invention claimed on it.

For this purpose, it was crucial to develop another type of method and form to be shared with the researchers and experts from the R\&D departments related to clean energies technologies. Fortunately, it was possible to count on the contribution of a government institution, a university and a private firm. That was not an easy task to find players willing to co-operate. Luckily, it was also possible to collaborate with experienced researchers, as this analysis was especially slow and laborious and required at least 3 hours to be completed, according to their feedback.

The researchers who co-operated, whose list is described in Appendix 1, did it voluntarily and with the agreement of their supervisors, conceding part of their work time for dedicating to it. The form which was given to them had ten pages and took from 3 to 4 hours to be analysed and filled in, according to them. Below follows an example of the form used with the researchers (excluding the texts) for assessing the level of disclosure of patent information through machine translation among them. An example of the textual part is available in Appendix 3.

\section{Figure 7: Part of the form shared with researchers for assessing the level of disclosure of patent information through machine translation}

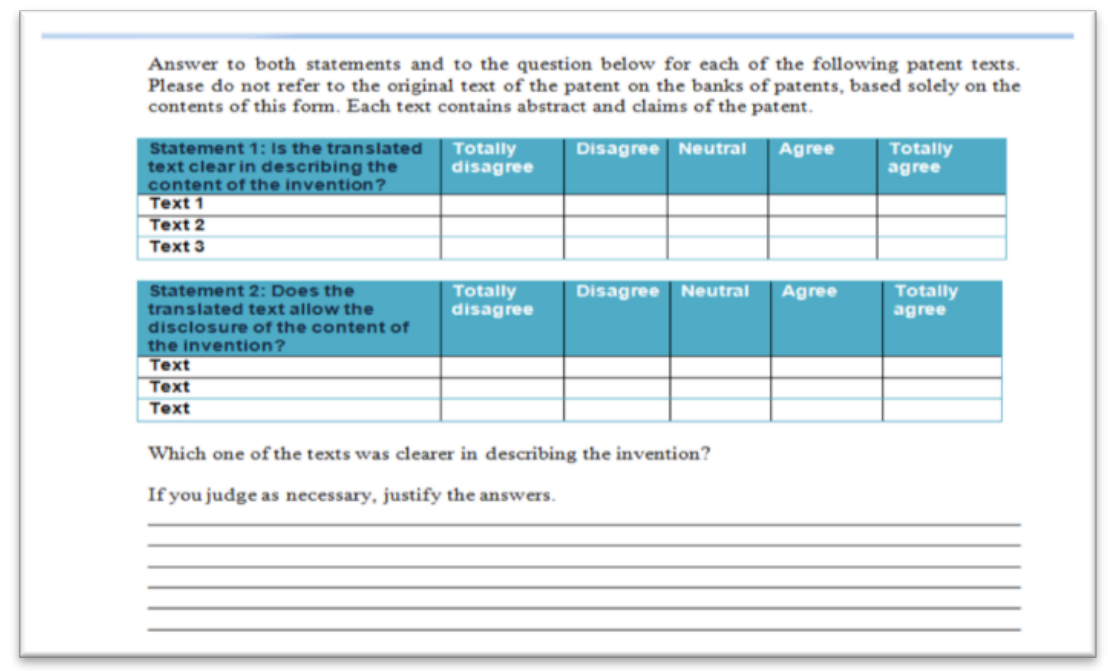

Source: Elaborated by this author based on the research plan and techniques ${ }^{213}$

213 See footnotes of the previous Section. 
The three texts shared with the researchers were chosen randomly among the most relevant results showed on Patsnap about the sample. Text number 1 was a (machine) translation into Portuguese of a patent written originally in German; text number 2, a translation into Portuguese of a patent written originally in English; and text number 3, a translation into Portuguese of a text written originally in Chinese. ${ }^{214}$ The researchers were not told about the original language of the texts. They just knew they were machine translated into Portuguese.

The last steps followed to conclude the analysis concerned working with interviews and with the documentation of representative cases of the different legal stages of a patent: application, examination, opposition and cases of infringement. First it was necessary to select the points of law that could best answer the main research question in the present work, being the one purposely retrieved here: how does accuracy of translation influence the dissemination of the disclosure of patent information on patent law? In Chapter 7 , it is thoroughly explained what was done for proceeding with the analysis. Besides, more details about how the interviews were planned and carried out are also discussed in chapter 7.

The reference to foreign documents was the main focus of analysis in the case of the content analysis involving infringement and opposition cases. After dealing with the cases, it was clear that each court can cope with the multilingual complexity of the patent system in a very particular way, and that the system presents plenty of discrepancies based on these distinct cultural/linguistic frameworks. Then it was important to categorize this relation associating it with national legal patent systems, as it is very likely that the language policy and strategies of the judges and courts depend a lot on a whole set of national cultural and legal particularities, which involve language and language regimes.

After searching for a total number of opposition cases, the result was an average number of 41 patents, and considering a margin of error of 10\%, a confidence level of $90 \%$ and a response distribution of $5 \%$, the minimum recommended sample size was 10 patents. For calculating this sample, a sample size calculator software was used. ${ }^{215}$ For the infringement cases, it was not necessary to narrow the sample as it was only possible to find 4 cases of infringement in Europe for the whole set of solar and wind power patents, even without setting any restriction of time, language or court.

The diagram below summarizes the steps followed to conclude the analysis:

214 It was not possible to obtain a direct machine translation from Chinese into Portuguese using the databases. Espacenet provides a machine translation of the text in Chinese into English, and Patsnap provides human translation of all the Chinese patents into English. We used the English translation of Espacenet and retranslated using Google Translator into Portuguese (a way a researcher would most probably naturally follow to understand the Chinese text).

215 The sample size calculator software used is available at: http://www.raosoft.com/samplesize.html 
Figure 8: Diagram representing the steps followed on the analysis
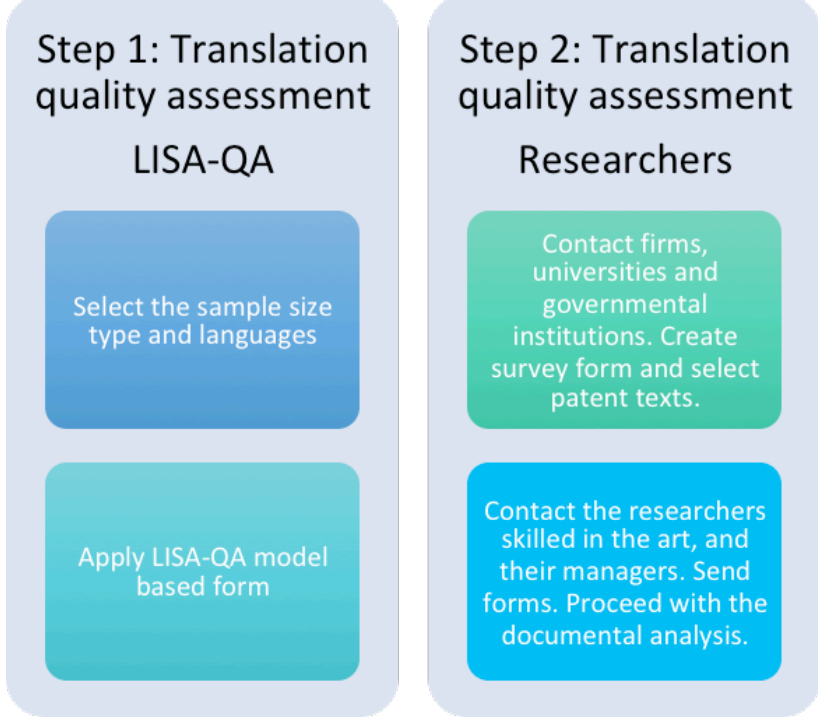

\section{Step 3: Influence of translation on distinct legal stages}

Select (office actions, opposition,

infringement) cases.

Proceed with the

documental analysis.

Interview judges,

attorneys, examiners

and other relevant

players

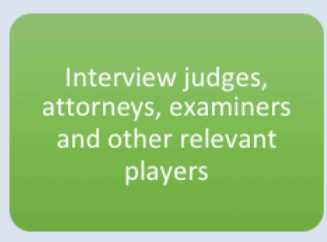

Source: Elaborated by this author based on the research plan and techniques ${ }^{216}$

\subsubsection{Theoretical background and detailed description of the methodological steps}

The purpose of this section is to discuss the methods used for the research. It is intended to present the set of methodological choices and developed activities. Organizing a "map" which details the methodological steps helped to select and employ different techniques and methods that allowed the investigation of the research question. Because of the lack of associated prior art or similar researches, it was necessary to create methodological strategies that allowed cross-referencing data and information both related to the legal aspects and the aspects associated with language and translation within the scope of the research question.

The methods proposed were meant to provide consistent answers to the research question. The scarcity of sources and literature demanded a focus on primary sources, exploited through the techniques of content analysis and semi-structured interviews. These techniques were studied and customized to attain the objectives of the research. The result was a combination of methods, explained in detail in Section 2.3.

The methodological approach was the inductive approach, as described by Berg. ${ }^{217} \mathrm{It}$ was used in order to draw conclusions from particular cases. The inductive method proceeds inversely to the deductive method, in that one generalization figures as a later product-specific data collection work. According to inductive reasoning, generalization should not be sought beforehand but found from the observation of individual cases sufficiently confirming this reality. ${ }^{218}$ 
As for the methodological procedure, the option was for the comparative method, according to Gil, who describes it as a method that proceeds by the research of individuals, classes, phenomena or facts, in order to highlight the differences and similarities between them. ${ }^{219}$ The contrast between the phenomena should also allow the analysis of data to be grounded on established theory at the same time as it is capable of developing theory. ${ }^{220}$

The chosen sample for the content analysis focused on green patents. This was due to the structure of their texts (considered more complex than the ones of, for example, pharmaceutical patents) and to their importance to an updated, systemic view, of innovation, related to sustainable development. However, due to the size and variety of the chosen sample, it was necessary to narrow it. The selected subset was clean energy patents, solar and wind energy, more specifically. The choice was made by virtue of the central status of these technologies in the main group.

The theoretical orientation was focused on a description of patent rights from a contemporary perspective. Hence it involved research related to the timeline of a patent, from the stages of examination and opposition to the evolution of court cases that, somehow, required (machine or human) translated information contained in patent databanks through the process of patent disclosure. It also comprised the review of the state of the art of the international debate on the patent system as an internationalized system, then requiring internationalized solutions. Furthermore, it called for the review of various aspects relevant to the formation of associated social systems and the position of the patent system among them. All the analysis was based on the idea of patent rights related to international agreements and guidelines, and to new scenarios allowed by the new possibilities offered by digital technologies. Putting it in a more specific way, the patent system was observed on the light of the fast communication and integration allowed by machine translation framed by searching tools and expert systems.

As a background for this research and from the near absence of research on the specific theme proposed here, it was necessary that its framework consisted of an exploratory investigation in the sense given by Selltiz, especially concerning: a) the approach of the literature, seeking to characterize the state of the art of translation concepts (involving human and machine translation), intellectual property, innovation and development, and patent rights; b) the study of primary sources, especially through documentary analysis of patents and case law documents; c) the interviews to be held with players participating in the processes to be investigated; and, d) the analysis of the examples and cases to be investigated and described that enabled the investigation of legal situations related to the sample patents. ${ }^{221}$

Therefore, it was decided to explore primary and secondary sources. In this sense, it was seen as fundamental, at first, to use the method of documentary analysis, starting

219 A. C. Gil, Métodos e técnicas de pesquisa social, 5.ed., São Paulo, Atlas, 1999, p. 16. See also: Berg, 2001, p. 255.

220 Ibid.

221 Selltiz, C., 'Planejamento de pesquisa. 'Métodos de pesquisa nas relações sociais, São Paulo, Ed. Herder e Editora da Universidade de São Paulo, 1967, pp. 57-160. 
it from the identification of materials related to the topic, its organization and analysis (categorization and contrast) as the constituent elements of the processes involving registration and intellectual protection of the selected sample. In this regard, it was important to access the selected expert systems, which contain a large arsenal of data on these patents, in addition to the databases of courts and patent offices, where reports and case law examples were collected.

To characterize the documentation obtained, as mentioned, the content analysis technique, as proposed by Krippendorff, was chosen. ${ }^{222}$ The analysis was carried out according to the steps for using this technique as described by the mentioned author. These steps were divided into: 1 . determination of the material; 2 . analysis of the situation in which the text originated; 3 . formal characterization of the material; 4 . determination of the direction of the analysis; 5 . theoretically informed differentiation of questions to be answered; 6. selection of the analytical techniques (summary, explication, structuring); 7. definition of the unit of analysis; 8. analysis of the material (summary, explication, structuring); 9. interpretation. According to Berg, the content analysis technique requires the use of an inductive approach, since the analytic induction is examined in relation to content analysis procedures. ${ }^{223}$ The next section will describe the theory and use of this technique in the present research in detail.

Besides, it should be noted, as has been reported, that the object of investigation here proposed requires longer-range analysis, which involves a foray into the process of interaction between the accuracy of machine translations and its effects on the legal framework, besides its relationship with the instruments for the legal protection of patent rights.

Therefore, it was intended to carry out an actual exploitation of reported experience of the processes involved in the creation and maintenance of patents through the patent system at the global level and the analysis of its relationship with the international legal scene. In addition, it was crucial to point out the real possibility of dialogue with many of the subjects participating directly, in different roles and functions, in these processes, using the interview technique, especially in the sense of an act of perceiving conducted between two people. ${ }^{224}$

In this sense, the type of interview used was the one called by Berg as semi standardized or semi-structured interview, seeking, in particular, to allow the interviewee to previously organize information and even provide primary sources, for example, documents and/or unpublished records or experiences, under specific conditions. ${ }^{225}$ These interviews were proposed to target players represented, mainly, by professionals belonging to courts, patent firms and patent offices, and aimed at collecting data on the relationship of patent law with translation and its social and economic impact. The semi-

222 K. Krippendorff, Content Analysis: An Introduction to its Methodology, Second Edition, Thousand Oaks, CA, Sage, 2004.

223 Berg, op. cit..

224 See Gil, 1999, pp. 109-112.

225 Berg, 2001, pp. 67-69. 
standardized interviews were then complemented by a moment of informal interview, as a way of allowing unexpected information to emerge from the dialogue with the chosen players. ${ }^{226}$

Consequently, it was intended, by using the research techniques mentioned (the interview, the literature review and the content analysis), to carry out a comparative study $^{227}$ of representative cases of the influence of translation accuracy related to the information contained in patent disclosure, in order to understand the key trends and problems of the patent system at the global level, its relationship with translation and its effects on the associated legal framework.

\subsubsection{Data collection techniques and investigated players: content analysis and interviews}

Berg describes content analysis as a technique in which researchers examine artefacts of social communication. These artefacts can be chosen among written documents or transcriptions of recorded verbal communications. Content analysis can also be defined as a technique for making inferences by systematically and objectively identifying special characteristics of messages. ${ }^{228}$

For Krippendorff, the main reference theorist of the technique, content analysis aims to make the inferences from the research matter (normally texts) replicable and valid, by distancing the analysis from the personal authority of the researcher, which requires the employment of specialized procedures. This way, by following the steps prescribed for the best use of the technique, the researcher can organize the content and better understand particular phenomena, as far as to make generalizations. As described before, content analysis is an inductive technique. For Krippendorff, being replicable and valid are indispensable characteristics of the research process. ${ }^{229}$

The advantage of using qualitative content analysis to legal studies is that it takes a holistic and comprehensive approach towards analysing data material and thus manages to cover the complexity of the social situations examined. As the data was collected from different sources, it was the ideal technique to be used.

The specific steps explained for classical content analysis were followed. These steps use a rule based and methodologically controlled approach in order to deal with the volume of data and gradually reduce it. The procedures of summary, explication and structuring being planned step by step help reducing the complexity of social phenomena and allow the researcher to work with a considerable quantity of data, as its main points are filtered in the process of analysis in an iterative process. ${ }^{230}$

226 Ibid.

227 The object of comparison was the information presented on the patent documents, the proceedings of the cases and the information collected through the interviews.

228 Berg, 2001, p. 240.

229 See Krippendorff, 2004, p. 18.

230 For a thorough description of the characteristics of the technique, see: F. Kohlbacher, 'The Use of Qualitative Content Analysis in Case Study Research', Forum Qualitative Sozialforschung/Forum: Qualitative Social Research, Vol 7, No 1, 2006. 
Figure 9: Content analysis procedures followed during the research

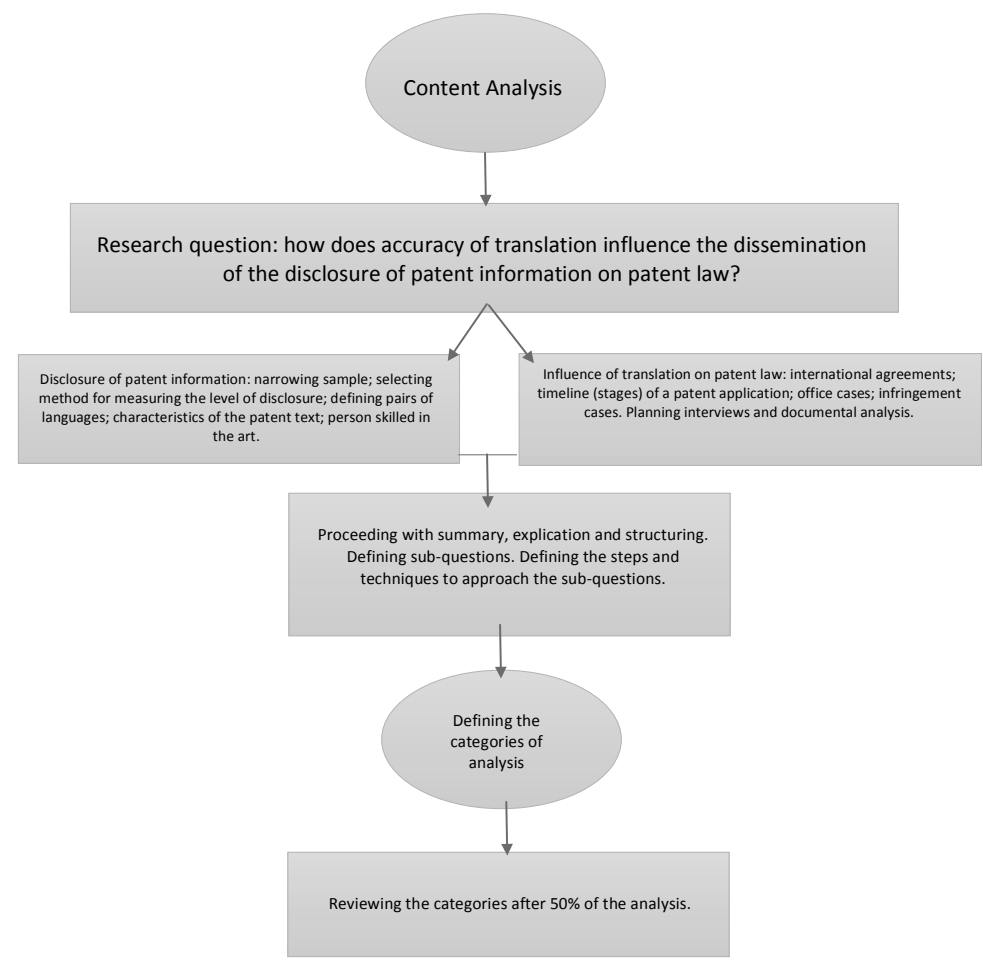

Source: The diagram was elaborated by this author based on the bibliographic review of content analysis

Above, the components followed to operate the content analysis are described. These components allowed a sequential model of qualitative investigation to be carried out, which made it possible to approach the object of study. The procedures which were used for analysing the studied matters were three distinct steps, which were carried out both independently or in combination, while necessary. These procedures can be conceptualized and characterized as used in this research as follows:

The first procedure used was summary. By summarizing the matter of research, it was aimed to reduce the material in such a way as to preserve the essential content. By doing it, it was possible to create a manageable corpus still reflecting the original material. The material abstracted consisted of information taken from patent documents in expert systems and case law. The main aspects chosen to be investigated in this phase were: a) In patent documents, translation discrepancies were analysed using a method called LISA-QA for translation assessment; b) in legal documents (searching reports, court cases background documentation,...), the analysis was based on statements collected from interviews with the involved players (see the results in Chapter 7, Section 7.5, especially 
over the level of influence of translation associated with different stages and players involved in the legal cases). ${ }^{231}$

The second step in dealing with the material of analysis was explication. This step involved explaining, clarifying and annotating the material, as prescribed by classical content analysis. The analysis focused on lexico-grammatical definitions and legal concepts, which determined which parts of the summarized material would be used. The chosen parts were: a) For patent documents: abstracts and claims; b) For court cases: pertinent documents involved in opposition and infringement cases associated with the data collected through the interviews. ${ }^{232}$

Through this way, the material for explication was determined, and this step was followed by a narrow context analysis related to each object, and a broader second level analysis, which involved all the objects and techniques together. Finally, the "explicatory paraphrase" was carried. That means the particular portions of selected texts were examined with reference to the total context. The main purpose of this step, in the case of patent documents, was to find inaccuracy in translated texts.

For the other set of legal documents, in turn, the main purpose was to investigate the presence of these translated patent texts as a basis of their proceedings and assess their influence on the decisions taken by the examiners, attorneys and courts. For dealing with the patent documents, the LISA-QA method was used for the assessment of the quality of the translations and also complemented with a form to be filled in by researchers dealing with the technologies corresponding to the chosen sample. For analysing the aspects more associated with the legal framework, an interview plan was elaborated, based on different types of questionnaires, directed to each group of interviewees. The list of interviewees is available in Appendix 1 and the interview guides can be consulted in Appendix 2.

The last step taken was the so-called structuring stage. The content obtained through the previous step was filtered out in particular structures that redefined the material to attend the purpose of the research. The patent documents were structured according to the defined categories: type of patents, parts of texts, pair of languages, type of analysis, receivers of the message of the translated text. The plan for the interviews was also based on defined groups and categories: the nationality and professional position of the interviewee determined the kind of questions to be asked. ${ }^{233}$ The first thing to carry out at this stage was the determination of the units of analysis, after which the dimensions of the structuring were established on the main theoretical basis and the features of the system of categories were fixed.

Subsequently, key examples were formulated as rules for coding the material in separate categories. In the course of the first assessment of the material the data sources

231 These steps were based on the mentioned works of Krippendorff (2004), Berg (2001) and Kohlbacher (2006).

232 See Chapter 4 for a better understanding of the methods and results related to the sample.

233 See Chapters 6 and 7 for the results. 
were marked. In a second scrutiny, the data were processed and extracted. The categories system was re-examined and revised as a consequence of the previous findings, among them: the results of abstracts and claims did not seem to show a considerable difference which would separate the analysis, so it was decided to work only with claims in other languages than English; the number of infringement cases involving the selected technologies was so small that it was possible to analyse all of them; the number of Chinese patents was so large (in searches) that it was necessary to exclude them from the filters to be able to work with a more varied sample. The material was reappraised until the final categories were found. At the final stage, the results were processed and interpreted. These were the most crucial steps of the whole analysis and the re-evaluation of the data and the procedures were carried out carefully in order to narrow the sample and define categories.

As mentioned, the other technique used for the present research was the semi-standardized interview. This technique was a means to follow up the analysis, by understanding the possible ways all the volume of translated information is "filtered" and transmitted through the patent system and how it can influence its legal framework. The interviews provided important information that formed a solid basis for more valid interpretation of the content. The questions that were selected to be presented to the players interviewed emerged from doubts that appeared during the review of the literature and the primary sources. In this regard, it was understood that some processes could only be cleared up with a direct confrontation with key players who participated on the different legal stages of patent prosecution.

For the purpose of constructing a better dialogue with the consulted players, different types of interviews were elaborated to the following groups of interviewees: patent attorneys, managers and political agents; patent examiners; judges; prosecutors; specialized translators. The chosen players were representative in terms of their importance for the analysed processes.

According to Berg, there are three kinds of interviews: the standardized (or structured) interview, the unstandardized (informal or non-directive) interview, and the semi-standardized (guided, semi-structured or focused) interview. The type of interview chosen for this research was the semi-standardized interview, which uses a formally structured guide of questions. The players interviewed were required to respond to each question. The advantage of this method was to offer each subject the same stimulus so that responses to the questions were appropriate to comparison and measurement.

Another reason that led to the choice of this method as a supportive strategy to content analysis was the fact that literature review by itself was insufficient for getting the necessary answers, and the previous contact with the sample generated clear doubts that should be resolved directly with these players. Therefore, it was necessary to plan the questions that would be uncovered during the interviews. Besides, the object of research, being an unexploited one, motivated many doubts. 
The interview instruments were, this way, carefully developed before the interviews. They were planned in a way they could be sufficiently comprehensive to elicit from the interviewees the information that emerged during the review of documents and previous analysis. It can be said that the results of the interviews were very useful to distance this author from her own pre-conceived ideas as some answers were unexpected. Many of the answers given by these players guided this research to previously unexpected ways to deal with the samples.

Due to the facility of access to players involved with the work at the Brazilian National Patent Office, some opportunities for informal interviews were also used, especially in moments of observation of the work of INPI's employees and the frequent contact with Professors from its Academia on Intellectual Property and Innovation.

Non-standardized interviews do not use schedules of questions and do not emerge from a different set of assumptions. Therefore, they are an ideal complement of standardized or semi-standardized interviews in situations where the interviewer can use extra time with the interviewed player to let unexpected information flow. In this case, it was critical to work with the assumption that all the necessary questions were not known in advance. Consequently, a predetermined schedule should not limit the contents of the interviews and there should be time given to a complementary conversation that did not follow a list of questions. Berg explains that in informal non-standardized interviews it is presumed that not all subjects necessarily find equal meaning in like-worded questions, so, in short, these subjects may possess different vocabularies. ${ }^{234}$

For working with the above-mentioned procedures, it was significant to conduct a comprehensive background literature review. The background information obtained through the literature review touched different areas due to the complexity of the chosen research question. The main areas researched by the review of literature were based on approximations, as there is no previous literature on the specific object of this research. The review was based on the following topics: patent rights and innovation (current configuration of the patent system in terms of innovation and economic development); law as a system based on communication; patent disclosure associated with patent rights; language regimes associated with patent law; patent writing and patent translation.

The literature review led the investigation to iterate the treatment of the chosen topic, by giving the basic topics to elaborate the questions for the interviews and the basis for the content analysis. The questions were being altered and refined as the information obtained through the combination of the studied areas gave a clearer and better delineated view of the patent system as a coherent, global structure. The review also helped to refine the research focus and the organization of the material. ${ }^{235}$

234 The explanations of the structure of unstandardized interviews are found in Berg, 2001, p. 68-71. See page 70 for the cited passages.

235 The studies of Berg were used to understand the association of literature review and the other chosen techniques. The work of the same author was important for identifying the necessary steps to be followed for carrying out the research procedures. See Berg, 2001, pp. 19-21 and pp. 214-216 
The steps followed for carrying out the procedures may be outlined as follows: 1. Identifying the research question; 2 . Conducting the background literature review; 3 . Refining the research idea and the research question; 4 . Determining the methods to be used through the data-collection process; 5 . Identifying and locating primary and secondary data sources; 6 . Confirming the authenticity and accuracy of source materials; 7. Analysing the data and developing a narrative exposition of the findings.

In steps number 6 and 7, it is important to clarify the order chosen to use the techniques and why it was proposed as such. The research started with the literature review, still in Brazil, during its first year. The choice to start with the theoretical review is justified by the lack of access, at that time, to some necessary expert systems, human sources and other resources which would only be available in Europe.

The second step taken was to investigate the available data and (including human) resources available in Brazil about the topic. That could help proceeding with a previous analysis of the object. It could also give a base for getting in touch with the Brazilian reality related to the studied phenomenon, which contrasts quite strongly with the European reality. That allowed the privilege of a broader vision of two representative realities of the patent system. In this regard, observing the Brazilian landscape was very useful for understanding the European one, as it represented a developing country model to serve as a comparison paradigm. It is also important to note that the results of the research, in this sense, can help other developing nations to better understand these contrasts.

Still in the part of the research developed in Brazil, in August 2015, case law involving patents and translation was searched in the digital archives of all the main courts of the country that could receive such cases. As a result, only one significant precedent in the Federal Regional Court of the Second Region (the most important court for IP cases in Brazil, as it covers Rio de Janeiro and cases involving INPI, the National Patent Office, as one of the parties). ${ }^{236}$ Following the logics of the sample chosen, a search on the key words "solar energy" and "wind power" for infringement cases was carried out in all courts databases of the country. It was difficult to find cases and identify translation related issues, which confirmed the necessity of a comparison with other national jurisdictions.

During August, the first interviews in Rio de Janeiro were scheduled. The set of questions to be asked was concluded and sent to the interviewees. In October, there was a visit that lasted two weeks in INPI in Rio de Janeiro. During the visit, it was possible to observe the work of the patent examiners and proceed with the interviews with key players. These players included: the current President of INPI; the Head of the Human Resources Department; professors who work for the Intellectual Property Academy; a judge from the Federal Regional Court of the Second Region that deals with patent cases;

236 Proc. № 200651015184614, TRF2 Justiça Federal Rio De Janeiro Vara: 38ci, Agrte : Sergio Ricardo da Silva, Agrdo vs Instituto Nacional De Propriedade Industrial - Inpi, Relator: Des. Fed.Messod Azulay Neto, 2a.Turma Especializada, http://www.trf2. gov.br/iteor/RJ0108210/1/22/200105.rtf (accessed 13 April 2018). 
the head of the Patent Examining Department; patent examiners. There was a second visit to INPI, in Rio de Janeiro, in November 2015, for carrying out the interviews which were not possible during the first visit. The list of interviewees is available at Appendix 2.

Retrieving the explanation about the steps to be followed in this research, it was finally possible to get to step 3, when the main goal of this investigation was approached: to understand to what extent, and how, translation influences the disclosure of patent information in infringement cases. As the process of disclosure was previously described and analysed, demonstrating how much machine translation is capable of actually disclosing the technical information contained by a patent document, it was possible to bring the analysis to a court level, by interpreting the connections between the process of disclosure and the decisions given in patent court cases, after previously investigating the different channels through which machine translation will impact on patent rights.

For bringing these results, it was also important to analyse the sample of clean energy patents that were in dispute. This procedure was followed by interviews with judges and patent attorneys, so that the information that do not show on the case law documents could be brought by the players directly involved in the process or complemented with examples of other cases, known to these players. For narrowing the sample, it was decided to work with cases of opposition and infringement.

The choice was based on the nature of the chosen points of law. Both opposition and infringement actions can be considered as the most connected ones with translation and language issues, as they are both deeply related to the disclosure of the technical content. They are, at the same time, the very heart of patent related lawsuit, in terms of the possible economic implications of patent law. They are also connected to each other, as a successful opposition action can prevent a further infringement action. The other possible points of law, available on the platform consulted, and separated in administrative and judicial types, would be: administrative hearings, cancellation proceedings/invalidity action; declaratory action establishing non-infringement; action relating to employee's invention; action relating to ownership; action linked to a contract; criminal action; "other actions".

For selecting the sample of opposition cases, the expert system Darts-IP was used. With this purpose, it proceeded as follows within the possibilities of the database used: 1. General search; 2. Search by legal perspective: Europe; Area/Country/Court: European Instances, EPO, Opposition Division; Date: "last year"; 3. Free text: "solar energy" and "wind power"; 4. Document language: English. 237

The database showed 10 cases filling the match for solar energy, but not all of them were really related to solar energy patents. It was necessary to complement this sample of 6 cases related to solar energy with 4 cases related to wind power. Those 10 cases represent a number which is significant enough for the type of analysis intended.

237 The database can be accessed at: https://www.darts-ip.com/ (accessed 15 July 2019). 
This number was also according to the results obtained by the software used for sample size calculation. ${ }^{238}$

After this stage, the research continued with the content analysis related to the opposition documents, considering the presence or absence of the following aspects: Courts, parties, direct reference of translation or language issues; transcription of translated documents or documents in a language different from the Court's language; claims of problems related to disclosure of technical information, type of decision of the EPO Opposition Division. All the documents of each of the 10 cases were read and analysed. For facilitating the search, this sample was restricted to solar energy patents, as the number of opposition cases is larger than the number of infringement actions.

For selecting the sample of infringement cases, Darts-IP platform was used. With this purpose, the procedure was similar to the one carried out with the opposition cases: 1. General search; 2. Search by legal perspective: Europe; Area/Country/Court: Europe; 2. First action type: infringement Action; 3. Free text: "solar energy" and/or "wind power"; any language; any period of time. In cases of infringement, it was not possible to select the documents languages, and the total number of cases did not allow narrowing the time period, as the total number reached only 4 cases.

Figure 10: Searching sequence of opposition cases
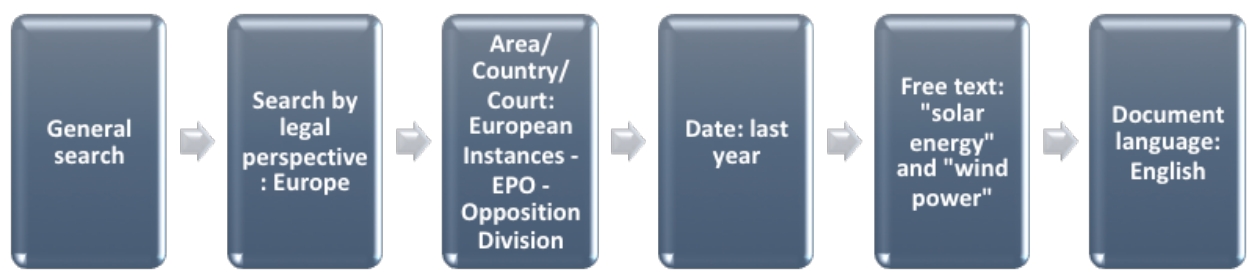

Source: Based on the searches for opposition cases carried out by this author in DartsIP database

Figure 11: Searching sequence of infringement cases
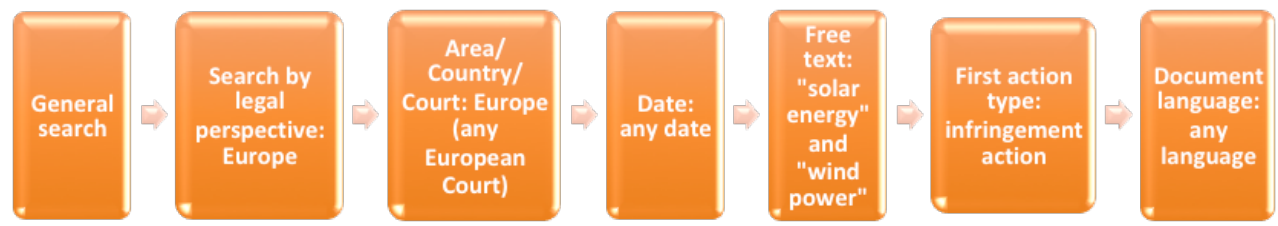

Source: Based on the searches for infringement cases carried out by this author in DartsIP database 
As in the opposition cases, the same content analysis procedures were applied to the infringement action documents, considering the presence or absence of the same aspects, but with some adaptations to this chosen point of law in what it's distinct from the opposition cases: analysed documents; Court (country/instance) level; parties; direct reference of translation or language issues; transcription of translated documents, most important decision taken by the Court. All the documents of each of the 4 cases were read and analysed. For facilitating the search, it was also important to work, in this sample, just with solar energy patents. The image below presents the sample form for the content analysis of opposition and infringement actions. It was important to fill in a form for each of the cases.

Figure 12: Sample form for content analysis of opposition cases

\begin{tabular}{|c|c|}
\hline \multicolumn{2}{|r|}{ OPPOSITION CASES } \\
\hline $\begin{array}{l}\text { Patent Title and } \\
\text { Publication Number (s) }\end{array}$ & $\begin{array}{l}\text { EP12715903(A) EP2695270(B1)All cases on this patent (1) / this patent family } \\
\text { (2)IPC:H02J 13/00, H02J 3/28, H02J 1/14 } \\
\text { OPTIMIZED LOAD MANAGEMENT } \\
\text { HÖHLE, Christian (DE); THIEL, Raimund (DE); MAGNUSSEN, Björn (DE) }\end{array}$ \\
\hline $\begin{array}{l}\text { Types of Documents } \\
\text { Court (country/instance) } \\
\text { level }\end{array}$ & $\begin{array}{l}2 \text { Complaints documents (EN) } \\
\text { Opposition Division (EPO) First instance }\end{array}$ \\
\hline Parties & $\begin{array}{l}\text { Fronius International } \\
\text { SMA Solar Technology }\end{array}$ \\
\hline $\begin{array}{l}\text { Direct reference of } \\
\text { translation or language } \\
\text { issues; }\end{array}$ & $\begin{array}{l}\text { The grounds of the Opposition request are: } 1 \mathrm{JP} \text { patent (and its } \\
\text { translation); } 6 \text { US patents; } 1 \text { WO patent; } 2 \mathrm{EP} \text { patents; } 2 \text { DE patents. }\end{array}$ \\
\hline $\begin{array}{l}\text { Transcription of translated } \\
\text { documents or documents } \\
\text { in a language different } \\
\text { from the court language; } \\
\text { Allegation of problems in } \\
\text { disclosing the technical } \\
\text { information }\end{array}$ & $\begin{array}{l}\text { There are no transcriptions of documents in foreign languages. There are } \\
\text { transcriptions of documents whose originals are in English. The contents } \\
\text { of the German and Japanese patents are described in English. Therefore, } \\
\text { the reasoning of the decision probably required a previous translation. } \\
\text { There is no such allegation. }\end{array}$ \\
\hline Main decision (s) & $\begin{array}{l}\text { As on the documents: "Accordingly, it seems to be justified } \\
\text { to revoke the opposed EP } 2695270 \mathrm{Bl} \text { in its entirety." }\end{array}$ \\
\hline Notes & \\
\hline
\end{tabular}

Source: Based on the Analysis of the Sample Described above on this Chapter 
Figure 13: Example of sample form for content analysis of infringement cases

\begin{tabular}{|c|c|}
\hline \multicolumn{2}{|r|}{ INFRINGEMENT CASES } \\
\hline Patent Publication Number & KIT DE FIXATION POUR PANNEAU SOLAIRE SUR UNE CHARPENTE. \\
\hline (s) and title & RENSONNET MICHEL (FR) - FR0952253(A); FR2944038(A1) \\
\hline Court (country/instance) & TGI de Paris (France) \\
\hline level & First instance \\
\hline Parties & COFAM ENERGY (France) \\
\hline & GLOBAL HIGH TECH \\
\hline & GREEN HIGH TECH ENERGIE CORP (France) \\
\hline Types of Documents & $\begin{array}{l}\text { Main proceedings (Substantive decisions) - in French; } \\
\text { Hearing - in English }\end{array}$ \\
\hline $\begin{array}{l}\text { Direct reference of } \\
\text { translation or language } \\
\text { issues; }\end{array}$ & No direct references concerning translation issues. \\
\hline $\begin{array}{l}\text { Transcription of translated } \\
\text { documents or documents } \\
\text { in a language different } \\
\text { from the court language; }\end{array}$ & No transcription of translated documents. \\
\hline $\begin{array}{l}\text { Most important decision } \\
\text { taken by the Court }\end{array}$ & $\begin{array}{l}\text { Condemns the defendants to pay a sum of money for damages caused to } \\
\text { the plaintiff company. }\end{array}$ \\
\hline Notes & $\begin{array}{l}\text { There are no references of translated documents, but the languages of } \\
\text { the two consulted documents related to the case are distinct, being the } \\
\text { document for the main proceedings presented in French, and the hearing } \\
\text { information sheet, which only contains the basic information about the } \\
\text { schedule of the hearing, in English. }\end{array}$ \\
\hline
\end{tabular}

Source: Based on the Analysis of the Sample ${ }^{239}$

Due to the scarcity of cases, the sample analysis was complemented with cases found on the associated literature and with cases suggested by the interviewees, which were found to be emblematic in terms of decisions that involved language and translation issues.

239 Information collected on Darts-IP, Fronius International vs SMA Solar Energy, 2017. EPO Opposition Division, EOKCJYGX5500DSU_20170621; COFAM Energy vs Green HighTech Energy, 2013. Tribunal de Grande Instance de Paris, fr-1110333_20130614. 


\section{CHAPTER 3}

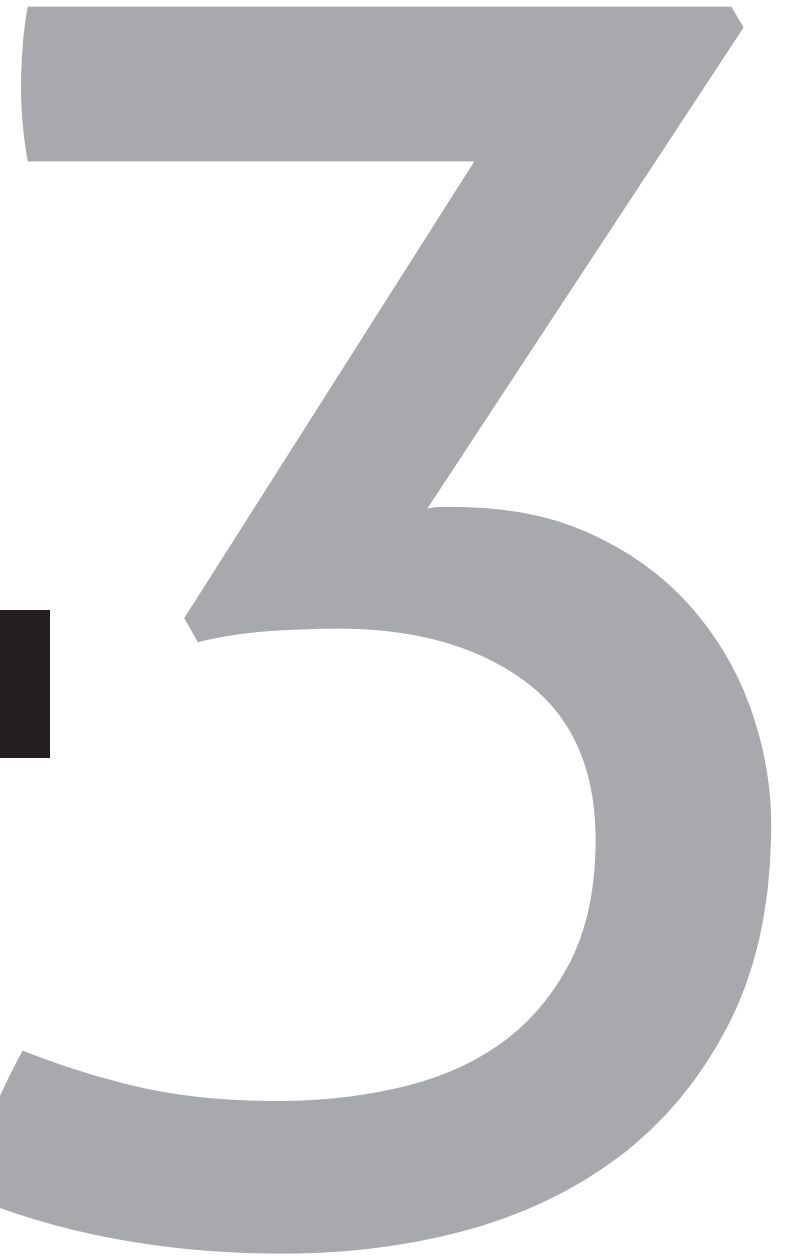




\section{Law as a communication system and the patent system as a system based on (especially machine) translation}




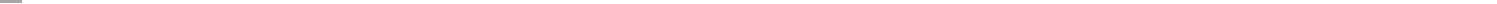




\subsection{Law as an autopoietic system based on communication by Niklas Luhmann: the communicative event and the "legal language"}

The purpose of this Chapter is to focus on the systemic nature of the patent system and on its relationship with communication, discourse and translation. The Chapter defines law as a system based on communication, as postulated by Niklas Luhmann. The theory of law as a social system constitutes a background to understand the role of translation to the patent system. Law being defined as a system based on communication, patent law can be considered as one of its sub-systems. From this perspective, the patent system can be demarcated as a (relatively) coherent global structure (an internationalized field of law) ${ }^{240}$, based on multilingual communication, and on particular discourses that characterize its levels of justification and application ${ }^{241}$.

The systems theory by Niklas Luhmann is rooted in a theoretical arsenal that was compiled from research in the field of biological sciences and whose leading exponents are the Chilean researchers Humberto Maturana and Francisco Varela, ${ }^{242}$ who developed, from their transdisciplinary studies, a theory that seeks to understand the systemic organization of living organisms.

There are some concepts based on this theory to understand Luhmann's theory. Since the goal of this research is not to deal with the systemic approach of Maturana and Varela, only three of the most relevant notions of their work are addressed. They are the notions of autopoiesis, operational closure and structural coupling. These notions are also fundamental to understand the concept of system for these authors and for Luhmann.

For Maturana and Varela, living beings are distinguished by their autopoietic organization. As they can be defined as holders of autonomy and autopoiesis, they are also able to recognize and specify their own laws. In this logic, the mechanism that makes them autonomous systems living beings is this ability to self-creation, or the ability to reproduce, which characterizes them as such. ${ }^{243}$

The Autopoiesis phenomenon allows environment and body to remain in continuous structural coupling, which means that the interaction of the organism with the environment is characterized by an incessant structural change. Thus, while the body is considered autonomous and operationally closed, accepting only changes that can be "translated" into its own structure, it undergoes transformations in this interactive process. $^{244}$

240 See Section 1.2 of this dissertation.

241 The theory of Klaus Günther complements the theory of law as a social system, enhancing the relationship between action, norm and situation and the relevance of the communicative act to the law and to its practical application through argumentation. See Sections 3.2 and 3.3 for a detailed analysis of justification and application of norms in patent law.

242 H. Maturana and F. Varela. A Árvore do Conhecimento: as Bases Biológicas da Compreensão Humana, São Paulo, Palas Athena, 2001.

243 lbid., p. 88.

244 Ibid., pp. 112-114. 
This is also valid for linguistic systems. If language is seen as a system, organized by a specific structure and set of rules, translation could be seen as the linguistic version of structural coupling. The evolution of languages, similarly to the evolution of living beings, would depend on their relationship with the environment, which basically is constituted of two levels, a linguistic one, related to other languages and their way to influence a particular language system, and new phenomena that require new ways to communicate in that very language, innovation being one of them. In the case of the patent system, communication is shaped into a specific code, a patent language, whose requirements are adapted to each and every language in which patents are written. ${ }^{245}$

The systems theory by Niklas Luhmann uses these concepts making them capable of providing an adequate theoretical arsenal to explain law in its relationship with the environment, that is, with politics, economics, society, or, in other words, with other systems with which it interacts directly. Law is therefore compared to a living system, which can be described as autopoietic, autonomous and able to interact with the environment in a structural coupling process. While this reciprocal relationship does not disintegrate, the system retains its integrity. ${ }^{246}$

Consequently, it is possible to affirm that the operational links between system and environment are possible, meeting certain inclusion and exclusion patterns. The system does not allow the entry of what will destroy it as such, working with a binary constitution, in a way allowed by its structural links when it assumes certain characteristics of its environment. Luhmann gives some examples of this process. One is when money is accepted, or when one can expect people to be able to determine the time. Another is the example of cells, which only accept certain ions (for example, nitro and calcium) through their membranes, rejecting others (such as caesium or lithium). Accordingly, he also defines structural coupling as a form consisting of two sides, or a form based on a primary distinction: what it includes is as important as what it excludes. The fact that the structural coupling is restrictive facilitates the influence of the environment on the system. ${ }^{247}$

A system, in this sense, is constituted as a restrictive structure, which involves inclusion and exclusion processes, characterized by its operational closure. It has to obey certain rules, which is also valid, according to the same theory, for the legal system. Law, as any other system, must comply with its operational closure feature. The system, in this logic, should be preserved to evolve autonomously, being able to maintain internal consistency to match up with the environment in which it operates, namely the social system. ${ }^{248}$ If the cognitive opening mechanism is corrupted by something not tolerated by the system, to allow the insertion of unrecognized elements, it loses its legitimacy and its normative force.

245 See Section 5.2.1 for a description of this specific code that characterizes patent documents.

246 N. Luhmann, Law as a Social System. Oxford University Press, 2004, pp. 380-385.

247 N. Luhmann, El Derecho de la Sociedad, $2^{\text {nd }}$ edn., Ciudad de Mexico: Hender, Universidad Iberoamericana, 2005, p. 316.

248 L. H. Cademartori and G. Baggentoss, 'A Coerência do Sistema Jurídico em Luhmann: uma proposta ao fechamento operacional e à abertura cognitiva da decisão judicial', Sequência Estudos Jurídicos e Políticos, no 62, Ano XXXII, 2011 , p. 324. 
Although Luhmann focuses on social systems, he creates a general system theory to explain them. He explores other systems to contrast with social systems, especially the psychic system. This last system is very illustrative, because it explains phenomena such as self-awareness and scientific or philosophical reflection. Luhmann reviews Husserl for establishing a relation between his general theory of systems with some of Husserl's concepts to explain the process of thinking. The ideas of subjectivity, temporality and intention play an important role in Luhmann's understanding of Husserl's theory. Subjectivity is the capacity of distinguishing the consciousness from the environment. Temporality refers to the characteristic of consciousness of apprehending what happened immediately before or anticipating what will happen immediately after. Intention would be considered as the operation unit of consciousness. ${ }^{249}$

The features that distinguish the psychic system from the social systems are extremely relevant for formulating a theory that explains the patent system(s). Psychic systems are defined by a two-level relation with the environment, or by a capacity of re-entry, which is the possibility of describing the system from inside, in a process of self-description, or from outside, in a process of hetero-reference. That is different when it comes to social systems. Social systems depend on the elaboration of related communication systems that have their references in themselves, being self-directed. They do not accept an external position, in this sense, as another communication system does not make sense in their internal logic. And so is the legal system defined: a subsystem of the social system based (as any other social system) on communication. ${ }^{250}$

The phenomenon of communication defines and explains the social systems and even the sociological analysis of these systems as restricted to a way of communicating: a social system, again, is based on these specific communication rules. For Luhmann, even the connection resulting from the information given about a given system and the prospective management intended to manipulate the system are based on a determined communication rationale and cannot exceed certain limits. ${ }^{251}$

Still according to Luhmann, the legal system is the result of a long and intricate evolution of social and cultural nature. Therefore, it has a communication structure that is configured in its own codes, in which it differs from other systems. Thereupon, law cannot be consolidated from arbitrary political acts or from rough communication, but from a set of rules developed in its own system, which, in turn, make it a subsystem of the social system. ${ }^{252}$

Historically, Luhmann explains that Law was consolidated as a system especially from the moment that an "unparadoxing" concept (Entparadoxierungskonzept) or project took root from the moment that the idea of Constitution assumed its positivity and differentiation. For Luhmann, the system is surprised by its own social differentiation to

249 N. Luhmann, Introdução à Teoria dos Sistemas, Petrópolis, Vozes, 2009, pp. 90-100. 
the point of not being able to recognize the positivity given with this differentiation. The legal system continues to require what he calls a super-regulative instance, with the way in which this instance is defined as politics, as a state, as an authority, as a society, or as nature, not mattering. He emphasizes then the global "positivization" of the law, which was possible by the independence and self-determination of the system. ${ }^{253}$

Once the legal system is differentiated, it is necessary to understand it according to its own logic, which guarantees autonomy in relation to other systems. However, that does not mean fetching its essence or nature, as they are embedded in all its complex evolutionary process, but to understand what its limits are, and these limits come from its own object:

Perhaps one can agree, at least, on the point that there is nothing to be gained from arguing over a 'nature' or 'essence' of law, and that the worthwhile question that should be asked is: what are the boundaries of law? This question points to the well-known issue as to whether these boundaries are analytical or concrete, that is, whether they are defined by the observer or by the object itself. If the answer is 'analytical' (and there are some who feel, wrongly, that they are bound by the theory of science to answer in this way), one allows each observer to decide his own objectivity and so ends up where one started from, that is, stating that interdisciplinary communication is impossible. It is for these reasons that our answer is 'the boundaries are defined by the object'. This means, in fact, that the law itself defines what the boundaries of law are, and what belongs to law and what does not. Answering the controversy in this way shifts to the question: how does the law proceed in determining its boundaries? ${ }^{254}$

Thus, the existence of limits on the legal system should be construed as specifically defined by the object itself, that is, the system in its own logic, and not by an observer who is credited with having the capacity to understand this system. At the same time, it should not be concluded that interdisciplinary communication, or an inter system communication, or even communication with environment is impossible. So Luhmann warns that the law itself should define the borders to its coupling process, putting, however, the question about how these borders are demarcated by it as a system. ${ }^{255}$

From this question, and based on the theory of biological systems, Luhmann argues that the system, as observed from its distinction, requires the construction of concepts. ${ }^{256}$ These concepts evolve over time, as different theories draw up and describe them, in an attempt to elucidate the system performance. For the law, the system operates from a communicational structure, whose boundaries are defined within the social

253 N. Luhmann, 'La Costituzione come Acquisizione Evolutiva', In: Zagrebelsky, G. (ed.) et al., II Futuro Della Costituzione, Torino, Einaudi, 1996.

254 Luhmann, 2009, pp. 57-58.

255 Ibid.

256 Ibid. p. 67. 
system. ${ }^{257}$ However, to keep the complexity of its internal reference, it should follow the operational closure mechanism, which implies the absence of conditioning to what occurs in the environment. ${ }^{258}$ Such boundaries thus must open partially so as not to corrupt the integrity of the system.

Hence, the theory of law as a system, developed by Niklas Luhmann, sees law as a functionally differentiated system of society, whose main purpose is to maintain stable society's expectations, represented by legal rules. Expectations are then directlyepitomized by the legal rules, which thus remain stable regardless of alleged infringements.

Law is thus a subsystem of the general social system, having communication as a basic element. It differs from the environment by the binary code control of what is "lawful" or "unlawful". For Luhmann, this occurs from a long evolution that culminates in overcoming hierarchy in contemporary societies. In a hierarchical model, politics and morals dominated the idea of justice. ${ }^{259}$

The law system is normative. And the normative act is considered to be the result of factual expectations, different from cognitive expectations. This means that it is based more on testing the communication channels and meeting at least minimum levels of expectations than on a high level of consciousness of its functioning. Still, expectations assume consciousness. As in systems theory the person is understood as a social construction, the expectation is thus transformed into communication. If the expectation stayed only at the level of consciousness, it would not be taken into account by society, and would not be taken to the communication plan. ${ }^{260}$

Thus, it is from the communication plan that the law constitutes itself as a system. Therefore, communication is considered as a central element of social systems, being even what defines them as systems. Luhmann outlines three categories which are essential to social systems: society, organization and interaction. Rejecting what traditional sociology defines as the main concepts of society - persons and actions - Luhmann chooses communication, or more precisely, the communicative event, for creating his theory of social systems. ${ }^{261}$

Luhmann, discussing the notion of positivity in the law, states that the law does not come from itself, without an external stimulus. The establishment of law as a social system's subsystem determines that what makes law a system is the fact that all elements that enter in it go through a process of filtering, which allows it to be recognized. This does not mean that the law does not resemble at all other social structures or forms of social communication, but it points to the fact that the law is more suitable for its intended purpose of establishing the congruent generalization of normative behavioural

257 Ibid. p. 74 .

258 L. H. Cademartori and G. Baggentoss, 2011, p. 324.

259 J. Andaku, 'O direito na teoria de Niklas Luhmann', Quaestio Juris, 11(1), 2018, 173-194. http://www.e-publicacoes.uerj.br/ index.php/quaestioiuris/article/view/25850/23306 (accessed 13 April 2018).

260 Ibid.

261 D. Seidl, 'Luhmann's theory of autopoietic social systems', Munich Business Research, 2004-2, http://www.zfog.bwl.unimuenchen.de/files/mitarbeiter/paper2004_2.pdf (accessed 13 April 2018). 
expectations, accepting other functional areas only in those linkages and those stimuli that are related to this particular function. ${ }^{262}$

As noted, this occurs through the communicative event, which requires a special code adopted by the law, nominated by the technical literature as legal language. In this sense, Luhmann's theory is congruent to the linguist approach of a communication system, especially the most paradigmatic of them, elaborated by Roman Jakobson, to whom communication involves the following basic elements: the addresser (speaker), the addressee, the code, the context, the channel. ${ }^{263}$ These elements are interconnected according to the theory mentioned and so they seem to be in Luhmann's perspectives about communication.

Luhmann has followed his contemporary linguists and was surely inspired by them in some of his elaborations. He mentions frequently Ferdinand du Saussure's works while explaining his theory of social systems, where he recognizes the arbitrary match between meaning and sign - a quite appropriate idea as the cornerstone to a system based on communication, as this relation (between meaning and sign) develops historically, in a complex way, depending on each linguistic and cultural context. ${ }^{264}$

Luhmann's general system theory can be considered as entirely founded on the idea of communication. By gathering a vast range of fields and theories, which include studies about complexity, evolution and linguistics, he develops a synthetic model of communication, revalidating the tension between sociological tradition and interdisciplinary approaches. ${ }^{265}$

For establishing a sociological concept of communication, Luhmann creates a synthetic model, whereby communication emerges as a synthesis of three selections: information, production (Mitteilung) and comprehension (Verstehen). Although his theory has been criticized for being anti-humanist, today it is widely recognized that it expanded the view of the process of communication in social systems, especially in law. ${ }^{266}$

Pignuoli divides the evolution of the General Theory of Social Systems into three stages. The first one, from 1964 to 1984, is characterized by taking action theories and cybernetics functional systems theory. The second one, from 1984 to 1990 , is characterized by the assumption of communication theories and self-referential autopoietic systems closed in operation (on this stage, the synthetic communicative model is already explained). The third one, from 1990 to 1997, is characterized by deepening the bond with the theory of form by Spencer Brown and the theory of observing systems, by von Foerster. ${ }^{267}$

262 D. Seidl, Sociologia do Direito II, Rio de Janeiro: Tempo Brasileiro, 1985, p. 18.

263 R. Jakobson, Linguística e Comunicação, São Paulo, Cultrix, 1991.

264 N. Luhmann, Introdução à Teoria dos Sistemas, Petrópolis, Vozes, 2009.

265 S. Pignuoli, El Modelo Sintético de Comunicación de Niklas Luhmann, Cinta Moebio, no 47, 2013, pp. 59-73, www.moebio. uchile.cl/47/pignuoli.html (accessed 14 April 2018).

266 Ibid.

267 Ibid. 
As seen, the synthetic communicative model is connected with other fields and theories, and, at the same time, sounds very much like a synthesis of its contemporary communication theories, as the one developed by Jakobson, mentioned above. What differentiates it from these theories is the fact that it overcomes the idea of linearity, considering communication as a dynamic process.

The concept of communication has undergone several transformations during the period of its evolution in the works of Luhmann to get to this point, that is, the synthetic model. According to it, communication was not only conceived as a special issue of sociology or as a promising concept for understanding social systems, but as the fundamental category of the theoretical perspective of these systems. Luhmann even considered that the concept of communication was a gap in sociology, because it lacked an organized disciplinary perspective. ${ }^{268}$

In this sense, the role of cybernetics was important for associating the new model of communication to social systems. Cybernetics had questioned the linear character that classical theories imposed to the concept of information. Cybernetics theory generalized the concept of information and made it applicable to all types of systems. One consequence was that the idea of transmission began to be understood as a subtype of a more general phenomenon called interchange of information. Information interchange was then interpreted as a dynamic, complex process, happening through the boundaries of autopoietic systems. ${ }^{269}$

This idea is consistent with the concept of meaning, which Luhmann subordinated to the notion of information, a fundamental notion of the social systems theory. Information, when it is being transmitted, adopts one from a multiplicity of possible states. Thus, the production of information is a type of sense production event, whose most important characteristic is the production of novelty. It consummates then a transformation in the system. Nevertheless, not all processing can be interpreted as a sense producing information. Only the processing of meaning involving novelty is considered as information, according to the social systems theory. ${ }^{270}$

Another very central idea of the theory of systems is the fact that the production of meaning in a system does not involve exchanging information, but self-reference. Autopoietic (or self-referential systems) are not capable of simply importing information. Therefore, in a system, all information is determined by a self-referential operation, which is not a simple exchange between the system and the environment surrounding it. That makes the addressee the most important element of a self-regulated system and the reception of the information a much more important function. It is incapable of transferring the system's information. Accordingly, in terms of a social system functioning, the communication never involves transfer but production of new meaning which 
processes external information, only possible when it is accepted by the system's own structure, since it is converted to its code. In this regard, the stage of comprehension, described by Luhmann's synthetic theory of communication, is the one that brings the social and sociological unit of communication. ${ }^{271}$

That changes the traditional concept of information, as information does not necessarily carry a linear direction, going from the addresser to the receiver, and being entirely processed there. Instead, it operates different processing functions, whose result does not necessarily coincide with the original information. Accordingly, information is not restricted to its transmission, because the decoding process is not passive. Contrary to that, it also produces information, re-introducing it into the system, as a new communication unit. $^{272}$

For Luhmann, there is a difference between reception and acceptance. In a system's structure, receiving information does not necessarily lead to its acceptance by the system, that means, to its introduction in the system's own code. Contrary to the linear conception proposed by the classical communication theories, the social systems theory sees communication as circular since it is always associated with other communication units, in a communication network. That is how communication processes are organized in an asymmetric way, containing different levels of the elements interacting over time. These communications networks are only allowed by the autopoietic structure of social systems. ${ }^{273}$

The reason for the existence of the systems is justified by the idea of double contingency in Luhmann's theory. For the application of this idea, Luhmann was inspired by the concept of Talcott Parsons, who developed a description of human interaction. Parsons describes a double contingency in the relationship between Alter (the addressee) and Ego (the addresser) in the process of human communication, where the Ego's selection is contingent on available alternatives, and the Alter's response will also be contingent on the selection of the Ego, and will result in an additional selection done by the Alter. ${ }^{274}$ The instability provoked by these selections, which means, by the double contingency, it is what creates certain types of systems. Legal systems, which are the ones that interest the present study, fit ideally in this theoretical model. ${ }^{275}$

The formulation of the theory of social systems having communication as its central unit was quite revolutionary and can be seen as a very useful approach to understanding the legal system, which, accordingly, may be interpreted through its communicative events. A focus on the relationship between action and communication is thus necessary to understand the functioning of a system and define its distinctive properties. Luhmann's innovations in conceptual art allowed this approach - though the

274 L. H. Cademartori and F.C. Duarte, F.C., Hermenêutica e Argumentação Neoconstitucional, São Paulo, Atlas, 2009, pp. $195-201$. 275 Ibid., p. 196 
identification of distinctive marks in different social systems, law being one of them. In this rationale, communication is defined both as an operating unit and a unit of analysis of a given social system. It can be said communication redefines every discipline, reestablishing its boundaries on a more dynamic, inter-disciplinary perspective, which allows every discipline to interface with traditionally under-served areas. ${ }^{276}$

Therefore, law, as a social system, has its own code and requires a comprehension of the information which is addressed to a certain public, as preconized by Luhmann's model. This code, which can be called a legal language, as is referred to in most literature, has its peculiarities, as any other technical language. Particular fields of law would also have even more peculiar ways of communicating and ways of organizing their language regimes. It is possible to imagine a network of law as a general system and its subsystems being each field of law.

There are exhaustive studies on legal language. Just to give some examples, some studies concern language and the so-called legal fiction, others refer to law and hermeticism, which tend to point to the boundaries where legal language stops to communicate because of its peculiar vocabulary and syntax. Anyway, speech rules play a very important role to the whole legal environment, coming to the operational levels of law or to the process of legislation. ${ }^{277}$

Discourse analysis, a linguistic approach developed on the late $20^{\text {th }}$ century, allows the recognition of patterns that particularize communities. It goes beyond the definition of a social system, whereas it identifies the subtleties of speech and their cultural and ideological peculiarities. ${ }^{278}$ This approach can be useful in terms of defining power categories or identifying hierarchical relations translated by these communities' speeches. Although that could be an interesting approach for dealing with the present research object, it was preferred not to go too far into it here, as our task demands the identification of a previous set, composed by structural elements, for sustaining the idea of an overall influence of translation on patent law. However, it is important to notice that communication through the patent system allows more thorough studies in terms of discourse analysis, which could evoke the association between power and hierarchy and language (s) in the global patent scenario. The social effects of the predominance of English as lingua franca could be, for example, a fruitful object of analysis.

Legal language is normally considered to be hermetic, difficult to understand by laymen. Legal texts can require a great effort from a reader whose aim is to analyse their content, and not only follow an interpretation tendency, which means legal texts are difficult in terms of close reading, as they may be full of technical terms and intricate dissertation.

276 Pignuoli, 2013.

277 See, for example: K. Petroski, 'Legal Fictions and the Limits of Legal Language', International Journal of Law in Context, 9 , 2013, pp 485-505.

278 Ibid. 
The fact that legal communication requires exhaustive detailed explanation, tending to erudition and hermeticism, does not justify a level of the use of intricate sentences or sophisticated vocabulary for mere futility. If legal language requires a level of depth that allows for very efficient communication, it does not mean it should use confusing sentences deliberately or prove itself through vain sophistication. That is why the boundaries of elaboration of a legal text should be self-justifying. ${ }^{279}$

When it comes to the patent system, as an internationalized field of law, this complexity increases, and the same happens to the work of lawyers, judges and other involved agents in patent cases. As a result, the forces of globalization and technology may be prejudicial to mediocre lawyers and benefit those who master languages and computers. ${ }^{280}$ The following Section discusses the two levels of legal discourse, as a basis to further present the peculiarities of patent language and translation in the level of elaboration of norms (justification) and their application to particular cases.

\subsection{Klaus Günther and the two levels of the legal discourse: justification and application of norms}

This Section aims to complement Luhmann's theory by an analysis of the theory of Klaus Günther over the role of discourse rules to the law in its levels of justification and application, related to the elaboration of norms and their application in particular cases. This analysis is relevant to explain that there are two levels of influence of translation on the dissemination of patent information. One is previous to the application of norms and characterized by the elaboration of international treaties whose aim is to respond to global expectations, and which are internalized ("translated) into national law. The other is the level of application, in which particular cases can enrol different arguments to define the application of said norms.

The role of translation is central both to the process of establishing and internalizing international agreements concerning patents (see Chapter 6, which reports to these theoretical premises in particular examples) and to the application of these norms in concrete cases (Chapter 7). Hence translation can be considered as a formative element of these two levels of discourses in patent law. The analysis of the theory of Klaus Günther is important to understand how these two levels of discourse operate in law and how they are related to communication (dissemination, disclosure, language, translation) in the patent system.

The conception of law as a system allows a more detailed analysis on its operational level, the level of justification and application of norms in specific cases. To

279 See Petroski, 2013.

280 'Translating and the law: Legal language', The Economist, Nov., 2012, http://www.economist.com/news/business/21566010services-specialising-language-and-culture-are-demand-legal-language (accessed 14 April 2018). 
advance with this analysis, Klaus Günther considered it necessary to adopt a sociological view of law, opting for the theory of social systems developed by Luhmann to support his analysis. One of the main points raised by Günther from the system's theory (and a starting point to his own theory) is the centrality of the relationship between action, norm and situation and the relevance of the communicative act to the law and to its practical application. ${ }^{281}$

However, although Günther enhances the value of Luhmann's system theory, he builds his own theory of argumentation on his critical contributions towards it. Günther develops a cognitive theory of law. For him, it is not enough to simply describe the law as a system because it does not solve its demand for a reasoned validity status on grounds recognizable by those on whom the law depends. For Günther, it is therefore the argumentation that must meet the expectations created by the law. Without this completion, the systems theory leaves gaps in the understanding of the legal system function. ${ }^{282}$

Determining the relation between action, norm, and situation is one of the major problems of the theory of society. The general question concerning the possibility of societal order can be translated into the more specific one as to how actors co-ordinate their action plans with one another in situations. The intended action and its goals are in a single context with cultural norms as well as with the specific facts of a situation, be they experiential states, expectable events, or other actors' attitudes requiring interpretation. The attempt to thematise this relation in terms of the application of norms is based on the assumption that in this way one can find out more precisely how a society relates to itself via the individual action of its members in particular situations. Even according to an altogether naïve pre-understanding, it ought to be clear that the self-understanding of a society continually changes in the process of applying moral, legal, and social norms in specific, but not identical situations. Formulated in this manner, a journey through theories of morality, law, and society would be necessary for solving this problem in order to discover in detail how the application of norms is implicitly or explicitly thematised. ${ }^{283}$

For Luhmann, the law assumes the role of a generalized medium that solves the problem of expectations of behaviour. It is not interpreted in a timely or specific way, which considers the peculiarities of each situation, in view of the possibilities not yet defined by the other (the alter). The law is to Luhmann a system that provides and integrates solutions to the problems of conduct through a licit/illicit binary code. ${ }^{284}$

281 Cademartori and Duarte, 2009, p. 194.

282 Cademartori and Duarte, 2009, p. 195.

283 K. Günther, The sense of appropriateness. Application discourses in morality and law. New York Press, 1993.

284 Cademartori and Duarte, 2009, p. 190, p. 194. 
What Günther identifies as a problem in Luhmann's system theory is the fact that it does not explain the relationship between the political program that gives the direction to the law and the code that defines it as an autopoietic system. Günther found that this relationship is explained by an argumentative zone that cannot be elucidated by the theory of systems alone but is essential to understand the law. ${ }^{285}$

Günther finds the key to the gap left by the system's theory in what he calls 'discourse ethics.' For him, it is this concept that enables a distinction between law and morality. In law, the moral principle that supports the validity of norms in terms both of its effects for each individual and its collective coverage can be applied only as a rule of argumentation. Plausible reasons can and should orientate the de facto execution of norms. That's why Günther sees application discourses as the realization of practical reason both in normative propositions and in the observation of norms that are already valid, which means both in the process of the elaboration of norms and in the decisions that form case law. ${ }^{286}$

Cognitivist ethics would not need to concern itself with the problem of motivation any further if, in the case of non-observance of valid and appropriate norms, a violation of the principle of universal reciprocity did not in turn occur. The criterion of validity which is established with the moral principle (U) expressly links the validity of a norm to the pre-supposition of its general observance. The acceptability of reasons advanced by the participants in discourse thus rests on the subsequent condition that the norm depends on the present circumstances of the fact and can only be implemented on the basis of this decision process. ${ }^{287}$

Günther identifies that the systems theory deals with a process of increasing uncertainty. The social system increases the degree of uncertainty due to the growing increase in its complexity. The law serves, therefore, a dynamic reality, to which it must be constantly re-adapted. It is the indispensability of the arguments that allows this adaptation, filling the gaps left by these constant changes. It is the growing relevance of the arguments on the scope of the application of norms that defines the relationship between situation and action in law. Each situation requires an examination of its relevant characteristics without the need of an established prediction by the positive-legal norm. ${ }^{288}$

Günther elaborates a procedural theory which offers an argumentative base for legal decisions by proposing a separation between justification and application legal discourses. His aim is to demonstrate how it is possible to achieve legitimacy in the decisions taken in the scope of disputes. For this, he states that issues concerning the validity of a norm must be separated from issues referring to its appropriate application. ${ }^{289}$

285 Ibid., pp. 198-201.

286 Günther, 1993, p. 252.

287 Günther, 1993, pp. 252-253.

288 Cademartori and Duarte, 2009, pp. 198-201.

289 See Günther, pp. 45-59; see also F. Pedron, A Contribuição e os Limites da Teoria de Klaus Günther: A Distinção entre Discursos de Justificação e Discursos de Aplicação como Fundamento para uma Reconstrução da Função Jurisdicional, 
In the case of the validity of a norm, the discourse rules should assert the validity of the norms that would subsequently be applied prima facie, by using a test of universalization, which would be possible through discourse; in the case of concrete application of norms, considering norms that are already valid, their application in concrete cases should be considered. The last case requires a previous selection of the most appropriate norms for that concrete case. Günther enhances here the uniqueness of each case. Each case being unique, each event rebuilt within each process should be considered as unique, too. ${ }^{290}$

For Günther, argumentation is the component that confirms or rejects the claim to validity of norms. Therefore, it should always observe the respect for discursive rules. The first point to be considered, in this sense, is the need to introduce the discourse related to the application of norms to complement the discourse related to justify their existence. The second point to be considered is the need of limiting the reasoning of a case, which is related to explaining the basis of court decisions as an application discourse, and therefore distinguish between justification and application discourses of legal norms when defining the legal activity in general. Thus, it can be said that Günther establishes a dual character of the legal discourse, one related to the application of norms (Anwendungdiskurs) and the other related to their justification (Begründungdiskurs), each of them being related to a separate stage of the legal activity. ${ }^{291}$

Argumentation serves the purpose of producing cogent reasons with which a validity claim can be redeemed or rejected. Logical and semantic rules, the principle of non-contradiction, semantic consistency when using a predicate, and the identity of meaning among speaker and hearer when using a term are all part of this. As a procedure, argumentation is a process of reaching understanding in which the participants enter a competition that serves the cooperative search for truth in special interactive conditions. This is linked to the presupposition that they are relieved of the pressure of action and experience and that they reciprocally recognize each other as participants enjoying equal rights. This pre-supposition is made possible by rules such as reciprocal truthfulness, or recognizing a distribution of the burden of argumentation. Finally, as a process, argumentation serves the purpose of reaching a rationally motivated agreement among the participants. General conditions of symmetry must prevail, ones which exclude all force except that of the better argument. They can be reconstructed in rules that stipulate a general participation of all competent speakers, equal opportunities for speaking, and equal opportunities for availing of these rights. These three levels or aspects of argumentation are represented, each in its own way, within practical discourses by $(U)$, so that $(U)$ 
can be transformed into the principle of discourse ethics (D), according to which a norm is valid only if "all affected in their capacity as participants in a practical discourse" accept (or would accept) it. ${ }^{292}$

In this sense, Günther's theory, as promoting a division in the legal discourse, into two types, also re-establishes the relationship between law and morality. There are theories that claim law is incapable of dealing with social problems with a minimum measure of justice. These theories, therefore, rely on a corrective role of morality in the legal system, which can be seen as a complement of the discourse of law or a support to the rule of law. Other theories, as the one elaborated by Günther, interpret it in a different way, accepting a relationship between law and morality from the perspective of an intersection or a common origin. According to this idea, the law would represent a kind of branch of morality, which, although restricted by its discourse rules, would still keep this common origin. In the first case, the moral corrects the law from outside, leading to discourse restrictions or censorship, while in the second, morality operates as an argument that justifies decisions in the legal system. ${ }^{293}$

Habermas criticizes the theory of Günther, claiming that it is necessary to replace practical reason by a subject-object relationship, as Günther continues to focus on practical reasons to justify the relationship between law and morality. That means the two authors present different interpretations about the relationship between law and morality, which is also important for explaining their interpretation about law and discourse. ${ }^{294}$

For Günther, the universality of normativity is based on a moral content and requires the support of standards of conduct. On the other hand, the law assures the coactivity needed to implement these same standards of conduct. Habermas, in his turn, addresses this relationship in a different way. For him, law and morality have a common origin, which does not always imply a concrete interaction between them. However, Habermas' theory preserves the division established by Günther in terms of application and justification discourses. ${ }^{295}$

What is important for this analysis is that, for Günther, there is a division or a gap between the norm grounded in the universal morality and its consideration in factual cases. Only in concrete cases and in terms of argumentation that underpins its application, the norm exerts its integrative function. As it is impossible to create a norm to attend each fact, the abstract validity needs to be elaborated in terms of a corresponding "factuality".296

292 Günther, op. cit., p. 42.

293 L. Streck, and S. Sito, A Crítica Hermenêutica e a Cisão dos Discursos em Klaus Günther, Estudos Jurídicos, no 17, 2012, http:// siaiap32.univali.br/seer/index.php/nej/article/view/4211/2431_(accessed 14 April 2018).

294 Habermas, H. Between Facts and Norms: Contributions to a Discourse Theory of Law and Democracy, MIT Press, 1996.

295 Ibid.

296 Ibid. 
The justification of the legal system, according to the presented theory, has a discursive nature. For Günther, all norms contain a reference to concrete situations of application, however tenuous this reference may be. Norms also present references to consequences and side effects that may result from their existence. Therefore, these elements are all connected, and their relationship will determine the validity of the norm, justifying its existence. These observations make clear that all these connections are possible through discursive elements, which means, language referred processes. ${ }^{297}$

The work of Klaus Günther, The sense of appropriateness: Application discourses in morality and law (Der Sinn für Angemessenheit: Anwendung Diskurse in Moral und Recht) ${ }^{298}$ is a milestone in the current argumentation theory debate, and is very useful to understand patent law, where the role of discourse presents many peculiarities, such as its multilingual structure. The criticism of Habermas does not invalidate its importance and works more as a complement or change in perspective for it than as a contradiction to its basics.

The respect to discourse rules, together with all its linguistic/cultural implications, becomes, under neo-constitutional, especially post-positivist theories, as the one developed by Günther, fundamental to understand the role of law in terms of the proposed fission. The discourse that sustains the justification of the existence of certain norms cannot be seen as the same as the one involved in decisions taken in disputes. That is so because these discourses don't share the same structures, origins, elements or functions, as Günther proves that dealing with concrete cases may require a different argumentation basis than the one used for elaborating a norm. ${ }^{299}$

To understand this division, it is important to describe the idea of adequacy, as advocated by Günther. At the moment of the application of a norm, there is no possibility to make decisions with the pursuit of purely formal criteria. Therefore, it is not possible to define criteria regardless of the application of the norm to the concrete case. That forces one to proceed to the complete description of the application situation before selecting these criteria for applying the norm. From there, the application discourse is guided, on the one hand, by the syntactic analysis of universal normative terms referring to a general and abstract case. On the other hand, one should check the possible meanings of factual references for the prima facie application of the norm. ${ }^{300}$

In the process of elaborating legal argumentation, the rules of interpretation and judicial precedents help to fulfil the role of specifying the potential implications and meanings of the case described in the norm. Therefore, the ones interpreting the case should highlight its contours of application in order to enhance its specific features. This allows the interpreter to semantically check whether the application of the set of

297 S. Moral, ¿Qué Discurso para la Moral? Sobre la Distinción entre Aplicación y Justificación en la Teoría del Discurso Práctico General, Doxa, no 21, 1998.

298 Günther (1993).

299 See L. H. Cademartori and F. C. Duarte, 2009.

300 A. Martins and C. Oliveira, A Contribuição de Klaus Günther ao Debate acerca da Distinção entre Regras e Princípios. Revista Direito FGV, vol. 2 no 1, pp. $241-254,2006$. 
lines pronounced by the norm matches the particularities of the case. ${ }^{301}$ In this regard, Günther argues that there is a gap between the identity of the normative description of the fact and the set of data brought by each case. He bases this statement on the theory of Tugendhat about impartiality, which relates moral learning and interpretation as a result of the experience of relativizing moral values to build the idea of the division of discourses:

Tugendhat also undertakes an analogous assimilation when he interprets the principle of impartiality as a directive of judgment. In doing so, he wishes to solve the problem of how moral learning processes resulting from experience are possible. If we have to interpret the principles to which we refer in moral conflict situations from the perspective of the first person, then this results in our not being able to integrate experiences we have as observers in the role of the third person into moral principles. On the other hand, however, the experience of the relativization of our moral convictions - an experience which recurs incessantly in history - points to the fact that we can obviously put forward the argument that certain experiences have been overlooked against the validity claim of moral principles. If that is not to lead to abandoning moral claims, then it must be possible on the basis of these experiences to change our moral principles. The precondition for this is that we are able to integrate the "outside view" from which we observe the relativity of our moral judgments, into the "inside view", from which we make moral judgments (...) This is always and unavoidably tied to a claim to universality, whereby we claim to be able to show every other person that our judgment is right (or, in Tugendhat's mode of expression, is "good") (...) As a solution to the above problem, Tugendhat proposes understanding the justification of the principle of impartiality as a principle of judgment. ${ }^{302}$

That signifies that the common points brought by the norm and the concrete case will never be sufficient to determine the appropriateness of the application of the norm prima facie. This distinction will then require a more complete description of the case, which may bring other characteristic features that may lead to other valid norms. ${ }^{303}$ That means the problem of conflict of norms will exist in the application discourse, and not in the justification discourse, as norms which are valid under unchanging circumstances can conflict with one another when all the circumstances of a situation are considered. ${ }^{304}$

Günther exemplifies this situation with a simple daily event. A man allegedly made a promise to attend the party of his friend Smith. The norm applicable to the case is that promises must be fulfilled. However, this norm may be waived if the full description of the situation gives evidence of other characteristic features. That confirms the gap 
between the norm applied prima facie and the whole set of reasons that can contradict it in the concrete case. In the example given by Günther, some of the reasons could be: there was not actually a promise to Smith; what has been told to Smith was that there was only a remote possibility that his friend could attend his party; although the promise occurred, another friend was in trouble and needed help at the exact time of the celebration... ${ }^{305}$

From this simple example, Günther seeks to draw attention to the fact that the complete description of a situation defined by the application of a norm can change or even avoid the application of that particular valid norm, even if it's considered as applicable prima facie. A remedy for this is the establishment of semantic rules that can justify the norms application in cases of doubts (that seems to be at the level of norms justification, according to Günther's theory). Günther cites Alexy for emphasizing the importance of these semantic rules for congruence in expressions used by the norms. He then gives the example of individuals a and b, who can be treated as $\mathrm{T}$ (being alike) in one specific case, but not in another case. That would also be an example of word usage rules necessary to establish congruence in norms:

Word usage rules secure the internal transition from the description of the situation and the norm to the conclusion by either establishing [festellen] or determining [festsetzen] (postulating) the semantic identity of the terms used in D and W. As rules, they are for their part in need of justification. If they only explicate an established word usage, then referring to language usage is sufficient. It is a different matter if they determine a new word usage. Then they are in need of justification $(. . .)^{306}$

This 'transition' determined by word usage does nothing more than confirm the division of legal discourse defended by Günther, as it both approaches the validity of the rule and its situational appropriateness. Additionally, Günther argues that authors who deal with argumentation do not question whether the appropriateness of the decision taken from the still limited semantic range contained by the norm can be justified in the same way as the rules that it already brings. For Günther, the relevant features of a case's circumstances still need another kind of justification, which follows a distinct rationale, and that's what he defines as application discourse. He summarizes this difference claiming that exhausting meanings and checking the generalizability of them represent distinct types of argumentative operations. ${ }^{307}$

Here it is defended that in both levels or in both operations, which means in norms application and justification, communication and translation will play a very important role. That is not different when it comes to the patent system. On the contrary,

305 Ibid. p. 232.

306 Ibid., p. 233.

307 See K. Günther, op. cit., pp. 233-234. 
as intellectual property can be considered as a highly internationalized branch of law, as explained in Section 1.1.3, discussions on language and translation tend to be central to its understanding.

There are plenty of particular examples of the role of communication and translation as key factors to maintain the integrity of the legal system. Some of these examples will be thoroughly discussed in the next chapters. They belong both to the level of elaboration of norms, as in the case of international treaties involving patent law or cases and circumstances of norms application, as in the sample involving patent law cases described on Chapter 7.

There are still scarce theories or studies about those cross-argumentation theories and language or translation studies related to patent law. A close observation of the patent system shows that these are still very rich topics for scientific investigation. Günther's division is a significant starting point for a comparison of how language and translation influences justification discourse and application discourse. A research which would deal specifically with this differentiation, anticipated by the present research, would be welcome not only to patent studies, but to IP studies, in general.

However, there are other division proposals with linguistic bases that select different discourse situations for comparing the effects of translation on law. Ramos proposes a division taken from the point of view of the translator. ${ }^{308} \mathrm{He}$ analyses legal translation samples divided into three inter-related contexts of text production within international and supranational law. The first division concerns law making by legislative, quasi-legislative or policy-making bodies with powers to design international or supranational rules; the second one, concerns the process of monitoring legal implementation, whose main control mechanisms entail reporting obligations by parties, conclusions and/or recommendations by the monitoring bodies; the third one, concerns the adjudication process, which refers to the application or interpretation of the legal instruments. ${ }^{309}$ The linguistic based proposal of Ramos does not conflict with Günther's theory.

Contrary to that, it fits the rationale proposed by Günther, which proves its congruence with discourse situations, as the study of Ramos confirms the need to separate the moments of elaboration and application, just adding an extra moment of monitoring, which can entail mainly a second step to elaboration. In consequence, it is evident that the legal arguments of Günther are very central to the understanding of any language/ translation analysis (either based on discourse situations or on structural elements) of legal translation.

In a previous observation, the respect for discourse rules as a fundamental part of the application of norms can be seen as a more dynamic or intense and varied process

308 F. Ramos, 'International and Supranational Law in Translation: from Multilingual Lawmaking to Adjudication', The Translator, 2014, vol. 20, no 3, 313-331, http://www.tandfonline.com/doi/pdf/10.1080/13556509.2014.904080 (accessed 14 April 2018).

309 Ibid. 
than the respect for discourse rules in the level of their justification/elaboration. In the second case, it is important to verify a set of questions to understand an international patent treaty or agreement in terms of its language/translation regime: why were these specific authentic languages chosen for this treaty? What are the official languages of the treaty and why were they chosen? Which criteria were respected for defining official and authentic languages? Was linguistic justice taken into consideration? Were there financial reasons to reduce the range of the languages included? What types of difficulties emerged in the process of elaboration (in the case of more than one authentic language) and translation into the official languages? Was there a language considered as lingua franca for the treaty? Was it considered as such for financial and practical reasons? Does this choice raise implications for linguistic rights of other signatory states which don't share the lingua franca as an official language? Are the treaties internalized into national regulations through accurate translation and interpretation?

There are many questions to be considered in the level of elaboration of international norms. However, this number is much higher when it comes to the application of these norms. There could be many unexpected questions following a particular case in terms of language and translation. These questions could, in turn, not only involve the main international treaties or agreements on intellectual property, or the national norms related to them (which can also reflect the quality of the translation and interpretation of these agreements), but a whole range of cultural aspects, as well as aspects related to the translation of the patent texts used as a basis for the argumentation of the parties.

Additionally, the application level of the norms, in patent cases, will involve a set of events that may change their legal route: the communication between local agents and foreign attorneys/clients, a whole assemblage of different documents and written communication that should be summarised by the agents, the language regimes of the States involved, the information given by the experts to provide justification for the case and the way the text of the cases are selected by legal technologists, just to give some examples.

\subsection{Justification and application discourses on the patent system}

The division established by Günther's theory between justification and application discourse is very central to organize the ideas relating to patent law and translation. As the present research discusses the role of translation on the legal stages of the patent, meaning both office and court stages, in the context of the presented theory, it is vital to visualize the influence of both justification and application discourses, as those stages depend on the way norms were previously elaborated, especially in terms of language regimes, and on their application to particular cases. 
In this respect, it is important to consider the very nature of patent rights, through the perspective of the dynamic and fast-changing character of the patent system, as a result of the speed of scientific and technological changes. Patent international treaties require a broad range of discussions involving various groups and fields, usually with contrasting ideas and interests. The same way, patent cases require a complex level of argumentation, which includes a level of justification, associated with an international scenario involving entangled agreements and treaties, when there are applicants or documents from different jurisdictions, besides the complete (technical and legal) description of the case itself and its implications in a national jurisdiction. On this matter, the principle of territoriality does not exclude the importance of international guidelines and agreements and a certain level of interaction of different jurisdictions..$^{310}$

Another essential question involving patent law and translation is how the existence or the conscious choice for a lingua franca, especially involving patent courts or patent offices, can influence the whole process related to patent rights, from justification to application discourses. In the level of justification, it is worth to highlight certain points: there are reasons for (unconsciously or not) establishing language regimes involving intermediate languages. These choices cannot always really justify the resources spent with language and translation and may intensify the distance created by language barriers. There are cases involving parties or documents from different nations decided in different ways in distinct jurisdictions (language can play an important role together with other factors). Firms and stakeholders may benefit from the fact that they share the same language as the so considered lingua franca when this language is their native language.

In the level of application, Section 7.4 will describe an emblematic case in which two huge firms - Samsung and Apple - needed the language-services of a firm called Trans-Perfect. The complexity of the case involved the translation of hundreds of pages of documents. Besides, it required the use of different systems related to privacy law and e-discovery. It involved the provision of professional translations of documents from at least three languages: French, Italian and Spanish. The case is representative in terms of the importance of language and translation to form the basis for a decision involving huge sums of investment and decisive economic results. The whole argumentation that underpins the decision is built over the complexity of the information present in the arguments brought by the parties. ${ }^{311}$

All the mentioned information, in turn, is not purely technical. There are discourse rules guiding it, if the term "discourse" is understood as the domain of language use, requiring functional choices at all levels of structure, defining patterns of sentences clauses, phrases or words. ${ }^{312}$ That becomes even more important when it comes to

310 See Chapter 7 for examples of proceedings and court rulings which mention previous decisions from other jurisdictions. The same chapter presents examples of cases whose decision were criticized by the international patent community for allegedly disrespecting international or regional agreements.

311 All the references available in Section 7.4.

312 M. A. K. Halliday, An Introduction to Functional Grammar, London, Edward Arnold, 1985. 
multilingual communication, extending the complexity of choices made by all the agents involved who produced, examined, translated and judicially analysed the documents.

A new element added to the complexity of patent cases, in the level of application, is the role of information technology related to language and translation services. Dealing with translation machines or with e-discovery software requires expertise and can demand skills related to both language and IT. The argumentation that is found in patent courts decisions should consider all these aspects, as they bring a whole set of new difficulties and can be interpreted through visions which update traditional theories on patent law. It is clearly a fast-changing scenario, that deeply involves language and translation as part of it.

This idea is easy to prove through an observation of the world language-services business, which is estimated, nowadays, to worth $\$ 34$ billion and is considered as a noticeably fast-growing business, growing at a rate of $12 \%$ a year. ${ }^{313}$ That leads necessarily both to growing complexity and specialization of these services, as it is impossible for one unique firm or professional to dominate it. The variety of languages involved, and some extraordinary difficulties found in the case of more pronounced cultural differences make the idea of a lingua franca very desirable as a reasonable solution to diminish these already abundant and huge gaps, simplifying and systematizing international patent rights.

A good reason for supporting this idea is the fact that fees from legal work involving language services can be very high and difficult to manage, as highly professional work is required. In the case of patents (which may differ considerably from other intellectual property fields, as trademarks or industrial design), the need of technical expertise makes the translation services even more difficult, if it is considered the difficulty to find a team of professionals who are able to work concomitantly with specific patent law, very particular technical fields (varying from medical discoveries to nanotechnology or electrical engineering) and a deep knowledge of a huge variety of foreign languages followed by legal/technical translation abilities. That all means that simplifying the patent system may be the best answer to a more efficient use of it.

Working mainly with data and examples from Brazil and Europe, as two different realities in terms of the patent scenario, had revealed some important aspects. The two chosen frameworks are very emblematic in terms of the representation of a patent system, and that led the research to some unexpected conclusions, explained in detail in Chapter 8. In terms of discourse matters (level of application) and their influence on patent law, there are some noticeable aspects.

The Brazilian patent system can be considered as a "highly" monolingual system, depicted by an "isolation tendency". It also presents low levels of innovation and most of its patent applications and granted patents belong to foreign applicants (around 80\%). The number of court cases decisions in Brazil represented by disputes involving patents was no more than 34 in 2015, which is a low number of disputes considering the total of

313 Translating and the Law: Legal Language. The Economist, November, 2012, http://www.economist.com/news/ business/21566010-services-specialising-language-and-culture-are-demand-legal-language (accessed 14 April 2018). 
patents granted $(2,800)$ in the year 2014 . The disputed patents equate to around $1,2 \%$ of the granted patents. ${ }^{314}$ The average number of patents disputed in 20 years, since 1996, is 27 per year. That is a very small number if compared to the average number of 1,350 decisions per year. ${ }^{315}$ There are some reasons for this. One of them is a huge disproportion between the attention given to patent rights in Europe and in Brazil. In Germany 80\% of litigations involving patents result in (partial or complete) grant revocations, while there are practically no cases of revocation in Brazil. In this regard, it is important to mention that the number of revocations in Germany includes upholding the patent in amended form, a solution which is legally provided, but not prevalent in Brazilian courts. ${ }^{316}$

In this regard, a case of revocation worth mentioning is the popular action, filed against the Brazilian patent office, questioning the grant of a patent for the drug Sofosbuvir, a case that contradicts international expectations related to patent rights. The Judge invalidated the patent under the argument of public interest. The decision can be questioned from the perspective of international agreements and inspired negative reactions from the international patent community. ${ }^{317}$

\section{Figure 14: Annual court decisions involving patents}

\begin{tabular}{|c|c|}
\hline 1996 & (6) \\
\hline 1997 & प(6) \\
\hline 1998 & (8) \\
\hline 1999 & $\mathbf{I}_{(3)}$ \\
\hline 2000 & $\mathbf{D}_{(9)}$ \\
\hline 2001 & $\mathbf{D}_{(10)}$ \\
\hline 2002 & (18) \\
\hline 2003 & $\mathbf{D}_{(10)}$ \\
\hline 2004 & $\mathbf{D}_{(23)}$ \\
\hline 2005 & $(61)$ \\
\hline 2006 & (25) \\
\hline 2007 & $\boldsymbol{D}_{(28)}$ \\
\hline 2008 & $U_{(40)}$ \\
\hline 2009 & $\square_{(31)}$ \\
\hline 2010 & (38) \\
\hline 2011 & (45) \\
\hline 2012 & $\mathbf{U}_{(21)}$ \\
\hline 2013 & (50) \\
\hline 2014 & (79) \\
\hline 2015 & (34) \\
\hline
\end{tabular}

Source: The numbers were taken from the official webpage of INPI: http://www.inpi.gov.br/

314 These numbers were taken from the official webpage of INPI. http://www.inpi.gov.br/

315 See Zeebroeck et al., 'Patent Litigation across Countries', Brussels, EPIP Conference 2011, available at: http://www.epip.eu/ conferences/epip06/papers/Keynotes/Nicolas\%20VAN\%20ZEEBROECK.pdf

316 See this information and some references at: M. Schweizer, 'German Federal Patent Court (partially) invalidates $80 \%$ of litigated patents', IPKat [Website], Feb. 2016, http://ipkitten.blogspot.sg/2016/02/german-federal-patent-court-partially. html; The court cases against the patent office in Brazil tend not to confront the administrative decision (see Section 7.4). The Brazilian Industrial Property Act (1996), Art. 47 provides that a patent can be partially amended. .

317 See: A. Nawrat, 'Brazilian court strips Gilead of its patent for Hepatitis C drug Sovaldi', Pharmaceutical Technology [website], https://www.pharmaceutical-technology.com/news/brazil-gilead-patent-hepatitis-c-sovaldi/ (accessed 8 December 2018). 
Arguably, that is also part of a process of isolation, which, in turn, may reach not only Brazil, but other developing countries. It is then important to clarify that "isolation" here does not mean a lack of contact with the rest of the world, but a poor level of interaction in terms of thinking of intellectual property beyond the walls of the national patent office, which also means beyond the barriers created by a very localized correlated administrative and court system.

This isolation process, which also presents linguistic/cultural and ideological roots, may prevent industries from being competitive and may limit countries in terms of knowledge production. Isolated systems tend to be late in terms of scientific and technological development and to present more gaps associated with the functioning of the patent system.

The small number of court cases involving patents and the complete lack of knowledge and discussion among the non-specialized population about intellectual property can be considered as signs of this delay. The isolation of the patent system implies the isolation of the innovation system in general, as the patent system should be seen as one of the main bases of the innovation system, although not the only one. ${ }^{318}$

For trying to change this reality, some questions should be necessarily asked and answered with scientific neutrality. Is there an ideological basis for preventing the patent system to reach an ideal level of integration in particular countries? What are the roots of the isolation of universities - as the main producers of knowledge - from Government institutions and industry? Why did the recent huge investment and TRIPS related new legislation not change this scenery? How can the studies involving intellectual property in Brazil be described in terms of a global reach? How far do they follow a global discussion? How many graduate courses are there on the topic in the whole country? How far do the studies of these courses go in terms of adding novel contribution to science universally? How much is learnt about IP in undergraduate courses and with what intensity and update level? How far is the societal relevance of studies involving IP being considered and what is its level of universality? Are instructors and professors being able to lead IP students to reach a global level of critical thinking and to push their researches to consistent scientific contribution? What is the relevance of IP rights to different groups of the society?

These questions are critical for understanding gaps that may corrupt the integrity of the patent system and for discussing the importance of the recent developments around a strong tendency to integration and harmonization, which may lead to reinterpretations of the principle of territoriality. They are also important as part of a discussion on language/ cultural integration. This conclusion is only possible after an understanding of the patent system as a system based on (multilingual, translated) communication. In this regard, national patent systems will present different levels of integration and interaction with the global patent system, with effects on the levels of application and justification of law.

318 For the association between patents and innovation, see: R. Merges, Robert, Justifying Intellectual Property, Harvard University Press, 2011. 
To summarize this Section, Luhmann's conceptions were complemented with the theory of Klaus Günther, who proposes a division in legal discourse between justification and application. Establishing this division is useful for understanding the intensity and type of complexity in the two levels of communication in patent systems, considering that, even in the level of application, which means, in particular court cases, a national system interacts with an international scenario of agreements, guidelines and expectations from foreign stakeholders.

By comparing the situations of more or less isolated systems, it is possible to infer that (linguistic, cultural, academic) isolation is a negative characteristic for a patent system, under the evidence that if a system is based on communication it should actually communicate (internally and with its environment). If the system is isolated, it will tend to lose its raison d'être, becoming weak or not corresponding to the expectations of its users. On this matter, court rulings pronounced in a national system may produce global effects, as demonstrated in Chapter 7.

This conclusion can be relevant for discussing the role of translation and communication in a national patent system and thus in particular patent cases. As affirmed above, patent cases tend to be complex and tend to reflect part of a local legal culture. They can also involve an infinite number of documents and communications in a broad variety of languages and require technical knowledge related to different fields. In this sense, integrating and simplifying patent systems represents a tendency and a solution for assuring the consistency of the global patent system, assuming patent law, as defended in Sub-Section 1.1.3, is considered as an internationalized field of law. ${ }^{319}$

At this point, debating the possibility of community patents and patent courts becomes relevant. Unifying and simplifying patent systems, for the reasons mentioned above, becomes crucial for the effectiveness of these systems and for the strengthening of legal certainty and transparency in its institutions, especially considering, as clear in examples of infringement cases, ${ }^{320}$ the difficulties involved in the level of the application of norms in national jurisdictions which, in fact, correspond to international expectations. The case of the PCT working as a global integrated system also clearly shows the positive results of integration and simplification - as it has allowed a much higher level of global interaction in terms of harmonization of concepts and rules, shared knowledge and disclosure of technological information. ${ }^{321}$

319 For the conception of patent law as an internationalized field, see Barbosa (2010). See also: D. Gervais 2002.

320 See Section 7,4.

321 See Chapter 5 of this dissertation. 


\subsection{Communication and translation as keys to maintain the integrity of the legal system}

As discussed in the previous section, according to Luhmann's theory, the legal system is an autopoietic structure based on communication, being a sub-system of the social system. Therefore, it has the capacity to interact with the environment and, at the same time, to develop and to auto reproduce on the basis of these same communication rules. If the contribution of Klaus Günther's theory about the division of discourses is added to the legal system, then it is possible to identify a system based on two kinds of communication: justification and application discourses. Therefore, it was decided to treat these two levels of the legal discourse differently, as concluded the previous section. That makes the inter-connection between language and translation and the legal system more complex, requiring extra attention while generalizing.

There are many questions to be asked concerning the relationship between the law and translation which precede the ones concerning patent translation. Legal language has peculiar features in terms of vocabulary and structure. However, it's not just that. Each linguistic system will also develop a way to recreate these features, which cannot be even interpreted as coming from a common, universal ground.

However, it can be said that there is a common abstract background that will allow different cultures to develop their legal systems accordingly to their own characteristics. Even though the legal discourse is likely to find corresponding structures in different languages, it is still subject to tradition, convention and usage considerations. That can also happen with two varieties of the same language, as is the case of the Brazilian and the Portuguese legal systems, just to give an example. Although these systems share the same language and some common cultural roots, they can be considered as noticeably different due to many other (cultural, geographical, historical, political...) factors.

Hiltunen describes the peculiarities of the grammar and structure of legal texts, by giving some examples taken from diverse British Acts. The author focuses on the materialization of the language of the legal code, which means on the level of a justification discourse, belonging to the stage of elaboration and publication of norms, or to the law as embraced in legal statutes. ${ }^{322}$

The study of Hiltunen ${ }^{323}$ may have excluded case law, jury instructions, wills or other kinds of legal communication purposely, probably because of the difficulties in finding regular patterns in it. Differing from parliamentary legislation, case law (as it is already in the level of application of the legal discourse) will present a much more "contaminated" structure, as it will tend to bring out other spheres of discourses necessary to ground the juridical decisions. In this sense, it is important to affirm that legislative

322 R. Hiltunen, 'The grammar and structure of legal texts', in P. Tiersma and L. Solan, The Oxford handbook of language and law, Oxford University Press, 2012, pp. 39-51. The excerpts are taken from page 39.

323 Ibid. 
language, or the language present in the Constitution and in the Parliamentary acts, brings a much clearer sample of legal language.

The patterns that can be analysed in legal language are mainly syntactic and lexical. The syntactic patterns are important because they determine the 'rules of the game' of language structure, being the central feature of their identification. Most of these characteristics are not random. ${ }^{324}$ Contrary to that, they obey discourse rules which allow the set of legal texts to represent a firm foundation for legal decision, which means, to its application. For that reason, legal discourse emerges from the main law's societal purpose: control and regulation. Its level of difficulty and hermeticism is necessary to maintain its integrity and accuracy. ${ }^{325}$

In this regard, clearness, explicitness and precision are mandatory features of the legal text. ${ }^{326}$ The complexity of the legal language as a signifiant reflects thus the strict requirements and the complexity of its signifié and is justified by a communication demand. ${ }^{327}$ As said by Hiltunen, the complexity of the law affects its language design in a way that it may involve stretching the capacities of the linguistic system well beyond the ordinary in order to meet stringent demands on the proper form of the text. Therefore, the linguistic features of the legal text should not be interpreted as a barrier to understanding its content, but as the only possible way to preserve its integrity. ${ }^{328}$

Reading, writing, interpreting and, of course, translating legal texts requires particular professional skills in language, which are not limited to the legal language. Professionals who deal with legal texts should show interdisciplinary knowledge, sophisticated communication skills and a daily effort to read and learn about unexpected matters. They should also be aware that the form of the text does make a difference.

It is then probable that legal texts will frequently generate communicative failure with the public in general, as the latter is not technically prepared for understanding their codes. This characteristic allows for different professionals and firms to mediate the communication processes involving legal and ordinary languages. For Hiltunen:

The fact that societies have specific professions especially designed to act as links between the public and the legal system itself suggests the potential risk of problems arising from the incompatibility of the routines of ordinary communication and those of the language of legal texts. ${ }^{329}$

324 Ibid.

325 lbid, pp. 39.

326 Ibid.

327 The reference is related to Ferdinand de Saussure's linguistic theory, which conceives that the signifié refers to the concept not in a direct way, being related to the mental representation of a thing. According to this conception, language is not a repertoire of labels that would reflect existing things. The signifiant, in turn, refers to the acoustic image of one word, to its 'physic apparatus.' For understanding Saussure's idea in detail, see his main work on linguistic theory: F. Saussure, F., Cours de linguistique générale, Paris, Édition Payot et Rivage, 1995.

328 Hiltunen, op. cit., p. 39.

329 Ibid., p. 39. 
Nevertheless, what seems to be a mere use of 'rare words' or 'intricate sentences' is not a chaotic way of communication. Legal language tends to repeat patterns both through its structure and its vocabulary use. It is even possible to characterize a typical 'legal syntax', meaning a certain combination of language elements (syntagmas) will reach a set of structural patterns (paradigms) effects that will influence the general meaning of the sentences, as well as the whole text's semantic structure. ${ }^{330}$

The study of Hiltunen, thus, investigates legal language as an object, and not as a process, which defines the difference between occurring in a structural study and in a discourse analysis study. The type of analysis selected by Hiltunen is the same one adopted to deal with the sample data of the present research. ${ }^{331}$ Research on discourse analysis can be very useful for investigating the legal language within the patent scenario, and it is recommended that further studies consider specially working with the influence of ideological speeches on the relation of national patent systems with the patent system at the global level. However, the focus in this study will be on a structural analysis, urgent in the sense of strengthening regulations and institutions related to patent rights.

The first important structural aspect to be considered is legal syntax. Some of the syntactic properties listed in Hiltunen's work considered as relevant to characterize legal language were: sentence length, the clausal structure of sentences, the types of subordinate clauses, and the position of the subordinate clauses in sentences. These are aspects which were observed during the sample analysis, described in Chapter 5, together with lexical elements. Therefore, it was chosen not to assess the semantic subtleties that reveal political or power relations in legal language, which would be a research on discourse analysis, but to focus on legal syntax and terminology.

A syntax analysis is basically the way the words are combined in sentences, clauses and phrases. These relations define the distinctiveness of a language and can also define the identity of varieties within a language, which is the case of legal language. The basic structure of a language can be first delineated by the relations between subject, verb and object (SVO), in both paradigmatic (concerning substitution) and syntagmatic (concerning position) terms. ${ }^{332}$ As these combinations vary from language to language, what is valid for the English language is not necessarily valid for other languages.

The first syntactic feature verified by Hiltunen as characteristic to legal language is sentence length, which he describes as a parameter of style. ${ }^{333} \mathrm{He}$ describes sentence length in legal language as longer than in the language used in other prose genres. Besides being long, sentences in legal texts tend to recurrently break their linear flow of

330 Ibid.

331 Discourse analysis deals with language and contexts. It investigates, for example, power relations behind linguistic choices. For understanding the scope of discourse analysis, it's important to access its classical works. The works of Michel Pêcheux are very representative in this sense. See: M. Pêcheux, Language, semantics and ideology, New York, St Martin's Press, 1982.

332 See Saussure, op. cit., pp. 276-286.

333 Hiltunen, op. cit., p. 42. 
information, which can make them more complex and difficult to understand, as they frequently show unusual syntactic arrangements. ${ }^{334}$

In terms of this feature of the structure of legal texts, Hiltunen gives an indication that can be helpful for a better understanding of legal texts, and also to better translations or to content analysis involving translations. He gives an example of how a sentence of 382 words can be simplified if it is organized in a list of points, based on repeated paradigms. ${ }^{335}$

Other characteristics of the legal text mentioned on the study are: predominance of clausal sentences (around $64 \%$ of the sentences are complex); predominance of nominal elements, which tend to be repeated in the text as a preferred strategy (instead of replacing these elements by pronouns or other deictic expressions); heavy and complex nominal elements (choices of vocabulary that express complicated concepts); discontinuous structure of the sentences due to the use of adverbial clauses; highly elaborated and precise general text structure. ${ }^{336}$

The legal text is also characterized by its hybrid character, its tendency to manifest intertextuality and, in the case of patents, the constant interplay between national and international levels. Legal texts can thus be considered as special-purpose texts which require excellent knowledge of the particular subject matter from their readers and translators. In their context, translation cannot merely be considered as an interlingual transfer, but should be seen as a cross-cultural, decision-making process, demanding vast reading and experience from legal professional translators. ${ }^{337}$

All this complexity is not arbitrary, concerning the communication purposes of the law, and it can be argued that it increases when these texts need to be translated into another language, and when it involves technical scientific knowledge, as in the case of patents. Nevertheless, the importance of this relation is still far for being acknowledged, as legal translation is still looked at as one of the various branches of special-purpose translation ${ }^{338}$, not to mention the position of legal translation concerning patent law.

Šarčević describes the role of legal translation in globalized societies and the responsibility of legal translators as follows:

As a result of increasing demand for the free movement of people, goods, and capital, legal translation affects all of us in one way or another. International trade, for example, could not function without legal translation. Similarly, the success of the Single European Market and the European Union is partly dependent on translation. The translation of municipal law has a relatively long tradition in plurilingual countries such as Belgium, Canada, and Switzerland. In response to increased emphasis on equal language rights, the European Council

337 S. Šarčević, New approach to legal translation, Kluwer Law International, 1997, pp. 1-7.

338 lbid. 
has recently adopted a special Charter to protect the language rights of ethnic or minority groups in multi-ethnic societies. Among other things, the Charter recognizes the right of minorities to use their own language in judicial affairs, thus increasing the demand for translations of national and regional legislation and regulations. ${ }^{339}$

It is possible, therefore, to conclude that creating communication bridges that allow the development of supranational and international debate and regulation in global fora represents a tendency that should only grow in network societies. The same can be affirmed when it comes to a shared legal system, as is the case of the Unitary Patent Court. Ramos observes the connection between the challenges of legal translation and the complexity of the legal international or supranational system. It is part of the task of the legal translator to deal with this complexity:

In fact, the challenges of linguistic mediation within a shared legal system lie primarily in the intrinsic complexity of the international or supranational system itself. It therefore proves essential for legal translators at international organisations to understand the multi-layered nature of each shared system and the different procedures and agents that shape its linguistic facets. In delineating the scope of translation of international and supranational law from this perspective, it becomes apparent that different sources and procedures for legal drafting, implementation and interpretation cannot be analysed in isolation from each other. ${ }^{340}$

It is important to note that the systemic character of the law is enhanced in the excerpt above, especially through the observation that the three levels of the completion of an international or supranational act should not be seen in isolation from each other. From that, a significant conclusion is that the consciousness of the systemic character of the law is crucial to a good understanding of the processes of translation and communication related to it. Its divisions in the levels of justification and application will also facilitate the perception of the operation of the system. Communication and translation, in the case of patent law, where there is a tendency to more interaction, and as its basis, characterize the different faces that the system and all its uncountable branches can assume.

Ramos enumerates the central international sources of law: international conventions, international custom, general principles of law recognized by nations and judicial decisions and the 'teachings' of the various nations (which include subsidiary academic material). ${ }^{341}$ In the case of patent rights, many examples of these international

339 Šarčević, op. cit., p. 1. See it also for a more detailed discussion on the importance of legal translation for economically strategic fields, pp. 23-32.

340 Ramos, 2014.

341 Ramos, op. cit. 
sources could be mentioned: the TRIPS Agreement, the Paris Convention for the Protection of Industrial Property, the PCT Agreement, the European Patent Convention, the general principles of national treatment, priority and independence of rights, all the studies and reports produced or disseminated by WIPO.

\subsection{Communication and translation in patent systems}

The previous sections argued that the patent system cannot be interpreted as any subsystem of the legal system. Although it carries characteristics of the legal system, it is tightly connected to other spheres - involving, at first sight, science, economics, industrial management, public policy, technology and innovation. In this regard, the debate gets to an intricate equation: the patent system, seen as a sub-system of the legal system, has a strong link with international foundations. Hence, translation constitutes its main basis of communication, defining its identity as a system.

Ramos'study is useful to reveal the relation between the language bonds with the level of interconnection of legal systems. This overview depicts a vast scope characterized by the interplay between different sources, as well as international and domestic layers, in the functioning of the legal machinery of each organization. The closer and more systematic the interconnection of these layers, the more dynamic the system. According to Ramos, translators of texts of complex court cases have the difficult task of dealing with interpretation issues and legal argumentation, which can also be a product of previously translated instruments, many of which containing linguistic discrepancies. ${ }^{342}$

Hence, the translation of patent texts and documents can be considered as a complex type of translation, demanding from professional translators a very high and broad qualification. ${ }^{343}$ That is because the task of the patent translator does not only require knowledge of the target language and the target culture. It requires more sophisticated skills, as this translator has to study and understand the specific legal systems concerning the source and the target languages, and also be able to deeply understand the content of the invention and transmit it precisely in the target language..$^{344}$

Patent translators should also have advanced language skills, as deep knowledge of grammar and structure of both source and target languages and understand the subtleties and responsibilities of their choices concerning the scope of the patent. One of the most challenging tasks of the patent translator is to produce a clear text for his audience in terms of source technical and legal aspects, which may often require more than 'simply translating' these texts, but elaborating explanations and support texts,

342 F. Ramos, 2014.

343 For a general view of the profile of legal translators, see: R. Stolze, The Legal Translator's Approach to Texts, Humanities, 2013, 2, 56-71, file:///C:/Users/Win7/Downloads/humanities-02-00056\%20(1).pdf 344 Ibid. 
also related to drawings, which should be clear and concise. ${ }^{345}$ Original patent texts may function in the original patent system, but create uncertainties in the target patent system if translated literally.

On the other hand, in the level of legal justification, communication and translation involving patent agreements may present some peculiar characteristics in comparison to other legal branches. The patent system is an important framework to support global scientific and technological production, being the main basis for fair global trade. Another important feature is its central relevance to economic development and therefore the sort of interests it entails, which comply the interests of the productive sector in the most varied areas, as well as the interests of independent inventors, governments and social organizations.

Some intergovernmental organisations and supranational organisations are considered as very important to the patent global system. The most central one is the World Intellectual Property Organization (WIPO), considered as the main global association for intellectual property. WIPO provides services, policy, information and cooperation associated with intellectual property and is responsible for the Patent Cooperation Treaty (PCT), the most important international patent agreement currently. WIPO is a self-funding agency of the United Nations, founded in 1967 and now with 188-member states. ${ }^{346}$

Patent organizations are involved with the vast flow of multilingual communication which defines the patent system. However, it is not only in this level that translation is important to patent law. As explained previously, specialized companies are becoming more and more profitable in this area. Besides, it is worth mentioning patent offices or law firms that hire permanent or freelance translators to deal with a great variety of documents. Patent translation may include documentation related to application and to disputes. The last ones may include patent searches and prior art documents to reason judgements about the invention and its patentability. ${ }^{347}$

Translation is also part of the daily tasks of patent examiners. In this respect, the interviews with patent examiners revealed that (extra) human translation is normally not required during the process of examination. However, according to all of the interviewed examiners, machine translation is very important and is part of their job, as well as developing translation and interpretations skills. They claimed that with the help of machine translation and patent families, they can solve all the language problems that come up during the examination process.

345 Ibid.

346 Besides WIPO, other international organizations play a relevant role which influences the patent system. The United Nations (UN), as a key 'mother' organisation leading an extensive range of issues, including being in charge of WIPO, is obviously one of them, and so is its International Court of Justice (ICJ). The World Trade Organization (WTO) also plays a very important role directly related to intellectual property. As a specialised organisation with an important dispute settlement function, WTO also works in cooperation with WIPO, as is clear in the TRIPS Agreement (an emblematic result of this mutually supportive relationship). It is important to mention the European Union, a multilingual supranational political and economic union, and the EPO, which is very close to establishing a unitary patent system and a unitary patent court. See: WIPO's Official Webpage: http://www.wipo.int/about-wipo/en/ (accessed 14 April 2018).

347 M. Olohan, Scientific and technical translation, Routledge, 2015, pp. 127. 
However, some of the key patent offices in the world also hire human translators, the EPO being the most multilingual of them. The EPO has 38 member states, which extend beyond the European Union (Turkey, Norway, Switzerland and Iceland are included). ${ }^{348}$ Although its official languages are just English, French and German, and the main flow of translations happens around these three languages, the Office represents a great variety of countries with their different languages, which can require other types of communications with its member states. ${ }^{349}$ JPO, SIPO and KPO (the Japanese, the Chinese and the Korean patent offices) have launched machine translation engines as a result of partnerships with the EPO. These engines made the search for patents in their languages much easier and now they are being used worldwide. ${ }^{350}$

The possibilities opened by machine translation make the so-called gist translation much more common in the daily activities of patent offices and organizations. As the searches on databases are mainly directed to basic information on prior art, the MT engines can provide intelligible information contained in claims, abstracts and titles of patents. In the case of patent examination, human translation or support can be considered as rarely necessary. This increase in the use of machine translation also considerably diminishes the costs of these organizations. A routine involving the use of machine translation in evaluating patentability tends to be improved, and examiners get more experienced and skilful in doing it.

Although specific MT systems provide much information about patents and are more and more adopted by patent organizations, they may not suffice in some cases. For instance, this may happen when cases involving patents require information from documents in an uncovered language or in-depth information which abstracts only, or inaccurate translations of the whole document, cannot provide.

Nevertheless, when it comes to the information given by the disclosure of patent information and its influence in infringement cases, a different scenario is found, with some important peculiarities. The patent system brings, by its own nature, a translatable landscape. When it accomplishes its own purpose, it is meant to be a system of easy communication and high level of interaction and dissemination of disclosed information.

This is explained by many reasons. The first reason is the universality of science. Scientific communication and scientific language are aimed at being universal and allowing the interchange of information between scientists worldwide. Thus, the ethos of science has for a long time been prescribed through the thought of its theorists and

348 Olohan, op. cit., p. 120.

349 The European Patent Convention, 16th Edition, June 2016, https://www.epo.org/law-practice/legal-texts/epc.html. See more details on the language regime of the EPO on Section 6.2.

350 See details about the mentioned partnerships on the EPO's Official Website: EPO and SIPO launch Chinese-English machine translation for patents, Dec. 2012; 'Japanese-English machine translation for patents goes live', June 2013, https://www. epo.org/news-issues/news/2012/20121206.html, https://www.epo.org/news-issues/news/2013/20130605.html . The Korean translation machine, different from the Japanese and Chinese examples, was not developed under the scope of 'patent translate'. It was made available by KIPRIS (Korea Industrial Property Rights Information Service) on behalf of users who should pay a tax for each translated document. See: 'Korean to English Translation Tool Available through Patentscope', WIPO's Website, Nov. 2011, http://www.wipo.int/patentscope/en/news/pctdb/2011/news_0015.html 
philosophers. The institutional goal of science is the extension of certified knowledge; and the scientific project, a common and inclusive project based on shared values believed to be right and good in terms of creating a dependable body of knowledge in a global level. ${ }^{351}$

The second reason, and a very important one, is the fact that patent applications are written to be examined. For that purpose, they follow certain rules and obey a rigid script so that they can be easily compared with other previous patents and understood by the examiner. They should also reach a global community and be intelligible for a person skilled in the art after their content is disclosed. Patent language is, therefore, meant to be clear and effective, which means it is (or at least should be) naturally pre-arranged for being translatable.

Contrary to the legal language, patent language should preferably use simple syntax and direct terminology. That is so because of the need for speed and precision required by international knowledge and trade. Contrary to the legal system, the patent system is fluid and technical, less metaphoric and more univocal. In this sense, it can be said that the kind of precision required by the patent system differs from the one required by the legal system, in general, being one of the most purely technical kinds of communication, which also changes the type of argumentation used.

Hence, the precision required by the law is one of finding the right word, the most up-to-date way to reach the understanding of the receiver and to capture reliance towards the system, which consists in a more general task. Meanwhile, the precision required by the patent system is one of finding the only word or the best (technically speaking) word, which means, the exact representation of elements, measurement, function and combination. That's why it is (literally) a pictorial representation, even frequently supported by drawings, being an adequate linguistic modality for machine translation. ${ }^{352}$ The table below sums up the most important differences between the "patent language", or the characteristics of the language used in patent documents and legal language, based on the studies presented above and on the analysis of the sample. ${ }^{353}$

351 R. Merton, The Sociology of Science: Theoretical and Empirical Investigations, University of Chicago Press, 1979, pp. 267-280.

352 This conclusion is based on the review of the literature on legal language (for example, Hiltuten, 2012) and on the analysis of the sample of patents (see Section 5.2).

353 Based on the studies on legal language presented in this Chapter and in Chapter 4 and analysis of the sample chosen for the present study. 
Table 9: Differences between "patent language" and legal language

\begin{tabular}{ll}
\hline Patent Language & Legal Language \\
\hline Simple sentences. & $\begin{array}{l}\text { Complex sentences with a predominance of } \\
\text { adverbial clauses. }\end{array}$ \\
\hline
\end{tabular}

Nominal elements, whose precision is in finding "the Nominal elements, whose precision is in finding "the only word" or a word which has a direct relation with a right word" for best expressing an idea.

very particular meaning.

In general, non-metaphoric. Based on argumentation, being metaphoric specially in the level of application.

Pictorial and succinct discourse. Analytic or prolix discourse.

Allows acceptable results in machine translation. But Requires a highly qualified professional for translating requires highly qualified translators, with technical and and interpreting it, with a deep knowledge of the legal knowledge, when human translation is needed. two languages and the two legal cultures involved.

Representation of elements, measurement, functions Representation of principles, norms and ideas. and combinations.

Sources: Studies on legal language presented in this Chapter and in Chapters 4 and 5 and analysis of the sample chosen for the present study ${ }^{354}$

\subsection{Conclusions and correlation of the chapter with the research question}

Chapter 3 focused on the systemic nature of the patent system and on its relationship with communication, discourse and translation. The Chapter describes law as a system based on communication, as postulated by Niklas Luhmann. The theory of law as a social system was reported as a background to understand the role of translation to the patent system. By recognizing the relevance of communication and discourse to legal systems, the patent system was defined as a (relatively) coherent global structure, based on multilingual communication, and on particular discourses that characterize its levels of justification and application.

Luhmann's theory was useful to explain translation as a fundamental element to the patent system. If the patent system can be interpreted as a sub-system of the legal system - after all, patents are public, territorial (to the date), property rights -, it can be acknowledged as an international, multilingual arrangement, where (especially machine) translation is a central element to its identity as a system.

The approach to Luhmann's theory was complemented by an analysis of the theory of Klaus Günther over the role of discourse rules to the law in its levels of justification and application, related to the elaboration of norms and their application in particular cases. It was concluded that the role of translation is central both to the process of establishing and internalizing international agreements concerning patents and to the application of these norms in particular cases. Hence translation can be considered as a formative element of discourses concerning the patent system.

354 The results of the analysis are presented on Chapter 5. See also references in Section 4.3. 
Furthermore, multilingual communication pervades the possibility of patent applications in different countries, the triage and analysis of prior art and even the oral communication in office interviews and court hearings. The advent of machine translation (more than, but together with digital tools) also changed the face of the patent system, intensifying its trend to harmonization and integration. The importance of machine translation as the basis of its communication can be recognized through the volume of multilingual information consulted by examiners and attorneys on a daily basis and on the increased universalization of disclosure of patent content. On this matter, it is worth reminding that prior art search and examination were practically limited to national documents before the development of quality machine translation.

This new configuration encourages national patent systems to integrate and interact with a global structure. The patent system became more globalized, and it is conceivable to identify general guidelines and centres of governance which make this definition possible. Automatic translation, together with the creation of digital databases, made multilingual search for prior art faster and easier, reducing the costs with translation and allowing an increasing number of applications in different parts of the world.

On the other hand, the patent system being defined as a (global) system, based on (especially machine) translation, raises the idea that translation can also work as an element of potential corruption or fragmentation of the system. Therefore, translation can be seen both as a linking element, which defines the identity of the patent system, and as a disruptive one, which can compromise its integrity. In this respect, Chapter 5 analysed the relation between translation and disclosure of patent information, and Chapters 6 and 7 bring particular examples where translation operated as an element of corruption of the patent system. 


\section{CHAPTER 4}

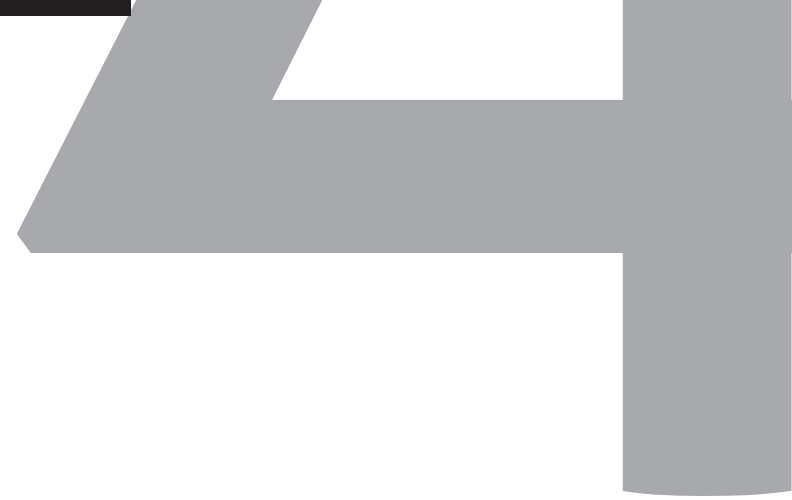




\section{Translation as a vehicle to patent rights}




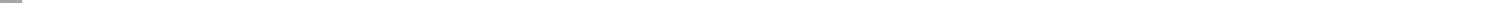




\subsection{Innovation, language and translation: historical developments and necessary updates}

This section aims to introduce possible associations between innovation, language and translation, in connection with the present research question, which refers to the influence of translation on the dissemination of the disclosure of patent information on patent law. Therefore, it does not intend to exhaust the topic, still poorly explored in scientific studies, although translation has long performed an important role to knowledge production and transfer. It provides a historical association between innovation, language and translation, which is important to foster discussion on the purpose of translation to the patent system and on the idea that, today, patents universally disclose the content of inventions, as language barriers became less of a problem.

After searching in academic databases or on internet websites for the association "innovation and language", the results are mainly related to innovation in its ordinary sense, as, for example: "innovation in language studies" or "innovative methods in language teaching". There are also results relating innovation (in its common sense, or with the meaning of "creativity"), information technology and language. ${ }^{355}$

The most relevant results that the literature search yielded were some nonacademic articles relating innovation and rhetoric, or the importance of language in creating an innovative "ecosystem" in companies. These articles are the ones that get closer to what could be interpreted as "a language of innovation". Their credit is in suspecting that relating language and innovation could be beneficial to both fields.

H. Doss ${ }^{356}$ writes an article to Forbes suggesting that innovation requires a "mode of speech" and warning that most companies are not able to understand that necessity, which explains the failure of most innovative initiatives in these same companies. The author describes this barrier in terms of a wrong use of speech, intuitively proposing that the "language of innovation" should be "learnt" by the managers and stuff of a company whose purpose is to increase innovation. His point of view is defended through a distinction between "the language of innovation" and the "language of command" and seems to present the speech that flourishes from the object of innovation itself as a solution for these corporations to increase their level of innovation:

We may think of this as a requirement for organizational leaders to speak two languages, to understand two different dialects, and to speak from two completely different points of view -- at the same time. At one point, we might talk about output -- products, patents, updates, improvements, and so on -- all of which we might be able to describe in rather precise language, and in

355 See, for example, the results of a simple search in Google Scholar: https://scholar.google.com/scholar?hl=nl\&as $\mathrm{sdt}=0 \% 2 \mathrm{C} 5 \& \mathrm{q}=$ innovation+language \&btnG=

356 H. Doss, The rhetoric of innovation, 2014, Forbes. https://www.forbes.com/sites/henrydoss/2014/12/16/the-rhetoric-ofinnovation/\#7055a0f69b93 (accessed 14 April 2018). 
terms we all share in common. We are comfortable with this language because it is empirical, accessible and common. But it is incomplete. At the same time that we are speaking the language of command, we need also to speak the language of innovation, of culture, of those things that occur to us as less empirical. ${ }^{357}$

The author continues his rationale, proposing that a simple demand for innovation is an order given in a language foreign to innovation language, which will not be understood or fulfilled by its supposed performers:

In many organizations, there is a demand for doing innovation, a demand to deploy innovation tactics and strategies, a demand for innovative output. This amounts to demanding innovation in command language, which is like a demand in English to speak French. Demanding that an organization innovate is akin to demanding that a rock roll uphill. The demand is clear, the actors are clearly defined, and the goal is clear. But the outcome is at best unlikely. ${ }^{358}$

The idea suggested by the author does not lead to a description of what is or what should be this "language of innovation". It is, though, convenient to retrieve it as a starting point to propose a possible association between language (in this case, speech and discourse) $)^{359}$ and the technological innovation seen as a process. What would characterize innovation as a discourse could be the subject of further studies.

Denning and Dunham also wrote a study called "Innovation and language action". ${ }^{360}$ They explain the level of failure of $96 \%$ for innovation initiatives through poor conduct of communication in corporation environments. They believe innovators should be prepared in terms of acquiring "certain skills". Those "skills" would be explained in terms of what they called a "language action". Language action would then be related to persuasive discourse and to the fact that innovation requires further communicational interactions than invention. According to their approach, the central claim of the languageaction framework is that purposeful actions and interpersonal co-ordination are the results of commitments people make in conversations. ${ }^{361}$

Interpreting innovation in terms of speech (a language structure, explained in a simple way) or discourse (a contextual production of this speech) ${ }^{362}$ could be one way to approximate linguistic studies and innovation as economic phenomena, in terms of economic results. But it is possible to go much further with this association, as innovation is

359 For the distinction of the two concepts: R. Wodak and M. Meyer (ed.), Methods of critical discourse analysis, SAGE, 2014. A classical reference of discourse analysis is the work of Pêcheux: M. Pêcheux, Language, Semantics and Ideology. New York, St Martin's Press, 1982.

360 P. Denning and R. Dunham, Innovation and language action, Communications of the ACM, Vol. 49, no 5, 2006.

361 Ibid.

362 For the distinction of the two concepts: R. Wodak and M. Meyer (2014); M. Pêcheux (1982). 
a global phenomenon which implies multilingual, multimodal, multiplexed, simultaneous exchanges from many-to-many. ${ }^{363}$ It is also important to enhance the density of the concept of innovation, which increases the possibilities of exploiting its interfaces with language and translation studies.

One of those interfaces is the relation between science and translation. It has only been slightly investigated by scientific studies and could still be much exploited through the lenses of the pair innovation/science. Montgomery presents a rare work in this sense, consisting of a historical approach on the influence of translation over science in different cultures. The author also defends expanding the subject area, interpreting it as a subject worthy of diverse enquiry. ${ }^{364}$

Montgomery's study proves the crucial role translation has played in the development of science, by showing it is involved in every level of scientific production. The study identifies the history of Science with the creation of new vocabulary in any language, through an evolution that implies choices that may mould one singular culture or allow knowledge transfer between different cultures. The author enhances the definition of knowledge as a mobile form of culture and indicates translation as its main vector. $^{365}$

Beyond any doubt, the transfer of learning has been critical to the building of societies, those we call "modern" most of all. Time and again, the introduction of new concepts and methods - Roman law, the system of Arabic numerals, the sonnet, Newtonian physics, linear perspective - has proved the source of new capacities for ordering, directing, and expanding human existence. Placing the knowledge of one people into the hands of another involves the transfer of certain powers: powers of expression in the case of literary or artistic knowledge; powers over the patterns and organization of life in the case of political, legal, or religious ideas; and, in the case of science, powers of imagination and practice with regard to the material world and uses of it. ${ }^{366}$

Another important point raised by Montgomery is the fact that translation is not a single, simple phenomenon. What is commonly defined as "translation" may carry very different perspectives, players, intentions, channels and results:

Even as employed in everyday speech, "translation" is more like a canopy under which gather great crowds of phenomena. What has been designated "translation" in

\footnotetext{
363 For the mentioned concepts, see: M. Castells and G. Cardoso, Gustavo, The Network Society: From Knowledge to Policy, Washington DC, Johns Hopkins Center for Transatlantic Relations, 2005/

364 S. Montgomery, Science in Translation: Movements of Knowledge through Cultures and Time, The University of Chicago Press, 2000.

365 Ibid., pp 1-17.

366 Ibid, p. ix.
} 
the strict sense, for example, has involved both oral and written exchange, sometimes simultaneously. It has been performed by individuals, by teams, by groups or entire communities, even by machines. Its materials have included original texts, copied and altered texts, reconstructed and stolen texts, fabricated, falsified, and even imaginary texts. Such texts, moreover, have comprised every conceivable type of prose and poetic document known to human society, as well as songs, tales, memories, and visions. In its methods, meanwhile, translation has indulged in unchecked libertas utilis (utilitarian paraphrase), laboured under the yoke of verbum pro verbo (word-for-word faithfulness), and explored the vast plains between. It has therefore yielded works that have been completely rewritten, beautifully adapted, ideologically reconstituted, or so literally decanted as to be incomprehensible and useless. ${ }^{367}$

The main value of Montgomery's work's is in showing that it is impossible to dissociate language, science and culture. And that the history of knowledge transfer (and here it is possible to read "the history of innovation" or "the history of disclosure"), is determined, in great part, by these linguistic exchanges. An example given in his work is how modern Japanese science developed through a process of translating, in his words, "nativizing"Western science. ${ }^{368}$

This process occurred in stages, according to the mentioned study. The book explains that in the early history of modern scientific development, in Japan, between 1770 and 1850, a great deal of Western science entered Japan via the Dutch language. ${ }^{369}$ After this time, these sources would change to scientific texts in French, German and English, but Dutch was the predominant "entrance door" to Western culture for almost one century. ${ }^{370}$

The example of the Japanese scientific development also illustrates that these exchange-through-translation processes are more complex than they seem to be, and do not simply convey univocal meanings. It is a process of transformation, of creating new meanings and new ways of innovating. Japan (and that brings together the current importance of the Japanese language to access some types of technologies), by "translating" foreign knowledge, became a top innovating culture in its own way.

Montgomery warns for the risk of diminishing the importance of translation in moulding scientific exchange in the present, by enhancing that the presupposition of the universality of science can overshadow our view of the exchanges that are carried nowadays:

The power of translation, including its ability to impose important transformations, has not diminished in the current era, despite the continuing jargonization and standardization of scientific discourse (...) This has to do with

367 Ibid., p. 3.

368 Ibid., pp 189-226.

369 Ibid., p. 227.

370 Ibid., pp. 189-226. 
the deeply embedded belief that, due to the nature of scientific discourse today, its transfer across languages counts as an unimportant literary event, a matter of simply passing coins from one hand to another. This belief has its foundation in another article of faith: the presumed universalism of scientific discourse. ${ }^{371}$

There are some very important points proved by Montgomery's work that should be enhanced in the present study. The first one is the idea that science shapes local languages, forcing them to recreate themselves through new words that represent new discoveries, new inventions, new interpretations of the reality. What is also relevant is that these re-creations are able to cross borders and "invade" other languages and cultures, through a process that cannot be taken as a simple transposition of meaning, but that was described by the mentioned author as a "transubstantiation" of the original meaning, the mother tongue always somehow lacking in both substance and words to translate a discipline. ${ }^{372}$ Anyhow, the transfer is assimilated, provoking philosophical, political and cultural transformations, as an example of science and technical knowledge being absorbed by other fields.

The historical approach of Montgomery's work covers some specific illustrative fragments from the past, moving to the idea of English as scientific lingua franca from the $20^{\text {th }}$ century on, and posing a very important question over how universal science really is. However, in today's times, there is much more to be exploited over the relation between science and translation.

The present work may be taken as one of the possible follow ups of the questions posed by Montgomery over the universality of science. In this context, the current global patent system, whose contemporary configuration was allowed by very recent developments, stands as the central channel of scientific communication, whose predominant vehicle of exchange is not human translation, as it was through all the historical stages shown by Montgomery, but machine translation.

As described in Chapter 1, nowadays, contemporary science cannot be dissociated from technology. At the same time, scientific exchanges are based on a totally different scenario of translation and communication than the ones depicted by Montgomery. What differentiates these scenarios, historically dated as until the end of the $20^{\text {th }}$ century and from the beginning of the $21^{\text {st }}$ century, is, from a general perspective, the advances allowed by information and communication technology and, from a closer view of the patent system, the revolution represented by machine translation.

All technological information is easily accessed in patent expert systems, with a global reach, in multilingual platforms with advanced quality of simultaneous machine translation. The knowledge transfer is conditioned, to a large extent, to what these systems may offer. The language of science is the language of innovation, whose depository is 
represented by patent multilingual databanks and whose main basis of interaction and communication is machine translation.

\subsection{Machine translation, human translation and English as lingua franca in patent systems}

The idea of translating natural languages through computers has faced a great resistance and has been even treated with scorn since it was first proposed, during the 1940s, until today. Today, there is a better acceptance of the idea that translation can be mechanized and even people who don't work directly with languages enjoy the benefits of accessing foreign texts through computer translations. ${ }^{373}$

Believing that translation is an art and that it necessarily implies personal choice, inferring a whole set of elections of values related to the subjectivity of the translator has not been enough to prevent widespread use of machine translation, which, in a certain way, makes from each of us a potential translator, as any user of computer translating systems is able to interact, to different extents, with these systems through a variety of other research instruments and systems.

In this sense, the antecedent education and subjectivity of the user (the same works for translators) will play a role in the best use of these systems. The comments that have been mocking these systems since their first prototypes are still present, but today even many translators benefit from machine translation systems and recognize their importance. In this sense, it is even possible to affirm that a professional translator is the one who makes the best use of machine translation and other translation technologies. ${ }^{374}$ Translators and language experts tend to be more aware of linguistic choices, being able to rebuild a sentence, search for synonyms and care about the clearness of a text message.

A person with linguistic skills will also be able to edit a translated text according to its target public, its level of formality and its jargons or technical terminology, as that requires awareness and research. Therefore, it is possible to affirm that there are many ways of using machine translation and it can improve as well as inspire the work of good translators. ${ }^{375}$

The first machine translation systems were very primitive in terms of vocabulary and quality of their translations. They were created in this atmosphere of scorn and resistance. The first one was developed from a partnership between IBM and the Georgetown University, in 1954. However, MT already counted on sponsors and researchers who believed it was possible to achieve good quality translations with improved computer hardware and developments in linguistic studies, as the ones carried

373 J. Hutchins, 'Machine translation and human translation: in competition or in complementation?', International Journal of Translation, 13, 1-2 Jan-Dec 2001, pp.5-20.

374 Ibid.

375 Ibid. 
out by Chomsky and other linguists. The 1970s showed a more intense development in machine translation, mainly in terms of computer-based tools for translators, operational MT systems, and theoretical research towards the MT methods. ${ }^{376}$

Ulitkin describes methods of measuring the quality of machine translation and shows Google and PROMPT have advanced in reference translations by using n-gram models and other similar metrics. ${ }^{377}$ The correlation with the reference translation has been improved significantly in the last years. According to the same study, the best match refers to the vocabulary level and the worst results happen in terms of grammar, which is related to the size of linguistic data bases and the depth of description of natural languages. It is important to remark that grammatical structures are hard to be described, since a language is a "living" and changeable system. ${ }^{378}$

The best qualities of translation are the ones into/from English, since this language, as one might expect, is a priority for current machine translation, as in the popular Google Translate. Even the patent translations from/into other languages than English are still intermediated by a translation into English. Therefore, there is an undeniable hegemony of the English language when it comes to patent translation. ${ }^{379}$

Machine translation can be both rule-based and based on statistical approaches, and the tendency is that machine translation gets improved by the combination of these two perspectives. ${ }^{380}$ These improvements made machine translation spread to large scale use, and nowadays it is useful in various fields, showing that the results of MT cannot be just considered as poorly translated texts anymore, but a way to accomplish a huge global flow of communication and to help those who already know a language as non-native speakers. $^{381}$

Machine translation has been especially important to multilingual communities, as Canada and Europe, helping to speed the levels of translation production in a way that professional translators wouldn't be able to accomplish. Although the help of machines has increased immensely the speed of production, it cannot be said that machine translation attains publishable quality without a human review. Sometimes, and not rarely for patent documents, it even requires a technical review, also when produced by domainspecific MT systems, as today there are sophisticated translation machines directed at patent translation. ${ }^{382}$

Christensen \& Schjoldager demonstrate that nowadays professional translation requires the use of machines, being no longer a purely human activity. Their study focuses on the influence of translation-memory technology on translators' cognitive processes and

376 See the whole history in detail on Hutchins, op. cit.

$377 \mathrm{~N}$-gram is a sequence of $\mathrm{n}$ items from a given sequence of text or speech, being a concept which belongs to the fields of computational linguistics and probability. See: I. Ulitkin, 'Human Translation vs. Machine Translation: Rise of the Machines'. Translation Journal, 2013. http://translationjournal.net/journal/63mtquality.htm (accessed 15 April 2018).

378 lbid.

379 Ibid.

380 I. Ulitkin, 2013.

381 Hutchins, op. cit.

382 Ibid. 
work-flows. According to them, translators should prepare for an increasingly digitalized future and be able to make the best use of the help of translation-memory technology by defining steps and strategies to follow on this interaction, which is noticeably different from a purely human process. ${ }^{383}$

Full automation does not work for translators, although MT can be seen as an important tool for them. Professional translation requires other sophisticated tools, as translation workstations and translation-memory technology tools. This set of tools facilitates the work of a professional translator without dismissing the intellectual challenges of this activity. It is also possible to assume that MT has its best use for those who have knowledge of both source and target languages. Although MT translation can be useful to speakers who are completely ignorant of either source or target language, they will tend, for obvious reasons, more to a poorer interaction with MT systems. ${ }^{384}$

There is a great variety of tools to support the translation activity, such as: spell checkers, grammar checkers, terminology managers, electronic dictionaries, either unilingual or bilingual, terminology databases, full-text search tools (or indexers), "concordancers" (programs that bring examples of the usage of a word or an expression, such as a bitext or a translation memory), bitext aligners, project management software (that helps to structure complex translation projects), translation memory tools (TM tools) and tools for crowd assisted translation. ${ }^{385}$

Some of the best free translation software packages are listed as: King Translate, Q-Translate, Lang Over, English to French Translator, Lingoes Translator, Babylon, Translation Wizard, Linguatic Dictionatic, Translator, TroDictionary and Advanced Quick Translate. ${ }^{386}$ And some of the best commercial systems are: Babylon (Gold), Power Translator, Prompt, Personal Translator, Systran, IdiomaX, Cute Translator, Word Magic and NeuroTran. Their cost varies from around $€ 200,00$ to $€ 600,000$. . $^{387}$

Another relevant concept to understand the implications of machine translation for communication is the concept of networking. The expansion of global trade has required much faster responses in a multilingual world. New services related to translation come up, as companies offer options that extend to rough translations, translations with the "treatment" of experts, editing and preparation for publication, as well as translations on specific areas, as happens with patent translation. ${ }^{388}$ According to Hutchins:

383 P. Christensen and A. Schjoldager, 'The Impact of Translation-Memory Technology (TM) on Cognitive Processes: Student Translators Retrospective Comments in an Online Questionnaire', in Sharp et al., Human-machine interaction in translation. Proceedings of the $8^{\text {th }}$ NLPCS Workshop, Copenhagen Business School, 2011.

384 Hutchins, op. cit.

385 From Wikipedia, computer assisted translation: https://en.wikipedia.org/wiki/Computer-assisted_translation (accessed 15 April 2018).

386 Source: List of Freeware, http://listoffreeware.com/list-of-best-free-translation-software/ (accessed 15 April 2018).

387 Source:Translation Software Review, Business [Website], http://translation-software-review.toptenreviews.com/_(accessed 15 April 2018).

388 Hutchins, op. cit. 
These services may be joined in the future by various forms of networked 'translation brokerage' services advising customers on the most appropriate human translation agency (as envisaged by O'Hagan 1996) and/or the most suitable MT service for their needs, e.g. in terms of costs, languages, speed, dictionary coverage, terminology control, overall translation quality, postediting support, etc. As a consequence, we may well see the emergence of more specialised MT systems for particular narrow subject domains and for particular language pairs - hopefully more languages than the current emphasis on the major commercial languages of the world (English, French, German, Japanese, Spanish). ${ }^{389}$

MT systems directed to particular narrow subject domains and to particular language pairs have become increasingly important in a global reach. That is the case of patent translation systems, which are nowadays used broadly in patent offices all over the world. These systems are mainly based on translation memory, which, in the case of patent translation, have helped developing more sophisticated translations for general purposes. That happened especially because patent translation is a rich source of translation memory.

As previously described, the scope of patent translation is different from the scope of other translations, presenting some peculiarities. The language used on patent writing is different from the one used on research papers, both in terms of vocabulary and structure. Both papers and patents are very important sources of scientific information, but they require different interpretative approaches and different ways of reading and using them as research sources. The terminology used in patent writing can be considered as more concise and creative than the terminology of research papers. The words and text structure are, of course, distinct, as the text of a patent is more related to a legal audience and has to follow different structure rules than the one of a paper. Patents are written in a way so that they can widen the scope of claims, which means patent translators should also be careful about adapting scholarly terms into patent terms. 390

For facilitating patent writing and translation, there is a variety of techniques, tools and methodologies available, resulting from academic and empirical research. Nanba et al. describe 6 methodologies for "translating" scholarly terms into patent terms and how efficiently they worked for a set of Japanese documents. For that they used synonym extraction techniques, in a study of cross-genre information access. It isn't necessary to enter in detail about this study here because the methods are very specific to Japanese language problems, but it is important to point out that this type of methods should be

389 Ibid.

390 H. Nanba et al., 'Automatic Translation of Scholarly Terms into Patent Terms Using Synonym Extraction Techniques', Irecconf.org/proceedings//rec, 2012, http://www.Irec-conf.org/proceedings/Irec2012/pdf/1043_Paper.pdf (accessed 15 April 2018). 
more explored in developing countries, where patent translation research still finds little support and where many articles are published, but few patents are granted. ${ }^{391}$

The study shows the relevance of cross-genre information retrieval, mentioning tasks such as retrieving patents relevant to a given journal article and using different methods for doing it, such as "Term Distillation", which focus on the distribution of the frequency of a word, that can show noticeable differences in distinct databases. ${ }^{392}$

A research paper is, obviously, very different from a patent in terms of text structure, as it also denotes different aims and readers. A paper, being a result of a scientific research based on a research question should contain, in essence, the following parts: abstract, introduction, method, results, discussion and conclusions. These parts are meant to describe the whole process of the research, followed by its conclusions and recommendations for further research on the same object. ${ }^{393}$ Therefore, it can be considered as extensive writing, where the researcher builds upon his discussion and refers to the findings of the research to other researchers and to the world at large. ${ }^{394}$

A patent application is a remarkably difficult legal document to write and translate with accuracy. There are also many forms and procedures to fill in and carry out for a patent application. The text of a patent is neither easy to write nor to read and can be considered as much more technical and fixed than the text of a paper, the last one giving its writer more freedom and flexibility. A patent is normally divided into the following sections: reference list summary page, drawing set, background of the invention, brief summary of the invention, brief description of the drawings, detailed description of the invention, claim set, prior art references and representative drawing. ${ }^{395}$

The summary page should include a patent number - used to identify the patent, the name(s) of inventor(s); a serial number, which is a unique number assigned to every patent application; an abstract, which indicates the general nature and essence of the patent's subject matter; the prior art references, that show all references considered by the patent office; and the representative drawing, an illustrated embodiment of the claimed invention. ${ }^{396}$

394 Based on the EPO's official guidelines for applicants. EPO's official guidelines for applicants, July 2017, 17th edition, http:// www.epo.org/applying/european/Guide-for-applicants/html/e/index.html (accessed 15 April 2018). See also 'Patent Samples', OC Patent Lawyer [website], https://ocpatentlawyer.com/patent-samples/ (accessed 15 April 2018). 


\section{Figure 15: Front page or summary page of a patent of a bicycle rear suspension, containing the patent number, the name of the inventor; the serial number, the abstract; prior art references and a representative drawing}

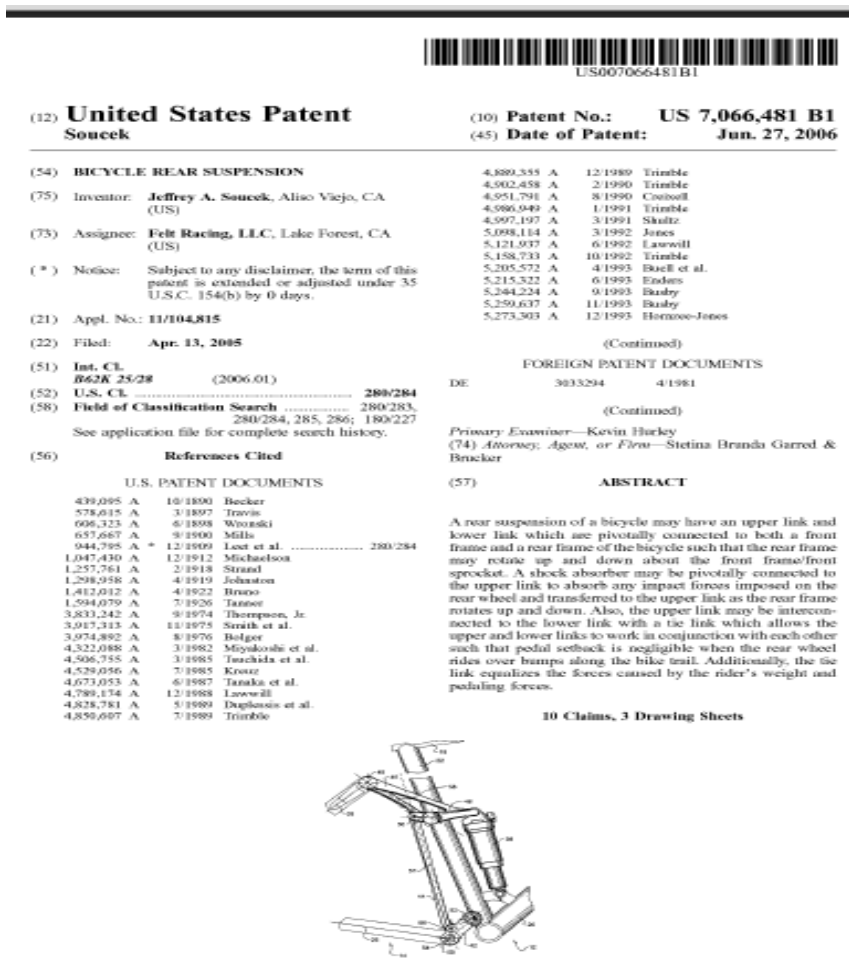

Source: OC Patent Lawyer [website] ${ }^{397}$

The drawing set aims to illustrate the invention and facilitate understanding of it. The written text of the patent application makes associations with the features of the invention relating them to the drawing set by reference numeral. The drawings also illustrate the claimed elements. The background, which is part of the invention section of the patent document, should describe the general nature of the problem to be solved by the invention and the state of art of the existing technology. ${ }^{398}$

In the case of the sample patent shown in figure 15, the background describes the solution of the problem brought by the invention, a bicycle rear suspension. The invention relates to a bicycle rear suspension system. The background of the patent document informs that the invention is thought suitable for mountain bikes. As this type of bike is designed to be ridden over dirt trails, a rear gear helps reducing sudden jolts in the pedals,

397 'Anatomy of a patent document', OC Patent Lawyer [Website], hittps://ocpatentlawyer.com/anatomy-of-a-patentdocument/ (accessed 12 November 2018). 
handlebar and seat of the bike caused by gravel, dirt, leaves, uneven terrain, boulders and elements which are common in dirt trails. ${ }^{399}$

The brief summary of the invention section is meant to provide a summarized version of the detailed description of the invention. The brief description of the drawing shows all figures, which are essential to illustrate the invention. The detailed description of the invention depicts the invention in detail. It is meant to enable a technician with ordinary skill in the art to practice the invention without much experimentation. This requirement ensures the disclosure of the invention, so that the public is able to use the invention after the patent's term expires. ${ }^{400}$

The claim set section defines the scope of patent protection allowed within the limits that the invention can reach. It is positioned at the back of the patent document. The claim section normally starts with a phrase such as "I Claim,"“"We Claim" or "What is claimed is." This section must distinguish the subject matter which the inventor claims as his/her invention. It defines the object of protection itself. There are some rules about how to write it, such as the one mentioned above of using the word "claim". It is also necessary to identify technical features of the invention associating them with the reference numbers of the drawings. ${ }^{401}$

It would be possible to extend these examples ad infinitum, enumerating the enormous set of technical rules for patent writing. What is important is that the thoroughly technical structure of the patent document enables machine translation to present satisfactory results in terms of patent translation. Papers are full of metaphors and present a much more sprawling and abstract textual structure. A paper does not follow such a rigid form or compromise with text structure. It leaves its writer partially free to produce his text. Some papers are even very flexible in terms of using "non-recommended" style for scientific production, showing a more subjective or informal structure. Therefore, the association between patents and machine translation, because of the very structure of patent texts, became so important and fruitful.

As commented before, patents can also be considered as a rich source of translation memory. In 2011, the European Patent Office (EPO) and Google developed a partnership after signing a long-term agreement to collaborate on machine translation of patents into multiple languages. The agreement determined that the EPO could use Google Translate technology to offer translation of patents on its website into 28 European languages, and also into Chinese, Japanese, Korean and Russian. The EPO, in its part, provided Google access to its files of translated patents. As patent translations extend to a broad range of technical and scientific text and, in general, present reasonable quality, the partnership enabled Google to improve considerably its machine translation 
technology for the languages used in patent registrations. It is important to clear up that the agreement was non-exclusive, with no financial elements involved. ${ }^{402}$

The result is the translation machine of the EPO, called Patent Translate, which became more and more efficient in terms of giving reliable results of patent information in all these 31 languages and is continuously improving in order to offer even more dependable translations. Currently, the only official European languages that are not served by Patent Translate are Irish and Maltese, as described by Figure 16 below.

Patent translate offers translation service for the three main parts of a patent: the abstract, the descriptions and the claims. It also offers some functionalities that can be useful for researchers. It is possible to select the part for which translation is wanted and then select the target language for having it translated by clicking once in the "translate" button. If the source text is in English, it is possible to have it translated into one of the 31 covered languages. Texts that are neither in English or in one of the other official languages are translated into English only, in the case of Chinese Patents, for example; into all the other languages, in the case of a source text in German, French or English; and into the official languages of the EPO (German, French and English), when the original text is, for example, in Portuguese. Once the researcher accesses the translation, he can mouse-over to compare with the original text sentence by sentence. He can also change the target language very easily by clicking on the language buttons (when these languages are available) on the right side of the screen. Patent translate leaves a note that is worth reproducing: machine translation cannot provide legally binding translations, but it can give you the gist of a text, which can help you to determine whether it is relevant. ${ }^{403}$

402 See EPO's news in 2011 on EPO's Official Website: http://www.epo.org/news-issues/news/2011/20110324.html (accessed 15 April 2018).

403 Espacenet. Patent search page. https://worldwide.espacenet.com/help?locale=en EP\&method=handleHelpTopic\&topic=translation 
Figure 16: The official languages of the EU and EPO states and their coverage within Patent Translate

\begin{tabular}{|c|c|c|c|c|c|}
\hline Country & EU member stane? & EPO member state? & Officlal language(s)" & Othclal languge in EU? & Available in Panemt translane to/from English \\
\hline Nhbonia & $\mathrm{N}$ & $\mathrm{Y}$ & Albunian & $\mathrm{N}$ & $\mathrm{Y}$ \\
\hline \multirow{3}{*}{$\begin{array}{l}\text { Austria } \\
\text { Betgium }\end{array}$} & $\mathbf{Y}$ & $\mathbf{Y}$ & German & $\mathbf{Y}$ & Y \\
\hline & & $\mathbf{Y}$ & Durch & $\mathbf{\gamma}$ & $\mathbf{y}$ \\
\hline & & & French & $\mathbf{Y}$ & $\mathbf{Y}$ \\
\hline Bulfarla & Y & $\mathbf{Y}$ & Bulparian & $\begin{array}{l}\mathbf{z} \\
\mathbf{z}\end{array}$ & 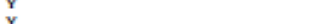 \\
\hline & & & & $\begin{array}{l}\text { X } \\
\end{array}$ & \\
\hline \multirow{2}{*}{ Cyprus } & $\mathbf{Y}$ & $\mathbf{Y}$ & Croarian & $\mathbf{Y}$ & $\mathbf{Y}$ \\
\hline & $\mathbf{Y}$ & $\mathbf{Y}$ & $\begin{array}{l}\text { Greek } \\
\text { Turkish }\end{array}$ & Y & 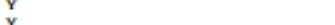 \\
\hline Crech Republic & $\mathrm{Y}$ & 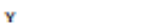 & Caech & Y & Y \\
\hline Denmark & $\mathbf{Y}$ & $\mathbf{Y}$ & Danish & $\mathbf{Y}$ & $\mathbf{Y}$ \\
\hline \multirow[b]{2}{*}{ Finland } & & Y & Estomanan & $\gamma$ & Y \\
\hline & $\mathbf{Y}$ & $\mathbf{Y}$ & $\begin{array}{c}\text { Finnish } \\
\text { Swertish }\end{array}$ & $\mathbf{Y}$ & $\begin{array}{l}\mathbf{y} \\
\mathbf{y}\end{array}$ \\
\hline France & 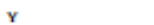 & $\mathbf{Y}$ & $\begin{array}{l}\text { Swench } \\
\text { Frenth }\end{array}$ & $\mathbf{Y}$ & $\begin{array}{l}\mathbf{y} \\
\mathbf{y}\end{array}$ \\
\hline Cermany & $\mathbf{Y}$ & $\mathbf{Y}$ & German & $\mathbf{Y}$ & $y$ \\
\hline Greeces & $\dot{\mathbf{y}}$ & $\dot{\mathbf{Y}}$ & Greek & $\dot{\gamma}$ & $\mathbf{Y}$ \\
\hline Hungary & $\mathrm{Y}$ & $\stackrel{Y}{Y}$ & Hungarian & Y & $\mathrm{Y}$ \\
\hline \multirow{2}{*}{ Ireland } & $\mathrm{Y}$ & $\mathrm{Y}$ & $\begin{array}{l}\text { leclandic } \\
\text { English }\end{array}$ & $\underset{\gamma}{N}$ & $\begin{array}{l}\mathrm{Y} \\
\mathrm{n} \mathrm{f}_{\mathrm{a}}\end{array}$ \\
\hline & & & urish & $\underset{\mathbf{Y}}{\mathbf{Y}}$ & $\operatorname{nom}_{N}$ \\
\hline Italy & $\mathbf{Y}$ & $\mathbf{Y}$ & Irakan & $\gamma$ & y \\
\hline Lanva & $\mathrm{Y}$ & $\mathbf{Y}$ & Larvian & $\mathbf{Y}$ & $\mathbf{Y}$ \\
\hline Liechnenstein & $\mathbf{N}$ & $\mathbf{Y}$ & German & $\mathbf{Y}$ & $\mathbf{Y}$ \\
\hline Lithaania & $\mathrm{Y}$ & $\mathbf{Y}$ & Lithuankan & $\mathbf{Y}$ & $\mathbf{Y}$ \\
\hline \multirow[t]{2}{*}{ Lxxemboury } & Y & 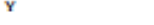 & French & 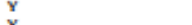 & $\begin{array}{r}\mathbf{Y} \\
\mathrm{Y}\end{array}$ \\
\hline & & & $\begin{array}{l}\text { German } \\
\text { Luxembourgish }\end{array}$ & Y & $\begin{array}{l}\mathrm{Y} \\
\mathrm{N}\end{array}$ \\
\hline Maxedonia & $\mathbf{N}$ & $\mathbf{Y}$ & Macedonian & $\mathrm{N}$ & $\begin{array}{l}\mathrm{Y} \\
\mathrm{Y}\end{array}$ \\
\hline \multirow{2}{*}{$\begin{array}{l}\text { Malta } \\
\text { Mand }\end{array}$} & $\mathbf{Y}$ & $\mathbf{Y}$ & English & Y & $\mathrm{n} / \mathrm{f}$ \\
\hline & & & Maltrese & $Y$ & $\mathrm{~N}$ \\
\hline Monaco & $\mathrm{N}$ & $\mathbf{Y}$ & French & 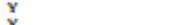 & $\begin{array}{r}\mathbf{Y} \\
\mathbf{Y}\end{array}$ \\
\hline $\begin{array}{l}\text { Nethertands } \\
\text { Nerway }\end{array}$ & & & Douch & y & \\
\hline $\begin{array}{l}\text { Notwayn } \\
\text { Poland }\end{array}$ & $\mathrm{Y}$ & Y & Polish & Y & Y \\
\hline Portupel & $\mathbf{Y}$ & $\mathbf{Y}$ & Portuguese & $\mathbf{Y}$ & $\mathbf{Y}$ \\
\hline Romania & & $\mathbf{Y}$ & Sominian & $\bar{y}$ & $\mathbf{Y}$ \\
\hline San Marino & $\mathrm{N}$ & $\mathbf{Y}$ & Itavian & Y & $\mathbf{Y}$ \\
\hline Sertia & $\underset{\mathrm{Y}}{\mathrm{N}}$ & $\begin{array}{l}\mathrm{Y} \\
\mathrm{Y}\end{array}$ & Sertian & $\underset{y}{N}$ & $\begin{array}{l}\mathbf{Y} \\
\mathbf{Y}\end{array}$ \\
\hline Slovenia & Y & $\begin{array}{l}\mathbf{Y} \\
\mathbf{Y}\end{array}$ & $\begin{array}{l}\text { Sllovaxizian } \\
\text { Sloven }\end{array}$ & $\mathbf{Y}$ & $\begin{array}{r}\mathbf{Y} \\
\mathrm{y}\end{array}$ \\
\hline & & & Spanish & & \\
\hline sweden & $\mathrm{Y}$ & $\mathbf{Y}$ & Swedish & $\gamma$ & $\mathbf{Y}$ \\
\hline \multirow[t]{4}{*}{ Switzertand } & $\mathrm{N}$ & $\mathbf{Y}$ & French & $\mathbf{Y}$ & $\mathbf{y}$ \\
\hline & & & German & $\gamma$ & $\mathbf{y}$ \\
\hline & & & Itrăan & $\mathbf{y}$ & $\mathbf{Y}$ \\
\hline & & & Bomansch & & $\mathbf{N}$ \\
\hline Turkey & & & Turkisht & $\mathbf{N}$ & Y \\
\hline $\begin{array}{l}\text { Uninted Kangdom } \\
\text { TOTMS }\end{array}$ & $\begin{array}{l}Y \\
z s\end{array}$ & $\begin{array}{l}Y \\
38\end{array}$ & $\begin{array}{l}\text { English } \\
32\end{array}$ & $\begin{array}{l}Y \\
24\end{array}$ & 祭2 \\
\hline
\end{tabular}

Souce: Adams (2016) ${ }^{404}$

As said, machine translation is not meant only for translators. It has become an important means of support to information and communication in various fields, and that is not different in the areas of science and technology and intellectual property, as it has a very productive use in the patent's world, overall. The use of machine translation became widespread in patent offices, especially because it is impossible to hire translators with technical expertise in all areas of a patent office, and patent examination increasingly requires speed and efficiency. Machine translation - used together with other research tools - has proved to be sufficient for patent examiners, since English is the only required second language in many of the offices. Besides, according to examiners from different parts of the world, before the advent of machine translation, the search for prior art was practically limited to national documents. ${ }^{405}$

404 S. Adams, 'Lost in translation? A review of the post-grant requirements for translation of patent specifications in Europe', World Patent Information, 44, pp.34-45, 2016.

405 Information obtained during interview 1, 2, 3 and 8 with patent examiners at INPI (Brazil). 
Brazilian patent examiners affirm they use English $90 \%$ of their time in their examining activity. For them, language barriers are not a problem in the process of examining, as they can easily search for the information required through patent families and through the use of machine translation tools provided by other Offices, as is the case of the Japanese Patent Office (JPO) or the Korean Intellectual Property Office (KIPO). These are languages which differ considerably from Portuguese in terms of roots and structure, and machine translation still seems to be sufficient for mediating the communication during the process of examination. ${ }^{406}$

The statements of the examiners bring another important discussion: the one that concerns English as lingua franca (or ELF) for the patent system. In this regard, it is possible to presume that machine translation tends to unsubscribe to the ideas of ELF being practical, less costly and universal, presenting a fairer alternative to it, when it is not possible or desirable to use ELF.

In this case, machine translation will serve a much broader range of languages and may encourage professionals to learn a little of these languages when their work demands a constant contact with them. For those cases, machine translation will always be somehow supported by human assistance or elucidation, even when the knowledge of its user about the target language is very small. In this sense, machine translation and human translation do not compete, but complement each other, and can work as an alternative to ELF as the only or best means of multilingual communication. But it still does not reduce the preference for ELF in various scenarios and situations.

There are many arguments for and against the usage of English as lingua franca in fields as internationalized as intellectual property, as a specific subject domain, especially in terms of a patent global system and in the set of treaties and agreements that regulate it. Patents involve great sums of investment and a complex global flow of multilingual communication, including frequent and concomitant machine and human translation.

The experts who assert the superiority of a monolingual regime see in it a great advantage in terms of a practical and easy solution to multilingualism. In fact, ELF can imply a reasonable reduction of costs with translation services and facilitate communication among players, as a multilingual group of people interested in the same object will obviously find it much easier to communicate in one common language, which will help them overcome their language barriers and find a common way to communicate. ${ }^{407}$

However, the ones who do not support ELF as an appropriate answer to multilingualism claim that ELF, from a language policy perspective, damages linguistic rights, as it privileges a language that has its own native speakers, giving it economic hegemony. They also argue that adopting ELF does not imply a cost reduction to a multilingual community, as it may shift the costs towards citizens whose mother tongue

406 Information obtained during interviews 1, 2, 3 and 8 with patent examiners at INPI (Brazil).

407 A. Firth, 'The Discursive Accomplishment of Normality: on 'Lingua Franca' English and Conversation Analysis', Journal of Pragmatics, vol. 26. no 2, 2006, pp.237-59. 
is not the same as lingua franca, defending translation and interpreting, although not free, may result in more equitable and reasonable costs. ${ }^{408}$

Multilingual communities raise important issues on translation. One of the most important discussions over the European integration refers to multilingual communication, especially on how the European Union institutions can deal with language diversity. In this sense, it is important to develop studies assessing the quality of language regimes not in absolute terms, but rather in terms of their consistency with the actors' goals, which define what we call a 'scenario'. 409

Gazzola discusses the language regimes in the European Union and the implication of assuming full multilingualism in Europe, proved by the fact that the Union working languages started as 11 and grew to 20, until today, therefore valuing multilingualism as a general principle of the community. For him, what could be interpreted as a senseless tolerance towards languages with a smaller number of speakers or less economic importance (he called them 'small' languages, ironically) and an irrational choice can be seen as related to a highly complex political question. ${ }^{410}$

Gazzola justifies this point of view by showing that languages fulfil different, inseparable functions, such as a communicative function, used for the transmission of information in a broad sense, and a symbolic function, connected with cultural and political behaviour, as with the sense of national identity. Hence, the solutions adopted by the European Union in terms of language and translation embody its compromise with different and opposing visions about multilingualism management. ${ }^{411}$

It is not possible to affirm, in absolute terms, that a specific language regime is recommended or not. The same way, it is not possible to precisely assess the costs of a given language and translation to specific patent systems. Therefore, a researcher will never be able to find universal principles that can function in any patent system in all times involving communication and translation. In this area, the solutions should be punctual and changeable, when necessary.

Gazzola gives the example of language and translation costs, that should not be evaluated in absolute terms, as it can be said, a language regime is expensive or not within a certain context. For instance, choosing ELF as the only communication alternative in a certain community may favour English speaking countries when it comes to representation in the community's courts. At the same time, the same choice may, for example, favour the whole community so considerably, in terms of economic returns, that it must be worth accepting the difficulties in adopting other official languages. ${ }^{412}$

408 M. Gazzola, 'Is ELF more Effective and Fair than Translation? An Evaluation of the EU's Multilingual Regime', International Journal of Applied Linguistics, vol. 23, no 1, 2013.

409 M. Gazzola, 'Managing multilingualism in the European Union: language policy evaluation for the European Parliament'. Language Policy, 2006a.

410 Ibid.

411 lbid.

412 Ibid. 
For that reason, it is better to consider that assessing a given language regime depends on a whole framework on which it will be based and on a whole set of criteria, that should be tested and made more flexible, additionally requiring periodical reevaluation. It is also very important to consider whether it is too expensive with respect to actors' goals, discussing the expected results for the community itself and for its members separately and finding ways to compensate eventual losses. ${ }^{413}$

Still according to Gazzola, it is impossible to find a unique ideal language regime to a multilingual community such as the European Union. It is preferable to follow a methodology that assesses different possible scenarios, in terms of public policy in a given community. In these scenarios, it is important to define actors' goals and different possible solutions in terms of language policy. Within a given scenario, it is easier to evaluate which language regimes, seen as a particular type of language policy, are best suited to comply with these goals, taking into account both (communicative and symbolical) dimensions of language. ${ }^{414}$

That is certainly valid for different patent systems. In the case of the present research, a natural follow up was the comparison of the scenarios of national patent systems. On this matter, Chapter 8 presents recommendations to patent offices related to their language regimes. Gazzola's study shows how useful it is to compare the advantages and the drawbacks of language regimes within different scenarios, in order to assess which models are the most appropriate to meet the actors' objectives. ${ }^{415}$ Likewise, asking what the actors' objectives are in different contexts is fundamental to adapt language policies for improving patent systems.

Keeping a fair vision of the phenomenon of multilingualism does not necessarily dismiss the idea of ELF. In terms of patent systems, it is important to affirm that multilingualism cannot totally replace ELF. That brings the idea that, contrary to what many supporters of multilingualism think, ELF can complement a multilingual regime. It is important to add that using ELF is unavoidable in certain scenarios, which happens in the case of the ones related to the patent system. It is natural that English will be the most used language in the examination of new inventions, in scientific analysis or in the process of understanding a new technology. It is also natural that the variation of English used for this purpose has different features than, for example, native, spoken English. ${ }^{416}$

ELF supporters have developed studies that show that ELF implies different behaviour in conversation than native English. By using these studies, they try to prove that ELF could be considered as different than English in its use by native speakers. In this 
regard, ELF can be interpreted as a business or scientific language, a language that is used to mediate communication among foreigners. It is considered as a multilingual way of using English that has developed a whole new structure different from the practices and representations of native speakers. For these researchers ELF does not bring a threat to linguistic diversity or to fairness in terms of linguistic rights. ${ }^{417}$

When it comes to the patent system and to the daily routine of patent examiners in national patent offices, ELF could not be more disseminated. It became a natural intermediate language, as most of the texts are accessed in English. A patent examiner normally uses documents belonging to patent families (mostly in English) for facilitating the prior art search. For examiners who speak other languages besides their native tongues and English, these texts can be accessed in these second languages, but it is more common to either access the texts in English or to access them through a machine translation into English (some patent offices, such as JPO, provide that). In Brazil, patent examiners claim $80 \%$ of the texts they access are in English. ${ }^{418}$

Concerning the adoption of ELF as a solution to integrate patent systems, an important Case is the one filed by Spain against the European Council, analysed in Section 6.2.3 of this dissertation. Action C-147/13, filed by Spain against the European Council before the CJEU, questioned the language and translation regime of the regulations for implementing a community patent and an associated Unitary Patent Court in Europe. ${ }^{419}$ The Actions sought annulment of the Unitary Patent Regulation and the associated translation Regulation, claiming that the language regime of the unitary system is contrary to the European Union language regime. ${ }^{420}$ The complaint was related to the maintenance of the trilingual regime of the EPO as the language regime of the unitary patent. Spain alleged violation of the principle of non-discrimination by the language arrangements established in Regulation 1260/12. On the basis of the Opinion of the Advocate General, the action was dismissed by the Court. ${ }^{421}$ As a consequence, Spain did not sign the Agreement for the enhanced patent cooperation. After a complete description of the case, Section 6.2.3 of this dissertation discusses the possibility of adopting ELF as a solution to the language and translation controversy claimed by the mentioned Action and associated with such agreements.

Along the same lines, accepting and adopting ELF also in developing countries can be a matter of economic survival. A country's linguistic resistance leads to a position of isolation from the global system. International Conferences, research and intellectual

417 Ibid.

418 Information given directly by patent examiners.

419 See: Judgement of 5 May 2015, Spain vs Council, C-147/13, ECLI:EU:C:2015:299, 5 May 2015, http://curia.europa.eu/juris/document/document.jsf?text=\&docid=164093\&pagelndex= 0\&doclang=EN\&mode=Ist\&dir=\&occ=first\&part=1\&cid=4884012 (accessed 25 November 2018); Opinion of Advocate General Bot, delivered on 18 November 2014, Case C-147/13, ECLI:EU:C:2014:2380, http://curia.europa.eu/juris/document/ document.jsf?text=\&docid=159763\&pageIndex=0\&doclang=EN\&mode=Ist\&dir=\&occ=first\&part=1\&cid=2838 (accessed 26 November 2018).

420 Ibid.

421 Ibid. 
production becomes limited to its boundaries. There are examples of countries where a small part of the population masters English and the scientific interests are, in general, local. That makes the scope of readings and scientific researches in some fields lack reasonable levels of novelty or end up being weakly elaborated - as scientific research requires global investigation, necessarily involving the knowledge of (at least) English as a second language. That also perpetuates a resistance to self-criticism related to an ideological position that claims affirming independence means despising foreign models and concentrating on local solutions. ${ }^{422}$

These positions become more problematic when it comes to patent law, since it is an internationalized field of law, requiring the ability of intense global networking - which becomes impossible with poor communication in foreign languages. The awareness of the advantages of English as a lingua franca is an important step for a more realistic view of the patent scenario.

It is also relevant to remember that different languages represent different systems, and, in this context, the idea of system is again important for understanding the process of communication and translation. In turn, the patent system, as a communication system, and a system that can be considered as a sub-system both of the legal system and the innovation system, requires specific rules and codes of communication, highly associated with its internal coherence and integrity.

Professional examiners learn how to deal with these codes in a multilingual communication process, in which English is the dominant language. Although these professionals are not translators, they deal with a kind of (at least instrumental) translation process very frequently, and normally in a way a standard professional translator wouldn't be able to, as patents require specific knowledge in separate scientific fields. That makes their profession uniquely demanding, also turning the patent system into a very rich scenario for language studies.

\subsection{A technical text is a text}

Technical texts are commonly taken as purely informative and objective. Another frequent approach assumes that technical translation is a homogeneous type or genre of translation in which texts are devoid of expressive features, polysemy or figures of speech, consisting of impersonal pieces of communication in different scientific fields, whose main difference is the technical vocabulary used in each.

However, there are studies that prove that technical texts are not only concerned with the transfer of facts, but, like other texts, with complex meaning. Depending on the

422 This is the position assumed by this author on the basis of the content analysis and interviews. The interviewees naturally compared different patent systems in terms of their levels of administrative efficiency and legal certainty. Language can be pointed as a main factor in defining those levels. 
type of technical text various communicative purposes can interact in different levels. In this sense, expressivity and creativity are not associated only with literary texts, which are not necessarily the most "difficult" ones or the ones which present the hardest challenges in translation. Technical translation can, in many ways, present examples of the expressive function. It can also convey challenges that are very hard to be solved by their translators. Therefore, it is important to remember that technical texts should not be considered as a genre, because other different genres may use technical language. ${ }^{423}$

That becomes clear when patent translation is compared with general legal translation (also with texts related to other forms of intellectual property rights). Both are considered technical translation but are radically different in terms of their challenges and characteristics, as shown in section 2.5 . Therefore, it is very relevant to clearly classify the types of translations that are related to the patent system, which are basically: I. Legal translation: translation of treaties, norms and other types of regulations (level of justification); translation of previous legal procedures, decisions and case law contracts and other official documents (level of application); II. Scientific translation: translation of patents, papers or other scientific documents; III. Other types of communication and documents (e.g. exchanged e-mails that can prove the infringement of a patent). Therefore, when it comes to patent systems, each type of document or regulation deserves a specific approach. Nevertheless, what these different types of technical texts have in common is the fact that translators should be aware they are dealing with two or more different (communicative and symbolic) systems. ${ }^{424}$

There are some frequent obstacles found in technical texts, which tend to be even more common in legal translation. Parent's study investigates the aspects of incongruity and ambiguity in the translation of international treaties. Incongruity happens when a concept exists in one system, but not in another one. An example is a legal concept that may exist in a national law system, as one of the source languages, when a translation is needed, but not in another one, that could be the one of the target languages. It can result, for example, from the differences between civil and common law systems or from cultural differences. There is an abundance of terms in the field of intellectual property that are difficult to translate into Portuguese. The term "disclosure", when referring to patent disclosure, does not find an accurate translation in Portuguese, for instance. ${ }^{425}$

Different from incongruity, ambiguity consists of an uncertainty of meaning or intention, as in the example of a contractual term in a sales contract that could use the words "buyer" and "seller", but could also use the term "purchaser". The last one would

423 K. Zethsen, The Dogmas of Technical Translation: Are They Still Valid? Hermes, no 23, 1999, https://tidsskrift.dk/her/article/ view/25549 (accessed 15 April 2018).

424 These conclusions are mainly the fruit of the empirical analysis carried out on this research, combined with the review of associated literature. From the literature review, it is important to highlight the approach of Fromer about the different layers of a technical document and an analysis of Fromer's research in Section 5.1. See J. Fromer, 'Patent Disclosure', 94 IOWA L. Rev. 539, 606, 2009, pp. 544-560, file:///C:/Users/Lenovo/Downloads/JeanneCFromerPatentDisclo.pdf (accessed 15 April 2018). The work of Montgomery (2000) also deserves attention, in the sense that it proves the formative relevance of translation to scientific development.

425 A. 'Parent, On Ambiguity and Incongruity of Terms in Translations of International Treaties, Vertimo Studijos', Vol. 2, 2009. 
create an ambiguous meaning. This ambiguity couldn't be preserved in many Latin languages, giving Portuguese as an example, as the term "purchaser" does not exist in this language, forcing the translator to use "seller" and "buyer". Thus, again there would be an incongruity led by the impossibility of maintaining an ambiguity. ${ }^{426}$

An example that should illustrate both ambiguity and incongruity was on the translation of Article 53b of the European Patent Convention from English, its original language, into German. The original text prescribes that European patents shall not be granted in respect of: (b) plant or animal varieties or essentially biological processes for the production of plants or animals; this provision shall not apply to microbiological processes or the products thereof. ${ }^{427}$

The German version of the European Patent Convention (EPC) has modified its meaning by replacing the term Tierarten (animal species) to Tierrassen (animal breeds), since the first term had a narrower meaning than the English term "animal varieties", as the first one created interpretation problems, since both English and German are official languages of the EPC. The term "animal varieties", as well as the French term "races animales" refer only to all animal species, whilst the German term "Tierarten" refers to subspecies. Thus, through this interpretation, for example, patents for animals produced by a microbiological process can be granted, although this term is not defined in the EPC. It is important to note that animal species in scientific language mean a subdivision of the races. ${ }^{428}$

Forbidding patents for animals could mean an excessive restriction. Although the expression "race animale" (Article 4 of the Directive of the European Biotechnology 44/98/ EC) ${ }^{429}$ is inaccurate, it admits the patentability of animals obtained by non-essentially biological processes. Patents relating to animals can be granted if they are not technically confined to a particular animal variety. However, the European Directive 98/44/EC allows the possibility of rejecting animal patents when this is contrary to public policy and ethical aspects. ${ }^{430}$

In fact, incongruity, represented by the absence of a term having the exact meaning or at least a very close one in the target language will be the most common problem found in technical translations. ${ }^{431}$ In this case, the first solution found resulted in problems of misinterpretation, which, in international law, can lead to far-reaching

426 Ibid.

427 EPO, Guidelines for Examination, 5.4.2 Essentially biological processes for the production of plants or animals, https:// www.epo.org/law-practice/legal-texts/html/guidelines/e/g_ii_5_4_2.htm (accessed 15 April 2018). See also: A. Abrantes, Problemas de tradução em acordos internacionais, Notícias em Patentes [website], 2015, http://patentescomentarios. blogspot.nl/2015/08/ (accessed 15 April 2018).

428 See: EPC, Article 53, Exceptions to patentability, http://www.epo.org/law-practice/legal-texts/html/epc/1973/e/ar53.html (accessed 15 April 2018). See also W. Cornish and D. Llewelyn, Intellectual property: patents, copyright, trademarks and allied rights, London, Sweet\&Maxwell, 2007, p. 228; See EPO, 1.1. Amendments made to Article 53 EPC as part of the EPC 2000 revision, Case Law of the Boards of Appeal of the European Patent Office, Sixth Edition, July 2010, p. 44 http://www.epo.org/ law-practice/case-law-appeals/case-law.html (accessed 15 April 2018).

429 Directive 98/44/EC of the European Biotechnology, http://eur-lex.europa.eu/legal-content/EN/TXT/ PDF/?uri=CELEX:31998L0044\&from=EN and available in Portuguese at http://eur-lex.europa.eu/legal-content/PT/TXT/ PDF/?uri=CELEX:31998L0044\& (accessed 15 April 2018).

430 F. Pollaud-Dulian, Propriété intellectuelle. La propriété industrielle, Economica, Paris, 2011, p.156, cited in A. Abrantes, 2015.

431 A. Patent, 2009. 
consequences. Although there is no such a thing as a perfect translation, a translated text can be improved in finding more appropriate terms or sentences to describe a certain object, as was the case of the German translation of the EPC.

The Uruguay Round lasted from 1986 to 1994 and is given as example of how ambiguity may be a crucial aspect in international debates and in the approval of international agreements. In 1999, thirty of the participating countries issued a statement claiming 'clearer and more precise rules' as a basis for the multilateral trading system', until the Round finally reached to its Final Act. ${ }^{432}$

The need to clear up these ambiguities was especially relevant to developing countries, which asked for lighter commitments and longer periods for adapting to the new treaty. These concessions were called 'special and differential treatment', which is also a vague and ambiguous term in itself and so did not truly represent a firm obligation on any of the interested parties. Parent perceives that when the 'demandeurs' are represented by developed countries they are more successful in obtaining precise concessions from vaguely formulated provisions. ${ }^{433}$

Montgomery observes that the presumed homogeneity of the current scientific discourse is a fallacy. He defends the notion that translation still plays a strong formative role in scientific development through knowledge transfer. ${ }^{434}$ He then gives examples of texts about mathematics, which are frequently seen as the extreme case of universal expression in science ${ }^{435}$, showing that these texts are as vulnerable to the difficulties of translation as other scientific texts. He also shows that mathematics, as any other science, will necessarily be subject to translational change and deformity when its texts are translated into other languages.

Another very important contribution of Montgomery to the discussion involving language and translation, that may be central to the debate about the role of translation in the patent system, is related to the idea of English as lingua franca in contemporary science. Montgomery argues against the indication of English as science's international speech, if this idea is taken as a simple solution to understand contemporary scientific communication. The first argument against the idea of a miraculous universal language that solved (or could solve) the problem of scientific communication is the fact that scientists don't speak the same English, so it does not make sense to speak of a "world English", or a lingua franca without considering the varieties of English used for scientific purposes, either with native accents or as a second language to speakers of many other languages. The same way English "invaded" the scope and use of other languages, being the new Latin of science, it "is invaded" by them through the vast variations in its use, which makes the flow of contemporary scientific communication more complex than it may seem. ${ }^{436}$

432 Parent, 2009.

433 Ibid.

434 Montgomery, 2000, pp. 253-271.

435 Montgomery, 2000, pp. 254.

436 Montgomery, op. cit., pp. 256-263. 
Montgomery also observes that different technical fields have favoured English in different levels, as, for example, works on chemistry and mathematics tend to use more the local languages than English, contrary to engineering, physics and biology. He also points to different sets of terminology in different varieties of English, among other factors belonging to distinct cultural and scientific realities. ${ }^{437}$

\subsection{Patent writing and patent translation}

There are many works on "how to write a patent" or how to elaborate the patent text for a patent application. Most of these works, which include books, manuals and articles on webpages, aim to help applicants to increase the chances for having their patents granted and "legally successful". 438 These works frequently contain examples of drafting lists and models of accurate writing of abstracts, claims and descriptions. They also normally bring examples of correct text structure, consistent terminology and clarity in responding to the criteria of novelty, inventive step and industrial application. There are works of this type directed to particular scientific or technological areas, such as "Writing chemistry patents", or "How to write a software patent", or to different personal intentions, as "Patent it yourself" or "How to write successful patent applications". There are also works focusing on parts of the patent text, "How to write a patent claim" or to different scopes of protection, as "How to write a process patent". There are even works focusing on different geographical scopes of protection, as "Patent application guide USPTO"439

All these works have in common the fact that they present the task of writing a patent as a very complex duty, which not only requires technical knowledge and a capacity to explain the content of an invention, but also demands adapting the text to specific language rules. In this regard, these works clearly show that the success in having a patent granted and avoiding opposition and disputes depends, to a certain extent, on effective writing. However, defining what is effective writing for patent documents is also more complicated than it seems to be at first sight, and may depend on which national system the application is directed to, which type of technology and scope of protection, among the other factors mentioned.

Sheldon enhances the complexity of the writing of a patent application by stating that there are few tasks more difficult than that of preparing a patent application for an important invention. ${ }^{40}$ Quaintly, the same author describes writing a patent as an art, comparing it to the routine of learning how to play a musical instrument:

\footnotetext{
437 Ibid.

438 See the following works: J. Sheldon, How to write a patent application. Practicing Law Institute, $3^{\text {rd }}$ Ed., 2015; B. DeMatteis, A. Gibbs and M. Neustel, The Patent Writer: How to Write Successful Patent Applications. Square One Publishers, 2006; D. Pressman, Patent it yourself, Nolo Press, 1985; F. Waller, Writing Chemistry Patents and Intellectual Property: a Practical Guide, John Wiley \& Sons, 2011; USPTO, Design patent application guide, https://www.uspto.gov/patents-getting-started/patentbasics/types-patent-applications/design-patent-application-guide, accessed 14 April 2018.

439 Ibid.

440 Sheldon, op. cit., pp. 1-1 - 1-2.
} 
Writing a patent application is similar to learning how to play the piano. The aspiring pianist can read book after book on how to play the piano, but reading alone will not make that pianist competent. The aspiring pianist needs to actually play the piano and benefit from the comments, suggestions, and teachings of a skilled mentor. ${ }^{441}$

Sheldon is not the only author to use a metaphor for describing patent writing. While he compares it to learning how to play the piano, DeMatteis et al. consider drafting a patent an activity similar to storytelling. For them, the draft of a patent should bring, in a sequential timeline, the background of the invention, "its story": what's been used in the past, what's being used now, and also how the invention overcomes problems with present day products. ${ }^{442}$

As learning "an art" may require time and effort, Sheldon asserts that even skilled practitioners benefit from ideas of other patent attorneys and agents, particularly when it comes to writing the claims of a patent application, making it clear that there is no final point in the process of learning how to write a patent, and determining that inevitably, some people will never be able to write a high-quality patent application, no matter how hard they try. ${ }^{443}$

Another warning of the cited author worthy of mention is that writing patents should never be developed as a "do-it-yourself" task, as the chance to disclose the idea without being rewarded for it will be very high, considering that unprofessional writing will probably lead to an unsuccessful application. However, there are also works that, as the one mentioned above, intend "to teach" an independent inventor to write a patent himself, which means they defend it as a possible task. ${ }^{444}$

According to the Patent drafting manual of WIPO, a patent application (in other words, a patent text) is divided into claims, detailed description (or specification), drawings, background, abstract and summary. ${ }^{445}$ According to the Manual, the claims are the first part to be written, and should clearly show that the agent "understood" the invention. ${ }^{446}$ For DeMatteis et al., the claims are the most crucial part of a patent to its grant and "legal success". They explain that the inventor should write the very first draft of what will be the patent in simple English, having the challenge to describe the invention in a way that makes it easier for the practitioner to "translate" it into patent legal language. ${ }^{447}$

Their book really focuses on the claims as the most essential part of a patent, outlining claims strategies and thoroughly defining types of claims, claim structure and the relation

\footnotetext{
441 Ibid., p. 5 .

442 DeMatteis et al., op cit, p. 121.

443 Ibid.

444 Ibid., p. 5.

445 WIPO. WIPO patent drafting manual, p. 33, http://www.wipo.int/edocs/pubdocs/en/patents/867/wipo_pub_867.pdf (accessed 15 April 2018).

446 Ibid., p. 34.

447 DeMatteis et al., From Patent to Profit: Secrets and Strategies for the Successful Inventor, SquareOne Publishers, 2005, p. 183.
} 
between claims, subject matter and scope. ${ }^{448}$ These last observations about how to write claims and parts of claims make it clear that there are differences in structure and style not only for each part of the patent, but for the different parts of the claims, classified by the authors as independent and dependent claims. ${ }^{449}$

The guide also emphasizes the importance of s stating that, although it is not the object of the exam, it should be effective in informing people about the invention's subject matter. That prescription indicates that style is important to a patent text as it is an element that can actually influence the decisions of its reader. The title, being the front door to the content of an invention, should bring the reader to an anticipation of the subject matter. ${ }^{450}$

A patent agent will want to consider the patent application's title fairly early. This title should broadly describe the invention. However, titles are not generally examined. Occasionally a patent examiner will decide that a title is not descriptive of the invention. It is best to avoid being overly narrow in the invention's title, although the title should sufficiently indicate the subject matter of the invention. ${ }^{451}$

The manual is not the only work to make reference to the importance of stylistic choices when drafting the patent document. Sheldon dedicates a section of his work to title writing. He emphasizes the function of the title for indexing and classifying the patent. ${ }^{452}$ DeMatteis et al. explain that it is significant to use and create efficient acronyms ${ }^{453}$ and to search for the most precise words for describing the invention by using a thesaurus. Their guide also brings examples of the use of combination of words instead of broad terms and examples of words with ordinary meaning (established meaning) in view of recommendations of relevant court cases. ${ }^{454}$

These are outstanding considerations of style on the researched works for a later association between style in writing and the translation of a patent document. However, the most important remark on that topic may be one also brought by DeMatteis et al., described in one of the chapters of their book under the title of "lexicography". According to the authors, applicants not only are allowed to, but are advised to make up words when the existing ones are not sufficient to describe the invention. That makes the inventor a creator also in terms of language, which may represent an important characteristic of patents as "texts to be translated".455

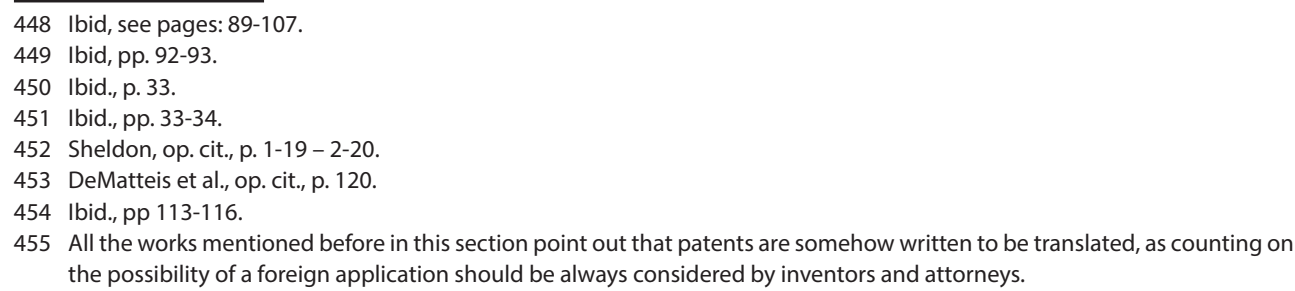


WIPO's Manual also, quaintly, states that a patent text is aimed at very specific receivers, such as the key audiences of the patent documents include judges and patent examiners. Patents may be reviewed by those groups in different types of legal contexts, so the drafts should be written considering the possibility of these events. ${ }^{456}$ DeMatteis et al. go even further, describing a patent writer plan and a long set of useful tools to facilitate the venture of "convincing judges and examiners of the value of the invention and not taking risks of misleading interpretations. ${ }^{457}$

No doubt writing accurate patent applications is a task for skilled, experienced practitioners, who may be represented by different professionals or firms directed to distinct technologies, and even to distinct levels of experience with the intended national or regional system. In this regard, Sheldon also advises about the risk of additional costs and the risk of further legal problems. For the author mentioned, whose work is one of the most important references of patent writing, the application, even when filled only in a national level, should be written with "an eye" overseas, as it may later be a vehicle for obtaining foreign patents. ${ }^{458}$

When comparing these works, it is possible to list some of the common characteristics which they (directly or not) refer to when it comes to patent drafting. Although the works mentioned are not aimed at describing the patent text as a text, but to facilitate the task of writing a patent document, they are unanimous in making it clear that:

- Patent texts are very difficult to be written, requiring various types of skills and varying in terms of: type of technology, national patent system, language, legal and commercial purposes.

- Patent texts require skilful, experienced professionals or a group of professionals, with legal and technical background, to write them. They should not be written by those of ordinary skills, because of the risk of having problems with their following legal stages, namely, validation, opposition or infringement.

- Patent texts are written to a specific group of receivers, which includes, especially, judges and patent examiners. They also have a persuasive, "conative" function, associated with the need of making it clear for examiners and judges that they fulfil the criteria of patentability. ${ }^{459}$

- Patents are written to be translated, even when they are first filed only nationally. The possibility of foreign applications is something that these authors recommend that the inventors keep in mind when preparing the application. That requires an even more skilled practitioner to translate the idea of the invention in legal patent language, because he/she must "have the

456 Ibid., p. 29.

457 DeMatteis et al, op cit, pp. 18-21.

458 Sheldon, op. cit., p. 1-5.

459 For the conative function of language, according to the communication model of R. Jakobson, see: R. Jakobson, 1991, pp. 350-377. 
feeling" of what would be a more translatable text, even when it is not going to be immediately translated in other languages.

- Patent language is not pure technical language, not being comparable to the language of technical manuals, for example. Style and semantic nuances matter considerably in patent texts.

- Patent texts are meant to describe a creation. Therefore, they may be ingenious in certain aspects, while being very strict in others. One of the most important creative features of writing a patent is the possibility of making up words that did not exist before in a language, the inventor acting as his own lexicographer. - The claims are the most important part of a patent to be considered while drafting the application.

If writing a patent application is such a complex and laborious task, where each detail can have a different impact on the patent legal existence, what to say about the translation of these applications? From here, this section aims to sum up some of the most relevant issues involving the association between writing and translation of patents. In this regard, Sheldon dedicates a very illustrative chapter to Foreign Patent Applications Based on a U.S. Application that will serve as the starting point for this discussion. ${ }^{460}$

No doubt patent applications ought to be written for being translated. That is so, especially because translation represents a major expense in the filing and prosecution of foreign patents and using some strategies in writing can reduce these expenses. According to Sheldon, there is more incentive in avoiding verbosity, repetition and circumlocution in a foreign application than in a national one. However, as it decreases considerably the costs of a translation, it would also spare time and money if avoided in the national original version of a patent. ${ }^{461}$

Sheldon then points to clarity, consistency and brevity as very important features to bear in mind while writing a patent, as indicators of its level of translatability. ${ }^{462}$ The more clear, accurate and concise the text is, the better will be the chances of obtaining good translations from it. He then advises to employ clear terms and to add explanations when the meaning of a term is unavoidably vague. He also suggests using certain resources to elaborate a well-structured, "organized" text, as numbered or lettered paragraphs and simple syntax. Sheldon finally suggests the strategy of reverse translation to prove the level of "clarity", in his words (but this could also be interpreted as "translatability") of the patent text. That means the text should be translated into another chosen language (for

460 See Sheldon, op. Cit., pp. 18-3 - 19-23.

461 lbid, pp. 18-10 - 18-11.

$462 \mathrm{lbid}$. Sheldon does not mention the type of language that the text should be translated into. It is assumed that it would be one intended in a possible future application. He also does not mention if the proposed exercise for assessing the clarity of the text should involve human or machine translation, or both. Sheldon does not employ the term "translatability", but makes it clear that some characteristics of the writing of a patent can facilitate its translation. For the concept of "translatability", see: L. Venuti, Rethinking Translation, London \& New York, Routledge, 1992. 
future application, for example) and then re-translated into English (or another source language) ${ }^{463}$

A very relevant point mentioned by Sheldon's work is the possibility of using only one translation in countries that share the same official language, as, for using his examples, Spanish for Spanish speaking Latin American countries, or French for France, Belgium and Switzerland. He then adds that the local agents will still charge for verifying the translation, but these charges will cost less than a full translation.

Filing only one translation in countries that share the same language is probably what happens in practice to most of the applicants. What Sheldon's work does not mention about this advisable, cost reducing practice is that the varieties of the same languages in different countries can be significantly discrepant, which does not only refer to linguistic (in general) or lexical peculiarities, but also to (sometimes major) cultural differences. In this regard, an "adaptation" made by the agent of the patent text to another variety of the same language can have a higher cost in losing accuracy than a professional translation from a totally different language would have.

Another big controversy directly involving patent writing and translation is related to the sufficiency of disclosure of a patent. If a patent document does not describe the invention precisely enough in order to disclose its content to the person skilled in the art, it loses its meaning. In terms of patent writing and translation, it is possible to affirm that the writing of the patent document failed to attend to its legal requirements. It is also possible to infer that the document is untranslatable, if that is the case, and should not be granted as a patent. There are some examples of patents whose sufficiency of disclosure could be questioned, as will be shown below. Before that, it is important to retrieve the definition of sufficiency of disclosure:

A detailed description of at least one way of carrying out the invention must be given. Since the application is addressed to the person skilled in the art, it is neither necessary nor desirable that details of well-known ancillary features should be given, but the description must disclose any feature essential for carrying out the invention in sufficient detail to render it apparent to the skilled person how to put the invention into practice. ${ }^{464}$

An outstanding, example of how the sufficiency of disclosure can affect patent law at the global level (through the lack of clarity and accuracy of a patent document) is the one of the patent of the anti-retroviral drug Efavirenz, used to treat human immunodeficiency virus (HIV) infection. The pipeline patent of the drug, PP1100250, was involved in a very controversial first experience with compulsory licensing in Brazil.

After the Brazilian Government issued the compulsory license to the patent, and after a long process of international negotiation, in the beginning of 2007, Farmanguinhos, an official pharmaceutical laboratory of Fundação Osvaldo Cruz, tried for almost two

463 Ibid.

464 EPO, Guidelines for examination. 
years to reproduce the active ingredient of the drug. Despite having access to all patent information, they were not successful. The active ingredient was finally imported from India, which allowed the manufacture of the drug in Brazil. Although the reason why India was able to reproduce the active ingredient was its better experience in the production of these substances, if the sufficiency of disclosure is addressed to the person skilled in the art, it is possible to conclude that the content of the patent was not sufficiently disclosed as a detailed description of at least one way of carrying out the invention must be given (...) to the person skilled in the art. ${ }^{465}$

The example shows that the writing of a patent (purposely or not) can affect the sufficiency of disclosure to the person skilled in the art, as, in this case, having more or less knowledge of the production of the invention interfered with its manufacture. Consequently, it also affects its translatability and dissemination in different countries. Evidently, the writing of the patent was not the only factor that played a role in the mentioned case, as it is also related to accumulated knowledge in reproducing similar technologies.

Another legal requirement associated with writing and translation is the duty of disclosure. There are very different interpretations of how the applicant should disclose prior art in different national patent systems. In the case of rigorous demand for presenting prior art results from other countries when filing the application, when the most representative country is probably the United States, ${ }^{466}$ there should also be variations in the results of the validation process. For Sheldon:

Clearly it makes no sense to prosecute a claim which is known to be wholly anticipated, even if the foreign patent office does not know of the relevant prior art. A more difficult decision is whether to inform a foreign patent office about prior art which is relevant, but which is thought not to invalidate the claim. The safe course is to provide information about any prior art of possible relevance, and to deal with the consequences during prosecution. If there is any likelihood of litigation, that is almost certainly the best course. In other circumstances, the facts of the particular case will drive the decision. ${ }^{467}$

465 For the definition of sufficiency of disclosure, see: EPO, Guidelines for Examination, Chapter III, 1. Sufficiency of Disclosure, https://www.epo.org/law-practice/legal-texts/html/guidelines/e/f_iii_1.htm (accessed 16 April 2018). Part of the information was collected directly from patent examiners involved in the case through interviews. For more information about the compulsory license of the drug in Brazil, see: W. Rodrigues and O. Solerll, 'Compulsory licensing of Efavirenz in Brazil in 2007: Contextualization', Rev Panam Salud Publica, vol.26, n.6, Washington, Dec. 2009, http://www.scielosp.org/ scielo.php?script=sci_arttext\&pid=S1020-49892009001200012\&lng=en\&nrm=iso\&tlng=en (accessed 14 April 2018); see also: Fiocruz, 'Fiocruz consegue produzir Efavirenz', published in 17/09/2008, https://www2.senado.leg.br/bdsf/bitstream/ handle/id/335604/noticia.htm?sequence=1 (accessed 15 April 2018).

466 See Sheldon, op. cit., p. 18-9.

467 Ibid. 
The case mentioned by Sheldon above about relevant prior art thought not to invalidate the claim will very often bring documents that can be decisive in building up the decision of the examiner. If the patent is granted, these documents (from the way they were interpreted by the examiner) may influence its further legal stages. The interviews with patent examiners showed that it is not rare in their task to count on relevant documentation which requires careful interpretation for grounding the validation, or not, of a patent. In these cases, they sometimes need to consult each other or to count on the support of professional translators or further documentation provided by the applicant. That does not ensure that they will not make mistakes that may lead to disputes in future. ${ }^{468}$ The examination of the inventive step involves a great deal of subjectivity and there are frequent cases where there are divergent opinions between examiners and attorneys, or experts hired by courts. ${ }^{469}$

Contrary to what happened in searching prior art about patent writing, it was not possible to find any relevant reference on "how to translate a patent". The only work found that could get close to this idea is a manual called "Making the move to patent translation - Japanese patent translation", elaborated by Martin Cross. ${ }^{470}$ One of the important observations brought by Cross relates to the function of patent translation, inquiring through the question "what are patent translations used for?". According to this author, they are used for prior art research into related technology information, disclosure statement, arguing with the examiner, litigation, filing in foreign countries. ${ }^{471}$

What is important about consciously associating the function of translation with the legal stages of the patent, as the author is doing with a practical purpose, is to understand how important patent translation is to the patent system and, therefore, how intrinsically related to its writing it should be considered. In other words, if the original text of a patent is not clearly and accurately written, or if it does not disclose the technology, or even if it is not "written to be translated" (if translatability is not a factor considered in the moment of drafting the application), it may affect the further legal stages of the patent and may create negative legal effects on the global patent system. A patent whose text is obscure may be a corruptive element to the patent system, by being the cause of divergence between its players and facilitating the emergence of infringement cases.

Cross also presents some basic rules for patent translations, in order to better reproduce the original text and reach success in foreign applications, namely: reproduce meaning, reproduce register, respect sentence breaks and carriage returns; one-to-one correspondence between source and target. ${ }^{472}$ Putting it in more specific linguistic terms, it seems that the author warns about following a technical, faithful translation, where the

468 Information collected directly with the interviewees. See Section 7.2.

469 These cases will be presented on Section 7.2.

470 M. Cross, 'Making the move to patent translation', Patent Translations Inc. [presentation], http://www.patenttranslations. com/Publications/Making\%20the\%20move\%20to\%20patent\%20translation.pdf (accessed 14 April 2018).

471 Ibid.

472 Ibid. 
translated text is as accurate for its target language audience as the original would be for its source language audience, which may involve only native speakers of this or that language.

Cross's prescription may seem very simple to put into practice from a more technical perspective. The problem to make it work is that keeping accurate meaning when translating complex patent documents may be a really challenging task for the translator. The passage also inspires some questions: Can the translated text be more accurate than the original text? Can cultural aspects mislead the interpretation of a translated text? Are all the current professional patent translators skilled enough to identify problematic linguistic and cultural aspects and find the best solutions to translate them? Can attorneys be "cheated" by the quality of translated texts presented by local agents? These questions will be addressed in Chapter 7.

For closing this section, some conclusions over the relation between patent writing and translation are presented below:

- Patents should be written to be translated, which means considering the possibility of foreign applications even when they are filed only nationally. That is justified by future possibilities of reaching other markets and by the fact that patents are made to be consulted and implemented internationally, through a global system.

- The ease with which the patent text can be translated requires the following features from the original text: clarity, consistency, accuracy, concision, simple syntax and specific terminology.

- Other ways of increasing the level of translatability of the original text are: adding explanations when the meaning of a term is unavoidably vague, using graphic and linguistic resources to organize the text, as numbered or lettered paragraphs, simple syntax and parallelism, working with a translation to a specific language and with the reverse translation into the original language.

- A patent document filed in a different variety of the same language may require as much attention in its adaptation as a translated text, as language proximity combined with cultural divergence may be very misleading in terms of meaning and understanding.

- If the original text of a patent does not meet the requirement of sufficiency of disclosure, its text may be considered useless for the patent system, as it discloses nothing. It can also be considered as untranslatable.

- The duty of disclosure may bring foreign prior art to the border of just being relevant to and truly anticipating the technology. These documents may be interpreted in a way that favours or invalidates the patent claim.

- If writing a patent text is an art, translating it should be considered as an art as well. But considering the fact that the largest part of the immense volume of global patent information is accessed through machine translation, then 
the real art becomes selecting and interpreting these texts, therefore, making the best use of machine translation and requesting a human professional translation when necessary. Such tasks usually involve several professionals, such as a patent attorney, a legal technologist experienced in e-discovery and one or several translators.

\subsection{Patent translation: limits and possibilities}

The regulations on the Unitary Patent Cooperation Agreement already demonstrate a concern with translation issues and include a very relevant predictive recital concerning the future of translation in the patent system. The document states that, during the application process, demands for translations will be totally eliminated after a transitional period when machine translation tools will be sufficiently improved to guarantee efficient communication involving patent texts and the disclosure of the information they contain. ${ }^{473}$

The following part of the document is worth transcribing:

The transitional period should terminate as soon as high-quality machine translations into all official languages of the Union are available, subject to a regular and objective evaluation of the quality by an independent expert committee established by the participating Member States in the framework of the European Patent Organisation and composed of the representatives of the EPO and the users of the European patent system. Given the state of technological development, the maximum period for the development of high-quality machine translations cannot be considered to exceed 12 years. Consequently, the transitional period should lapse 12 years from the date of application of this Regulation, unless it has been decided to terminate that period earlier. ${ }^{474}$

The recital makes it clear that European patents will still be granted in one of the official languages of the European Patent Office. The transitional arrangements will require additional translations on a temporary basis. However, these translations will have no legal effect and will be used for information purposes. After the transitional arrangements, no further translations will be required. The period mentioned will terminate when "highquality" machine translation for all the languages of the member States becomes a reality. The quality of the translations will be subject to an evaluation by an expert committee every two years. The first evaluation starts from the sixth year after the Unitary System

473 See Council Regulation (EU) no 1260/2012 of 17 December 2012, implementing enhanced cooperation in the area of the creation of unitary patent protection with regard to the applicable translation arrangements, http://eurlex.europa.eu/ LexUriServ/LexUriServ.do?uri=OJ:L:2012:361:0089:0092:EN:PDF (accessed 15 April 2018).

474 Ibid., Art. 13. 
enters into force. ${ }^{475}$ What is interesting about the text of the regulation mentioned is that it clearly affirms that high-quality machine translation will be achieved by the end of 12 years in a level that filing human translation will not be necessary anymore.

The content of the regulation has been object of dispute, as in mentioned Action filed by Spain against the European Council, whose in-depth analysis is presented in Section 6.2.3 of this dissertation. Spain has argued the regulations are not justified on public interest grounds, as there is no provision for making available a translation of, at least, the claims, as neither the development of machine translations nor the obligation to submit a full translation in the event of a dispute are measures which are sufficient in that regard. ${ }^{476}$ Spain claims that the regulations could lead to legal uncertainty and negatively affect competition. ${ }^{477}$ From the perspective of the present research, the case is open to numerous conclusions ${ }^{478}$. One of them is that, although the Regulation may lack in clarity in aspects such as languages and places of litigation and may be reviewed in terms of the chosen official languages for the community patent, the set of rules regarding the current role of machine translation to the disclosure of patent information is not groundless.

The prognosis of said Regulation may sound senseless to acquired common sense over the role machine translation has been playing to the patent system in the last decade. Nevertheless, this fast improvement not only makes sense, but has already become a reality to patent examiners and attorneys and to frequent users of patent platforms. This improvement is happening so fast that some considerable changes have also been observed during the process (and time period) of the present research.

One example concerns the main tool for patent related machine translation: the device created by the European Patent Office, called Patent Translate. According to patent examiners who were interviewed, the last two years made a lot of difference to translations from Asian languages, like Japanese, Chinese and Korean, with an emphasis on Japanese. This same device is the object of research and improvement at the moment, with the use of new technologies and continuous research and evaluation. Other devices are also being developed and improved, with different purposes and target audiences, in a rapid evolution difficult to follow and portray here, as there are daily changes and related progress. ${ }^{479}$

For instance, the World Intellectual Property Organization (WIPO) has recently developed a tool called WIPO Translate, for instant translation of patent documents. WIPO Translate is a world-leading instant translation tool, specially designed for patent documents. The tool promises to be ground breaking in terms of the quality of translation. For developing more "natural" results in terms of sentence structure, it uses the emerging technology named neural machine translation. This type of automatic translation is

475 Ibid.

476 Spain vs Council, C-147/13, ECLI:EU:C:2015:299.

477 Ibid.

478 See Section 6.2.3.

479 Information collected directly with EPO officers and patent examiners. 
developed on complex neural network models. These models, in a different way from the phrase-based ones, use the information contained in previously translated texts and sentences. As a consequence, they are constantly improving and being updated. WIPO Translate is available to any user, free of payment or any charges, through its database, PatentScope. ${ }^{480}$

Scientific research is late in recognizing what has long been known in practice in network societies: machine translation is here to stay ${ }^{481}$. Gonzalez writes an article about the future of machine translation on the webpage of Sajan, a company specialized on language and translation services, describing the rapid evolution of MT according to her own professional practice. She remembers a first experience with computer assisted translation (CAT) after a request from a client, in 1990. During that time, automatic translation tools were very limited and still unexploited. After that first demand, the company started to incorporate IBM Translation Manager into its services. Gonzalez describes how the pair of languages and memory options were still scarce and how much resistance was found among linguists and project managers to learn the new tools. For the role of CAT tools, after 20 years of using it, she asks three important questions: can you think of the translation business without translation memory? Do you think that the translation volume has gone down? Do you think translators are slower or that quality is worse with the use of CAT tools? ${ }^{482}$

Computer assisted translation and machine translation represent two different things, that will probably always co-exist in the future of translation, although the first one preceded the second one. Machine translation is a rapid tool. The translation is done automatically, without the aid of a human being. Computer assisted translation requires a skilled linguist to operate its tool, normally accessible through different types of software, used in combination or in isolation. CAT works exclusively as a support to human translation - never as a substitute. That means the difference is who is mainly responsible for the translation: a machine or a human translator. ${ }^{483}$

After understanding the difference between CAT and MT, it is logical to affirm that if CAT tools faced resistance from professional translators, machine translation is seen as a real threat ${ }^{484}$, which inspires ideas and common statements of rejection, intended to diminish its value and mock its quality. For Gonzalez, contrary to that, machine translation represents the next phase in the translation business ${ }^{485}$, which means translation companies

480 See: A. Nightingale, WIPO's New Tool: Complex Patents Now Easily Translated, Intellectual Property Watch [Web blog], November, 2012， http://www.ip-watch.org/2016/11/02/wipos-new-tool-complex-patents-easily-translated/?utm _ source=IP-Watch+Subscribers\&utm_campaign=4fbbaf7a19-WEEKLY_SUMMARY\&utm_medium =email\&utm_term =0_ b78685696b-4fbbaf7a19-353256161

481 The slogan refers to the title of an article on machine translation on the Website of Sajan, a company specialised on language and translation services. See: Gonzalez, E. 'Machine Translation is here to stay', 2018, https://www.sajan.com/thefuture-of-machine-translation-its-here-to-stay/ (accessed on 15 April 2018).

482 Ibid.

483 L. Bowker, L. Computer aided translation: a practical introduction. University of Ottawa Press, 2004,p. 4.

484 Gonzalez, 2018.

485 Ibid. 
and professionals should be prepared for facing this new phase realistically. That also means the activities and the business related to translation simply change, maybe drastically, implying other ways of viewing the interaction between human translators, CAT and translation machines.

For Gonzalez, facing the growing use of machine translation in translation service businesses requires from these businesses an understanding of the importance of postediting skills among their collaborators, as not all the good translators are necessarily good post-editors. ${ }^{486}$ It is also very clear that language and translation businesses tend more and more to offer combined services, such as triage and "gisting", which intend not only to deliver texts translated from various languages, but to identify and uncover the appropriate texts (depending on the purpose) among huge amounts of digital material. ${ }^{487}$ In the case of patent law, an important new function emerges in this new legal context: the one of the legal technologist.

Machine translation has had a rapid evolution. So rapid that theoretical studies probably did not reach the point of its current development and scope. There are some works describing its stages of evolution, from its origins in the idea of a universal language, much earlier before the advent of computers, ${ }^{488}$ to each of its first projects and their ups and downs, as the famous ALPAC report ${ }^{489}$ to, finally, fast real-time response available, in mass scale, both online and through MT software for personal computers. There is also currently a considerable volume of publications over related specific technical issues, such as researches on statistical approaches, quality assessment or improvement of technical tools. $^{490}$

All those studies are very important to understand and characterize the various facets of machine translation and how it grew from distrust of sponsors and users to a mass global use, which extends to a much broader audience than professional translators, but reaches the translation of various types of websites, social media, besides being a tool for the most diverse professional use and daily personal use.

From the perspective of classical studies or historical approaches of machine translation, it is probably right to confirm that "the future" of machine translation has arrived, not only in terms of its increasingly broader scope, but also in terms of the vital

486 Ibid.

487 See the advertisement of two of the largest translation companies in the world, Mission Essential and Transperfect, on their websites: http://www.missionessential.com/ and http://www.transperfect.com

488 See J. Hutchins, Machine translation: past, present, future. Ellis Horwood Ltd, 1986. See also: J. Hutchins, The history of machine translation in a nutshell (self-published source), 2005, http://www.hutchinsweb.me.uk/Nutshell-2005.pdf

489 Hutchins, J. (1986), p. 166-167. See also Hutchins, 2005, where Hutchins describes the ALPAC report as follows: By 1964, the US government sponsors had become increasingly concerned at the lack of progress; they set up the Automatic Language Processing Advisory Committee (ALPAC), which concluded in a famous 1966 report that MT was slower, less accurate and twice as expensive as human translation and that "there is no immediate or predictable prospect of useful machine translation." It saw no need for further investment in MT research; and instead it recommended the development of machine aids for translators, such as automatic dictionaries, and the continued support of basic research in computational linguistics.

490 See, for example: F. Koehn et al. (coord.), 'Moses: Open Source Toolkit for Statistical Machine Translation', Proceedings of the ACL, Prague, 2007; P. Kishore et al., BLEU: A Method for Automatic Evaluation of Machine Translation, ACL '02 Proceedings of the 40th Annual Meeting on Association for Computational Linguistics, 2002, pp. 311-318; H. Somers, 'Example-Based Machine Translation', Machine Translation, vol. 14, no. 2, 1999, 113-157. 
importance it has gained to professional activities such as patent examination or patent prosecution, and specially in terms of the high quality and vast array of languages it has achieved through the cutting-edge neural technology. ${ }^{491}$

Neural machine translation is a recent approach to machine translation, whose first proposals emerged in 2013. It differs from classical statistical machine translation, as it builds a single neural network that can be jointly tuned to maximize the translation performance. The traditional statistical approach is based on separately tuned components. $^{492}$

Koehn observes the speed of the recent improvement of neural machine translation, and how it now represents a breakthrough innovation among MT technologies. The new technology surprises in quality assessment in most pairs of languages and, therefore, is now the focus of attention of technical research which intends to improve its strengths and mitigate its weaknesses. ${ }^{493}$ There is still no research about how it affected the patent system and activities such as patent examination and prior art search, but both patent attorneys and examiners recognize astounding development during the last two years. $^{494}$

Within a year or two, the entire research field of machine translation went neural. To give some indication of the speed of change: At the shared task for machine translation organized by the Conference on Machine Translation (WMT), only one pure neural machine translation system was submitted in 2015. It was competitive but was outperformed by traditional statistical systems. A year later, in 2016, a neural machine translation system won in almost all language pairs. In 2017, almost all submissions were neural machine translation systems. ${ }^{495}$

An article published on WIPO's webpage pressroom emphasizes the high level of accuracy of neural technology applied to WIPO's patent translation tool. It also reiterates that the tool has been specially trained to provide quality translations from Asian (Chinese, Japanese, Korean) languages into English. The purpose is to maximize disclosure of patent information to the users of the patent system. ${ }^{496}$ Neural machine translation is presented

491 See: 'Machine learning is fun', Medium [Website]: https://medium.com/@ageitgey/machine-learning-is-fun-part-5language-translation-with-deep-learning-and-the-magic-of-sequences-2ace0acca0aa (accessed 16 April 2018).

492 D. Bahdanau, et al., 'Neural machine translation by jointly learning to align and translate', Published as a conference paper at ICLR, 2015, https://arxiv.org/pdf/1409.0473.pdf

493 P. Koehn, 'Statistical machine translation draft of chapter 13 neural machine translation', Johns Hopkins University, 2017, p. 6, https://arxiv.org/pdf/1709.07809.pdf

494 Information collected directly with interviewees, who were unanimous in recognizing a remarkable improvement in quality of machine translation during the last two years.

495 P. Koehn, 2017, p. 6. The WMT conference is built on a series of conferences and workshops on machine translation, bringing tasks on associated methods and technologies. See webpage for the Conference in 2017: http://www.statmt.org/wmt17/ index.html (accessed 20 December 2018).

496 WIPO, 'WIPO Develops Cutting-Edge Translation Tool for Patent Documents', 2017. http://www.wipo.int/pressroom/en/ articles/2016/article_0014.html (accessed 20 December 2018). 
as the answer to accuracy, clarity and speed on the process of disclosure, a future that has just arrived from its cutting-edge point.

This future is led by an abundance of possibilities, which include tasks for different pairs of languages, knowledge areas and linguistic concepts. The WMT Conference of 2017 gives an idea of how vast these research branches are. Here follows a list of some of them: a new translation task, a biomedical translation task, an automatic post-editing task, a metrics task (assess MT quality given reference translation), a quality estimation task (assess MT quality without access to any reference), a multimodal translation task, a task dedicated to the training of neural MT systems, a task on bandit learning for MT. 497

Besides technical research directed to the improvement of technologies and methods of neural machine translation, it is important that a broader range of studies may analyse its impact on different areas of knowledge and economic structures. These types of studies are not only scarce, but practically inexistent. One of the most important areas to be observed is the patent system, for its central importance to the development and improvement of machine translation itself and for the main justification of the existence of the patent system: universal disclosure of the content of inventions.

\subsection{Conclusions and correlation of the chapter with the research question}

Chapter 4 is focused on explaining the idea of translation as a vehicle to patent rights. To achieve this, the first step was to portray the historical role translation played to science and to innovation. Historically, translation has long operated as a vehicle of knowledge transfer between nations, even way before the development of automatic translation and other digital translation tools. This historical view was relevant for understanding the fast pace of the recent developments of translation and its current central role to the patent system. Section 4.1 concludes that the role of translation to knowledge transfer was radically overhauled when machine translation finally allowed a universal dissemination of scientific creations, by disclosing patent information in a global level.

Section 4.2 reviewed the concept of translation from a contemporary perspective. The Section presented the concept of translation as a mosaic of definitions and acknowledged that it is not anymore possible to totally distinguish machine translation from human translation. In this regard, human translation became an activity performed with the support of digital translation tools. The same way, machine translation requires the participation of a human interlocutor or operator, who will make a better or worse use of it.

Accordingly, machine translation and human translation are used and combined in different stages of the patent timeline. They are continuously present and important

497 Transcribed from the list of shared tasks of the webpage for the Conference in 2017: http://www.statmt.org/wmt17/index. html (accessed 20 December 2018). 
in all of them, as illustrated with particular cases in Chapter 6 and 7. Section 4.2 is concluded with a discussion over the role of English as lingua franca to the patent system. It considered English as the main language of communication for the patent system, without undermining the importance of all the applications and information in all the other languages.

Section 4.3 characterized patent texts as texts, with the purpose of contradicting the falsified self-evident idea that technical texts are "easy to translate". The Section presented a review on the meaning of technical translation, enhancing the particular features of patent texts. It concluded that patent texts can be more complicated than other technical texts in many aspects, as they are written with a view to legal purposes, aiming at specific audiences and intending to broaden the scope of protection as much as possible. Patent texts also combine technical and legal purposes. That is why patent translations are relatively expensive, as they require a high level of technical and legal expertise.

Sections 4.4 examined patent writing in terms of its translatability. The Section first presented a review about "how to write a patent text". Patent texts were particularized as texts written to be translated, due to possible foreign applications and to the requirement of universally disclosing their content. From this perspective, patent texts are meant to be disclosed, and disclosure, in turn, is related to the connection between writing and translation. The level of translatability of patent texts depends on standards of text structure, consistent terminology and clearness in responding to the criteria of novelty, inventive step and industrial application.

In conclusion, Section 4.5 discusses the limits and possibilities of patent translation, arguing that the prognosis raised by the language regulations of the Unitary System, related to dispensing the submission of translation as part of a patent application in a maximum term of 12 years, is coherent with the role that machine translation has assumed to the patent system and correct in terms of acknowledging the value of machine translation for universally disclosing patent information. On the other hand, which is also clearly stated by the mentioned regulations, machine translation should not be considered as legally binding, and human translation will always be necessary. In fact, human translation will probably be considered more and more valuable, when used in combination with digital translation tools and automatic translation, requiring, from professional translators, critical thinking and cognitive capacity to combine technical, legal and linguistic skills.

As described above, Chapter 4 discussed the nature of the patent system and the structure of a patent document in association with language and translation. Chapter 5 follows up this discussion by providing the results of the empirical analysis over the level of disclosure of patent information through machine translation. It also debates the definition of disclosure in association with different national law and cultural approaches, especially over related legal concepts, such as the ones of novelty and inventive step. 
CHAPTER 5

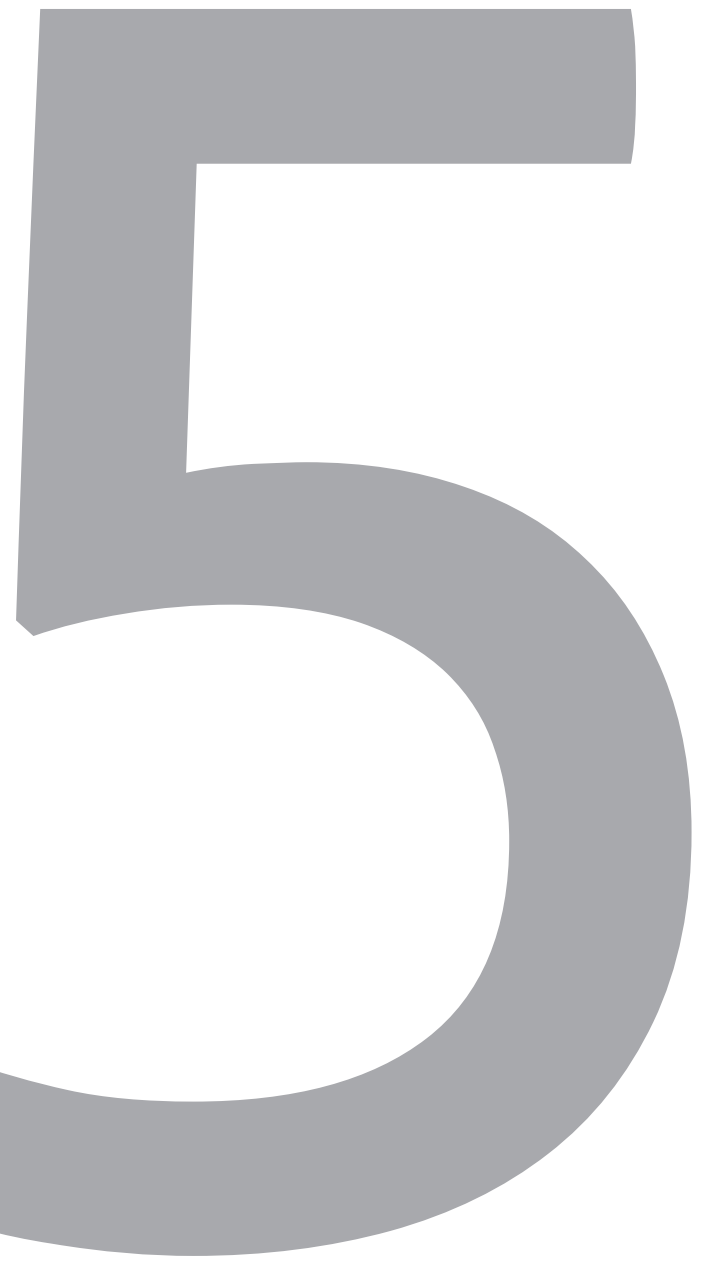




\section{Patent translation and its influence on the disclosure of technological information}




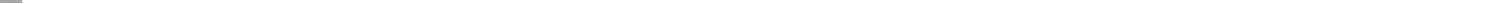




\subsection{Translation and disclosure of patent information}

This Chapter analyses the level of disclosure of patent information through machine translation, as related to the proposed research question. This Section introduces the association between disclosure and translation, from a legal perspective, whereas the following Section presents the results of the analysis of a sample of 100 patents, concerning the average level of disclosure of technological information through machine translation, an analysis complemented by a survey filed in by scientists representing the persons skilled in the art. ${ }^{498}$ The results are crucial to answer to the argument that patents do not disclose the content of the patented inventions, a frequent argument to oppose the existence of patent rights.

Knowledge imparting is one of the main reasons that justifies the existence of the patent system, since the disclosure of technological content is one of its fundamental bases. Yet the concept of disclosure of patent information still remains unclear, as its role for the process of patent bargain is still subject to questioning and doubts and to the necessity of searching for improvement. The disclosure can be basically defined as the public dissemination of the content of an invention, or, in more technical terms, the clear revelation of the inventive matter of new technology. 499

Nevertheless, conceptualizing disclosure is not that simple, as its definition also depends on national law and legal understanding of related concepts, as the ones of novelty, inventive step ${ }^{500}$ and sufficiency of disclosure. To take the most important one for the present analysis, "sufficiency of disclosure" can be defined as a legal demand according to which a patent application must reveal its invention in a detailed description of at least one way of carrying out the invention, which should be understandable to a person skilled in the art. ${ }^{501}$

To Fromer, patent disclosure is so central to the patent system that the way it performs (or underperforms) can directly affect technological progress and its main premise, which is fostering innovation. Her article claims that the disclosure function is failing to fulfil its task as it should in the patent system due to what she calls four systemic reasons, namely: inadequacies of the writer, the index, the reader and enforcement. She also points to the focus of scholarship and court decisions on doctrinal texts, and the lack of consistent studies containing theoretical and institutional analysis. ${ }^{502}$

Pointing out the limitations of the theories on patent disclosure is a very important contribution of Fromer's work to be brought to the present research. Fromer suggests that

\footnotetext{
498 See Chapter 2 for a detailed explanation over the methodology and techniques used.

499 A. Gibbs and B. DeMatteis, Essentials of Patents, PatentCafe, 2003, p. 14.

500 For the concepts of novelty and inventive step, see S. Jain, Patents Procedures and Practices, Universal Law Publishing, 2010, pp. 6, 65, 140 and 204.

501 EPO, Guidelines for Examination, Chapter III, 1. Sufficiency of Disclosure, https://www.epo.org/law-practice/legal-texts/ html/guidelines/e/f_iii_1.htm (accessed 16 April 2018).

502 J. Fromer, Patent disclosure, 94 IOWA L. Rev. 539, 606, 2009, pp. 544-560, file:///C:/Users/Lenovo/Downloads/ JeanneCFromerPatentDisclo.pdf (accessed 16 April 2018).
} 
the literature on the concept of patent disclosure has not yet been able to understand the real importance of patent disclosure because of an emphasis on aspects that remain outside the patent document. In this regard, she refers to this limitation as a current insignificance of the patent document. ${ }^{503}$

The central point of Fromer's analysis relevant to the present research is an emphasis on the patent document and on the sense it makes. The patent document is a text, in other words, a vehicle of communication, where an update of the concept of disclosure related to the linguistic structure of the document matters. That's what Fromer describes, with other words and with a different approach, when she presents a proposal to restructure the patent text (meaning: to follow some suggestions to write a patent in a way that really discloses the relevant technical information):

I argue herein that the patent document, the mechanism of disclosure demonstrated in the previous Part to be primary, does not do nearly enough to convey information useful to stimulate inventive activity because, due to the legal rules of the patent system, the document is poorly structured and does not contain some of the most pertinent technical information. These problems allow, if not encourage, the writer to under-divulge. This Section then suggests how the patent document can be restructured to vitalize its relevance in stimulating further innovation, thereby forcing the writer to provide more useful information.

In the section mentioned, Fromer describes the patent text as divided into two most relevant layers: the legal layer and the technical layer. She then observes that the attention given to the legal layer frequently jeopardizes the technical layer, in a way that patent writing does not comply with disclosure requirements. Whilst the scope of the legal layer is related to the extension and limits of the patent rights, the technical layer is (or should be) directly associated to the central premise of patents of fostering innovation, then being addressed to technologists interested in understanding how an invention works and the PTO and courts attempting to assess whether this disclosure is adequate. ${ }^{504}$

For the same author, this confusing mix of technical and legal information, normally produced by attorneys, for purposes that are more legal than technical, makes it difficult for the scientist or researcher who wants to access the content of the invention to understand it. The solution proposed by Fromer is disentangling these two layers, making them distinct, and ignoring any duplication, as, for example, in the specifications of the patent. Fromer then details her daring proposal, with explanations and examples. ${ }^{505}$

Without considering the merit of how feasible these prescriptions are for producing clearer and more adequate patent texts, it is undeniable that patent disclosure

503 Fromer, op. cit., pp. 560-563.

504 Fromer, op. cit., p. 566.

505 Fromer, op. cit., pp. 563-579. 
is related to the structure of the patent text and is not always accomplished in the current configuration of the patent system. After reading the examples given by Fromer, it is also easy to figure why the structure and writing of a patent will influence its further developments. The translated texts will probably repeat or even worsen the deficiencies of the original text. If the original text does not sufficiently disclose the technical content, the content will not be disclosed through translation.

As the present research focuses on the way patent content will be brought to a global level through its translation to various languages or its simple access to the ones interested in it through machine translation, the level of disclosure allowed by the original text is crucial to all the further stages of the patent, defining the whole functioning of the patent system at the global level and at national levels. Additionally, professional human translations of prior art documents, combined with machine translation, will influence the decisions taken in different jurisdictions through different languages and legal cultures. As described in section 1.2. of the present thesis, the notion of disclosure is central to patent law and is in the heart of the definition of patent bargain. Moreover, besides being confronted with the characteristics of the patent document structure, it is challenged by the special features of the patent language described on the previous section, and also by the structure of the patent system. Patents and patent texts are considered as impenetrable, especially when accessed by the layman or by the ones who are not used to operate patent databases as part of a professional routine. The complexity of the patent system can be explained by some of its characteristics:

a) Difficulties of reaching patent texts through expert systems and searching devices (many scientists and researchers, able to understand the technical description of inventions belonging to their own knowledge field, would find difficulties in making the best use of searching for necessary technological information through the mentioned platforms, which require prior learning and experience to be operated;

b) Difficulties of reading and understanding these texts for someone who is not an expert in that technology field (in this case, they can be hard to understand also for an examiner or attorney belonging to another field);

c) Difficulties in understanding the content of patents or even in finding some patents because of the structure of the patent text (section 3.4 discussed a case where the sufficiency of disclosure of the patent was questioned by a group of scientists);

d) Language barriers (as difficulties related to language and translation can affect everybody, from the layman, to scientists and even to those belonging more directly to the patent system or mastering the pair of languages involved). ${ }^{506}$ 
Most of the people who don't belong to a "patent environment" have never accessed a patent text nor know how to search for it or have an idea about its importance to technologies they use in their daily lives or to the economy of their countries. Not all IP experts are familiar with patent searches and with the structure of a patent document. Many scientists have never accessed patents (or benefit from them) in their specific technological field. That creates doubts about the influence of patents on the idea of open science and knowledge sharing. ${ }^{507}$ The patent system remains unreachable to most people - even to many groups who could directly benefit from it. It is accessible for a restricted group, whose understanding of it is also fragmented. That's why the patent system still counts on very limited discussion related to textual issues at a theoretical level, showing timid interfaces with related subjects that extend to language/translation and speech/discourse production. ${ }^{508}$

As mentioned, patent searching systems can seem very intricate to people who are not familiar with patent searches and so are the texts of patents. Actually, the players who best know about patent texts and search engines are probably the ones who directly interact with the patent system, as patent attorneys and patent examiners. Curiously, attorneys end up having a good knowledge of languages, besides their necessary knowledge of patent law and of the technological field they work for. Patent examiners, in turn, also acquire a high level of language knowledge, besides their necessary knowledge of the technological field of the patents they examine and of, at least, the patent law of their country or region. ${ }^{509}$ Language, therefore, for the general public, given the exception of the above-mentioned players, presents an extra difficulty for access to patent texts.

The complexity of the patent text, together with the language barriers and limitations of searching tools can be described as contradictory to the disclosure of technological content. The latest improvements of machine translation can be seen as a promising way to diminish these barriers and facilitate access to, and harmonization of, the patent system at a global level. However, these improvements should not be interpreted in isolation, and should be combined with the improvement of the searching tools and studies aiming to review the writing of a patent in terms of increasing its level of disclosure and translatability. In this sense, there is still a vast field to be explored in further studies. Some possible ways to be followed will be listed and explained in Section 8.5 of the present study.

507 For the access to the patent system related to the idea of disclosure, see: U. Jansson, Patent Documents as a Source of Technological Information, WIPO Roving National Seminar on Industrial Property, 2000, http://www.wipo.int/edocs/mdocs/ sme/en/wipo_ip_et_00/wipo_ip_et_00_9.pdf (accessed 16 April 2018).

508 See Fromer, op. cit., for a detailed explanation over the lack of a theoretical understanding of the patent document or its efficiency in disclosing technological content.

509 See an example of the description of the careers of patent attorney and patent examiner on: University of Kent [Website], Careers and Employability, https://www.kent.ac.uk/careers/workin/patent.htm 


\subsection{Sample analysis - clean energy patents: results and conclusions ${ }^{510}$}

\subsubsection{A language of innovation}

As a result of this study, it is believed that the "language of innovation" deserves to be investigated and described as such. It is not simply a "patent language", as it does not convey only the language of patent documents. In fact, it would be difficult to elaborate an exhaustive list of all the documents and oral situations that compose such a language. Some examples could be: scientific communication in general, when involving inventiveness; scientific papers related to innovative products or to associated research; the whole set of legal texts that regulate the subject both at national and international levels; all the set of documents of offices and departments dealing with technology transfer, and with interaction at university, industry, government levels, using the language (in practical and theoretical terms) related to entrepreneurship, to the establishment of incubators and technological parks.

Some of the characteristics of the language of innovation, particularly when referring to the description of inventions, are: technical precision, usage of simple and short sentences, predominance of nominal technical vocabulary, descriptive and pictorial text, predominance of sentences in a "neutral" verb tense or mode (as in English, the simple present tense, the infinitive and the gerund), parallelism (sentences which tend to repeat the same syntactic structure), besides many other characteristics that will not be described exhaustively here..$^{511}$

That may sound very similar to scientific language in general, but the language of innovation has its peculiarities. That means it may be considered as a sub-division of the scientific language, narrowing the last one's characteristics to a specific purpose: to reach the market with new products. In this regard, communication purpose is important to define technical jargon and text structure. Therefore, the fact that it is possible to recognize the distinctive nature of the language of innovation leads to the conclusion that it should be considered as such and should be an object of future studies. At first sight, it should be acknowledged that the innovation language is a global language, deeply attached to fast communication provided specially by machine translation, with a predominance of English as an intermediate language.

Patents are the main textual reference of the "language of innovation" and machine translation its main interaction channel. The language of innovation is likely to create neologisms and to spread their existence. Some (new) technical words are difficult

510 As explained in Chapter 2, which describes the methodological choices of this research, content analysis was supported and complemented by interviews. That is why information collected in interviews will be part of the conclusions of this section.

511 The purpose of the present research is not based on a linguistic contribution, but on a contribution to patent law. Linguistic characteristics and descriptions are purposely cut short here, as they are used as a mere tool to reach the legal answers intended by the research. Therefore, for a detailed linguistic approach intended to describe the mentioned aspects of what is called herein as an "innovation language", further studies focusing on the language structure of patent texts are recommended. 
to translate because they don't have a counterpart in other languages. That explains, for instance, the invasion of English words related to new electronic devices, like computers and mobile phones, in other languages. Inventions require novelty, and novelty, not rarely, requires new words or new combinations of words to be described. Sometimes, as in the example above, words are imported to one language from another. All this makes "the innovation language" a special, interactive, multilingual and fast channel of communication.

Patents being the most relevant textual reference of the language of innovation also make the "patent language" a subdivision of it, with its specific features. The innovation language (and also the patent language) is not a language in the sense of a national tongue, but in the sense of a speech with particular characteristics used in a particular context, as jargon or partial language..$^{512}$

Inventions represent a specific type of intellectual creation. For this reason, precision is another characteristic of the language of innovation, as the publication of an invention should consistently describe its content. This demand related to the patent text is justified by the need to disclose the invention universally as a requirement to hold the temporary monopoly guaranteed by a patent. That's why patents have to express the contents of inventions in a very clear way, according to the demands of the examination in order to be granted. That way should also be a translatable way, allowing therefore the disclosure of the invention at a global level in all the different available languages in patent databases.

In this respect, as detailed in the next section, one of the most important conclusions of the present research is that patents clearly disclose, to a great extent, the contents of inventions: even if the languages involved in the translated text are distant; even if the texts presented to the person skilled in the art are translated by machines; even if the reader does not have any knowledge of the original language; whether the texts are long or short. It also happens if the person skilled in the art accesses only the texts of the patents, without following the drawings and the description that go after the claims, which would make the understanding much easier, and even if the readers are not English speakers and retranslate the patents into a language (which is not strong in the patent world) like Portuguese.

However, there are still some limitations in this "Babel" represented by the patent system and its flow of communication. One of them is the fact that not all the databases or patent offices' search services offer the possibility of machine translation. That makes the machine translation services related to patents still limited and liable to a much broader expansion and sophistication. Another limitation is the fact that "older patents" of various national patent offices have not been available in digital platforms so far. ${ }^{513}$

512 For the mentioned concepts, see: N. Baron, 1981. Speech, Writing, and Sign. Bloomington, IN: Indiana University Press, p. 135-137.

513 Information obtained through interviews. 


\section{Table 10: Characteristics of the Language of Innovation ${ }^{514}$}

Main written references

All scientific written communication in general, when involving inventiveness; scientific papers related to innovative products or to the search of them; the whole set of legal texts that regulate the subject both in national and international levels; all the set of documents of offices and departments dealing with technology transfer, and with university/industry or (and) government interaction; all set of written documents related to entrepreneurship, to the establishment of incubators and technological parks.

\begin{tabular}{|c|c|}
\hline Structural features & $\begin{array}{l}\text { Technical precision, usage of simple and short sentences, } \\
\text { predominance of nominal technical vocabulary, descriptive and } \\
\text { pictorial text, predominance of sentences in a "neutral" verb tense } \\
\text { or mode (as in English, the simple present tense, the infinitive and } \\
\text { the gerund), parallelism (sentences which tend to repeat the same } \\
\text { syntactic structure), precision and clarity, presence of neologisms and } \\
\text { imported words (specially from English to other languages). }\end{array}$ \\
\hline Main associated fields & $\begin{array}{l}\text { Science and technology; law; economics; intellectual property studies; } \\
\text { technical and scientific language studies; translation studies directed } \\
\text { to this specific field should be seen as a separate study area. }{ }^{515}\end{array}$ \\
\hline Main contexts for oral manifestations & $\begin{array}{l}\text { Conferences, working and research environments involving science, } \\
\text { technology and innovation; R\&D departments; patent offices; } \\
\text { technology transfer offices. }\end{array}$ \\
\hline Relation with the scientific language & $\begin{array}{l}\text { The innovation language can be considered as a sub-category of the } \\
\text { scientific language, receiving through other influences from the fields } \\
\text { mentioned above. }\end{array}$ \\
\hline Other characteristics & $\begin{array}{l}\text { A global language, deeply attached to fast communication provided } \\
\text { specially by machine translation, with a predominance of English } \\
\text { as an intermediate language or lingua franca. Is likely to generate } \\
\text { neologisms and to spread their existence. A strategic, interactive, } \\
\text { multilingual and fast channel of communication. }\end{array}$ \\
\hline Some examples of its jargon & $\begin{array}{l}\text { Abstract (referring to patents), claims, novelty, inventive step or } \\
\text { non-obviousness, utility, industrial application, publication, prior art, } \\
\text { etc. (patent related vocabulary); triple helix, incubation, university- } \\
\text { industry interaction, open innovation, spin-off, start-up, disruptive } \\
\text { innovation, technological paradigm, etc. (economic vocabulary } \\
\text { related to the process of innovation). }\end{array}$ \\
\hline
\end{tabular}

Source: Elaborated by this author on the basis of the sample's analysis and the literature review

514 The characteristics of the innovation language and its contexts and influences are not described exhaustively, as we don't want to limit the understanding of its complex structure. Perhaps these aspects may not be portrayed in a limited set of features, as a language is a live and very intricate element by itself.

515 Information obtained through Interviews 3, 14 and 26. 


\subsubsection{Machine translation enables the disclosure of technological information through the patent system}

Searching for a patent in a foreign language may still be a tough task. Linguistic proximity is an important factor, because technical terms tend to be very similar in languages belonging to the same family of languages. That became very clear during the analysis of patents in French, Italian and Spanish, having Portuguese as the target language. Although the translation may present the same average score of other (nonLatin) languages, there is a sensation of comfort in comparing the original and translated texts given by this similarity. That probably means that the universe of a language in its general use completely differs from its technical use to access patent documents. ${ }^{516}$

That indicates that using a close language (in terms of language families) without really "mastering" this language for getting information about a certain technology may be a strategic move in certain situations. In the present research, although this author may consider herself to be much more familiar with English than with Italian, for example, it was sometimes much easier to understand the content of inventions in Italian due to the similarity of the technical vocabulary. In the same logic, it was also easier to understand the original text than the translated text. Therefore, further studies exploiting the contents of patents on translated texts considering linguistic proximity may be very useful for proposing ways of using technological information in patent banks and to suggest better organization of patent databases or better ways for scientists to exploit them.

One reason for the still poor quality of translations involving close languages is the fact that English permeates patent machine translation, including the ones related to languages as close as Spanish and Portuguese, working as a hub in statistical machine translation. ${ }^{517}$ This is an important factor which affects the value of the translated text for disclosing the contents of the patent. During the analysis, it was observed that there are very frequent cases in which cognates or sentence structures that could be easily translated from Spanish, Italian or French into Portuguese were inconsistently translated, also as an effect of the fact that these translations were not directly performed. The good news is that this situation is already being changed by the advent of neural network based technologies.

Another aspect that should be considered and can be the subject of further (more detailed) studies, is the quality of the original texts. In the present analysis, the French patents obtained the best score according to LISA-QA method, reaching an average of only 14,25 errors, which can be considered as a translation of a very high quality. That shows the level of quality of a translation does not only depend on linguistic similarity, although this is also a factor to be considered. In the case of the French patents the

516 This idea should also be the object of further studies, in terms of how much proximity of languages can help scientists access patent information, creating, for example, privileged groups of languages. This can be the object of research on how language barriers to foster innovation for the non-privileged groups could be minimized, for example, making the information more available in languages whose arsenal of technological information is scarcer.

517 P. Brown et al., A Statistical Approach to Machine Translation, Computational Linguistics, 16(2), 1990, 76-85. 
clarity of the original texts was evident, their writing being characterized by short and simple sentences and adequate text organization (parallelism to facilitate understanding, precision in the usage of nouns, general coherence among the sentences, etc.). The graph below shows the average score obtained by each language or group of languages:

Figure 17: Average score obtained by each language according to LISA-QA

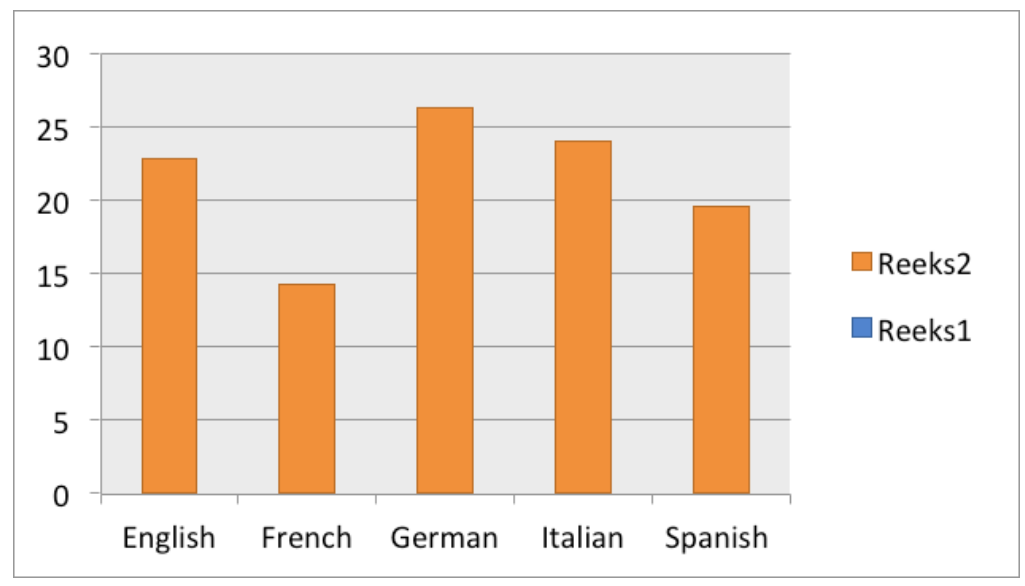

Source: Based on the results of LISA-QA's analysis

German was the language with the highest results in number of errors, which can be due to the factor of linguistic distance or be related to some characteristics of the grammar structure of the German language. By observing the texts in German, it was also clear that, contrary to the texts in French, many of them presented long sentences (in long texts), complex sentence structure with lots of subordinate clauses and intricate adjectivation. Still the difference between the lowest and highest results (in this case, French and German patents) can't be considered as a very large variation, since the difference is 12 points only (not much according to LISA's standards). Both in French and German patents, all the inventors and agents belonged clearly to French and German national origins, which was not the same with the English patents, whose number of foreign inventors was clearly considerable. Although the focus was not on the relation between the nationality of the inventor and the language of the patent, this could also be subject of further studies.

There was no significant difference in the scores obtained by type of technologies. The results were similar to solar energy and wind power technologies. The results were also similar for the scores obtained in abstracts and claims, with a small advantage for the claims in terms of quality of the translation (the average score for the abstracts was 26,5 and the average score for the claims was 22,75 ). That's explainable by the fact that claims tend to be more technical than abstracts, presenting the inventions in a more detailed 
and structured way. The fact that abstracts have to inform the contents of the patents in a concise way may result in a less clear text. Therefore, it is possible to conclude that the claims (supported by the abstract and the other parts of a patent) are the central textual part for the disclosure of the technological information contained on the patent.

This study was therefore able to show how and to what extent a patent can disclose technological information through machine translation. In this regard, some important results were reached through LISA-QA analysis. By using this methodology, it was possible to identify the types of mistakes that affect the quality of patent machine translation. The types of errors analysed through this methodology are: mistranslation, accuracy, terminology, language (syntax) and style. These errors can also be categorised (and weighted by 1, 5 or 10 respectively) as minor, major and critical. The results (average number) obtained in terms of types of errors related to error categories for English (the first analysed sample and the largest one, with 50 patents) and the general results for the Latin languages and for German are shown on the two graphs below:

Figure 18: Relation between type of errors and severity of errors - English patents sample
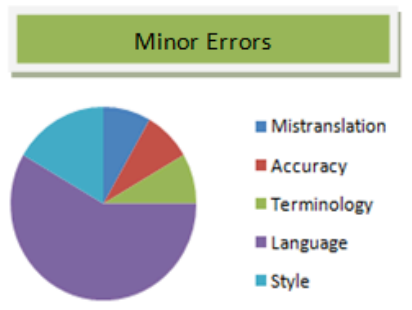

Mistranslation

Accuracy

= Terminology

E Language

instyle
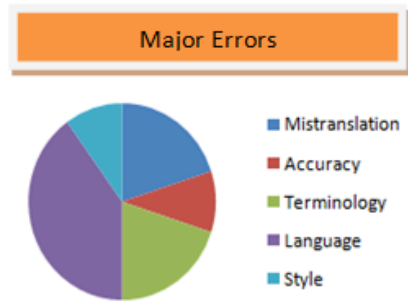

- Mistranslation

accuracy

= Terminology

n Language

astyle
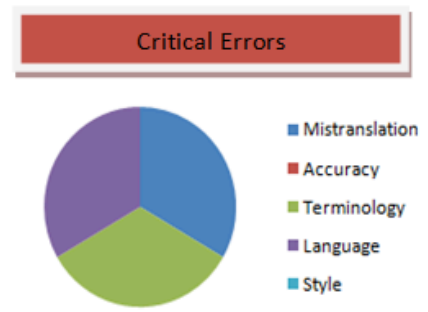

Source: Based on LISA-QA analysis

Figure 19: Relation between type of errors and severity of errors - Latin languages patents sample
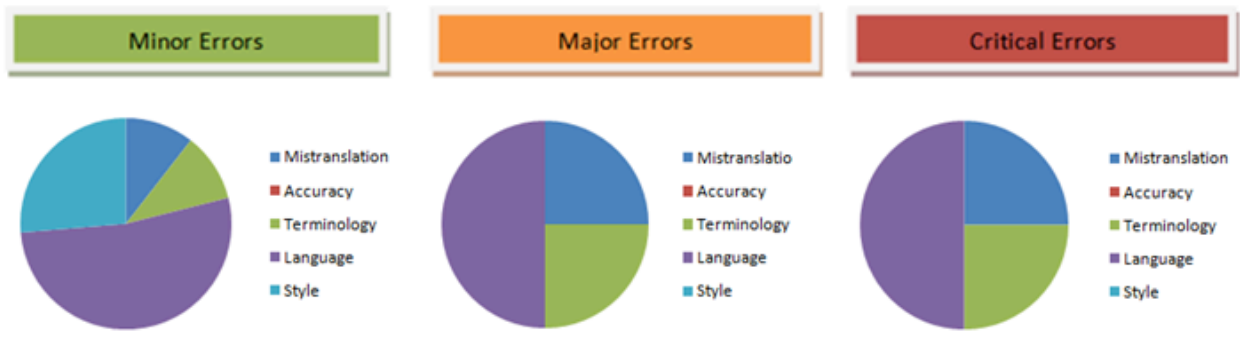

Source: Based on LISA-QA analysis 


\section{Figure 20: Relation between type of errors and severity of errors - German language patents sample}
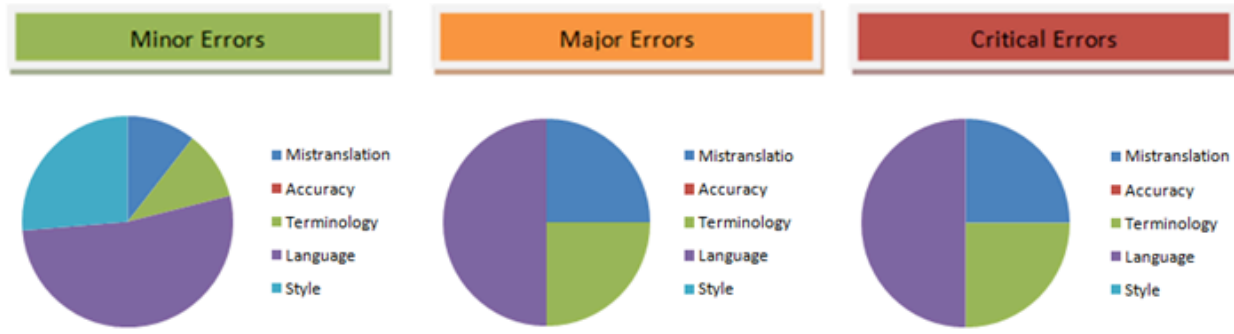

Source: Based on LISA-QA analysis

The graphs above show that the variety of errors tends to diminish as the degree of severity of the error grows. That may also have positive indications to machine translation - as the largest varieties of errors don't occur in the critical level of severity. The results also show that language structure is the most important challenge to improving machine translation, as all the languages show a considerable number of language errors in all levels, notably in German patents. German was also the language with the smallest variety of errors. That may have an explanation. As the language structure problems are frequent, also reaching the largest average in major and critical errors, the other errors that could exist cannot even be identified.

As said, LISA-QA presents a certain degree of subjectivity. However, if patent translation is made for being understood by a foreigner who does not master the original language, its results are convenient for the type of answers which are searched for in the present research. That means that even if there were inaccuracies in the analysis, most of the results show a typical understanding of a non-native speaker for machine translated patent information, supported by the view of native speakers and non-native technical experts.

The types of errors vary from language to language and also from the three different degrees of severity. German presents the largest number of critical language structure errors, with a certain margin of difference compared to all the other languages, having an average of 5 for language errors, being followed by the other languages in 2 (English, Italian and Spanish) and 1,5 (French). These numbers still do not compromise so critically the quality of the translation, as the total score should be divided by 2 (for covering 100 words).

In the other categories of critical errors, like terminology, accuracy and style, German is not discrepant with the other languages, though not presenting mistranslation mistakes. German is also discrepant in language errors for major and minor mistakes, presenting a larger number of incidences for this type of error. It also presents a larger number for minor style errors, which do not truly affect the understanding of the text. Still, 
it can be said that German/English translation presents the most discrepant results, but only in the two situations mentioned.

French, contrary to German, is the language that presents the lowest score in errors. However, it is the only one that presents major errors of style. It is also the language with the fewest language errors in all the three degrees of severity. Spanish and Italian tend to repeat the same (or very similar) scores in all categories, which is easy to explain, as both are Latin languages with many structural similarities to each other and also to the target language, Portuguese. The three graphs below are presented to give a better idea about the distribution of types of errors related to language and severity of error.

Figure 21: Average of errors according to type of errors, language and severity of error minor errors

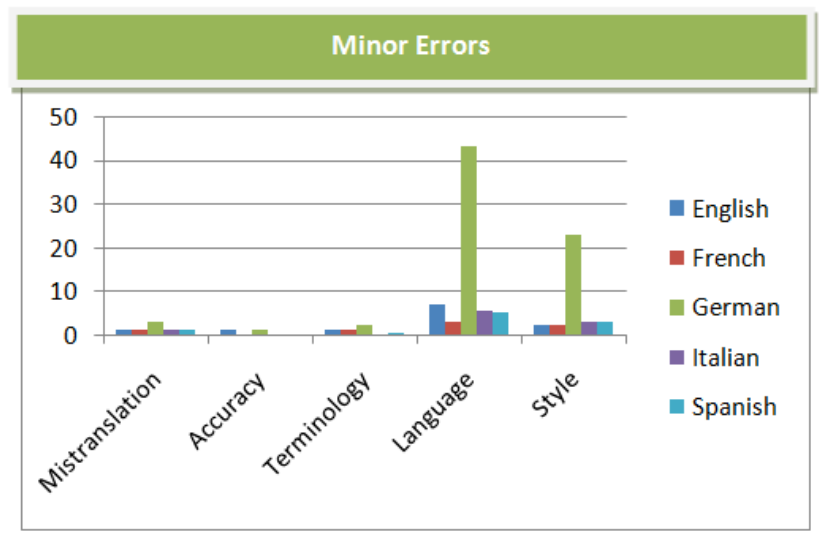

Source: Based on the analysis of the sample of clean energy patents

Figure 22: Average of errors according to type of errors, language and severity of error major errors

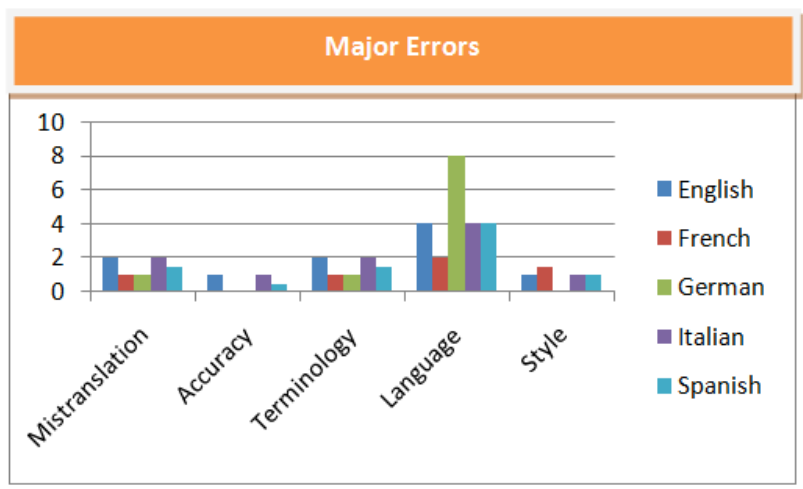

Source: Based on the analysis of the sample of clean energy patents 
Figure 23: Average of errors according to type of errors, language and severity of error -
critical errors

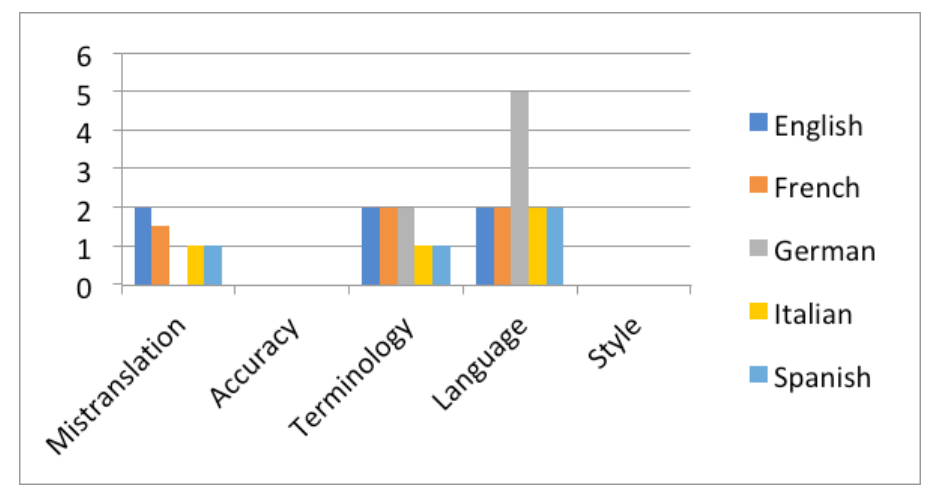

Source: Based on the analysis of the sample of clean energy patents

One of the most important findings of the present study is that patents clearly disclose the contents of a new technology through machine translation. Although the analysis was strict, tending to shoot higher in case of doubts, when considering the errors, it was still very clear that machine translation discloses the contents of the patents. This is the answer for a very important legal question in terms of patent rights, which has been asked and debated for a very long time: "do patents really globally disclose the information contained in a new technology?" This question, in turn, leads to another (more contemporary) interrogation: "does machine translation disclose the information contained in a patent document?"This last question is connected with the economic nature of patent rights and needed to be updated in association with machine translation, the main tool of communication which enables patents from all over the world to be easily and immediately accessed and understood.

That leads to another important conclusion: asking if a patent really discloses the contents of a new technology is a different question today than it was just two decades ago. The information technology tools, and machine translation, especially, have changed this question into a question that focuses on the relation of patents with language and communication in the digital era. It is important to emphasize that not all the current discussions and debates around patent rights are taking this important aspect into consideration. ${ }^{518}$

As shown above, most of the errors in all the categories are errors of language structure (or syntactic errors, more precisely). That does not contradict the problem to be considered as the main complication in machine translation in general, as machine translation fails in the accuracy in grammar, complex syntactic, semantic and pragmatic 
structures, having as results nonsensical errors in grammar and meaning processing. ${ }^{519}$

In second place, the most frequent errors are terminology errors, which grow according to the level of severity of the error. Errors of "accuracy" and style disappear as critical errors, certainly because of their own nature, as style or accuracy (the use of the most accurate word) do not totally compromise the meaning of a sentence. What the method calls "mistranslation" can convey many types of errors, the most common one being a word completely changed by another without an apparent reason, which could lead to the categories of accuracy or style. There are details about language structure errors that vary from language to language, as, for example, the use of adjectives tends to be a problem in a translation from English or German into Portuguese (and supposedly to any Latin language). The table below summarizes different specific aspects observed during the analysis of each chosen language:

\section{Table 11: Different Aspects shown by each Language}

\section{Different aspects shown by different source languages}

English Average result LISA-QA (claims) 22,75. Most problematic aspect observed and registered in the "notes": use of many adjectives in one syntagma, which makes the translation difficult into Portuguese (opposite order of adjective + noun). Larger incidence of language errors in the three types of errors.

Chinese Average result LISA-QA 32. Most of the errors are concentrated on terminology and language structure. The researchers (native speakers of Chinese) who participated on the analysis affirmed the patent was still "understandable" although machine translation produced a "bad text".

French Average result LISA-QA (claims) 14,25 (almost half of the result for English). Most problematic aspect observed and registered in the "notes": terms which have cognates in Portuguese and whose translations did not present these cognates, being not as accurate as they could be (valid for terminology and for language, as some word order which correspond in both French and Portuguese were wrongly inverted because of the interference of English as an intermediate language in MT). Larger incidence of language errors in minor and major errors and of terminology errors in critical errors.

German Average result LISA-QA (claims) 26,25 (the highest score in terms of quantity of errors in Indo-European languages). Relatively high score in language errors due to major differences between German and Portuguese in terms of language structure (position of nouns and adjectives, position of the verb in subordinate sentences are noteworthy). Relatively high score in errors (mainly in "language" and "terminology") related to composed words in German which are not properly "decomposed" when machine translated. ${ }^{520}$ The larger incidence of errors is in language errors. There is also a considerable tendency to terminology errors (probably related to composed words).

Italian Average result LISA-QA (claims) 24 (higher than English). Most problematic aspect observed and registered in the "notes": terms which have cognates in Portuguese and whose translations did not present these cognates, being not as accurate as they could be. Larger incidence of language errors for the three types of degrees of severity of errors.

519 H. Li, A. Graesser and Z. Cai, Comparison of Google Translation with Human Translation, Proceedings of the Twenty-Seventh International Florida Artificial Intelligence Research Society Conference, 2014, https://www.aaai.org/ocs/index.php/FLAIRS/ FLAIRS14/paper/viewFile/7864/7823

520 It is possible to mention plenty of examples, as the translation for 'eine Lichteintrittsscheibe' into Portuguese, 'uma máquina de lavar de entrada de luz', when it should be 'um disco de entrada de luz' (in English, it makes sense as light entry washer, but in Portuguese, the first translation refers to a "washing machine", instead of a light entry device). 


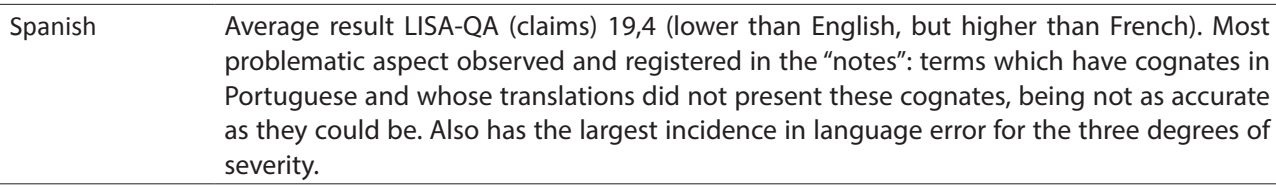

Source: Based on sample analysis

The Chinese patents were analysed separately as they required the support of Chinese native speakers who were also familiar with the patent system. For the same reason, it was only possible to reach a reduced number of patents to be analysed by a group of Master students who agreed to cooperate. However, there was the chance to talk to these same collaborators and listen to their points of view carefully about the translated texts.

All the collaborators agreed that there was a high number of mistakes on the translated texts. The average score of errors obtained through all the analysis was $42 \%$, which is considerably higher than the highest score shown by the German patents $(26,25)$ among Indo-European languages. This result indicates that the disclosure of patent information can be highly compromised when two very different languages are involved, as is the case of Chinese and English. Still, according to the collaborators, the disclosure is possible - especially with the support of the drawings in the description section and, if necessary, some technical human support.

For the types of mistakes analysed by the collaborators, the results were also different from the ones presented by the Indo-European languages, since "language structure" not the predominant category for the errors found, but accuracy and language structure (1,5 score) for minor errors, mistranslation (7,0 scores) for major errors and terminology $(6,5$ scores $)$ for critical errors. That certainly indicates that the correct translations of technical terms (terminology) from Chinese into English still has a long way to go for a better result in terms of disclosure, as the critical errors are considered as the ones with the highest level of interference in the quality of the translated text. Another point that should be enhanced is the fact that the results and considerations were not discrepant depending on the collaborator, as they tended to repeat the same opinions and scores. The graph below shows the average of score per type of error to minor, critical and major errors. 


\section{Figure 24: Relation between type of errors and severity of errors - Chinese language patents sample}

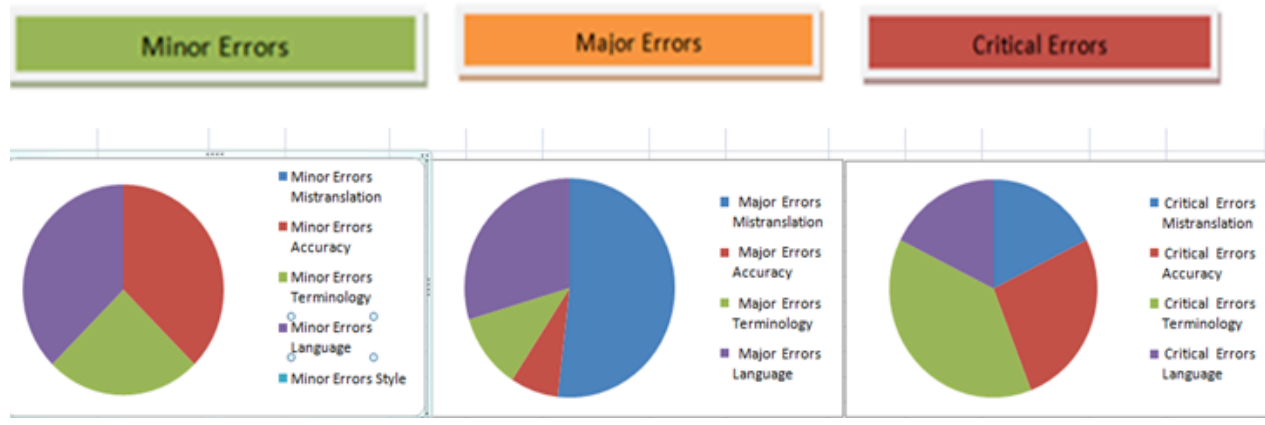

Source: Based on LISA-QA Analysis

Regarding the issue of whether machine translation discloses or not the contents of a Chinese patent, from their perspective, machine translation can be sufficient to disclose the contents of a Chinese patent, but not very accurately. The reasons the collaborators pointed to that are the following: this type of translation requires accuracy in indicating specific terminologies, which can be confusing when machine translated. It also demands some necessary arrangements of language structures, which they saw as problematic in the case of the Chinese patents. The translations present too many mistakes, if they are rigid in their analysis.

However, they added that if the content is neither too technical nor too professional in a particular field, or if the technical knowledge of the reader can truly facilitate the disclosure, the accuracy of machine translation from Chinese to English (vice versa) can be satisfied with only minor revisions, such as daily conversations. That would then depend on some basic support from a native speaker. ${ }^{521}$

They also pointed out that the cultural differences can greatly affect the efficiency with which the source text is translated into the target language. Probably the main reason for this phenomenon is that daily conversations accept more simple language structures and words than professional documents. In Chinese, as related by them, people will always try to refine the words and make it professional for this type of document, which can make the translation process more complex. The cultural differences also affect the different standards in drafting patent claims.

Language and culture discrepancies are not the only obstacle to the disclosure of patent information. It is not always possible to obtain machine translation in searching platforms. It also depends on between which languages the translation is to be made. For instance, it was not possible to obtain direct translations from Spanish into Portuguese, which made it necessary to copy the text and use Google Translator for obtaining the translation. It is also more difficult to select patents in some languages than in others. 
That depends on factors such as knowledge of the searchers related to the languages searched, availability of the patents in their original language and in English, keywords (and the languages that these keywords can reach) chosen for the search, and also on the platform being used for the search. That all leads to the need for simplified and complete platforms that enclose all different national systems, where searchers find most of these solutions in only one place. Currently, the advantages of one database may still be very different from the others - and it is clear that many of these systems do not "communicate" with each other. In sum, the content of inventions should be protected, but not the content disclosed by their patents.

The idea is not only valid for the databases or expert systems where the patent documents or information are available, but also for the legal system concerning patent regulations and guidelines and the whole set of theoretical concepts belonging to national systems that may be more or less related to the guidelines of the global patent system. The fact is that the dichotomy between national (isolated/fragmented/territorial) systems versus an international (global/multilingual/network based) system is central to understanding the patent system. In this respect, a system that has huge impacts on research and trade at a global level should not be interpreted as an isolated or fragmented structure. The second set of elements of the mentioned dichotomy should prevail over the first ones.

Therefore, as the patent system responds to international expectations, it should be seen as a global, multilingual, complex apparatus which demands minimum levels of integration and harmonization from the national systems. That is valid for the economic and legal implications of its existence. This leads to the conclusion that the more a national system is aware of this necessity of harmonization and integration, and aware of the very nature of the patent system, the more successfully this system will reach a level of excellence in offering its services at the global level, from both the legal and economic perspectives.

All the information collected from the databases (and through interviews) shows quite clearly that English is the central language of the patent system, which does not really (or totally) mean it is a lingua franca. ELF is certainly valid in certain situations and regions, but it is still not possible to generalize. In the case of the European Union, the exit of the United Kingdom from the Union (the so called "Brexit") raised new linguistic issues - which could also somehow influence both the European and the Unitary Patent. The "Brexit" made it clear that political, economic and linguistic issues walk together in supranational systems, as it even led to thoughts of excluding English as an official language of the EU, and from the European Patent system. ${ }^{522}$

522 The discussion ended up in the statement that English remains as one of the EU official languages, but, for some days, that was not as obvious as expected. About this discussion, see: S. Morgan, English will remain an official language of the EU, Euractive [Website], 2016, https://www.euractiv.com/section/languages-culture/news/english-will-remain-an-officiallanguage-of-the-eu/ (accessed 18 April 2018). 
Being an important element of economic and legal systems, language is also a natural barrier to integration and communication. In the case of the patent system, it is important that it does not work as a parallel strategy for protection or secrecy, as the function of patent rights is to universally disclose the technical and scientific information contained in patent documents.

The average score of the total of patents which were analysed shows that, in general, machine translation produces a reasonable level of quality in patent translation, having an average score of 20,1 (including English, French, German, Italian and Spanish patents). That does not mean there are no isolated cases of very inaccurate translations, as, in the analysed sample, a patent text in German, which reached the highest score of number of errors (75\% of errors). There were also cases of extremely accurate translations, as the one reached by a patent whose original text was in Spanish (scoring only 3\%).

The fact that machine translation, in general, fulfils the raison d'être of the patent system does not mean that it cannot or should not be improved. There are many aspects in which this systemic association (patent information disclosure + machine translation) should be enhanced in order to reinforce the credibility and fairness of patent rights. Below, some aspects related to the improvement of the association between patent information disclosure and machine translation are presented.

It is understood that patent databases can still be considerably improved and bring new functionalities, especially to scientific audiences. Even though these platforms have advanced a lot in the last decade, they can offer a whole new variety of possibilities of search. It is also important to argue that the advent of semi-automatic search platforms does not affect the necessity of improving the existing search engines and of creating new ones. ${ }^{523}$

\section{a. How may patent systems and databases contribute more to the disclosure of patent information?}

In terms of possible improvements in patent databases and search engines (referring only to the analysed databases), there are some conclusions and recommendations:

- The analysed databases and search engines offer no possibilities of searching by language, except for Espacenet, which enables searches in the worldwide collection in German, French and English. Espacenet also enables a search per patent office or type of patent (in the case of the European patent and WO patent). However, if one searches for "CN patents", for example, the results will show the titles of the patents as "not available".

- Filters allowing searches per language would be useful for facilitating the access to technological information in many ways, especially if they could

523 See an article containing a discussion over semi-automatic search tools on: 'Looking for answers on Ansera', IPKITTEN [Blogspot], 2017, http://ipkitten.blogspot.de/2017/11/looking-for-answers-on-ansera.html?m=1 (accessed 16 April 2018). 
be combined with filters allowing searches by nationality. Filters which allow searches by nationality give different results from filters which would allow searches by original language. There is still a lot to be developed and improved in patent databases in this sense. The searches are still limited in terms of a language approach, considering that language and translation are the bases of communication in the patent systems.

- Many titles of patents are not translated in Patsnap. Therefore, if all Chinese patents on solar energy are wanted, the results of the search will be hundreds of pages in Chinese, for example, having also the titles of many of the patents in Chinese. The only way to access the contents of the patent, in this case, is accessing each one of the patents abstracts, which takes time and can be quite discouraging for less experienced searchers, who intend to exploit the technological information of the mentioned patents. This example is quite emblematic of one of the most representative obstacles to the disclosure of patent information through machine translation, although it refers to a problem concerning the search engines, which is not directly related to the MT engines.

- Darts-IP does not allow searches per language but enables searches per patent office/type of patent. It also shows the translation of the title of the patents in English, if one searches, for example, a patent from SIPO using the "free text search" for "solar energy". However, Darts-IP is a legal platform, not giving access to all the information available on the other two systems.

- The search engines could use the advantages of language similarity for creating new filters, in order to facilitate the research on technological information involving similar languages.

- The same way databases should include search engines filters "by language", they should allow the exclusion of languages in the search. An example of the utility of this possibility is the fact that, during the searches performed for this research, it was not enough to exclude the filter for SIPO patents to avoid patents whose claims were in Chinese.

- It would be useful to be able to cross original language and place of application/ type of patent in search engines. Therefore, if the searcher wants WO patents whose original language is Chinese, there should be possibilities for filtering the two kinds of criteria.

- Developing filters for searching by nationality of the inventor or the applicant could also be useful for certain types of search.

- The language and the "universality" of the keyword used in the search changes significantly the results of the search, which differs also in each database. In the three databases mentioned, the search for the term "solar" gives a wider range of results than the term "wind", for example. A scientist would tend to 
operate a search in English or in his native tongue. The search engines could give more possibilities of search per keyword, for example, redirecting the search to one language or to a group of languages (by using the same word in these languages). That also confirms the importance of having an awareness of the multiple possibilities of this linguistic mosaic at the time of the survey. In the above-mentioned example, the term "wind" gives results in English mostly, and the term "solar" offers a broader variation of languages.

In terms of possible improvements in machine translation used in patent search platforms, the following conclusions and recommendations should be considered:

- The advantage of language similarity should be more exploited in order to avoid unnecessary inconsistencies between languages as close as Spanish and Portuguese or languages from the same linguistic families. There are already many studies concerning this issue, ${ }^{524}$ but there is still a lot to be done in practice for combining better patent machine translation and search engines.

- The translation of patents from German into Portuguese presented the poorest quality. That may be valid for other languages (except English) which do not belong to the family of Latin languages. Further interdisciplinary studies are necessary to confirm this conclusion and to present solutions for this limitation of MT used for languages which are very different in terms of syntax. This also indicates that machine translation has improved more for: a) groups of languages which, lately, have been receiving concentrated efforts in terms of patent translation (especially English, Japanese and Chinese) ${ }^{525}$; b) specific groups of languages of the same family, as was the case of the Latin languages analysed in this research; two languages when either the source or the target language is English. These characteristics clearly compromise the disclosure of patent information when the languages involved do not belong to one of the three groups described above. However, as observed before, this reality is changing.

- There is still much to be developed in terms of terminology translation, as confirmed by the percentage of errors of terminology in all levels of severity, with the minor terminology errors being the most frequent ones. This shows that terminology does not always completely obstruct disclosure, but its translation accuracy can be improved in order to assure better communication. Studies evaluating the possibility of exploring crowd sourcing among scientists whose native languages are considered as more peripheral inside the patent system could be an adequate way to expand the interest in intellectual property in their countries. Also some national databases seem to be better than others in providing information disclosed by patents.

524 See the studies of Hajič et al., 2000; Brown et al., 1990 and Brisset, 1990.

525 Information collected directly with interviewees and through LISA-QA based assessment. 
In terms of other possible improvements that could be exploited in further studies:

- There are still many possible topics of research relating patent searching systems and devices to language and translation. The users of the system are not always conscious of the limitation of their searches and the unlimited possibilities of improvements in search tools related to language and translation. ${ }^{526}$ Research involving the daily routine of examiners in different countries and the possibilities of improving and crossing the information contained in different systems through different devices can bring relevant results for the improvement of patent information disclosure.

- Any method used for analysing the quality of machine (or human) translation will present subjective aspects and may imply a considerable margin of error. In the present analysis, it was decided to shoot high in counting the errors. In case of doubt, the error was classified according to the highest score for severity. Other methods and other studies evaluating machine translation quality in the patent system are important and necessary.

- Still according to what was suggested in the previous paragraph, searches could be faster, more varied and led by a broader rank of possibilities. That would not serve only patent examiners. More sophisticated functionalities and tools would be especially interesting for the technological use of these systems. In this sense, studies on possibilities of individual language and language grouping filters could offer new possibilities. A tool which would allow finding all the patents worldwide, whose original language was Chinese, automatically translating their titles into English and allowing a search with key words in English, for example, could be very helpful for the use of patent databases for research and development. Another example would be a database which would "translate" the text of patents into simpler texts, for educational purposes.

- If a survey of the languages used in the documents cited in the search report of a patent examiner in Brazil were done, it would probably show that $80 \%$ of the investigated documents were in English. That is a consequence of the fact that examiners make their searches mainly in English. Having search devices in Portuguese in Espacenet, for example, or other free databases, might be interesting for the examiner in terms of shortening the prior art investigation, for understanding whether in fact the invention is new before finding a basis for his decisions about an application. But for the examiner that seems more

526 This lack of consciousness of the possibilities of improvement of search systems and devices, observed in the interviews, is natural, as it's not part of the routine of a patent examiner (or any other user of the system) to evaluate and improve prior art search. However, the interviews with patent examiners were still a rich source of information for understanding communication flows inside the patent system. 
important when he wants to search in a national database. Everything changes when the searches are made by inventors or by less experienced researchers. ${ }^{527}$

- According to the patent examiners interviewed, the search by type of patent is not very useful for examiners because they are interested in the art, either if it is a utility model, or an invention, granted or not. The search by office is also not always useful, but a search by language could be interesting to find documents in Portuguese, in Brazil, for example, since they would get them faster, without having to use the database of INPI. ${ }^{528}$ The above-mentioned types of search mechanisms would be especially interesting for other types of research, such as the one whose aim is the technological use of patent databases or the ones aimed at e-discovery.

- Developing countries should invest more in language and translation related patent studies. First because this would be a way to encourage leaving a position of isolation in the IP international system. Second, because there is a whole new field to explore on the border of law, economics and language and translation studies, which offers an opportunity for consistent scientific contribution.

- Studies associating the nationality of the inventors, the locality of the applicants and the language of the patent applications with machine translation could also reveal important information for the patent system.

- Studies associating the quality of writing of the original texts and the texts translated by machine could also bring relevant information for improving disclosure and communication. In this study, it was clear that long and confusing original texts tend to produce more errors in their machine translated versions.

- Patent databases are still limited in terms of language and translation. In this regard, the expansion of the possibilities of search would facilitate a larger range of results, including the ones focusing on language and translation in order to improve the disclosure and dissemination of scientific information. That would also be very relevant for facilitating the retrieval of information to form a basis for patent court cases. In this type of study, interviews with patent attorneys and legal technologists are recommended.

The table below shows some of the advantages and some of the limitations of the three databases analysed in terms of language and translation.

527 Based on interviews with patent examiners.

528 Information received directly from patent examiners. 
Table 12: Advantages and limitations of patent databases in terms of language search

\begin{tabular}{|c|c|c|}
\hline Database & Advantages & Disadvantages \\
\hline Espacenet & $\begin{array}{l}\text { - Possibility of search by language in English, } \\
\text { French and German. }\end{array}$ & $\begin{array}{l}\text { - These are the only languages in which it's } \\
\text { possible to make a general search in the } \\
\text { worldwide collection of } 90 \text { countries. } \\
\text { - Although it's possible to operate searches } \\
\text { by patent office/type of patent, the titles } \\
\text { of the patents do not always appear in } \\
\text { English, appearing also as "non- available" } \\
\text { or in the original language. }{ }^{529}\end{array}$ \\
\hline Patsnap & $\begin{array}{l}\text { - Possibility of search by patent office or } \\
\text { nationality/type of the patent. } \\
\text { - Possibility of obtaining the economic } \\
\text { importance or "value" of the patent in each } \\
\text { patent (there isn't a search filter for that, but } \\
\text { one could exploit the possibility to cross this } \\
\text { information with patent nationalities) }\end{array}$ & $\begin{array}{l}\text { - It's not possible to search by (any) } \\
\text { language. } \\
\text { - Many titles of patents are not translated. } \\
\text { - Although the system "promises" to give } \\
\text { the versions of each patent in some } \\
\text { languages (it differs from patent to } \\
\text { patent), it's not possible to find these } \\
\text { versions in many of these patents. }\end{array}$ \\
\hline Darts-IP & $\begin{array}{l}\text { - Possibility of search by area, country or Court. } \\
\text { - Possibility of visualising translated titles of } \\
\text { patents searched by area, country or Court } \\
\text { (quite advanced in comparison with the } \\
\text { other two databases). } \\
\text { - Possibility of searching by document } \\
\text { language in searches for case law documents. }\end{array}$ & $\begin{array}{l}\text { - Darts-IP is a legal platform, focusing } \\
\text { on legal cases. Therefore, although it } \\
\text { is more complete than the others in } \\
\text { terms of crossing nationality/language/ } \\
\text { scientific information, it does not allow a } \\
\text { search focusing on economic aspects, for } \\
\text { example. }\end{array}$ \\
\hline
\end{tabular}

Source: Based on the content analysis and on the interviews with examiners

Although the Google Patents platform was not used in this research, one aspect related to this platform caught the attention. Examiners in Brazil prefer to use Google Patents instead of Espacenet, seeing on it a more functional platform. They alleged the documents retrieved are more relevant and the platform ranks the documents by subject, not performing a literal search, as do the other platforms they have been working with. They affirmed they do not know how it happens, but the results seem to be more relevant. ${ }^{530}$ They listed the other following reasons to prefer Google Patents:

1. Google Patents retrieves documents by order of relevance (although the default is supposed to sort by classification);

2. It is possible to use more key words than in Espacenet. When you use four key words, the platform presents the results with highlight colours for each term, which helps the examiner identify the information he needs;

3. Google Patents already shows on its first screen a preview of the sections that interest the examiners, which saves time in the examination process;

4. The platform offers proximity operators, which helps finding more precisely the required information for analysing the prior art;

529 That depends on the type of application. In the case of BR (Brazilian) patents, the search gives titles in English and Portuguese, which probably is connected with the patent being or not a WO patent, as in Brazil, applications should be mandatorily in Portuguese.

530 Information collected directly in interviews with patent examiners. 
5 Espacenet limits the number of search terms, which makes the search less efficient;

6. Google Patents already suggests a classification in its first screen.

7. Another advantage of Google Patents is that it seeks Japanese patents and already shows the document (including descriptive report) translated into English.

8. The impression of the examiners is that the Google search algorithm goes far beyond the match of terms than the one of Espacenet, for example;

9. The operations of searches on Google Patents are more intuitive than on Espacenet, in addition to being universally used (it is easier to match these searches with other types of searches on the internet);

10. When the search employs only terms or key words, examiners believe that Google is more efficient than Espacenet; but when it comes to bibliographic data, they believe that Espacenet should be more efficient, given its database structure. After getting to this conclusion, they asked: "until when?";

11. If the searching tools of Espacenet are compared with the ones of DEPATISnet, it is clear that the last one has fewer resources. The same is valid for the searching tools of JPO, KPO, SIPO, New Zealand and Australia, and probably for any other of the most important patent offices worldwide. For obvious reasons, this is even more valid for platforms which give access to the information of smaller patent offices or patent offices of developing countries.

12. The patent examiners consider the translation tools in Espacenet as very efficient and useful, although they see they can still improve (it was clear that Espacenet presents advantages to the other platforms in their opinion, in this case). The association between the translated paragraphs and the original text is considered as very helpful. ${ }^{531}$

Patent examiners are only one "corner" of possible approaches to the patent system at the global level. Many other players would offer a different view of patent search possibilities and possible improvements of searching databases and engines. Just to mention a few of them: scientists and/or inventors; R\&D department managers; academic researchers of law; academic researchers of economics and other fields intended to investigate the patent systems; lawyers, judges, experts and other legal players dealing with administrative or court cases involving patents; "IP professionals" in general (translators, managers of public institutions and TTOs, etc.).

After presenting the conclusions above, it is important to retrieve one of the fundamental questions at this point and obtain some answers and confirmations: how much of the information contained in patents is disclosed through machine translation? The answer allowed by a first view of the results of the analysis was "much", or "around 
$80 \%$ of it (which may mean totally or almost totally, in most cases, if the texts were not considered and analysed in isolation, and researchers were given support of drawings, descriptive reports, and other sources of information).

However, the impressions given by examiners reveal more than differences between searching tools, as they give evidence that disclosure also depends on these tools and on their interaction with them. Likewise, the way the examiners describe these platforms clearly confirms that harmonizing, exchanging information and expanding systemic rules, gathering efforts for improving their functioning, is very advantageous for patent law in many ways, as this real and confusing "Babel" needs to be simplified and understood in order to better attend to the interests of all the players involved, especially in terms of the legal and social interests associated.

In this sense, fragmented systems are not able to fulfil the main reason for the existence of the patent system at the global level and the main justification for the exclusive rights assured by a patent: the disclosure of patent information. In this regard, the existence of patents per se does not guarantee the disclosure of their contents. And the fact that they are disclosed does not mean that they are efficiently and fairly disseminated. Disclosure does not truly happen if, for example, a Latin American scientist interested in what is happening in China around a specific technology does not have easy, intuitive and fast access to Chinese patents (considering even, and especially, the ones published only in China). It also does not truly happen if the ways attorneys have to follow to retrieve this information are too long, too intricate or so full of intermediary agents that it loses its reliability in a specific national patent system.

Therefore, fragmentation may corrupt the patent system, which should be seen as an international system by nature. As science is characterized by its universality, so should be the disclosure of patented innovative inventions. Moreover, the concept of novelty is absolute when it comes to granting patents to new inventions. The more integrated the sub-systems are to the largest global system, the better it is for maintaining its integrity and improving its efficiency and fairness.

That confirms the ground-breaking character of the European Unitary Patent and the European Unitary Court and the importance of thinking and researching possibilities for patent supranational systems and, if not so far, at least for more cooperation and understanding around patent rights. This is also confirmed by the benefits brought by the PCT, which enabled many of the translations currently available in databases, and much of the existing information about patents worldwide. That would have been impossible to reach in a fragmented system and that also shows much can still be done for improving the patent system in terms of harmonization and integration.

Understanding the patent system through language and cultural aspects means understanding the patent system per se, as it is deeply related to language and (especially legal) culture. The multiplicity of patterns and ways to operate searches is a handicap and it needs to be understood and improved. For a researcher or a small company, 
searches still represent a great difficulty, and, sometimes, an unnecessary waste of time. It is impossible to find all the necessary information in the same place, and crossingreferencing information can be quite difficult when linguistic distance is too long or when the information needed is available only through costly platforms.

Confirming the language analysis done in Step 1 (Section 2.3.1) required contacting researchers working in the technology field of the sample, proceeding to Step 2 of the analysis (ibid.). These researchers were asked to analyse three different machine translations for three patents, the first one having German as its original language; the second one, English; and the third one, Chinese. The researchers did not know the original languages of the patents, as they received the machine translated texts in Portuguese. The translations of the two first patents were obtained by Patent Translate. The translation of the third patent was first translated into English by Patent Translate and then submitted to Google Translator for a translation into Portuguese.

The participants are members of Government, University and industry. First, it was necessary to contact their managers to ask for permission for the collaboration with the research. Then a form was sent to them with the three patent texts, as explained in detail in Chapter 2. It was challenging to find candidates who agreed to collaborate, as the set of patents and questions contained long texts, resulting in a form of 10 pages. ${ }^{532}$ It was chosen to be strict in this cooperation, selecting the parts of the patents that would lead the researchers to focus only on the text of the patent.

That is why they were only given access to the abstract and the claims, not being allowed to consult the description or the drawings. They were unanimous in stating that if the texts were combined with the drawings or if they had access to the specifications of the patent document it would have been much easier to understand the translation. Even so, they were unanimous in concluding that machine translation, in general, discloses patent information, giving details about their perception of the translated texts. The purpose of that part of the research was making sure that the results given by Lisa-QA, in the first steps of analysis, would not be dissonant with the perception of the persons skilled in the art, considering they are the most relevant players to whom patents are disclosed.

Four researchers helped carrying out Step 2. And this number was considered enough for the following reasons: repetition of opinions of the researchers; availability of this specific public to participate; difficulties and time wasted in the analysis, as the texts were long and required close reading; the fact that this step was mainly used for confirming the first step, which already required exhaustive analysis of 100 patents.

The researchers were unanimous in responding that the three machine translated texts were not clear in describing the content of the invention in a way that is easily understood or replicable. However, they considered the texts still clear enough to disclose the inventions contained on it and were also unanimous about that. The ones who marked the answer "disagree" referring to disclosure of the invention, justified that 
they did so because the invention did not really belong to their scope of knowledge, adding they had not dealt with that type of technology in practice.

One curiosity is the fact that Text 3 was considered the clearer one by the four researchers, both in terms of textual structure and in terms of scientific disclosure. That was not expected due to the fact that the original language of Text 3 is Chinese, a language which is much more distant from Portuguese than German or English (corresponding to the other two texts), both in terms of origin and structure. That clearly proves that the way the patent document is written may interfere with more than the original language in its disclosure through machine translation. Another interesting common observation is related to Text 1 (machine translated from German into Portuguese). The researchers noted that the fact that the claims make too many references to the drawings (which were not available to them) made its understanding very difficult.

In addition, they observed that Text 2 (English-Portuguese) was very technical, with some errors of translation of technical terminology. They also noticed that Text 1 presented a confusing description of the components of the invention and that the fact that Text 3 brings an algorithm and brings more concise and clear writing made its understanding easier. From the observations about the difficulty in understanding Text 1 (German-Portuguese), it was concluded that the association with the drawings would probably change the reaction of the researchers and that the fact that the invention itself brings a simpler or more complex inventive step can also interfere with any understanding gained through a machine translated text in a foreign language. The three analysed patents were granted. It was not possible to find the commercial value of Patent A (Text 1 - originally in German), but Patent B (Text 2 - originally in English) presented a value considered as very high $(\$ 1,000.000,00)$ and Patent $C$ (Text 3 - originally in Chinese) presented a low market value $(\$ 5,400,00)$, which does not necessarily diminish its commercial importance.

The observations given by the researchers clearly show that more technical details and a clearer structure would increase the translatability of the original texts through machine translation. They also made it clear that working with "the layers" of the patent text, giving attention to clear writing of the technical layer ${ }^{533}$ will increase the level of disclosure of the original text to other languages through machine translation, making the patent system more reliable and efficient.

\subsection{Conclusions and correlation of the chapter with the research question}

Chapter 4 explained the structure of the patent system in association with language and translation and the characteristics of the patent text. The subsequent step, described on Chapter 5, was analysing the level of disclosure of patent information 
through machine translation, as part of the answer to the proposed research question. The results of the analysis of a sample of 100 patents demonstrated that the average level of disclosure of technological information through machine translation is almost $80 \%$. It is a high score, considering the current standards of translation assessment. The sample analysis did not include the related drawings on the description section of a patent document, which could have raised the level of disclosure to almost $100 \%$.

The conclusion was based on the manual analysis of a sample of clean energy patents, through a methodology called LISA-QA. This method was complemented with a thorough analysis made by scientists (representing the person skilled in the art), who work in the field of the sample technologies. The survey confirmed the results of the first step of analysis. The results showed that the quality of the translation still depends on the pair of languages involved and on the structure of the original text.

Those results are important to answer to the argument that patents do not really disclose their content. The level of disclosure of technological information through patent documents is still frequently questioned and used to oppose the existence of the patent system. On this point, the present thesis demonstrated that patents do not only disclose technological information, they do it in a universal level, with the support of machine translation and digital platforms.

Chapter 5 also glossed over the idea of disclosure as a polysemic concept. On this matter, the definition of disclosure is far from being consensual in distinct jurisdictions. It varies according to national law and theoretical approaches. It also counts on different interpretations related to legal sources in contrast with theoretical sources. Disclosing technological information is one of the main justifications for the existence of patent rights. Hence, the concept still requires a more integrated perception of its current role to the patent system.

The definition of disclosure and the perception of its importance as a means to foster innovation is also contingent to national law and cultural approaches, especially over related concepts, such as the ones of novelty and inventive step. This thesis brought up the main legal and theoretical references that associate translation and disclosure in the European patent system. However, further contributions that may compare other national regulations and approaches and bring solutions in terms of a more harmonized understanding of the concept of disclosure are recommended.

Chapter 5 concluded that translation is a vehicle to patent rights and that machine translation universalized the disclosure of patent information. The next Chapter, which confirms this thesis, analyses the influence of translation in cross-border patent agreements. It reports to some of the most important agreements in patent law, namely, the PCT, the European Patent Convention and the European Patent with Unitary Effect. Those agreements were particularly chosen because they demonstrate a tendency to integration and harmonization in the patent system, as debated in Chapter 1, which 
is deeply associated with the thesis that (especially machine) translation has reshaped patent law by universalizing the disclosure of patent information. 
CHAPTER 6 


\section{Patent translation and its influence on cross-border agreements}




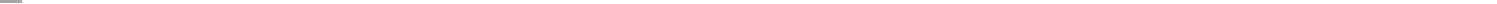




\subsection{The Patent Cooperation Treaty (PCT): patent information, language and translation}

\subsubsection{Regulations, history and operation of the PCT}

The previous chapters demonstrated that the patent system is located in an intercultural, multilingual space, which covers a huge volume of technological information from different countries, in many languages. The purpose of this Chapter is to show that the influence of translation on patent law starts from cross-border (international and regional) agreements and guidelines, which represent the foundation of what can be called the global patent system. This Section discusses the translation regime of the PCT and the advantages of the Agreement to harmonize patent law at the global level. First, it presents a brief history of the PCT and explains, in general lines, the way it operates in order to facilitate patent protection in all its Member States. Describing the functioning of the PCT is relevant to explain its importance to the dissemination of disclosure of patent information. After all, the PCT configures "the international patent system" par excellence. ${ }^{534}$

The Patent Cooperation Treaty, or PCT, is an agreement that, as is clear from its name, aims to intensify cooperation between States on patents, streamlining the path of patent application claims from application to grant, improving the dissemination of technical information that makes up the content of these patents. Therefore, it is important to note that the PCT does not grant "international patents", as is commonly thought, but facilitates cooperation and patent applications filing between the signatory countries.

Administered by the World Intellectual Property Organization (WIPO), the Treaty entered into force on 24 January 1978 and was amended subsequently in 1979, 1984 and 2001. Since then, it complements the Paris Convention in the pursuit of patent rights. While not providing the grant of "international patents", as stated above, it enables requesting patent protection for an invention simultaneously in a group of more than 145 countries, instead of filling several separate applications nationwide.

The work and the responsibility of granting patents competes exclusively to each of the patent offices of the countries where protection is sought, or offices designated by these countries, which is in line with the Principle of Independence of the Paris Convention. The decision of granting a patent is exclusive to the Board of a designated country, keeping also the Principle of Territoriality. ${ }^{535}$

The PCT's innovative nature occurs, as explained above, because the Treaty allows the simultaneous application for protection in a number of countries through the filing of a single international patent application. This brings various advantages over the request made traditionally through the Paris Convention, such as avoiding the multiplicity of filing

534 That is how WIPO refers to the Agreement. See: 'PCT - The International Patent System', WIPO [website], https://www.wipo. int/pct/en/ (accessed 7 December 2018).

535 SeeWIPO's PCTYearly Review 2015, pp. 11-14, http://www.wipo.int/edocs/pubdocs/en/wipo_pub_901_2015.pdf(accessed 17 April 2018). 
requirements; avoiding the multiplicity of research publications; avoiding the multiplicity of tests and procedures; and reducing costs, such as costs with translation and required national fees. ${ }^{536}$

One of the main advantages offered by the PCT consists of the possibility for the applicants to assess the market conditions for their invention during the international phase of the application. The patent filing on the PCT postpones the major costs associated with internationalizing a patent application. The applicants thus gain time to select the most receptive markets for the patented object and can optimize their subsequent cost of translation and national fees in the national phase. Without the PCT, an applicant would have to file an application in each country to have the same priority range given by the PCT with a single application.

Moreover, the fact that the PCT consists of an integrated system brings a number of other advantages, quite significant from the point of view of scientific and technological development, such as providing a strong basis for patenting decisions; harmonizing formal requirements, protecting from recurring errors and evolving to meet the needs of users, by enhancing functionality and creating more integration. The PCT is available to large corporations, universities around the world and research institutions when they need to seek patents at the international level. ${ }^{537}$

All nationals or residents of a Contracting State of the PCT can file an international application. In most cases, PCT applications can be presented in the National Office, which is the PCT Receiving Office. Once the international application is made, it produces the same effects as a national application in each of the PCT signatory countries that has been designated by the applicant in the application. ${ }^{538}$

The rules applicable to international requests, which include all contractors Countries, were internalized by those countries, because the differences in national and regional standards implied a multiplicity of procedures and higher costs. As a result, the international application causes one set of expenses, to be disbursed in a single currency in the Receiving Office, which reports to the International Bureau representing the International Searching Authority competent to carry out the researches. The fees for an international application are the transmission fee, intended to remunerate the work of the Receiving Office; the search fee, intended to remunerate the work of the Administration in charge of the international search; and the international fee, intended to remunerate the work of the International Office. ${ }^{539}$

536 WIPO, Patent Cooperation Treaty (PCT), Done at Washington on June 19, 1970, amended on September 28, 1979, modified on February 3, 1984, and on October 3, Art. 3, 2001, http://www.wipo.int/export/sites/www/pct/en/texts/pdf/pct.pdf, (accessed 17 April 2018).

537 See M. Bryan, The Patent Cooperation Treaty (PCT): Use and Future Developments [presentation], WIPO, Geneva 2014, http://www.aipla.org/learningcenter/library/papers/roadshows/2014WIPORoadShows/Shared\%20Documents/PCT.pdf (accessed 17 April 2018).

538 See Arts. 9 and 10 of the PCT.

539 See Regulations under the Patent Cooperation Treaty (as in force from July 1, 2017), Rules no 14, 15 and 16, http://www. wipo.int/export/sites/www/pct/en/texts/pdf/pct_regs.pdf (accessed 17 April 2018). 
Figure 25: Overview of the PCT System

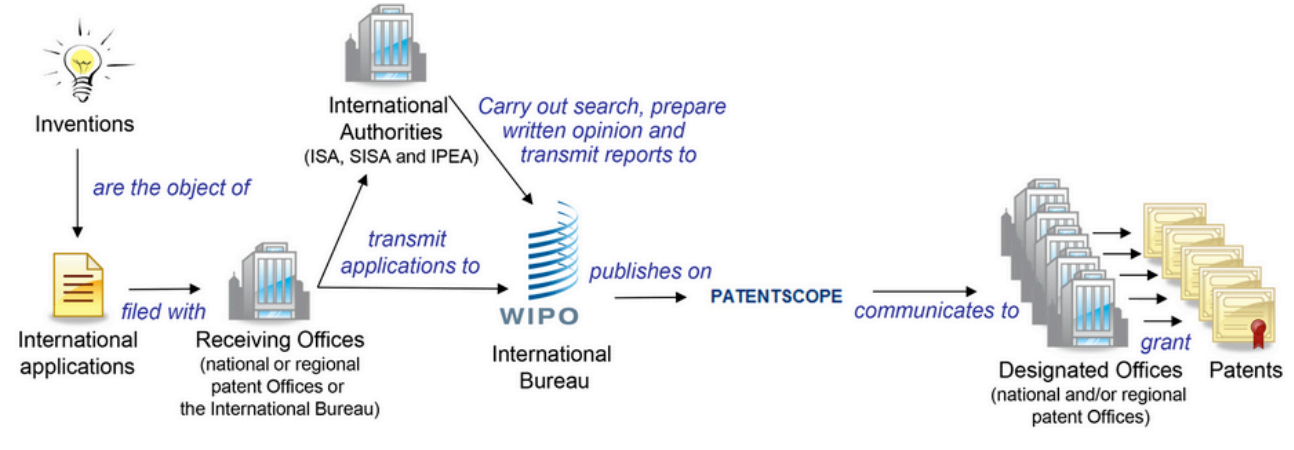

Source: WIPO PCT FAQs ${ }^{540}$

The international phase of the application becomes the subject of an international search. This search consists of a high-level search, using patent documents and patent related literature, drafted in the languages permitted by the Agreement. The results of this search can be quite advantageous for the applicant, since its quality is assured by the standards of the PCT with regard to documentation, qualifications of the examiners and search methods. The International Searching Authority is selected among experienced patent offices that the PCT Union Assembly (supreme administrative body created by the PCT) must designate. The European Patent Office (EP) and the Office of Patents and Trademarks of the United States of America (US) are the most commonly designated authorities to proceed with the international search. ${ }^{541}$

The process of patent application in the PCT is, hence, divided into two phases: the international phase and the national phase. In the international phase the first filing of international application occurs in a single office, with a unique set of requirements and one formal language. Then, the international search is performed. The application is published after eighteen months, together with the research report. After that, before the national phase, the supplementary international search and the international preliminary examination is provided. After 30 months, it enters the national phase, which requires the submission of translations and payment of fees to the designated countries. ${ }^{542}$

540 WIPO, Frequently Asked Questions, http://www.wipo.int/pct/en/faqs/faqs.html (accessed 16 April 2018).

541 lbid.

542 See Arts. 15, 16 and 17 of the PCT. 
Figure 26: Overview of the PCT Stages

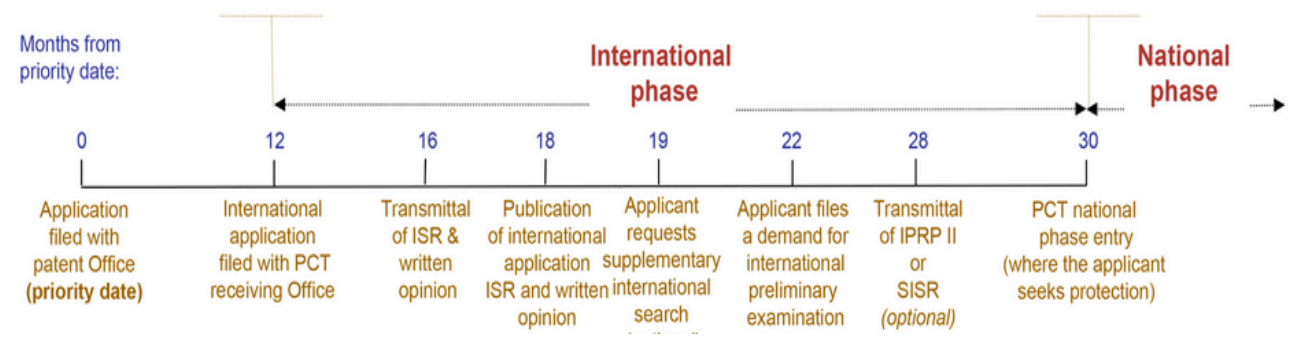

Source: WIPO PCT FAQs ${ }^{543}$

\subsubsection{The advantages of a harmonized system}

The PCT has several advantages for scientific institutions, and various possible uses. Most of these advantages and uses, deeply associated with disclosure of patent information, are related to its systemic character, which enables it to harmonize and streamline patent applications globally. In this sense, it consists of an integrated system that represents a lever for scientific development. This is justified by a number of benefits, which affect the patent examiner at the national level, the researcher, the entrepreneur and the system itself, which gains the ability to be improved. Thus, good reasons it is considered as the cornerstone of the international patent system, as it provides a global framework for the registration through a simplified process. ${ }^{544}$

Just because it is characterized as a basis of the "international patent system", the PCT can evolve to meet users' needs. That includes the enhancements and new features that have been developed from an increasingly widespread use. This could not have taken place in a fragmented process in several national applications. The new functionalities of the PCT involve more access to translated texts, more quality data which can be used for various purposes and more legal certainty to the users, as the applications have to be examined by the national offices if they were presented according to the procedure prescribed by the PCT.

One of the PCT's enhancements is the Third-Party Observation System, which allows third parties to submit relevant observations about the degree of novelty and

543 WIPO, Frequently Asked Questions, http://www.wipo.int/pct/en/faqs/faqs.html (accessed 20 December 2018).

544 See M. Bryan, op. cit. 
inventiveness of the request issued by the PCT. The purpose of the system is to improve patent quality, providing more complete information to offices to support decision making. The system can be accessed online or on PATENTSCOPE or e-PCT bases. The submission of observations can be made until 28 months after the priority date. Submission has no cost and can be done anonymously. Applicants can answer them up to 30 months, the date of expiry of the international phase. ${ }^{545}$

Another important feature developed that can be useful to scientific institutions is the Indication of Availability of License. Applicants may indicate, at the time of order, or within $\mathbf{3 0}$ months, that the technology is available for licensing in a specific form for this. This indication may be revoked at any time during the 30 months of priority, and the service is free. Such licensing indications are made available to the public and can be searched in PATENTSCOPE. According to statistics from WIPO, universities and research institutions are the main users of this functionality. ${ }^{546}$ This is another feature that contributes to a higher level of dissemination of disclosure of patent information.

The PCT also offers a very useful feature to researchers, called WIPO Pearl. It is a multilingual platform of technical and scientific terminology organized from the PCT patent applications. Its creation aimed to promote accuracy and consistent use of language translation of technical terms in different languages. Currently, it contains 91.152 terms grouped into 14.951 concepts, and enables searches for term and conceptual search. The platform is integrated with PATENTSCOPE and covers 10 languages: Arabic, Chinese, English, French, German, Japanese, Korean, Portuguese, Russian and Spanish. Terms are validated from a "term reliability score." When the user does not find any equivalent in the target language in the database, WIPO's MT engine can offer a proposal for translation. ${ }^{547}$ This is another example of how a more harmonized system can improve disclosure.

Among the other developed features that promote scientific dissemination and access to information, it is worth mentioning the PCT-Patent Prosecution Highway Pilot (PCT-PPH), which brings together a number of bilateral agreements, forming a network of working partnerships to improve and speed up the patent granting process. Such partnerships help to improve the quality of the examination (in all PCT offices involved) and to improve the written opinions and preliminary reports of the International Searching Authorities. $^{548}$

Therefore, an integrated system leads to a much higher flow of information, and processes more transparent and harmonized grants of patents. Integration also favours cost reduction possibilities, including legal processes mediated by the Arbitration and Mediation Centre of WIPO (AMC), which already offers $25 \%$ reduction of fees in cases where at least one of the parties held its request or was named as inventor of a request via the PCT. ${ }^{549}$

545 Ibid.

546 Ibid.

547 Ibid. WIPO Pearl is available from: http://www.wipo.int/wipopearl/search/home.html (accessed 16 April 2018).

548 WIPO, PCT-Patent Prosecution Highway Pilot (PCT-PPH and Global PPH), http://www.wipo.int/pct/en/filing/pct_pph.html (accessed 17 April 2018).

549 See M. Bryan, op. cit. 
Figure 27: PCT-PPH

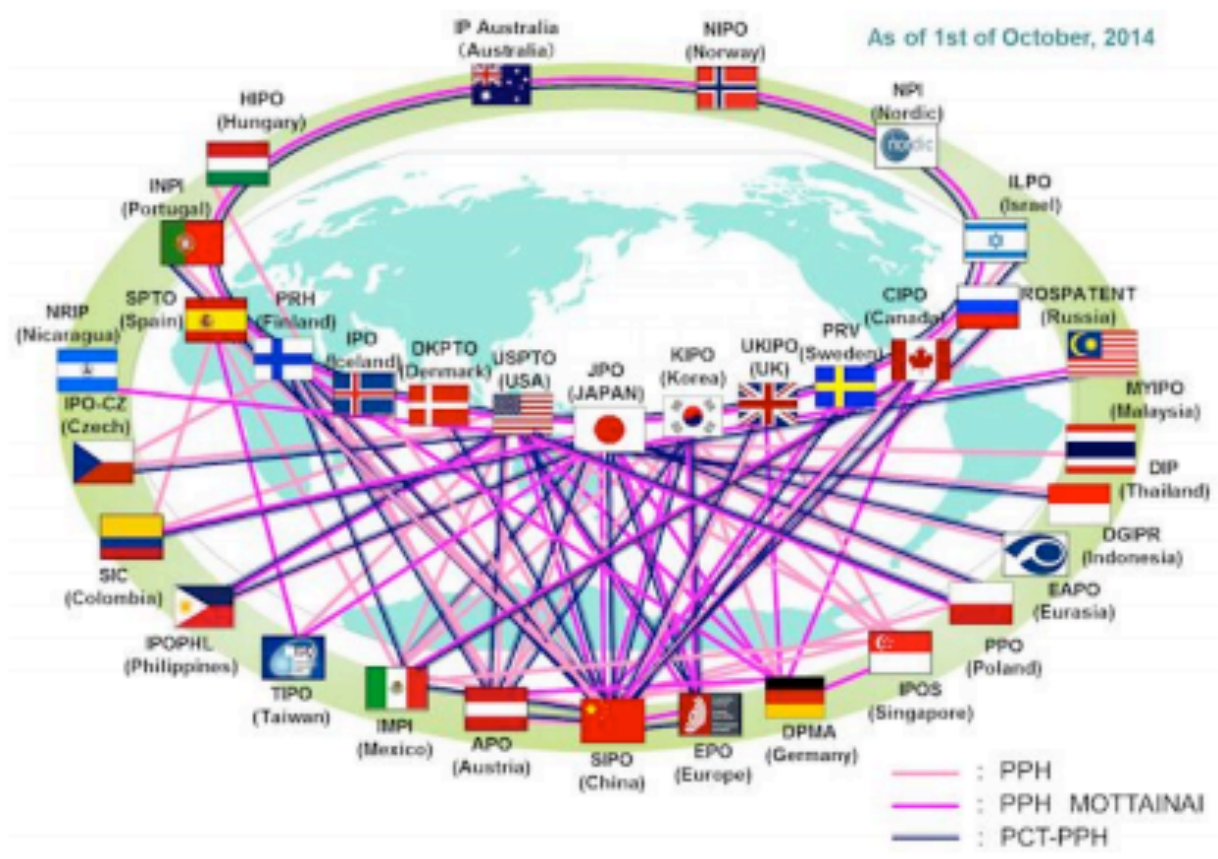

Source: M. Bryan, 2014

\subsubsection{The use of the PCT for the strategic management of technology: why universalizing disclosure is important to patent law}

There are many possible uses for information disclosed by patents. Holger points out that the information in patent databanks should be used for strategic planning purposes. Accordingly, he developed a conceptual framework showing the use of patent information in core technology management areas. The main areas of use are: concurrent monitoring, technology assessment, portfolio management in research and development, identification and evaluation of potential sources for external generation of technological knowledge, especially through mergers and acquisitions of technologies and human resources. ${ }^{550}$

Because of its strategic value, it is argued that the recovery and assessment of patent data should be institutionalized within the organization in order to ensure continuous and systematic use of patent information in decision-making processes. To do this, Holger defines two major recipients: (1) senior management, which uses this information for decision-making in areas of technology management and (2) external stakeholders such as shareholders and analysts. In the case of universities and research

550 See E Holger, 'Patent Information for Strategic Technology Management', World Patent Information, 2003. http://hadjarian. org/portfolio/1-s2.0-S0172219003000772-main.pdf (accessed 16 April 2018). 
institutions such decisions involve partnerships with companies and should be taken on the directions of research undertaken and on new investments in research.

In addition, the information contained in patents can be allocated to sub-fields of interest, including business units, products, courses or technological inventions. This enables an accurate analysis of competitors. The available databases offer the opportunity to retrieve data systematically and on a large scale. Furthermore, patents are an objective measure of R\&D activities, because they are examined and eventually granted by the patent office. In the case of filing via the PCT, the applications will undergo a high-level exam, which grants reliability to the available information. Likewise, there is a great amount of technological information contained in patents, which are classified according to standard regimens, for example, the International Patent Classification (IPC). This facilitates the detailed analysis of specific technological aspects. Compared to other sources of information, patents are often considered the best source for the recognition of technological change. ${ }^{551}$

Holger categorizes also indicators that are the basis for monitoring competitors and the evaluation of technologies to market. Among the indicators defined by the author are: i. Activities related to patents, which refer to the number of applications and the extension of patent costs; ii. Portion occupied by technology, i.e. the firm's position in a given technology sector; iii. Partnerships, or number of patents together with other institutions; iv. Scope, which refers to diversity and the number of classes in the IPC employed; v. Technology Quality, which refers to the technology provided by the returns; I. and Frequency of citation of the patent. From these evaluations, one of the most important decisions to be taken is the share of investments that will be spent on a particular technology. ${ }^{552}$

The PCT provides a Yearly Review, bringing statistics on both the international and the national phase. These statistics show information on PCT applications by country of origin, PCT applicants, PCT applications by fields of technology, national phase entries by country of origin and national phase entries by office. Some of the latest reports highlight indicate trends related to intellectual property and technological innovation.

The highlights of the report published in 2015 were as follows: PCT applications grew 4.5\% due to China and the USA; Japan recorded its first decline in records in 22 years; China increased its presence among the main applicants of the PCT; information technology has become the field of technology with the highest number of requests; entries in the national phase grew sharply, due mainly to the USA and Japan. ${ }^{553}$

The type of information provided by the Report can support the development of patent portfolios in order to provide a basis for research directions. According to Holger, this type of data is crucial to the most important decisions to be made in technology

551 Ibid.

552 Ibid.

553 WIPO, PCT Yearly Review, 2015. 
management in terms of investment of $R \& D$ resources. For this author, since senior management must decide how much of the $R \& D$ resources will be spent on which type of technology, it is necessary to elaborate patent portfolios, whose concepts have been developed in order to facilitate this decision-making process. ${ }^{554}$

The key numbers showed by last years'WIPO's PCT Review (Figure 28) and the first PCT Review in 2011 make it clear that the system has a successful consolidation process in the years covered by the reviews. Although there is a decrease of $3.4 \%$ in national phase entries, followed by a $6.2 \%$ decrease in applications filed, these numbers still show a positive growth trend and a natural tendency to stabilize as the system started to be largely used in the last two decades. It is also worth mentioning that the decrease of the national phase entries is lower than the number of applications filed, which can show the system still can reach higher levels of impact in the global scale. A result that deserves to be highlighted refers to the trends related to the number of applicants, which grew 2.5 percent.

What these numbers show clearly is that harmonization can be seen as a necessary trend to the patent system, proved by the positive results and growth tendencies of the PCT and through its obvious advantages to scientific development.

Figure 28: 2011 and 2014 PCT key numbers review

\begin{tabular}{llllll}
\hline \multicolumn{2}{l}{$\mathbf{2 0 1 1}$} & & \multicolumn{3}{c}{$\mathbf{2 0 1 4}$} \\
\hline Number & Trend & Description & Number & Trend & Description \\
\hline 477,500 & $+7,7 \%$ & National phase entries & 565,500 & $+4,3 \%$ & National phase entries \\
\hline 181,900 & $+10,7 \%$ & Applications filed & 214,500 & $+4,5 \%$ & Applications filed \\
\hline 163,670 & $+7,7 \%$ & Published applications & 49,621 & $+8,7 \%$ & Applicants \\
\hline 44,113 & $+6,2 \%$ & Applicants & 148 & $0 \%$ & Member States \\
\hline 144 & $+2 \%$ & Member States & 124 & $0 \%$ & $\begin{array}{l}\text { Countries in which applications } \\
\text { were filed }\end{array}$ \\
\hline 128 & $+4 \%$ & $\begin{array}{l}\text { Countries in which } \\
\text { applications were filed }\end{array}$ & 55,3 & $+0,3 \%$ & $\begin{array}{l}\text { Share of national phase entries } \\
\text { in worldwide non-resident } \\
\text { filings }\end{array}$ \\
\hline
\end{tabular}

Source: Table based on PCT yearly reviews for 2012 and $2015^{555}$

Other numbers that are relevant to understand the evolution of the PCT and its possible use for strategic management of technology are related to the main applicants and type of technology with the highest share of applications. It is noticeable in the results shown in figure 29 and 30 that the top 10 applicants develop technologies that either are

554 Holger, 2003.

555 See WIPO, PCT Yearly Review 2015, and PCT Yearly Review 2012, http://www.wipo.int/edocs/pubdocs/en/patents/901/ wipo_pub_901_2012.pdf and http://www.wipo.int/edocs/pubdocs/en/wipo_pub_901_2015.pdf (accessed 20 December 2018). 
closely related to computer technologies or are specifically representative of this field. That becomes even clearer in the second table (Figure 30), that shows the results for applications by fields of technology. These data show the importance of the information contained in software patents and the relevance of studies that may aim to assess this information.

\section{Figure 29: Ten main applicants}

\begin{tabular}{|c|c|c|c|c|c|c|c|c|}
\hline & \multirow[b]{2}{*}{ Technical field } & \multicolumn{5}{|c|}{ Year } & \multirow{2}{*}{$\begin{array}{r}2014 \\
\text { share }(\%)\end{array}$} & \multirow{2}{*}{$\begin{array}{r}\text { Change from } \\
2013(\%)\end{array}$} \\
\hline & & 2010 & 2011 & 2012 & 2013 & 2014 & & \\
\hline I & Electrical engineering & & & & & & & \\
\hline 1 & Electrical machinery, apparatus, energy & 9,172 & 11,355 & 13,455 & 15,049 & 15,220 & 7.3 & 1.1 \\
\hline 2 & Audio-visual technology & 5,619 & 5,839 & 6,377 & 6,855 & 6,815 & 3.3 & -0.6 \\
\hline 3 & Telecommunications & 4,878 & 4,987 & 4,996 & 5,268 & 5,420 & 2.6 & 2.9 \\
\hline 4 & Digital communication & 10,592 & 11,651 & 12,636 & 14,117 & 16,165 & 7.7 & 14.5 \\
\hline 5 & Basic communication processes & 1,277 & 1,204 & 1,300 & 1,292 & 1,292 & 0.6 & 0.0 \\
\hline 6 & Computer technology & 9,542 & 10,496 & 12,454 & 14,782 & 17,653 & 8.4 & 19.4 \\
\hline 7 & IT methods for management & 2,084 & 2,363 & 2,936 & 3,768 & 4,114 & 2.0 & 9.2 \\
\hline 8 & Semiconductors & 5,862 & 6,509 & 6,908 & 7,331 & 7,186 & 3.4 & -20 \\
\hline II & Instruments & & & & & & & \\
\hline 9 & Optics & 4,192 & 4,551 & 5,118 & 6,302 & 5,976 & 2.9 & -5.2 \\
\hline 10 & Measurement & 6,430 & 6,571 & 7,312 & 7,992 & 9,000 & 4.3 & 126 \\
\hline 11 & Analysis of biological materials & 1,790 & 1,786 & 1,724 & 1,854 & 1,839 & 0.9 & -0.8 \\
\hline 12 & Control & 2,131 & 2,161 & 2,346 & 2,575 & 3,126 & 1.5 & 21.4 \\
\hline 13 & Medical technology & 10,484 & 10,767 & 11,375 & 11,950 & 13,996 & 6.7 & 17.1 \\
\hline
\end{tabular}

Source: Based on PCT yearly reviews for 2012 and 2015

Figure 30: Applications by fields of technology

\begin{tabular}{|c|c|c|c|c|c|c|c|c|}
\hline & \multirow[b]{2}{*}{ Technical field } & \multicolumn{5}{|c|}{ Year } & \multirow{2}{*}{$\begin{array}{r}2014 \\
\text { share }(\%)\end{array}$} & \multirow{2}{*}{$\begin{array}{r}\text { Change from } \\
2013(\%)\end{array}$} \\
\hline & & 2010 & 2011 & 2012 & 2013 & 2014 & & \\
\hline I & Electrical engineering & & & & & & & \\
\hline 1 & Electrical machinery, apparatus, energy & 9,172 & 11,355 & 13,455 & 15,049 & 15,220 & 7.3 & 1.1 \\
\hline 2 & Audio-visual technology & 5,619 & 5,839 & 6,377 & 6,855 & 6,815 & 3.3 & -0.6 \\
\hline 3 & Telecommunications & 4,878 & 4,987 & 4,996 & 5,268 & 5,420 & 2.6 & 2.9 \\
\hline 4 & Digital communication & 10,592 & 11,651 & 12,636 & 14,117 & 16,165 & 7.7 & 14.5 \\
\hline 5 & Basic communication processes & 1,277 & 1,204 & 1,300 & 1,292 & 1,292 & 0.6 & 0.0 \\
\hline 6 & Computer technology & 9,542 & 10,496 & 12,454 & 14,782 & 17,653 & 8.4 & 19.4 \\
\hline 7 & IT methods for management & 2,084 & 2,363 & 2,936 & 3,768 & 4,114 & 2.0 & 9.2 \\
\hline 8 & Semiconductors & 5,862 & 6,509 & 6,908 & 7,331 & 7,186 & 3.4 & -20 \\
\hline II & Instruments & & & & & & & \\
\hline 9 & Optics & 4,192 & 4,551 & 5,118 & 6,302 & 5,976 & 2.9 & -5.2 \\
\hline 10 & Measurement & 6,430 & 6,571 & 7,312 & 7,992 & 9,000 & 4.3 & 12.6 \\
\hline 11 & Analysis of biological materials & 1,790 & 1,786 & 1,724 & 1,854 & 1,839 & 0.9 & -0.8 \\
\hline 12 & Control & 2,131 & 2,161 & 2,346 & 2,575 & 3,126 & 1.5 & 21.4 \\
\hline 13 & Medical technology & 10,484 & 10,767 & 11,375 & 11,950 & 13,996 & 6.7 & 17.1 \\
\hline
\end{tabular}

Source: Based on PCT yearly reviews for 2012 and 2015

\subsubsection{PCT's language regime}

Language policy plays a crucial role in the area of IP rights, especially when related to patents, which increasingly require more complex language and translation services, as the patent documents are related to more sophisticated inventions and to a progressively globalized scenario. However, these relations are still under-explored in 
academic research and literature, whereas analysing them demands and enables various types of approaches.

The existing contributions that relate language studies and patent studies aim to draw attention to translation costs, as the ones required to enter the PCT's national phase. Few of them are focused on the language regimes related to the patent system at the global level and there are almost no studies relating translation aspects to patent law. Nonetheless, the PCT itself shows a wide range of language and translation features that are worth describing. Under the light of the present research question, the Treaty had a strong impact on the dissemination of the disclosure of patent information. Hence describing the complexity of its language regime is crucial to understand how it occurred.

The first aspect is the fact that WIPO counts on language services on its own structure, and as the PCT is under WIPO's governance, it is important to describe and understand the central roles of these services for the patent system. WIPO counts on a Conference and Language Department (CLD), which provides an institutional communication service and is divided in the Conference Division and the Language Division. The latter includes an interpreting section and six translation sections. The other departments are the PCT translation service of the Deputy Director General (DDG), under the Innovation and Technology Sector and the translation section of the DDG Brand and Designs. ${ }^{556}$

As the PCT is considered a multilingual international network, its language regime is a very central aspect of its activities. In virtue of that, there are language norms worth mentioning both in the Treaty itself and in its Regulations and Administrative Instructions. For explaining the PCT language regime, the norms concerning language and translation inside the Treaty's text will be described and, when necessary, combined with PCT Regulations or Administrative Instructions.

Article 15, which refers to the International Search aspects, gives the prerogative to the ISA to require a translation prepared by the applicant in a language prescribed for international applications, when it cannot handle the language presented in the first application. This translation, when required, will be presented in the form prescribed for international applications. That first aspect of the language regime in the PCT refers to the first step that follows an international application, which is, as mentioned, the international search. ${ }^{557}$ The term "prescribed", as used by the Treaty, for this purpose, finds its explanation on Rule 12, which defines it as a language accepted by the International Searching Authority. ${ }^{558}$

The same rule also defines the languages that should be accepted by the receiving Office, determining that it should accept at least one language which is both a language

\footnotetext{
556 M. Gazzola, The evaluation of language regimes: theory and application to multilingual organizations. John Benjamins Publishing Company, 2014, p. 221.

557 PCT, Art. 15.

558 See WIPO, Regulations under the Patent Cooperation Treaty (as in force from July 1, 2017), Rule No 12, http://www.wipo.int/ export/sites/www/pct/en/texts/pdf/pct_regs.pdf (accessed 17 April 2018).
} 
accepted by the International Searching Authority and a language of publication. ${ }^{559}$ There are 10 languages of publication, as defined in Rule $48^{560}$, which are: Arabic, Chinese, English, French, German, Japanese, Korean, Portuguese, Russian and Spanish. The term "publication" refers to the disclosure of the content of the international application, which happens as soon as possible after the expiration of 18 months from the earliest filing date. As the patent's content reaches the whole world through the process of disclosure, it can be considered as an important tool to scientific development, as explained in section 1.2. Gazzola $^{561}$ shows a table of selected Receiving Offices presenting languages accepted by them for filing international applications:

\section{Figure 31: Languages accepted in selected Receiving Offices}

\begin{tabular}{|c|c|c|c|c|c|}
\hline \multirow{2}{*}{$\begin{array}{l}\text { Receiving Office } \\
\text { China }\end{array}$} & \multicolumn{5}{|c|}{ Languages accepted for international applications } \\
\hline & Chinese & English & & & \\
\hline Canada & English & French & & & \\
\hline European Patent Office & English & French & German & & \\
\hline France & French & & & & \\
\hline Germany & German & & & & \\
\hline Italy $^{18}$ & English & French & German & Italian & \\
\hline Japan & English & Japanese & & & \\
\hline Republic of Korea & English & Japanese & Korean & & \\
\hline Netherlands & Dutch & English & French & German & \\
\hline Spain & Spanish & & & & \\
\hline Sweden & Danish & English & Finnish & Norwegian & Swedish \\
\hline Switzerland ${ }^{19}$ & English & French & German & & \\
\hline Russia & English & Russian & & & \\
\hline$U K$ & English & & & & \\
\hline US & English & & & & \\
\hline $\begin{array}{l}\text { WIPO International } \\
\text { Bureau (IB) }\end{array}$ & & & Any lang & & \\
\hline
\end{tabular}

Source: Gazzola (2014), p. 226

Rule No 12.1(a) prescribes that receiving offices may accept languages which are not accepted by the ISA for the purposes of international search. In this case, the applicant is required to provide a translation into a language accepted by the ISA. The same rule also states that the request should be filed in any language among the 10 languages of publication which the receiving office accepts for the purposes of the international search. ${ }^{562}$

562 See WIPO, Regulations under the Patent Cooperation Treaty, as in force from July 1, 2017. 
There are also norms about the language of elements and parts of the patent and language of indications furnished under rules that include inventions relating to biological material and applications that disobey basic rules defined by Article 11 of the Treaty. Indications in relation to deposited biological material are an example of this specificity, as they must be in the language in which the international application is filed, and provided that, where a translation of the international application is required, should be furnished in both the language in which the application is filed and the language of that translation. ${ }^{563}$

Furthermore, the PCT asserts that the international search report should be translated as provided in the Regulations and the translations should be prepared by or under the responsibility of the International Bureau. ${ }^{564}$ The regulations, on the other hand, prescribe that every international search report should be in the language in which the international application to which it relates is to be published. ${ }^{565}$

What the Treaty's text requires for the International Search Report is also valid for the Declaration issued by ISA when the international application relates to subject matter which does not require a search, and in the particular case decides not to search, or when the description, the claims, or the drawings, fail to comply with the prescribed requirements to such an extent that a meaningful search could not be carried out. ${ }^{566}$ Also important to mention is the prescription for the International Search Report or the mentioned declaration to be translated into English, when it is not written in English. ${ }^{567}$

The languages of publication are Arabic, Chinese, English, French, German, Japanese, Korean, Portuguese, Russian or Spanish. If the international application is filed in one of those languages that application will be published in the language in which it was filed. If the international application is not filed in a language of publication and a translation into a language of publication has been furnished, that application will be published in the language of that translation..$^{568}$

Besides, for guaranteeing universality to the publication, the PCT provides that if the international application is published in a language other than English, the title of the invention, the abstract and any text matter pertaining to the figure or figures accompanying the abstract should be published both in that language and in English. The translations, if not furnished by the applicant, should be prepared under the aegis of the International Bureau. ${ }^{569}$

The applicant of an international application can request an international preliminary examination. The demand should be presented in a prescribed language. It should also indicate the elected States in which the applicant intends to use the results

565 WIPO Regulations under the Patent Cooperation Treaty, Rule No 43.

566 WIPO, PCT, Art. 18.

567 WIPO, Regulations under the Patent Cooperation Treaty, Rule No 45.

568 WIPO, Regulations under the Patent Cooperation Treaty, Rule No 48.

569 The rule is also valid for the International Search Report. 
of the international preliminary examination, as the examination will depend on this information to assess the industrial applicability of the invention in these States. The PCT also prescribes that additional contracting States may be elected later.

Another important aspect worth mentioning about the international preliminary examination is that it should be made separately from the international application. Thus, it can be considered as an optional stage of the international application. The objective of the international preliminary examination is to formulate a preliminary opinion on the questions whether the claimed invention appears to be novel, to involve an innovative step and to be industrially applicable. It can be considered as an important opportunity for the applicant to avoid unnecessary costs, if entering the national phase is revealed to be not viable..$^{570}$

There are many language and translation aspects related to the international preliminary examination. The first one is associated to the language of the demand for an IPE. The demand should be in the language of the international application or, if the international application has been filed in a language other than the language in which it is published, in the language of publication. The PCT Regulations also establish that if a translation of the international application is required, the demand should be in the language of that translation.

In situations when neither the language in which the international application is filed nor the language in which the international application is published is accepted by the International Preliminary Examining Authority, the applicant must furnish on the request a translation of the international application into a language which is both a language accepted by that Authority, and a language of publication. ${ }^{571}$

Upon the request of the International Preliminary Examining Authority, the written opinion issued by the International Searching Authority will, when not in English or in a language accepted by that Authority, be translated into English by or under the responsibility of the International Bureau. The International Bureau will transmit a copy of the translation to the International Preliminary Examining Authority within two months from the date of receipt of the request for translation, and should, at the same time, transmit a copy to the applicant. ${ }^{572}$ The written opinion expresses a preliminary conjecture about the claimed invention in terms of its level of novelty, inventiveness or non-obviousness, and its industrial applicability. It also assesses whether the international application complies with the requirements of the PCT and its Regulations in so far as checked by the International Searching Authority.

570 WIPO, PCT, Arts. 32 and 33.

571 WIPO, Regulations under the Patent Cooperation Treaty, Rule 55.

572 WIPO, Regulations under the Patent Cooperation Treaty, Rule 62bis. 
Table 13: PCT's Language and translation aspects in different stages of patent application

\begin{tabular}{|c|c|c|}
\hline Stage & PCT Language and Translation Main Aspects & $\begin{array}{l}\text { Rule or } \\
\text { Article }\end{array}$ \\
\hline $\begin{array}{l}\text { Handling the } \\
\text { application to the } \\
\text { receiving office }\end{array}$ & $\begin{array}{l}\text { The Receiving Office should accept at least one language which is } \\
\text { both a language accepted by the International Searching Authority } \\
\text { and a language of publication. It may accept languages which are not } \\
\text { accepted by the ISA since a translation into a language accepted by the } \\
\text { ISA is provided. }\end{array}$ & Rule 12 \\
\hline International Search & $\begin{array}{l}\text { The International Search Authority can require a translation prepared by } \\
\text { the applicant in a language prescribed for international applications. }\end{array}$ & Art. 15 \\
\hline $\begin{array}{l}\text { International Search } \\
\text { Report }\end{array}$ & $\begin{array}{l}\text { The ISR shall be translated into the language in which the international } \\
\text { application to which it relates is to be published. The translations shall } \\
\text { be prepared by or under the responsibility of the International Bureau. }\end{array}$ & $\begin{array}{l}\text { Art. } 18 \\
\text { and Rule } \\
43\end{array}$ \\
\hline $\begin{array}{l}\text { International } \\
\text { Publication }\end{array}$ & $\begin{array}{l}\text { The languages of publication are Arabic, Chinese, English, French, } \\
\text { German, Japanese, Korean, Portuguese, Russian or Spanish. An } \\
\text { International application can be published in the language in which it } \\
\text { was filed if it is a publication language or in the language of a furnished } \\
\text { required translation. }\end{array}$ & Rule 48 \\
\hline $\begin{array}{l}\text { International } \\
\text { Preliminary } \\
\text { Examination }\end{array}$ & $\begin{array}{l}\text { The demand for an IPE shall be in the language of the international } \\
\text { application or, if the international application has been filed in a } \\
\text { language other than the language in which it is published, in the } \\
\text { language of publication. If a translation of the international application } \\
\text { is required, the demand shall be in the language of that translation. }\end{array}$ & Rule 55 \\
\hline
\end{tabular}

Source: Elaborated by this author inspired on the PCT Agreement ${ }^{573}$

As seen, the language regime adopted by the PCT is intricate, requiring a good understanding of the PCT procedures. In this regard, by evaluating the PCT's language and translation regime, it becomes clear how essential language and translation issues are for the whole patenting process, from the decision to make an international application to the prior art research and the stages that follow it until the patent is granted in the national phase. Gazzola summarizes the functioning of the language regime in the PCT as follows:

Let us recapitulate. Generally speaking, the language regime of the ROs is such that inventors have the possibility to file a patent application in (one of) the official language(s) of the state in which the application is filed (with several exceptions), but they require a translation into one of the languages of publication if the language used by the applicant is not one of the languages of publication. At the same time, the system is such that inventors have also the possibility to file an application in one language only, typically one language of publication. For example, if a Swedish company chooses to draft and file an international application directly in English and the ISA chosen for international search is the European Patent Office (which works in English, French and German), the company does not need to provide any translation. ${ }^{574}$ 
The Administrative Instructions of the PCT also bring language and translation related content, as do the instructions about the forms used by authorities in charge of international applications. According to the Administrative Instructions, the language of the Forms used by any receiving Office must be the same as the language in which the international application is filed. However, there are more details provided by the Instructions about these forms.

Where the international application is to be published in the language of a translation, the receiving Office must use the Forms in the same language. The instructions also determine that the receiving Office may, in its communications to the applicant, use the Forms in any other language being one of its official languages. The language or languages of the Forms to be used by any International Searching Authority should be specified in the agreement approved by the PCT Assembly for appointing the ISAs. The language or languages of the Forms to be used by any International Preliminary Examining Authority should be specified in the same mentioned agreement, as it also appoints the PEAs. ${ }^{575}$

Still according to Section 103 of the Administrative Instructions, the language of the Forms used by the International Bureau will be English where the language of the international application is English, or French where the language of the international application is French. Where the language of the international application is neither English nor French, the language used in the Form issued by the International Bureau in its communications to any other International Authority should be English or French according to the wishes of such Authority. This instruction is also valid for the IB's communications with the applicant, which should be in English or French according to the preferences of the applicant. ${ }^{576}$

The Administrative Instructions also describe language and translation procedures related to languages to be used in correspondence, which include letters from the applicant to the receiving office and letters to the International Bureau. As a general rule, it can be said that the languages of the International Bureau are English and French, and letters directed to the Bureau can be in either of these languages in cases where applications are neither written in English nor in French. When the language of the application is English, such should be the language of the letters to the IB, and the same is valid for French. ${ }^{577}$

575 WIPO, Administrative Instructions Under the Patent Cooperation Treaty, as in force from July 1, 2017, Section 103, http:// www.wipo.int/export/sites/www/pct/en/texts/pdf/ai.pdf, (accessed 17 April 2018).

576 Ibid.

577 WIPO, Administrative Instructions Under the Patent Cooperation Treaty, Section 104. 
Table 14: Forms Used by International Authorities according to PCT Administrative Instructions - Section 103

\begin{tabular}{|c|c|}
\hline Stage & $\begin{array}{l}\text { Forms Used by International Authorities according to PCT Administrative Instructions } \\
\text { - Section } 103\end{array}$ \\
\hline Receiving Offices & $\begin{array}{l}\text { General Rule: Same language as the one used in the international application filing. } \\
\text { Conditioning aspects: } \\
\text { Publication in the language of a translation the receiving Office shall use the } \\
\text { Forms in such language. } \\
\text { Communications with the applicant Forms in any other language being one of the } \\
\text { RO's official languages. }\end{array}$ \\
\hline $\begin{array}{l}\text { International } \\
\text { Searching Authority }\end{array}$ & $\begin{array}{l}\text { The language or languages of the Forms to be used by any International Searching } \\
\text { Authority shall be specified in the agreement approved by the PCT Assembly for } \\
\text { appointing the ISAs. }\end{array}$ \\
\hline $\begin{array}{l}\text { Preliminary } \\
\text { Examining Authority }\end{array}$ & $\begin{array}{l}\text { The language or languages of the Forms to be used by any International Preliminary } \\
\text { Examining Authority shall be specified in the agreement approved by the PCT } \\
\text { Assembly for appointing the PEAs. }\end{array}$ \\
\hline International Bureau & $\begin{array}{l}\text { English: where the language of the international application is English. } \\
\text { French: where the language of the international application is French. }\end{array}$ \\
\hline International Bureau & $\begin{array}{l}\text { Where the language of the international application is neither English nor French: } \\
\text { Communications to any other International Authority shall be English or French } \\
\text { according to the wishes of such Authority. } \\
\text { Communications with the applicant shall be in English or French according to the } \\
\text { wishes of the applicant. }\end{array}$ \\
\hline
\end{tabular}

Source: Inspired in the PCT's Administrative Instructions Section 103

Preparation, identification and transmission of the copies of translations of international applications also obey the rules defined by the Instructions. The most important of them are summarized below, reminding us that these translations are furnished by the applicant mainly for the purposes of the International Search and the International Publication. ${ }^{578}$

As discussed before, where the language in which the international application is filed is not accepted by the International Searching Authority, a translation into a prescribed language is required. In this case, the receiving Office will be responsible for the prompt preparation of any additional copies required where the translation is furnished in less than the number of copies required for the International Search. In this case, the receiving Office may fix a fee and collect it from the applicant. ${ }^{579}$

When providing these copies, the Receiving Office should mark the words"record copy - translation (rule 12.3)" in the upper left-hand corner of the first page of the original copy of the translation and transmit that copy to the International Bureau; and also mark 
the words "search copy - translation (rule 12.3)" in the same space on one additional copy of the translation, which should be transmitted to the International Searching Authority. A third copy with the words "home copy - translation (rule 12.3)" should be provided and kept in the files of the Receiving Office. These words can also be written in the language of publication. Similar procedures are valid when it comes to translations required for the purpose of the International Publication. ${ }^{580}$

\subsection{The language regime of the European Patent Office and the European Patent with Unitary Effect}

\subsubsection{The European Union's approach to language and translation and the language regime (s) of the EPO}

This Section describes the language regime of the EPO and its implications for the Unified Patent System in Europe. But before explaining how the EPO deals with language and translation and detailing the unified patent system, it is important to present a brief overview of the European Union's approach to language and translation.

The European Union has shown a strong commitment to multilingualism since its foundation. According to the Treaties that established the European Union, it is up to the European Council to fix the Union's language regime, and it should be decided by unanimous vote. The language regime should be according to the Statute of the Court of Justice, with Article 290 of the EU Treaty and Article 64 of the Euratom Treaty. Regulation no. 1, approved in 1958 by the Council, enforces the language regime of the European Union institutions. Since then, the language regime has been extended to new languages on the demand of new Member States. ${ }^{581}$

The most complete (probably a unique) work describing the language regime of the EPO is the book by Gazzola, mentioned above. ${ }^{52}$ Therefore, for understanding language issues related to the EPO, the analysis will be based on his work and on primary sources. There are also some aspects worth mentioning, as a parameter to understand other offices regimes, as language can illuminate a comparison and a better understanding of differences between distinct patent systems. In the present work, the case of Brazil will be emphasized, and it is hoped that it will help to understand the importance of language regimes to national patent systems through a comparative view.

580 Ibid., Section 305bis.

581 M. Gazzola, 'Managing multilingualism in the European Union: language policy evaluation for the European Parliament', Language Policy, 2006a. See also the mentioned Treaties: European Union, Statute of the Court of Justice, 2012, http://curia. europa.eu/jcms/upload/docs/application/pdf/2012-10/staut_cons_en.pdf; Treaty on European Union, 1992, http://europa. eu/eu-law/decision-making/treaties/pdf/treaty_on_european_union/treaty_on_european_union_en.pdf; Euratom Treaty, 2010, http://europa.eu/eu-law/decision-making/treaties/pdf/consolidated_version_of_the_treaty_establishing_ the_european_atomic_energy_community/consolidated_version_of_the_treaty_establishing_the_european_atomic_ energy_community_en.pdf

582 Gazzola, 2014a. 
The first European patent application was filed on 1st June 1978, but the origins of the European Patent System go back to at least 1949 when the Council of Europe, the forerunner of the present EU, advocated setting up a European Patent Office. ${ }^{583}$ The history of the EPO itself starts with the Signature of the European Patent Convention (EPC) by 16 countries, in 1973. In 1977, the EPC entered into force in 7 countries. Together with that, during the same year, the European Patent Organization and the European Patent Office were founded. In 2013, there was a celebration of the 40 years of the EPC. ${ }^{584}$

The European Patent Organization is divided in two organs, the Administrative Council of the Organization and the European Patent Office (EPO). The Administrative Council, made up of representatives from the Contracting States, exercises legislative powers on the name of the Organization. It is also responsible for policy issues and the supervision of the Office's activities. ${ }^{585}$ The EPO is organized into a Receiving Section, different Search Divisions, Examining Divisions (which count on three-members: the previous search examiner and two examiners appointed by the director as second member and chairman), Opposition Divisions (normally composed of three experienced examiners, one of whom having been involved in the substantive examination phase), 38 Boards of Appeal, a Legal Division and an Enlarged Board of Appeal. ${ }^{586}$

The Organization currently counts on 38 member States, comprising all the member states of the European Union together with Albania, Croatia, Macedonia, Iceland, Liechtenstein, Monaco, Norway, San Marino, Serbia, Switzerland and Turkey. ${ }^{587}$ In turn, these 38 member states count on a total population of about 600 million inhabitants. The EPO is the second largest intergovernmental institution in Europe. The Office counts on a staff of around 7000 employees, of which almost 4000 are examiners. As a self-financing institution, it has a budget of 1.7 billion EUR per year, coming from the revenues of fee covers, that allow it to operate without any public money. ${ }^{588}$

The EPO has three official languages, in which all of its proceedings are managed. The EPO does not conduct court cases in the strict sense of it, unless the court-like proceedings before the second-instance Board of Appeals are considered. These proceedings are also run in one of the three official languages of the EPO. In most of the cases, the vast majority of the actions filed before the EPO have the support of a qualified European Patent Attorney, who analyses the examination in order to generate the required documents in the language of proceedings with the necessary linguistic quality by the action. ${ }^{589}$

583 R. Pitkethly, 'The European Patent System: Implementing Patent Law Harmonization, International Symposium on Innovation and Patents', 1999. http://users.ox.ac.uk/ mast0140/EJWP1099.pdf (accessed_16 April 2018).

584 A. Bassanini, The European Patent Office: an introduction to the EPO and the European patent system [Presentation], at:http://www.uibm.gov.it/attachments/Presentazione_Anna_Bassanini.pdf (accessed 16 April 2018).

585 See EPO's Official Website, Legal foundations, http://www.epo.org/aboutus/organisation/foundation.html

586 Ibid. See also: Gazzola, 2014, p. 289.

587 A. Plomer, 'A Unitary Patent for a (Dis)United Europe: The Long Shadow of History Published online. Max Planck Institute for Innovation and Competition', IIC, vol. 46, no 5, 2015, http://paperity.org/p/73432280/a-unitary-patent-for-a-dis-unitedeurope-the-long-shadow-of-history (accessed 18 April 2018).

588 Bassanini, op. cit.

589 All the information was collected directly with EPO's officers or from its official website: https://www.epo.org/index.html 
Figure 32: Structure of the European Patent Office

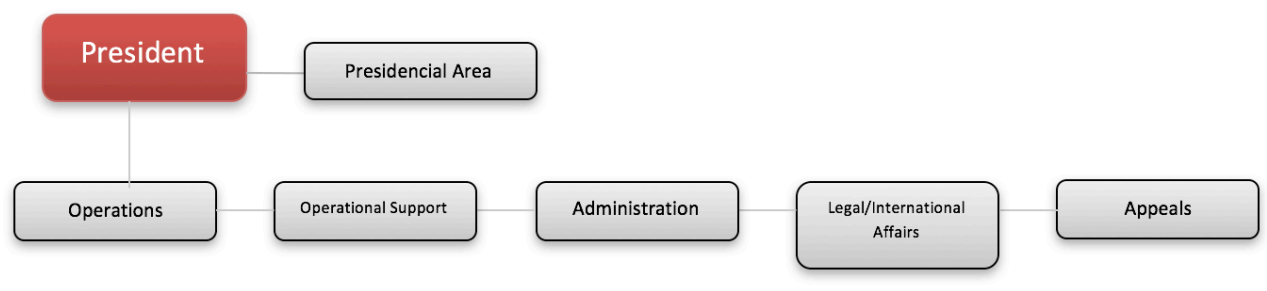

Source: Based on Bassanini's image ${ }^{590}$

Machine translation of patents is provided by the EPO's Patent Translate system and can be useful not only for examiners but for all the users of the patent system, also the ones belonging to the patent related legal setting. The service provided by patent translate was introduced with the purpose of making it possible for users to access the translation of patent documents into English (and the other official languages of the EPO) from as many as 31 other languages, which include Asian languages and Slavic languages, such as Russian. ${ }^{591}$

For that purpose, besides the collection of European Patents, the EPO has added the national patent collections of other States, as the ones of China, South Korea, Japan and also Russia, to the system. The system developed by Patent Translate improved Google's Translate software in such a way that it is able to generate purpose-oriented translation for people searching for patent information in the databases of the EPO, especially Espacenet, which gives direct access to it. Therefore, the existence of Patent Translate is connected to information and searching destinations. ${ }^{592}$

The EPO is the largest provider of information of this kind, which means patent documents disclosed in that large variety of languages, at a global level. Patent examiners from all over the world use Espacenet and Patent Translate for accessing documents which were not available before, which makes Patent Translate a very relevant tool in the improvement of disclosure of patent information. ${ }^{593}$

According to the information given by the Office, there are up to 30.000 machine translation requests per day from a wide variety of users from all over the world, which is not restricted to patent examination purposes. That number evidences the fact that Patent Translate certainly helps to render patent searching more efficient and more comprehensive to the users of the patent system. ${ }^{594}$

590 Bassanini, 2015.

591 Ibid.

592 lbid.

593 Ibid.

594 Ibid. 
The official position of the EPO also states that machine translation is not intended for legally binding purposes. It is then a very important tool to help users to identify pertinent patent documents and the information contained by those documents, but it should not replace human translation of documents for court cases or any other related use. Therefore, it should be seen as an information tool. It is also relevant to observe that the legal proceedings before national courts follow the respective national legal provisions, including those of language, which changes after the complete establishment of the Unitary Patent Court. 595

Gazzola describes the language structure of the EPO as a very sophisticated and central sector in the Office, implying high costs with personnel and essential functions for its operations. ${ }^{596}$ That makes sense thinking that the EPO is a multilingual patent organization, generating technical information in many languages. Knowledge dissemination configures the most important function of a patent office, which is to provide knowledge as a public service by disclosing and spreading the technical information contained in patents. This process certainly involves a whole set of foreign languages and a complex translation flow, whereas intellectual property, as described above, is an internationalized field, deeply related to global trade and to scientific knowledge, which is by nature a universal asset. Hence, the information contained in patent databases should reach a global scale efficiently.

The EPO's structure reflects this requirement of patent law as a global field deeply related to international trade. That is shown by a very elaborately designed language and translation regime to deal with multilingual communication in a linguistically diverse system. Therefore, the EPO does not economise on translation services, since its direct cost of translation services is estimated at around $€ 8.2$ million per year and the total primary cost estimated at $€ 14.6$ million, if one considers indirect costs. The EPO's official languages are English, French and German, and the Office's language service is divided into separate sections for each of these languages. The three sections are made up of 38 permanent staff members. The EPO also holds an interpreting unit responsible for hiring freelance professionals for language interpretation. ${ }^{597}$

Gazzola's research demonstrates the importance of language and translation regimes in IP's scenarios and the numbers presented for the EPO make it a good model for reflecting about this issue or for contrasting it with the realities of patent offices in developing countries. In this regard, it can be said that modernizing a patent office should take into consideration language planning. It can be affirmed that high levels of interaction are important for the development of a national patent system.

Besides translating about 30,000 standard pages per year ${ }^{598}$, the EPO makes frequent use of interpreting services, as outsourced interpreters work in the three official

595 Ibid.

596 Gazzola, ibid., pp. 239-303.

597 Gazzola, ibid., p. 291.

598 Ibid., p. 291. 
languages at meetings of the Administrative Council and its subordinate committees and at oral proceedings in the procedures of patent opposition and appeal. The Office also hires these interpreters for meetings requiring communication in non-official languages. These meetings involve communication with representatives of non-European countries, especially Japan, China and the Republic of Korea. There are about 120 freelance interpreters working with the EPO for the three working languages out of a total of 4,000 interpreters per year. An interpreter receives an average payment of $€ 1,100$ per day. ${ }^{599}$

Some questions tend to rise during the assessment of the EPO's language regime. The first one is related to the afore mentioned high costs of in-house and outsourced translation services. If the costs with translation are so elevated, why not adopt only one language as a procedural language in the Office? That question may be answered by the fact that a substantial number of applications are either in German or in French, as applications in German represent a considerable $26.7 \%$ of granted patents and French represent $8.7 \%$ (numbers are an average of the period 1981-2010). ${ }^{600}$ Adams presents this proportion as a broadly stable one at 6:3:1 (to English, German and French publications, in this order) from the first publications until currently. German is also the most shared language among the member States. ${ }^{601}$

Another issue that seems important while understanding the difficulty in establishing the language regime of an office with the characteristics of the EPO is the fact that translation costs tend to have a negative impact on the number of the applications from countries which do not share one of the official languages of the Office. Validating the European patent for all members of the EPO also involve huge costs with translation, especially if the applicant chooses to validate the patent in a larger number of countries. According to Adams, as the number of members of the EPO grew, and most of them did not share one of the Office's official languages, the Office was faced with increasing volumes of granted patent rights which these new members were not capable of understanding. This led the States to invoke their rights to call for translations in national official languages. ${ }^{602}$

The (provisional) way out from this impasse was given by Article 65 of the European Patent Convention (EPC). This Article allows national legislation to require the deposit of a full translation after a patent is granted, by stating that any contracting State should require the owner of the patent to supply to its central industrial property office $a$ translation of the patent as granted, amended or limited in one of its official languages at his option or, where that State has prescribed the use of one specific official language, in that language. ${ }^{603}$

\footnotetext{
599 Ibid.

600 Ibid., p. 309.

601 S. Adams, 'Lost in translation? A review of the post-grant requirements for translation of patent specifications in Europe', World Patent Information, 44, 34e45, 2016.

602 Ibid.

603 Ibid., see also: Convention on the Grant of European Patents (European Patent Convention, EPC) of 5 October 1973, as revised by the Act revising Article 63 EPC of 17 December 1991, and the Act revising the EPC of 29 November 2000, Article 14(2).,: https://www.epo.org/law-practice/legal-texts/epc.html (accessed 17 April 2018).
} 
However, the solution found in Article 65 is the type of solution that brings another same size problem. By mitigating the burden of language barrier to member States through the right to demand translations in one official language, Article 65 creates a similar, if not a heavier, burden to patent proprietors. It multiplies the number of translations that would be needed if only the patent offices would be in charge of providing translations just when necessary. ${ }^{604}$

That means that a broad solution has not yet been found to the patent related translation issue. A step towards simplifying translation procedures was given with the signature of the London Agreement, which was intended to mitigate the burden implied by the requirements on patent owners to lodge post-grand translations. With this purpose, member States had to commit to reducing the number of translation requests or to endorsing the re-use of English, French and German translations. Countries whose official language is English, French or German no longer require translation of European patents into one of those languages. Other contracting states have to choose English, French or German as a "prescribed language. ${ }^{605}$

The answer for these issues is a complex one and may have some elucidation in the evaluation of the interaction of machine translation and human translation, as discussed in Section 3.2. It may also be answered by alternative ways or attractive features for these users, as the ones proposed for the European Unitary Patent and the European Patent Court, such as simplified administration and significantly reduced fees. ${ }^{606}$

Before discussing the European Patent with Unitary Effect, it is important to understand how Europe came to this answer as a possible solution to old (translation and administration included) problems of harmonization related to the European patent system. Since the first developments of the patent system (s) in Europe, it has been possible to make considerations of the legal conditions to the development of diverse translation demands or solutions at different points in time. However, it is intended here to focus on the last decade, especially after digital tools not only made possible, but required, an intense flow of communication involving patents in various languages and the specific characteristics of Europe as a multilingual continent resulted in a lively debate associating translation and patent law.

Adams presents a study about how language and translation regimes have changed in time in Europe, creating different translation related legal backgrounds over

604 EPC, Art. 65.

605 Adams, 2016.

606 For a better understanding of this discussion, see the results of the EPO's Major Conference on Unitary Patent and Unified Patent Court, 16 July 2015. See news about the Conference on the EPO's official website: http://www.epo.org/news-issues/ news/2015/20150723.html (accessed 25 July 2015). 
the past decades. He also associates these diverse backgrounds with the burden of the patent proprietors to sustain the property rights related to their inventions allowed by different agreements and national regulations. ${ }^{607}$

In his study, Adams investigates and classifies the different requirements for a patent applicant or proprietor to prepare translations related to their patent documents. He sees these different legal moments in five distinct phases, or regimes, pointing out that three of the described regimes, and their legal demands, are still in force in Europe. ${ }^{608}$

The five European "translation regimes phases" described by Adams are: Phase I: national patent protection only (prior to the start of operations at the EPO); Phase II: initial operations at the EPO (since the European Patent Office's first operation in 1978); Phase III: the implementation of the London Agreement (referring to the application of Article 65 of the EPC, concluded in 2000, but only in force since 2008, with 21 signatory members from the 38 members of the EU); Phase IV: the European Patent with Unitary Effect transitional period (from the moment the Unitary Patent entered into force); Phase V: European patent with unitary effect after the transitional period (the prescribed duration of the transitional period is from 6 to 12 years after the Unitary Patent comes into effect). ${ }^{609}$

Thinking about all the co-existing regulations that result from these concomitant phases and the tangled interaction of members of various groups of states under different agreements, national regulations and languages, it is really easy to get (legally) "lost in translation", as proposed by the metaphor used by Adams. And here it is assumed that being "lost in translation" (of patent regulations and documents) specially assumes this legal perspective and gives rise to some questions: how can a Unitary Patent Court deal with this multilingual (+ legal) complexity? What are the best solutions for simplifying this intricate system, which is extremely difficult to understand for those who are not directly in touch with it? How to diminish the burden, especially the costs with translation and legal management to patent owners?

It is clear that the system must be simpler to understand and less fragmented in legal terms, when it comes to language/translation regimes. It is also clear that there are necessary efforts to make this integration possible. Most of all, it is unambiguous that a more integrated and simplified system would bring advantages to both its users and managers, to scientific society in general and to the European Union in political and economic terms.

That leads hence to the discussion of the European Unitary Patent and the European Unitary Patent Court, which is considered as a very central debate in the European Union currently. The possibility of creating a Unitary European patent together with a Unitary European Court was close to becoming a reality, before it was delayed by news over the exit of the UK from the EU. The idea was that the EPO will be in charge

607 S. Adams, Lost in translation? 'A review of the post-grant requirements for translation of patent specifications in Europe', World Patent Information, 44, 34e45, 2016.

608 Ibid.

609 Ibid. 
of granting and administering this Unitary Patent following the fundamental fact that patents are key drivers for innovation, employment and economic development. ${ }^{610}$

\subsubsection{European Unitary Patent and Unitary Court}

The initiative for the creation of a unitary patent in Europe was practically born with the creation of the EPO. For Arnold, it dates from even earlier, since 1947, when France, Belgium, Luxembourg and the Netherlands signed an agreement at The Hague to set up what became the International Patent Institute and, as a result of this event, in 1949, the Council of Europe started to structure the European Patent Office. The embryo of the unitary patent, which would ease administrative procedures and reduce costs, was already there. It is thus remarkable that the project took almost 70 years to be built until it was finally set in motion in 2016, but still with the risk of not entering into force in $2018 .{ }^{611}$

Only in 2011, the Council of the European Union in Brussels issued a document whose subject was a Proposal for a Regulation of the Council and the European Parliament implementing enhanced cooperation in the area of the creation of the Unitary Patent protection and a Proposal for a Council Regulation implementing enhanced cooperation in the area of unitary patent protection with regard to the applicable translation arrangements. Through this document, the Competitiveness Council authorized enhanced cooperation among 25 European countries in the creation of unitary patent protection. ${ }^{612}$

Still according to the same document, the proposal for a Council Regulation in the area of the creation of unitary patent protection has determined applicable translation arrangements based on Article 118(2) of the Treaty for the Functioning of the European Union, which provides its translation regime in line with the requirements of the Council's authorizing Decision. ${ }^{613}$

Therefore, it is important to emphasise that one of the first official documents about the unitary patent cooperation already demonstrated a pre-occupation with translation and included rules to regulate it. The document states that these preliminary translation arrangements maintain the possibility of filing patent applications in any language of the Union at the EPO, ensuring compensation of the costs related to the translation of applications filed in languages other than an official language of the EPO. This reduction of costs with translation can be quite attractive to applicants who wish to apply in non-official languages. Translation costs will decrease considerably also in terms of eliminating a national phase. ${ }^{614}$

610 Over the possible entry into force of the Unitary Patent in 2018, see: Will 2018 be the Year of the Unitary Patent and the UPC?, Mewburn Patents [Website], 2018, http://mewburn.com/will-2018-year-unitary-patent-upc/ (accessed 17 April 2018).

611 R. Arnold, A Short History of the Unitary European Patent and the Unified Patent Court, CIPA Congress, 2015, http://www. cipa.org.uk/pages/journal/article?35DC374C-278B-4E30-9A9A-9FC679FD27C6 (accessed 17 April 2018).

612 Interinstitutional File, Council of the European Union. Brussels, 23 June 2011, 2011/0093 (COD) 2011/0094 (CNS) 11328/11, http://register.consilium.europa.eu/doc/srv?l=EN\&f=ST\%2011328\%202011\%20INIT (accessed 17 April 2018).

613 lbid.

$614 \mathrm{lbid}$. See Section 2 of the same Document. 
The regulations state that European patents continue to be granted only in one of the official languages of the EPO. Likewise, they provide that no further translations will be required with the exception of transitional arrangements which will terminate when highquality machine translations become available. ${ }^{615}$

This reliance in machine translation as the main answer to linguistic variety may be a positive and pragmatic answer to the patent system on a global scale, especially to patent proprietors, who are faced with growing costs with translations and national fees. In fact, it can be affirmed that machine translation has already become an essential tool in the area of patent examination and prosecution all over the world, as the main resource used by examiners and attorney during patent search.

On the basis of periodical evaluation, the Regulations provide that machine translation has to reach a level of quality good enough to discard the afore mentioned additional translations. On this matter, the Commission can present a proposal to the Council for terminating the transitional period. On the other hand, the document prescribes that the transitional period lasts from 6 to 12 years from the date of its application. In the case of a dispute, a mandatory translation obligation applies to the patent proprietor. ${ }^{616}$

An agreement on these regulations was reached with all delegations of the participating Member States, although with the condition that the Commission presents a preliminary assessment of the state of the development of machine translation at the European Patent Office, at the time when the draft regulations are adopted in the Council. ${ }^{617}$

Although these discussions went so far in 2011, it was only in 2012, that there really occurred serious negotiations by member states of the European Union for the creation of a European Unitary patent together with a unified European Patent Court. This breakthrough agreement was achieved in the face of resistance from some groups and countries. Although the European unitary package is not yet in force, there are preparations for the creation of the Unitary Patent Court (UPC) and for the Unitary Patent to soon provide supranational protection for inventions in 25 countries across Europe. This number has recently grown, as Italy has just requested accession to the procedure of the unitary patent package. ${ }^{618}$ The agreement is still under ratification by EU member states. ${ }^{619}$ According to the EPO's planning, the first unitary patent was supposed to be issued as early as the second half of 2016. Although it has not happened as planned, the Preparatory Committee for the Unitary Court was established and is composed of all the Signatory States to the Unified Patent Court Agreement.

The purpose of the Preparatory Committee is to manage the work streams already established for the functioning of the Unitary Court. There are five work streams

615 Ibid.

616 lbid.

617 Ibid. See Section 6 of the Document.

618 EPO hosts major conference on unitary patent and unified patent court, 23 July 2015, EPO [Website], http://www.epo.org/ news-issues/news/2015/20150723.html (accessed 17 April 2018).

619 Unitary Patent \& Unified Patent Court, EPO [Website], http://www.epo.org/law-practice/unitary.html 
which the Committee will have to conduct before the Court is fully established: legal framework; financial aspects; information technology; facilities, and human resources and training. The Preparatory Committee will exist until the complete establishment of the Court, which is presumed to last two years. ${ }^{620}$ The following extract summarizes the Court's function and competence:

The Unified Patent Court (UPC) will be a court common to the Contracting Member States and thus part of their judicial system. It will have exclusive competence in respect of European patents and European patents with unitary effect. The exclusive competence is however subject to exceptions during the transitional period. The UPC's rulings will have effect in the territory of those Contracting Member States having ratified the UPC Agreement at the given time. The UPC will not have any competence with regard to national patents. ${ }^{621}$

As shown, the (still expected) establishment of the Unitary Patent Court is remarkable in terms of being unique in the world history of intellectual property rights, as it is the first agreement to overcome the principle of territoriality always observed in patent law (or other forms of intellectual property protection) related international treaties. The Agreement represents a big step to recognize that integration and harmonization should be intrinsic to the legal structure that supports the patent system. This "new system" created by the Unitary Patent does it though without excluding the existence of national patents and the competence of national courts to deal with actions concerning these patents whose validation occurred only at the national level. As left clear by the extract above, the Unitary Court will be part of the judicial system of the contracting states, but only in what concerns European Patents (with or without the unitary effect).

The importance of the Unitary Court and the Unitary Patent is a considerable improvement not only for the European patent system, as it creates opportunities for independent inventors, firms and other innovative institutions at the global level. This can be justified by the fact that patent owners will be able to count on reduced costs in fees and translations. A single court for litigation, with all the requirements defined for the qualification of its judges and teams and a more harmonized legal structure, will also provide better services and better safeguard the principle of legal certainty. Such changes value the investments made in science and innovation by companies, universities and governments and offer more efficiency to the patent system as a whole.

Back to History, Arnold describes that a Preparatory Committee was established to set up the UPC in March 2013. The Committee's work included establishing: IT, facilities, the legal framework, finance and human resources and judicial training. The most prominent products of the Committee's work were the 17th Draft of the Rules of Procedure, which was the subject of a public hearing in Trier on 26 November 2014, and

620 The information was taken from the official website of the Unitary Court: https://www.unified-patent-court.org/ (accessed 17 April 2018).

621 Ibid. 
the Call for Expressions of Interest from Candidate Judges issued in September 2013, which allowed the elaboration of a provisional list of candidate judges, in July 2014. The last product to mention was the decision to concentrate training of candidate judges from those Member States that lack experienced patent judges, which started in early 2015.622

The expertise of the judges of the Unitary Court is an aspect carefully observed in the Agreement. Only judges with previous experience in the field of patents can be appointed. The pool of judges of the Court will be composed of legally qualified judges ('lawyer judges') and technically qualified judges (from each field of technology). These judges will be appointed from the Court of First Instance, whether they are full-time or part-time judges of the Court. The professional continuous training of the judges is valued to the point of predicting an individual training plan for each judge and creating a permanent training structure based in Budapest. The judges will be nationals of the Contracting Member States, being appointed from regional lists for the regional panels of the First Instance. ${ }^{623}$

The qualification, the previous experience, the multiple nationalities and the continuous training of the judges forms an adequate framework to deal with a multilingual and multicultural system. In this regard, it is easy to prove that a more internationalized legal system will be much more effective in dealing with the complexity of the patent system than a fragmented system served by various national realities. The most internationalized and the less fragmented the system is, the better are the chances to improve and strengthen it, as it assuredly represents a gathering of strengths and expertise from its participants. That matches the scenario portrayed by Adams:

The drafting of the EU regulations on unitary effect foresaw a time when human translations of granted patents could be largely replaced by machine versions. Apart from certain situations during legal proceedings, the final form of the unitary effect regime dispenses completely with all responsibility on the part of the patent owner to provide post-grant translations, in favour of an ad hoc system of machine translation. ${ }^{624}$

Sousa \& Silva describe the most important similarities and differences between the European "conventional" patent and the European unitary patent. He observes that the unitary patent will still be granted by the EPO, in Munich, the responsible institution for examining and granting the European patent, although it will make some radical changes in the European patent systems, offering alternatives to the applicants who wish to protect their invention in Europe. ${ }^{625}$

622 Ibid.

623 Agreement on a Unified Patent Court (2013/C 175/01), Official Journal of the European Union, Art. 16-19, http://eurlex. europa.eu/LexUriServ/LexUriServ.do?uri=OJ:C:2013:175:0001:0040:EN:PDF (accessed 17 April 2018).

624 Adams, op. cit.

625 O. Sousa e Silva, 'O Tribunal Unificado de Patentes', Revista de Direito Intelectual, n. 2014-I, pp.243-257. 
The unitary patent will enter into force in the territory of all the Member States of the European Union which have joined the enhanced cooperation ${ }^{626}$ when signing the Agreement. In contrast with the European patent, the unitary patent will not need validation in each State. That's the so-called unitary effect, which makes the European unitary patent the first one with supranational effects in the world. What existed until now were systems that allowed a simultaneous grant, but still requiring national validation.

Contrary to what happens with the European patent in force, it will not be necessary for the applicant to hand in a translation of the patent description to validate it in the countries that are part of the Agreement, and the patent claims following the grant of a patent will be automatically valid in all contracting member States. The national institutes of Industrial Property will not have the responsibility for validation and grant of these patents, although they will receive a portion of the revenues of the European Unitary Patent maintenance from the fees charged by the EPO. ${ }^{627}$

There are some features that differentiate separate national applications from European Patent applications, and from the applications for a European Patent with Unitary Effect. In the case of national applications, a translation is required at the moment the application is filed or shortly after it. In the case of the European Patent, there is already a great advantage in this sense, as translations are only required on the grant of the patent (but it is still necessary to proceed to a full application in a country by country structure, which means that translations will be required in each country where the applicants want to validate their patents). In contrast, the European Patent with Unitary Effect is designed to eventually demand no translations at all. Only during the transitional period (from 6 to 12 years) a translation into one of the European Union official languages will be necessary. ${ }^{628}$ According to the EPO's official webpage:

Once the unitary patent takes effect, the current requirement for translations into official EU procedural languages will be a thing of the past. But inventors will still be able to obtain patent texts in their own languages: An automated translation tool for patents on the EPO website, Patent Translate, offers free translations between English and 31 other languages. ${ }^{629}$

626 According to the European Union Law, enhanced cooperation is a procedure where a minimum of 9 EU countries are allowed to establish advanced integration or cooperation in an area within EU structures but without the other EU countries being involved. This allows them to move at different speeds and towards different goals than those outside the enhanced cooperation areas. See EUR-Lex, Glossary of Summaries, http://eurlex.europa.eu/summary/glossary/enhanced_cooperation.html (accessed 17 April 2018).

627 Deloitte, Patente Europeia com Efeito Unitário, jan., 2015, http://cip.org.pt/wpcontent/uploads/2015/03/CIP_PatenteEuropeia_Report2015.pdf (accessed 17 April 2018).

628 Sousa e Silva, 2014.

629 Emphasis added. EPO, Unitary Patent \& Unified Patent Court, https://www.epo.org/news-issues/issues/unitary-patent.html (accessed 17 April 2018). 
Therefore, the unitary patent, by allowing a centralized examination in a vast set of languages, will imply substantial advantages to the applicants. Among these advantages are reducing costs with translation and taxes and diminishing drastically a whole set of bureaucratic procedures, by giving the holders of patent rights a uniform protection in a large territory and a unitary and specialized jurisdiction. A specialized unitary court also tends to diminish the chance of procedural mistakes and the implementation of such a court can contribute to the standardization of the legal framework and the relevant case-law, which may represent a benefit to all firms that apply for patents. That is why the unitary patent system represents an unquestionable initiative to encourage innovation and assure quality and transparency in the whole process, which extends from examining and granting a patent to judging patent disputes.

During the transition period, as explained, from 6 to 12 years, the Unitary Patent Court will count on the contribution of the contracting member States. After this period, it is expectable that the Court will be self-financing. The national patent offices will have no responsibility for validation and granting of the unitary patent, but they will still have a share of the revenues of the fees charged by the EPO for the application and maintenance of the unitary patent. Contracting Member States hosting local divisions, or the central division, will provide the facilities necessary for that purpose. ${ }^{630}$

Arguably, the unitary patent can be seen as a great incentive to innovation in developing countries. While it markedly simplifies the bureaucratic procedures and reduces costs with translation, legal representation and maintenance - which can be seen as a real burden - it will probably intensify the flow of interaction with such countries and encourage their firms, even smaller ones, to apply for protection (the participation of countries such as Brazil in applications in Europe is already proving its worth: in 2013, there were 690 applications and 80 granted patents). With the unitary patent, this participation will certainly grow, and this can be considered as a positive aspect of the unitary patent in terms of global development. ${ }^{631}$

630 Arts. 36 and 37 of the Agreement.

631 Deloitte, 2015. See table with the number of patent applications and granted patents at the EPO on Page 87. 


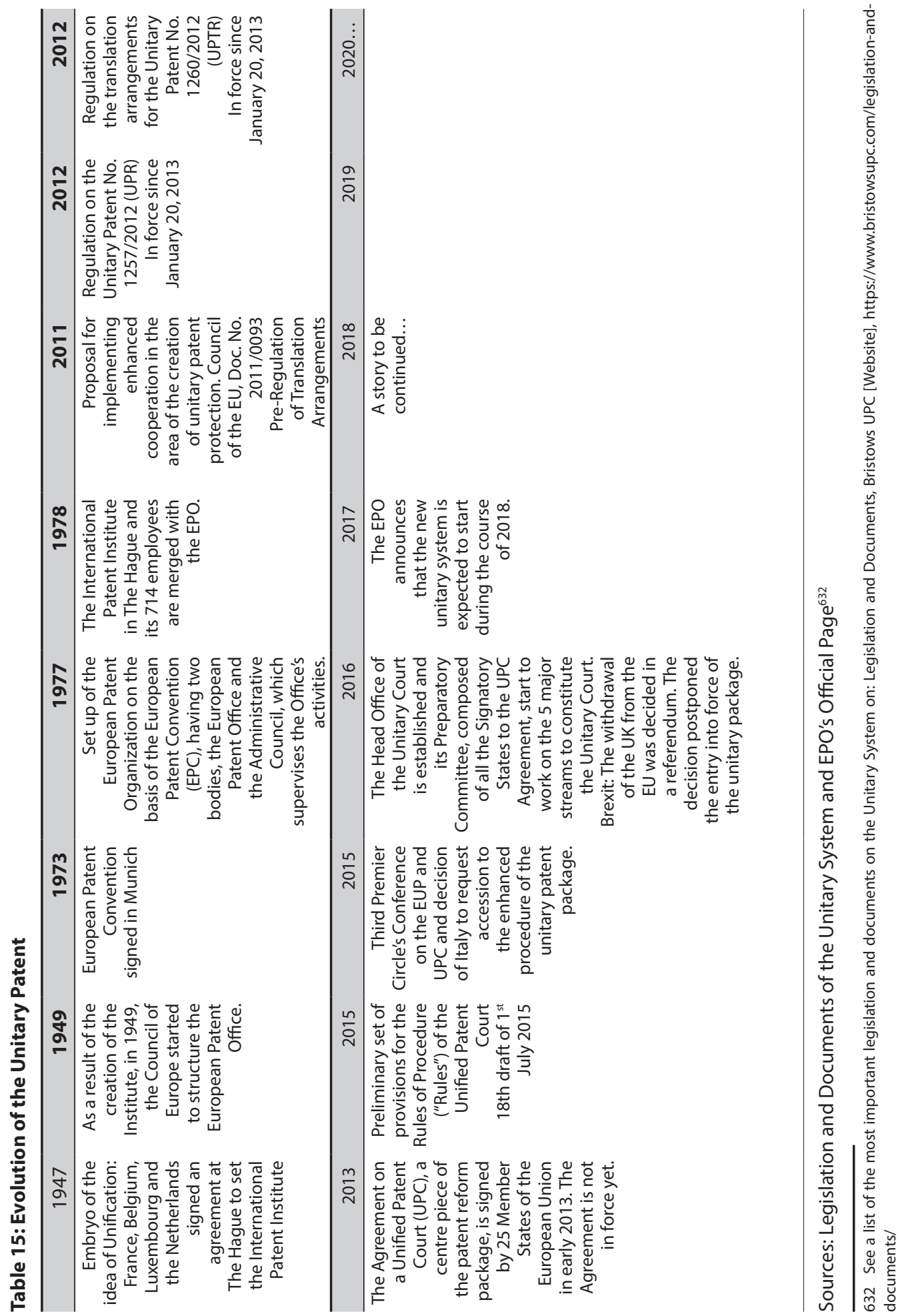


Sousa e Silva observes that the unitary patent is allowed to co-exist with the European conventional patent and with national patents in European countries. The first case happens when the applicant chooses to have a European patent but does not request the unitary effect. The legislation allows the applicant to ask for the unitary effect within one month after the application for the European patent. ${ }^{633}$ The last case (national patents co-existing with the unitary patent) will be necessary in the countries that did not sign the Agreement, namely, in Spain, Poland and Croatia. ${ }^{634}$

The Unitary Patent and the Unitary Court are not aimed to work exclusively with machine translation. That means an ongoing requirement for both human and machine translation will continue to exist. The difference is that the use of both types of translation may be optimized in a more integrated system. After all, this is what constitutes the very concept of system, and that is not different for the patent system. Integration, in this sense, also deeply affects the language regime and an optimal, more rational use of machine translation combined with human translation or with the ability to deal with translation technologies. $^{635}$

In the case of the debate brought by this research, different national legal regimes relating to the deposit of translations and different ways to (legally) deal with these translated texts still create unnecessary asymmetries in the patent system. Nevertheless, Phase II of the European patent system historical evolution, represented by the creation of the EPO and the conception of the so-called European patent was already a very big first step towards a pan-European patent system, which completely re-wrote the reality of Phase I, when totally uncoordinated national systems coexisted. ${ }^{636}$

In this regard, one conclusion must be clearly stated. Discussing patent systems is different from discussing cultural identities and peculiarities. What is valid for the second scenario is definitely not valid for the first one. This necessity to put apart - at least at a management level - these two spheres is demonstrably serious and should be carefully taken into consideration in any investigation relating translation/language and the patent system. Patent systems and cultural systems are, in this sense, opposite sides of social conditions. Cultural systems should be preserved and kept alive - so should be languages, dialects and minority manifestations. But patent systems are closely related to the universality of science, to foreign trade and to the consequences of globalization, including fast and automatic communication enabled by digital tools. Hence patent rights serve this vast and complex global system, owing it fair, transparent and reliable solutions.

633 Sousa e Silva, op. cit.

634 Spain did not sign the Agreement for not agreeing with the language regime of the unitary patent. Croatia, in turn, did not sign it because it entered the EU after the Agreement was signed. For more details, see Sousa e Silva, 2014.

635 For more details about the concept of system used to fundament the vision of the patent system defended on this study, see Chapter 3, Section 3.2, where the system is depicted as a restrictive structure, which involves inclusion and exclusion processes, characterized by its operational closure, which means, by its own rules. The more coherent and uniform it is, the less it tends to be corrupted or mischaracterized as a system.

636 For the definition of the mentioned phases, see Adams, 2016. 
Even with the advent of the European Patent with Unitary Effect, the simultaneous levels of protection and the exclusion of countries will still cause an undesired fragmentation in the system, which negatively affects its functioning. Besides, there are aspects of protection that will still be considered as a national issue, such as the compulsory licensing, which will be governed by the law of each State. ${ }^{637}$ Although there are few isolated cases of resistance, the unitary patent system has also inspired many controversies in some of the signatory countries, especially due to language and translation issues. These negative reactions can be explained by some factors. As the new system radically changes the whole functioning of the national patent systems, it affects directly groups of interest, public and private institutions and the industrial sector. Some of these controversies will be summarized below in the next topic from this Section.

The table below shows the most important characteristics of the Unitary Patent Court:

Figure 33: Summary of UPC's functioning and regulation

Structure and location

Competence

Composition

Rules of procedure

Transitional period
Court of First Instance (central division in Paris and two sections in London and Munich, besides several local and regional divisions), a Court of Appeal (Luxembourg) and a Registry (Luxembourg)

The Court will have exclusive competence to judge (in respect of European patents or European unitary patents): actions for actual or threatened infringements of patents; actions for declarations of non-infringement of patents; actions relating to the use of the invention prior to the grant of the patent; actions for compensation for licences on the basis of Article 8 of the EU Regulation (public offer of licensing), among other actions. The criminal actions will be judged by the States courts.

First Instance Court: 3 judges of multinational origin; Court of Appeal: 5 judges of multinational origin. The Court will comprise both legally qualified judges and technically qualified judges.

The Rules of Procedure shall be adopted by the Administrative Committee of the Unitary Court, on the basis of broad consultations with stakeholders and the opinion of the European Commission about its compatibility with Union law. The general rule is that the proceedings shall be open to the public, unless there are reasons to make them confidential. The proceedings before the Court are divided in a written, an interim and an oral procedure.

Up to seven years after the Agreement entered into force, actions for infringement of European patents may still be brought before national courts. Five years after the Agreement, the Administrative Committee will carry out a consultation with the users of the patent system and a survey on the number of European patents still brought to national courts. The transitional period may be prolonged for up to 7 years.

Source: Sousa e Silva (2014) and Agreement on a Unified Patent Court (2013/C 175/01, arts. 7, 8, 9, 32, 41, 83)

The language regime, as the most controversial issue of the unitary patent, ended up being a considerably complex set of rules. The official languages of the Unitary Patent are the same as the official languages of the EPO: English, German and French. The 
Unitary Patent Court language regulations are the ones that inspire more controversies, being considered as vague and confusing by patent attorneys, who fear a misuse of the flexibility of the system. ${ }^{638}$ The Agreement on a Unified Patent Court gives basic guidance on its language regime, for instance, in the languages used in the three different types of Courts involved and provides other necessary arrangements. Below, it is intended to summarize the most important rules concerning language and translation. ${ }^{639}$

The Agreement determines that the language used in the procedure of the regional and local divisions will be the languages of the countries where they are located, since it is an EU official language. The language of the central division of the Court will be the language of the patent, which is one of the official languages of the EPO, which will tend naturally to a predominance of English, as most of the non-European applicants use it. In the Court of Appeal, the language used in the First Instance Court will be adopted. In this case, if the parties request, the language of the patent can also be used. Another possibility is that the competent panel may decide on the use of the language in which the patent was granted as the language of proceedings. Any panel of the Courts may dispense with translations when such procedure is not necessary. ${ }^{640}$

\section{Table 16: Language regime of the Unitary Patent Court}

\begin{tabular}{|c|c|}
\hline $\begin{array}{l}\text { Regional and local divisions of } \\
\text { the Court of First Instance }\end{array}$ & $\begin{array}{l}\text { Official European Union language which is the (or one) official language } \\
\text { of the Contracting Member State hosting the division. Contracting } \\
\text { Member States still may designate one or more of the official languages } \\
\text { of the EPO as the language of proceedings. }\end{array}$ \\
\hline $\begin{array}{l}\text { Central division of the Court of } \\
\text { First Instance }\end{array}$ & $\begin{array}{l}\text { The language of the proceedings in the Central Division shall be the } \\
\text { language in which the patent was granted. English will naturally } \\
\text { predominate. }\end{array}$ \\
\hline Court of Appeal & $\begin{array}{l}\text { The language of proceedings before the Court of Appeal is the same } \\
\text { used in the Court of First Instance. The parties may agree on the use of } \\
\text { the language of the patent. }\end{array}$ \\
\hline $\begin{array}{l}\text { Other relevant language } \\
\text { arrangements }\end{array}$ & $\begin{array}{l}\text { - Any panel may dispense with translation requirements when it is } \\
\text { deemed appropriate. } \\
\text { - At the request of one of the parties, the courts may provide } \\
\text { interpretation services to assist the parties during the oral proceedings. } \\
\text { - A defendant having his residence in a Member State may have the } \\
\text { right to obtain, upon request, translations of relevant documents in the } \\
\text { language of the Member State. } \\
\text { - During the transition period, an application in German or French should } \\
\text { be followed by a translation into English. The Idea is that all the patents } \\
\text { become available in English, the most usual language in technology } \\
\text { and science. }\end{array}$ \\
\hline
\end{tabular}

Source: Sousa e Silva, 2014, and Agreement on a Unified Patent Court (2013/C 175/01, arts. 49-51)

638 Information collected directly through interviews. See also: Council Regulation (EU) 1260/2012. http://eurlex.europa.eu/ LexUriServ/LexUriServ.do?uri=OJ:L:2012:361:0089:0092:EN:PDF

639 Ibid.

640 Council Regulation (EU) 1260/2012; Sousa e Silva, op. cit.; and Agreement on a Unified Patent Court (2013/C 175/01, arts. 49,50 and 51). 
The advent of the European Patent with unitary effect (the so-called Unitary Patent) and the Unitary Court are very important for strengthening the European patent system and even to expand and invigorate the patent system in a global scale. Understanding the patent system as a system is very relevant for affirming the value of a pan-European patent system for patent law at both regional and global levels. A patent system should be seen as a restricted and homogeneous structure, with its own rules, involving inclusion and exclusion processes of elements and operations that are not acceptable in its logic and affirming itself in reliable, clear results that validate its existence.

National, fragmented structures which don't truly merge in a systemic architecture may somehow delineate a system, in the case of patent rights. That is how patent national systems are organized. The same is valid for the current conformation of the (traditional) European Patent. However, such fragmented structures are difficult to control and easy to corrupt - which do not make them clearly characterized as systems. In this regard, the traditional European Patent can still not be considered as a "European Patent". Yet the Unitary Patent will represent a large step in reaching a more homogeneous design in the European patent system. Likewise, the global patent system can be called a system, but there are still many gaps and discrepancies among national patent law that should be mitigated for it to reach an optimal level of functioning.

In terms of a systemic constitution, it is possible to visualize the current European Patent system as an asymmetric structure, more like a mosaic linked by significant advances in terms of harmonization than a consolidated homogeneous configuration. In comparison to other patent systems, it still represents great advances in terms of integration and harmonization. This fragmentation creates vulnerability to the system, as it may be corrupted by discrepancies or gaps in, for example, less structured national legal systems, especially in cases of court disputes involving patents.

In this regard, it is also important to recognize the Unitary Effect and the Unitary Court as promising answers for strengthening the European patent system in a way it can really turn into a reliable, coherent structure, which can open doors to more international integration in patent law. Some of the factors that lead to this conclusion are: qualification of judges, harmonization of decisions, capacity to deal with the complex linguistic European reality, capacity to better use machine translation and other digital tools, capacity of obtaining controllable results, predictable by the example of the PCT or even by the example of the classical EP system as already a big step from national systems only.

Imposing a new (more simplified) language regime to the member States may sound too harsh at a first sight and may lead to a classic and interminable discussion on linguistic rights. But it should be clear that this discussion may be softened when it comes to the patent system, for reasons already mentioned above, where it is attested that patent systems and cultural systems are on opposite sides of social conditions from the linguistic point of view. A simplified and harmonized patent system will provide motivation for the States to better prepare to a more interactive approach in terms of 
accessing the "innovation language". And here it is not referring to English or any specific language, but to an attitude towards the patent system. This attitude implies allowing linguistic interaction, besides preparing for it, and an awareness of a livelier participation in global innovation.

\subsubsection{Spain's actions against the regulations of the Unitary Patent}

Back to the history of the Unitary Patent, as reported before, the negotiations of 2012 led to the adoption of Regulations 1257/2012/EU and 1260/2012/EU on 17 December 2012 and to the signing of the Agreement on the UPC in Brussels on 19 February 2013. Some of the significant reactions to the Agreement and its language regulations were the Cases C-146/13 and C-147/13, launched by Spain, seeking annulment of the Regulations. The cases are worth of description and analysis. ${ }^{641}$

Both actions sought the annulment of Regulation (EU) No 1257/2012, aimed at creating the unitary patent in Europe. Action C-147/13 was particularly related to the provisions of the afore mentioned Regulation (and associated Regulation No 1260/2012) concerning language and translation. Also relevant to the context of the present research, Spain argued, in both cases, against an allegedly unlawful assignment of powers to the EPO, claiming the Regulation breached the values of the rule of law. As according to the complaint, the Regulation provides for protection based on the European patent, whereas the administrative procedure for the grant of such a patent is not subject to any form of judicial review which ensures the correct and uniform application of EU law and the protection of fundamental rights. ${ }^{642}$

Concerning the aforementioned plea, the Opinion of the Advocate General stated that the Unitary Patent Regulation does not incorporate the granting procedure for European Patents. The contested Regulation merely establishes a special agreement for enhanced cooperation through the unitary effect and does not regulate the conditions for the grant and validity of the European Patent. ${ }^{643}$ The Advocate General declared that the European Union accepted the rules on the grant of the European patent before the regulation was enacted.

Additionally, the Opinion reiterated that the validity, nullity and infringement of the unitary patent are subject to judicial review by the UPC, and the administrative decisions of the EPO relating to the grant of a unitary patent may be the subject of administrative appeals. The mentioned plea was also considered as lacking in clarity, as it did not refer to the infringement of any fundamental right in particular. ${ }^{644}$

641 Judgement of 5 May 2015, Spain vs Council, C-147/13, ECLI:EU:C:2015:299, 5 May 2015; Judgement of 5 May 206, C-146/13, ECLI:EU:C:2015:298; Opinion of Advocate General Bot, delivered on 18 November 2014, Case C-146/13, ECLI:EU:C:2014:2380; Opinion of Advocate General Bot, delivered on 18 November 2014, Case C-147/13, ECLI:EU:C:2014:2380.

642 Judgement of 5 May 206, C-146/13, ECLI:EU:C:2015:298.

643 Opinion of Advocate General, Case C-146/13.

644 Ibid. 
Likewise, the Opinion of the Advocate General and the Judgement of the CJEU have endorsed the content of recitals 24 and 25 of Regulation (EU) No 1257/2012, which state that establishing a Unitary Patent Court is essential for ensuring the proper functioning of the Unitary Patent and for ensuring consistent case-law, legal certainty and cost-effectiveness for patent proprietors. ${ }^{645}$ The Opinion of the Advocate General has also pointed that since the beginning of the patent law harmonisation process in Europe, the EU legislature was determined to create an EU patent on the basis of the EPC system. On the grounds of the mentioned arguments, Action C-146/13 was dismissed by the CJEU. ${ }^{646}$

Under the light of the research question that guided this research, what remains important from the aforementioned Opinion and Judgement is the fact that they reiterate a tendency of more integration and harmonization of the patent system and show a glaring inconsistency of pleas which may evoke the violation of human rights, or the inconveniency of integrating the domestic patent protection framework to a regional patent, concerning an Agreement which establishes an international patent (in the event, the first genuinely international patent in the history of IP rights). In short, the decision of Case C-146/13 proves that there is nothing in the essential nature of such an Agreement, concerning a cross-border patent, that can harm its signatory States or, as the case is particularly related to the European Union law, undermine, from a general perspective, the values related to the rule of law or the right to effective legal protection.

Different from Action C-146/13 is well-founded Action C-147/13, Spain's nullity action against Regulation 1260/12 on the language/translation regime for the unitary system. The action alleged violation of the principle of non-discrimination by the language arrangements established in Regulation 1260/12, which keeps the trilingual language regime of the EPO (English, German and French being its three official languages) as the basis of the language regime of the Unitary patent. ${ }^{647}$ The pleas presented by the Kingdom of Spain are commented below.

The first plea invokes the infringement of the principle of non-discrimination on grounds of language. The Kingdom of Spain claims that adopting the contested regulation violates the principle of non-discrimination established in Article 2 TEU, considering the language regime of the unitary patent detrimental to persons whose language is not one of the official languages of the EPO. The plea was also based on the argument that the access to translations of documents which confer rights on the public is not guaranteed, as the specification of a unitary patent will be published in the language of the proceedings and will not include the possibility of further translations. ${ }^{648}$

The Opinion of the Advocate General related to this plea states that envisaging a translation of the unitary patent into all the EU official languages is neither practicable nor justifiable under EU law. The Opinion considers that since the Treaty of Lisbon, the

645 Judgement of 5 May 206, C-146/13, ECLI:EU:C:2015:298; Opinion of Advocate General, Case C-146/13.

646 Opinion of Advocate General, Case C-146/13, 44.

647 Judgement of 5 May 2015, Spain vs Council, C-147/13, ECLI:EU:C:2015:299.

648 Ibid. 
TFEU has given the Council legal basis for establishing 'language arrangements for the European intellectual property rights. He also considers that EU law admits different linguistic regimes regarding the context of different treaties, allowing them to limit the number of languages used. ${ }^{649}$ The question that remains, and will be discussed below, after a brief description of the other pleas, relates to weather the choice of this particular legal arrangement does really not violate the principle of non-discrimination on grounds of language, considering the phase of national validation is no more required after the unitary patent enters into force.

The most important subsequent pleas can be summarized as follows:

(i)Theadministration of the compensation schemefor the reimbursement of translation costs being delegated to the EPO breaches the principles set out in Meroni v High Authority ${ }^{650}$; (ii) Article 4, which governs 'translation in the event of a dispute' is incorrect, as that provision does not relate to 'language arrangements' for a European intellectual property right in accordance with the second paragraph of Article 118 TFEU, but incorporates certain procedural safeguards in the context of legal proceedings; (iii) The contested regulation infringes the principle of legal certainty as it: limits access to information for economic operators, does not specify the arrangements relating to publication of the grant of unitary effect, does not indicate the ceiling for costs with translation or its method of calculation. It lastly claims that the system of machine translation did not exist when the contested regulation was adopted. ${ }^{651}$

Based on the Opinion of the Advocate General, the Court (convincingly) concludes that references in EU Treaties to the use of languages cannot be interpreted in terms of a general principle to the effect that anything that might affect the interests of a European Union citizen should be drawn up in his language in all circumstances. The Court considers (and is relatively right in doing so) that the language regime of the unitary patent is impartial in reaching the objective of creating a uniform and simple language arrangement. The Court also acknowledges that said language regime facilitate access to patent protection especially for SMEs. ${ }^{652}$

Still regarding the aforementioned language regulation, the Court emphasizes that the Regulation differentiates between the official languages of the EU in order to accomplish a legitimate objective: the translation regime of the unitary system should

649 Opinion of Advocate General Bot, Case C-147/13, ECLI:EU:C:2014:2380, pars 28-40.

650 A delegating authority cannot confer upon the authority receiving the delegation powers different from those which it has itself received under the treaty (general principle). See: Meroni v High Authority, 1957/1958, ECR 133, https://eur-lex.europa.eu/ legal-content/EN/TXT/?uri=CELEX\%3A61956CJ0009 (accessed 27 November 2018).

651 Ibid.

652 Judgement of 5 May 2015, Spain vs Council, C-147/13, ECLI:EU:C:2015:299; Opinion of Advocate General Bot, Case C-147/13, ECLI:EU:C:2014:2380. 
be simple and cost-effective, in order to ensure legal certainty, stimulate innovation and benefit EU enterprises. ${ }^{653}$ It is worth transcribing point 35 of the ruling:

The legitimacy of such an objective cannot be denied. One of the choices facing an inventor when planning to obtain protection for his invention by the grant of a patent concerns the territorial scope of the desired protection, which will be decided after an overall assessment of the advantages and drawbacks of each option, which includes complex economic evaluations of the commercial interest of having protection in the various States compared with the sum of the costs entailed in obtaining the grant of a patent in those States, including translation costs. ${ }^{654}$

Additionally, the Court acknowledges that the Regulation provides the necessary balance between the interests of economic operators and the public interest, by presenting a number of mechanisms which facilitate the access to translated texts: a compensation scheme for the reimbursement up to a ceiling of translation costs for some applicants, a transitional period until a high quality machine translation system is available for all the official languages of the EU, and a number of provisions applicable in the event of a dispute, as a full translation of the unitary patent for operators suspected of infringement in the event of a dispute. ${ }^{655}$

Less cogently, and based on the Opinion of the Advocate General, the Court recognises the Council's decision to differentiate between the official languages of the European Union, and to choose only English, French and German, as appropriate and proportionate to the legitimate objective related to that regulation. Pursuant to the aforementioned Judgement, the Action was dismissed, and the contested regulations, integrally maintained. ${ }^{656}$ Still in 2014, Regulation 542/2014/EU amending the revised Brussels Regulation to provide for the UPC was approved. ${ }^{657}$

Under the light of the present research, apart from punctual claims on the lack of legal basis of the unitary system's within the scope of the European Union law, two main aspects of the complaints lodged by Spain against the Council remain important: the discussion around the infringement of the principle of non-discrimination on grounds of language, and the allegations that the regulations lack more clear specifications concerning language and translation (publication of the grant of unitary effect, indication of the ceiling for costs with translation or its method of calculation,...).

653 Judgement of 5 May 2015, Spain vs Council, C-147/13, ECLI:EU:C:2015:299.

654 Ibid.

655 Ibid. See paragraphs 42-47.

656 Ibid. See paragraphs 20, 32, 39, 45 and 47.

657 Regulation (EU) no 542/2014 of the European Parliament and of the Council of 15 May 2014, https://eur-lex.europa.eu/ legal-content/EN/TXT/?uri=celex\%3A32014R0542 (accessed 28 November 2018). 
First, the maintenance of the trilingual language regime of the EPO seems arbitrary from the perspective of a European international patent, which no more triggers the requirement for national validation. On this matter, there is no possible objective justification for keeping the French language (for example) as an official language of the unitary system while excluding Spanish, the second language in the world in number of native speakers. ${ }^{658}$ The argument used by the Advocate General restates the provisions of the regulations and does little to mitigate the controversy:

Furthermore, the EU legislature made the choice to take the EPO system as the basis, which is a consistent choice, as that system had already proven itself, so that the use of English, French and German, in connection with the EPUE is not insignificant, these being the official languages of the EPO. This choice ensures a degree of stability for economic operators and practitioners in the patent sector who are already used to working in these three languages (...) In addition, it would appear that the choice of these languages is commensurate with the linguistic realities in the patent sector. As the Council states, the majority of scientific works are published in English, French or German. There is therefore no doubt that European researchers can understand patents published in those languages. Similarly, it is clear from the abovementioned Commission impact assessment and from the arguments put forward by the Kingdom of Sweden that English, French and German, are the languages spoken in the Member States from which the most patent applications in the Union originate (...) Consequently, I consider that the limitation to the three official languages of the EPO is appropriate having regard to the legitimate objectives pursued by the EU legislature. ${ }^{659}$

The solution of keeping the trilingual regime as a way to ensure a degree of stability for economic operators and practitioners in the patent sector who are already used to working in these three languages, although not fully convincing, brings a realistic argument for reproducing the EPO's language regime in the unitary system. As contested by the Council and the interveners, differences of view between Member States over the linguistic regime have frustrated all previous unitary patent projects. ${ }^{660}$ In this regard, it is understandable that the existing regime should be preserved at least during the first years of the transitional period of the unitary system. However, the regulations do not provide for future re-evaluation of said language regime.

658 See: J. Paolillo and D. Anupam, Evaluating language statistics: the ethnologue and beyond, UNESCO Institute of Statistics, 2006, http://uis.unesco.org/sites/default/files/documents/evaluating-language-statistics-the-ethnologue-and-beyonden_0.pdf (accessed 28 November 2018).

659 Opinion of Advocate General Bot, Case C-147/13, ECLI:EU:C:2014:2380, pars. 58-59.

660 Ibid., par. 25. 
The arguments that follow are way more refutable. The Advocate General states that the choice of the trilingual regime is commensurate with the linguistic realities in the patent sector, pointing that the majority of scientific works are published in English, French or German. However, this argument does not respond to the definition of the patent system as a means to widely disseminate technological information and to foster innovation. In this regard, the unitary system should not aim to keep a scenario where the majority of patent applications are permanently associated with said languages. The number of applications in each language or in each country can change and should not be tied to the idea of an immutable reality, considering the fast changing and dynamic current scenario for innovation.

The Opinion of the Advocate General presumes that there is no doubt that European researchers can understand patents published in those languages, ${ }^{661}$ meaning the three official languages of the EPO. First, the statement sounds vague and unfounded, as not all the European researchers can understand or make the best use of a patent document written in German, for example. Moreover, it does not preclude the claim that the unitary patent language regulation infringes the principle of non-discrimination on grounds of language.

As aforementioned, language and translation have long been recognized as central elements to European integration. There are currently 24 official languages in the Union. Nevertheless, the support of the EU for language diversity goes far beyond its official languages and involves around 150 regional or minority languages under the idea of being united in diversity. ${ }^{662}$ From this perspective, there is enough research and historical evidence that the relationship between language and identity is not contradictory to the process of European integration. ${ }^{663}$ In order to sustain this model, the functioning of the EU depends on high quality translation and interpretation. As an illustration, the entire EU system requires over 2000 translators and 800 interpreters per day on average. ${ }^{664}$

Article 2 of the TEU establishes the principles that found the Union, which include respect for human rights, non-discrimination, tolerance, justice and solidarity. ${ }^{665}$ Likewise, Article 18 of the TFEU determines that any discrimination on grounds of nationality shall be prohibited. ${ }^{666}$ It is important to enhance that the EU's multilingualism policy is founded on the protection of Europe's rich linguistic diversity and on promoting language

\footnotetext{
661 Ibid., par. 58.

662 J. Grindheim \& T. Lohndal, 'Lost in Translation? European Integration and Language Diversity', Perspectives on European Politics and Society, Vol. 9, No 4, 2008.

663 See J. Grindheim \& T. Lohndal, 2008.

664 'European Parliament - never lost in translation', 01 October 2008, http://www.europarl.europa.eu/sides/getDoc. do?pubRef=-//EP//NONSGML+IM-PRESS+20071017FCS11816+0+DOC+PDF+V0//EN\&language=EN $\quad$ (accessed 24 December 2018).

665 European Union, Treaty on European Union, 1992, https://europa.eu/european-union/sites/europaeu/files/docs/body/ treaty_on_european_union_en.pdf (accessed 18 April 2018).

666 Treaty on the Functioning of the European Union, https://eur-lex.europa.eu/legal-content/EN/ TXT/?uri=celex\%3A12012E\%2FTXT (accessed 23, December 2018).
} 
learning. ${ }^{667}$ Towards this end, Regulation $n^{\circ} 1 / 58$, determining the languages to be used by the European Economic Community, which included only Dutch, French, German and Italian in its first draft, was amended many times in order to include all languages of the Member States of the EU, reaching the current number of 24 official languages. ${ }^{668}$

At this point, it is relevant to mention Article 10 of the Universal Declaration of Human Rights, which proclaims the right to a fair trial, implicating that anyone has the right to full equality by an independent and impartial tribunal. ${ }^{669}$ In this vein, the Declaration explicitly entails associated rights, as the right to non-discrimination based on language, or on political, jurisdictional or international status of the country or territory to which a person belongs. ${ }^{670}$ Hence, linguistic rights comprise important human and civil rights. Under these auspices, the European Charter for Regional or Minority Languages was adopted, in order to protect regional and minority languages, which are languages traditionally used by a minority group within a given territory of a State and which are not considered as official languages of the same State. ${ }^{671}$

In full view of the aforementioned regulations and considerations, the up-todate trilingual regime of the European Patent Office may be considered as the cause of different types of inequalities among (especially European) users of the current European patent system. ${ }^{672}$ Together with other factors, the restrictive regime can affect the distribution of costs to file applications and the full access to disclosed information. ${ }^{673}$ The establishment of the unitary system can intensify these inequalities if not rationalized in terms of affiliating its language policies both with the principles of the European Union and the very nature of the patent system. The solutions are not simple.

As discussed in Chapter 1, the structure of the patent system is related to the universality of science and with the widest possible access to the disclosed information, which goes far beyond the European borders. In this sense, patent law is a highly internationalized field of law, which is closely associated with international trade and fair competition. ${ }^{674}$ Additionally, the justification of the patent system is given by the

667 European Union, 'Multilingualism', https://europa.eu/european-union/topics/multilingualism_en (accessed 24 December 2018).

668 Regulation $n^{\circ} 1 / 58$, determining the languages to be used by the European Economic Community, https://publications. europa.eu/en/publication-detail/-/publication/e27878a8-d455-4515-8e18-99bf6160b651/language-en (accessed 25 December 2018). See also: M. Gazzola, 'Language Policy and Linguistic Justice in the European Union: The Socio-Economic Effects of Multilingualism', ELF Working Papers, 2014, https://www.unige.ch/fti/elf/files/7314/5865/9208/elfwp15.pdf (accessed 25 December 2018).

669 The Universal Declaration of Human Rights, https:/www.ohchr.org/EN/UDHR/Documents/UDHR_Translations/eng.pdf (accessed 5 January 2019).

670 Ibid. See Article 2.

671 Council of Europe, European Charter for Regional or Minority Languages, 1992, http://conventions.coe.int/treaty/ en/Treaties/Html/148.htm (accessed 5 January 2019). See also: The World Conference on Linguistic Rights,"Universal Declaration of Linguistic Rights", Barcelona Spain, June 1996, http://www.un.org/en/universal-declaration-human-rights/ (accessed 5 January 2019).

672 Gazzola, M., 'Identifying and Mitigating Linguistic Inequalities in the Management of Patent Information in Europe', World Patent Information, no. 40, 2015a, pp. 43-50.

673 Ibid.

674 See especially Section 1.2 of Chapter 1. 
universal disclosure of patent information and its function of fostering innovation. ${ }^{675}$ These characteristics require simplified, efficient and fast communication standards, which pervade an intercultural scenario. Consequently, the fewer the languages included in a given patent system, and the widest the reach of said languages, the better for its performance.

On the other hand, there are many reasons to believe that a stronger European patent system will significantly favour all the Member States of the Union. It is unquestionable that a unified system will establish an excellent centre of governance of patent information at the global level. However, following a full model of multilingualism is neither viable nor rational, considering the conditions for patent application and examination, undeniably more critical than the conditions for disclosure, in this particular event. ${ }^{676}$ That leads to the point that rational criteria for a periodical re-evaluation of the new system's language regime should be a central topic of debate and studies.

In view of this context, the action filed by Spain leaves scope for a variety of interpretation approaches and for necessary further debate that should include: the possibility of re-discussing the criteria for defining the official languages of the unitary system, based on, for example: a periodical assessment of the number of patent applications in each language; the possibility of adopting a monolingual system having English as lingua franca, as a practical (but not harmless) solution.

As aforesaid, it is clear that the number of official languages of the unitary system should be restricted. Equally evident is the fact that it will not be possible to reach a perfect solution in terms of the definition of these official languages. As there are abundant reasons to keep the language regime simple and clear, the solution is finding more objective criteria that do not arbitrarily favour one language or a set of languages but may give the best results for the European community as a whole. That does not mean this solution must be adopted straightway, as it is also understandable that the transition period should, at least temporarily, benefit from the stability of an already operative system.

Regarding the pleas related to the lack of clear specifications on the unitary patent regulations concerning language and translation (publication of the grant of unitary effect, indication of the ceiling for costs with translation or its method of calculation...), it is important to admit that the mentioned regulations still inspire hesitation and distrust among the main users of the patent system, especially concerning the functioning of the Unitary Court. The regulations present gaps that will probably be filled in only after the system is fully established. Most of the interrogations of these stakeholders are described and discussed in Chapter 7 of this dissertation, while Chapter 8 presents a set of recommendations for the language regime of the unitary system.

675 See Sub-sections 1.2.1 and 1.2.2 of Chapter 1.

676 As demonstrated in Section 5.2, machine translation suffices to disclose patent information for the person skilled in the art. Therefore, in the case of the whole European community, universalizing the disclosure and use of patent information depends more on establishing policies related to disseminating the use of patent searching tools and platforms than on overcoming language barriers. 


\subsubsection{Other controversies and negative reactions towards the Unitary Patent System}

The advent of the unitary system inspired lots of other controversies and adverse reactions. One example, frequently used by the opponents of the new system, is a study presented by Deloitte, at the request of the Business Confederation of Portugal (CIP), which aimed to evaluate the impact of the introduction of the European Patent with Unitary Effect and the implementation of the Unified Patent Court on Portuguese companies. This study clearly summarizes the contents and the tone of the criticism directed to the Unitary Patent System. However, it is easy, and important, to find counter-arguments on the opinions presented by this study opposing the unitary package, especially the ones concerning language and translation. ${ }^{677}$

The study starts with a claim that the percentage of European patent applications of Portuguese companies is too small to justify its ratification of the Agreement. Portugal had only 199 applications for European patents in 2013, which is not comparable to the numbers presented by other European countries, such as the UK, with 6,469, and Germany, with 32,022 . This number is still more insignificant if non-European countries, like the United States $\left(64,967\right.$ applications) and Japan $(52,437)$ are considered. ${ }^{678}$

It also infers that without a previous study to assess the differences in judicial costs to be incurred in the Unitary Court compared to the costs of a patent litigation before national authorities it is not possible to assess its impact on Portuguese companies, which would make the participation of Portugal in the Unitary System too risky for its industrial fabric. ${ }^{679}$

The only verifiable argument presented by the studies is the one related to the costs of maintaining the local division of the Unitary Court, which also include the idea of transition or "adaptation" costs. These costs are estimated by the study as administrative costs, income from the infrastructure where the local division will be based and costs of judges' salaries. The amount presented by the study is the sum of the costs involved during the transition period with the maintenance of the local division and is calculated as 6,425 million Euros to the year of 2016 (the study was prior to the ratification of the Agreement of Portugal, and these costs are still not a reality, as the local division was not established yet). Besides, the costs of the contribution of Portugal as a Member State are presented as part of the risks and worries involved with the participation in the Unitary System. These last costs are estimated to be from 269,000 to 518,000 Euros in 2016 (the last value is based on a "pessimist perspective"). ${ }^{680}$

The arguments and results presented by this study are valid and important as an exercise of dealing with the uncertainties presented by the new system. The worries and concerns experienced by all the involved sectors are also legitimate and should be carefully assessed. However, the opinions presented by the referred study are easy to oppose, if analysed in the context of a situation which is also based on previous experiences and

677 Delloitte, op. cit.

678 Ibid.

679 Ibid.

680 Ibid. 
evidence in the patent system, since the PCT and the European Patent are good examples of how integration can in fact improve the system, in general, and work as an incentive to innovation in particular cases.

The fact that the percentage of the Portuguese patents granted in the EPO is still a very small one sounds more like an argument in favour of the Unitary System than against it. The new system will encourage firms (especially small ones) to apply for patent protection, as the cost of protection (as well as the cost for court disputes) for these firms will be certainly reduced - not to mention the fact that they can still chose the traditional European Patent or national patents. Therefore, the first argument retrieved from this study is unjustifiable.

The last argument presented, although more palatable in many senses, is also not sufficient to oppose the unitary system and even the (already concluded, in the case of Portugal) ratification of a country with the economic features of Portugal. The changes proposed by the Unitary System can be seen as a good opportunity and a powerful apparatus to new perspectives in the national environment in terms of innovation and intellectual protection, especially to small and medium companies, very relevant to support such economic realities as the one in Portugal. Also, the estimated costs with the maintenance of the Court's local division and the contribution as a Member State are not so high if compared to the benefits of the system to the European Union and to Portugal as part of it. ${ }^{681}$

The fact that the new system brings a prospect of uncertainty is not a good argument for not supporting it. No doubt the new system brings a new paradigm to the law and to patent rights, with a certain margin of risk to all the Member States which signed the Agreement. However, none of the possible "damages" brought by it in the worst possible perspective would be irreversible, and the transition period is well planned in a way that it considers a slow adaptation process. Therefore, taking the risk is certainly worthwhile in this case, and cannot be seen as a shot in the dark, as there are some positive perspectives even presented by the same study.

Although the study focuses on unidentified risks and constraints, it also highlights that the implementation of a Unitary Court will certainly contribute to the harmonization of the legal framework and case law in this area, which it understands as a benefit even to Portuguese companies. Other positive sides identified by the study are: the ratification of the Agreement in Portugal will benefit the companies which apply for patents in more than 5 countries (it will maybe encourage other companies to do the same?); the ratification of the Agreement can (and should) be followed by public policies which encourage Portuguese companies to strengthen research, development and innovation, which can represent a positive change to its industrial sector; the European Unitary Patent clearly presents benefits at the level of encouraging intellectual protection and will be an additional incentive to protect the accomplished investments in Portuguese R\&D departments. ${ }^{682}$

681 Sousa e Silva, op. cit.

682 Ibid. 
Some possibilities opened by the Unitary Court also inspire mistrust in the users of the patent system. One of them is about the fact that once a patent is invalidated by the Court, it becomes invalidated in the whole territory covered by the agreement. In this regard, some questions come up: will the local divisions of the Unitary Court be affected by the peculiarities of the places where they are located, considering that the legal system is also associated with cultural aspects? Can these local or linguistic differences negatively affect the unitary system? Will the idea of invalidation (or any other decision) in the whole territory covered by the Agreement provoke an increase in national applications, weakening the traditional European Patent? Will machine translation tools improve to a level of deserving the trust of the system's users? What kind of unexpected problems will come up with an integrated system? Will it be really more attractive than the classical European Patent system or the application for national patents?

Another unexpected controversy is related to the exit of the United Kingdom of the European Union, the so called "Brexit", determined by a historic referendum that took place in June 2016, in which the majority of the British population decided to leave the European Union. This event brought many questions and opinions referring to the future of intellectual property in Europe, especially to the future of the enhanced cooperation on unitary protection and on the establishment of a Unitary Court.

There are many possible results involving the exit of Britain from the EU and the Unitary Patent system. As there are no consolidated studies yet about this issue, due to its proximity in time and to the question marks it still raises among IP experts and professionals, it will only be possible to sum up the main possibilities of consequences based on different types of declarations and opinions, which are not fundamentally elaborated as academic or scientific research yet.

Some of the questions related to the enhanced cooperation in terms of patent protection in Europe raised by Brexit are: does Brexit prevent the creation of the Unitary Patent and Unitary Court? If not, how badly it can affect its creation and establishment? Will the United Kingdom still take part of the unitary system, considering the Unitary Patent regulations only allow EU members to join the enhanced cooperation? Until when? What happens with the leadership until now performed by the UK in the Unitary System?

The answers to most of these questions are still unclear, since the Agreement restricts the Cooperation to EU members only. However, there are already discrepant opinions to that position and, for the time being, the UK is still part of the enhanced cooperation. There are some possibilities that could make it work in future. One of them is that the European Patent Convention member states agree that the Unitary Patent (and Court), according to its current rules and regulations, would include the UK as a "nonmember of the European Union".683

683 W. Tilmann, 'The Future of the UPC After Brexit', Hogan Lovells [website], http://www.theunitarypatent.com/the-unitarypatent-regulation-and-upc-agreement-after-brexit (accessed 18 April 2018). 
There are some other issues pointed out by academics and experts. Tilmann points a relevant one over what happens during the time gap between the decision approved by vote on the occasion of the referendum and the actual exit from the EU by the UK, which is likely to delay the set-up of the new unitary system, as the date for the first unitary patent to be released, September/2016, has already been postponed for an uncertain time. Another problem involves the location of one of the seats of the Central Division of the UPC in London, as specified by the UPC regulations. Other questions brought by the same author enquire if the unitary system will be as attractive without the presence (or at least the leadership) of the UK and what are the implications of opting out of the Unitary Court, as those implications are still very unclear. ${ }^{684}$

Jaeger observes that the position of the UK is so crucial to the unitary package that if it does not ratify it, the Agreement cannot enter into force as it is anymore, since the only option would be a change in the Agreement's clause which makes reference to the UK's consent to its entry into force. That means the non-ratification of the Agreement by the UK, after Brexit, would require a re-opening of the whole Agreement. ${ }^{685}$ Fortunately, it seems that finally the UK is ready to ratify the UPCA, as the result of last formal requirements and approvals of a meeting of Her Majesty's Most Honourable Privy Council, which took place on 8 February 2018 at Buckingham Palace. ${ }^{686}$

In any case, there is no doubt that the future of the Unitary Patent and the Unitary Court has been, to a greater or lesser extent, put in danger by the decision of the UK to leave the European Union. The fact that the Unitary Patent is valid in all signatory States of the Agreement, without any extra demands for translations or validation and maintenance fees, is exactly what characterizes its strength. The absence or weakened participation of one of the lead European countries in terms of number and quality of patents is something to be regretted.

\subsection{Accuracy of translation of international treaties and national legal effects}

Language and Translation play a very central role in global environment, especially in regard to International law and its effects on national legal instruments. This role is taken into consideration in the process of elaborating, establishing and interpreting

684 'Would Brexit mean the end of the Unitary Patent and the Unified Patent Court?', HGF Intellectual Property Specialists [Website], May 2016, http://www.hgf.com/updates/blog/2016/05/would-brexit-mean-the-end-of-the-unitary-patent-andthe-unified-patent-court/ (accessed 18 April 2018).

685 T. Jaeger, Reset and Go: The Unitary Patent System Post-Brexit, IIC - International Review of Intellectual Property and Competition Law, vol. 48, no 3, 2017, pp 254-285, https://link.springer.com/article/10.1007/s40319-017-0569-y (accessed 18 April 2018).

686 A. Johnson, UK finally ready for the Unified Patent Court, Kluwer Patent Blog [Web blog], http://patentblog.kluweriplaw. com/2018/02/13/uk-finally-ready-for-the-upc/ (accessed 18 April 2018). 
international treaties and will find references in international legal instruments, such as the Vienna Convention on the Law of Treaties. ${ }^{687}$

The Vienna Convention recognizes the ever-increasing importance of treaties as a source of international law, ${ }^{688}$ defining a 'treaty' as an international agreement concluded between States in written form and governed by international law, whether embodied in a single instrument or in two or more related instruments and whatever its particular designation. ${ }^{689}$ The Convention stipulates that a treaty can be authenticated in two or more languages, being the texts authoritative in each of its authentic languages. ${ }^{690}$

Still on this matter, the Convention provides that the terms of the treaty are presumed to have the same meaning in each authentic text. ${ }^{691}$ In this respect, it defines the context of interpretation of a treaty as comprising any agreement or instrument made in connexion with the conclusion of the treaty and allows the introduction of special meanings to terms, as well as the application of supplementary means of interpretation. ${ }^{692}$ As stated by the Convention, a treaty shall be interpreted in good faith in accordance with the ordinary meaning to be given to the terms of the treaty in their context and in the light of its object and purpose. ${ }^{693}$

An important study by the European Commission presents language-related aspects in international forums, in treaty-making powers of the European Union, as well as the specific translation methods of treaties concluded by the EU and the impact of the terminology of international law on the European Union legislation. The study also works on the highlights of the main regulatory instruments of international law on language rights and identifies the role and nature of linguistic rights, investigating the relationship between linguistic diversity and economic efficiency. ${ }^{694}$ The study presents a division of language and translation related aspects in two levels, macro and micro, which are useful to illustrate the present analysis:

At international level, language and translation come to play a role when sovereign states conclude agreements among themselves (macro level), or in the context of international trade when goods, services, capital and persons cross national borders (micro level). Some language-related aspects of international trade are regulated at international level (patents) and even if they are not, their existence cannot be ignored by the relevant instruments of international law (labelling) altogether. ${ }^{695}$

\footnotetext{
687 Vienna Convention on the Law of Treaties, signed at Vienna 23 May 1969 entry into force: 27 January 1980, https://www.oas. org/legal/english/docs/Vienna\%20Convention\%20Treaties.htm (accessed 16 November 2018).

688 Vienna Convention, pmbl.

689 Ibid.

690 Vienna Convention, Art. 33, 1.

691 Vienna Convention, Art. 33, 3.

692 Vienna Convention, Arts. 31 and 32.

693 Vienna Convention, Art 31, 1. Underline added for emphasis.

694 European Commission, Studies on Translation and Multilingualism: Language and Translation in International Law and EU law, 2013, http://www.termcoord.eu/wp-content/uploads/2013/08/Study_on_language_and_translation_EU.pdf (accessed 18 April 2018).

695 Ibid., p. 5. Underline added for emphasis.
} 
When considered all the possible effects of a complex network generated by an international treaty involving a whole set of national legal frameworks and international relations, taking the TRIPS Agreement as an example, translation plays an important role both in an official and non-official context. In this regard, the relation between the language in which the treaty was drafted as a commonly agreed language and the translated texts should be a constant object of study. As the original legal text will not be regularly amended, the quality of these translations can be continuously reviewed and improved. ${ }^{696}$

On one hand, the treaty's depositary is in charge of preparing further versions of the treaty in any additional languages ${ }^{697}$ On the other hand, when the treaty is internalized by a contracting State, in the form of national law, each country has (or should have) translators prepared for dealing with specific matters of translation and interpretation. These translators should have at least an average knowledge of the area concerned by the treaty.

\section{Table 17: Important concepts related to translation of international treaties}

\begin{tabular}{ll}
\hline International Treaty & Written agreements between states that bind themselves in written form \\
by a set of obligations; & Can be bilateral (2 states or a state and an international organization or by \\
& $2 \mathrm{IOs}$ ) or multilateral (several states or IOs or entities); \\
& Might be applied directly or indirectly (being internalized in national law) \\
by national courts and confer rights or impose obligations on individuals.
\end{tabular}

\begin{tabular}{ll}
\hline Language Regime & $\begin{array}{l}\text { A set of rules and arrangements implemented to manage multilingual } \\
\text { communication, typically as regards the choice of official languages of an } \\
\text { organisation and their respective use. }\end{array}$ \\
\hline Authentic Language & $\begin{array}{l}\text { The language(s) defined by the international treaty to constitute its } \\
\text { authentic text. A treaty might have one or several authentic languages. }\end{array}$
\end{tabular}

Authoritative Interpretation Only the authentic text(s) (in its or their authentic language or languages) of a treaty is (are) authoritative for the purposes of interpretation.

Multilingualism The use of two or more languages, either by an individual speaker or by a community of speakers.

Language rights The use of one's language intended to guarantee fair treatment of individuals and to preserve linguistic diversity. The purposes of establishing language rights include the protection of linguistic minorities, and the exercise of classic fundamental rights: procedural guarantees, freedom of expression and non-discrimination.

Source: Based on the study of the European Commission and on the study of M. Gazzola ${ }^{698}$

When it comes to the official translations of the treaty, the previously mentioned study of the European commission points out some categories and methods to be considered while preparing teams for dealing with treaties and legal text translations. Some

696 Ibid.

697 Vienna Convention, 77, 1 (a).

698 European Commission, 2013. M. Gazzola, 2014a. 
of these methods and categories are: bringing translation closer to drafting; managing multilingual terminology databases; setting model conventions with commentaries and making the relevant case-law available in several languages; developing and demanding language awareness of drafters and translators. ${ }^{699}$ The last-mentioned category, language awareness, is maybe the most important one to be considered as an object of reflexion, but the most difficult one to be attained.

Language awareness, in this case, concerns the consciousness that the translation of an international treaty requires more than a purely technical translation ability. The choices of the translators of international agreements can have serious impacts on regional and national law, even at the level of secondary law. In consequence, the translation of international agreements requires conscious linguistic choices resulting from knowledge of the subject matter and, if necessary, a dialogue with experts and policy makers. ${ }^{700}$

Other concepts that can be considered very relevant to the present study are the concepts of authentic or non-authentic translations, related to authentic and non-authentic languages of international agreements. The authentic languages of an agreement are considered in first hand translations of this agreement, from a draft written in a commonly agreed one. Nonetheless, there are many cases where the official language of a contracting party is not among the authentic languages of the agreement, which will generate a non-authentic translation as the main source of information concerning the contents of the agreement. ${ }^{701}$ Ramos mentions some experiences of multilingual co-drafts involving international law, as in the Third United Nations Conference on the Law of the Sea, 1973-1982, which led to the Convention on the Law of the Sea of 10 December 1982, adding that translation still remains the predominant means of producing multilingual legal instruments even in authentic languages. ${ }^{702}$

Language rights can be considered as a new chapter of international law. ${ }^{703}$ Linguistics itself is a new science, dating from the early 20th century, with Ferdinand de Saussure making a distinction between the notions of "langue" and "parole" in his formulation of structural linguistics. ${ }^{704}$ However, earlier instruments of linguistic justice can be found, especially in terms of having a fair trial. The mentioned study of the European Commission points to different uses and levels of language rights. The study illustrates the use of language rights as a tool for preserving peace and security; a guarantee of fair treatment of individuals while the preservation of linguistic diversity is also an objective followed by international law. ${ }^{705}$

Rahmatian gives the example of how far translation inconsistencies can affect international relations, pointing out the political effects of the translation of legal texts 
from Chinese to English. According to the mentioned author, the United States tended to take little notice of China's significant improvements on intellectual property protection and enforcement due to simple mistranslations of the original Chinese original legal texts. These misinterpretations resulting from bad translation led to increased political pressure. ${ }^{706}$

Some examples of inaccuracies involving translations of international treaties follow below. These inaccuracies are able to influence the correlated legal framework of a country. The problems of the translation of such important texts can figure on details such as punctuation marks (having a strong effect though) to incongruities, ambiguities and other semantic barriers coming from the fact that two different languages also represent two different systems.

The fact is that a country can lose more than it is easily visible. And that may be caused by a lack of a language and translation planned regime in areas involving intellectual property and foreign trade. One example of this is the delay of a trade agreement between Brazil and the African countries of Sacu due to 205 translation errors from English into Portuguese. The Treaty was prevented from coming into force by the delay of its approval for more than five years. The Agreement involved five African countries and the Mercosur and was not insignificant from an economic point of view. ${ }^{707}$

Signed in 2008, the Treaty provides discounts on import tariffs on 1,064 products and has been fully ratified by all signatories, except Brazil. The Brazilian Parliament approved the text in 2010, but a presidential decree to promulgate it was never published because diplomats have identified translation errors committed by a company hired by the Foreign Ministry itself. A new text, a priori, without errors, returned to the agenda of the Brazilian Parliament in July 2015. ${ }^{708}$

The errors were crude and demonstrate the amateurism with which the international trade communication was treated in that particular case. "Olive oil" instead of "oil", "holiday" instead of "business day", and "other toys" where it should be read specifically "tricycles and scooters" are some examples of words wrongly translated. ${ }^{709}$

There are many examples of translation problems that can be mentioned in IP international treaties involving translation from English into Portuguese. ${ }^{110}$ It is possible to mention some examples of translation fails or infelicities found on the translation of the TRIPs Agreement, the European Patent Convention, the PCT and the CUP. By observing the translation of these treaties, it is easy to find approximations of meaning or passages that

706 A. Rahmatian, Neo-Colonial Aspects of Global Intellectual Property Protection, The Journal of World Intellectual Property, vol. 12, no. 1, pp. 40-74, 2009, http://www.farzadalvi.com/wp-content/uploads/2012/01/Rahmatian-2009.pdf (accessed 18 April 2018).

707 'Erros de Tradução atrasam Acordo Comercial entre Brasil e Países Africanos', Veja, 4 Aug. 2015, http://www.abece.org.br/ Noticias/ComercioExteriorRead.aspx?cod=6005 (accessed 18 April 2018).

708 lbid.

709 Ibid.

710 Those cases were collected by Abrantes (2018) and shown on the web page 'Notícias em Patentes'. The author mentioned gently shared and discussed these cases with this author. See: Abrantes, 'Correção de Erros de Tradução', Patentes Comentários [Web blog], http://patentescomentarios.blogspot.com.br/ (accessed 18 April 2018). 
required a non-exact solution on the target-language. However, some examples are really the result of lack of attention, or lack of technical knowledge or even misinterpretation of the source-text.

That is the case of one passage of Article 23b of the TRIPs. According to this Article, "Members may exclude from patentability also: plants and animals other than micro-organisms, and biological essentially processes for the production of plants or animals other than non-biological and microbiological processes". According to a review of International Agreements elaborated by Fundação Getúlio Vargas ${ }^{711}$, in Brazil, the Portuguese version of Article 27.3 (b) of TRIPs completely changes its meaning just by misplacing a comma. ${ }^{712}$

The comma, which should be placed both after the word for micro-organisms and the word for animals, is placed only after the word for animals. This change results in the exclusion from patentability not only of micro-organisms, as in the original text, but also of the essentially biological processes of plants and animals. In this sense, the translated version leads to the understanding that TRIPS does not give the possibility to a Member to exclude from patentability essentially biological processes. ${ }^{713}$

What the article stipulates, in fact, is that Members may exclude from patentability plants and animals, except micro-organisms, which means that microorganisms cannot be included in this possibility of non-patentability. Nonetheless, the essentially biological procedures should have the same treatment given to plants and animals, and not be excluded, as should be micro-organisms. ${ }^{714}$

Another translation innacuracy found on the translation of TRIPs is on its Portuguese version in Article 27.2. The passage determines that "members may exclude from patentability inventions, the prevention within their territory of the commercial exploitation of which is necessary to protect ordre public or morality, including to protect human, animal or plant life or health or to avoid serious prejudice to the environment, that provided such exclusion is not made merely because the exploitation is prohibited by their law. ${ }^{715}$

When a term is inappropriately translated in an international agreement, it will frequently multiply its effects in a whole set of national legal texts and procedures. In

711 Fundação Getúlio Vargas (FGV) is a Brazilian private institution for teaching, research and extension. It was founded in 1944 with the initial goal of preparing qualified people for the government of Brazil. It is still a renowned education institution that provides various studies in undergraduate and graduate programs. See its official webpage: https://portal.fgv.br/

712 The passage in Portuguese is written as: 'Os Membros também podem considerar como não patenteáveis: plantas e animais, exceto micro-organismos e processos essencialmente biológicos para a produção de plantas ou animais, excetuando-se os processos não-biológicos e microbiológicos'. For comparing the TRIPS Agreement in English and in its translation into Portuguese: http://www.inpi.gov.br/legislacao-1/27-trips-portugues1.pdf; https://www.wto.org/english/ docs_e/legal_e/27-trips.pdf

713 Ibid.

714 Abrantes, 'Problemas de tradução em acordos internacionais', Notícias em Patentes [web blog], 2015, http:// patentescomentarios.blogspot.com.br See also: FGV, Projeto releitura dos acordos da OMC, 2012, capítulo 15. Acordo sobre Aspectos dos Direitos de Propriedade Intelectual Relacionados ao Comércio (TRIPS), http://ccgi.fgv.br/node/132 (accessed 18 April 2018).

715 Ibid. 
this sense, inappropriate translation produces legal ripple effects. The text of Article 27.2 of TRIPS, in its Portuguese translation, refers to "public order or morality" which would be an inappropriate translation of the French "ordre public", kept as so in English. ${ }^{716}$ The French term's meaning differs from 'public order' or 'ordem pública', in Portuguese, being closer in meaning to "public authority" than to "public order". The term is used as "public order" (ordem pública) both in Article 18 of the Brazilian Industrial Property Act and the Portuguese translation of the TRIPS. ${ }^{717}$ The example denotes a common translation deviation, which is the literal translation of a term which assumes a different relevant authoritative interpretation in the target language. ${ }^{718}$

However, 'ordem pública', being close in semantics to 'public order', in English, means 'the maintenance of public security', whereas the French term "ordre public" refers to a broader concept, meaning the foundations that do not put at risk of threatening the stability of the institutions of a given society. According to the mentioned work of FGV, the expression "ordem pública", used in the Portuguese translation, should be read with the full meaning of the expression in French "ordre public", as it is not possible to provide a literal translation. ${ }^{719} \mathrm{~A}$ solution that could have been adopted by the translator would be keeping the original term, as it was done in English, and explaining why it was necessary to do so. Yet this is not a common solution or a well seen one among translations into Portuguese, especially into Brazilian Portuguese. ${ }^{720}$

This illustrates a case of a concept which belongs to a particular legal tradition but does not find an ideal correspondence in the target language. Ramos points out that such examples:

(...) must not be taken at face value; their legal scope within the shared system is defined through the relevant authoritative interpretation and is not necessarily the same as in national law (...) As regards EU law, the possible coexistence of concepts with different national and supranational meanings behind the same terms was confirmed by the CJEU (...) This exacerbates the risk of overlapping, polysemy and interpretation disparities (...), thus reinforcing the need for conciliatory interpretation criteria to define semantic boundaries in integration processes. $^{721}$

716 For accessing the TRIPS Agreement in English and in its translation into Portuguese: http://www.inpi.gov.br/legislacao1/27-trips-portugues1.pdf; https://www.wto.org/english/docs_e/legal_e/27-trips.pdf

717 D. Gervais, The TRIPS Agreement - Drafting History and Analysis, Sweet \& Maxwell, 2003, quoted in Notícias em Patentes [web blog], 2015.

718 lbid.

719 Ibid.

720 This statement is restricted to the observation of translated agreements during this research. For theoretical fundaments on the idea of keeping traces of the source language in the translated text, see Section 4.3.

721 Ramos, 2014. 
Another relevant example relates to the translation of Article 4F, of the Paris Convention (Convention D'Union De Paris, Cup). The concept of "invention unit" is presented in the referred article as follows: If the examination reveals that an application for a patent contains more than one invention, the applicant may divide the application into a certain number of divisional applications and preserve as the date of each the date of the initial application and the benefit of the right of priority, if any. ${ }^{722}$

In Portuguese, this passage is translated as "if the examination reveals that the patent application is complex", instead of "if the examination reveals that an application for a patent contains more than one invention", as it is in the English translation. The difference in meaning of the two translations is evident. So, it is important to ask which one of them is closer to describe the original text in French and to cater to the process of examination. ${ }^{723}$

In accordance with the law of each country in which the examination is performed, a patent application can be considered as complex for reasons other than the lack of unity of invention, for example, when it contains a prohibited combination of claims for the manufacture and use of the same invented object. Although article $4 \mathrm{~F}$ is applied in such cases, overtaking the content of the regulation, it is probably used more often in cases where the application has more than one invention, when paying no attention to the "invention unit" requirement. ${ }^{724}$

The Brazilian Industrial Property Act defines that a request for an invention patent must refer to a single invention or a group of inter-related inventions so as to comprise a single inventive concept, which refers to the principle of inventive unit. Once the examination detects the lack of unit, the applicant will have the opportunity to divide his application as allowed by the Industrial Property Act. ${ }^{725}$

Yet, this is not the only way through which INPI may issue an opinion concerning the technical division of the application, since the Act does not define the situations in which the application division is allowed. Yet there is a Normative Act (Normative Act No. 127/97) that regulates this possibility of a division request when the technical examination identifies application as complex, or as containing a group of inventions comprising more than one inventive concept, or even as containing more than one utility model. ${ }^{726}$

In 2013, an Instruction (Instruction No. 30/2013) was published reviewing the wording of the mentioned passage as published. The new text simplified the former one to "when the technical examination detects that the application contains a group of inventions comprising more than one inventive concept, or more than one utility model",

\footnotetext{
722 Abrantes, Notícias em Patentes [web blog], 2015; Paris Convention for the Protection of Industrial Property of March 20, 1883, http://www.wipo.int/wipolex/en/treaties/text.jsp?file_id=288514 (accessed 18 April 2018).

723 Ibid.

724 See Abrantes, Notícias em Patentes, 2015; See also: G. Bodenhausen, Guide to the Application of the Paris Convention for the Protection of Industrial Property, 1967, WIPO, 2007, http://www.wipo.int/edocs/pubdocs/en/intproperty/611/wipo_ pub_611.pdf (accessed 18 April 2018).

725 Abrantes, Notícias em Patentes, 2015.

726 Ibid.
} 
eliminating the idea of a "complex application". Therefore, the new wording excluded the possibility of INPI to ground a division request on the idea of complex application, which restricted considerably this type of request. As the Paris Convention leaves it to national law to define the conditions in which they may ask the applicant to divide the application, there is no legal contradiction with the Paris Convention and the new instruction. ${ }^{727}$

However, if the translation of the Paris Convention into Portuguese had been observed, the text wouldn't have changed, as the former text was more coherent with it. It would also be more coherent with the authentic French text, where the same mentioned passage claims that:

Si l'examen révèle qu'une demande de brevet est complexe, le demandeur pourra diviser la demande en un certain nombre de demandes divisionnaires, en conservant comme date de chacune la date de la demande initiale et, s'il y a lieu, le bénéfice du droit de priorité."'728

Therefore, it can be concluded that the translation into English cited previously is not very accurate because an application can be complex for reasons other than lack of unity of invention, as the example of the complexity of the set of claims. In this regard, a complex patent application can give rise to a request for division. The French legislation relates to the invention unity in Article L.612-4, which is associated with complex requests. The French court uses the term "vice of complexity (vice de complexité) in such situations, which is, by the way, not considered a cause for invalidation of the patent. ${ }^{729}$

\subsection{Conclusions and correlation of the chapter with the research question}

The previous Chapters concluded that: translation is a vehicle to knowledge transfer; the patent system can be currently characterized as an intercultural space; the patent system can be considered a (global) system, which is based on translation as a means of communication; machine translation has reshaped the patent system, universalizing the disclosure of patent information; machine translation enables the disclosure of technological information contained in patents.

727 Ibid. . In interview 19, a European patent attorney observed that this restriction creates difficulties in some applications, and questioned its consonance with the Paris Convention

728 WIPO, Convention de Paris pour la Protection de la Propriété Industrielle, 20 mars 1883, http://www.wipo.int/treaties/fr/ text.jsp?file_id=288516 (accessed 18 April 2018).

729 F. Pollaud-Dulian, Propriété intellectuelle. La propriété industrielle, Economica, Paris, 2011, p.261; J. Pierre, Droit de la Propriété Industrielle, Paris, Litec, 1996, p.59; A. Chavanne and J. Burst, Droit de la Propriété Industrielle, Précis Dalloz, Paris, 1976, p.47. 
Chapter 6 confirms the thesis that (especially machine) translation constitutes the basis of the patent system and has radically changed its current configuration. Translation pervades all the (office and legal) stages of a patent and is important to the whole structure of the patent system. In this regard, it is crucial to recognize the global nature of patent rights. The patent system is located in this intercultural, multilingual space, and covers a huge volume of technological information from various nations, which means, in many of their languages.

This influence starts from international and regional treaties and guidelines, which represent the foundation for a global patent system. Cross-border agreements are interpreted and internalized in different ways, when incorporated in national patent law. In light of this, Chapter 6 discussed the influence of language and translation on the most important patent agreements from the perspective of language and translation. Section 6.1 explained the language/translation regime concerning the PCT and the advantages the Agreement has represented to harmonize patent law. Section 6.2 focuses on the European patent system and its set of correlated agreements, concluding with an analysis of the language regime and regulations concerning the imminent unitary system. Section 6.3 presented examples of inaccuracies of translations which compromised the internalization of international agreements, producing negative legal effects.

The example of the PCT was reported as a paradigm of harmonization and improvement. Section 6.1 glossed over its historical developments, language regulations and its functionalities and results, in order to underpin a comprehensive analysis of its positive results for the patent system in a global level. These results are interpreted in view of the advantages of (language related) integration and harmonization. Arguably, the PCT represented a new era for disclosure of patent information and for the manipulation of associated data.

On this point, sub-section 6.1.3 presented some of the main advantages of the PCT in terms of disclosure of patent information, which extend to concurrent monitoring, technology assessment, portfolio management in research and development, identification and evaluation of potential sources for external generation of technological knowledge, among many other gains. It is important to emphasize that all those benefits are associated with easier access to patent information and with the reduction of costs with translation. In other words, they are all related to improving the disclosure of patent information.

Section 6.2 reviewed the language regime of the European Patent Office and the one proposed to the European Unitary System. From the perspective of language and translation, the step represented by the Unified Patent and the Unified Court is seen as an important development in terms of reduction of costs, harmonization and integration of the patent system. Its advantages are not only relevant to Europe but will result in relevant global impact.

One of the main burdens for a true community patent to become a reality is still represented by language barriers. In this regard, the proposed language regulations for 
the Unitary System are important for defining the central role of machine translation as the main tool associated with the disclosure of patent information. These regulations are still subject to discussion and controversy. Yet they epitomise a step towards future in terms of harmonizing the patent system and assuring legal certainty to its users. Additionally, the Agreement is described as a trend in redefining the limits of territoriality in patent law.

Section 6.3 presented particular examples on the effects of translation concerning the internalization of international agreements into national legal instruments. It portrayed the complex network related to patent international treaties in association with national legal frameworks from the perspective of language and translation. It showed that there are steps and methods to be considered while establishing the language/ translation regime of an international treaty. These methods have limitations and may find serious resistance from (also potential) signatory countries, as was the case of the Unitary System. Lastly, the section discussed translation errors which implied critical effects on the internalization of international agreements into national law.

Chapter 6 has explained the influence of translation on the dissemination of the disclosure of patent information at the level of justification of norms. ${ }^{730}$ Chapter 7 follows with an analysis of the influence of translation on the level of application of norms. ${ }^{731}$ The analysis is separated by office and court stages, associated with the legal timeline of a patent. It starts with the office stages (prior art search, examination, opposition...) and follows with the analysis of court cases concerning patent infringement.

730 See Chapter 3 for the definitions of justification and application in legal discourse. 


\section{CHAPTER 7}

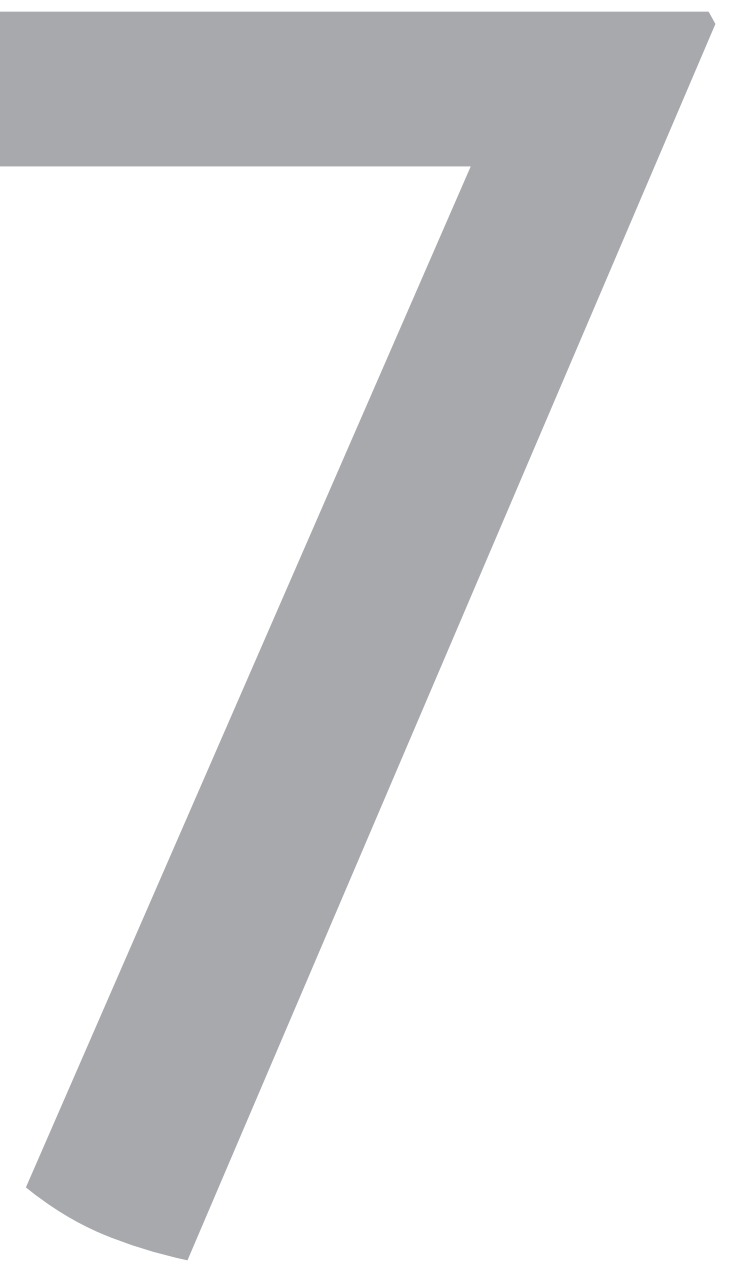




\section{The influence of translation on the different legal stages of a patent}




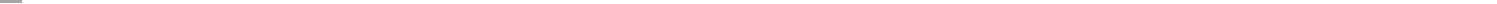




\subsection{Translation on the timeline of a patent}

The purpose of this Chapter is to report the results of the empirical analysis, obtained through the combination of content analysis and interviews. ${ }^{732}$ The analysis is separated by office and court stages, associated with the timeline of a patent. This section establishes a reference for the legal timeline of a patent, as legal stages can considerably diverge in different jurisdictions. The following sections present and interpret the results of the analysis in office stages and court cases. It brings particular examples of the influence of translation on the disclosure of patent information in the mentioned (pre and postgrant) phases of protection.

The patent process has long been analysed and explained from a technical perspective, related to its legal and economical requirements, in terms of the concepts associated with patent rights and its economic implications. However, patent law has still not been sufficiently described or assessed from the perspective of language and communication. The present research led to an understanding of the timeline of a patent from the standpoint that concerns its legal concepts, on different stages in which translation plays important roles in influencing the functioning of the patent system. However, understanding the timeline of a patent is not so simple, especially when it comes to its association with translation, and allows different theoretical perspectives, that should be more exploited in further studies. ${ }^{733}$

The patent timeline, related to the patenting process, is explained by distinct authors in different ways, sometimes as if it were a homogenous process. The only categorization that was found is related to technical issues and associated with a national or regional system, as for example, a description of "the patent process in the US", "EPO patenting process", "UK patent application timeline" or simply "patent application timeline".734

Once more, there is a scarcity of theoretical studies approaching how different timelines can affect the global patent system. The existing books on the topic also tend to be guides on how to proceed with a patent application or reference works presenting the basic concepts related to patent rights to various types of audience. There are also works and papers about the backlog issue, normally associated with a national patent system. ${ }^{735}$ It is understood that scientific studies should go beyond technical guidance or the backlog

732 See Chapter 2 for the details of the methodology used.

733 In Chapter 8, recommendations to further studies concerning the timeline of patents are presented.

734 Most of the texts found on this subject are schematic explanations or guides available at patent offices' websites or on specialized companies' pages or blogs. See, for example: EPO's Website, EPO - The patenting process, https://www.epo. org/learning-events/materials/inventors-handbook/protection/patents.html; USPTO, USPTO Patent Application Initiatives Timeline, https://www.uspto.gov/patent/initiatives/uspto-patent-application-initiatives-timeline; Withers\& Rogers, UK patent application timeline, https://www.withersrogers.com/wp-content/uploads/2015/03/uk_patent_application_time_ line.pdf (all accessed 18 April 2018).

735 See, for example, the following works: Jain, S. (2011). Patents procedures and practices. Universal Law Publishing; A. C. Abrantes, Introdução ao sistema de patentes, Lumen Juris, 2011; A. Gibbs and B. DeMatteis, Essentials of patents, John Wiley \& Sons, 2003; P. Drahos, The Global Governance of Knowledge: Patent Offices and their Clients, Cambridge University Press, 2010. 
issue to assess this topic, as there is still much to be exploited on the interpretation of the different stages of patent prosecution in distinct national patent systems, for example, from the perspective of its users. ${ }^{736}$

Studying the effects of translation on the different stages of the timeline of a patent may not be as obvious as it must seem at first sight. As each national legal system has its own definition of what is the timeline of a patent, presenting different legal stages that can considerably differ between them, it is important to choose one reference to be the object of the analysis. For defining the timeline that will be considered as reference to the present object of research, it was important to compare some of the guidelines of the two most influential patent offices in the world, the EPO and the USPTO, consulting their procedures as the main references in patenting to most of the other patent offices in Western countries.

The timeline proposed by the EPO starts with considerations to be taken before filing a patent application. These considerations are related to how worthy it may be to file an application. They consider, for example: the life cycle of the product, the right time for applying for the patent, the possibilities of the patent to survive legal challenges after being granted and the payments related to the enforcement of the patent. ${ }^{737}$

After the decision is taken for proceeding with the application, the timeline presented by the EPO is divided into the following stages: 1. Beginning the process (presenting the necessary documentation to start the process); 2 . Filing date and initial examination (which involves a period of 12 months during which foreign applications can be also filed in a way they keep the priority date. 3. Search. 4. Publication (important for the period when the disclosure of the invention starts). 5. Substantive examination. 6 . Decision to grant a patent. 7. Validation (which involves a national stage where translation is very relevant. 8. Opposition. 9. Appeal. ${ }^{738}$

The timeline defined by the USPTO is remarkably different from the one presented by the EPO. Their timelines differ in terms of terminology and also in the possible stages that follow the grant or rejection of a patent. The European system presents an additional stage of "opposition" (corresponding to a post-grant review in the American system) and a stage of appeal. ${ }^{739}$ It also differentiates between the stages of decision to grant $a$ patent, validation and publication, with a clear explanation of their legal implications. The corresponding stages in the American system to decision to grant a patent and publication, are allowance and issue. It is clear that these are different concepts to stages

736 European patent attorneys, as observed during the interviews, have different perceptions over, for example, the patent system in the US, in Latin America and in Asia. Some of those attorneys are used to deal with patent prosecution in different countries and can point advantages and disadvantages of each of them.

737 EPO's Website, EPO - The patenting process, https://www.epo.org/learning-events/materials/inventors-handbook/ protection/patents.html

738 Ibid.

739 According to the EPO's website: The appeal is filed with the EPO's boards of appeal in a judicial procedure in which a board acts as the department of final instance in grant, opposition, limitation and revocation procedures before the EPO, https://www.epo. org/applying/european/appeals.html (accessed 5 December 2018). An appeal must be filed in writing (including fax or online filing with EPO software) within two months of notification of the contested decision. 
that can be considered as similar, as decision to grant a patent and allowance have different connotations in the two systems (the first one is a regional system and also requires a subsequent national validation stage). The images below show representations of the timelines of the EPO and the USPTO:

Figure 34: Representation of the patenting process at the EPO

\section{Stages of a patent at the EPO}

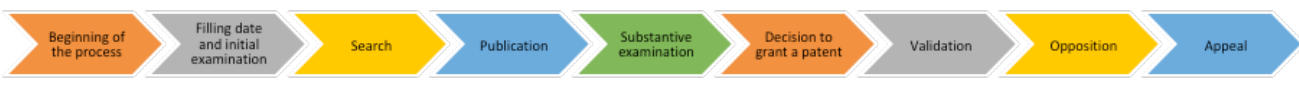

Source: elaborated by this author based on the description of the process at EPO's webpage ${ }^{740}$

Figure 35: Representation of the patenting process at the USPTO

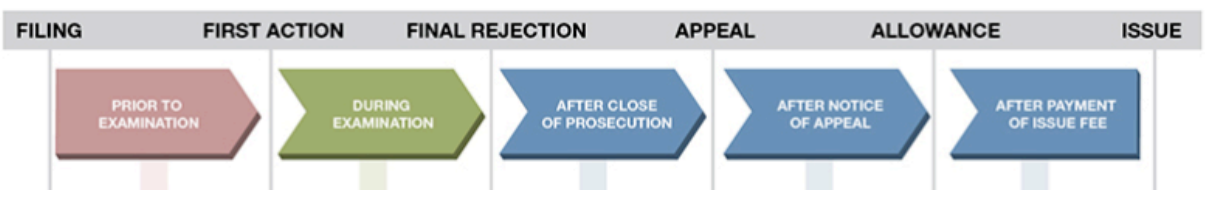

Source: the image was taken from the official webpage of USPTO and is a fragment of the whole timeline of a patent presented by their page ${ }^{741}$

Opposition cases are defined and regulated by Article 100 of the European Patent Convention. It is possible to file an opposition to a patent in three different situations: when the subject-matter is not patentable, when the invention is not plainly disclosed and when the patent's subject-matter extends beyond the content of the application. ${ }^{742}$ The second case should be highlighted, as it is directly involved with the disclosure of patent information, but translation can also play an important role in the other cases.

There are three types of possible decisions at the end of an opposition case: either the patent is maintained as granted, or in an amended form, or the patent is revoked. As is clear on the graph below, the number of oppositions represent only around $3 \%$ of the number of examinations. Although the number of oppositions is low, it can still be considered as a very relevant stage on the patent prosecution process in terms of preventing further infringement cases or other legal challenges.

740 Ibid.

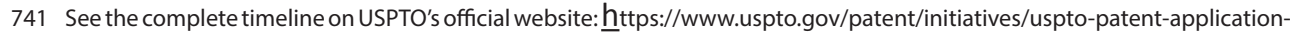
initiatives-timeline

742 See EPO's official website for information about opposition procedures: https:/www.epo.org/applying/european/ oppositions.html 
Figure 36: EPO's Annual Report 2015

\begin{tabular}{|c|c|c|c|}
\hline \multirow{2}{*}{ Searches } & 2015 & & \multirow{2}{*}{$11.8 \% \oslash$} \\
\hline & 2014 & 213008 & \\
\hline \multirow{3}{*}{ Examinations } & 2015 & 122949 & \multirow{3}{*}{$18.3 \%$ } \\
\hline & & & \\
\hline & 2014 & 103915 & \\
\hline \multirow{3}{*}{ Oppositions } & 2015 & 3713 & \multirow{3}{*}{$17.6 \%$ ? } \\
\hline & & & \\
\hline & 2014 & 3157 & \\
\hline \multirow{3}{*}{ Total } & 2015 & 364739 & \multirow{3}{*}{$14.0 \%$} \\
\hline & & & \\
\hline & 2014 & 320080 & \\
\hline
\end{tabular}

Source: EPO's Official Website ${ }^{73}$

There are many interpretations of the timeline of a patent according to other national systems or approaches. It was decided to take the timeline of the European system as a reference both to the type of patenting process and terminology used. The reasons to make this choice are related to the accuracy of the examination and to the kind of relation between the patenting process and the subsequent legal stages of a patent, considering especially the possibility of an infringement case and how a more accurate examination, with a chance of a rigorous opposition stage, can prevent it. It was also taken into consideration that the EPO has been a pioneer and a reference in patent translation, and that these longer stages, implying detailed examination and a thorough prior art search before validation, evidence the role of accurate translation in each stage.

As the subsequent stages of the patent also interest the present analysis, especially when it comes to the possible challenge of an infringement case, it was necessary to customize a patent timeline that could sum up the relation between each stage and the problems with translation in a clearer way. The timeline was based on the stages as described at the webpage of the EPO, which made it clear that the stage of examination could be divided into two different moments, prior art search and office actions, which may imply different associations with human and machine translation. The result was a timeline that can be applicable to other national patent systems, understanding each system will have a different interpretation, and sometimes also sub-phases, to each stage. The timeline is represented by the following image: 
Figure 37: Timeline of a patent from the perspective of language and translation

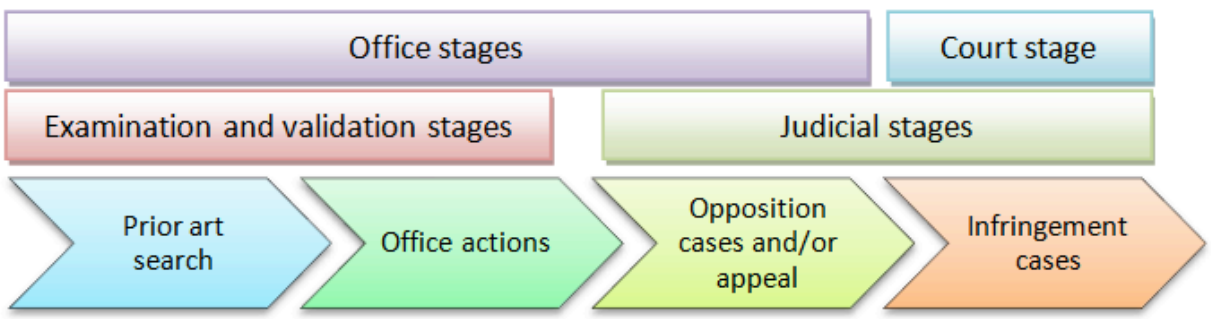

Source: Based on the timeline of the EPO and on generalizations made by patent attorneys during interviews744

Through the interviews, it was observed that the role played by human and machine translation varies in each stage. After asking the interviewees to give a score to the percentage of machine and human translation in each phase of the patent, the following figures were obtained:

\section{Figure 38: Average percentage of use of human and machine translation in each legal stage of a patent}

\begin{tabular}{|l|l|l|}
\hline Legal stage & Human translation & Machine translation \\
\hline Prior art & $20 \%$ & $80 \%$ \\
\hline Office Actions & $80 \%$ & $20 \%$ \\
\hline Opposition cases & $50 \%$ & $50 \%$ \\
\hline Infringement cases & $50 \%$ & $50 \%$ \\
\hline
\end{tabular}

Source: Elaborated by this author based on the answers of the interviews ${ }^{745}$

The numbers make sense if associated with the tasks that characterize each stage. The figures are approximated, and require further studies to variations in, for example, different patent systems. They are only used to illustrate the whole process. During the prior art search, patent examiners mostly rely on machine translation, and very rarely demand a human translated document to confirm a decision or clear up doubts related to foreign patents. ${ }^{746}$ Further stages will require more use of human translation.

Office actions are normally based on human translation. Patent attorneys have observed that they need to trust the local agents for the quality of these translations, as, many times, the translations are done in languages they don't master. In this regard, it was observed that the level of professionalism and the background of the translators who

744 See previous footnotes for the webpages of the EPO and the USPTO.

745 Information collected directly with interviewees. See Chapter 2 for the methodological approach.

746 Japanese patent examiners observed that they have easy access to human translation in case they identify a necessity of checking the content of a foreign document. However, not all the national offices can count on human translation support just as easily, many of them having to rely on machine translation only or to find the same document in English through another application. 
work for local agents can vary considerably in different countries. Some systems count on professionals without the adequate experience and knowhow, which can interfere in the whole process. ${ }^{747}$ This relation also depends on each office, as some offices allow the direct communication of examiners and attorneys, while others don't.

Opposition and infringement cases may present considerable variations individually. Some cases demand "gist translation" of a great volume of prior art or relevant documents that can prove or counter prove validity or infringement. After this triage, the most relevant documents pass through rigorous human translation. That's the configuration of "big" patent cases, like the one between Apple and Samsung commented on in Section 7.4. In any manner, nowadays, complex cases involving foreign companies or foreign documents will always rely, to a certain extent, on machine translation for the process of prior art search, and for triage and "gisting" of documents, and also during the production of human translation, a process which does not exempt the use of machine translation or computer aided translation anymore.

\subsection{Translation and patent prosecution on PTO's stages: patent examination, opposition and appeal}

\subsubsection{Examination guidelines and translation regimes in different national systems}

Patent prosecution is the process of applying for patent protection in a patent office. ${ }^{748}$ There are some differences between the patenting process timeline of the EPO and the USPTO, as presented in Section 7.1, worth noting for establishing a relation between the process of examination/grant and the role of language and translation in each stage of the patenting process. An important difference is related to the level of accuracy of the examination and to the role of the patent office to the patent system in terms of the legal stages that follow the validation of a patent. In this sense, the stages which are followed in the office are crucial for preventing the patent from being legally sued. Those differences related to the length and effectiveness of the pre-judicial or office stages are frequently associated with the accuracy of examination, which involves the analysis of translated applications and foreign prior art.

It is possible to categorize patent systems through their level of accuracy in finding prior art and precision in taking reflected decisions in granting or refusing patents. Some patent systems are centred in a precise and laborious examination process. Others facilitate the process of obtaining a patent and rely on a strong judicial structure acting together with anti-trust and competition enforcement organizations. The two models are well represented by the European and the American patent systems.

747 Further studies evaluating the type of education received by patent translators in different national or institutional contexts are recommended. See Chapter 8.

748 USPTO's Website, Submitting patent applications or patent prosecution correspondence, https://www.uspto.gov/patentsapplication-process/filing-online/submitting-patent-applications-or-patent-prosecution (accessed 18 April 2018). 
In the case of the European system, an accurate examination and a rigid internal process of opposition and appeal are effective in avoiding future legal challenges, protecting the integrity of the patent system and the value of the patent document. In this sense, the European system is clearly focused on a long and incisive examination process, which grants strong patents, difficult to be challenged legally. ${ }^{749}$

This idea was confirmed by the interviews carried out for the present research, which indicated that the European and Asian offices are considered as very accurate in finding prior art. Some examiners remarked that the examination in the USPTO can be less accurate than in, for example, some Asian patent offices, which makes it easier to have a patent granted in the American system, even if there is pre-existing prior art. That leads to more disputes involving claimed infringement and to a patent policy centred on anti-trust and competition enforcement organizations, and, mainly, based on the judicial system. In this regard, there is abundant literature discussing the nature of the American patent system in contrast with other systems. ${ }^{750}$

As going deep into the implications of the mentioned policies does not concern the present research, it was decided to focus on the idea of accuracy during the examination, a concept that will be closely related to language and translation and, as previously shown, to the notion of disclosure of technological content. In this regard, it is important to observe, as proved by the study of Farrel, J. \& Merges, that errors which occur in the patent office during the process of examination are rarely fixed during litigation. ${ }^{751}$

The accuracy of each system - decided both through the quality and rigour of the examination - determines the role of the patent office in the legal framework related to the rights enforced by a patent and to the interests that are prioritized by patent policies. Those interests could be categorized as two conflicting interests: public interest, deeply related to the ideas of accuracy and disclosure, and interest of the applicant (coinciding with the interests of the office in granting more patents). Those poles are not exclusive and can be reconciled in a system that is capable of providing a reliable examination and, at the same time, can guarantee the pace and fairness that will favour the applicant, avoiding a subsequent infringement case. ${ }^{752}$

What is important in the present work is the fact that an accurate examination implies, overall, the full access and understanding of foreign prior art, normally allowed by machine translation and, sporadically, counting on formal or informal human support. For understanding the role of translation on patent examination, it was important to analyse the interviews with patent attorneys, examiners and patent translators. In this

749 See: EPO, Opposition, https://www.epo.org/applying/european/oppositions.html (accessed 18 April 2018).

750 See, for example, B. Hall, 'The global nature of the patent system', Toronto IP Conference, 2001, https://eml.berkeley. edu/ bhhall/papers/BHH01_Toronto_Maskusdiscussion.pdf; J. Farrel and R. Merges, Incentives to Challenge and Defend Patents: Why Litigation Won't Reliably Fix Patent Office Errors and Why Administrative Patent Review Might Help. Berkeley Technology Law Journal, vol. 19, no. 3, 2004, pp. 943-970, http://www.jstor.org/stable/pdf/24116722.pdf (accessed 18 April 2018).

751 Merges and Farrel, 2004.

752 Ibid. 
regard, players from different national systems demonstrated a different perception of the process. By comparing their answers, it was possible to propose some guidelines for a more integrated global system, based on the accuracy and effectiveness of the examination, which is presented in Chapter 8. Some cases are described, later in this Section, to illustrate how translation errors involving prior art can influence office cases, changing the decision of the patent office and, probably, avoiding subsequent legal challenges. These cases show how important accuracy is for keeping the integrity and reliability of the patent system.

A relevant aspect, regarding language and translation during the process of examination, is related to how much or how often patent examiners need to rely on machine translation and how often they have the necessity and the opportunity to obtain support from a human translator. The examiners were unanimous in saying they rely on machine translation as a daily routine. They added that they try to find an English translation for prior art that is difficult to understand only through machine translation, concerning, for example, Asian patents, in the case of non-Asian offices. Brazilian examiners affirmed that they don't have any human translation support, except in very exceptional cases. They also declared they don't consider any eventual human support as necessary, as it is always possible to access the same information through the patent family. ${ }^{753}$

In contrast with the Brazilian examiners, Japanese examiners consider human support as necessary in special cases. They affirmed they can easily require human translation for prior art documents that, for some reason, remained unclear. In this regard, European examiners observed that they can also count on human translation, if necessary. However, normally, they consult each other, as their team of examiners is multinational and multilingual. Examiners from different countries also pointed to the importance of the possibility of consulting other examiners, or exchanging knowledge with other colleagues, in the same office, especially with the ones who are skilled in languages they don't master. ${ }^{754}$

The attention given to (machine and human) translation is noticeable both in the European and the Japanese patent office. Both offices produce assessment reports of machine translation, invest in product developers and experts to constantly improve their translation machines and recognize the value of the association between translation and patents from its recent, but revolutionary, history. ${ }^{755}$

There are also considerable differences concerning the regulation over language and translation for patent examination in different national patent offices.

\footnotetext{
753 Information collected directly through interviews.

754 Ibid.

755 The information was directly collected from the interviews. The level of consciousness of the importance of translation during the whole process of patent prosecution is shown by some aspects that differ in each patent office: translation products developed by or with the support of the office, regular reports involving translation assessment, possibility of accessing human translators, scientific research produced with the support of the Office, partnership with translation machine products developers, reaction on the level of influence of machine translation over the accuracy of the examination (the interviewees were asked to give a score).
} 
Those differences may concern the language of the application, subsequent required translations, translations presented due to office actions requirements and possibilities of correcting translations or filing additional translations during the whole process of the examination or on the demand of office actions. Below follows a discussion over some examples that include Brazil, Japan, the United States and Europe. Some regulations are more or less detailed in terms of the translation of technical terms or abbreviations. Those rules are closely related to cultural aspects and to the organizational culture of each office. Some regulations leave more room to the examiner's autonomy in deciding on language and translation issues or making requirements to the applicant through office actions, as is the case in Japan. Some present more detailed regulations, which condition the decision of the examiner to a set of general guidelines, as is the case in Brazil. ${ }^{756}$

In Brazil, Normative Instruction 17/2013, item 4.1, specifies that the patent application must be presented in the Portuguese language, no other language allowed. ${ }^{757}$ In addition, the Administrative Procedure Law 9784/99, in its article 22 § 1 states that the proceedings of the administrative process must be elaborated in written vernacular, with the date and place of its realization and the signature of the responsible authority. ${ }^{758}$ Item 4.3.1 of the mentioned regulation provides for the possibility of submitting the application in the Latin alphabet and in a foreign language, however, it establishes the period of 60 days for the presentation of a simple translation of all documents originally in a foreign language. ${ }^{759}$ Brazilian patent examiners observe that, although the regulations allow such an application, in practice, the great majority of the applications are filed in Portuguese from the beginning of the process of prosecution.

The tendency to detailing language and translation procedures is also clear in other requirements of the Brazilian examination guidelines. An interesting example concerns the translation of foreign technical terms. The Brazilian Act of the Administrative process states that translation into Portuguese of a foreign word must be requested only when that term in Portuguese is broadly disseminated in the associated technological area. Otherwise it is preferred to retain the technical term as known in the art, using the original foreign word. ${ }^{760}$

Technical terms or abbreviations of a foreign language should not be translated, except when there is a respective technical term in Portuguese of common use among the technicians of the associated area. So, usual terms of the technique such as bitmap, boot, buffer, byte, cache, cookies, desktop, dial-up, firewall, login, mouse, online, pixel, plug-in, prompt, ram, script, among others, should not be translated, because they are customary

756 Information collected directly with interviews.

757 See EPO's Guidelines for Examination, Part C, 4.14.

758 Brazilian Federal Government, Lei 9787/1999, https://www.planalto.gov.br/ccivil_03/Leis/L9784.htm apud parecer PROC/ DICONS 278/2003 de 05.09.2003 (accessed 18 April 2018).

759 INPI, Resolução 158/2016, http://www.inpi.gov.br/menu-servicos/patente/legislacao-patente-1 (accessed 18 April 2018).

760 Brazilian Federal Government, Lei 9787/1999, https://www.planalto.gov.br/ccivil_03/Leis/L9784.htm apud parecer PROC/ DICONS 278/2003 de 05.09.2003 (accessed 18 April 2018). 
in the art. Terms whose meaning is recognized by the technician should not be used in Portuguese at the risk of compromising the clarity of the application. ${ }^{761}$

Once such terms acquire corresponding terms in Portuguese, the Portuguese words should be preferred. The same is not valid for terms in Portuguese which are used in daily language, such as the corresponding terms to broadcast, browser, bus, clock, database, domain, e-mail, hard disk, multimedia, network, setup, switch, upgrade, among others. There is also a consideration about the time of the application related to the use of these technical terms. The examiner should read the patent application as if he would be reading it at the time of filing the application (or priority, if any). Therefore, the use of terms that would only later become consolidated in the state of the art is not allowed. ${ }^{762}$

In Japan, the search report may use a non-literal translation of the original document in a foreign language. This happens in cases where the literal translation compromises the clarity of the text. The aim of this regulation is that the content of the invention is clearer. Even in these cases the scope of the revealed matter must be limited to the one disclosed in the first document filed in the same foreign language. Therefore, there can be no extension of the scope of the original document. ${ }^{763}$

As in most patent offices, the internal administrative regulations allow that translation errors are corrected at any time during the application procedure. In the case of Japan, this rule presents an extra flexibility: the examiner has the autonomy to correct small mistakes of translation without having to issue an office action, when he judges necessary. Japanese patent examiners affirm they have a high level of autonomy and power of decision in their function, which is also valid for decisions related to language and translation issues. They also recognize these issues are frequent in their daily routine, representing an important facet of the examiner's task. ${ }^{764}$ JPO produces regular reports assessing machine translation in comparison to human translation of patent documents. ${ }^{765}$

The machine translation displayed in the right-hand column above was considered as a translation with maximum quality (score 5, as indicated). However, it is still possible to find considerable discrepancies between this translation and the human translation, made by a professional, shown in the left-hand column. The report considers the machine translation of the document as efficient in reproducing the general content of the patent. However, it identifies some errors of syntax and some semantic differences. ${ }^{766}$

761 INPI, Resolução 158/2016.

762 Ibid.

763 Information collected directly with Japanese examiners. Seethe Japanese law for translation and examination guidelines: JPO. Guidelines for patent examination, http://www.japaneselawtranslation.go.jp/law/detail/?printID=\&id=42\&re=01\&vm=03; See also: R. Baechtold, Intellectual property review. Law Business Research: London, 2014, p.45.

764 INPI, Resolução 158/2016.

765 An example of a JPO assessment report can be found at: https://www.jpo.go.jp/shiryou/toushin/chousa/pdf/kikai_ honyaku/h28_03.pdf

766 Ibid. 
Figure 39: Parts of a JPO survey assessing the quality of machine translated documents

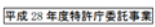

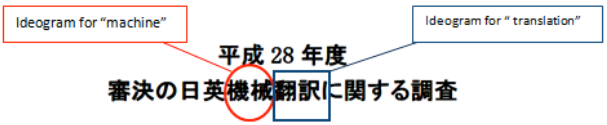

調查報告事

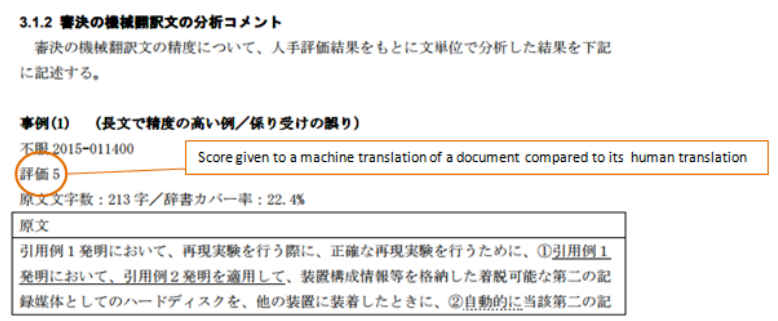

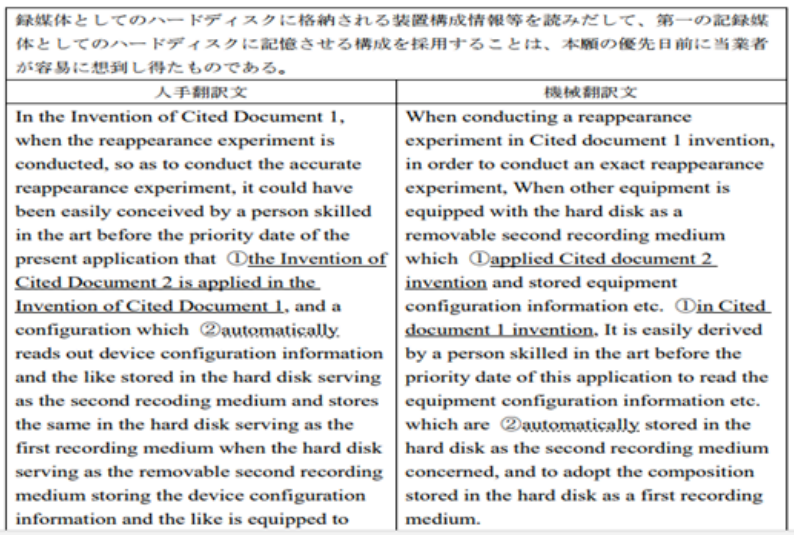

Source: JPO's official website ${ }^{767}$

The document, which also brings translations with low scores, such as 2 or 1 , clearly shows that the experience of the examiner and the accuracy of the examination will play a role in making the best use of machine translated documents. Machine translation has truly developed in the last years, but it can still lead to wrong decisions in granting patents.

$767 \mathrm{JPO}$, 平成 28 年度 審決の日英機械翻訳に関する調査 ('Survey on Japanese-English machine translation of Heisei 28th trial decision', indicated by one of the interviewed patent attorneys), https://www.jpo.go.jp/shiryou/toushin/chousa/pdf/ kikai_honyaku/h28_03.pdf (accessed 18 April 2018). 
The EPO shows maximum flexibility concerning the amendment of translation errors during the whole process of prosecution. The European Patent Office also allows translation correction during the stage of opposition, as long as the amendment respects the limits defined by the scope of the previous claims. Examiners are allowed to correct small errors and applicants can amend the application before grant. ${ }^{768}$

Any error in the translation filed can be corrected at any time during proceedings before the EPO, i.e. during pre-grant proceedings and also during opposition proceedings, bringing the translation into conformity with the application as filed in the original language (e.g. with the originally filed Japaneselanguage PCT application). However, correction of the translation during opposition proceedings will not be allowed if it contravenes Art. 123(3), i.e. if it implies an amendment of the claims which extends the protection conferred. ${ }^{769}$

The guidelines for the examination are also flexible in France, to use an example of national administration in the European Union. France's regulations state that if the person skilled in the art can use common general knowledge in the field of technology to rectify certain errors or to cover certain gaps or inaccuracies in the patent application, they will not be considered significant enough to characterize insufficiency of disclosure. ${ }^{770} \mathrm{On}$ the other hand, an ambiguous description or a description that contradicts the claims cannot be considered for correction by the examiner, since it does not enable the person skilled in the art to carry out the invention. The insufficiency of disclosure should not be confused with the imperfection of the result, which in itself is not cause for nullity, unless the imperfection is so relevant as to cause the text not to disclose the content of the invention. ${ }^{771}$

In the United States, translation errors can be corrected with the request of a Reissue even after the patent is granted. Provisional applications may be deposited in languages other than English by the applicant, according to 35USC 119 (e). The guidelines also state that if there is an error in the English translation, the applicant may rely on the disclosure of the originally filed non-English language U.S. application to support correction of an error in the English translation document. Amendments to correct translation errors

768 EPO (2017). Guidelines for Examination in the European Patent Office, November, 2017, http://documents.epo.org/ projects/babylon/eponet.nsf/0/D94333C1A028BC0AC12581C90057921F/\$File/guidelines_for_examination_2017_en.pdf 769 Ibid.

770 "Sufficiency of disclosure" can be defined as a legal demand according to which a patent application must reveal its invention in a detailed description of at least one way of carrying out the invention, which should be understandable to a person skilled in the art. See: EPO, Guidelines for Examination, 1. Sufficiency of Disclosure, https://www.epo.org/lawpractice/legal-texts/html/guidelines/e/f_iii_1.htm (accessed 18 April 2018).

771 See: France, Directives d'Examen de I'INPI, Chapitre X - Rectification d'erreurs, https://www.sedlex.fr/wpcontent/ uploads/2014/04/Directives_brevet_completes.pdf ; F. Pollaud-Dulian, Propriété intellectuelle. La propriété industrielle, Economica, Paris, 2011, p.249. 
are not considered new matter. In the American system, introduction of new matter is prohibited by 35 USC $\S 132 .{ }^{772}$

Examination Guidance and Training Materials of the USPTO focus on a deep understanding of case law, as in Parts I and II of Best Practices in Examination, which are divided as follows: Part I: Understanding Case Law and the Federal Court System; Part II: How to Evaluate and Analyse Legal Arguments Based on Case Law; Part II Legal Analysis Writing Workshop Slides - with Talking Points, Blank Worksheet, Answer Key. ${ }^{773}$

In this regard, China's regulations differ considerably from most of the others. In China, translation errors cannot be corrected after the filing of the application, unless the spelling mistakes are considered obvious, in which the examiner of the application can recognize and correct the error. ${ }^{774}$

In Brazil, translation inaccuracies can be amended at any time during the prosecution. The examiner is not allowed to correct these errors. What he/she can do is to point out the errors and suggest corrections, but the new reports containing the correction will always have to be presented by the applicant. ${ }^{775}$ European patent attorneys observe that the deadlines for responding to the administrative actions are short, considering the difficulties related to translating all the documents and the difficulties in communicating with local agents and with the national patent office. ${ }^{776}$

A modification of the EPC, in force since 2007, aimed to make the administrative proceedings more flexible. The change concerns the amendment of Rule 40 of the EPC, that establishes the minimum conditions for filing an application. To be considered valid, it is now sufficient that the document presented in the filing date contains the description of the invention or refers to a patent application anywhere in the world, in any language. It is therefore not mandatory to present claims or a description of the invention in the languages accepted by the EPO: English, French and German, in order to have a valid filing date. The applicant will have a limited time, two months, to present the patent application into one of the official languages. ${ }^{777}$

For a patent application in JPO, this rule is more flexible. The application can be filed in any language and the applicant has one year, from the filing date or the priority date, to submit a translation of the document into Japanese. ${ }^{778}$ In Brazil, applications may

772 USPTO, Guidelines for the Examination of Patent Applications Under the 35 U.S.C. 112(a) or Pre-AIA 35 U.S.C. 112, para. 1, “Written Description” Requirement [R-07.2015], https://www.uspto.gov/web/offices/pac/mpep/s2163.html (accessed 18 April 2018).

773 USPTO, Examination Guidance and Training Materials - Best Practices in Examination. Available at: https://www.uspto.gov/ patent/laws-and-regulations/examination-policy/examination-guidance-and-training-materials

774 R. Baechtold, 'The intellectual property review', Law Business Research, London, 2014, p.45.

775 INPI (2016). Resolução 158/2016.

776 Information collected directly with the interviewees.

777 European Patent Convention, Rule 40, https://www.epo.org/law-practice/legal-texts/html/epc/2016/e/r40.html; the information over the modification was directly given by a patent examiner, and can be consulted among the amendments carried out on the revised version of the EPC published in 13 December, 2007, https://www.epo.org/law-practice/legaltexts/html/epc/1973/e/r40.html

778 JPO, How to Apply for a Patent, a Utility Model, Industrial Design, Trademark to the Japan Patent Office, htttps://www.jpo. go.jp/english/faqs/apply.html 
be filed in any language, and the term for submission of the Portuguese translation (the official language) is 60 days from the filing date. ${ }^{779}$

Tyler Young presents an interesting collection of the "world's strangest patent filing requirements", most of them related to language and translation regulations. Some of the curiosities described by him are worth to be summarized here. One of them is the language regime of Iceland. Young notices that most of the countries don't have more than two official languages, in which a translation of patent application must be filed, with different deadlines, depending on the country. Many countries also allow the application to be filed in any language. In this regard, the regulations of Iceland are peculiar. Although the country has only one official language, Icelandic, it accepts applications in five languages, which is the largest number from all patent offices. The languages accepted are: Icelandic, English, Danish, Swedish, or Norwegian. The claims and abstract must be submitted in Icelandic, and a translation into English or Icelandic has to be filed at grant. ${ }^{780}$

Another interesting case is the one of Sweden. Sweden has opted out of legally binding translations. That means the Swedish courts will consider the language of the priority filing in cases when a translation is found to be inaccurate. He then points out that an incorrect translation may have the power to alter the scope of a patent, making it vulnerable to constant infringement. For Young, the unusual Swedish regulation makes translation a mere formality. ${ }^{781}$

A peculiar case mentioned by Young is the one of Belgium. Belgium has three official languages: Dutch, French and German. If a company is located out of Belgium and files an application for a patent, it must use any of the three official languages. However, curiously, if the company is located in Belgium, it must file the application in the predominant language of its region. ${ }^{782}$ Patent attorneys find the regulations for prosecution in Belgium confusing and difficult to follow, mainly because of language issues. $^{783}$

Besides their language regimes, there are some other important features that may play a role on the level of accuracy of examination in each national patent system, within the perspective of language and translation, especially in reading, interpreting, finding and analysing prior art. Experienced patent attorneys from different parts of the world, and also patent examiners, observed that the examination in Asian countries, especially in Japan, is very accurate and reliable. ${ }^{784}$ On the other hand, the rate of granted patents is considerably higher in the USPTO than in the other IP5 countries' offices, and there are some studies questioning the superficiality of its examination. ${ }^{785}$

\footnotetext{
779 Ibid.

780 T. Young, The World's Strangest Patent Filing Requirements. Multiling [Website], http://www.multiling.com/globalization2/11-strangest-patent-filing-requirements-in-the-world

781 Ibid.

782 Ibid.

783 Information collected directly through interviews.

784 Information collected directly through interviews.

785 See: IP5 Statistics Reports, https://www.fiveipoffices.org/statistics/statisticsreports.html)
} 
The accuracy of the examination, which is, as shown, deeply related to language and translation on the current global patent system, may be associated with administrative and cultural aspects, such as: level of autonomy of the examiner (a more decentralized system seems to be more effective in terms of giving reliable results); financial autonomy of the office; tradition in dealing with multilingual, internationalized systems; level of interaction between the National Office and the global patent environment.

It is also relevant to comment on human resources policies that are probably influencing the quality of the examination combined with a good level of productivity. Flexible work and smart work strategies, as well as more autonomy to examiners are proved to give better results in terms of quality and accuracy of the examination. ${ }^{786}$ The process of examination requires very detailed text reading and analysis in a complex, multilingual global platform. The mentioned strategies are recommendable ways to tackle the difficulties of the task of the patent examiners. These strategies may be crucial to the quality of their work, influencing also the results of the patent office. Policies on gender equality and diversity may also be related to positive results in terms of productivity. ${ }^{787}$

In respect to human resources strategies, further theoretical studies are recommended. Those studies should go beyond technical aspects and could benefit from qualitative research, that, for example, associates the quality of the examination (reading, translating, analysing...) with more or less flexibility or autonomy in the work environment. It is also recommended that researchers develop studies that consider national language legislation in association with the current structure of the global patent system and with the idea of integrating a multilingual, digital, complex system based on (especially) machine translation.

\subsubsection{Examples of PTO's cases where translation played an important role}

According to the interviews conducted during this research, as well as to the documental analysis, the influence of translation over patent prosecution is diffuse and difficult to measure, as it is related to subjective aspects, such as text interpretation, legal culture and different ways to understand and read texts in foreign languages. However, it is more significant and present than it may seem to be at first glance. Examiners were unanimous in admitting that they rely on machine translation as a daily routine and make decisions based on their own understanding of the translated texts, as it would be impossible to deal with such a huge amount of information using human translation. ${ }^{788}$

They also elucidate that machine translation has increased the quality of the examination and is now part of the activities associated with patent prosecution. Some declarations of examiners and attorneys are worth transcribing:"machine translation plays

786 See the case of the UKIPO for smart and flexible work strategies: https://www.gov.uk/government/organisations/ intellectual-property-office/about/recruitment

787 The case of the UKIPO is also an emblematic one in terms of success in gender and diversity policies: https://www.gov.uk/ government/organisations/intellectual-property-office/about/equality-and-diversity

788 Information collected directly through the interviews. 
a crucial role"; "there is plenty of subjectivity in the analysis of translated texts, especially when it comes to the inventive step", "Google translator (meaning 'machine translation')? To get some kind of feeling, but I said this is a work of law, so you cannot do anything based on your feeling, so if you cannot really understand the sentence then you will ask someone next to you or..."; "well... I think there are cases where there is not time enough for a really accurate analysis when there are language barriers, normally it is possible to find it in English, but not always."; "translation is a mess".789

Therefore, the cases that will be described below in this section can be considered as the tip of the iceberg. These examples are representative of translation problems found in examination proceedings, office action and opposition cases. Their discrepancies were identified because they show very evident differences, difficulties in finding the right words in target languages or infelicities involving translation. The universe of examples would be much vaster if all the subtleties between languages that may influence the decisions taken in the whole process of prosecution were to be considered. The most important thing is to recognize that the patent system is based on multilingual (mostly) digital communication and that the answers for its improvement are not clear or simple but require a conscious understanding of its complexity. Below follow some examples of remarkable cases involving translation and patent prosecution.

In EPO patent EP695351 relating to stem cells of transgenic animals, there was a conflicting interpretation of the term "animal", which, in the English language, includes humans. In equivalent patents in Germany, the word used was "tier", and in France "animal", meaning "animal" excluding humans. In 2002, the European Patent Office, after receiving 14 protests from different countries, invalidated the mentioned patent, admitting that it was an ethical mistake to authorize it in $1999 .{ }^{790}$

Decision T353/03 of the Boards of Appeal of the EPO discussed an error where the translated text turned a detailed sentence into a sentence with a broader meaning. The sentence of the original text "the cavity space volume shall not exceed $25 \%$ of the cubic root of any wavelength", was translated as " the cubic root of the cavity space shall not exceed $25 \%$ of any wavelength", modifying the scope of the claim. The applicant submitted the original application of the request made in Swedish, corroborating the original text, which was accepted by the Boards of Appeal since Swedish is considered the official language of the receiving office in Sweden, and, therefore, the amendment does not violate Article 123 of the EPC. T171 / 84 OJ 1986 proclaims that an error in an example is considered non-harmful when it can be identified and corrected using common general knowledge. ${ }^{791}$ Takenata also points to a difference of regulation over the correction of this type of errors between the PCT and the Rules of the EPO, observing that the patent was originally a Euro-PCT application:

789 Statements collected through the interviews.

790 D. Stauder and M. Singer, European Patent Convention: A Commentary, Thomson, Cologne, 2003, p. 369. See also: L. Neto, Novos Direitos ou Novos Objetos para o Direito. Porto, 2010, p. 179.

791 T. Takenaka, Patent Law and Theory. Edward Elgar Publishing, 2009, p. 306. 
Where the PCT authority refuses to correct a translation error, the more lenient 'Rule 139' EPO practice (...) can be requested where the EPO is acting as the Designated or Elected Office for a PCT application that has entered the European regional phase (and become a Euro-PCT). A case highlighting the 'obvious error' principle is EPO Boards of Appeal Decision T 353/03 (...) to support this case, the applicant submitted a copy of the corresponding page from the original Swedish PCT application documents and its English translation to the EPO along with an accompanying amended set of claims and description. ${ }^{792}$

An important case involving machine translation of prior art is case T 1332/12, which admitted a corrected translation of a prior art document in an opposition appeal. The opposition division admitted a lack of inventive step, after document D7T, a JPO machine translation, was confronted with a different translation submitted by the appellant, who alleged the machine translation of the document was inaccurate in many aspects. The decision opens a precedent to other cases which can bring similar allegations of inaccurate machine translation of prior art. A complete description of the case follows below:

The opposition division decided that the subject-matter of claim 1 of the main, first, second and third auxiliary requests lacked inventive step over the disclosure of document D7 (JP 07-131734 A) and the common general knowledge of the person skilled in the art (Articles 56 and 100 (a) EPC). For the analysis of inventive step, the opposition division referred to document D7T, which was a JPO machine translation of document D7 into English. The patent proprietor (appellant) filed an appeal against this decision and requested that the decision be set aside. In the statement of grounds of appeal, it requested that the patent be maintained in amended form. It submitted arguments as to why the subject-matter of claim 1 of each of the requests met the requirements of Article 56 EPC. With a letter dated 12 October 2015, the appellant submitted a different translation of document D7 (D7JPO) because "the Japanese and the original and the previously translated prior art document D7T is not precise in many aspects". In a communication under Article 15(1) RPBA, annexed to the summons to oral proceedings, the board indicated that it tended to agree with the opposition division's finding that the second and third auxiliary requests lacked inventive step. It also indicated that it had to be discussed whether translation D7JPO should be admitted into the appeal proceedings (Article 13(1) RPBA). ${ }^{793}$

792 Ibid.

793 T 1332/12 () of 11.10.2017, https://www.epo.org/law-practice/case-law-appeals/recent/t121332eu1.html (accessed 2 December 2018). T 1332/12 - Admission of corrected translation of prior art in opposition appeal, Delta Patents [Website], 2017, http://dp-patentlaw.blogspot.de/2017/11/t-133212-admission-of-corrected.html (accessed 18 April 2018). 
Patent attorneys mentioned cases of discrepant opinions between examiners and attorneys. This seems to be a common situation and, not rarely, it involves machine translation of prior art and its interpretation by the examiners. In some patent systems, European attorneys complain that it is difficult to change the decisions through office actions. According to the attorneys, translation is a major problem and a major cost in Brazil, for example, and in most of the countries in Latin America. For them, it is also relevant to consider whether or not it is worth to sue the office, due to the backlog and lack of specialization involving the national patent courts. One of the patent attorneys mentioned cases concerning the interpretation of machine translated prior art, which were questioned by the attorneys in terms of the grounds of the examiner's decision. These cases were associated with the following families of patents and their divisional patents: The first patent family: Patent application: PI0619531-8, Divisional patents: PI0622402-4, PI0622403-2, PI0622401-6, PI0622405-9, PI0622404-0, PI0622406-7; The second patent family: Patent application: PI0305962-6, Divisional patents: PI0318835-3, PI0318833-7, PI0318834-5, PI0318838-8, PI0318836-1, PI0318837-0. ${ }^{794}$

Cases with "creative" or intricate titles, presenting a very low level of translatability into other languages or even of clear understanding in the original language are not rare. De202017104506 is an example. The application was criticised for not providing the patent office with patent figures, description or patent claims, and being too vague in its title and abstract. It is also accused of presenting an untranslatable title and a confusing abstract. Documents like the one mentioned probably require more than human talent to be translated or even understood. They seem not to disclose the content of the patent on purpose, strategically using linguistic artefacts in order not to supply details of the technology and, at the same time, taking advantage of the benefit of the priority date. ${ }^{795}$

Today the European Patent Office published a patent application from Apple that was originally filed in Germany back on September 05, 2017, or days before Face ID was introduced at the new Steve Jobs Theater. The name of the patent is titled "Krümmungsbasierter Gesichtsdetektor." Google couldn't translate that title into anything meaningful. (...) As you can see from the screenshot of the filing below, Apple provided the patent office with no patent figures, no description or patent claims. All that was provided for public consumption appears to relate to Apple's new Face ID. ${ }^{796}$

794 Information collected directly through interviews.

795 See: An Apple Patent Application Relating to Face Mapping Surfaced today in the European Patent Office's Database, Patently Apple [Website], 2017, http://www.patentlyapple.com/patently-apple/2017/10/an-apple-patent-application-relating-toface-mapping-surfaced-today-in-the-european-patent-offices-database.html (accessed 18 April 2018).

796 The screenshot is available on the mentioned webpage, (see previous supra notes). The patent application is available at: https://worldwide.espacenet.com/publicationDetails/biblio?DB=EPODOC\&II=0\&ND=3\&adjacent=true\&locale=en_ $E P \& F T=D \&$ date $=20170905 \& C C=D E \& N R=202017104506$ U1 \& KC $=$ U1 \# 
Patent examiners comment that there are patent applications which can confound or even mislead the examination because of their text structure. A patent text may bring different purposes or strategies on the way it is written. In some national offices, the results of the examination or office action, which may include text issues, may be discussed through an oral proceeding or interview, gathering one or more examiners and the patent attorney(s). ${ }^{797}$

The EPO and the JPO offer the possibility of interviews and oral proceedings as part of a systematic process following detailed regulations. Their guidelines also regulate the possibility of telephone consultations, more convenient in less controversial cases. ${ }^{798}$ The Brazilian Patent Office allows examiners to carry out interviews. But there are no formal regulations or legal provisions. ${ }^{799}$

Over the problem of confusing texts, it is recommended to pursue further studies over how obscure writing can mislead patent examination. It is also important to study whether these inaccuracies are or are not the consequence of a textual strategy to bias the result of the examination. Evidently, these inaccuracies may influence the translatability of the patent and its disclosure in a global level after an unclear patent is granted or even when its application is admitted, in cases as the one mentioned above.

There is an abundance of examples of structural or text errors that affected the process of prosecution, as the ones below:

In 2014 an article in the American Chemical Society magazine detected an error in the structure of a compound known as TIC10 or ONC201. The compound had obtained patents in the United States (US8673923) and Europe (EP2701708) and is used in the treatment of cancer. If such an error renders the claimed compound inactive, there may be grounds for invalidating the patent due to its failure in meeting the criterion of patentability. ${ }^{800}$

In T80/05 patent EP699754 relating to the BRCA1 gene for the treatment of breast cancer had the sequence corrected during the processing of the application, which resulted in the loss of priority, but not in the loss of the patent. This was possible because the error was in an area not subject to mutations where different nucleotide sequences would ultimately encode the same amino acid sequence. If the error was in the amino acid sequence itself, the application, according to the EPO practice, could have been rejected. ${ }^{801}$

Some offices provide the possibility of the applicant to request a human translation for a machine translated prior art document that was crucial as the basis for

\footnotetext{
797 Information collected directly through interviews.

798 See: EPO, Guidelines for examination, 2.2. Interviews, https://www.epo.org/law-practice/legal-texts/html/guidelines/e/c vii_2_2.htm; JPO, Guidelines for examination, 2.2. Communication through interview, telephone and facsimile, https:// www.jpo.go.jp/tetuzuki_e/t_tokkyo_e/files_guidelines_e/all_e.pdf

799 Information collected directly with interviewees

800 D. Smith, When Structure is Wrong, Patents may Fall?, IPKitten [Website], 2014, http://ipkitten.blogspot.com.br/2014/05/ when-structure-is-wrong-patents-may-fall.html (accessed 18 April 2018).

801 Ibid.
} 
an examination decision. That is the case of the JPO and the EPO. In Brazil, the fact that this possibility is not formally regulated for being allowed through an Office Action leads the applicant to appeal to court, if the need for a more accurate translation is identified during the prosecution. In 2006, an injunction against INPI was filed in order to prevent the Office from invalidating application MU7906109 on the basis of a German document. The decision of the Court and the lack of possibility of obtaining the translation through an office action reveals the delay of the Brazilian system and legislation over the role of machine translation in patent examination..$^{802}$

The judge concludes, on the ground of the only existing Brazilian Regulation on the matter (Art. 151 and 157 of the Civil Procedure Code and articles 224 of the Civil Code), that the Brazilian legal system does not allow evidence (administrative or judicial) in a foreign language without translation and that a document written in a foreign language may only be accompanied by a vernacular version, signed by a certified translator. The final decision determines the suspension of the administrative proceeding for invalidating application MU7901609, until the certified translation of the mentioned document is joined to the decision report. It also prescribes that the local authority may proceed with the examination on the basis of the same document, immediately after the document is provided, and also based on the other documents in the file, maintain its decision of not granting the patent if it judges it right to do so. ${ }^{803}$

Taking into account the costs of providing a certified translation in Brazil, as well as the (financial and personal) costs with filing an injunction in the only court that accepts cases against the National Patent Office, the difficulty in requesting an accurate translation directly to the Patent Office during the prosecution process creates a hindrance in the system. Systems which offer the possibility of requesting a human translation from the office, then confronted with the opinion of other examiners through an interview or oral proceeding, or the judgement of a committee designated for the case, will present much better results in terms of an accurate examination based on accurate translations.

In this case, the legal structure in Brazil does not consider the fact that the examination is, nowadays, to a great extent, based on machine translation. The only possible legal solution is then founded on a vicious cycle: the examiner does not grant the patent authorized by one or many foreign machine translated documents (which may be a more common situation than it seems to be); the applicant files an injunction in the competent court to request a certified translation of the document(s) (implying high costs, intricate bureaucratic procedures and a considerable time before the decision is taken); the court approves the request of the document, which has to be provided by the Office, without entering into the merit of the quality of the examination or of how

802 PROC. № 200651015184614, Trf2 Justiça Federal Rio De Janeiro Vara: 38ci, Agrte: Sergio Ricardo Da Silva, Agrdo : Instituto Nacional De Propriedade Industrial - Inpi, Relator: Des.Fed.Messod Azulay Neto - 2a.Turma Especializada, http://www.trf2. gov.br/iteor/RJ0108210/1/22/200105.rtf (accessed 18 April 2018).

803 Ibid. 
the inaccurate document may have influenced it. A structure where the applicant (or any interested party) will have the possibility, in different levels (telephone consultations, interviews involving other examiners, opposition, appeal), of contesting the Office's decision will be indubitably more efficient, integrate and fair.

In PI9715364, a recent office action, in Brazil, recognized that the term phosphorescent substance was mistakenly used in the text thereof, resulting in a lack of clarity in the description of the subject matter of the application. The claims of the patent document refer to a white light emitting device and the error occurred due to the technical translation of the word "phosphor" (from English into Portuguese). The examiner understood that the term, in a broader sense, means "luminescent substance", pointing out that the accurate technical translation, in this case, is crucial to the correct understanding of the claims, since the luminescent substance present in the coating material of the white light emitting device emits "fluorescence", and not "phosphorescence". In sum, 'phosphor' cannot be translated as 'fosforescência' or 'substância fosforescente' in Portuguese. ${ }^{804}$

In the case mentioned above, the examiner justified the analysis using the example of EP0936682 B1, a patent belonging to the family of the referred application. In this case, regarding the objection to the term "phosphorescent substance", the applicant chose to follow the suggestion of the examiner, and substituted it by "fluorescent material" in the claims. ${ }^{805}$ That can be mentioned as a case of accurate examination, important to avoid further legal challenges involving the process of prosecution, and showing clearly the importance of a quality examination, which should consider even less obvious inaccuracies in the translated document. The case was shared by a patent examiner in order to support the present research, together with 27 other cases, where the search reports mention similar issues involving translation of technical terms ${ }^{806}$ All the 27 examples show cases where actual translation inaccuracies were identified by the examiner and corrected by the applicant in order to continue the process of prosecution.

Section III-F-5 of the Case Law Book of the Boards of Appeal offers a vast range of examples where translation procedures were important to its decisions in various ways, which extend from a translation not filled in the required time, a debit order filled in error

804 The example was kindly shared by a patent examiner. The decision, in Portuguese: "PI9715364 A expressão substância fosforescente foi empregada equivocadamente no texto do mesmo, acarretando em falta de clareza na descrição da matéria do presente pedido (que se refere a um dispositivo de emissão de luz branca). Esse equívoco ocorreu devido à tradução técnica da palavra 'phosphor' (do idioma Inglês) para o idioma Português; que, num sentido mais amplo, significa substância luminescente. A tradução técnica correta nesse caso é muito importante, uma vez que a substância luminescente presente no material de revestimento do dispositivo emissor de luz branca do presente pedido, emite fluorescência e não fosforescência, vide, por exemplo, EP0936682 B1 pertencente à família do presente pedido. No que diz respeito à objeção ao termo substância fosforescente, a recorrente optou por seguir a sugestão do examinador de substituir a mesma pela expressão material fluorescente nas reivindicações."

805 Ibid.

806 The reports were directly shared by a patent examiner and refer to the following documents: PI0618793358, Pi0618938356, PI0117164347, PI01 16241326, PI0117339364, PI0804483364, PI04009471365, PI06168550365, PI0207920365, PI0201923365, PI0516223364, PI0103851362, PI0309286359, PI0619631358, PI0215744357, PI10208198353, PI0117237237284, PI0117236284, PI0208514319, PI0117160318, PI0306693347, PI0308575351, PI0418459340, PI1014241364, PI0208870364, PI9803501352, PI0304839362. 
in Dutch and a PCT application originally filed in Japanese with no attached translation. ${ }^{807}$

In the first case, the notice of appeal was judged as not to have been received and the appeal was deemed not to have been presented, with as its legal consequence the inadmissibility of the appeal. For the case of the debit order filed in Dutch, the board understood that a debit order did not have to contain text in a language at all, if it presented its information clearly, leaving aside the question of whether a debit order in a non-official language was effective or not. Therefore, in this case, a translation into one of the official languages of the EPO was not required. The third case led to the conclusion that a PCT application in a non-official language should lead to the same treatment of the applications filed in the language of a contracting state which does not share one of the official languages of the EPC.808

The Book also mentions a case in which a second "late translation" was attached by the proponent of an opposition action. This translation was supposed to "correct" the first translation presented in conformity with the original claims. The Boards of Appeal did not consider this second translation, justifying its decision by pointing to the lack of evidence of the alleged non-conformity of the first translation. The decision was explained as follows:

Shortly before the oral proceedings before the board in case T 265/11, the appellant (opponent) filed an uncertified translation of the claims of the international application underlying the patent. It argued that it was evident from this translation that certain features were different in the originally filed claims with respect to the English translation filed on entry into the European phase (Art. 158(2) EPC 1973), and requested that the newly filed translation be used as a basis for the analysis under Art. 123(2) EPC. The board affirmed that an international application for which the EPO is a designated or elected Office, and which has been accorded an international date of filing, is equivalent to a regular European application (Art. 150(3) EPC 1973; now Art. 153(2) EPC). For the application in question, R. 7 EPC 1973 (cf. R. 7 EPC) applied mutatis mutandis to the translation filed under Art. 158(2) EPC 1973. As no evidence had been provided that the translation already on file was not in conformity with the original text of the application, the board, in accordance with R. 7 EPC 1973, assumed that translation to be in conformity with the original text of the application for the aforementioned purpose. ${ }^{809}$

807 EPO, Case Law of the Boards of Appeal, Eighth Edition, August, 2016, Chapter III-F, http://www.epo.org/law-practice/legaltexts/html/caselaw/2016/e/clr_iii_f_1.htm (accessed 18 April 2018).

808 Ibid.

809 Case Law of the Boards of Appeal of the European Patent Office Sixth Edition July 2010, p. 649, available at: http://www.epo. org/law-practice/case-law-appeals/case-law.html 
A patent attorney described an office case where the only relevant prior art, a document in Japanese, presented problems of lack of clarity in its machine translation, which generated a long proceeding of discussion and appeal, still unsolved, with the office. The prior art document, which could affect the novelty of the invention, presented a passage which was difficult to understand, first through machine translation and later also through human translation. The attorney observes that the unclear passage still remained as unclear as it was through machine translation after it was translated by a professional translator. In the words of the attorney:

So, what happened there is that the only relevant prior art against our patent was an $\underline{x . x}$ document. Which means only novelty is relevant. So, you can't combine the document, our document, as you usually can. In this particular legal situation, you could only look at this one document. So, it's only this document, and if it didn't exist you would immediately get it granted, so there was just one obstacle. And for that one document to be relevant it was vital that its own priority claims or the priority claims of the prior art document was valid. And the document itself was in English, but the priority claim was from a Japanese, I think Japanese, at least Asian, I have to check it. An Asian document. Now the examiner said, look, your claim does not explicitly occur in this priority document, we can't explicitly find all the features in the document, so that is good for us, right? But I think you can find it implicitly, as our... between the lines, so to say, if a skilled person, somebody who knows this technology, he will understand all the other things that are not explicitly there, but kind of implicitly. So, in such situations it's very important that the subtleties of the language are fully understood, right? Now it turned out that in the prior art document itself, in the English document, there was one passage which may or may not implicitly disclose our claim, and we couldn't read the prior art document, as it was in an Asian language, even though we could see that just that part had changed, between the prior art and the English document itself. So, they changed something, we couldn't say what it was. We knew they changed something. And machine translation was so helpless, it wasn't actually so helpless, but it was not good enough to actually say it is or it's not it. So, they objected about it, and in that case the office then postponed the oral proceedings and had a full translation made by themselves, and in the end, yeah, that particular section that was unclear was, of course, still unclear, and we still had a lot of discussion about it. So, it's in appeal now. So, we will have to see where it goes. ${ }^{810}$

810 The statement was collected directly through an interview. The number of the patent will not be revealed here due to ethical reasons, in order to preserve the anonymity of the interviewee. The name of the office was replaced by the underlined word office and the number of the document by x.x. 
Another patent attorney gave an example that may also be emblematic of a common discrepancy between machine translated documents. He showed a PCT application made by his firm and the machine translated versions of it made by two patent offices` translation machines: the JPO's translation machine and Espacenet's Patent Translate. Without discussing the relative merits of the quality of the two options, the two translations into English of the Japanese text were completely different. ${ }^{811}$ These discrepancies can probably influence decisions in terms of prior art search and examination and ask for joined forces in order to reach more harmonization and improvement in patent translation.

Another interesting case was shared by a Japanese patent attorney. The words "enzyme" and "oxygen" are translated into similar, if not identical ideograms, in Japanese. This ambiguity generated a bad translation of a Japanese text into German, where the corresponding word to oxygen was translated by "Enzym", the word in German for "enzyme". The mistake was only perceived after the patent was granted, and the patent was revoked in a court case. The case shows that a bad translation in an early stage can create further legal problems to a company, leading to unnecessary expenses and concerns. $^{812}$

Patent examiners observed that they frequently rely on a text from the same patent family or on an English translation of a patent document that represents prior art to an application. One examiner commented that this happens on a daily basis, which means, examiners constantly trust these translations or "other versions" of the patent. In this respect, there can be semantic losses in the texts considered during the process of examination, as the original text is only consulted, if it's consulted at all, through machine translation:

Today I examined an application whose most important prior art document is a Japanese patent. I looked at the English text, but I have no idea of what is there on the original Japanese text. Yes, of course translation may influence patent examination. ${ }^{813}$

\subsection{Main aspects in patent court cases involving translation}

It is undeniable that language and translation play a very central role in the patent legal system at the global level. And that does not only happen in more complex cases involving parties from different jurisdictions. The influence extends to national systems, no matter how apparently isolated they are. Therefore, it is here defended that the patent

811 The case was shared by a patent attorney. The number of the patent will not be revealed in order to preserve his anonymity.

812 The court case will not be mentioned in order to preserve the anonymity of the attorney. The ideograms are:“酵素" and “酸素”

813 Information collected directly through interviews. 
legal system is a sub-system of the general legal system, also related to other systems (as the economic system), being based on language and translation.

That is different from simply stating that the legal system is based on communication, and communication, in turn, is founded on language, to be more precise, on a linguistic system. This international, multilingual, intercultural component is very central to the patent system, flowing through all its branches, versions and subsystems - as it is proposed here, in the absence of better categories. Translation thus impacts profoundly, mostly in a diffuse, intricate way, sometimes in a subtle (but crucial) level on the functioning of the global patent system. It is spread through all its levels and may pervade them, interacting with different digital tools, cultural factors, administrative and legal frameworks and personal interpretations. It is predictable to a certain extent, deserving further studies that can go deeper into many of its aspects.

When this vision is limited to the court stages of a patent, three very relevant questions emerge, as ways of approaching this thesis's research question associated with the ultimate stage of the legal challenges of a patent, an infringement action: a) Does translation affect the decisions in infringement cases involving patents?; b) Does it mislead these decisions? (that question may sound redundant with question "a", but it brings a very important differentiation, related to the negative effects, which are here considered as more than just a pervasive influence, involving a particular, measurable effect); c) If they do (or at least have the potential to) mislead these decisions, what could be done to minimize these negative effects?

To try to answer these questions, and in order to illuminate the debate on the influence of translation on patent disputes, some key aspects were considered for analysis. As shown before, this influence is extensive, broad and complex and could be searched for in many different types of sources. It was shown that translation is present in all the legal stages and levels of the patent system, as, for example, the internalization of patent related international agreements, the different national timelines of patent prosecution and the office stages, such as examination and opposition. Those previous stages may cause a network effect or a snow ball effect, the first metaphor referring more to the legislative structure, and the second one to the role of translation during the stages of prosecution, within the different timelines and regulations of each national patent system. The preliminary stages are decisive to avoid infringement actions.

The number of infringement cases compared to the number of granted patents varies from country to country. The percentage is, on average, not very high, but it is always crucial to the companies involved and to the enforcement of patent rights. It is also very dependent on the previous stages, as shown in Section 7.2.2. The United States presents one of the highest percentages of litigations compared with the number of patent grants: an average of $4.9 \%$, from 1991 until $2015 .{ }^{814}$ In Germany, one of the highest rates of

814 A. Marco et al., Patent Litigation Data from US District Court Electronic Records (1963-2015), USPTO Economic Working Paper, no 2017-06, https://papers.ssrn.com/sol3/papers.cfm?abstract_id=2942295 
infringement cases in Europe, the average is $2.11 \%$, from 2000 until $2008 .{ }^{815}$ In Brazil, the average of cases, in 2017, was curiously only $1 \%$, not referring to the patents granted in 2017 or recent years previous to that, but to older patents, considering the backlogs both in the patent office and in the related courts. ${ }^{816}$ The reasons for these numbers may differ considerably from country to country.

Figure 40: Patent case filling and grants in the US - 1991-2015

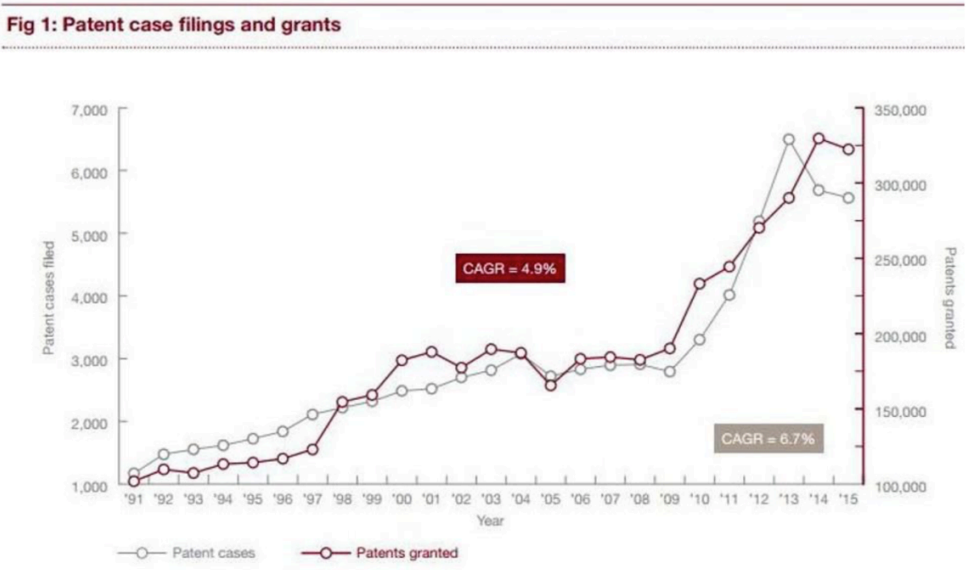

Years are based on September year-end.
Sources: Performance \& Accountability Report (USPTO) and Judicial Facts and Figures (US Counts)

Source: Patent Litigation Data from US District Court Electronic Records (1963-2015) $)^{817}$

Table 18: Number of court cases and patent grants in Brazil 2005-2017

\begin{tabular}{l|l|l|l|l|l|l|l|l|l|l|l|l|l}
\hline Year & 2005 & 2006 & 2007 & 2008 & 2009 & 2010 & 2011 & 2012 & 2013 & 2014 & 2015 & 2016 & 2017 \\
\hline $\begin{array}{l}\text { Granted } \\
\text { patents }\end{array}$ & 2833 & 2785 & 1855 & 2824 & 3153 & 3620 & 3806 & 3137 & 3326 & 3121 & 3895 & 4771 & 6250 \\
\hline $\begin{array}{l}\text { Court } \\
\text { cases }\end{array}$ & 93 & 40 & 37 & 45 & 50 & 48 & 57 & 26 & 53 & 88 & 69 & 62 & 88 \\
\hline
\end{tabular}

Source: RPI (INPI) 818

815 K. Cremers et al., 'Patent litigation in Europe', European Journal of Law and Economics, vol. 44, 2017, https://link.springer. com/journal/10657

816 INPI, Despacho 18.1. Revista de Propriedade Intelectual, 2017, http://revistas.inpi.gov.br/rpi/

817 A. Marco et al., Patent Litigation Data from US District Court Electronic Records (1963-2015), USPTO Economic Working Paper, no 2017-06, https://papers.ssrn.com/sol3/papers.cfm?abstract_id=2942295

818 The information of the number of patent grants compared to the number of court cases was collected directly with a patent examiner. It can be obtained in each year of the publication of the Journal of Intellectual Property (Revista de Propriedade Intelectual), INPI (from 2004 until 2017). The Journal is available at: http://revistas.inpi.gov.br/rpi/ (last accessed 18 April 2018). 
In the following section of this chapter, the legal challenges of a patent in a court level will be described and discussed. They were narrowed into court cases comprising infringement actions. For carrying the analysis, it was decided to consider as the most important sources the patent documents and the court cases documents, in a context where the cases involve foreign documents, requiring some type of translation and text interpretation. ${ }^{819}$ Interviews were important to clear up some aspects and to add emblematic cases known by the patent attorneys to have involved problems with translated documents.

It was also mandatory to narrow the point of law to work with during the analysis, choosing, as mentioned, infringement cases, as the most relevant legal challenge involving patents and translation. Initially, the sample was limited to solar and wind energy patents, following the same sample that underpinned the analysis described on Chapter 5. As the number of cases did not suffice in giving a general vision of the aspects that should be analysed, the sample size was increased with cases mentioned directly by patent attorneys. The main aspects considered were based on the previous research on literature and patent documents. The analysis focused on the following aspects found in each case:

- Type of foreign documents (papers, other patents, etc.)

- Court (country/instance) level

- Parties

- Direct reference of translation or language issues;

- Transcription of translated documents or documents in a language different from the court language;

- Allegation of problems in disclosing the technical information

- Main decision (s)

- Notes

It was pre-supposed and confirmed that the documents by themselves would not clearly show the influence of translated texts on the decisions. The fact that foreign documents are mentioned in a case does not necessarily mean that they were crucial to the final decision taken by the court. However, the quantity of documents and the way they are mentioned on the proceedings can be a noticeable sign of their level of relevance to the case. Even though, the interviews brought the most relevant cases, bringing details on how translation played a role to the decision taken by the court, which was something difficult to identify only through the analysis of the proceedings.

During the interviews, it was possible to discuss the details of the cases and to understand the association between the decisions and the translated documents. It was also easier to access and investigate the presence of other sources of foreign documents that could influence the case. It was understood that there are subjective and cultural

819 The word "interpretation" is not used here in the sense of orally translating a language into another, but in the sense of decodifying, understanding and reframing the text's information. 
aspects crucial to the way the foreign documents are managed and processed during the cases, as, for example, the relation of each judge with the multilingual complexity of the patent system (through, for example, the advantages of a technical background and a multilingual education) and the level of integration of each country's legal system to the global patent system.

As mentioned before, most of the techniques were a result of the opening of new grounds of a topic where little has been published in academic research. Therefore, it is not intended to exhaust the topic or to present a causal explanation on how translation infelicities influence court decisions. The goal of the present research is to produce a realistic picture of the way translation interacts with and influences patent law and to propose feasible solutions to mitigate the associated gaps it can produce in the patent system.

\subsection{Patent and translation: examples of court cases}

Patent attorneys observe that it is not rare that an inaccurate translation can be used with the intention to bias a case. As infringement cases are based on written documentation, and frequently involve translated foreign documents, the use of speech and words by a human translator will evidently make a difference in influencing the case's decision. This difference is, most of the times, difficult to be identified and described.

A Japanese attorney, interviewed during this research, mentioned cases where the counterparty attorneys filed translations of prior art documents later considered to be (deliberately?) inaccurate with the intention to direct the decision of the judge. The interviewed attorney had to compare the original text with its translation in order to identify inaccuracies and request a more accurate translation. In the mentioned case, the attorney requested a new, accurate translation of the same document by the counterparty. ${ }^{820}$

The attorney observed it is very complicated to try to identify these inaccuracies in translations presented as part of the documentation to underpin the decision of the case. It requires experience, intuition and knowledge of the source and target languages. All the foreign information which grounds a case can strongly bias its result without being suspected by the harmed party. An experienced attorney will compare translated texts with their original versions in order to carefully identify infelicities or unclear content. However, no attorney is experienced enough with all the languages involved in order to identify errors and request new translations. ${ }^{821}$

There are cases of corrections of translated terms which dismissed the query to the original text. One example is re Oda 443 F.2d. 1200 (CCPA 1971). The Court decided that the error of translation of the original Japanese text into English using nitrous acid

820 See, for example: Japan, Superior Court of Intellectual Property, Heisei 23, Rokuke, 10410, 2012, Available (in Japanese) at http://www.courts.go.jp/app/hanrei_jp/detail7?id=82581 (accessed 18 April 2018).

821 Information collected directly through interviews. 
instead of nitric acid, present in various parts of the specification of the patent, although not written in the claims, could be corrected through a Reissue. The nature of the error was considered as obvious, as it could be identified when a person skilled in the art read the patent. The text of the document referred to specific conditions where the nitrous acid could not exist. The error could be detected by a chemist without resorting to the Japanese source document. ${ }^{822}$

Chisum \& Farmer describe cases where translation had a relevant impact on the decisions of American courts. Their article is very illustrative in showing how frequently translation can change the scope of inventions, resulting in further legal impact. Some of the cases described bring unexpected textual discrepancies and nuances that are sufficient to bias a legal decision. ${ }^{823}$

Gambro Lundia AB v. Baxter Healthcare Corp. (1997) is an example of how notes or statements of applicants over foreign documents may raise doubts about an attempt to induce the interpretation of their content. In the case mentioned, the Federal Circuit recognized that the statements presented by the applicant over a German document were "over-statements", exaggerating what was written on the original text. ${ }^{824}$

The Federal Circuit agreed that an applicant's statements distinguishing a German language reference were 'at least over-statements. However, it concluded that 'in the context of [the applicant's] overall effort to show that the German reference does not anticipate its invention, these exaggerations do not rise to the level of gross falsification.' ${ }^{25}$

The same authors mention a case of the type of error which, according to what was observed during this research, easily occurs in patent translation. The case was related to an unclear sentence on a claim, namely "stop means formed on a rotatable with said support finger", which was "corrected" by a district court as "stop means formed on and rotatable with said support finger". The decision was then reversed by the Federal Circuit. ${ }^{826}$ The case shows how apparently obvious corrections for one court may not be so obvious for other courts.

Some cases show the influence of language and translation on decisions taken by courts in a very high degree. The type of influence which can occur clearly depends on how prepared the court, the judge and the agents, are to deal with the complexity of the patent system. Patent cases analysis may require thorough studies and highly specialized reports developed by technical experts that should constitute the bases for decisions.

822 S. Lundberg, S. Durant and A. Mccrackin, Electronic and software patents. The Bureau of National Affairs, 2005, p.9-14; D. Chisum, and S. Farmer, 'Lost in translation': the legal impact of patent translation errors on claim scope'. In: Takenaka, T. Patent law and theory - a handbook of contemporary research, Edward Elgar, 2008.

823 D. Chisum and S. Farmer, 2008.

824 Ibid.

825 Ibid.

826 Ibid. 
The necessary analysis of a considerable number of documents which will be foreign to each court and to each judge plays a role which is neither causal nor isolated but is still determinant.

Besides, the proceedings do not always clearly show how the documents are accessed and understood by these judges, which kind of specialized opinions they consulted for basing the decision and why the same foreign documents can be interpreted in opposite ways in different courts. Different courts may have divergent approaches and particular ways of dealing with foreign documents. A good example is Wobben Properties vs. Siemens AG, for which decisions belonging to three different European courts and the Board of Appeal of the EPO, present considerable discrepancies..$^{827}$

One of the courts where the infringement case takes place is England \& Wales High Court C.Div (United Kingdom). The whole argumentation against infringement by Siemens relies on two documents: A Japanese application filed in 1980 and published in 1981 as JP 56- 150999 ("Shozaburo", as called by the Court). Judgment Approved by the court for handing down Wobben $v$ Siemens ii) The article "Probabilities of sudden drop in power from a wind turbine cluster" written by E.A. Bossanyi and published in September 1982 ("Bossanyi"). ${ }^{828}$

The EPO opposition division rejected an opposition by Vestas on 16th January 2003, but they did not have Bossanyi cited to them. In proceedings between Wobben and Siemens AG, the Landgericht Düsseldorf rejected Wobben's claim for infringement. Wobben appealed and on 15th April 2015 the Oberlandesgericht Düsseldorf directed that the matter be considered by a court appointed expert. In proceedings between Wobben and Gamesa Corp Technology SA in Spain, the Spanish Court found the patent valid and infringed by certain Gamesa turbines. As I read the Spanish judgment Bossanyi was not cited. It is not clear to me from the judgement whether the Gamesa turbines work in the same way as Siemens' HWRT. (...) Conclusion 211. The patent is invalid. Even if it was valid it would not be infringed. ${ }^{829}$

The decision of the Spanish Court on a case involving the same patent considered the patent as valid and accepted the claim of infringement. Other decisions are mentioned, as the one by the EPO rejecting an opposition on the same patent (also discrepant with the England and Wales High Court's decision of considering the patent as not valid). The proceedings also mention that Landgericht Düsseldorf rejected Wobben's claim for infringement, a decision similar to the English and Wales High Court's one. ${ }^{830}$

827 Wobben vs Siemens AG., 2015, EWHC 2114 (Pat), F.S.R. 18, HP13E02610.

828 lbid.

829 Ibid.

830 Wobben vs Siemens, 2015. The proceedings make reference to all the mentioned previous decisions. 
In this case, it seems that the decision taken by the England and Wales High Court is well grounded, and its fundaments are clear and accurate. As the concept of novelty is absolute, any document published anywhere in the world before the filing/priority of the patent in question is prior to it. The validity of the patent, however, is national. One can only be accused of counterfeiting within the territory of the country that issued the patent. That means Wobben would be right in suing Siemens for infringement if its patent was valid. But the case proved it was not, as the criteria of novelty and inventive step, questioned by Siemens through the presentation of two documents, one being a Japanese patent, were not considered when the patent was granted.

The case described above is not rare, according to the statements of patent attorneys. For a better explanation of its structure, it is interesting to understand the following example: $\mathrm{A} 1$ has a patent (AP) in Japan, and B1 has (a "similar") one (BP) in the UK. A1 applied for the patent only in Japan, so A1 has "no rights" to allege counterfeiting in any other country, as for example, in Brazil. A1 cannot use its Japanese patent for alleged counterfeiting in the UK. Regarding the nullity of BP, as it was deposited after AP, and AP was published in Japan, then the patent BP should not have been granted, as there was prior art for lack of novelty. However, the technology is free in the UK and in Brazil, as it is unpatented, and everyone can use it. It is a typical case that leads to alleged infringement, involving different national systems, that may end up in questioning the validity of one of the patents. It is also a typical case involving translation and interpretation of foreign documents written in languages that are not official at the court judging the case. ${ }^{831}$

In the case mentioned above, according to the decision of the EWHC, Wobben's patent should have been revoked when it was opposed. In this case, it was opposed by another company different from Siemens - as presented in the procedures - but it was not revoked by the Patent Office. The decision of the judge in the UK, based on the opinions of an Australian and an American expert hired for the case, was to consider it invalid, as it should not have been granted. The Court did not comply with the claim for infringement. The case may be an example where an inaccurate examination of prior art during the stages of prosecution at the patent office triggered the development of legal disputes over the invention. The case also illustrates the universality of the patent system and the relevance of finding and correctly interpreting prior art. It illustrates, ultimately, that an inaccurate examination may be the cause of discrepant decisions in distinct courts, as the result of a snow ball effect.

When analysing different court cases concerning the same patent or patent family, it is easy to identify contrasts in the way national courts deal with foreign documents. A good example is W. A. D. vs. Vestas Benelux. et al.. It comes to a case moved by a German firm, Aloys Wobben, against a Danish one in its branch in the Netherlands, Vestas Offshore

831 The word "interpretation" is used as "the action of explaining the meaning of something", and not as "an oral translation". See definition at https://www.merriam-webster.com/dictionary/interpretation 
Applications. ${ }^{832}$ The content of the patent, EP1040564(B1), concerns a method for operating a wind power station.

In the mentioned case, the document for the main proceedings is written in three languages: Dutch, English and German. The German patent which supports the claim is transcribed from its original text in the substantive decisions proceedings. The predominant language of the lawsuit document is Dutch, but it also mentions the English translation of a document presented by the defendant. ${ }^{833}$ It is not possible to understand merely by the presence of these documents, or the multilingual format of the proceedings, how much they influenced the decision, or how much the fact that they are being mentioned, analysed and discussed in their original languages could carry positive or negative effects to the case's results. All the attorneys who were interviewed agreed that language knowledge, experience, and technical background may be relevant to the quality of a court's decision. They also agreed that more "internationalized" and specialized courts may give better grounded decisions. ${ }^{834}$

Concerning the differences between monolingual and multilingual courts, it is possible to conclude that working with documents in their original language (depending on the court and the languages involved) remains as a feasible solution found in some courts for complex patent cases. That requires fluency from the judges in the languages involved by the case, which is probably not so rare in some European Courts, and considering some specific languages, as shown by the document of The Hague District Court (Rechtbank Den Haag). The case makes it clear that monolingual and multilingual courts differ considerably in the way they access documents that support their decisions. Therefore, it is recommended that those differences should be the subject of further studies. $^{835}$

Infringement cases found in Brazil show a completely different reality. European patent attorneys who are experienced in working in this region of the world have severe criticism over its legal framework. Their objections relate especially to the reliability and efficiency of the court system. There is a huge backlog concerning infringement actions or actions against the patent office. The backlog in the courts follows the backlog in the examination and make many companies give up the decision of patenting their inventions in Brazil, or, when they do not, after the patent is granted, to think twice before litigating another company for infringing their patent. ${ }^{836}$

832 W. A. D. vs. Vestas Benelux, Rechtbank Den Haag (The Netherlands), 2008, nl-HA-ZA-07-1473_20080116 nl-ha-za-07-1473.

833 Ibid.

834 Information collected directly through interviews.

835 The Unitary Patent's and the Unitary Court's regulations on translation arrangements don't make it clear whether the proceedings of a dispute should be written in one of the official languages only or could directly mention foreign documents in their original languages (being them the official languages of the EPO or not). See Regulation 1260/2012 (on language regime) http://eur-lex.europa.eu/LexUriServ/LexUriServ.do?uri=OJ:L:2012:361:0089:0092:EN:PDF

836 See, for example: L. Yeung and P. Azevedo, Measuring the Efficiency of Brazilian Courts from 2006 to 2008. Insper-SP, 2008, http://effectius.com/yahoo_site_admin/assets/docs/MeasuringtheEfficiencyofBrazilianCourtsfrom2006to2008_ EFFECTIUS_newsletter16.344135324.pdf ; Over the examination backlog, see: Jr. Garcez and J. Moreira, The Backlog of Patent In Brazil: The Right to Reasonable Duration of the Administrative Procedure, Rev. Direito GV, vol.13 no.1 São Paulo, 2017, http://www.scielo.br/scielo.php?pid=S1808-24322017000100171\&script=sci_arttext\&tlng=pt 
The decisions in Brazil investigated here as part of the sample analysis presented some common characteristics with the observations of the patent attorneys: a) there is a tendency to consider the action against the Patent Office as unfair; b) in two similar decisions involving the classical association between validation and infringement, the proceedings allege that the infringement claims are unfair, due to the fact that the defendant companies, which first fabricated the product, have never applied for a patent for this same product; however, there is no recommendation or notice that the (new) patent should be invalidated, due to its lack of novelty, meaning the previous administrative process in granting the new patent is not questioned. There is also no clear indication of a thorough analysis of prior art foreign documents, which should be used for reversing the decision of the patent office, in case of a previous error in granting the patent. ${ }^{837}$ As errors in examination are not so rare, especially due to the volume of foreign documents grounding prior art search, further instances of opposition, appeal and, finally, an efficient specialized court system, should act in order to support the national patent system.

The cases in Brazil clearly form a vicious cycle, in which a possible error of the National Patent Office will probably not be corrected by a further legal case. This perception, although not sufficiently investigated, confirms the idea that the solution for enforcing the rule of law in the patent system is an actual integration and harmonization of this system at a global level, as fragmented and isolated systems prove to present more disorganized and less solid and reliable structures. They also confirm the relevance of the existence of various instances of objecting to the grant of a patent and the importance of the technical background and technical support among/for judges and attorneys involved in patent cases. The mentioned cases are highly related to translation issues, as they probably contained inaccuracy in searching for prior art, which couldn't be appropriately corrected in further stages due to the way the national legal system is structured and associated to the administrative system. ${ }^{838}$

Different courts present diverse interpretations of concepts, regulations and agreements on patents. Although this may not be directly associated with a specific translation error or discrepancy in a document, these cultural differences on interpreting what seems to be obvious concepts or premises for the patent system may lead to different results even in associated systems. A famous case that is worth mentioning is Aerotel Ltd v Telco Holdings Ltd. ${ }^{839}$ Aerotel's patent, which formed the basis of the claim for infringement was considered to fulfil the requirement for an inventive step, but rejected as not to be considered patentable subject matter. The decision taken by the Court of

837 The cases will not be namely cited for ethical reasons. The issue requires further investigation and the intention of the present research is not to find "someone to blame" for a probable gap in a patent national legal framework, but to point those gaps in order that they can be further investigated and improved.

838 The cases were part of the sample analysis and are not going to be mentioned nominally for ethical reasons.

839 Aerotel Ltd vs Telco Holdings Ltd, uk-2006-ewhc-997-pat_20060503 [2006] EWHC 997 (Pat), 2006. See also a summary of the case in Wikipedia at: https://en.wikipedia.org/wiki/Aerotel_Ltd_v_Telco_Holdings_Ltd 
Appeals of England and Wales was broadly criticized by patent attorneys and experts for disregarding the EPC and the TRIPS Agreement on the criteria for patentability and excluded subject matter. ${ }^{840}$ The case illustrates discrepancies between different national patent courts in interpreting premises, concepts and guidelines given by agreements to which they are signatory. These discrepancies will be important cross-references in the way foreign documents will be read and considered in the decisions taken by the court and for the patent jurisprudence of each country, as the reasoning of this case was used in subsequent similar cases.

Patent documents are complicated to be translated. Due to their characteristics and to the crucial role translation can play in a court case, a translation of a patent costs more than translations of other types of documents. That's why a fee per line, in Europe, costs, on average, EUR $4,00 .{ }^{841}$ But should all these high costs be reimbursed to a foreign defendant, when the costs of the appeal proceedings are imposed to them in order that they can follow the litigation and can carry out a proper prosecution? According to a decision taken by the Court of Appeals in Düsseldorf, Germany, in 17 July 2009, the answer is 'yes'. The decision is to refund to the non-German speaking foreign party in severally $61.538,62$ euro together with interest to the amount of 5 percentage points over the base interest rate after $\S 247$ BGB. The Court considers the applicant's appeal against the decision to award the costs admissible and well founded. The decision applied in particular to the translation of the pleadings changed in the process, of documents, evidence protocols and expert reports as well as of judicial protocols, decrees and decisions. ${ }^{842}$

The District Court of Düsseldorf was not as lenient on a case moved by a German company against a defendant based in Slovakia. The Court decision determined that the addressee of a complaint cannot refuse to accept an order, due to the fact that it is written in a foreign language, if there is evidence that his language skills allow him to understand the document. The evidence found by the German Court was a letter, written in German, sent by the addressee (the manager of the Slovakian company) in the previous year to the decision. In view of the refusal to attend the complaint, the plaintiff asked for the claim to be decided by default judgment. ${ }^{843}$ The judgement's final decision determined that:

840 See supra note 839 . See: Aerotel Itd v Telco Holdings Ltd and others, in re patent application gb 0314464.9 in the name of neal macrossan rev 1: ca 27, Swab.co.uk [Website], Oct. 2006, http://swarb.co.uk/aerotel-Itd-v-telco-holdings-ltd-andothers-in-re-patent-application-gb-0314464-9-in-the-name-of-neal-macrossan-rev-1-ca-27-oct-2006/ (accessed 18 April 2018).

841 See: DE - Cost reimbursement for translation expenses / infringement, EPLAE Patent Blog [web blog], htttp://eplaw.org/ de-cost-reimbursement-for-translation-expenses-infringement/; see the case law: No name available (2009), Court of Appeals Düsseldorf, Germany, 17 July 2009, Docket No. 2 W 29/09, http://www.justiz.nrw.de/nrwe/olgs/duesseldorf/j2009/ I_2_W_29_09beschluss20090717.html (accessed 18 April 2018).

842 Ibid.

843 Name not available. District Court of Düsseldorf, Default Judgment of 12.01.2010, 4b O 286/08, 2010, https://openjur. de/u/456587.html ; see also: 'District Court Duesseldorf confirms rightful service of a patent infringement complaint without a translation', Kluwer Patent Blog, http://patentblog.kluweriplaw.com/2010/06/08/904/ (accessed 18 April 2018). 
The defendant is convicted to reimburse up to $€ 250,000.00$ in case of avoidance of an order fee to be fixed by the General Court for each case of the infringement, or alternatively as a punishable detention order, or a term of imprisonment of up to six months. In the case of repeated infringement up to a total of two years. ${ }^{844}$

When searching for patent cases involving big multinational companies known for actively enforcing their patent rights, the "level of internationalization" of the cases surprise in geographical vastness and variety and in the number of foreign documents (to each court) mentioned in the proceedings. For example, a search for cases whose parties are described through the keywords "Apple" and "Nokia" leads to 45 cases in six different countries (Japan, Germany, Finland, the United States, Sweden, the UK), including different courts from some of these countries. Most of those cases proceedings are only available in local languages and are difficult to access and understand to non-native speakers. It is frequent to find a vast combination of different types of documents (articles, submissions, other patent documents...) which the defendant party relies on as grounds of invalidity of the allegedly infringed patent. ${ }^{845}$

The complexity of international patent infringement cases grows when the number of parties is larger. In Adjustacam LLC vs. Amazon.com ${ }^{846}$, the plaintiff's complaints for patent infringement involved 58 defendants, mostly multinationals as big as Eastman Kodak, Amazon.com and General Electrics, for infringing the patent for a camera clip. Without entering the merit of the number of documents in different languages that such a case involves, there are some aspects, which underpinned the decision taken by the court, that are illustrative for the problem investigated in the present research. The Court refers to language operational claim construction, in cases where the applicant acts as his own lexicographer, as a matter to be reflected by the prosecution history of the patent. In the mentioned case, it is considered that the prosecution did not show that the patentee clearly disclaimed the proposed interpretation of the invention. ${ }^{847}$

The allegedly infringing parties relied on an argument based on the textual construction of Adjustacam's patent claims, referring to the actual meaning and interpretation of the term "hinge member". The decision on the preliminary proceedings is founded on comparative text tables and references to case law involving language issues:

\footnotetext{
844 Name not available. District Court of Düsseldorf (2010), Default Judgment of 12.01.2010, 4b O 286/08, https://openjur. de/u/456587.html (accessed 18 April 2018). Translated by this author.

845 The search was executed in DartsIP platform, which offers a search by parties, using key words for the companies' names. The platform is available at: https://app.darts-ip.com

846 Adjustacam LLC vs. Amazon.com (2010), Inc. E.D.Tex._6-10-cv-00329_1, Texas Eastern District Court.

847 Adjustacam LLC v. Amazon.com (2010), Inc. 6-10-cv-00329-120410-markman, Texas Eastern District Court.
} 
The parties agree that the "hinge member" is a "structural element that joins to another."The parties, however, disagree whether the hinge member must form a "hinge joint" or can include any form of "joint"(...) Plaintiff's proposed construction evolved over the course of the briefing. Plaintiff ultimately argues that the "hinge member" is not limited to hinge joints. Specifically, Plaintiff contends that the claims and specification describe the "hinge member" as both "rotatably attached" and "hingedly attached." Therefore, an object that is "rotatably attached" is necessarily broader than a "hingedly attached" object...848

Without entertaining the merit of the decisions taken on this particular case, all favourable to the defendants in all the levels of appeal in the involved American courts, ${ }^{849}$ the case may illustrate a potential gap in the patent system resulting from inaccurate examination. If the same case had been brought to foreign courts, the chances of misinterpretation of the text would be huge and difficult to follow. The inaccurate text becomes a main source of potential legal problems in distinct national courts. It carries, therefore, a problem of translatability, due to the fact that the patent system is global, and the patent text is meant to be translated into different languages than its original one and to be read by foreign players, for whom the original language may be unknown. Those gaps also indicate that patent trolls may be largely associated with language issues.

Chimsun \& Farmer ${ }^{850}$ give an example which is not directly related to translation, but may be the root of serious translation and understanding problems, when the granted patent will be searched as prior art. The case is also very illustrative about how a simple, short word, such as the preposition "to" can be the object of huge discrepancies and misunderstandings, proving that the problem of translation is frequently connected to the original text. The example given happened between two American companies, Chef America, Inc. v. LambWeston. The problem occurred "inside" the same language, but still configures a permanent gap in the patent system, after the patent is granted without the necessary attention to the impracticality of its text, which can be related to the sufficiency of disclosure or to the scope of protection. The decision of the Court, in this case, does not prevent the patent from being a potential cause for further problems. ${ }^{851}$

Exemplary of how much can turn on the meaning of a simple word is Chef America, Inc. v. LambWeston, Inc. (2004). The patent claimed a process for producing a dough product. Its claims required, inter alia, heating the dough 'to' 400 to 850 degrees. The court refused to read 'to' as 'at' (i.e., meaning heating the dough in an oven 'at' the 400 to 850 -degree range) - even though baking

848 Ibid.

849 See Adjustacam LLC vs. Amazon.com (2015), U.S. Court of Appeals, Federal Circuit ,Inc. fcg150917399_20150917; Adjustacam LLC vs. Amazon.com (2016), Texas Eastern District Court , Inc. E.D.Tex._6-10-cv-00329_814; Adjustacam LLC v. Amazon.com (2017), U.S. Court of Appeals, Federal Circuit 2017,Inc. fcg170705141_20170705

850 Op. cit.

851 Ibid. 
dough 'to' those temperatures burns it 'to a crisp', thus defeating the invention's purpose. It noted that the patent owner did not argue that the claim language was a draftsman's mistake and did not seek a certificate of correction by the PTO or by the district court, as was potentially available under Novo Indus. ${ }^{852}$

The case illustrates the risk of a ping-pong effect of a national patent system between the PTO and the courts. The courts tend to repeat the decision taken by the PTO, even when the examination was not sufficiently accurate to avoid subtleties as the one mentioned on the case. Errors like the one described above are common and can happen frequently, as patent texts are not written by language experts. The instances of appeal and courts should be neutral enough to reconsider the decision taken by the PTO.

It is undeniable that patent cases are becoming more and more complex in terms of language and translation issues. The same is true when it comes to the work of a patent attorney or a judge in cases involving patent disputes. An article of the British Journal "The Economist" describes the level of expertise necessary to attend the new demands of globalization and technology related to international legal cases..$^{853}$

The same article reproduces the opinions of a lawyer of famous patent cases. He describes the main layers of difficulty in international litigation involving patents or intellectual property, in general, since they specially relate to the right of demanding documents which are necessary to the case from the counterparty. For him, the first layer of difficulty is language. The second one is culture. Electronic communication, for example, may vary in a considerable way from country to country, which may turn a critical evaluation into a quite complicated work. The third layer described by the lawyer is local law. Some countries have little tradition of discovery, some have strict privacy laws. That can make the discovery task more difficult. The article also brings another relevant point: electronic communication has turned discovery into a very broad task. Lawyers have to deal with a huge volume of electronic material, most of it probably irrelevant for the case, for finding the right information. ${ }^{854}$

The demands of such cases have led to very profitable businesses. Complex patent cases are not meant for one lawyer or for small companies, because they demand a great level of expertise, which include linguistic and technical skills, and knowledge about local cultures. Therefore, there are big companies specializing in it and having massive sums in financial revenues.

The Economist mentions a huge case in which the firms - Samsung and Apple - hired a language-services firm called TransPerfect. The company used a system for protecting the privacy of communications, meeting both French and American Law. It also provided professional translations of documents from French, Italian and Spanish, which were relevant to the case, and were critical to guarantee victory to one of the parties. ${ }^{855}$

\footnotetext{
852 Ibid.

853 See: 'Translating and the Law: Legal Language', The Economist, Nov., 2012, available at: http://www.economist.com/news/ business/21566010-services-specialising-language-and-culture-are-demand-legal-language 
As discussed in Section 3.3, the world language-service business is estimated to be worth $\$ 34$ billion and is considered as a fast-growing business, as it grows at a rate of about $12 \%$ a year. It is impossible that one unique firm dominates it, in view of the complexity of services and to the extension of language varieties involved. Fees from legal work involving language and translation can be very high, when highly professional work is required. . $^{86}$

Specialized firms can work for both parties in the same case, as happened in the dispute involving Apple and Samsung. When Panasonic, which was still a struggling Japanese electronics-maker, purchased Sanyo, in 2009, the documentation required in the United States for approving it was so voluminous that the same language-services company, TransPerfect, made a profit of $\$ 25$ million in fees for translations that extended to around 100 million words. ${ }^{857}$

These companies may be also specialized in using "e-discovery" software. Although lawyers alone can get help from these systems to filter huge amounts of electronic data, in more complicated cases, involving international deals and lawsuits, such software is best used by legal technologists, who have to be skilful with searches by language. As legal translation requires high levels of accuracy, machine translation is not sufficient to provide the whole documentation and information translated from a foreign language in a complex patent case, where high quality professional aid is required. ${ }^{858}$ That sustains the need for deepening researches involving IP law and translation and, more specifically, patent infringement cases, and the influence of (human and machine) translation on their progress.

\subsection{Complementary results obtained through the interviews}

The purpose of writing this section is to complement the analysis of the cases presented in the previous sections with aspects observed during the interviews that were not directly related to the interview guides, but which may contribute to the discussion over translation and patent law. As detailed in Chapter 2, semi-structured interview guides were supplemented with the possibility of informal questions. In a context of more flexibility to discuss the object, the interviewed agents tended to provide extra information over facts and evidences which deserve attention, and which were confirmed by the analysis of the sample.

The reality of language aspects in patent prosecution, according to its main stakeholders (judges, attorneys and examiners), is still poorly exploited, sometimes taken for granted, sometimes seen from a dispersed or fragmented view, in scientific studies. In the case of the present research topic, it was easy to observe how clearly (although also 
how differently) the mentioned players understand the importance of translation to the patent system, and how this relation is still constrained to limited, not rarely obsolete, interpretation in scientific studies and in the legal patent scenario. The fact that the topic inspires resistance simply demonstrates that it still allows grounds for rich discussion.

Another important point is the asymmetry between the evaluations of the interviewed agents. In this sense, policy makers, judges, attorneys, examiners, translators and academics seem to inhabit different worlds, when it comes to their interpretation about the role of translation in the patent system, while, in truth, they represent different components of the same structure. In this regard, it was fruitful to combine these divergent interpretations in order to reach general conclusions related to the research question.

Patent attorneys with extensive experience in different jurisdictions tend to present the broadest standpoints of the whole process of patent prosecution in relation to language and translation. They could easily point gaps and provide examples of different types of cases involving problems with translation or with translation regimes. Patent judges and patent examiners also show awareness of the discrepancies between different patent systems and the importance of (especially machine) translation to the current patent scenario.

However, the theoretical interpretation of many academics and policy makers, representing the "thinkers of the patent system", not rarely persists in finding its roots in an old model of strong territorial borders related to language and translation in patent law. This model is still attached to an era of slow, costly, manual translation, and to a fragmented set of very localized legal interpretations, regarding patent law, in which different national structures could barely communicate with each other. As only recently disclosure was universalized by machine translation, it can be said that this era has just ended, and a new one of easy access to the novelty of inventions and a much more dynamic process of knowledge transfer has just started.

The average score given by patent judges and attorneys on the interviews for the influence of translation in court cases varied with the way this question was understood and interpreted. However, the first reaction was a loud "yes". All the interviewees agreed that translation plays a crucial role not only in disputes, but in the whole process of patent prosecution. Besides, an important aspect was raised in more than one interview. The level of this influence depends on the languages concerned. In this regard, when there are Asian and European languages involved the score given was from 8 to 9.859

The mentioned conclusion is relevant because Asian countries, specially Korea and Japan, are exactly where some of the most valuable patents are, as well as the largest quantity of them. Therefore, it is possible to infer that cases involving Asian documents and Western (especially English and German) languages get the highest influence by both machine and human translation, requiring access to translated documents from the phase of filing an application to the moment that a dispute is established. Translation 
is important for attorneys (and other supporting agents) to the phase of e-discovery, in common law jurisdictions, or for presenting requested evidence, in the case of civil law jurisdictions, and to carry out the triage of various types of documents. It plays a role in the whole process of underpinning a complex case and finding reliable arguments towards priority, validity or non-infringement. It can bias or influence the decision taken by a judge in various ways in an infringement case.

Attorneys also pointed out that translation is a burden in patent prosecution in Latin American countries. The case of Brazil was mentioned, with an emphasis on the following aspects: the backlog concerning the examination; the lack of reliability in the process of examination (some examiners are really qualified, offering a very accurate examination; some may be less experienced, which may result in a less accurate examination); lack of legal certainty when it is necessary to question the decisions of the patent office or to file a court case against its decision; backlog and bureaucracy concerning the office stages and the court stages; lack of reliability on the quality of translations provided by specialized offices. It is important to emphasize that all those stages involve high costs with translation, short deadlines to present those translations and general difficulties of communication. ${ }^{860}$

If a definite conclusion should be presented about the results of the interviews over how much translation can influence decisions in patent cases involving foreign documents, the best option would be a score of eight in a scale from zero to ten, as a general answer. This influence is not easily measurable, as it comes to languages and their subtleties, but it is easily inferred from the answers given by the interviewed stakeholders, which presented some variations over the interpretation of the question.

The influence of machine translated documents is a constant issue in patent prosecution and in each phase of the path followed by a patent document until the final decision in a dispute. It is more relevant than expected at first glance, and it provides some important conclusions, like the fact that improved machine translation leads automatically to an improved patent system and to more global justice related to innovation, disclosure and patent rights. The more professionalized each national (or regional) system is, the more it can also contribute to justice regarding patent law at the international level.

Another important conclusion refers to the possibility of increasing the allowance of English as an application language in national patent offices. English has undeniably become a lingua franca to the patent system, to a certain extent. Having it as one of the allowed application languages is a tendency and an opportune decision, which has already been taken by some countries. It is believed that it would also be an appropriate solution for peripheral countries in the context of the global patent system, like Brazil or other examples in Latin America, as the number of applications would certainly increase if the barrier of language would be mitigated.

European patent attorneys commented that the whole process of communication with Latin America involves translation and that it certainly makes it much more costly 
and slower than it should be. In this case, the necessity of hiring human translators monitored by the local agent during the whole process of prosecution represents a real burden. ${ }^{861}$ Solutions such as revoking the requirement for the translation of abstracts and titles at the application and extending deadlines during the prosecution would be welcome. Another solution would be to increase the chances of oral understanding and direct communication with the examiners in English or in another common language to both applicant and examiner. It would also be important to add office stages in which the applicant can request a review of the decision. One of the interviewed attorneys mentions the ease with which applications are filed in some countries, particularly in countries which accept English as a filing language, though observing that there may be still problems with the translation into English:

In the Netherlands, nowadays, if they are granted in English you only have to translate the claims, and you must make full translation of the description either in English... into English or Dutch. And it's the translation of the claims into Dutch. Yeah, you don't have to file anything at all, so it's just that you prepared it for granting, that's the way it is. That is, of course, a major aspect of translation. And for some clients I file the Dutch patent application in Dutch, but some (including Dutch) clients prefer to receive the whole application in English, because their patent involve many things, but they simply aren't that good in English, and especially not in the English way of reading patents, because if you read some of those patents, sometimes it's quite difficult to understand ${ }^{862}$

The co-existence of foreign parties and languages is already a part of the legal patent scenario in an unavoidable way. In Europe, due to the number of languages and different States with considerable cultural differences, this complexity is shown even more clearly. This multilingual/multicultural scenario features the nature of patent law and integrates patent cases through its reasoning documentation and all the other ways of establishing oral and written communication. English is predominant as an intermediate language in this scenario, too, as the most important language used in prior art search or as a target language for consulting prior art through machine translation. ${ }^{863}$ Patent attorneys also highlight the importance of the latest (and further) improvements of machine translation to the patent system, as clear through the statements below:

(about human translation) (...) they add all those translation costs, of course, they increase the difficulty, they increase the cost of your court case, and they increase the difficulties. If you have to translate everything to some exotic

861 Information collected directly through interviews.

862 Statement collected directly through interview 7, parentheses added.

863 Information collected directly through interviews. 
language, and if you get, of course... if you have high quality machine translation, that could make it easier to defend yourself. ${ }^{864}$

(About the need to learn foreign languages around only a decade ago) When I was working at X Corporation, I studied Japanese for a while. Why was that? There was a specific course to translate, only to read Japanese and to translate it into English. That was the only purpose. Not to speak it, not to write it, just read and translate. Because those days you couldn't have a translation of the Japanese patent in English, unless you paid a fortune. And I thought, well, maybe I can learn something about the Japanese language and might quickly scan it, at least to get a guess if it might be important, and then decide, ok, now I will ask a professional translator to translate it or not. But the Japanese is... we studied for half a year, more than half a year, it was almost a year, and then I can remember the teacher said: now you are as far as if you were starting now to study Portuguese, and everyone... what do you mean? And you are so far that you can look up the words on a dictionary. ${ }^{865}$

Well, I rely on that now as well. (ok) I can't do business in Japan if I don't have machine translation, it's as simple as that. If you get three Japanese documents cited against you, you have no clue what's in there. And you can't have everything translated, it would be too expensive. The Japanese would be particularly expensive. So, I definitely rely on machine translation. A lot!!! (Ok) And if those are better, I'm sure that the quality of my work would improve. ${ }^{866}$

(...) if the quality of the translations is improved, then the European patent system can rely on them. The mind-set of the people has to change. And the mind sets of the people will only change if the quality of the translations is efficient (...) But I think in the end we will rely on computer translations, (...) we also trust if I transfer money to you. But this is the same. We will trust in the system... or think about what bank is (...) because we are not transferring any money. We are simply doing some algorithms, I get plus five, you get minus five, and we believe this. And this is the same for language, I think. We have to believe that the translation is correct, or is $99 \%$ correct $(. . .)^{867}$

The text of the patent and its description of the invention being incomplete and unclear compromises its whole chain of disclosure, affecting the raison d'etre of patent rights. In this case, translation is also contaminated, which makes an unclear and

864 Statement collected directly through interview 23, parentheses added.

865 Statement collected directly through interview 16, parentheses added, name of the company omitted.

866 Statement collected directly through interview 23.

867 Interview 7. 
incomplete text a pervasive element of the whole patent system, necessarily influencing legal decisions. That makes the opposition and appeal stages very important moments on a patent's path.

While working only with the original sample, clean energy patents in Europe, the fact that only 4 relevant cases of patent infringement were found clearly shows that infringement actions are not frequent with this kind of patents and that patent rights are, in the analysed context, being successful in fulfilling their core function and in presenting a real systemic, integrated structure, in the sense presented in the first chapters of this research. For the analysed patents, the European patent system works in terms of preventing and avoiding further legal challenges. On the other hand, national courts are discrepant in terms of interpreting and deciding the cases.

Furthermore, patents are, in general, appropriately disclosed at the global level, as Espacenet provides easy access and quality machine translation to their content, the examination is accurate, and the Boards of Appeal is effective in avoiding inconsistencies that could be a source of subsequent court cases. This reality is different from the patent system in other countries and regions of the world. For example, at first glance, search for infringement cases in Europe and the United States, with no limitation of time period, and using as key words "solar" and "wind", 143 cases of patent infringement court cases were found in Europe, while 1,279 cases in the United States. ${ }^{868}$

It is also possible to affirm, for the same sample, that the number of opposition actions shows that the office procedures are efficient in terms of avoiding infringement cases as much as it is probably possible, since the case in the European system, where the examination is, in general, reliable and accurate, and where most of the textual problems concerning the patent are solved through the various office stages that precede and, in this case, prevent infringement actions.. ${ }^{869}$ Infringement actions put at risk the reliability of the patent system and should not replace the office stages of examination and appeal. That gives an even stronger argument to strengthen the European patent system through the settlement of the unitary patent and the unitary court and make worries and controversies over further linguistic issues, to a great extent, unjustifiable.

Patent judgements are highly technical, as shown by the analysed judicial documents. All the judgements are based on information that only a judge who is also specialized can properly deal with in order to protect the rule of law. The decisions are

868 The searches were carried out in DartsIP, available at: https://app.darts-ip.com . The discrepancy of the number of court cases in Europe and the United States is probably defined by the structure of each patent system, which includes number of grants, accuracy of the examination, strictness and number of stages in appeal proceedings. When the same search was carried out for Brazil, only 25 cases of infringement were found. The reasons why Brazil presents a very small number of cases is probably different from the reasons few cases were found in Europe. According to the interviewed patent attorneys who are used to file patents in Brazil, many clients give up filing a court case in the country due to reasons such as: backlog in Brazilian courts, lack of reliability of the system, especially when decisions of the patent office are questioned, cost of the actions (especially because of translation costs).

869 In interviews with Judges and other important players from the IP environment, it was mentioned that the reasons why there are few court cases against the Brazilian INPI may be related to an exactly opposite reason. The legal system related to patents in Brazil is not specialized, counts on a disorganized structure and a huge backlog, which affects not only the process of validation, but the decisions of patent holders to file court cases. 
based on technical arguments, which include theoretical approaches, graphs, equations, etc., requiring a high level of specialized knowledge. ${ }^{870}$ At the same time, the documents show clearly that the legal environment involving patents is an international and multicultural environment by nature. It is not possible to avoid this characteristic. Patent attorneys and judges of patent cases necessarily deal with this multilanguage reality and should be highly prepared to take informed decisions among all this complexity, which entails broad technical knowledge and linguistic/cultural knowledge.

In this sense, the European patent system can be considered as a highly developed, professionalized one. The fact that patent attorneys need to pass an exam that involve technical, legal, and linguistic knowledge makes the system very reliable and the work done by attorneys, which includes the first steps of patent writing and the decision to file or not an application, coherent with the aims of patent rights. This differs from countries where patent attorneys do not need to be certified, and normally only have an education in law, sometimes even without any formal background in intellectual property law.

In some countries, patent attorneys learn the process of patent prosecution only through practice, as most of the university degrees in law do not focus on intellectual property law. In many countries, patent attorneys do not need to have a background on the technical field. In the United States, an examination is required for being certified as a patent attorney. In Brazil, or in other Latin American countries, no examination or any proof of qualification is required to work in this specific field of law. For the present researched topic, this makes a big difference for the quality represented by that particular patent system as part of the patent system at the global level, and leads to the necessity of more integration and harmonization. Foreign attorneys have to rely on local agents, also in terms of providing accurate translations into local languages. That may change the legal path of the patent document, influencing the content of the office actions and the results of court cases. If a national patent system does not provide the necessary level of accuracy to the process of patent prosecution, it will directly affect the integrity of the global patent system.

European attorneys comment on the requirements to become a patent attorney and on the relation of their profession with language and translation skills:

So, the patent profession is not a cross section of the known world, I would say. It's usually people with an international focus and, you learn to deal with different cultures. And that's also something that I had to learn as I started working as a trainee patent attorney. ${ }^{871}$

It's hard to all speak the same language around this world. But it's not just language, it's also, like I said, it's culture. And I see in the different countries, yeah, should I say, different patents getting granted. Different countries also have

870 The proceedings of the cases present considerable differences in terms of the legal patent culture of each country. The more specialized the system is, the more the decisions tend to be clear, transparent and well grounded.

871 Statement collected directly through interview 19. 
a different patent culture. And that's not just the language, but it's also cultural, and that's something that you also have to understand as a patent attorney, when you are working with your colleagues abroad, getting patents granted for your clients, for all your clients abroad. For example, if you see that, if you look at Japanese patents, they are usually very detailed, and also the claims are also directed to a tiny detail. That's how they do it there..$^{872}$

(...) for the EQE, you see that the non-native speakers, the Dutch not so, because they... we learn from a young age, we learn our languages in school, so... as a small country we have a lot of "abroadness" (sic), but specially from Southern Europe and from Eastern Europe the people there, they have more trouble passing the EQE, because of the languages, because you have your exam paper in English, French and German, and you can reply in your language, as long as it's a language of a member state (...), I often have like 3 pages or something, maybe five including drawings, but you have to read 20 pages. And if you don't know, if you are not fluent in the language, it is really hard. ${ }^{873}$

(...) just this morning, in fact, I had a set of claims that were translated for granting - that were translated into German and French, and I speak German possibly well, but my French is worse, so in the German claims I noticed that one of the verbs, it was ok but it wasn't perfect, would have been (...) if it had passed through, it would have been ok, but could be better. So, I spoke to... I changed to whatever it should be, and that was it. In the French one, I have corrected some errors as well, but it was an error, they really had to make an error, for getting it fixed or something like this. I definitely... what I can check, what I get from translators, of course, I can see more in German than French. ${ }^{874}$

The most common pair of languages appearing in the same case, for the chosen sample of patents and in European courts only, is English and German, both in opposition and infringement cases. This information was given by the interviewees and confirmed by the sample analysis. A frequent situation was to find the complaints in German followed by the main proceedings (substantive decisions) available in English in Darts-IP, the database mainly used. Just one case which mentioned foreign patents officially presented a translation for one of these documents. ${ }^{875}$ Most of the cases involve companies which are foreign to each other, and there are cases whose documents are brought in more than one or even more than two original languages. ${ }^{876}$

\footnotetext{
872 Interview 19.

873 Interview 19.

874 Interview 23.

875 Data collected through DartsIP, according to methodology explained on Section 2.4.

876 Ibid.
} 
The whole set of Regulations concerning the European Unitary Patent Court does not (and could probably not, in any case) mention how the main proceedings or substantial decisions should refer to foreign documents or foreign patents. Since the main body of the proceedings is in one of the EPO's official languages, would it be preferable to refer to a text in the same language used on it or to make direct transcriptions of the analysed documents? Could there be a common rule in this sense and on how to consult a foreign document that would be suitable to the use of all the judges? Until the moment, the language regime of the Unitary System is not clear in regulating those aspects. It seems that the legislators and experts working for the Unitary System count (and are probably right in doing so) on a self-regulatory process after the new system enters into force. ${ }^{877}$ When it happens, there is a lot to be done in terms of language and translation regulations to make the system clear to its users.

It seems that the whole educational background of the attorneys and judges, together with their nationalities and their own history in dealing with foreign languages can play a role in patent prosecution. As the Unitary Court is the first supranational court dealing with this matter, the results are unpredictable in this sense. If one observes, as shown on table 19, that each national system (or each court, or even each judge) has different tendencies in dealing with the multilingual complexity of the patent world, it is difficult to tell how a supranational court, with judges and officers with different national origins (different legal and IP cultures and different language backgrounds) will find its ways. It is also difficult to predict to what extent these cultural and linguistic aspects can be harmonized or regulations can be more precise in determining guidelines. In any event, to the date, they are also unclear (in many cases, outdated) in most of the national systems. ${ }^{878}$ Patent attorneys and judges expressed their concerns about the Unitary System:

That's going to be fun. Because nobody knows how to do it. Yeah, I heard from colleagues who went to mock oral proceedings, mock unitary patent court, mock proceedings... 'yeah'! It depends on who does the mock trial. The Germans made it look very German. And there is of course also a big language issue. I haven't really studied what the requirements are, but if you end up before the Romanian or the Bulgarian section, yeah, you probably can do some English. (I understood you can apply in any of them). Yeah, but I don't know them (in a court case, I mean). How proficient those judges will be in English if I go to a court and I have a Romanian Judge or a Greek Judge, and they have an experienced guy from Germany, and I want to speak English. (...) Yeah, but my approach is that we first wait and see until the day is there. ${ }^{879}$

877 The conclusion is inferred from information collected directly through interviews.

878 The previous Section discussed a case in Brazil in which the general language regulations for the national public administration were applied to a patent case, not considering the peculiarities of the process of patent examination and the frequent use of machine translation to analyze prior art. See Section 7.4.

879 The statement was collected directly through interview 19. 
What we have now is purely national courts, in which all the judges speak the same language. So, there is no issue if you have to deal with documents in national languages. Every judge will understand the documents and there is no issue of translation. In an international court, it changes, because there you have an international panel (...) and, by definition, you have a panel with not the same language expertise. And that may create a difference in the sense that, between the judges... some judges may be English native speakers, some others may not... Well, don't take English as an example, because most of the patent lawyers must be fluent in English, but it is not the same for French, for instance, or German. But for the non-French judges, French will be a problem. They will understand most of the documents, but to conduct a hearing and to really understand the subtleties of the arguments... that may be difficult. (...) it is not necessarily the case that all the judges will have the same expertise in the same language. The interpretation issues may not be the same for all judges (...) if you translate everything in language $A$, for judge $A$, and in language $B$, for judge $B$, and in language $C$, for judge $C$. And then they have to confirm and decide what is the correct interpretation. And they don't have a common language to deal with. And that may cause difficulties from the practical point of view, maybe in the interpretation of claims, if you don't share one language in which you can say, ok, it's clear in language A, for instance. ${ }^{880}$

One problematic aspect, which I think hasn't received the attention that it should have is that at the moment, if a small company, a medium size company, I go to the EPO, I get a patent granted, I validate it in the Netherlands, for example, because I'm located there and I have to set it in Germany because I do business there a lot. Just those two countries. Then my competitor sees that I have this grant here, a software patent, let's say, in my case. He files an invalidation sue. Because, before its straight invalidation, the court case will go to the central court, which is in Paris for software cases. So, my local small company will now be hold off to Paris where there is no business, there is no legal representative. We have to hire a French lawyer; he has to do a French court case. A huge investment. And if he does not do it, definitely he is going to lose his patent. Previously, if his competitor attacked him, he would either end up in the Netherlands or he would end up in Germany, two countries in which he has a presence. So, for that particular scenario I think that might be a problem. ${ }^{881}$

880 The statement was collected directly through interview 20. The nominal references were altered to general ones in order to preserve the anonymity of the interviewer.

881 Interview 23. 
(...) and if the patent gets killed in Lithuania, then it's over, because it is a unitary patent. This is a problem. So many people fear that, not Lithuania, I think, because I like the word very much, but it can also be an Italian court or if they can kill the patent by whatever action the unitary patent dies, and if you today have a court case in Italy, and the patent is revoked, then it's revoked in Italy. And this of course has an influence in the courts of the patents in the countries, but it's still alive, and if nobody fights it, it stays alive. And this is of course something that people are fearful about. ${ }^{882}$

(...) I can pick any EU language, including Spain (sic), Spanish, for example, which does not even cooperate. So, you could just look at the list of prices of the translation companies and pick whatever language which is cheapest, and the last time I checked it was Romanian. So, it would be at least most cost effective for my clients to get a grant and file a Romanian translation, because it is... assuming you don't want to do a machine translation I don't want to go that far... so I use Romanian, which is much cheaper than some other languages. I think that's weird. ${ }^{883}$

(Do you think the unitary system can negatively affect your profession?) Yeah, in some ways, we just had a big discussion with some colleagues from our office and with other offices as well. You just see a shift in business model, for those who need, because, yeah, there will be less translations, there will be less fee payments for annuities. Yeah, so where you make your money is going to change. And it will be... and that trend has been ever since l've started as a patent attorney. The money you make for your appeal hours from your local clients, that's what's going to save you in the end. ${ }^{884}$

Although the Unitary System raises doubts and insecurities among the main users of the patent system in Europe, it is clear that this kind of interaction proposed by a supranational court is singularly beneficial and relevant to the development of the patent system at the regional and the global levels. It can, by its nature, produce emblematic results that will make patent rights advance to more legal certainty, control and efficiency, as was the case of the settlement of the European Patent without the unitary effect. That happens because the whole idea is based on the principle of harmonization and the notions of interaction, integration and knowledge exchange, substantially crucial to such an internationalized and complex field of law. The Unitary Court may also be a starting point also for harmonizing patent related legal proceedings and to get to a consensus over the cultural and linguistic diversity that characterizes the European patent system.

882 Interview 7.

883 Interview 23.

884 Interview 23. 
For illustrating the discrepancies related to the way courts can deal with foreign documents and translation, some of the differences identified through the sample analysis and also brought up during the interviews will be summed up. At least four different situations in dealing with foreign documents in Courts' proceedings were identified. These situations are portrayed below and associated with the type of relation the court carries with the idea of the patent system as an international system. The possibility of having highly "multilingual courts" and the other possibilities for the use of languages on legal proceedings are described in the table below.

Table 19: Possibilities of dealing with foreign documents in patent courts (predominant situations)

Monolingual documents 1: The court only adopts one official language. The court only admits documents which are translated into its official language.

Monolingual documents 2: The same situation of monolingual documents as 1, but the case can directly mention foreign documents written in foreign languages to both the court and the parties.

Monolingual documents 3: The country has more than one official national language and the court, according to its language regulations, elects one of the official national languages of the country, for instance, depending on the region. The documents will be translated into the selected language. Some language regimes allow that the parties elect the language(s) used.

Multilingual documents: The documents are cited in their original language, which can be in three or more languages that are frequently used by the court. Many of the judges are fluent in these languages, and the court prescribes or allows their use without the obligation to request a translation.

Source: Elaborated by this author based on the results of the content analysis and interviews

Finding out which position each national patent system occupies can tell a lot about the efficiency of this system and its level of internationalization, either if it is through an integrative model, as, for example, the Dutch system, or if it is in a hegemonic model, as could be portrayed by the American or the British systems, due to the importance of the English language to the patent international scenario. This analysis is not intended to be exhaustive, as a small sample was the base to propose this categorization. Anyway, through the contact with the sample and the interviews, it was possible to clearly identify that national patent systems and national "patent courts" (or courts in charge of patent cases in a national level) also carry their peculiarities in terms of language and translation. It was then possible to propose the following categories for the four situations described: 
Figure 41: Classification of national patent system in terms of their interaction with foreign documents

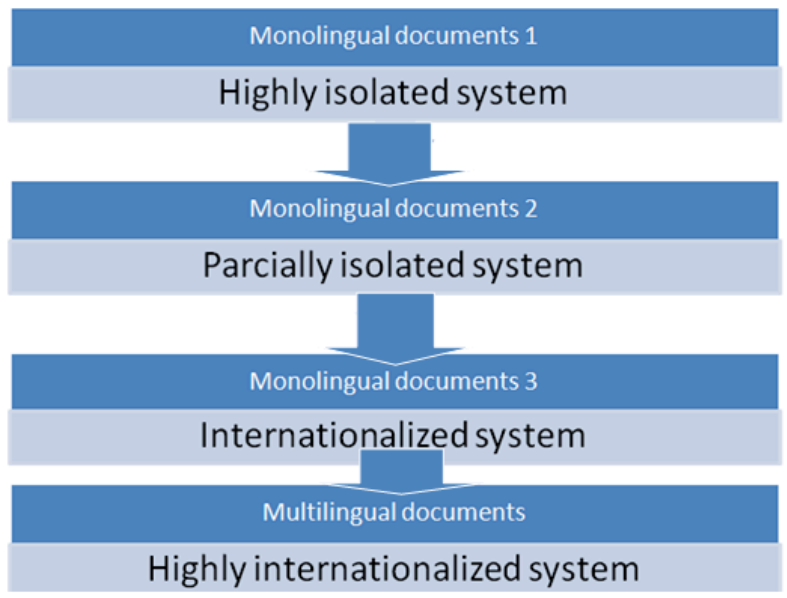

Source: Based on the sample analysis of patent cases $^{885}$

Through the observation of these different ways of dealing with prior art and their reasoning documentation, it is concluded that there are different standards for national systems in integrating to the international scenario represented by the global patent system. If these national patent legal systems differ, if their courts are organized in distinct ways, if they have a predominating model of coping with the global system and dealing with the whole set of grounding documentation in the process of litigation, that clearly gives different results, no matter how diffuse or how specific these effects can be. Those cultural differences can, for example, bring impairment to the case, harming one of the parties or demanding a different type of behaviour from the users of this or that system.

The tables above were drawn with a didactic purpose, as those differences could be much investigated and described more accurately. The idea is to make it clear that patent law presents considerable divergences in terms of language and translation, and associated cultural aspects, in dealing with the large amount of multilingual information that characterizes the structure of the patent system today.

For more detailed results about the integration between national legal systems and the global patent system, further studies are recommended. The goal of the present study is not to exhaust this issue, but to call the attention to both its existence and importance in analysing patent law from the perspective of language and translation. The sample of court cases analysed just confirmed what was already an assumption obtained during the interviews and step 1 of the methodology. ${ }^{886}$

885 See section 2.4 for the methodology used.

886 See Section 2.4 . 
Below follow two tables that show the answers obtained in opposition and infringement cases for the analysed aspects. There are interesting aspects to be observed both in opposition and in infringement cases. Some examples of these aspects, in opposition cases, are: the number of cases bringing lack of disclosure as a basis for opposition, the number of cases bringing translations enclosed with the complaints document or the number of parties representing companies operating in different countries. In infringement cases, it is important to consider, among other factors: kind of decisions taken (infringement allegations accepted or not, types of penalties imposed, role of foreign prior art documents), citations or transcriptions of foreign documents and languages used in these cases, differences in language regimes and in the way they are applied to the proceedings depending on the Court's language policy.

It is important to emphasize that, although the results of the chosen sample do not necessarily apply to other types of patents, they bring important information about the research object, which was complemented by the cases brought by the attorneys. Notwithstanding, some of these aspects should be the object of further, more detailed studies, that could include other national or regional patent systems especially considering different ways of managing patent foreign documents according to national law. The tables below are important to describe the efficiency of the European system in avoiding opposition and infringement cases, as, among more than 10,000 applications concerning solar and wind energy patents, the number of opposition and infringement cases is relatively small.

Table 20: General results of the content analysis of the opposition cases

\begin{tabular}{|c|c|}
\hline \multicolumn{2}{|r|}{ OPPOSITION CASES } \\
\hline Parties & 7 from the 10 cases have parties which are foreign to each other \\
\hline $\begin{array}{l}\text { Direct reference of translation or } \\
\text { language issues; }\end{array}$ & $\begin{array}{l}\text { Just } 3 \text { of the } 10 \text { cases documents present direct reference to translation. } \\
\text { Most of them refer to documents which are written in other languages in } \\
\text { the same language of the proceedings. }\end{array}$ \\
\hline $\begin{array}{l}\text { Presence of foreign documents as } \\
\text { grounds of the opposition }\end{array}$ & $\begin{array}{l}\text { From } 10 \text { cases, } 8 \text { of them clearly present foreign documents as evidence. } \\
\text { The other } 2 \text { would require deeper research to understand if there is or } \\
\text { not any prior art reference in foreign languages. }{ }^{887}\end{array}$ \\
\hline $\begin{array}{l}\text { Allegation of problems in disclosing } \\
\text { the technical information }\end{array}$ & $\begin{array}{l}6 \text { cases allege lack of sufficiency of disclosure of the opposed patents. } \\
\text { These allegations are reasoned accordingly to Art. 100-b of the EPC. }\end{array}$ \\
\hline Main decision (s) types & $\begin{array}{l}\text { From the } 10 \text { cases, } 5 \text { did not show any decision yet, } 3 \text { decided for } \\
\text { revoking the opposed patent and } 2 \text { for maintaining it. }\end{array}$ \\
\hline
\end{tabular}

Source: Based on the sample analysis and on Article 100 of the EPC 888

887 The search was carried out in DartsIP.

888 EPO, The European Patent Convention, Art. 100. Available from: https://www.epo.org/law-practice/legal-texts/html/ epc/2013/e/ar14.html, see more details on the language regime of the EPO on Section 6.2. 
Table 21: General results of the content analysis of the infringement cases

\begin{tabular}{|c|c|}
\hline \multicolumn{2}{|r|}{ INFRINGEMENT CASES } \\
\hline Parties & 2 of the 4 cases have parties which are foreign to each other. \\
\hline $\begin{array}{l}\text { Direct reference of translation or } \\
\text { language issues; }\end{array}$ & $\begin{array}{l}2 \text { of the cases make direct reference to foreign texts, and } 2 \text { don't. One } \\
\text { of the main proceedings documents is written in } 3 \text { languages: Dutch, } \\
\text { English and German. }\end{array}$ \\
\hline $\begin{array}{l}\text { Presence of foreign documents as } \\
\text { grounds of the infringement }\end{array}$ & $\begin{array}{l}\text { From } 10 \text { cases, } 8 \text { of them clearly indicate foreign documents as evidence. } \\
\text { The other } 2 \text { would require a direct contact with the judge and the } \\
\text { involved parties to understand if there is or not any foreign language } \\
\text { reference. }\end{array}$ \\
\hline $\begin{array}{l}\text { Language variation on the analysed } \\
\text { documents }\end{array}$ & $\begin{array}{l}\text { Only one of the cases presents all the documents only in English. } \\
\text { Two cases present their documents in two pair of languages: French } \\
\text { and English and German and English. The last case presents its main } \\
\text { proceedings document written in three languages, as it makes direct } \\
\text { reference to foreign documents in Dutch, German and English. }\end{array}$ \\
\hline Main decision (s) types & $\begin{array}{l}\text { From the } 10 \text { cases, } 5 \text { did not show any decision yet, the other } 5 \text { cases } \\
\text { involved decisions related to the validity of one of the patents. } 3 \text { of them } \\
\text { decided for revoking the patent subsequently granted. }\end{array}$ \\
\hline
\end{tabular}

Source: Based on the sample analysis

The most common situation is that the document makes reference to evidence documents in the main language of the proceedings, even when their original language is diverse from it and when a translation was not explicitly presented. As referred to the table above, one of the infringement cases found is written in three languages (Dutch, English and German). The references are not translations, but direct access to the original texts of evidence documents. Although rarely, this is a situation that can occur in such cases, especially in Courts of societies (and legal environments) characterized as multilingual ones, which is the case of the Netherlands.

The more fragmented the patent system can be considered, the bigger the chances of notorious discrepancies, as the ones found on the decisions related to EP96930129(A), as, for instance, in infringement case Wobben vs Siemens (2015). ${ }^{889}$ International agreements and supranational solutions are the best response for these discrepancies, which represent a risk for the integrity of the patent system and related systems. That is incongruent with the function of law as a promoter of common good and of the fair resolution of disputes.

National or regional systems can differ considerably in terms of their organization, regulation and structure. If one compares the legal structure of the patent system in South America, in the United States and in Europe, for example, many differences will be found in terms of language regulation and associated legal praxis. One important divergence between the (Northern and Southern) American, and the European system is the fact that, in the first ones, the courts are not specialized, and the attorneys in charge of patent 
related cases are not required to have a technical education in the matter, but to have law as their main educational background. When necessary, they count on the support of experts in the matter, which can be limited in some countries. ${ }^{890}$

What is clear on the case law documents in Brazil is the fact that the discussion carries a much less detailed technical base than on the cases analysed in Europe. Another important divergence is that the competent Court, in Brazil, tends to confirm the administrative decisions of the Brazilian National Patent Office, without discussing their validity. This can be due to lack of enough technical support to review the decisions and to the fact that the system is not prepared for dealing with the required technical information. ${ }^{891}$ Another noticeable distinction is the role of the Brazilian National Health Surveillance Agency (called Anvisa in its abbreviation in Portuguese), from which is required an examination of prior consent to medicament patents, which allegedly competes with the role of the National Patent Office, creating a problem of legal uncertainty to the users of the Brazilian legal system, when it comes to this type of patents and increasing the backlog and the difficulties with bureaucratic proceedings. ${ }^{892}$

These comparisons are useful for understanding the difficulties of working with fragmented systems in a field which should respond to global expectations. The fact that the patent system is still very diverse is a source of the majority of its inaccuracies. Some countries still don't have a robust legal structure to adequately fulfil the requirements of the complexity demanded by patent rights, which can give rise to different ways of corrupting the integrity of the system, as through patent trolling. Those gaps and inefficiencies may also lead companies to give up protection or to avoid a court case in some countries. In this sense, the comparison between different national or regional systems can be very illustrative. Patent attorneys and patent examiners observe some discrepancies and gaps that give rise to inconsistencies in national patent systems or that may create difficulties in the Unitary System in Europe:

(...) so, in the Netherlands it's one Court in The Hague, which deals with these patent cases, because in this Court they have judges, which are lawyers, but with technical knowledge, so at least they can understand the arguments, because the arguments are often technical. For instance, in the United States, this is not the case, which simply means that in the morning, as a judge, you

890 In Brazil, the requirements for acting as an auxiliary of Justice Expert are defined by art. 145, §§ 1 and 2 of the Civil Procedure Code, that requires university level with enrolment in class competent body, and expertise in the field to which the matter that required their support comes. The mentioned code is available in Portuguese at: http://www.planalto.gov.br/ ccivil_03/_ato2015-2018/2015/lei/l13105.htm

891 The information was collected and discussed through interviews

892 The interference of a National Health Surveillance Agency in the intellectual property legal system has no precedent in the Brazilian or in the international law. For this information and for the current discussion involving the roles of Anvisa and INPI in the examination of drug patents in Brazil, see: M. Trigo and V. Trojan, 区A anuência prévia da Anvisa em relação à concessão de patentes e sua causa de conflitos jurisprudenciais com o INPI区, Revista Jurídica, n. 121, 2016, available at: http://revistavisaojuridica.uol.com.br/advogados-leis-jurisprudencia/121/sumario.asp See also: S. Tojal and P. Pessôa, A Anuência Prévia na Concessão de Patentes de Medicamentos e a Regulação Econômica da Indústria Farmacêutica, Revista de Direito Sanitário São Paulo, v. 8, n.3, PP. 148-165, 2008. 
can do a death sentence and then in the afternoon you do a patent case. So, in the United States, in the court system, there are not judges who do only patent cases. (...) There are proceedings, and you are simply assigned to a certain case as a judge, and, in my opinion, it's better if you have judges which have a legal, a legal... of course, they are legally qualified, but they have technical knowledge as well. And, in addition, in many cases, you have a jury, and the jury is also full of people who are very nice people, but they don't... aren't technically qualified, and they are of course not also legally qualified, and then they have to judge the case. So, if you bring good arguments and it sounds good then you have a good chance to win, but this is the American system. ${ }^{893}$

(...) And, in the end, you have to translate (...) translate the claims into French and German, and there is a provision somewhere in the law that is no longer used that if you translate the claims in a narrower way in French, they have a narrower scope of protection, then you are bound by this in French. You understand? (...) here there was an influence (...) I remember when I was a patent attorney in yyy, that we had to check the French translation to see whether the scope of protection was the same, because we were told that if in France something is wrong with the translation or a wrong word was used then you are bound by the words in French. ${ }^{894}$

(About the local branches of the Unitary Court) And I don't know what the judges will do. Perhaps the judges in Lithuania only look at the Lithuanian text. And not at the English text, the original English text $(. . .)^{895}$

(About language strategies in patent applications) That's probably the majority, I don't know. I don't know what the percentage is, but perhaps... how many European Patents are granted in English, is that 70, 80\%? (...) But I think it's huge. But there is another side of the court, I think, certain companies on purpose don't use English. I think I told you this. Companies like www companies, or Pharmaceutical companies, they choose French (...) to make it difficult to reach the documents. This is on purpose $(. . .)^{896}$

(Can abad translation, for example, influence the results of an examination or of a court case?) Yeah, of course if you ask about it in the validation process, you have a gross problem in the claims. Due to bad translations, you have a narrow scope. Then... well... then it might be a problem, because they may rely on this

893 Statement collected directly through interview 7.

$894 \mathrm{lbid}$. The name of the mentioned company was omitted.

895 Statement collected directly through interview 7.

896 Interview 7. 
translation... In many cases you can... if you notice it, file an amendment, an amended translation, but the time that you filed the wrong translation and then right translation may influence those parties who thought... well, I'm allowed to do that because it is based on the translation. And then you have a problem. So... a translation that has been made by a man or by a computer, in both cases, can have the same problem. ${ }^{897}$

The patent system shouldn't become "a McDonald's", where you easily grant all the patents. The examination process is very complex. It requires time and knowledge from the examiner. It is not for anyone. You become a type of linguist as well... I have the sensation that the American system is very superficial. And this is a problem. The Japanese examination is very precise. They... the examiners... have a lot of autonomy. That makes a difference. In some offices, like (...) the load of work is too big for the number of examiners. This cannot work. The problems should be solved during the process of validation, not in courts. If it's all in courts, it starts to favour big companies only. It follows another logic, not the one of justice. ${ }^{898}$

For some reason that I don't understand, Japanese patent examiners are better than us. I don't know how, they always find extra prior art. ${ }^{899}$

The office, they write their letter in Spanish (for Mexico) or in Portuguese, in the case of Brazil. They send it to me, or to the agent. They have it translated into English. They send it to me. I have the letter. We respond the letter in English. It goes back to the agent. They translate it again. They translate it again into Portuguese. There are a lot of translations!!! If that could be, if the agent could directly forward the Portuguese text to me, I could work on that. That might actually not be very good for a local agency. If the office would accept all the documents in English, yeah, it would definitely make it easier. So, I have one Mexican case here... it is very... Also for people in Brazil, it would be easier to work and offer their services to European companies, but...900

\footnotetext{
897 Interview 23. The question was kept in parentheses for didactic reasons.

898 Statement collected directly through interview 27.

899 Interview 5.

900 The statement was directly collected through interview 19 . The parentheses were added. It seems that the communication with the National Patent Office in Brazil is difficult and bureaucratic, as the whole process has to be intermediated through the local agents, with translation costs to each and every communication, short deadlines to present responses to the office actions, and, sometimes, according to the attorneys, bad quality translations. Many offices in the world allow a direct communication between the Office and the applicant. This communication happens very often in English or in a language that both the applicant and the examiner master. The model of communication followed by Brazil, Mexico and some other countries in Latin America should be updated, considering the current structure of the patent system. It is a great burden to potential applicants and a reason why many foreign companies give up applying for patents in those countries.
} 
As shown on this chapter, national discrepancies concerning language and translation aspects can represent critical gaps in the global patent system, creating legal uncertainties and burdens for its users. Problems such as the ones described above (difficulties in communicating with some patent offices, gaps left by the accuracy of the examination in others, differences in finding prior art, etc.) may bring huge inconsistencies to the enforcement of patent rights in some countries, corrupting the image of the whole patent system globally and creating tendencies that are undesirable to patent law.

As defended on the present research, translation is the basis of the patent system, but not to be forgotten is its global, international, digital, multilingual structure. The patent system has changed radically, in the last decade, due to the improvement of machine translation and to the use of digital tools and platforms that can facilitate the searches and the flow of communication between officers, companies, legal professionals, translators and other users of the system. The volume and variety of information, together with the increasing ease on accessing and understanding it, also plays a role.

However, the system needs to be understood and exploited as such, following the pace of these fast changes, requiring some transformations of its use and interpretation and on the mind-set of its main players in terms of updating national regulations. In this sense, the difficulties in communicating with some offices is unjustifiable, since it is clear that it characterizes old features of a bureaucratic, analogic structure. It is also indefensible that patent offices are not able to offer an examination accurate enough to avoid appeals, and, when appeal was unavoidable, appeal proceedings strict enough to prevent unnecessary court cases, bringing disputes that could have been solved inside the office's structure.

All those changes are connected with the flow of communication between the offices, with the level of integration of each national patent system to the global system and to the original justification of its existence; namely, disclosure. It all requires a globalized vision and a fast, efficient use of the new tools available. The statements of patent attorneys and examiners are probably the best testimonies of those fast changes and of the challenges and advantages related to the current structure of the patent system.

(On the increasing use of machine translation and the possible changes resulting from the Unitary System) Companies that rely on translation for their business... they could have problems. Would you see that the Portuguese, Spanish... Spain being the prime example, of course. Many are - I'm not sure about the court case, but certainly about the validation part. Spain requires a full translation. There are more patents going in than going out. So, a lot of the patent work going on there is based on translations. And that disappears. That isn't nice of course. For us, we have relatively few translations, because we also have... outgoing patent work. And the translation that we have, we outsource. So, if it disappears, of course the cost goes down and... yeah... only makes us 
more competitive. So, for us it wouldn't be a problem at all, but if you rely on translations for your income, it will definitely... ${ }^{901}$

I had the occasion to machine translate some German. And I was positively surprised about how much better the quality of that translation became in the past years. That's spectacularly much better. If that tempo, if that speed goes up, then maybe I do have to worry about certain areas in machine translations, so it's something that is not a problem at the moment, I guess, but... ${ }^{902}$

About machine translation, also sometimes we have now fully available multiple machine translations, and they are not equally good. So sometimes it happens that I get it, for example, I get a translation done by my agent, as machine translation, using whatever they use for it. I don't know. And then I can just as easy cut and paste the same text into a google translate, or WIPO has its own too, and see if it's any better, and sometimes it is, sometimes it isn't. ${ }^{903}$

(For translation, in general) It definitely has an impact. If you could avoid this, it would reduce costs a bit, I guess. I have no idea how much of percentages translation costs are in Court cases. (...) Depends on the language, right? A Dutch German translation is much less expensive than a Dutch Japanese translation. Another thing is, of course, if you have a European patent which is granted, and you want to get it validated in European countries, you need to get..., every country has its own requirements, some countries require you to have everything translated like Austria, Belgium. Some countries want you to translate the claims, like the Netherlands. Some countries don't require anything, like Germany. ${ }^{904}$

I think that the machine translation systems have expanded the scope of searchable documents in my office. Even if its quality does not meet the examiner's expectation, anyway, they help examiners to search and understand the prior art documents written in foreign languages..$^{905}$

Another important point brought by patent examiners is the fact that the advance of machine translation should be combined with the improvement of searching tools and platforms. There is no point in easily accessing any patent document in the world, if the filters or possibilities of search are still very limited. They mention that searching platforms

901 Information collected directly through interview 23. Parentheses added.

902 Information collected directly through interview 23.

903 Ibid.

904 Ibid.

905 Interview 14. 
are still incomplete in translating titles of Asian patents, and that it is not always possible to easily understand the content of the patent only through the translation of its title. One examiner observed that searches still offer a monumental volume of global information which is irrelevant in technical terms. He suggests that the searching systems have still a lot to be improved in this sense, as there are many possibilities of new filters.

Undoubtedly the translation machines have expanded the universe of searchable documents for prior art searches by patent offices. In the past, in my office, few examiners have cited Chinese documents as prior, and nowadays this is much more common, because of the availability of such texts in English by translation machines. However, we must take into account that it is not enough to have the translations, it is necessary to advance in the mechanisms of search so that this gain is not neutralized. When you increase the number of searchable documents, you also have to advance the search engines, so that it continues to achieve good results. Even considering advances in translation machines and search engines, I suppose that, in some cases this will bring into the search a universe of documents considered less relevant. For example, even if the Zambian documents have all been translated, I think the prior art search would gain little in having such documents in certain areas, because there is no technological interest. That is, I understand that perhaps there is interest in Zambian documents in a few technological areas... The thesis that search engines will make all the documents available for search seems unrealistic to me, seems to me to disregard the technological relevance of many of these documents. ${ }^{906}$

\subsection{Conclusions and correlation of the chapter with the research question}

Together with Chapters 5 and 6, Chapter 7 constitutes the hard core of this thesis, bringing up the results of the empirical analysis and discussing particular examples of patent law concerning language and translation, by combining documental analysis and interviews. The analysis is separated by office and court stages, associated with the timeline of a patent.

Section 7.1 established a reference for the legal timeline of a patent - as these stages considerably differ in distinct national systems. In this regard, presenting a universal timeline" represented a preliminary translation issue. The discrepancies related to national timelines affect by themselves the integrity of the patent system. Similar concepts and definitions that seemingly carry the same connotation can be discrepant in different national jurisdictions. After a comparative analysis, the European patent system was chosen as the main reference. Accordingly, the following stages were considered: office 
stages: examination (application, prior art search, office actions, validation), opposition and appeal; and court stages, restricted to infringement cases.

Section 7.2 offered an overview of the office stages. Sub-section 7.2.1 discussed examination guidelines in terms of language/translation regimes in different patent systems, showing that these guidelines are related to the accuracy of the examination, which, in turn, will give legal certainty to the system, preventing further infringement cases. Some features during the examination stage were found to play a positive role in granting strong patents: flexibility in terms of communication between the office and the applicant; possibility of counting on human translation to support the examination when necessary; experience and (including linguistic) knowledge of the examiners; possibility of direct communication or interviews to discuss office actions; level of autonomy of the examiner to take decisions.

It was also concluded that the more bureaucratic the translation proceedings are, the less efficient and accurate will tend to be the examination, and that a direct communication in a common language between the examiner and the applicant (attorney/agent) is recommended. The accuracy of the examination is defined by the role of the patent office on the legal framework. It also entails the full access to foreign prior art and clear and well-defined stages to oppose the office's decision. The same Section discussed peculiarities of the language regimes belonging to different national offices, in association with strategies used by the applicants in dealing with them. All the described discrepancies point to the necessity of searching for solutions in terms of integration and harmonization.

Section 7.2.2 analysed particular office cases where translation played an important role. These examples evidence the relevance of language and translation to examination proceedings, opposition and appeals, proving language and translation issues to be frequently present in those stages. The section brought up abundant recent examples of office actions which called for corrections in translations of applications in order to proceed to granting the patent, showing that an incorrect translation can broaden or narrow the scope of a patent, being able to bring it future challenges, or to make it more vulnerable to infringement actions. The Sub-section also enhanced the importance of the role of intermediate agents, such as patent translators and local patent attorneys, in offering reliable translations for the original application.

The examples included examination reports indicating translation errors, some of them as critical as to completely change the scope of the patent. They also concerned cases of opposition, extending from textual nuances, requiring more sophisticated reading and interpretation, to evident mistranslations, compromising ethical issues or the disclosure of the invention. The sub-section also presented cases where the office admitted or refused subsequent translations of prior art, which changed (or not) the decision for granting the patent. 
Section 7.3 presented the main aspects concerning patent translation in court cases, describing the way different courts deal with foreign documents. The section showed that different conducts of dealing with language and translation and interpreting foreign documents can imply different results in national court systems, resulting in lack of legal certainty to the global patent system. The section associated examples of proceedings in infringement cases with statements of patent attorneys over gaps and discrepancies between different courts. In this respect, it was concluded that, in terms of language and translation, courts may operate with very divergent methods in different countries, which is related to legal culture, administrative frameworks and personal interpretations.

Section 7.4 examined court cases involving problems with translation or interpretation of foreign documents. The analysis evidenced that inaccurate translations can bias decisions related to infringement cases. This can be related to subtle inaccuracies in translated prior art, to infelicities concerning the original texts or to inaccurate translations purposely presented to change the scope of protection and influence judicial decisions. When it comes to the last example, experienced attorneys frequently detect these discrepancies, particularly in translations presented by the counterparty. Cases related to long and controversial discussions over a conjunction or preposition, or a subtle nuance of meaning of a singular word, are not rare.

Other examples are: cases of corrections of translated terms by the court which dismissed the query to the original text; cases where the scope of the patent could be wrongly interpreted by the use of incorrect technical terms; cases where the non-observation of inaccuracies, during the opposition or appeal stage, originated infringement actions, leading the Court to question the validity of a granted patent; cases where patent trolls took advantage of ambiguities found in patent documents; cases concerning the same documents leading to opposite decisions in different jurisdictions.

Translation costs can be considered as part of the highest ones during patent prosecution. They vary from country to country and depend on the source and target languages, on the complexity of the case and on the quality of the services. Translations of patent documents are considered highly specialized translations. Section 7.4 also discussed the relation between the quality of translation services and the strategic use of translation in complex patent cases, which involved large sums at stake and huge amounts of translated documents.

Finally, Section 7.5 concluded the analysis by presenting complementary information collected through interviews which are believed to contribute to answer to the research question. In this regard, it is worth to mention the following conclusions: different jurisdictions may offer different problems related to translation and communication (e.g., European patent attorneys observed they have more problems with translation and communication in Latin America than in Asia, due to bureaucratic demands, short deadlines, difficulties with local agents and translation regimes); improved machine translation automatically leads to an enhanced global patent system and to more global justice related to innovation and patent rights; the advent of quality automatic translation improved patent prosecution and allowed businesses and uses of patent information 
which were not feasible before; accurate examination and effective opposition and appeal procedures are a way to protect the integrity and reliability of the patent system; the patent system should be interpreted as a package (when one of its parts does not carry out its task, the whole structure is affected). 


\section{CHAPTER 8}

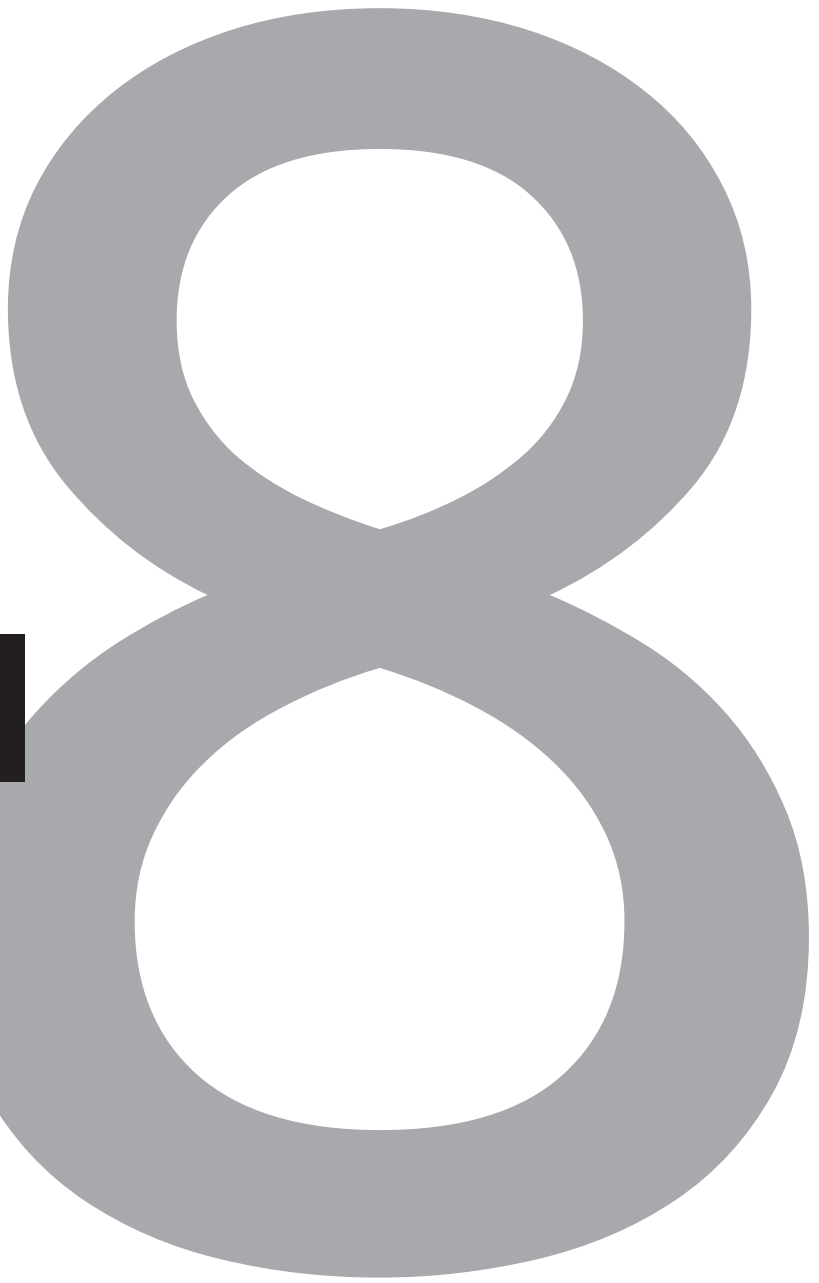


Summary, conclusions and recommendations 


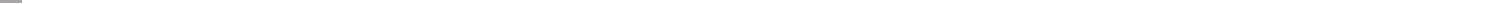




\subsection{Achieved results: main points and conclusions}

\subsubsection{Office, opposition and infringement cases: the influence of translation on patent law and its snowball effect}

Patent translation exerts a prevalent, all-encompassing, pervasive influence on patent law. Translation is widespread through the whole patent system and all of its structures and elements, starting from its centres of governance and its international regulations. In this regard, it is important to recognize the global nature of patent rights and the universality of disclosure, which makes the patent system multilingual and complex, as it covers a huge volume of technological information from nations (and many of their languages) which enforce patent rights, as well as an enormous and varied array of regional or national regulations belonging to different legal cultures.

This influence starts from the roots of the global patent system and shows evidence of diverse reading and interpretation of international, regional and national translation regimes and corresponding regulations. Those differences affect the patent system globally and the idea of patent law as a field associated with global trade and international expectations. Although it was considered neither productive nor honest to try to directly associate court decisions with "faulty" translations or with fragments of translated texts which played a role on those cases, it was possible to identify patterns and establish generalizations on how translation influences those cases, by crossing the results of the content analysis of the proceedings with the results of the semi-structured interviews.

There are abundant examples of examination reports indicating translation errors, some of them as critical as to completely change the scope of the patent. ${ }^{907}$ According to the statements of patent examiners, finding those errors depends on the experience and knowledge of the examiner. On the other hand, less mature or more isolated national patent systems tend to offer less accurate translations provided by the local agents. This can be a problem, as the attorneys who rely on these services are usually not able to assess their quality due to language barriers. At the same time, the decisions taken as well as the accuracy of the examination vary from examiner to examiner and may entail further legal consequences, leading to what may be described as a snow ball effect, as the outcomes get more serious insofar as the errors are not corrected in each further legal stage. ${ }^{908}$

There is plenty of subjectivity in the analysis of translated texts, especially when it comes to the inventive step. Controversial office decisions are susceptible to reviews and, if those reviews still remain questionable, to opposition cases. Cases of opposition can involve textual nuances, requiring more sophisticated reading and interpretation, to gross translation errors, which could have serious ethical implications. The cases presented showed some of these discrepancies. Some examples worth mentioning are:

907 For all the cases and reports, see Section 7.2.2 of Chapter 7.

908 Ibid. 
a case where a patent related to stem cells of transgenic animals could be interpreted as admitting human cloning; evident errors that could completely change the calculation of a mathematic formula; cases of patent (untranslatable) texts presenting very obscure writing which were anyway granted by the office; cases where the ambiguity or similarity of words in the source language jeopardized their translation in the target language.909

The section brought further cases where an earlier wrong interpretation, during the opposition or appeal stage, may be the cause for infringement actions, leading the Court to question the validity of a granted patent which actually should not have been granted, due to the existence of foreign prior art. In one of the cases representing this example, two courts, in two different European countries, have adopted opposite decisions, one favouring the plaintiff, and the other, the defendant. ${ }^{910}$

With the reference to the assessed office and court cases, the most important patterns identified on the proceedings of the cases and confirmed by interviews were: inaccurate translations purposely used to bias the decision of office/court cases; errors in interpreting machine translated prior art, during the examination, which can produce further legal effects (cases of opposition, infringement...); obscure writing which produces unclear (human/machine) translations - sometimes remaining obscure even after a judicial decision; a word (consisting mainly of a preposition, another linking word or a technical term) which is source of problems with legal interpretation from source language to target language..$^{911}$

The most common configuration of court cases involving problems with translation can be described as follows: $\mathrm{A} 1$ has a patent (AP) in country $\mathrm{J}$, and B1 has (a "similar") one (BP) in country U. A1 applied for the patent only in J, so A1 has "no rights" to allege counterfeiting in any other country, as for example, in countries $U$ or $B$. Regarding the nullity of BP, as it was granted after AP, and AP was published in J, BP should not have been granted, as there was prior art for lack of novelty. The technology disclosed by AP is free in any other country where it remained unpatented, and everyone can use it. This structure configures a typical case that leads to alleged infringement, involving different national systems. It frequently leads the court to questioning the validity of one of the patents. The decision can be the one of invalidating the latest patent, by indicating that it should have been revoked when it was opposed or that it should not have been granted. It can, in reverse, consider the second patent as infringed. In any case, the consequences for one of the companies involved tend to be drastic, if the decision is not well informed. The fact is that there are recurrent cases of discrepancies between different jurisdictions in this type of decision. ${ }^{912}$

909 For all the examples of opposition cases and their analysis, see Section 7.2.2.

910 See all the cases and their analysis in Section 7.4 of Chapter 7.

911 Ibid.

912 See Section 7.4 of Chapter 7. 
Moreover, it was concluded that infringement cases typically involve huge stakes and an enormous volume of translated texts. The profit of translation companies does not rarely edge millions in fees for translations, which involve documents from many different countries and languages, and which can reach averages of millions of translated words. As clear, analysing all the translated documents of such cases or justifying the judicial decisions which somehow were affected by their route constitutes an impracticable task. ${ }^{913}$

Translation costs are still among the highest in patent cases. They vary depending on the country, the pair of languages, the magnitude and complexity of the case or the quality of the experts or companies in charge for translation. Patent documents are related to difficult, highly specialized translations. The world language service business is estimated to be worth $\$ 34$ billion and represents a fast-growing business. It cannot be carried out by one company alone and gets increasingly complex, in view of the nature of the services and of the number of languages and areas involved. Fees from legal work involving language and translation are very high and require highly professionalized work. Specialized firms can work for both parties in the same case, as happened in the dispute involving Apple and Samsung analysed in Chapter 7.914

Patent attorneys mentioned cases of discrepant opinions between examiners and attorneys. This seems to be a common situation and, not rarely, involves machine translation of prior art and its interpretation by the examiners. European attorneys complain that it is difficult to change the decisions taken by the examiners through office actions in some national patent systems. According to the attorneys, translation is a major problem and a major cost in most of the countries in Latin America, for example. In addition, the services associated with translation lack in quality and, not rarely, documents should be corrected. Still according to the mentioned attorneys, it is also relevant to consider whether or not it is worth to sue the office, due to the backlog and lack of specialization involving the national patent courts. ${ }^{915}$

Some cases indicate potential gaps in the patent system resulting from inaccurate examination, showing that granting a patent whose text is not clear may, for example, favour patent trolls, and create the mentioned snow ball effect at the global level, as courts can take divergent decisions in similar cases. An inaccurate text of a granted patent increases the chances of misinterpretation in other languages and in other jurisdictions. The patent then entails a problem of translatability, associated with the global nature of the patent system. This conclusion indicates that patent trolls may be largely associated with language issues, and this association should be subject to further studies. ${ }^{916}$

913 Ibid.

914 See Section 7.4.

915 For examples of cases and their analysis, as well as associated statements given by attorneys, see Sections 7.4 and 7.5

916 For examples of such cases, see Section 7.4 


\subsubsection{Translation discloses patent information and enables the universal dissemination of innovative inventions}

One of the key findings of this research was obtained by means of the analysis of the level of disclosure of patent information through machine translation engines, as part of the answer to the proposed research question. The conclusion was that the level of disclosure of technological information through machine translation is almost $80 \%$, a level that can be considered high in terms of the current standards of translation assessment. ${ }^{917}$ From this result, it was possible to deduce that the advent of machine translation engines overhauled the patent system, by enabling the dissemination of the disclosure of patent information to reach a universal level. This conclusion was confirmed by the interviews with selected stakeholders, which revealed that machine translation turned the patent system into an increasingly internationalized, coherent, global and multilingual structure, whose main basis of communication is translation. ${ }^{918}$

This (high) level of disclosure was also associated with radical changes on patent law, especially in terms of the characteristics of office, opposition and infringement cases. The results led to relevant generalizations regarding how translation affects patent procedures and patent cases, after proposing a timeline for the legal stages of a patent, portrayed through different ways that define this influence. Problems of ambiguity and incongruency were deemed to be the most common ones found on the translated texts related to the sample. ${ }^{919}$

Also regarding the level of disclosure of patent information in association with (human/machine) translation, the results demonstrated the relevance of the original text of the patent to its translation and future examination in different countries. Some features of the writing of the prior patent were enhanced: clarity, consistency and brevity are important to the appropriate disclosure and may influence its translation and the use of translated texts in further legal stages or legal challenges; the claims of the patent are the most crucial part of its text in terms of defining the scope of the invention; some strategies can be used to facilitate the task of the future translators and non-native readers and examiners of patents, such as performing a reverse translation of the patent or using lists and schemes to facilitate the understanding of its scope. ${ }^{920}$

The sufficiency of disclosure was also analysed in the light of the association between the original writing and translation. In this regard, Chapter 7 brought up cases in which the person skilled in the art was not able to carry out the invention due to aspects related to the way the patent was originally written. Those patents were considered "untranslatable". ${ }^{921}$ Similarly, the duty of disclosure was found to frequently use translated

917 Due to the importance of the concept of disclosure to the patent system and to this research a whole Chapter was dedicated to this discussion. See Chapter 5.

918 See Section 7.5.

919 See Section 5.2. See also Chapter 7.

920 See Section 4.4 .

921 Section 4.4. 
information and to require (sometimes complex) decisions weather to present or not a prior art document. ${ }^{922}$

The conclusion concerning the level of disclosure of patent content enabled by machine translation was based on the manual analysis of a sample of 100 patents, through a methodology called LISA-QA. This method was complemented with a thorough analysis made by scientists who work with the sample technologies, representing the persons who are "skilled in the art". Their answers confirmed the results of the first step of analysis. ${ }^{923}$

The results also evidence that the quality of the translation is still highly dependent on the pair of languages involved. However, other factors can play a role: complexity of the invention, clearness of the original text, structure of the original text and clarity of the drawings. The drawings were not considered in the analysis, as the access to them would have made the understanding of the patent text much easier for the persons skilled in the art. Since the intention was to focus on text and translation, they were excluded from the survey form. ${ }^{924}$

The analysis also revealed that the variety of errors tends to diminish as the degree of severity of the error grows. The great majority of critical errors found in machine translated patent texts were, mainly, errors of syntax (or language structure) and, in second place, errors of terminology (inaccurate translation of technical terms). The translation between two languages of the same family was not always as satisfactory as it would be expected. That happened because English still worked as an intermediate language in the process of machine translation when the analysis was done, due to limitations of statistical machine translation. This will not be the case anymore, as, with the improvements of neural technologies, a direct approach between, for example, Spanish and Portuguese, is easier to be established. Clearly, the speed of improvement of machine translation is so high that another true revolution has happened, with the remarkable advance of neural technologies, during the elaboration of this thesis. ${ }^{925}$

Another important conclusion is the fact that the very concept of disclosure is not consensual in the patent system, varying according to national law and theoretical approaches. Disclosing technological information is one of the main reasons that vindicates the maintenance of patent rights. Imparting knowledge in order to foster innovation is one of the fundamentals of the patent system. ${ }^{926}$ Therefore, the concept of disclosure is far from being harmonious and clear when it comes to national law and still requires a more comprehensive approach that can minimize these differences.

Disclosure is also subject to controversies or to common sense evaluation which is not based on scientific assessment. On this matter, the results bring critical and novel contribution for a clearer understanding of disclosure, which can work as strong

922 Section 4.4 .

923 Sections 5.2 and 7.3.

924 See Section 5.2.

925 See Section 5.5.

926 Section 5.1. 
justification to the existence of the patent system and lead to necessary improvement in patent law. In this regard, it was proved that disclosure is highly associated with translation when it comes to patent rights and that the advent and improvement of machine translation enabled the easy and universal access to patent content.

Arguably, even the creation of enhanced machine translation technologies was only possible due to the existence of the patent system. Patents are an excellent source of translation and information memory. The new translation tools have not only benefited from the previous technologies available on patent databases, but from decades of efforts in translating patents, which are now accessible, measurable and generative through the patent system.

The main research question that motivated the present research was based on the assumption that the influence of translation on the patent system has been under-estimated or even taken for granted by scientific studies and by the users of the system. These numbers and conclusions explain the role of translation to the disclosure of patent information, not leaving aside its complexity, and can represent an important contribution to understand and improve patent rights and to justify their existence in terms of dissemination and disclosure of the content of inventions.

The results also demonstrated that a trend to integration and harmonization was followed (and at the same time fostered) by the overcome of language barriers, which used to obstruct the dissemination of the disclosure of patent content across borders. Disclosure was universalized by the advent of machine translation together with (but more than) the possibility of accessing digital tools and increasingly sophisticated patent databases. Prior art search was found not to be any more limited to national technologies. The patent system is now able to widely integrate and communicate, enabling a much more dynamic flow of interaction and knowledge transfer related to the disclosure of inventions. ${ }^{927}$

This changes the role of the patent system in terms of fostering innovation through the disclosure of patent information at the global level. Only since a recent decade of fast changes the whole world has easy and fast access to an extensive volume of multilingual information on new technologies. The advantages ought to be considered as obvious, as all this information can be accessed and controlled in various ways.928

Being the fundament of the patent system, translation can be seen as both a formative element, which gives coherence to the system, and as an element of its potential corruption or disintegration. The patent system was defined by its complex, global and multilingual nature determined through the association between innovation, disclosure and patent law, and on the basis of global expectations, a fundamental conceptual framework and centres of governance in an intercultural space.

927 Sections 1.1.3 and 4.2.

928 These advantages were discussed in Section 6.1.2 of this dissertation. 
From this perspective, it is important to acknowledge that patent texts will always offer new challenges and chances for their readers. As texts, they cannot be conceived as a set of words with a univocal meaning, and so will be their translated versions. Patent texts can be way more complicated than other technical texts, as they are written with a view to legal purposes, aiming at specific audiences and intending to broaden the scope of protection as much as possible. Patents are hence identified with an increasingly intensive flow of huge amounts of translated information, their disclosure being circumscribed to a global network that constitutes the patent system.929

On the other hand, translation has played a historical role for innovation, still poorly explored in scientific studies. As a phenomenon which cannot be defined as a single, simple process, translation has been crucial to the transfer of knowledge across borders and has been critical to the building of societies through the import and absorption of new technologies. This was only possible because knowledge was disclosed and disseminated through different ways, a process which has changed on time and has been radically reshaped through the advent of machine translation and a subsequent more structured, harmonized and globalized patent system..$^{930}$

Machine translation changed the face of disclosure of technological information and overhauled patent rights. This revolution can be considered a very recent development, having still much to be investigated and understood. In this respect, it is important to enhance that machine translation enabled a global configuration of the patent system, which still has a long way to go in terms of reaching an ideal level of harmonization and depends upon legal approaches on translation related aspects and definitions. ${ }^{931}$

The importance of translation to innovation is not a new event. Innovation has shaped languages and societies through new discoveries, new inventions, new interpretations of the reality, which require new words and a lively transubstantiation of the content which is being translated. This process of re-creation or transformation of cultural/linguistic reality is only possible because it implies more than a simple transposition of meaning, but new applications of the original meaning. The target language always somehow lacks the possibility to translate the original content. However, that is what makes the dissemination of disclosure a creative and dynamic process of communication by itself. ${ }^{932}$

Today, the universal dissemination of the disclosure of patent information provides that knowledge is fast accessed and assimilated universally. This implies specific philosophical, political and cultural transformations related to knowledge production and absorption across borders. Those changes have also considerably influenced patent law, demanding new perspectives over office, opposition and infringement cases. The cases involve a much larger volume of translated information, which require both technical

929 Sections 4.3 and 4.6 .

930 Sections 4.1 and 1.2 .

931 See Section 4.1 of Chapter 4.

932 Section 4.1. 
and legal knowledge to be narrowed, selected and interpreted. On the other hand, the fact that all this information is disclosed universally conveys significant advantages to knowledge transfer and innovation. In this regard, harmonized solutions for the patent system in a level of global expectation are necessary. On the other hand, those solutions are deeply connected to the role of translation as the basis that fundaments the patent system as an internationalized structure. ${ }^{933}$

Conceptual differences and different roles of machine translation and human translation and their combined use also influence patent law in all of its structures and stages. Machine translation is still the object of suspicions and mockery, but even human translation frequently benefits from automatic tools. Machine translation and human translation became complementary, as human translation associated with the patent system requires the use of translation technologies and, on the other hand, a translation provided by a machine requires a human interlocutor who will interact with it in different ways, depending on factors as critical thinking, technical experience or language knowledge. ${ }^{934}$

Another essential feature on the association between translation and disclosure on the patent system is the role of English as lingua franca. English is and probably will remain the main language of communication on the patent system. However, it does not compete with or depreciate the applications and information in all the other languages. The way all the other languages interact with English inside the patent system may be an important object for further studies, as this interaction can be described as a two(or multiple) way path: the same way English has significant influence on these other languages, patent related English as lingua franca shows characteristics which are different from native English. ${ }^{935}$

The limits and possibilities of patent translation are now contingent to different prognosis raised by national, regional and international language and translation regulations and regimes. One example which is noteworthy to retrieve concerns the language regulations of the European Unitary System. The regulations are affirmative in acknowledging the relevance of machine translation to disclosure. They portray machine translation as a key feature of the European Union and predict a short-term period for the availability of high-quality machine translation to access patent content. ${ }^{936}$

The foresight may be deemed absurd to conventional opinions. However, the increasingly crucial role of machine translation to the patent system does not only represent a likely event, but a consequent development on the recent records of the patent system. The legal literature shows plenty of cases where translation has influenced the disclosure of patent information. Translation can affect the scope of an invention, by altering the disclosed content. The same way, inaccurate translations can corrupt the whole process

933 Chapters 1,3 and 7.

934 Section 4.2.

935 See Section 4.2 and Chapter 7 of this thesis.

936 Sections 4.5 and 6.2 . 
of examination and grant. There are cases where newly filed translations can substitute previous translations and fundament a review of the examination. Decisions taken by examiners or judges made on the basis of machine or human translated prior art can be reconsidered under the light of a newly filed human translation..$^{937}$

In short, since (especially machine) translation is the basis of the global patent system, its improvement and governance may be considered as vital to a more harmonized and coherent configuration of patent rights in a short-term. At the same time, as it represents only a tool, to be used or misused by human beings, the background of its users (patent examiners, attorneys, judges, translators) and the level of consciousness of its possibilities will determine its future course. From this perspective, follow-up studies are crucial for accompanying the pace of these developments and for opening a continued debate over their optimal use in patent law.

\subsection{Translation and its influence on international agreements as a network effect}

The influence of translation on patent law has its roots on cross-border (international and regional) agreements and guidelines, which constitute the basis of what was defined in this thesis as the global patent system. Cross-border agreements and national regulations were considered from the perspective of a justification level of the law, as confronted with the level of application in the legal discourse. Different from office, opposition and court cases (application level), the influence of translation on cross-border agreements and their internalization as national or regional regulations tend to follow the logic of a network effect. ${ }^{938}$

The network effect contrasts with the snow ball effect because it cannot be described as a growing effect which takes place in a specific timeline (the one of the "legal life" of a patent). Different from that, it is a constant effect which pervades all the structures of the whole system. When an international agreement defines language and translation rules to its member states, these rules will affect many of the structures of the national systems and will determine the functioning of the international or regional system reached by the agreement. On the other hand, if an international agreement is wrongly translated into one of the languages of the member states or even if it is confronted by its legal culture (a possibility which may also be defined as a translation issue), it will again affect the whole system, as the national legal system may function as a corruptive element or may frustrate the expectations of the other signatory states of the agreement..$^{939}$

937 Chapter 7.

938 For the concepts of application and justification of norms related to legal discourses, see Section 3.2.

939 Chapter 6. 
Notwithstanding, patent cross-border agreements, in general, present notable positive effects for the dissemination of the disclosure of patent information both in national and global levels. The example of the PCT was discussed in terms of harmonization and improvement of the patent system. The results showed positive outcomes interpreted in view of the advantages of (language related) integration and interaction among national systems. The PCT represented an important step in terms of harmonizing the patent system, by giving it a common substratum, and offering positive results that strengthen patent rights and their function in disclosing patent information and supporting innovation at the global level. ${ }^{940}$

The PCT ensures that the international search report is translated, as provided in its Regulations, under the responsibility of the International Bureau. The PCT also enables broad and easily accessible dissemination of the disclosed content, which can be used for concurrent monitoring, technology assessment, portfolio management in research and development, identification and evaluation of potential sources for external generation of technological knowledge. Those benefits are related to language and translation and improved with the advent of quality machine translation engines. Veritably, an international patent database associated with an elaborate language regime tends to provide more quality information than national patent databases. In this regard, further studies investigating the quality of searches in national databases compared with regional or international ones (as Espacenet and Patent Scope) are necessary. ${ }^{941}$

The step represented by a unified patent and a unified court is defended as a revolutionary one in terms of harmonizing and improving the patent system. The advantages of the unitary system will affect not only Europe but will benefit patent rights in the global level. Those gains are deeply associated with the idea of disclosure and with the possibility of strongly mitigating language barriers and costs with translation. The system will probably attract more oversea applicants and turn Europe into an even more important centre of governance and dissemination of knowledge. ${ }^{942}$

There are categories and methods to be considered while formulating treaties and legal texts translations. These methods have limitations and may find critical resistance from signatory countries, as in the case of the Unitary System. The Cases C-146/13 and C-147/13, launched by Spain, seeking annulment of the language and translation regimes of the unitary system, illustrate these reactions. ${ }^{943}$

The actions alleged violation of the principle of non-discrimination by the language arrangements established by the unitary system, which keeps the trilingual language regime of the EPO (English, German and French being its three official languages). Although the Actions were dismissed, and the contested regulations, maintained by the court, the discussion around the infringement of the principle of non-discrimination on

940 See Section 6.1 of Chapter 6.

941 Ibid.

942 See Section 6.2.

943 See Sections 6.2.3 and 6.2.4. 
grounds of language, and the allegations that the regulations lack more clear specifications concerning language and translation remain important. The maintenance of the current language regime of the EPO seems arbitrary from the perspective of a regional patent, which no more requires national validation. On this matter, there is no possible objective justification for including English, French and German in detriment of other European languages, as language and translation have long been recognized as central to European integration. ${ }^{944}$

The trilingual regime of the European Patent Office may be associated with inequalities among its users, as it impacts the costs to file applications and the access to disclosed information. The unitary system should not intensify these inequalities by dissociating its language and translation regimes with the principles of the European Union. On the other hand, the solutions for conciliating these principles with the very nature of the patent system are complex. A starting point to search for solutions should include considering the possibility of re-discussing the criteria for defining the official languages of the unitary system, based on, for example: a periodical assessment of the number of patent applications in each language; the possibility of adopting a monolingual system having English as lingua franca, as the most feasible, although still harmful, solution. ${ }^{945}$

Apart from a discussion over the language and translation regimes of patent associated cross-border agreements, it is important to acknowledge that those agreements entangle a whole set of national and international legal frameworks concerning language and translation. Translation inaccuracies may produce critical consequences on the internalization of international agreements into national law. There are plenty of examples of inaccurate translations of international agreements which extend from evident and frequent errors on the translated text to subtleties which can entail great delays on the signature or implementation of the agreement. ${ }^{946}$

Another common situation, which can also be defined as a problem of translation, happens when the agreement is confronted with a different local legal culture, which cannot fully absorb or put in practice its content. There are cases of patents which were not granted or whose grant was legally opposed due to reasons which are unconnected with the criteria of patentability or which breach national regulations, as ideological or political reasons. The same happens when the local structure is not prepared or mature enough to provide fair trials due to lack of technical expertise of its actors, lack of access to appropriate technical support or problems related to backlog or administrative deficiencies. ${ }^{947}$

944 See Section 6.2.3.

945 Ibid.

946 For these examples and their analysis, see Section 6.3.

947 See Section 7.4 for examples of such cases. 


\subsection{Recommendations to improve the dissemination of the disclosure of patent information in courts and patent offices}

Language and translation are deeply associated with the dissemination of the disclosure of patent information. Due to the systemic nature of the patent system, a system based on multilingual communication in an intercultural scenario, translation performs as a linking element, which defines the identity of the system and determines its existence and improvement as a global system. At the same time, as a fundamental component of communication, translation can act as a disruptive factor, through inaccuracies which can frustrate the expectations of the users of the system or corrupt the rule of law or the legal certainty associated with patent rights.

Translation regimes are associated with legal and administrative cultures and are central to harmonize discrepancies between courts and offices in different jurisdictions. This section provides recommendations to mitigate the gaps identified through the results of the content analysis and interviews, as part of the conclusions of this research.

The core recommendation is to increase the level of integration and interaction between patent offices and patent courts. This can be done through cross-border agreements of many types: agreements for establishing regional patents (the European unitary system represents the first step to create an international patent); agreements of patent prosecution highways and other types of cooperation related to examination; agreements on reducing translation costs.

However, increasing integration and interaction requires more than implementing international or regional agreements. It is also necessary to intensify the levels of mutual evaluation, discussion and information exchange. This may involve not only patent courts and offices, but other sectors and players of the society, such as policy makers, industry managers and academic researchers. It is advisable to propose international forums to discuss translation (and its costs) in association with the local legal culture related to patent law.

Until now, initiatives aimed at receiving feedback from the users of the patent system are only provided by particular patent offices. In some countries, there is little room for the users of the system, especially patent attorneys and examiners, to discuss possible improvements related to language and translation costs or burdens. On this matter, it is believed that such forums and events can have a positive impact to integrate the system and find solutions for the existing gaps. Other recommendations for courts and offices related to disclosure and translation deserve consideration:

- Offices should reduce as much as possible the bureaucracy related to translation. In this regard, consulting the main users of the system for the best solutions is mandatory, as they can vary from office to office. Those solutions may include: longer deadlines to respond to office actions, direct communication 
with examiners in a common language, changes in national regulations or a simplified language regime.

- Patent offices and patent courts should be seen as part of a global system. As so, they respond to global expectations. Regulations which disfavour this definition or affiliate language and translation regimes to national bureaucratic burdens should be reviewed.

- Accurate examination in terms of the criteria of patentability related to accurate writing and sufficiency of disclosure is imperative for avoiding further infringement cases.

- The existence of a stage of opposition with an adequate structure for reviewing the decision of the examiner associated with the interpretation of texts or translated documents is critical for preventing infringement cases. This stage should admit the possibility of the applicant to request a human translation for a machine translated prior art document that was crucial as the basis for an examination decision.

- Patent judges should be specialized in patent law. Patent attorneys should have the appropriate technical qualification for dealing with specific types of patents. Patent judges should also receive all the necessary technical support from experts in specific technologies.

\subsection{Recommendation concerning translation and disclosure in the language regulations of the European Unitary Patent and Unitary Court}

The recommendations related to disclosure and translation concerning the regulations of the unitary system are based on relevant and repeated observations of interviewees (patent attorneys, examiners, judges, policy makers and translators), on the analysis of Actions C-146/13 and C-147/13 launched by Spain before the Court of Justice of the European Union and on the documental analysis of the regulations compared to the current regulations concerning language and translation related to the "current" European patent. The regulations of the unitary system, being the most controversial of them the Council Regulation (EU) No 1260/2012 of 17 December 2012, still inspire distrust and hesitation from the mentioned stakeholders.

- The actions filed by Spain demand necessary further debate involving the (to the date) trilingual regime of the European patent system and require the possibility of re-discussing the criteria for defining the official languages of the unitary system, based on, for example, a periodical assessment of the number of patent applications in each language or the statistics shown by periodical innovation indexes. 
- Also to be discussed is the possibility of adopting a monolingual system having English as lingua franca, as a practical, and probably the best (but not harmless) solution.

- The results show that the number of official languages of the unitary system should be restricted, due to the nature of the patent system and to the necessity of simplifying language and translation procedures as much as possible, in order to reach the best level of disclosure of the information revealed by patents. In this regard, a multilingual language regime is unsustainable.

- The system should anyway encourage the use of English as an intermediate language. Although it is undeniable that this solution brings negative implications in terms of linguistic rights, it may work as the less harmful solution in specific cases. This represents a realistic approach in terms of considering that English is already, to a great extent, a lingua franca in the environment of the global patent system.

- After the set-up of the unitary system, the European Union should promote training programs and policies in order to facilitate the access and use of patent information through patent search tools and platforms. These programs should focus on peripheral countries and languages, in terms of number of application and innovation indexes. With the advent of machine translation, language is no more a barrier for the ones who know how to manage the information on the mentioned systems. Programs aiming to facilitate the use of those platforms as sources of knowledge and industrial strategy represent an important solution for reducing the inequalities related to the European patent system.

- It is recommended that an SME of a member State should always have the right to bring the litigation to a chosen branch of the Unitary Court, when being sued by a bigger company. The choice should be justified in terms of the costs of the litigation (including translation costs) to the SME. This solution could also reduce the risk of marginalizing specific local branches of the Unitary Court.

- The requirement for a translation of the whole patent, into the language of the State where the alleged infringement took place should not be mandatory when the proprietor is a small or medium company and the defendant is a big company.

- The judges of the Unitary Court should have all the possible provisions of translation, which should not be restricted to the access to translators only, but include the services of legal language experts. The language regime of the Unitary Court should be carefully planned and constantly reviewed and made clearer to the users of the system. Academic research can function as an important support in its settlement.

- Interested parties should have the right to request a more accurate translation into English (when the filing language is German or French) from the applicant, under justification and when they consider it necessary for the adequate disclosure of patent information, in the cases mentioned on Recital 12 of said Regulation. 


\subsection{Recommendations to improve search tools and expert systems in terms of optimizing the use of machine translation to disclose and disseminate patent information}

Patent search tools and expert systems can still improve a lot in terms of optimizing the disclosure of patent information as well as the worldwide dissemination of technological content. Disclosure and dissemination are associated with the idea that inventions should be protected, but the same is not valid for the access to their content and for its use for new creations. The quality of searches tends to increase with the use of machine learning and artificial intelligence. Semi-automatic searches probably represent an important future supporting tool for patent examination. ${ }^{948}$ Nevertheless, they should be seen as a tool to support the quality of the search, and not as a substitute for human analysis or for many other possibilities of search systems, databases and new tools which could facilitate the scientific use of all the information disclosed by patents. Even automatic search will probably always require the addition of traditional search, as its results must be subject to verification. These recommendations do not go as far as to reach automatic search tools and their association with disclosure, but possible contributions to the search engines used to the present. ${ }^{949}$

- Patent search engines and databases would benefit from undergraduate or scientific initiation research involving IT students and natural sciences students. There are many possibilities of creating new, "smaller" databases crossing information on some specific languages and fields to serve purposes such as better understanding of the inventions and using the knowledge contained in specific fields or types of patents.

- Many national search platforms still offer considerable language related barriers to their users. Those barriers are accentuated by problems related to their lay out or to the organization of their content. These platforms should be submitted to periodical reviews by their users and should be improved in terms of becoming more user friendly.

- Regional search engines could simplify the search in countries which share the same language or similar languages, Latin America being the best example.

- New platforms and tools can be developed aiming to "translate" the content of patents into other types of discourses, such as legal reviews (and not only associated legal cases), videos or texts with educational purposes involving groups of patents; reviews following technological paths of particular types of inventions. The sky is the limit to disseminate disclosed information for fostering innovation and encourage scientific intercultural exchange.

948 See: 'Looking for answers on Ansera, IPKITTEN Blogspot, 2017, http://ipkitten.blogspot.de/2017/11/looking-foranswers-on-ansera.html?m=1 (accessed 18 April 2018).

949 For previous recommendations concerning search engines under another research question, see Larroyed (2019). 
- Search tools should contain filters to search by language, with the possibility of crossing searches by language with searches by country/region of application (these options are still limited in the existing tools). There is a difference between searching for US patents and searching for patents in English all over the world; - Searches by country of prior application should always provide easy automatic translations of the titles (especially in Asian languages or languages which use a non-Latin alphabet).

- Filters for searching by nationality of the inventor or the applicant could be useful for certain types of search.

- Expert systems should provide automatic translations of keywords.

- Translation of terminology is still a problem in disclosing patent information through machine translation and should be a focus for the improvement of searching tools.

- Syntax is still a challenge for the improvement of patent machine translation and should be emphasized in the improvement of translation tools.

- Some older Asian (or other national/regional) patent documents are not available for translation in search engines. Patent offices should work on their files and search engines in order to give access to these patents.

\subsection{Recommendations for future developments and studies}

One of the contributions of working with topics on which little has been published in scientific research is the fact that they lead to new perspectives to look at a specific area. Therefore, they tend to open the way to other new topics of research and possibilities of scientific investigation. It was not different with the present research. During the whole process of data collection and analysis, various possibilities for new studies and ways of exploiting the border between language/translation, dissemination/disclosure and patent law were popping up. This section summarizes the recommendations believed to be the most relevant ones to continue investigations involving this topic. The recommendations for further studies are listed below as draft research questions:

- How do national patent language regimes influence the dissemination of the disclosure of patent information?

- How can national patent language regimes and regulations improve in order to contribute to a more harmonized and efficient patent system at the global level?

-What are the effects of regional or international agreements to disclose and disseminate patent information?

- Is English as lingua franca the solution to reach an ideal level of universal disclosure of patent information? 
- How can patent writing affect patent translation?

- How can national legal cultures affect the dissemination of disclosed patent information?

-What is the relationship between language, dissemination of patent information and linguistic rights?

- How has translation influenced the dissemination of innovative inventions from a historic perspective?

- Can patent information be used for language learning?

- How does language and translation affect the integration of a patent national system to the patent system at the global level?

- How can language be used to bias patent cases?

-What are the professional requirements for a patent translator? What kind of education can create qualified professionals to better perform this function?

-What is legal discourse and what is scientific discourse in patent documents? How can they best interact in order to disclose patent content?

-What is the role of political, ideological and cultural discourse patterns on national patent systems?

-What kind of new search engines could be developed in terms of maximizing the disclosure of patent information for different social groups?

For concluding this section, it is important to acknowledge that there is a mismatch between the advances in machine translation and the disclosure of patent information provided by national patent systems. The main reasons for this mismatch are associated with the quality of the examination and the way the patent offices and courts are structured. Another important case for the mentioned gaps are represented by the language and translation regimes associated with these offices and courts. Not rarely, these regimes belong to the past and should be re-evaluated in terms of the changes represented by the advent of quality machine translation which changed the global configuration of the patent system. Likewise, the new digital tools on communication and translation, which are a key part of the association between this new scenario and the process of patent prosecution, require a comparative assessment of these language regimes, resulting in substantiated recommendations for their updating, integration and harmonization.

The same happens with interdisciplinary research involving language/legal/ technical aspects of the patent system. Interdisciplinary research involving those areas is still looked at with suspicion and prejudice based on defensive ways of thinking and ideas. However, interdisciplinary programmes focusing on those fields could bring new perspectives to patent studies and necessary solutions to the improvement of the patent system. All the questions raised above represent significant problems in the current 
patent system and are far from forming an exhaustive list of the possibilities of language/ translation/disclosure related research topics.

\subsection{Fallacies and generalizations to be avoided in dealing with the subject of patent translation and disclosure}

In the course of this work, and after dealing with debates and questions over the topic, it was possible to collect a large set of false assumptions and erroneous arguments proved to be fallacies on interpreting the role of translation to the patent system. Common sense leads to prejudice against machine translation and to the assumption that human translation done by certified or renowned companies is always "right". In sum, the topic, not rarely, raises resistance, especially from audiences that are not acquainted with the daily activity of patent attorneys and examiners or from those who have their own fixed perceptions. ${ }^{950}$

Actually, some of the most important issues discussed on the present work may be not easy to recognize, if the ideas over the topic are pre-conceived and lack scientific honesty or an effort to analyse and understand it. Therefore, as a final contribution of the present research, a list of these preconceptions and fallacies and a short answer to them is summarized below, with the intention to contribute to a continuous reflexion over the nature of the patent system and its relationship with translation, disclosure and dissemination of patent content.

The first fallacy over the relation between machine translation and disclosure is the idea that machine translation is not to be taken seriously and will never replace the work of a human translator. The common sense tends to believe that it is evident that machine translation cannot be the basis of the disclosure of a patent document. Yet the results of this research showed that both patent attorneys and patent examiners have to rely on machine translation regularly to perform their activities. They also showed that the advent of quality machine translation has enabled businesses with offices or countries which were not possible before due to language barriers. ${ }^{951}$ The results of the sample analysis demonstrated that machine translation discloses around $80 \%$ of patent content, which consists of a level considered as high in terms of translation quality assessment. ${ }^{952}$

The legal literature indicates that machine translation is part of the process of patent prosecution and, although it is not legally binding, it represents an important support tool for the whole process. ${ }^{953}$ The patent system only became global in terms of disclosure and dissemination of patent information after the advent of quality machine

950 For a similar approach on fallacies and generalizations under another research, see Larroyed (2019).

951 See Sections 6.2, 6.3, 6.4 and 6.5 for examples of patent cases and for the results of the interviews.

952 See Sections 4.2 and 4.3 for the results of the sample analysis.

953 See Section 1.2.4. 
translation. Furthermore, before the use of quality machine translation, in only one decade ago, the examination was restricted to national prior art. ${ }^{954}$

The second fallacy goes to the opposite direction of the first one, and is related to the belief that the quality of machine translation has improved so much that, with the support of drawings, patents are easily and totally disclosed. This idea can be associated with believing that machine translation is not used as the basis of disputes and cannot play any role in patent cases. Nevertheless, patent texts are full of subtleties, and their meaning can easily change when they are translated from one language to the other, affecting the scope of the patent. Therefore, a misinterpretation of prior art, through machine translation, during the process of patent examination is not rare and can have a snow ball effect, being the reason to further legal challenges. The same is true for the process of triage of evidence documents, for informing the arguments of the parties in infringement cases. That is why the figure of the legal technologist became important in patent cases.

It is possible to presume, from the small percentage (around 2\% in Europe) of patents which raise a dispute that studying the influence of translation on patent court cases is not relevant scientifically. Nevertheless, this number varies depending on the jurisdiction and can be higher than $2 \%$. Normally, those cases have a lot at stake, being able to cost the survival of an SME or to unfairly cause serious damage to a companies investing in innovation, corrupting the patent system and impairing legal certainty related to patent law..$^{955}$

Assuming that machine translation does not play a role in the patent system is not rare. However, machine translation universalized the dissemination of the disclosure of patent documents and reshaped the patent system into a global structure. Machine translation is present in all the legal stages of a patent and can play a crucial role in any of them. It permanently interact with human translation during the stages of examination and opposition and in infringement cases.

Another common fallacy related to the current topic is presuming that studies on language or translation related to the patent system should be restricted to language departments. This presumption disregards the fact that the patent system is complex and requires a lot of previous, technical knowledge from a researcher, related to its structure and to its filiation to intellectual property rights. The ideal environment for a multidisciplinary study associating these fields will depend on the research question that motivates the study. The existence of multidisciplinary studies will promote important bridges between the mentioned fields, which can benefit both of them.

Other distorted ideas involve the translation budget impact related to machine translation. The decrease of costs in searching for prior art is a relevant consequence of the advent of machine translation. It encourages companies to file more patents and to file more cases against their competitors when necessary. Machine translation enables a pre-search of documents before they are selected to professional human translation. This

954 See Chapters 6 and 7, especially Section 7.5.

955 See Section 7.2.2 for the statistics and references. 
possibility completely changed the configuration of the patent system. Further studies are recommended to analyse this impact. ${ }^{956}$

Statements and arguments diminishing the value and importance of machine translation are neither useful nor realistic for understanding the current scenario of the patent system. Professionals who regularly deal with patent searches benefit from the use of machine translation and will profit even more from its use as far as its quality increases. Furthermore, the use of machine translation in disclosing patent information tends to increase its level of dissemination among other users and social groups, as new tools and databases are still to come. 
CHAPTER 9

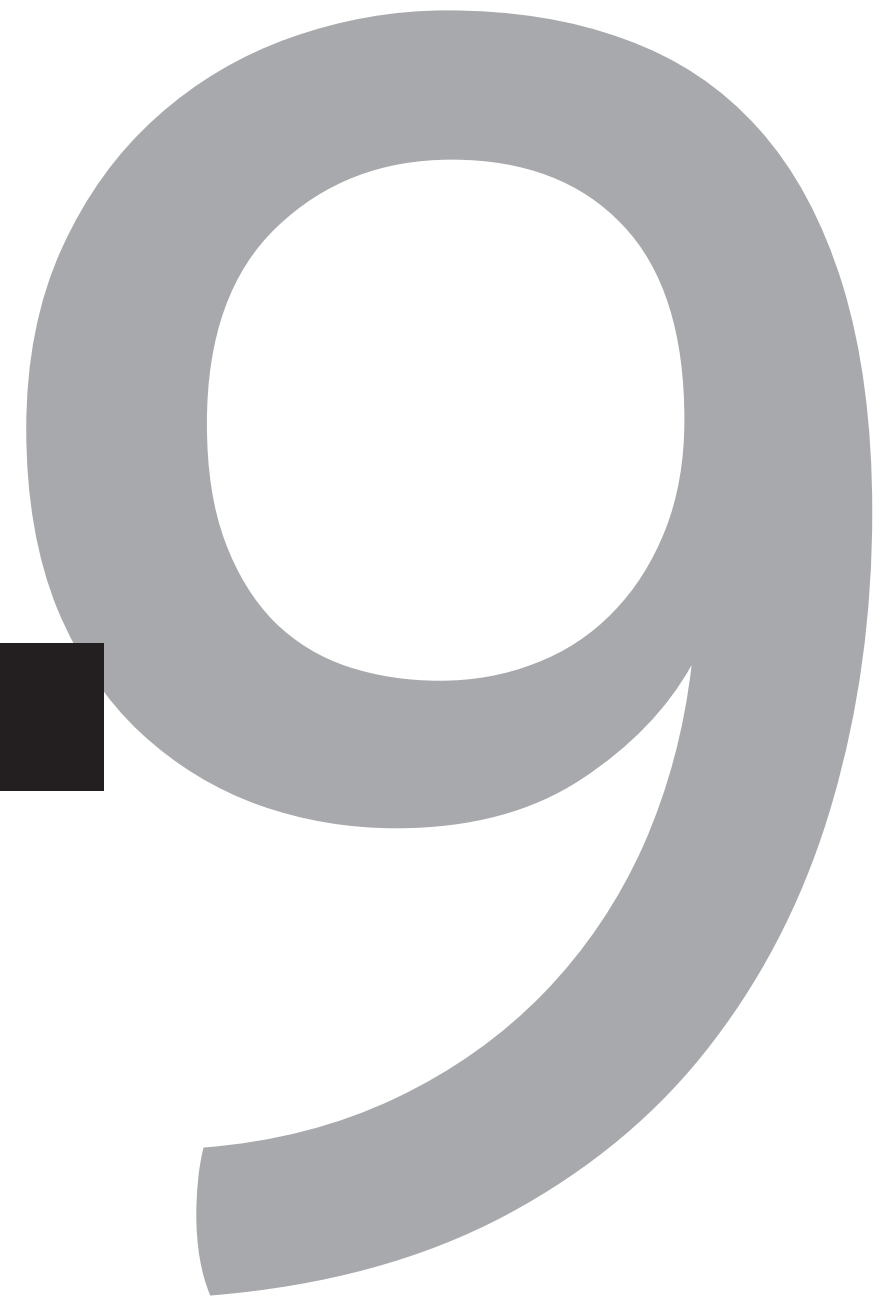


References 


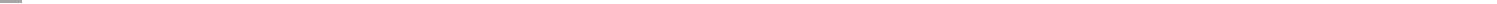




\subsection{Literature}

Abrantes, A. C., 'May Patents Contribute to Innovation in the Sector of Information Technology?', PIDCC, II (02), 2013, pp. 45-72, www.pidcc.com.br_(accessed 18 April 2018).

Abrantes, A. C., Introdução ao sistema de patentes, Lumen Juris, 2011.

Adams, S., 'Lost in Translation? A Review of the Post-Grant Requirements for Translation of Patent Specifications in Europe', World Patent Information, no 44, 2016, pp. 34-45.

G. Allen, Intertextuality, Routledge, 2000.

Asante, M., et al., The global intercultural communication reader, $2^{\text {nd }}$ ed., Routledge, 2014, pp. 17-18. See also: E. Hall and W. Whyte, 'Intercultural communication: a guide to men of action', Human Organization, vol. 19, no. 1, 1960, pp. 5-12. JSTOR, JSTOR, www.jstor.org/stable/44124458 (accessed 8 november 2018).

Ardissone, C., Ideias, Instituições e Lideranças na Política Brasileira de Propriedade Intelectual: uma abordagem comparada dos Governos Fernando Henrique Cardoso e Luiz Inácio Lula da Silva (19952010), PhD Dissertation. PUC, Rio de Janeiro, 2011.

Arnold, R., 'A Short History of the Unitary European Patent and the Unified Patent Court', CIPA Congress, 2015 http://www.cipa.org.uk/pages/journal/article?35DC374C-278B-4E30-9A9A9FC679FD27C6

Arnold, R., 'A Short History of the Unitary European Patent and the Unified Patent Court', CIPA Congress, 2015, http://www.cipa.org.uk/pages/journal/article?35DC374C-278B-4E30-9A9A9FC679FD27C6 (accessed 17 April 2018).

Baechtold, R., The Intellectual Property Review, Law Business Research, London, 2012.

Bahdanau, D., et al.,'Neural Machine Translation by Jointly Learning to Align and Translate', Published as a Conference Paper at ICLR, 2015, https://arxiv.org/pdf/1409.0473.pdf

Barbosa P., and D. Barbosa, O Código de Propriedade Industrial conforme os Tribunais, Rio de Janeiro, Lumem Juris, 2011.

Barbosa, D., Uma Introdução à Propriedade Intelectual. Rio de Janeiro, Lumen Juris, 2010.

Baron, N., Speech, Writing and Sign, Bloomington, Indiana University Press, 1981.

Bassanini, A., The European Patent Office: An Introduction to the EPO and the European Patent System [Presentation], 2015, http://www.uibm.gov.it/attachments/Presentazione_Anna_ Bassanini.pdf (accessed 18 April 2018).

Benjamin, W., 'The Task of the Translator' [first printed as introduction to a Baudelaire translation, 1923], in Illuminations, trans. Harry Zohn; ed. \& intro. Hannah Arendt, NY, Harcourt Brace Jovanovich, 1968, pp.69-82.

Berg, B., Qualitative Research Methods for the Social Sciences, Boston, Allyn \& Bacon, 4th edition, 2001.

Bodenhausen, G., Guia para la Aplicacion del Convenio de Paris para la Proteccion de la Propriedad Industrial, WIPO, Geneva, 1969, http://www.wipo.int/edocs/pubdocs/en/intproperty/611/ wipo_pub_611.pdf (accessed 18 April 2018).

L. Bowker, L. Computer Aided Translation: a practical introduction. University of Ottawa Press, 2004. 
Brenner, N., Beyond State-Centrism? Space, Territoriality, and Geographical scale in Globalization Studies, Theory and Society, Kluwer Academic Publishers, 1999.

Brewster, R., The Surprising Benefits to Developing Countries of Linking International Trade and Intellectual Property. 12 Chicago Journal of International Law, 1 (54), 2011, https://scholarship. law.duke.edu/faculty_scholarship/2635/

Brisset, A., Sociocritique de la traduction: Théâtre et altérité au Québec, Longueuil, 1990.

Brown P., et al., A Statistical Approach to Machine Translation. Computational Linguistics, 16(2), 1990, pp. 76-85.

Cademartori, L. H., and G. Baggentoss, 'A Coerência do Sistema Jurídico em Luhmann: uma Proposta ao Fechamento Operacional e à Abertura Cognitiva da Decisão Judicial', Sequencia Estudos Jurídicos e Políticos, Ano XXXII, no 62, 2011.

Cademartori, L. H., and F. C. Duarte, Hermenêutica e Argumentação Neoconstitucional, São Paulo, Atlas, 2009, pp. 195-201.

Carvalho, N., A Estrutura dos Sistemas de Patentes e de Marcas: Passado, Presente e Futuro, Rio de Janeiro, Lumen Juris, 2009.

Castells, M., and G. Cardoso, The Network Society: From Knowledge to Policy, Washington DC, Johns Hopkins Centre for Transatlantic Relations, 2005.

Chakroun, N., Patents for development: improved patent information disclosure for incremental innovation, Cheltenhan, Edward Elgar, 2016, pp. 45-46.

Chang, H-J., Kicking Away the Ladder-Development Strategy in Historical Perspective, London, Anthem Press, 2002.

Chesbrough, H., Open Innovation: The New Imperative for Creating and Profiting from Technology, HBS Press, 2003.

Chisum, D., and S. Farmer, 'Lost in Translation: The Legal Impact of Patent Translation Errors on Claim Scope'. In: Takenaka, T., Patent Law and Theory - a Handbook of Contemporary Research, Edward Elgar, 2008.

Christensen, P., and A. Schjoldager, 'The Impact of translation-memory technology (TM) on cognitive processes: student-translators' retrospective comments in an online questionnaire', In Sharp et alii, Human-machine interaction in translation, Proceedings of the 8th NLPCS Workshop, Copenhagen Business School, 2011.

Coase, R., 'The Federal Communications Commission', 2 Journal of Law, 1959, pp. 1-40;

Coase, R., 'The Problem of Social Cost', 3 Journal of Law and Economics, pp. 1-44, 1960.

Coase, R., The Federal Communications Commission, Journal of Law and Economics, no 2, 1959, pp. $1-40$.

Coase, R., The Nature of the Firm. Economica, no. 4, pp. 386-405, 1937.

Cornish, W., and Llewelyn, D., Intellectual property: patents, copyright, trademarks and allied rights, London, Sweet \& Maxwell, 2007.

Cremers, K., et al., Patent litigation in Europe, European Journal of Law and Economics, vol. 44, 2017, https://link.springer.com/journal/10657

Culler, I., Ferdinand de Saussure. Cornell University Press, 1986. 
Deloitte, Patente Europeia com Efeito Unitário, January, 2015, http://cip.org.pt/wpcontent/ uploads/2015/03/CIP_Patente-Europeia_Report2015.pdf (accessed 17 April 2018).

DeMatteis, B., et al., From Patent to Profit: Secrets and Strategies for the Successful Inventor, SquareOne Publishers, 2005, p. 183.

DeMatteis, B., A. Gibbs and M. Neustel, The Patent Writer: How to Write Successful Patent Applications. Square One Publishers, 2006.

Denning, P., and R. Dunham, Innovation and Language Action, Communications of the ACM, Vol. 49, no 5, 2006.

Devlin, A., The Misunderstood Function of Disclosure in Patent Law, Harvard Journal of Law \& Technology, vol. 2, no 23, 2010.

Drahos, P., 'Global Property Rights in Information: the story of TRIPS at the GATT', Prometheus, vol. 13, no 1, 1995.

Drahos, P., 'The Universality of Intellectual Property Rights: Origins and Development', World Intellectual Property Rights Organization [Website], Intellectual Property and Human Rights, 1999, http://www.wipo.int/edocs/mdocs/tk/en/wipo_unhchr_ip_pnl_98/wipo_unhchr_ip_ pnl_98_1.pdf (accessed 18 April 2018).

Drahos, P., The Global Governance of Knowledge: Patent Offices and their Clients, Cambridge University Press, 2010.

Etzkowitz H., and L. Leydesdorff, 'The Dynamics of Innovation: from National Systems and "mode 2 " to a Triple Helix of University-Industry-Government Relation'. Research Policy 29, 2000, pp. 109-123.

Etzkowitz, H., 'The Evolution of the Entrepreneurial University'. Technology and Globalisation, vol.1, no 1, 2004.

Evans, D., Language and Identity. Discourse in the World, Bloomsbury, 2015, pp. 3-9, p. 201.

Farrel, J. and R. Merges, 'Incentives to Challenge and Defend Patents: Why Litigation Won't Reliably Fix Patent Office Errors and Why Administrative Patent Review Might Help', Berkeley Technology Law Journal, vol. 19, no. 3, 2004, pp. 943-970, http://www.jstor.org/stable/pdf/24116722.pdf (accessed 18 April 2018).

Fiani, R., Saber Tecnológico para Quem e para o Quê? A questão das patentes. Anais da 64a Reunião Anual da SBPC, São Luís, MA, Brazil, 2012.

Firth, A.. 'The Discursive Accomplishment of Normality: on Lingua Franca English and Conversation Analysis', Journal of Pragmatics, vol. 26. no 2, 2006, pp.237-59.

's, J., 'Patent Disclosure', 94 IOWA L. Rev. 539, 606, 2009, pp. 544-560, file:///C:/Users/Lenovo/ Downloads/JeanneCFromerPatentDisclo.pdf (accessed 15 April 2018).

Garcez, J., and J. Moreira, The Backlog of Patent In Brazil: The Right to Reasonable Duration of the Administrative Procedure, Rev. Direito GV, vol.13 no.1 São Paulo, 2017, http://www.scielo.br/ scielo.php?pid=S1808-24322017000100171\&script=sci_arttext\&tIng=pt

Gazzola, M., 'Conti Precisi sull'importanza Economica delle Lingue nei Brevetti Industriali'. La Crusca per Voi, 42, 2011. 
Gazzola, M., 'Identifying and Mitigating Linguistic Inequalities in the Management of Patent Information in Europe', World Patent Information, no. 40, 2015a, pp. 43-50.

Gazzola, M., 'Il Multilinguismo Svizzero nel Sistema Europeo dei Brevetti', Babylonia, no. 12, 2014c.

Gazzola, M., 'Is ELF more Effective and Fair than Translation? An Evaluation of the EU's Multilingual Regime', International Journal of Applied Linguistics, vol. 23, no. 1, 2013.

Gazzola, M., 'La Valutazione della Ricerca el' Internazionalizzazione Dell'università: quali Effetti sulla Diversità Linguistica?', Plurilinguismo Contatti di Lingue e Culture, 15, 2010.

Gazzola, M., 'Language Policy and Innovation. An Evaluation of the Language Regime of the PCT System', Elf Working Papers, 2014b.

Gazzola, M., 'Managing Multilingualism in the European Union: Language Policy Evaluation for the European Parliament', Language Policy, 2006a.

Gazzola, M., 'Partecipazione, Esclusione Linguistica e Traduzione. Una Valutazione del Regime Linguistico dell'Unione Europea'. Studi Italiani di Linguistica Teorica e Applicata, no. 2, 2014d.

Gazzola, M., and F. Grin, 'La puissance économique du français', in Maurais et al., L'avenir du français, Éditions des Archives Comteporeines, 2007a.

Gazzola, M., and F. Grin, 'The Dylan Linguistic Indicators', Version May 2013, http://www.dylanproject.org/Dylan_en/GAZZOLA_GRIN_DYLANindicators.pdf_(accessed 23 April 2018).

Gazzola, M., and F. Grin, Assessing efficiency and fairness in multilingual communication, John Benjamin's Publishing Company, 2007b.

Gazzola, M., and T. Malloy, 'The Aspect of Culture in the Social Inclusion of Ethnic Minorities Evaluation of the impact of inclusion policies under the Open Method of Co-ordination: Assessing the Cultural Policies of Six Member States of the European Union', ECMI Report, 60, December, 2006b.

Gazzola, M., and A. Volpe, 'Linguistic Justice in IP Policies: Evaluating the Fairness of the Language Regime of the European Patent Office', European Journal of Law and Economics, vol. 38, no. 1, 2014e, 47-70.

Gazzola, M., F. Grin, and B. Wickström, 'A Concise Bibliography of Language Economics', CESIFO Working Paper No. 5530, Category 1, Public Finance September, 2015b.

Gazzola, M., I Diritti Linguistici, Pisa, Multilinguismo e Societá, 2009.

Gazzola, M., The Evaluation of Language Regimes: Theory and Application to Multilingual Organizations, Amsterdam, John Benjamins Publishing Company, 2014a.

Gazzola, M., Una Tassa Linguistica sui Paisi Anglofoni? Equitá e Comunicazione Internazionale in Europa, Lingua Italiana d'Oggi, 2008, http://www.academia.edu/667476/Una_tassa_linguistica_ sui_paesi_anglofoni_Equit\%C3\%A0_e_comunicazione_internazionale_in_Europa

Gazzzola M., and Guerini, F.,'Le Sfide della Politica Linguistica di Oggi', Collana di Educazione Bilingue, 2012.

Gervais, D., The TRIPS Agreement - Drafting History and Analysis, Sweet \& Maxwell, 2003.

Gervais, D., The Internationalization of Intellectual Property: New Challenges from the Very Old and the Very New, Fordham Intellectual Property, Media and Entertainment Law Journal, Vol. 
12, no 4, 2002, https://ir.lawnet.fordham.edu/cgi/viewcontent.cgi?article=1232\&context=iplj (accessed 19 November 2018).

Gibbs, A., and B. DeMatteis, Essentials of patents, John Wiley \& Sons, 2003.

Gil, A. C., Métodos e técnicas de pesquisa social, 5.ed., São Paulo, Atlas, 1999.

Goldstein, J., Complexity Science Applied to Innovation - Theory meets Praxis. The Innovation Journal: The Public-Sector Innovation Journal, vol. 13, no. 3, article 1, 2008.

Gollin, M., 'Using Intellectual Property to Improve Environmental Protection', Harvard Journal of Law \& Technology, Vol. 4, 1991.

Grindheim, J., and T. Lohndal, 'Lost in Translation? European Integration and Language Diversity', Perspectives on European Politics and Society, Vol. 9, No 4, 2008.

Guennif, S., 'Evaluating the Usefulness of Compulsory Licensing in Developing Countries: a Comparative Study of Thai and Brazilian Experiences regarding Access to AIDS Treatments', Bioethics, vol. 17, 2017, pp. 90-99, http://onlinelibrary.wiley.com/store/10.1111/ dewb.12124/asset/dewb12124.pdf;jsessionid=5C9C6F807C795335A2A3432575179833. f04t04? v=1\&t=jdndjmip\&s=ae82f55af61a454f79a82501853f218a168a3c55

Günther, K., The sense of appropriateness. Application discourses in morality and law, New York Press, 1993.

Hajič, J. and K. Kuboň, 'Machine Translation of Very Close Languages', Proceedings of the sixth conference on applied natural language processing, 2000, pp. 7-12, http://dl.acm.org/citation. $\mathrm{cfm}$ ?id=974149

Hall, B., 'The global nature of the patent system', Toronto IP Conference, 2001, https://eml.berkeley. edu/ bhhall/papers/BHH01_Toronto_Maskusdiscussion.pdf

Halliday, M.A.K., An Introduction to Functional Grammar, London, Edward Arnold, 1985.

Hannigan, J., Environmental sociology, London and New York, Routledge, 2014.

Hausmann, H., et al., The atlas of economic complexity, Harvard/MIT, 2006, https://atlas.media.mit. edu/static/pdf/atlas/AtlasOfEconomicComplexity_Part_I.pdf

Hiltunen, R., 'The grammar and structure of legal texts', in Tiersma, P. \& Solan, The Oxford handbook of language and law, Oxford University Press, 2012, pp. 39-51.

Holger, E., Patent Information for Strategic Technology Management, World Patent Information, 2003, http://hadjarian.org/portfolio/1-s2.0-S0172219003000772-main.pdf

Huang, M., et al., 'Globalization of collaborative creativity through cross-border patent activities', Journal of Informetrics, vol. 6, 2012, 226-236.

Hutchins, J., Machine translation: past, present, future. Ellis Horwood Ltd, 1986.

Hutchins, J., 'Machine Translation and Human Translation: in Competition or in Complementation?' International Journal of Translation, vol. 13, no. 1-2, Special theme issue on machine translation, edited by Michael S. Blekhman, 2001, pp.5-20.

Hutchins, J., 'The history of machine translation in a nutshell' (self-published), 2005, http://www. hutchinsweb.me.uk/Nutshell-2005.pdf 
Jaeger, T., 'Reset and Go: The Unitary Patent System Post-Brexit', IIC - International Review of Intellectual Property and Competition Law, vol. 48, no 3, 2017, pp 254-285, https://link.springer. com/article/10.1007/s40319-017-0569-y (accessed 18 April 2018).

Jain, S., Patents Procedures and Practices, Universal Law Publishing, 2010, pp. 6, 65, 140 and 204.

Jakobson, R., Linguística e Comunicação, São Paulo, Cultrix, 1991.

Jansson, U., Patent Documents as a Source of Technological Information, WIPO Roving National Seminar on Industrial Property, 2000, http://www.wipo.int/edocs/mdocs/sme/en/wipo_ip_ et_00/wipo_ip_et_00_9.pdf (accessed 16 April 2018).

Kitch, E., 'The Nature and Function of the Patent System', Journal of Law and Economics, vol. 20, no. 2, pp. 265-290.

Koehn, F. D., et al. (coord.),'Moses: Open Source Toolkit for Statistical Machine Translation', Proceedings of the ACL, Prague, 2007.

Koehn, P., 'Statistical Machine Translation Draft of Chapter 13 Neural Machine Translation', Johns Hopkins University, 2017, p. 6, https://arxiv.org/pdf/1709.07809.pdf

Kohlbacher, F., 'The Use of Qualitative Content Analysis in Case Study Research', Forum Qualitative Sozialforschung/Forum: Qualitative Social Research, Vol 7, No 1, 2006.

Krippendorff, K., Content Analysis: An Introduction to Its Methodology, Second Edition, Thousand Oaks, CA: Sage, 2004.

Landes, W., and Posner, R., The Economic Structure of Intellectual Property Law, Harvard University Press, 2003.

Landes, W., and Posner, R., The Political Economy of Intellectual Property Law, Washington D.C., AEIBrookings Joint Centre for Regulatory Studies, 2004.

Larroyed, A., Os Efeitos da Tradução no Sistema de Patentes, PhD Dissertation, UFSC, Florianopolis (2019, as yet unpublished).

Larroyed, A., and L. H. Cademartori,'O Efeito do Acordo TRIPS sobre o Sistema Jurídico Internacional sob a Ótica da Teoria Sistêmica de Niklas Luhmann: o Caso Brasileiro', in L. Cademartori and S. Mota, Direito: Teoria e Sistemas, Florianópolis, Ed. Insular, 2015.

Larroyed, A., and L. O. Pimentel, 'A Atual Legislação de Proteção Intelectual para Software na Rússia - Conceitos e Entendimentos', X Congresso de Direito da UFSC, 2015.

Larroyed, A., et al., 'A Relação Histórica entre a Metrologia e a Propriedade Intelectual no Brasil: Coincidências, Semelhanças ou Interdependência?', Revista Enciclopédia Biosfera, vol. 11, no. 21, 2015.

Leopardi, M., and H. Esteves, 'Droits de Proprieté - Éléments pour la Construction d'un Concept Interdisciplinaire', XIII Colloque International de I'Association Charles Gide pour l'Étude de la Pensée Economique, Paris, 2010.

Li, H., A. Graesser, and Z. Cai, 'Comparison of Google Translation with Human Translation', Proceedings of the Twenty-Seventh International Florida Artificial Intelligence Research Society Conference, 2014, https://www.aaai.org/ocs/index.php/FLAIRS/FLAIRS14/paper/viewFile/7864/7823

Lianos, I., 'A Regulatory Theory of IP: Implications for Competition Law', CLES Working Paper Series, 2008, https://www.ucl.ac.uk/cles/research-paper-series/research-papers/cles-1-2008 
Luhmann, N., 'La Constituzione come Acquisizione Evolutiva', in G. Zagrebelsky (coord.). et al., II Futuro Della Costituzione. Torino: Einaudi, 1996.

Luhmann, N., El Derecho de la Sociedad, Ciudad de Mexico, Hender, Universidad Iberoamericana, 2005.

Luhmann, N., Introdução à Teoria dos Sistemas, Petrópolis, Vozes, 2009.

Luhmann, N., Law as a Social System, Oxford University Press, 2004.

Luhmann, N., Sociologia do Direito II, Rio de Janeiro, Tempo Brasileiro, 1985.

Lundberg, S., S. Durant, and A. Mccrackin, Electronic and software patents, The Bureau of National Affairs, 2005, pp. 9-14.

Lundvall, B.,'National Innovation Systems - Analytical Concepts and Development Tool', Industry and Innovation, vol. 14, 2007.

Machlup F., and E. Penrose, 'The Patent Controversy in the Nineteenth Century', The Journal of Economic History. New York, Economic History Association, vol. 10 no. 1, 1950, pp. 1-29, http:// c4sif.org/wp-content/uploads/2010/09/Machlup-Penrose-The-Patent Controversy-in-theNineteenth-Century-1950-b.pdf.

Marco, A., et al., Patent Litigation Data from US District Court Electronic Records (1963-2015), USPTO Economic Working Paper, no 2017-06, https://papers.ssrn.com/sol3/papers.cfm?abstract_ $\mathrm{id}=2942295$

Martins, A., and C. Oliveira, 'A contribuição de Klaus Günther ao debate acerca da distinção entre regras e princípios', Revista Direito GV, vol. 2 no. 1, 2006, pp. 241 - 254.

Maskus, K., 'Intellectual property rights and economic development', Case Western Reserve Journal of International Law, no 32, 2000, pp. 447-485.

Maturana, H., and F. Varela, A Árvore do Conhecimento: as Bases Biológicas da Compreensão Humana, São Paulo, Palas Athena, 2001.

May, C., and S. Sell, Intellectual Property Rights: a critical History, London, Lynne Rienner Publishers, 2006.

Merges, R., Justifying Intellectual Property, Harvard University Press, 2011.

Merton, R., The Sociology of Science: Theoretical and Empirical Investigations, University of Chicago Press, 1979.

Montgomery, S., Science in Translation: Movements of Knowledge through Cultures and Time, The University of Chicago Press, 2000.

Moral, S., '¿Qué discurso para la moral? Sobre la Distinción entre Aplicación y Justificación en la Teoría del Discurso Práctico General', Doxa, vol. 21 no. 1, 1998.

Montobbio, F. and V. Sterzi, 'The Globalization of Technology in Emerging Markets: A Gravity Model on the Determinants of International Patent Collaborations', World Development, vol. 44, 2013, pp. 281-299.

Moura, M., and T. Rafagnin, 'O Direito na Teoria de Niklas Luhmann', Quaestio Juris, 11(1), 2018, pp. 173-194, http://www.e-publicacoes.uerj.br/index.php/quaestioiuris/article/view/25850/23306 (accessed 18 April 2018).

Mueller, J., Patent Law, New York, Aspen Publishers. 
Murthy, K. and T. Alam, Globalisation and Patents: A Study of Patents filed by India, MANTHAN: Journal of Commerce and Management, vol. 1, no. 2, 2014, pp. 29-46.

Lillis, B., Globalization and harmonization of intellectual property, Buffalo Law Journal, Dec 31, 2015, https://www.bizjournals.com/buffalo/news/2015/12/31/globalization-and-harmonization-ofintellectual.html (accessed 7 november 2018).

Nanba, H., et al., Automatic Translation of Scholarly Terms into Patent Terms Using Synonym Extraction Techniques, Irec-conf.org/proceedings/Irec， 2012， http://www.Irec-conf.org/proceedings/ Irec2012/pdf/1043_Paper.pdf

Nelson, R., Capitalism as an engine of progress, Research Policy, vol. 19, no. 3, 1990.

Neto, L., Novos Direitos ou Novos Objetos para o Direito. Porto, 2010, p. 179.

Neto, Novos Direitos ou Novos Objetos para o Direito. Porto, 2010.

Olohan, M., Scientific and technical translation, Routledge, 2015.

Papineni, K., et al., BLEU: A Method for Automatic Evaluation of Machine Translation, et al., BLEU: A Method for Automatic Evaluation of Machine Translation, ACL '02 Proceedings of the 40th Annual Meeting on Association for Computational Linguistics, 2002, pp. 311-318.

Parent, A., On Ambiguity and Incongruity of Terms in Translations of International Treaties. Vertimo Studijos, 2009.

Pêcheux, M., Language, Semantics and Ideology, New York, St Martin's Press, 1982.

Pedron, F., 'A Contribuição e os Limites da Teoria de Klaus Günther: a Distinção entre Discursos de Justificação e Discursos de Aplicação como Fundamento para uma Reconstrução da Função Jurisdicional', Revista da Faculdade de Direito - UFPR, Curitiba, no. 48, 2008, pp. 187-201.

Perez, C., Technological Revolutions and Technoeconomic Paradigms. Cambridge Journal of Economics, 34, 2010, pp. 185-202.

Petroski, K., Legal Fictions and the Limits of Legal Language, International Journal of Law in Context, 9, 2013.

Pignuoli, S., 'El Modelo Sintético de Comunicación de Niklas Luhmann', Cinta Moebio, no. 47, 2013, pp. 59-73, www.moebio.uchile.cl/47/pignuoli.html

Pimentel, L. O., O Acordo sobre os Aspectos dos Direitos de Propriedade Intelectual Relacionados com o Comércio, Revista Sequência, UFSC, Florianópolis, 44 (23), 2002, https://periodicos.ufsc. br/index.php/sequencia/article/view/15338/13929

Pitkethly, R., 'The European Patent System: Implementing Patent Law Harmonisation', International Symposium on Innovation and Patents, 1999, http://users.ox.ac.uk/ mast0140/EJWP1099.pdf

Plomer, A., 'A Unitary Patent for a (Dis)United Europe: The Long Shadow of History Published online. Max Planck Institute for Innovation and Competition', IIC, vol. 46, no 5, 2015, http://paperity.org/

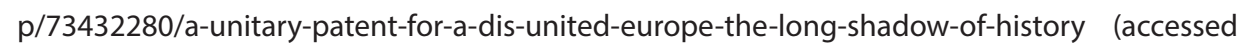
18 April 2018).

Pollaud-Dulian, F., Propriété intellectuelle: La propriété industrielle, Paris, Economica, 1901.

Posner, R., and R. Coase, 'The Nature of the Firm', 4 Economica, 386-405, 1937. 
Rahmatian, A., 'Neo-Colonial Aspects of Global Intellectual Property Protection', The Journal of World Intellectual Property, vol. 12, no. 01, 2009, pp. 40-74, http://www.farzadalvi.com/wp-content/ uploads/2012/01/Rahmatian-2009.pdf (accessed 18 April 2018).

Ramos, F., International and Supranational Law in Translation: from Multilingual Lawmaking to Adjudication. The Translator, vol. 20, no. 3, 2014, 313-331. http://www.tandfonline.com/doi/pd f/10.1080/13556509.2014.904080 (accessed 18 April 2018).

Riley, P., 'Language, Culture and Identity: An Ethnolinguistic Perspective', Continuum, 2007, p. 6.

Russia, Fundamental Principles of Civil Legislation of the U.S.S.R. and Union Republics, 1961, reviewed in 2006. Retrieved from http://www.wipo.int/wipolex/en/details.jsp?id=6775_(accessed 18 April 2018).

Sanders, A., and Shabalala, B., 'Intellectual Property Treaties and Development', in D. Gervais (ed.), Intellectual Property Trade and Development, Oxford University Press, 2014, http://ssrn.com/ abstract $=2178423$ (accessed 18 April 2018).

Šarčević, S., New approach to legal translation, Kluwer Law International, 1997, pp. 1-7.

Saussure, F., Cours de linguistique générale, Paris, Édition Payot et Rivage, 1995.

Scotchmer, S. and Green, J., Novelty and disclosure in patent law, The RAND Journal of Economics, vol. 21, no. 1, 1990, pp. 131-146, https://www.jstor.org/stable/pdf/2555499.pdf (accessed 8 November 2018).

Schumpeter, J., Capitalism, Socialism and Democracy, London, Taylor \& Francis e-Library, 2003.

Seidl, A., Luhmann's theory of Autopoietic Social Systems, Business Research, no. 2. 2004, http:// www.zfog.bwl.uni-muenchen.de/files/mitarbeiter/paper2004_2.pdf (accessed 18 April 2018).

Seidl, A., Sociologia do Direito II, Rio de Janeiro: Tempo Brasileiro, 1985, p. 18.

Sell, S.,'Intellectual Property and Public Policy in Historical Perspective: Contestation and Settlement', vol. 38, no. 267, 2004, http://digitalcommons.Imu.edu/llr/vol38/iss1/6 (accessed 18 April 2018).

Selltiz, C., 'Planejamento de pesquisa', in Métodos de pesquisa nas relações sociais, São Paulo, Ed. Herder e Editora da Universidade de São Paulo, 1967, pp. 57-160.

Sheldon, J., How to Write a Patent Application. Practicing Law Institute, $3^{\text {rd }}$ Ed., 2015.

Somers, H., 'Example-Based Machine Translation', Machine Translation, vol. 14, no. 2, 1999, 113-157.

Somssich, R. (Research Coord.), Studies on translation and multilingualism: language and translation in international law and EU law, European Commission, 2013,https://publications.europa.eu/ en/publication-detail/-/publication/04af98d5-bbda-4b46-ba73-5238e8297a89/language-en (accessed 22 April 2018).

Sousa e Silva, P., 'O Tribunal Unificado de Patentes', Revista de Direito Intelectual, no. 2014-I, pp. 243257, http://www.ptcs.pt/public/wax_documents/PSS-TUP.pdf (accessed 3 July 2018).

Stauder, D., and Singer, M., European Patent Convention: A Commentary, Thomson, Cologne, 2003.

Stauder, D., and Singer, M., European Patent Convention: A Commentary, Thomson, Cologne, 2003, p. 369.

Steiner, G., After Babel. Aspects of Language and Translation, Oxford University Press, 1992.

Stokes, D., O quadrante de Pasteur: a ciência básica e a inovação tecnológica, São Paulo, Editora da UNICAMP, 2005. 
Stolze, R., 'The Legal Translator's Approach to Texts', Humanities, no. 2, 2013, 56-71. file:///C:/Users/ Win7/Downloads/humanities-02-00056\%20(1).pdf (accessed 18 April 2018).

Streck, L., and S. Sito, A crítica hermenêutica e a cisão dos discursos em Klaus Günther, Estudos Jurídicos, n. 17, 2012. http://siaiap32.univali.br/seer/index.php/nej/article/view/4211/2431 (accessed 18 April 2018).

Szalewski, J. and P. Schmidt, Droit de la proprieté industrielle, Paris, Litec, 1996.

Takenaka, T., Patent Law and Theory. Edward Elgar Publishing, 2009.

Tojal, S., and Pessôa, P., A Anuência Prévia na Concessão de Patentes de Medicamentos e a Regulação Econômica da Indústria Farmacêutica, Revista de Direito Sanitário, São Paulo, vol. 8 no. 3, pp. 148-165.

Trigo, M., and V.Trojan, 'A anuência prévia da ANVISA em relação à concessão de patentes e sua causa de conflitos jurisprudenciais com o INPI', Revista Jurídica, no. 121, http://revistavisaojuridica.uol. com.br/advogados-leis-jurisprudencia/121/sumario.asp (accessed 18 April 2018).

Ulitkin, I., 'Human Translation vs. Machine Translation: Rise of the Machines', Translation Journal, 2013, http://translationjournal.net/journal/63mtquality.htm (accessed 18 April 2018).

Van Zeebroeck N., et al., 'Patent litigation across countries', Brussels, EPIP Conference, 2011, http:// www.epip.eu/conferences/epip06/papers/Keynotes/Nicolas\%20VAN\%20ZEEBROECK.pdf (accessed 18 April 2018).

Venuti, L., The Translator's Invisibility, New York, 1997.

Venuti, L., Rethinking Translation, London \& New York, Routledge, 1992.

Vermeer, M., A New Era in Russian Copyright Law: Protecting Computer Software in the Post-Soviet Russian Federation, Transnat'I L. \& Contemp. Probs., no. 147, 1995.

Waller, F., Writing Chemistry Patents and Intellectual Property: A Practical Guide, John Wiley \& Sons, 2011.

Weiming, T., 'The context of dialogue: globalization and diversity', in M. Asante et al., 2014, pp. 496514.

Willis, B., The Arguments for and Against the TRIPS Agreement, 2013, http://www.e-ir.info/2013/12/23/ the-arguments-for-and-against-the-trips-agreement/ (accessed 18 April 2018).

Wodak, R., and M. Meyer (ed.), Methods of critical discourse analysis, SAGE, 2014.

Yeung L., and P. Azevedo, Measuring the Efficiency of Brazilian Courts from 2006 to 2008, São Paulo, Insper, 2008, http://effectius.com/yahoo_site_admin/assets/ docs/MeasuringtheEfficiencyofBrazilianCourtsfrom2006to2008_EFFECTIUS_ newsletter16.344135324.pdf (accessed 18 April 2018).

Zethsen, K., The Dogmas of Technical Translation - Are They Still Valid?, Journal of Linguistics, no. 23, 1999.

Zucoloto, G., Nota Técnica No 09. Panorama da Propriedade Industrial no Brasil, Brasília, 2013, http:// www.ipea.gov.br/agencia/images/stories/PDFs/nota_tecnica/130422_notatecnicadiset09.pdf (accessed 18 April 2018). 


\subsection{European Union and EPO Documents}

Agreement on a Unified Patent Court, 2013/C 175/01, http://eurlex.europa.eu/LexUriServ/ LexUriServ.do?uri=OJ:C:2013:175:0001:0040:EN:PDF_(accessed 18 April 2018).

Agreement on the application of Article 65 EPC - London Agreement, 17 October 2000, http:// documents.epo.org/projects/babylon/eponet.nsf/0/7FD20618D28E9FBFC125743900678657/ \$File/London_Agreement.pdf (accessed 18 April 2018). Regulation (EU) 1257/2012 of the European Parliament and of the Council of 17, December 2012, http://eurlex.europa.eu/ LexUriServ/LexUriServ.do?uri=OJ:L:2012:361:0001:0008:EN:PDF (accessed 18 April 2018).

Council of Europe, European Charter for Regional or Minority Languages, 1992, http:// conventions.coe.int/treaty/en/Treaties/Html/148.htm (accessed 5 January 2019). Council Regulation (EU) 1260/2012 Of 17, December 2012, implementing enhanced cooperation in the area of the creation of unitary patent protection with regard to the applicable translation arrangements, http://eurlex.europa.eu/LexUriServ/LexUriServ. do?uri=OJ:L:2012:361:0089:0092:EN:PDF (accessed 18 April 2018).

Directive 98/44/EC of the European Parliament and of the Council, 6 July 1998,

EPO, Examination at the EPO as PCT Authority, November 2017 Edition, https://www.epo.org/lawpractice/legal-texts/guidelines-pct.html (accessed 18 April 2018).

EPO, Guidelines for Examination in the European Patent Office, November 2017 Edition, https:// www.epo.org/law-practice/legal-texts/guidelines.html (accessed 18 April 2018).

EPO, Handbook of quality procedures before the EPO, $1^{\text {st }}$ Edition, 2012, http://documents.epo.org/ projects/babylon/eponet.nsf/0/45c8bcf3d8593a00c12579a50052bd6a/\$FILE/Handbook_of_ quality_procedures_en.pdf (accessed 18 April 2018).

EPO, National Law relating to the EPC, $18^{\text {th }}$ Edition, October 2017, https://www.epo.org/law-practice/ legal-texts/national-law.html (accessed 18 April 2018).

EPO, The European Patent Convention, $16^{\text {th }}$ Edition, https://www.epo.org/law-practice/legal-texts/ epc.html (accessed 18 April 2018).

EPO's Official Guidelines for Applicants, July 2017, 17th edition, http://www.epo.org/applying/ european/Guide-for-applicants/html/e/index.html_(accessed 18 April 2018).

EUR-Lex, Glossary of Summaries, http://eurlex.europa.eu/summary/glossary/enhanced_ cooperation.html (accessed 18 April 2018).

European Commission, Studies on Translation and Multilingualism: Language and Translation in International Law and EU law, 2013, http://www.termcoord.eu/wp-content/uploads/2013/08/ Study_on_language_and_translation_EU.pdf (accessed 18 April 2018).

European Union, Euratom Treaty, 2010, https://europa.eu/european-union/law_en (accessed 18 April 2018).

European Union, Statute of the Court of Justice, 2012, http://curia.europa.eu/jcms/upload/docs/ application/pdf/201210/staut_cons_en.pdf (accessed 18 April 2018). 
'European Parliament - never lost in translation', 01 October 2008, http://www.europarl.europa. eu/sides/getDoc.do?pubRef=-//EP//NONSGML+IM-PRESS+20071017FCS11816+0+DOC+PDF + VO//EN\&language $=E N$ (accessed 24 December 2018).

European Union, Treaty on European Union, 1992, https://europa.eu/european-union/sites/ europaeu/files/docs/body/treaty_on_european_union_en.pdf (accessed 18 April 2018). Decision of The Administrative Committee Rules on The European Patent Litigation Certificate and Other Appropriate Qualifications Pursuant to Article 48(2) of the Agreement on a Unified Patent Court,_https://www.unified-patent-court.org/sites/default/files/Draft-EPLC-2015-07-01final-clear-10-9-15.pdf (accessed 18 April 2018).

Treaty on the Functioning of the European Union, https://eur-lex.europa.eu/legal-content/EN/ TXT/?uri=celex\%3A12012E\%2FTXT (accessed 23, December 2018).

European Union, 'Multilingualism', https://europa.eu/european-union/topics/multilingualism_en (accessed 24 December 2018).

Regulation $n^{\circ} 1 / 58$, determining the languages to be used by the European Economic Community, https://publications.europa.eu/en/publication-detail/-/publication/e27878a8-d455-45158e18-99bf6160b651/language-en (accessed 25 December 2018). UPC, Letter from Chair and Vice-chair of Preparatory Committee after First Meeting, 27 March 2013, http://www.unifiedpatent-court.org/images/documents/roadmap-201409.pdf (accessed 18 April 2018).UPC, Setting up of the Preparatory Committee, Information from the Presidency, 8 March 2013, http:// www.upc.documents.eu.com/PDFs/2013-03-08_Setting_up_Preparatory_Committee_UPC_ st07265.en13.pdf (accessed 18 April 2018).Declaration of the contracting states concerning the coming into operation of the UPC, 19 February, 2013, http://data.consilium.europa.eu/doc/ document/ST-6572-2013-INIT/en/pdf (accessed 18 April 2018).UPC, Detailed split of subjectmatter over central division courts, http://www.bristowsupc.com/assets/files/UPC\%20Split\%20 of\%20subject-matter\%20over\%20central\%20division\%20courts.pdf (accessed 18 April 2018). UPC, Preparatory Committee roadmap, updated 16 September 2014, http://www.unifiedpatent-court.org/images/documents/roadmap.pdf_(accessed 18 April 2018).

Interinstitutional File, Council of the European Union. Brussels, 23 June 2011, 2011/0093 (COD) 2011/0094 (CNS) 11328/11, Proposal for a Regulation of the Council and the European Parliament implementing enhanced cooperation in the area of the creation of unitary patent protection, http://register.consilium.europa.eu/doc/srv?l=EN\&f=ST\%2011328\%202011\%20 INIT_(accessed 17 April 2018).

Directive 98/44/Ec of the European Parliament and of the Council of 6 July 1998, on the legal protection of biotechnological inventions, https://eur-lex.europa.eu/legal-content/EN/ TXT/?uri=celex:31998L0044 (available in Portuguese at: http://eur-lex.europa.eu/legalcontent/PT/TXT/PDF/?uri=CELEX:31998L0044\&) (accessed 18 April 2018). Preparatory Committee's Interpretative Note on the consequences of the application of Article 83 UPC Agreement, 29 January 2014, http://www.unified-patent-court.org/news/71-interpretativenote-consequences-of-the-application-of-article-83-upca_(accessed 18 April 2018). 
Regulation 1215/2012 (Brussels I Regulation amended to take into account the UPC) as amended by Regulation 542/2014 (consolidated version) on jurisdiction and the recognition and enforcement of judgments in civil and commercial matters, http://eur-lex.europa.eu/legal-content/EN/TXT/PDF/?uri=CELEX:02012R121520150226\&qid=1432130841601\&from $=E N \quad$ (accessed 18 April 2018). Rules of Procedure of the Unitary Patent Court, $18^{\text {th }}$ Draft, $1^{\text {st }}$ July 2015, http://www.bristowsupc. com/assets/files/UPC\%20Rules\%20of\%20Procedure\%2018th\%20Draft.pdf (accessed 18 April 2018).

Rules of Procedure of the UPC, 17 th Draft, 31 October 2014, http://www.unifiedpatentcourt.org/ images/documents/UPC_Rules_of_Procedure_17th_Draft.pdf (accessed 18 April 2018). Oral Hearing on the 17th Draft of the Rules of Procedure of the Unified Patent Court, $\quad 3^{\text {rd }} \quad$ November 2014, http://www.unified-patent-court.org/images/ documents/Digest_Legal_Group_17th_Draft_RoP.PDF (accessed 18 April 2018). UPC, Preparatory Committee roadmap, 25 June 2013, http://www.upc.documents.eu.com/ PDFs/2013-03-08_Setting_up_Preparatory_Committee_UPC_st07265.en13.pdf (accessed 18 April 2018). 


\subsection{Case Law}

Adjustacam LLC v. Amazon.com (2010), Inc. 6-10-cv-00329-120410-markman, Texas Eastern District Court.

Adjustacam LLC v. Amazon.com (2017), U.S. Court of Appeals, Federal Circuit 2017, Inc. fcg170705141_20170705.

Adjustacam LLC vs. Amazon.com (2015), U.S. Court of Appeals, Federal Circuit ,Inc. fcg150917399_20150917.

Adjustacam LLC vs. Amazon.com (2016), Texas Eastern District Court , Inc. E.D.Tex._6-10cv-00329_814.

Aerotel Ltd vs Telco Holdings Ltd, uk-2006-ewhc-997-pat_20060503 [2006] EWHC 997 (Pat), 2006.

COFAM Energy vs Green High Tech Energy, Tribunal de Grande Instance de Paris, fr-1110333_20130614, 2013.

EPO, Case Law of the Boards of Appeal of the European Patent Office, Seventh Edition, 2013. See especially: T 243/96 (p. 80), T 1599/06 (p. 146), T 1023/02 (p. 268), T 605/93 (p. 366), J 23/87 (p. 562), J 22/86 (p. 573), T 418/07 (582).

EPO, Case Law of the Boards of Appeal, Eighth Edition, August 2016, Chapter III-F, Language of Filing and Date of Filing of a European Patent Application (all cases described on the mentioned Chapter are relevant), http://www.epo.org/law-practice/legal-texts/html/caselaw/2016/e/clr_ iii_f_1.htm (accessed 28 April 2018).

Fronius International vs SMA Solar Energy, EPO Opposition Division, EOKCJYGX5500DSU_20170621, 2017.

Japan, Superior Court of Intellectual Property, Heisei 23, Rokuke, 10410, 2012, Available (in Japanese) at http://www.courts.go.jp/app/hanrei_jp/detail7?id=82581 (accessed 18 April 2018).

Name not available. District Court of Düsseldorf, Default Judgment of 12.01.2010, 4b O 286/08, 2010, https://openjur.de/u/456587.html (accessed 18 April 2018).

No name available (2009), Court of Appeals Düsseldorf, Germany, 17 July 2009, Docket No. 2 W 29/09, http://www.justiz.nrw.de/nrwe/olgs/duesseldorf/j2009/I_2_W_29_09beschluss20090717. html (accessed 18 April 2018).

Judgement of 5 May 2015, Spain vs Council, C-147/13, ECLI:EU:C:2015:299, 5 May 2015, http:// curia.europa.eu/juris/documentdocumentjsf?text=\&docid=164093\&pagelndex=0\&doclang= EN\&mode=Ist\&dir=\&occ=first\&part=1\&cid=4884012 (accessed 25 November 2018).

Judgement of 5 May 206, C-146/13, ECLI:EU:C:2015:298, http://curia.europa.eu/ juris/document/document.jsf?text=\&docid=164092\&pagelndex=0\&doclang=en\&mode= Ist \&dir=\&occ=first \&part=1\&cid=5301416 (accessed 26 November 2018).

Meroni v High Authority, 1957/1958, ECR 133, https://eur-lex.europa.eu/legal-content/EN/ TXT/?uri=CELEX\%3A61956CJ0009 (accessed 27 November 2018).

Opinion of Advocate General Bot, delivered on 18 November 2014, Case C-146/13, ECLI: EU:C:2014:2380, http://curia.europa.eu/juris/document/document.jsf?text=\&docid 
$=159764$ \&pagelndex=0\&doclang=en \&mode=Ist \&dir=\&occ=first $\&$ part $=1 \& c i d=3008161$ (accessed 26 November 2018).

Opinion of Advocate General Bot, delivered on 18 November 2014, Case C-147/13, ECLI:EU:C:2014:2380, http://curia.europa.eu/juris/document/document. jsf?text $=\&$ docid $=159763 \&$ pagelndex $=0 \&$ doclang $=E N \&$ mode $=$ lst $\&$ dir $=\& o c c=$ first \&part=1\&cid=2838 (accessed 26 November 2018).

Proc. № 200651015184614, TRF2 Justiça Federal Rio De Janeiro Vara: 38ci, Agrte : Sergio Ricardo Da Silva, Agrdo vs Instituto Nacional De Propriedade Industrial - Inpi, Relator: Des. Fed. Messod Azulay Neto, 2a. Turma Especializada, http://www.trf2.gov.br/iteor/RJ0108210/1/22/200105.rtf (accessed 13 April 2018).

Regeneron Pharmaceuticals vs Kymab Novo Nordisk, EWHC, 2016; Novartis AG v Johnson \& Johnson Medical Ltd EWCA, 2010; T 435/91, Case Law of the Boards of Appeal, Decision of 9 March 1994, https://www.epo.org/law-practice/case-law-appeals/pdf/t910435ex1.pdf (accessed 21 December 2018).

T 0243/96, Decision of 25 May 1998, https://www.epo.org/law-practice/case-law-appeals/recent/ t960243fu1.html\#D4N_T_1996_0243 (accessed 23 December 2018).

W.A.D.vs.VestasBenelux, RechtbankDenHaag (The Netherlands),2008,nl-HA-ZA-07-1473_20080116 nl-ha-za-07-1473.

Wobben vs Siemens AG., 2015, EWHC 2114 (Pat), F.S.R. 18, HP13E02610. 


\subsection{Other Policy Documents}

Brasil, Código de Processo Civil, de 16 de março de 2015, http://www.planalto.gov.br/ccivil_03/_ ato2015-2018/2015/lei/l13105.htm (accessed 28 April 2018).

Brasil, INPI, Instrução Normativa № 031/2013,

Brasil, Lei № 9.609, de 19 de fevereiro de 1998. Dispõe sobre a proteção da propriedade intelectual de programa de computador, sua comercialização no País, e dá outras providências, http:// www.planalto.gov.br/ccivil_03/leis/19609.htm (accessed 12 April 2018).

Brasil, Lei № 9.784, de 29 de janeiro de 1999, regula o processo administrativo no âmbito da Administração Pública Federal, https://www.planalto.gov.br/ccivil_03/Leis/L9784.htm (accessed 24 April 2018).

Brazilian Federal Government, Lei 9787/1999, https://www.planalto.gov.br/ccivil_03/Leis/L9784. htm apud parecer PROC/DICONS 278/2003 de 05.09.2003 (accessed 18 April 2018).

FGV, Projeto releitura dos acordos da OMC, 2012, capítulo 15. Acordo sobre Aspectos dos Direitos de Propriedade Intelectual Relacionados ao Comércio (TRIPS). Retrieved from http://ccgi.fgv. br/node/132 (accessed 24 April 2018).

France, Directives d'Examen de I'INPI, Chapitre X - Rectification d'erreurs, https://www.sedlex.fr/ wpcontent/uploads/2014/04/Directives_brevet_completes.pdf (accessed 24 April 2018).

http://www.inpi.gov.br/menu-servicos/patente/in_31_in_17_2013_administrativo_ versao_03_12_2013_0.pdf (accessed 24 April 2018).

INPI, Despacho 18.1. Revista de Propriedade Intelectual, 2017, http://revistas.inpi.gov.br/rpi/ (accessed 24 April 2018).

INPI, Resolução 158/2016, http://www.inpi.gov.br/menu-servicos/patente/legislacao-patente-1 (accessed 18 April 2018).

INPI. Norma de Execução No 1/2015. Institui o Procedimento de Preenchimento do Relatório de Busca.3 July 2015, file:///C:/Users/Win7/Downloads/procedimentos\%20(2)\%20(1).pdf (accessed 24 April 2018).

IP5 Statistics Reports, https://www.fiveipoffices.org/statistics/statisticsreports.html) (accessed 24 April 2018).

JPO Assessment Report for Machine Translation, https://www.jpo.go.jp/shiryou/toushin/chousa/ pdf/kikai_honyaku/h28_03.pdf_(accessed 24 April 2018).

JPO, How to Apply for a Patent, a Utility Model, Industrial Design, Trademark to the Japan Patent Office, https://www.jpo.go.jp/english/faqs/apply.html_(accessed 24 April 2018).

JPO, 平成 28 年度 審決の日英機械翻訳に関する調査 ('Survey on Japanese-English machine translation of Heisei 28th trial decision', indicated by one of the interviewed patent attorneys), https://www.jpo.go.jp/shiryou/toushin/chousa/pdf/kikai_honyaku/h28_03.pdf (accessed 18 April 2018).

Revision of Examination Guidelines for "Amendment of Description, Claims and Drawings (New Matter)", JPO, 2010, http://www.jpo.go.jp/tetuzuki_e/t_tokkyo_e/pdf/amendment_claims_ drawings_e/02.pdf (accessed 24 April 2018). 
Russia, Fundamental Principles of Civil Legislation of the U.S.S.R. and Union Republics, 1961, reviewed in 2006, http://www.wipo.int/wipolex/en/details.jsp?id=6775 (accessed 12 April 2018).

Russia. The Criminal Code of The Russian Federation. Adopted by the State Duma on May 24, 1996. Adopted by the Federation Council on June 5, 1996. Federal Law No. 64-FZ of June 13, 1996 on the Enforcement of the Criminal Code of the Russian Federation, http://legislationline.org/ documents/section/criminal-codes/country/7 (accessed 24 April 2018).

The Universal Declaration of Human Rights, https://www.ohchr.org/EN/UDHR/Documents/UDHR_ Translations/eng.pdf (accessed 5 January 2019).

The United States Department of Justice, Antitrust Guidelines for the Licensing of Intellectual Property, 1995, http://www.justice.gov/atr/public/guidelines/0558.htm\#t23 (accessed 13 April 2018).

The USA Department of Justice. Antitrust Guidelines for the Licensing of Intellectual Property, 1995, http://www.justice.gov/atr/public/guidelines/0558.htm\#t23 (accessed 24 April 2018).

USPTO, Examination Guidance and Training Materials - Best Practices in Examination. Available at: https://www.uspto.gov/patent/laws-and-regulations/examination-policy/examinationguidance-and-training-materials_(accessed 24 April 2018).

USPTO, Guidelines for the Examination of Patent Applications Under the 35 U.S.C. 112(a) or Pre-AIA 35 U.S.C. 112, para. 1, “Written Description” Requirement [R-07.2015], https://www.uspto.gov/ web/offices/pac/mpep/s2163.html (accessed 18 April 2018).

Vienna Convention on the Law of Treaties, signed at Vienna 23 May 1969, entry into force: 27 January 1980, https:/www.oas.org/legal/english/docs/Vienna\%20Convention\%20Treaties. htm (accessed 16 November 2018).

WIPO, Administrative Instructions Under the Patent Cooperation Treaty, as in force from July 1, 2017, Section 103, http://www.wipo.int/export/sites/www/pct/en/texts/pdf/ai.pdf, (accessed 17 April 2018).

WIPO, Paris Convention for the Protection of Industrial Property, 1883, http://www.wipo.int/wipolex/ en/treaties/text.jsp?file_id=288514 (accessed 24 April 2018).

WIPO, Patent Cooperation Treaty (PCT), Done at Washington on June 19, 1970, amended on September 28, 1979, modified on February 3, 1984, and on October 3, 2001, http://www.wipo. int/export/sites/www/pct/en/texts/pdf/pct.pdf (accessed 17 April 2018).

WIPO, PCT Yearly Review 2015, and PCT Yearly Review 2012, http://www.wipo.int/edocs/pubdocs/ en/patents/901/wipo_pub_901_2012.pdf_(accessed 24 April 2018).

WIPO, Regulations under the Patent Cooperation Treaty (as in force from July 1, 2017), http://www. wipo.int/export/sites/www/pct/en/texts/pdf/pct_regs.pdf (accessed 17 April 2018).

WIPO, World Intellectual Property Report: The Changing Face of Innovation, 2011, http://www.wipo. int/edocs/pubdocs/en/intproperty/944/wipo_pub_944_2011.pdf (accessed 24 April 2018).

The World Conference on Linguistic Rights,"Universal Declaration of Linguistic Rights", Barcelona Spain, June 1996, http://www.un.org/en/universal-declaration-human-rights/ (accessed 5 January 2019).

Working for IPO, UKIPO's Website, https://www.gov.uk/government/organisations/intellectualproperty-office/about/recruitment (accessed 24 April 2018). 
WTO, Acordo Sobre Aspectos dos Direitos de Propriedade Intelectual Relacionados ao Comércio

(TRIPS Agreement's translated into Brazilian Portuguese), 1994, http://www.inpi.gov.br/ legislacao-1/27-trips-portugues1.pdf (accessed 24 April 2018).

WTO, Agreement on Trade-Related Aspects of Intellectual Property Rights (TRIPS Agreement), 1994, https://www.wto.org/english/docs_e/legal_e/27-trips.pdf (accessed 24 April 2018). 


\subsection{Articles on Journals and Webpages}

'A question of utility', in The Economist, Aug. 8, 2015, http://www.economist.com/ node/21660559 (accessed 24 April 2018).

'An Apple Patent Application Relating to Face Mapping Surfaced today in the European Patent Office's Database', Patently Apple [website], 2017, http://www.patentlyapple.com/patentlyapple/2017/10/an-apple-patent-application-relating-to-face-mapping-surfaced-today-in-theeuropean-patent-offices-database.html (accessed 18 April 2018).

'Corn Law', Encyclopaedia Britannica [website], http://www.britannica.com/event/Corn-Law-Britishhistory (accessed 12 April 2018).

'DE - Cost reimbursement for translation expenses / infringement', EPLAE Patent Blog [web blog], http://eplaw.org/de-cost-reimbursement-for-translation-expenses-infringement/

'District Court Duesseldorf confirms rightful service of a patent infringement complaint without a translation', Kluwer Patent Blog, http://patentblog.kluweriplaw.com/2010/06/08/904/ (accessed 18 April 2018).

'EPO and SIPO launch Chinese-English machine translation for patents', EPO's website, Dec. 2012, https://www.epo.org/news-issues/news/2012/20121206.html (accessed 18 April 2018).

'EPO's Partnership with Google' [EPO's official website], 2011, http://www.epo.org/news-issues/ news/2011/20110324.html (accessed 24 April 2018).

'Erros de Tradução atrasam Acordo Comercial entre Brasil e Países Africanos', Veja, 4 Aug. 2015, http:// www.abece.org.br/Noticias/ComercioExteriorRead.aspx?cod=6005 (accessed 18 April 2018).

'Japanese-English machine translation for patents goes live', EPO's website, June 2013, https://www. epo.org/news-issues/news/2012/20121206.html (accessed 24 April 2018).

'Korean to English Translation Tool Available through Patentscope', WIPO's website, Nov. 2011, http:// www.wipo.int/patentscope/en/news/pctdb/2011/news_0015.html (accessed 24 April 2018).

'Looking for answers on Ansera', IPKITTEN [blogspot], 2017, http://ipkitten.blogspot.de/2017/11/ looking-for-answers-on-ansera.html?m=1 (accessed 16 April 2018).

'Patent Samples', OC Patent Lawyer [website], https://ocpatentlawyer.com/patent-samples/ (accessed 15 April 2018).

'Translating and the Law: Legal language', The Economist, Nov. 2012, http://www.economist.com/ news/business/21566010-services-specialising-language-and-culture-are-demand-legallanguage (accessed 24 April 2018).

'Translation Software Review', Business [Website], March 2018, http://translation-software-review. toptenreviews.com/ (accessed 24 April 2018).

'Would Brexit mean the end of the Unitary Patent and the Unified Patent Court?' In: HGF Intellectual Property Specialists [website], May 2016, http://www.hgf.com/updates/blog/2016/05/wouldbrexit-mean-the-end-of-the-unitary-patent-and-the-unified-patent-court/ (accessed 24 April 2018). 
Abrantes, A.C., Problemas de tradução em acordos internacionais, Notícias em Patentes [website], 2015, http://patentescomentarios.blogspot.de/2015/08/problemas-de-traducao-em-acordos. html (accessed 29 April 2018).

Bryan, M., The Patent Cooperation Treaty (PCT): Use and Future Developments [presentation], WIPO, Geneva 2014, http://www.aipla.org/learningcenter/library/papers/ roadshows/2014WIPORoadShows/Shared\%20Documents/PCT.pdf (accessed 17 April 2018).

Doss, H., The rhetoric of innovation, 2014, Forbes. https://www.forbes.com/sites/ henrydoss/2014/12/16/the-rhetoric-of-innovation/\#7055a0f69b93 (accessed 14 April 2018).

Empresa Brasil de Comunicação, 'Parceria entre Google e EPO fará tradução de pedidos de patentes estrangeiras no Brasil e de brasileiras no exterior', 9 April 2012, http://memoria.ebc.com.br/ agenciabrasil/noticia/2012-04-09/parceria-entre-google-e-epo-fara-traducao-de-pedidos-depatentes-estrangeiras-no-brasil-e-de-brasilei (accessed 24 April 2018).

Homepage of Patent Database Darts-IP, http://www.darts-ip.com/ (accessed 13 April 2018).

Homepage of Patent Database Espacenet, http://www.epo.org/searching-for-patents/technical/ espacenet.html\#tab1 (accessed 13 April 2018).

Homepage of Patent Database Patsnap, http://www.patsnap.com/ (accessed 13 April 2018).

INPI's Partnership with EPO and Google Aiming at Developing Patent Translation [website], http:// memoria.ebc.com.br/agenciabrasil/noticia/2012-04-09/parceria-entre-google-e-epo-faratraducao-de-pedidos-de-patentes-estrangeiras-no-brasil-e-de-brasilei (accessed 24 April 2018).

Johnson, A., 'UK finally ready for the Unified Patent Court', Kluwer Patent Blog [web blog], http:// patentblog.kluweriplaw.com/2018/02/13/uk-finally-ready-for-the-upc/ (accessed 18 April 2018).

LISA-QA Best Practice Guide - Implementing Machine Translation, http://www.mikedillinger.com/ papers/MT_BPG2004.pdf and http://web.archive.org/web/20110102030235/http://www.lisa. org/globalizationinsider/2010/08/the_lisa_qa_mod.html (accessed 24 April 2018).

LISA-QUA metric in the Localization Industry Standards Association [official website]: http:// web.archive.org/web/20110101195746/http://www.lisa.org/LISA-QA-Model-3-1.124.0.html (accessed 24 April 2018).

List of Freeware, List of Freeware [website], http://listoffreeware.com/list-of-best-free-translationsoftware/ (accessed 15 April 2018).

Maastricht University (2016). Research Programme of the Faculty of Law 2016-2021. https://www. maastrichtuniversity.nl/about-um/faculties/law/research/research-programme (accessed 13 April 2018).

Machine learning is fun', Medium [website]: https://medium.com/@ageitgey/machine-learningis-fun-part-5-language-translation-with-deep-learning-and-the-magic-of-sequences2ace0acca0aa (accessed 16 April 2018).

Nightingale, A., WIPO's New Tool: Complex Patents Now Easily Translated. Intellectual Property Watch, November 2012, http://www.ip-watch.org/2016/11/02/wipos-new-tool-complex-patentseasily-translated/?utm_source=IP-Watch+Subscribers\&utm_campaign=4fbbaf7a19-WEEKLY_ 
SUMMARY\&utm_medium=email\&utm_term=0_b78685696b-4fbbaf7a19-353256161 (accessed 24 April 2018).

Official website of the European Unitary Patent Court: https://www.unified-patent-court.org/ (accessed 24 April 2018).

Raosoft Sample Size Calculator, http://www.raosoft.com/samplesize.html (accessed 13 April 2018).

Schweizer, M., 'German Federal Patent Court (partially) invalidates $80 \%$ of litigated patents', IPKat [website], Feb. 2016, http://ipkitten.blogspot.sg/2016/02/german-federal-patent-courtpartially.html (accessed 24 April 2018).

Smith, D., When Structure is Wrong, Patents may Fall?, IPKitten [website], 2014, http://ipkitten. blogspot.com.br/2014/05/when-structure-is-wrong-patents-may-fall.html (accessed 18 April 2018).

Tilmann, W., 'The Future of the UPC After Brexit', Hogan Lovells' [website], http://www. theunitarypatent.com/the-unitary-patent-regulation-and-upc-agreement-after-brexit (accessed 18 April 2018).

UPC, Legislation establishing the UPC regime (with all the Agreements and Regulations), Bristows [website], http://www.bristowsupc.com/legislation-and-documents/ (accessed 24 April 2018).

USPTO, Design patent application guide, https://www.uspto.gov/patents-getting-started/patentbasics/types-patent-applications/design-patent-application-guide (accessed 14 April 2018).

Will 2018 be the Year of the Unitary Patent and the UPC?, Mewburn Patents [website], 2018, http:// mewburn.com/will-2018-year-unitary-patent-upc/ (accessed 17 April 2018).

WIPO Pearl, http://www.wipo.int/wipopearl/search/home.html (accessed 16 April 2018).

WIPO, 'WIPO Develops Cutting-Edge Translation Tool for Patent Documents', 2017. http://www.wipo. int/pressroom/en/articles/2016/article_0014.html (accessed 24 April 2018).

WIPO, Frequently Asked Questions, http://www.wipo.int/pct/en/faqs/faqs.html (accessed 16 April 2018).

WIPO, PCT-Patent Prosecution Highway Pilot (PCT-PPH and Global PPH), http://www.wipo.int/pct/ en/filing/pct_pph.html (accessed 17 April 2018).

WIPO. WIPO patent drafting manual, p. 33, http://www.wipo.int/edocs/pubdocs/en/patents/867/ wipo_pub_867.pdf (accessed 15 April 2018).

WIPO, What is Intellectual Property? 2015, http://www.wipo.int/edocs/pubdocs/en/intproperty/450/ wipo_pub_450.pdf, (accessed 12 April 2018).

Withers \& Rogers, UK patent application timeline, https://www.withersrogers.com/wp-content/ uploads/2015/03/uk_patent_application_time_line.pdf (accessed 18 April 2018).

Would Brexit mean the end of the Unitary Patent and the Unified Patent Court?, HGF Intellectual Property Specialists [website], May 2016, http://www.hgf.com/updates/blog/2016/05/wouldbrexit-mean-the-end-of-the-unitary-patent-and-the-unified-patent-court/ (accessed 18 April 2018).

Young, T., The World's Strangest Patent Filing Requirements. Multiling's [website], http://www. multiling.com/globalization-2/11-strangest-patent-filing-requirements-in-the-world (accessed 24 April 2018). 


\section{APPENDIX}

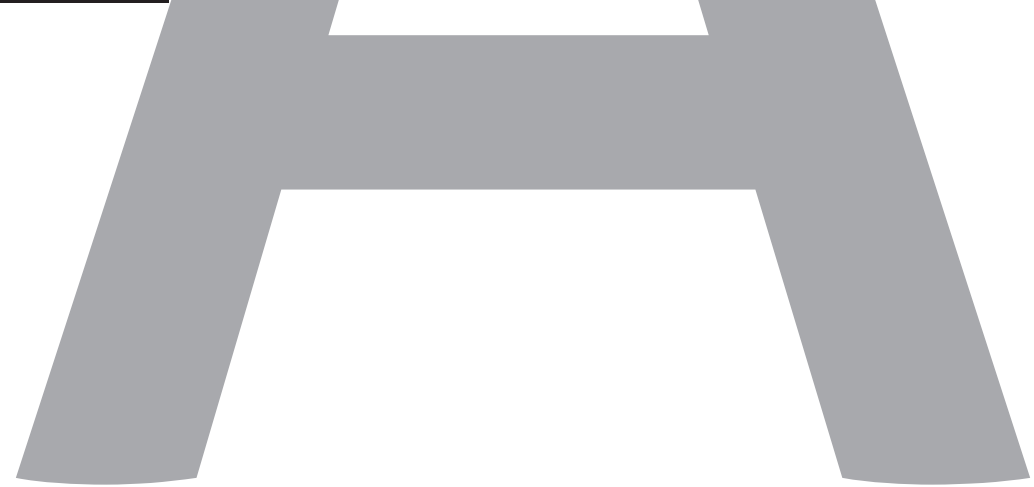




\section{Appendix 1: List of Interviewees and Collaborators}

Appendix 2: Interview Guides

Appendix 3: Forms used for Survey and Content Analysis

Valorization

About this author 


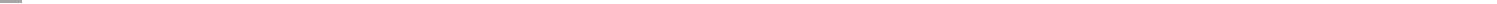




\section{Appendix 1: List of Interviewees and Collaborators}

\section{Interviewees}

Adriana Brigante Deorsola - Researcher in Industrial Property (INPI, Brazil) at the Coordination of International Integration and Global Issues.

André Fontes - Judge of the Federal Regional Court of the 2nd Region (Rio de Janeiro and Espírito Santo). Member of the 2nd Specialized Panel at the Federal Public Ministry, where he worked as General Attorney and, later, as Regional Prosecutor.

Antonio Carlos Souza de Abrantes - Head of the Division of Computer and Electronics of INPI's Patent Board.

Araken Alves de Lima - Head of INPI's Office in the State of Santa Catarina, Brazil.

Bertrand Le Chapelain - Multilingual engineer. Patent examiner at the EPO. Involved in machine translation projects, particularly concerning translation of Asian languages into English. Project Manager to develop tools for examiners for translation, for IP5 File Wrapper access and for prior art search.

Carmen Salvador - Lawyer, EPO's Patent Law Directorate. Member of the EQE Examination Committee.

Cees Mulder - Professor of European Patent Law in a Global Context at Maastricht University; European Patent Attorney; Tutor in training courses for EQE Papers C and D (Maastricht University); CEIPI tutor and epi speaker. Senior lecturer in European Patent Law: European Patent Convention, Patent Cooperation Treaty, Patent Law Treaty and Paris Convention.

Catia G. da Silva - General Coordinator of the PCT Board of Patents -INPI, Brazil.

Deniz Karci - Patent translator.

Guido Vermeer - Head of Translation Department; Project manager, Trainer STE - Etteplan. Han Deokwon - Senior Deputy Director - Korean Intellectual Property Office; Judge of Intellectual Property Trial and Appeal Board - Korean Intellectual Property Office; Deputy Director/Patent examiner - Korean Intellectual Property Office. Guest Researcher Maastricht University.

Gisela A.S. Nogueira - Electrical engineer. Vice-Coordinator of the PCT, INPI, Brazil.

Hans Peter Henrik Grieneisen - Head of the Board of Innovation and Technology of the National Institute of Metrology, Quality and Technology (Inmetro, Brazil). PhD in Physics (Massachusetts Institute of Technology).

Hirano Takashi - Patent examiner at JPO. PhD Researcher at Max Planck Institute for Innovation and Competition.

Ingrid Cailhol - Administrator of relations with Latin America - European Patent Office; Administrator in the European Commission.

Kitty Veldman - European Patent Attorney and Partner - Algemeen Octrooi en Merkenbureau; Before European Patent Attorney at Philips Corporation, NL. 
Krishnamani Jayaraman - Legal Officer in Biotechnology, Research and Development (R\&D), Intellectual Property, Technology Transfer, and Life Sciences. Researcher in Intellectual Property Law and Knowledge Management from Maastricht Graduate School of Law.

Liane Elizabeth Caldeira Lage - Chemical Engineer, Vice-Director of the Patent Examination Board at INPI, Brazil.

Nyske Blokhuis - Dutch \& European Patent Attorney. EP\&C - Intellectual Property Experts. Tutor EQE training.

Peter Blok - Judge in the Commercial Law Chamber of the Court of Appeal in The Hague. Previously Judge in the Intellectual Property chamber of the District Court of The Hague, and coordinator of that chamber. Professor in the Centre for Intellectual Property Law of Utrecht University.

Rafaela Di Sabato Guerrante - Head of the Department of Research in Innovation and Intellectual Property at INPI.

Ryoko Oshikamo - Japanese Patent Attorney. Researcher at Max Planck Institute for Innovation and Competition.

Sander van Rijnswou - Associate partner European \& Dutch Patent Attorney. Tutor EQE training. Patent attorney specialized in inventions having a mathematical or software background.

Stefan Luginbühl - Lawyer in the Directorate of International Legal Affairs of the European Patent Office. Currently involved on the development of the unitary patent system in Europe, with emphasis on the unitary patent and the uniform patent litigation system.

Shin Tokii - Japanese patent attorney. Researcher at Max Planck Institute for Innovation and Competition.

Tetsutaro Yukutake - Patent examiner at JPO. PhD Researcher at Munich Intellectual Property Law Center.

\section{Collaborators}

Giovanni B. Souza - Electrical engineer, MSc in Industrial Mechatronics. Currently working on Electronic Automation of Electrical and Industrial Processes. Professor Assistant at IFSC, Brazil.

Lindsay Yang - Patent specialist. MSc. Intellectual Property Law - Maastricht University. Lu Lingxiao - Researcher of Intellectual Property Law, Maastricht University.

Marcos Trevisan Vasconcellos - Electrical Engineer, Head of the Department of Instruments, Software and Environment, Brazilian National Institute of Metrology, Innovation and Technology.

Paulo C. R. Brandão - Electrical Engineer. Researcher at the Brazilian National Institute of Metrology, Innovation and Technology. 
Tianyu Hang - Paralegal at Rouse; Master of Law Maastricht University; Bachelor of Laws China University of Political Science and Law.

Viola PendI - Researcher of International and European Law - Public International Law University of Amsterdam.

Zedequias Alves - Electrical Engineer, currently a Professor Assistant at the Federal Institute of Santa Catarina. 


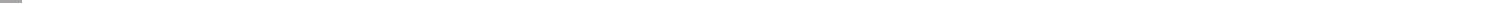




\section{Appendix 2: Interview Guides}

The following sets of questions represent the basic interview guides that worked as a reference to interviews with different stakeholders of the patent system. These guides were customized according to the nationalities of the interviewees. They were also adapted and translated into Portuguese for the interviews which took place in Brazil.

\section{Questions to Judges}

1. Could you comment what brought you, in terms of your personal, public and professional career, to devote to intellectual property, keeping it as the object of your activities and reflections?

2. Could you mention cases of disputes involving patents and aspects related to translation?

a. Is there a specific case that deserves attention? How can I find this case?

b Is there a case involving solar or wind power patents?

3. Do you consider that the translation processes related to patent examination and dissemination of information contained in patents may cause effects on the legal framework? Which of these effects could you mention?

4. Do you think machine translation can somehow (directly or indirectly) influence court cases involving patents? If you had to give a score about how much it can influence the mentioned cases, which score would you give from zero to ten? What about human translation?

5. How do you interpret the connection between translation, the patent system and the European judiciary?

6. Are there any protocols involving translation that the Court should use when dealing with cases involving patents? Do you need to hire translators sometimes? How often?

7. Do you ever use machine translation in your professional activities? How often?

8. The fact that the judge has more or less knowledge in foreign languages may influence the decisions or the good or bad interpretation of the documentation? How much (please give a score from zero to ten)?

9. Doyou have any other comments on the relationship between patents and translation and its legal effects?

\section{About the Unitary Court}

- What kind of legal effects do you think will emerge from the set-up of the Unitary Court? Which could be the most problematic aspects?

- Do you think it can have negative effects on the national legal systems?

- Why is there such a heated reaction concerning language and translation issues as the major controversies about the unitary patent and the unitary court? 
- The Regulations for the Unitary Patent state that no further translations are required with the exception of transitional arrangements which are proportional and require additional translations on a temporary basis, without legal effect and purely for information purposes. These transitional arrangements will terminate when highquality machine translations become available, subject to an objective evaluation of their quality by an independent expert committee every two years (starting from the sixth year of application). Will machine translation suffice for all the legal purposes associated with the European Patent system? Do you think machine translation suffices in terms of disclosing patent technical information necessary to Courts?

- Are language and translation truly the major challenges for the establishment of the Unitary Patent Court? If yes, why?

- What are the advantages of the Unitary Court in terms of language and translation? And the disadvantages?

- $\quad$ Are there States which will be favoured by its language regime?

\section{Questions to Translators/Managers of Translation Companies}

1. Could you comment what brought you, in terms of your personal, public and professional career, to devote to technical translation, keeping it as the object of your activities and reflections?

2. What type of translations your company provides concerning patent documents?

3. Could you mention cases of difficulties in translating patent documents? Is there room for subjective choices that may generate different results?

4. Do you consider that the translation processes related to patent examination and disclosure of information contained in patents may cause effects on the legal framework? Which of these effects could you mention?

5. Do you think machine translation will one day suffice as the only means to provide patent information, dispensing with the support of human translation?

6. Do you think machine translation can somehow (directly or indirectly) influence court/opposition cases involving patents? If you had to give a score about how much it can influence them, which score would you give from zero to ten? What about human translation?

7. How do you interpret the relationship between translation, the patent system and the European judiciary?

8. Do you ever use machine translation in your professional activities? How often?

9. The fact that the translator has more or less knowledge and experience may influence the reasoning of a patent case or the good or bad interpretation of the documentation? How much (give a score from zero to ten)?

10. The Regulations for the Unitary Patent state that no further translations are required with the exception of transitional arrangements which are proportional and require additional translations on a temporary basis, without legal effect and purely for 
information purposes. These transitional arrangements will terminate when highquality machine translations become available, subject to an objective evaluation of their quality by an independent expert committee every two years (starting from the sixth year of application). In this regard, will machine translation suffice for all the legal purposes associated with the European Patent system? Do you think machine translation suffices in terms of disclosing patent technical information necessary to Courts?

11. How will the set-up of the Unitary System influence the activities of translation firms and services?

12. Do you have any other comments on the relationship between patent translation and the legal system?

13. Can machine translation affect the decisions in court cases involving patents?

14. Can it mislead these decisions? If (machine and human) patent translation can mislead these decisions, what could be done to minimize these negative effects?

\section{Questions to Patent Attorneys}

1. Could you comment what brought you, in terms of your personal, public and professional career, to devote to intellectual property, keeping it as the object of your activities and reflections?

2. Could you mention cases of disputes involving patents and aspects related to translation (if you have experienced any)?

a. Is there a specific case that deserves attention? How can I find this case?

3. Do you consider that the translation processes related to patent examination and disclosure of information contained in patents may cause effects on the legal framework? Which of these effects could you mention?

4. Do you think machine translation can somehow (directly or indirectly) influence court/opposition cases involving patents? If you had to give a score about how much it can influence them, which score would you give from zero to ten? What about human translation?

5. How do you interpret the relationship between translation, the patent system and the European judiciary? (Can different language regimes influence this relationship?)

6. Are there any protocols involving translation that you should use when dealing with cases involving patents? Do you need to hire translators sometimes? How often (give a score from zero to ten)?

7. Do you ever use machine translation in your professional activities? How often?

8. The fact that the patent attorney or the judge has more or less knowledge in foreign languages may influence the reasoning of the case or the good or bad interpretation of the documentation? How much (give a score from zero to ten)?

9. How much do you have to consult or use translated texts? (zero to ten) 
10. Do you have any other comments on the relationship between intellectual property and translation and its legal effects?

\section{About the Unitary Court}

- What kind of legal effects do you think will emerge from the set-up of the Unitary Court concerning language and translation? Which could be the most problematic aspects?

- Do you think it can have negative effects in the national legal systems?

- The Regulations for the Unitary Patent state that no further translations are required with the exception of transitional arrangements which are proportional and require additional translations on a temporary basis, without legal effect and purely for information purposes. These transitional arrangements will terminate when highquality machine translations become available, subject to an objective evaluation of their quality by an independent expert committee every two years (starting from the sixth year of application).

- In this regard, will machine translation suffice for all the legal purposes associated with the European Patent system? Do you think machine translation suffices in terms of disclosing patent technical information necessary to Courts?

- Are language and translation truly the major challenges for the establishment of the Unitary Patent Court? If yes, why?

- What are the advantages of the Unitary Court in terms of language and translation? And the disadvantages? Do you consider that non-native companies regarding the three official languages will be in a position of disadvantage? Are there States which will be favoured by its language regime?

- After the British exit of the European Union, do you see relevant changes in the Unitary Patent or the Unitary Court?

\section{Questions to Patent Examiners}

1. Can you briefly describe what brought you, in your personal and professional life, to dedicate yourself to intellectual property?

2. What are the advantages and disadvantages of working as a patent examiner in your country?

3. What are the main difficulties faced by a patent examiner concerning language and translation?

4. Do you think translation machines have expanded the universe of searchable documents for the prior art searches by patent offices?

5. As a patent examiner, do you feel an improvement in translation machines in the last years? Could you give a score from zero to ten to that? 
6. Is it necessary to advance the mechanisms of search so that the gain represented by machine translation is not neutralized by limited searches? In which aspects they could advance?

7. Are there difficulties regarding the understanding of foreign language texts in examining the prior art? How can these difficulties (if there are any) be remedied? In what languages they arise most often? Is machine translation sufficient to provide an adequate understanding during the examination? Have you ever had to rely on the help of human interpretation?

8. What languages do you know? With what level of oral and written fluency?

9. How do you see possibilities of harmonizing the patent system to the activities of patent examiner? Do you think that the Unitary Patent System could have any impact in the activities of (European, Brazilian, Indian, Japanese, Korean...) patent examiners? Do you consider as possible any types of such agreements in $\mathrm{X}$ country (India, Japan...)?

10. What are your personal opinions about the Unitary System?

11. Doyou think an error by the examiner caused by a mistranslation or misunderstanding of a foreign patent document can indirectly influence or lead to a court case?

12. Do you think search tools or systems could improve in terms of language and translation, making it easier for the examiner to find foreign prior art?

13. How often do you consult machine translations? Please give a score from zero to ten.

14. Do you have any additional comment on the relationship between language regimes, translation and intellectual property and on how it could be improved? 


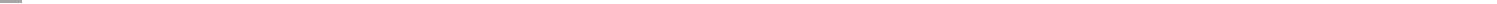




\section{Appendix 3: Forms used for Survey and Content Analysis}

A. Example of LISA-QA Form and text for the Assessment of Patent Translation Quality

TITLE: Efficient systems and methods for construction and operation of mobile wind power platforms

Value: $\$ 85,000 \$ \$(A) \quad$ Assignee.: V SQUARED WIND

Inventor (s): FREDA, ROBERT, M. West, Roxbury, MA

Pub. N.: US8937399

Pub. Date: 20 Jan 2015

App. N.: US13/912966

App. Date: 07 Jun 2013

\begin{tabular}{|c|c|c|c|c|c|}
\hline \multirow{2}{*}{ Doc. Language (s): } & Minor $=$ & & Major $=5$ & & Critical $=$ \\
\hline & Abstract & Claims & Abstract & Claims & Abstract \\
\hline
\end{tabular}

Mistranslation

Accuracy

Terminology

Language

3

1

3

Style

\begin{tabular}{|c|c|c|c|c|}
\hline Total score & Abstract & 16 (8 in 50 words) & Claims & 46 (200 words) \\
\hline Reference value & Abstract & 10 scores & Claims & 20 scores \\
\hline
\end{tabular}

B. Researchers' Survey Form (the questions were followed by 10 pages of patent texts)

Answer to both statements and to the question below for each of the following patent texts. Please do not refer to the original text of the patent on the banks of patents, based solely on the contents of this form. Each text contains abstract and claims of the patent.

\begin{tabular}{|c|c|c|c|c|c|}
\hline $\begin{array}{l}\text { Statement } 1: \text { Is the translated } \\
\text { text clear in describing the } \\
\text { content of the invention? }\end{array}$ & $\begin{array}{l}\text { Totally } \\
\text { disagree }\end{array}$ & Disagree & Neutral & Agree & $\begin{array}{l}\text { Totally } \\
\text { agree }\end{array}$ \\
\hline \multicolumn{6}{|l|}{ Text 1} \\
\hline \multicolumn{6}{|l|}{ Text 2} \\
\hline \multicolumn{6}{|l|}{ Text 3} \\
\hline $\begin{array}{l}\text { Statement 2: Does the } \\
\text { translated text allow the } \\
\text { disclosure of the content of } \\
\text { the invention? }\end{array}$ & $\begin{array}{l}\text { Totally } \\
\text { disagree }\end{array}$ & Disagree & Neutral & Agree & $\begin{array}{l}\text { Totally } \\
\text { agree }\end{array}$ \\
\hline \multicolumn{6}{|l|}{ Text } \\
\hline \multicolumn{6}{|l|}{ Text } \\
\hline Text & & & & & \\
\hline
\end{tabular}

Which one of the texts was clearer in describing the invention?

If you judge as necessary, justify the answers. 


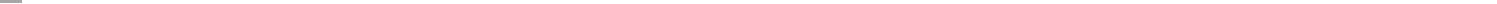




\section{Valorization}

Since 2013, the University of Maastricht requires a Valorization Addendum as part of its doctoral theses. The goal of writing this valorization section consists in increasing the visibility and explaining the societal impact of the research. ${ }^{957}$ In other words, this section intends to explain the social and economic relevance of the present research, demonstrating why its results compensate the time and values invested on it and how they can be used to improve new products, services and policies in the area of the research. Therefore, in this section, it is intended to provide a didactic and concise description of the social and economic value of the present research.

First and foremost, it is important to explain what the patent system is, what it represents to society and why translation is so important to its functioning today. A patent is an exclusive right granted for an invention, which is a product or a process that provides, in general, a new way of doing something. ${ }^{958}$ There are various examples of exciting inventions, which can extend from a new drug that can cure a serious disease to a new device of a mobile phone or a clever idea for a new type of can opener.

The patent system is important for various reasons: it discloses technological information at a global level, making it available for innumerable uses; it encourages innovation; it protects the rights of inventors and investors; it reduces transaction costs in the process of patent bargain; it provides the existence of huge databanks containing all types of technological information; it enables many important ways of controlling, classifying and exploiting this information (developing of patent portfolios, basing decisions in technological planning and management, evaluating the quality of a technology, identifying competitors and even human resources,...). Above all, patents are an important element of enforcement of the rule of law and promotion of fair competition in democratic societies, in a globalized, knowledge-based era.

Although patents are granted nationally, at least to the date, the patent system operates at the global level, being, therefore, multilingual. That is why translation is so important for its functioning and plays a role during the whole timeline of a patent. In this context, machine translation, together with the advent of digital information and communication tools, has represented a true revolution to patent rights, facilitating the process of the disclosure and the dissemination of patent information. These new technologies really changed the face of the patent system, making the volume of documents (and the access to them) increase dramatically. These changes are recent, dating from no more than one decade ago. They are also happening very fast, as it is possible to follow continuous high impacting changes involving patent searching tools and machine translation. This research is a seminal work in the sense of understanding, describing and analysing those changes, in order to give a contribution on the functions,

957 Regulation Governing the Attainment of Doctoral Degrees, Maastricht University, 2013, file:///Users/macbook/Downloads/ UM_Regulation_governing_the_attainment_of_doctoral_degrees.pdf (accessed 4 June 2018).

958 WIPO, What is a Patent?, http://www.wipo.int/patents/en/ (accessed 4 June2018). 
features and future perspectives of patent translation and dissemination of the disclosure of patent information in the legal framework.

Below, the main questions related to the valorisation of this research are answered, in short, one by one. The complete answers are detailed in different parts of the dissertation, also indicated below. ${ }^{959}$

1. Relevance: What is the social (and/or economic) relevance of your research results (i.e. in addition to the scientific relevance)?

- Patent systems are central to regulate global trade and disseminate scientific knowledge. Language and translation constitute their basis of communication. As the volume and complexity of multilingual documents grow intensively, translation can influence the whole legal path of patents. Understanding and refining these flows of communication is important to improve the patent system and, therefore, to provide legal certainty to its users. An improved patent system is vital to fair competition, that is to say, to inventors and investors, directly, and to the agents associated with its legal framework (policy makers, patent attorneys, examiners, judges, translators...).

2. Target groups: To whom, in addition to the academic community, are your research results of interest and why?

- The same target groups mentioned in the answer to question 1. This research is practically a first reference in understanding the patent system from a language/translation perspective. Its results include recommendations for patent offices, possibilities of improving patent search tools and proposals on harmonizing the system, which comprises a set of results related to the Unitary Patent System in Europe.

3. Activities/Products: Into which concrete products, services, processes, activities or commercial activities will your results be translated and shaped?

- The main product of my research is the book, represented by this dissertation, which can be considered as a significant theoretical reference to the role of translation to the patent system. The set of recommendations contained by this book can be the basis to reformulate and improve the patent system in various levels, which may allow: more integration between national patent offices, improvement in searching tools and on the use of translated information to disclose technological content, recommendations on the language regime of the Unitary System in Europe, recommendations to developing countries in reaching higher levels of integration to the global system. During the period of research, there were publications, presentations and debates, in order to share and discuss the results not only with the scientific community, but with the agents mentioned in the answer to question 1.

959 The questions were transcribed from the Regulation Governing the Attainment of Doctoral Degrees, Maastricht University, 2013 
4. Innovation: To what degree can your results be called innovative in respect to the existing range of products, services, processes, activities and commercial activities?

- The present research can be called innovative in the maximum degree, concerning the idea of an original contribution to patent law studies. Firstly, because it exploited an interdisciplinary topic poorly investigated before by other studies, dealing with empirical work and with a context of no prior art available. The researcher had to deal with the challenge of creating a methodology by combining techniques in order to exploit the existing primary sources.

5. Schedule \& Implementation: How will this/these plan(s) for valorization be shaped? What is the schedule, are there risks involved, what market opportunities are there and what are the costs involved?

- A reference work can be implemented or consulted from the date it is published, with no deadline. It can inspire changes to the legal framework, the creation of new search databases or the improvement of the existing ones. Furthermore, the research results were shared and debated, in diverse occasions, with the European Patent Office (EPO), the European Intellectual Property Institutes Network (EIPIN) and with the Brazilian Patent Office (INPI). 


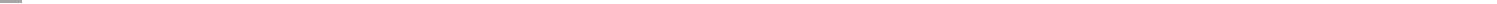




\section{About this author}

Aline A. Larroyed was born in São Paulo, Brazil. She holds bachelor and master's degree in language studies, both from the Federal University of Brasília, Brazil. She also attended a Programme on Comparative Studies at the University of Sofia, Bulgaria, where she worked as a teacher of Portuguese language and Brazilian culture. From 2001 to 2002, she lived in Turkey, where she had the opportunity to cooperate with language/translation research projects of the University of Haceteppe and the University of Ankara. Afterwards, Aline has worked as a Professor Assistant at the Catholic University of Brasília, Brazil, in the department of language and translation studies. In 2011, she started a new carrier as a Civil Servant, working with innovation, intellectual property and technology transfer, at the Brazilian Institute for Metrology, Quality and Technology, after competing with around 20,000 candidates from all over the country and being awarded first place in the selection process. The new carrier required training courses and specializations in the area. In 2012, Aline started attending the Graduate Programme of the Academy of Intellectual Property and Innovation of the Brazilian PTO (INPI). In 2014, she entered the PhD Programme in Intellectual Property Law at the University of Santa Catarina, which led her to a common project with the Graduate School of Law in Maastricht University and to the opportunity of developing a $\mathrm{PhD}$ research which could combine her experience with language/translation and intellectual property. From 2017 to 2018, she worked as a visiting researcher at the Max Planck Institute for Innovation and Competition. 
